\title{
LA-ICP-MS TRACE ELEMENT ANALYSIS OF PLANKTONIC FORAMINIFERA AND APPLICATION TO MARINE ISOTOPE STAGE 31 IN THE SOUTHWEST PACIFIC OCEAN
}

BY

ANNETTE BOLTON

\author{
A thesis \\ submitted to the Victoria University of Wellington \\ in fulfilment of the requirements for the degree of \\ Doctor of Philosophy \\ in Geology
}

Victoria University of Wellington

2011 
Even if it's so tiny you can't see it,

it is designed with ornament and elegance,

down to the fractal,

down to the quark,

down to the emptiness of an electromagnetic field, there is still design and elaboration.

--Jan Haag, 2000 


\begin{abstract}
Trace element/Ca ratios were measured by LA-ICP-MS in Gs. ruber and N. incompta from a wide range of core top and plankton tow samples in the Southwest Pacific Ocean, with particular focus on linking measured $\mathrm{Mg} / \mathrm{Ca}$ ratios to observed (near-) surface ocean temperatures. Mean $\mathrm{Mg} / \mathrm{Ca}$ ratios measured in the ultimate chamber $\mathrm{F}$ of Gs. ruber are significantly lower compared to chambers F-2 and F-1, which show no statistical difference. These observations led to the development of three new $\mathrm{Mg} / \mathrm{Ca}$ - ocean temperature calibrations that can be used to reconstruct SST from LA-ICP-MS trace element analysis of $G s$. ruber over a temperature range of $14.7-28.8^{\circ} \mathrm{C}$. In contrast to the LA-ICP-MS study of Gs. ruber, the planktonic species $N$. incompta shows no systematic difference in $\mathrm{Mg} / \mathrm{Ca}$ between the final four visible chambers at one core top site, nor between the F-3 and F chambers at any sites. In addition, there was no correlation between $\mathrm{Mg} / \mathrm{Ca}$ ratios and ocean temperature in either reticulate or crystalline forms. This may reflect migration of this species within the water column that is not uni-directional, that this species does not dwell at the same depths at each core top site, or point towards further unidentified controls on $\mathrm{Mg}$ incorporation into N. incompta that require further study.
\end{abstract}

The chamber specific calibrations developed for Gs. ruber in this study, and a calibration developed using the same techniques for G. bulloides [Marr et al., 2011] were applied down core to $\mathrm{Mg} / \mathrm{Ca}$ ratios measured from ODP Site 1123. The SST derived from $\mathrm{Mg} / \mathrm{Ca}$ ratios reveal that during the MIS-31 interglacial, SSTs were approximately $4-5^{\circ} \mathrm{C}$ warmer than today and $8-9^{\circ} \mathrm{C}$ warmer than those from MIS-29 and 30. A comparison of SSTs measured from Gs. ruber and G. bulloides, suggests that they are responding to local insolation changes. $G$. bulloides records colder temperatures than Gs. ruber, which reflects differences in their relative depth in the water column. Paired $\mathrm{Mg} / \mathrm{Ca}$ and $\delta{ }^{18} \mathrm{O}$ data reveal significant changes in ice volume over the sampling period. Increases in SSTs recorded by the planktonic foraminifera lead the seawater stable isotope record by $10 \mathrm{kyr}$ suggesting a significant influence from changes in Northern Hemisphere ice sheet volume during MIS-31. In some intervals, the SST leads the benthic stable isotope record by $8 \mathrm{kyr}$ and shows deviations in benthic $\delta^{18} \mathrm{O}$ from synchronous planktic samples.

In G. bulloides and Gs. ruber, $\mathrm{Mn}$ and $\mathrm{Mg}$ were the only trace elements to show systematic glacial-interglacial changes from MIS-34 to MIS-29. This correlation could imply that $\mathrm{Mn} / \mathrm{Ca}$ ratios in the foraminifera are recording changes in ocean chemistry related to changing water mass circulation at ODP Site 1123 as past ocean temperatures changed.

Size-normalised weights (SNW) of G. bulloides tests show systematic variations from MIS34 to MIS-29. For much of the record, SNW is anti-correlated with SST in a manner similar to the modern relationship between SNW and SST in the Southwest Pacific Ocean. However, immediately prior to the MIS-31 Southern Hemisphere insolation maxima, SNW increase with SST suggesting a fundamental change in surface ocean carbonate chemistry occurred that is unique to this time. 


\section{Acknowledgements}

There are many people and organisations to which I am forever indebted for their generous support both financially, academically and emotionally. First I must thank the Commonwealth Scholarships and New Zealand Vice Chancellors Committee for selecting me for candidature at Victoria University of Wellington. Thank you to the Antarctic Research Centre for your additional financial support on my various ventures overseas, to ANU and to the Urbino Summer School.

Many scientists have generously shared their time and expertise. Thank you to my supervisors Prof. Joel Baker, Prof. Lionel Carter and Dr. Gavin Dunbar, for taking me on as your student, and bringing me from knowing very little about foraminifera, to dreaming about them at night (not necessarily a good thing). There are many more of you behind the scenes that have helped in this project in some way, the girls at NIWA, Dr. Helen Bostock, Dr. Lisa Northcote and Dr. Helen Neil, for supplying me with samples, ideas, support and allowing me to spend some time at sea onboard the R.V. Rangaroa. Thank you to the guys at GNS science, for materials, timely advice and moral support, particularly to Dr. Martin Crundwell and Dr. George Scott. Dr. Gregg Brunskill and Dr. Irena Zagorskis (AIMS) also provided samples and supplementary data, thank you. Thanks to Stuart Bush for help with the thin sectioning, Prof. Richard Tilley and Dr. David Flynn for your assistance with the SEM, Dr. John Patterson for your advice and use of your plasma asher and Prof. Euan Smith for your assistance with statistical analyses. Big thanks to Kylie Christiansen and Matt Ryan for help with the laborious tasks. Thank you to John Creech and Prof. Euan Smith for developing MATLAB scripts and John again for your assistance with the new microprobe.

I must thank all of those people who I have become friends with over the years. There are too many to name so I apologise if you are reading this and your not here, but without you this journey would have surely have been less fun, chaotic and lacking in good Kiwi beer. To those who I have shared many fascinating conversations in our office, Jess, Jules, John, Katie, Sarah, Alexa, and Julene. Thanks for your ministrations of coffee, cheese and cookies in the last final months and listening to me go on about 'bugs' and at least looking as though you were half interested. Last but not least thank you to all my family and friends for your unwavering support, kindness, patience and love. Finally, I would like to dedicate these final words to the person who endured the best and the worst of me during my time at VUW. Simon, thank you for still being here! 
Table of contents

page vi

Front matter

Title page

Preface

Abstract

Acknowledgements

List of tables

List of figures

List of abbreviations

$\begin{array}{llr}\text { Chapter } 1 \text { Introduction } & 1\end{array}$

1.1 Objectives of this thesis 1

1.2 Structure of this thesis 3

1.3 Earth's climate - an overview 4

1.3.1 What drives the climate system 4

1.3.2 Thermohaline circulation 5

1.3.3 Why does global climate vary? 6

1.4 Foraminifera as archives of palaeoclimate and palaeoceanographic change 9

1.4.1 Modern planktonic foraminifera 9

$\begin{array}{ll}\text { 1.4.2 Life processes and calcification } & 10\end{array}$

1.4.3 Geochemistry of foraminiferal tests 11

1.4.4 Trace elements in seawater and foraminiferal calcite 12

1.4.5 $\mathrm{Mg} / \mathrm{Ca}$ as a palaeothermometer in planktonic foraminifera 13

1.4.6 Stable Oxygen isotopes $\left(\boldsymbol{\delta}^{18} \mathrm{O}\right) \quad 14$

1.4.7 Complexities of using Oxygen isotopes as a palaeoclimate proxy in foraminiferal calcite 17

1.4.8 Stable Carbon isotopes $\left(\boldsymbol{\delta}^{13} \mathrm{C}\right) \quad 17$

1.4.9 Vital effects 20

1.5 Regional Oceanography 20

1.5.1 Surface waters in the Southwest Pacific Ocean 21

1.5.2 Deep waters in the Southwest Pacific Ocean 24

1.5.3 Oceanography at ODP site 1123

1.5.4 Application of foraminiferal trace element data from ODP 
Chapter 2 Materials and methods

2.1 Fossil and plankton tow material

2.1.1 Recovery of foraminifera from marine sediment cores and preparation of foraminifera for LA-ICP-MS

2.1.2 Basis for the adopted foraminifera cleaning technique

2.2 LA-ICP-MS analysis of trace elements in foraminiferal calcite

2.2.1 Summary of analysis, accuracy, standardisation and inter-laboratory calibration for foraminiferal $\mathrm{Mg} / \mathrm{Ca}$ palaeothermometry

2.2.2 Data reduction and screening techniques 37

2.3 An inter-laboratory comparison 38

2.4 Other methods for examining trace element ratios in foraminifera 44

$\begin{array}{lll}2.5 & \boldsymbol{\delta}^{18} \mathrm{O} \text { and } \boldsymbol{\delta}^{13} \mathrm{C} \text { stable isotope analysis } & 45\end{array}$

Chapter 3 Environmental vs. biological controls on $\mathrm{Mg} / \mathrm{Ca}$ variability in Globigerinoides ruber (white) from core-top and plankton tow samples in the Southwest Pacific Ocean

$\begin{array}{lll}3.1 & \text { Abstract } & 48\end{array}$

3.2 Introduction 49

$\begin{array}{lll}3.3 & \text { Background } & 50\end{array}$

3.4 Materials and methods $\quad 50$

3.4.1 Regional setting and core top and plankton tow locations $\quad 50$

3.4.2 Sample preparation 53

3.4.3 Trace element analysis of Gs. ruber in the Southwest Pacific Ocean 55

3.5 Results 57

3.5.1 Elemental profiles through the tests of Gs. ruber 57

3.5.2 The distribution of $\mathrm{Mg} / \mathrm{Ca}$ within a population 60

3.5.3 A log-normal model for the distribution of $\mathrm{Mg} / \mathrm{Ca}$ measurements 64

$\begin{array}{lll}3.6 & \text { Discussion } & 66\end{array}$

3.6.1 Impacts of dissolution 66

3.6.2 Laser ablation trace element profiles 67

3.6.3 An LA-ICP-MS derived Mg/Ca vs SST calibration for Gs. ruber in the Southwest Pacific Ocean 
3.6.4 Intra-individual mean $\mathrm{Mg} / \mathrm{Ca}$ variability $\quad 68$

3.6.5 Inter-individual $\mathrm{Mg} / \mathrm{Ca}$ variability $\quad 70$

$\begin{array}{lll}3.7 & \text { Summary and conclusions } & 72\end{array}$

$\begin{array}{lll}3.8 & \text { Supplementary material } & 73\end{array}$

3.8.1 Trace element analysis of $\mathrm{Ba}, \mathrm{Zn}$ and $\mathrm{Sr}$ in Gs. ruber tests $\quad 73$

Introduction $\quad 73$

Methods $\quad 74$

Results and Discussion $\quad 74$

$\mathrm{Ba} / \mathrm{Ca}$ ratios $\quad 74$

$\mathrm{Zn} / \mathrm{Ca}$ ratios $\quad 75$

$\mathrm{Sr} / \mathrm{Ca}$ ratios $\quad 76$

3.8.2 Oxygen isotopes 79

Introduction $\quad 79$

$\begin{array}{ll}\text { Methods } & 79\end{array}$

Results and discussion $\quad 80$

3.8.3 Weight and size determinations 83

Introduction $\quad 83$

Methods $\quad 83$

Results and Discussion $\quad 84$

3.8.4 Summary and Conclusions $\quad 84$

Chapter 4 Evaluating complexities in the application of the $\mathrm{Mg} / \mathrm{Ca}$

palaeo-ocean thermometer to the planktonic foraminifera

Neogloboquadrina incompta from the Southwest Pacific Ocean

4.1 Abstract 86

$\begin{array}{lll}4.2 & \text { Introduction } & 87\end{array}$

$\begin{array}{lll}4.3 & \text { Regional setting of this study } & 90\end{array}$

$\begin{array}{lll}4.4 & \text { Methods } & 94\end{array}$

4.4.1 Sample preparation $\quad 94$

4.4.2 Trace element analysis by LA-ICP-MS 94

4.4.3 Electron microscopy 95

4.5 Results 96

4.5.1 Morphological variation in N. incompta 96

4.5.2 Weight variation between reticulate and crystalline forms of

N. incompta 99

4.5.3 Trace element depth profiles of N. incompta tests 100

$\begin{array}{lll}\text { 4.5.4 Intra-test } \mathrm{Mg} / \mathrm{Ca} \text { variability } & 102\end{array}$ 
4.5.5 $\mathrm{Mg} / \mathrm{Ca}$ - ocean temperature calibration for N. incompta from the Southwest Pacific Ocean?

4.5.6 Electron microprobe element maps of $\mathrm{Mg}, \mathrm{Al}$, and $\mathrm{Mn} / \mathrm{Ca}$ in N. incompta tests

4.6.1 Mg/Ca variability within test walls of $\mathrm{N}$. incompta

4.6.4 Palaeoceanographic implications

Chapter 5 Ocean response to MIS-31 at ODP Site 1123

5.1. Abstract

5.2 Introduction

\subsection{Materials and methods}

5.3.7 Estimation of the 'salinity proxy' from

$$
\text { G. bulloides }
$$

\section{$5.4 \quad$ Results}

5.4.2 $\mathrm{Mg} / \mathrm{Ca}$ ratios and palaeotemperatures recorded by Gs. ruber and G. bulloides

5.4.3 Other trace element data

(Al, $\mathrm{Mn}, \mathrm{Sr}, \mathrm{Ba}$ and $\mathrm{Zn} / \mathrm{Ca}$ ) in Gs. ruber and G. bulloides

5.4.4 Stable isotope data and the $\delta^{18} \mathrm{O}_{\text {sw }}$ 'salinity proxy' from G. bulloides 
5.5.2 Palaeo-SSTs during MIS-31 to 29

5.5.3 $\delta^{18} \mathrm{O}$ and palaeo-salinity during MIS-33 to $29 \quad 146$

5.5.4 $\quad \delta^{13} \mathrm{C}$ during MIS-33 to 29

5.5.5 Other trace elements (Ba, $\mathrm{Mn}, \mathrm{Zn}$ and $\mathrm{Sr} / \mathrm{Ca}$ )

5.5.6 Weights - changes in carbonate chemistry during early MIS-31?

5.6 Summary and implications for future global warming scenarios

5.7 Conclusions

$\begin{array}{lll}\mathbf{5 . 8} & \text { Supplementary material } & 158\end{array}$

5.8.1 Complementary data from ODP Site $1123 \quad 158$

5.8.2 Estimation of $\delta^{18} \mathrm{O}_{\text {sw }}$ from salinity relationships 159

5.8.3 Identification of outliers

Chapter 6 Conclusions and suggestions for future work

6.1 Trace element determination in "modern" planktonic foraminifera (Gs. ruber and N. incompta) by LA-ICP-MS

6.2 Ocean-climate response at ODP Site 1123 during MIS-34 to 29174

$\begin{array}{lll}\text { 6.3 Suggestions for future work } & 176\end{array}$

$\begin{array}{lll}\text { 6.4 References } & 177\end{array}$

Appendices $\quad 205$

Appendix A: Chapter 3206

Appendix B: Chapter $4 \quad 230$

$\begin{array}{ll}\text { Appendix C: Chapter } 5 & 247\end{array}$

$\begin{array}{ll}\text { DVD Contents } & 267\end{array}$

Complete set of raw and processed data from project (DVD) attached to back of this thesis. 


\section{List of Tables}

\begin{tabular}{|c|c|c|}
\hline Table 1.1 & Residence times of trace elements in seawater. & 12 \\
\hline Table 2.1 & $\begin{array}{l}\text { Comparison of the GJR-carbonate using LA-ICP-MS analysis from } \\
\text { VUW and the University of Utrecht. }\end{array}$ & 34 \\
\hline Table 2.2 & $\begin{array}{l}\text { Summary of the LA-ICP-MS acquisition protocol during analysis of } \\
\text { foraminifera. }\end{array}$ & 35 \\
\hline Table 2.3 & $\begin{array}{l}\text { Typical operating conditions of the LA-ICP-MS during foraminiferal } \\
\text { trace element analysis. }\end{array}$ & 36 \\
\hline Table 2.4 & $\begin{array}{l}\text { Statistical summary of inter-laboratory comparison's of TE/Ca ratios } \\
\text { measured at VUW and ANU }\end{array}$ & 42 \\
\hline Table 2.5 & $\begin{array}{l}\text { Summary of the mean trace element ratios for the same fragment } \\
\text { analysed at VUW and ANU. }\end{array}$ & 44 \\
\hline Table 3.1 & $\begin{array}{l}\text { Core top and MOCNESS tow sample locations, seafloor depths, } \\
\text { SST and calibrated }{ }^{14} \mathrm{C} \text { ages. }\end{array}$ & 53 \\
\hline Table 3.2 & Summary of Gs. ruber $\mathrm{Mg} / \mathrm{Ca}$ data for each chamber at all study sites. & 61 \\
\hline Table 3.3 & $\begin{array}{l}\text { Summary of this study's } \mathrm{Mg} / \mathrm{Ca} \text { chamber specific calibrations and } \\
\text { selected existing calibrations for Gs. ruber (white). }\end{array}$ & 63 \\
\hline Table 3.4 & $\begin{array}{l}\text { Mean } \mathrm{Ba} / \mathrm{Ca} \text { and } \mathrm{Zn} / \mathrm{Ca} \text { and standard deviation (S.D.) of for each } \\
\text { site (sites in grey are plankton tows). }\end{array}$ & 75 \\
\hline Table 3.5 & $\begin{array}{l}\text { Variation of } \mathrm{Sr} / \mathrm{Ca} \text { in individual chambers of Gs. ruber from core top } \\
\text { and plankton tow samples. }\end{array}$ & 78 \\
\hline Table 3.6 & $\begin{array}{l}\text { Significant differences in } \mathrm{Sr} / \mathrm{Ca} \text { between individual chambers } \\
\text { analysed in Gs. ruber at different sites. }\end{array}$ & 79 \\
\hline Table 3.7 & $\begin{array}{l}\text { Gs. ruber } \delta^{18} \mathrm{O}_{\mathrm{c}} \text { with calculated and measured } \delta^{18} \mathrm{O}_{\mathrm{w}} \text { compared to } \\
\text { annual SST (WOA05) and } \mathrm{Mg} / \mathrm{Ca} \text { derived SSTs. }\end{array}$ & 82 \\
\hline Table 4.1 & $\begin{array}{l}\text { N. incompta and N. pachyderma calibrations adapted from Von Langen } \\
\text { et al. [2005]. }\end{array}$ & 88 \\
\hline Table 4.2 & $\begin{array}{l}\text { Details of core-top and plankton tow samples from the Southwest } \\
\text { Pacific Ocean. }\end{array}$ & 92 \\
\hline Table 4.3 & $\begin{array}{l}\text { Summary of } \mathrm{Mg} / \mathrm{Ca} \text { ratios for } N \text {. incompta chambers } \mathrm{F}-3 \text { and } \mathrm{F} \text { at all } \\
\text { study sites. }\end{array}$ & 105 \\
\hline
\end{tabular}




\begin{tabular}{|l|l|l|}
\hline Table 4.4 & $\begin{array}{l}\text { Individual Sr/Ca in chambers F-3 and F from reticulate and } \\
\text { crystalline tests of N. incompta. }\end{array}$ & 106 \\
\hline Table 4.5 & $\begin{array}{l}\text { Summary of Mg/Ca chamber specific calibrations and existing } \\
\text { calibrations for N. incompta and N. pachyderma }\end{array}$ & 109 \\
\hline Table 4.6 & $\begin{array}{l}\text { N. incompta samples from ODP Site } 1123 \text { selected for trace element } \\
\text { mapping post LA-ICP-MS. }\end{array}$ & 110 \\
\hline Table 5.1 & Age control points for core ODP Site 1123. & 158 \\
\hline $\begin{array}{l}\text { Tables } \\
\text { 5.2a and b }\end{array}$ & Two sample t-test for Mg/Ca ratios from selected samples & 161 \\
\hline Table 5.3 & $\begin{array}{l}\delta^{18} \mathrm{O}_{\text {sw }} \text { from } \mathrm{North} \text { of Chatham Rise (courtesy of H. Neil, } \\
\text { unpublished data). }\end{array}$ & 162 \\
\hline Table 5.4 & Estimation of $\delta^{18} \mathrm{O}_{\text {sw }}$ using existing calibrations for Gs. ruber. & 163 \\
\hline Table 5.5 & Estimation of $\delta^{18} \mathrm{O}_{\text {sw }}$ using existing calibrations for G. bulloides. & 164 \\
\hline Table 5.6 & Dixon's Q test for outliers & 167 \\
\hline
\end{tabular}




\section{List of Figures}

\begin{tabular}{|c|c|c|}
\hline Figure 1.1 & Schematic of the global thermohaline circulation system. & 6 \\
\hline Figure 1.2 & The three modes of the Earth's orbital variation. & 7 \\
\hline Figure 1.3 & $\begin{array}{l}\text { Schematic of changes in } \delta^{18} \mathrm{O} \text { in oceans during glacial and } \\
\text { interglacial periods. }\end{array}$ & 15 \\
\hline Figure 1.4 & $\begin{array}{l}\text { Schematic of the generation of carbon isotope gradients in the } \\
\text { ocean. }\end{array}$ & 19 \\
\hline Figure 1.5 & Generalised chart of the Southern super-gyre. & 22 \\
\hline Figure 1.6 & $\begin{array}{l}\text { Chart of the surface ocean currents of New Zealand and } \\
\text { surrounding regions. }\end{array}$ & 23 \\
\hline Figure 1.7 & $\begin{array}{l}\text { Chart of the New Zealand region and the main elements of the } \\
\text { abyssal circulation including the deep western boundary current } \\
\text { (DWBC), and the overlying but deep-reaching Antarctic } \\
\text { Circumpolar Current (ACC). Figure taken and modified from } \\
\text { Carter et al. [1998a]. }\end{array}$ & 25 \\
\hline Figure 1.8 & This studies $\delta^{18} \mathrm{O}$ compared with the LR04 $\delta^{18} \mathrm{O}$ benthic stack & 28 \\
\hline Figure 2.1 & $\begin{array}{l}\text { Example of mounted foraminifera and the laser ablation sample } \\
\text { cell. }\end{array}$ & 32 \\
\hline Figure 2.2 & Example of laser ablation profiles from Gs. ruber. & 38 \\
\hline Figure 2.3 & Inter-laboratory LA-ICP-MS trace element analyses of Gs. ruber. & 40 \\
\hline Figure 2.4 & Inter-laboratory LA-ICP-MS trace element analyses of G. bulloides. & 41 \\
\hline Figure 2.5 & $\begin{array}{l}\text { Comparison of laser ablation profiles analysed in the same } \\
\text { fragments of Orbulina universa at different laboratories. }\end{array}$ & 43 \\
\hline Figure 3.1 & $\begin{array}{l}\text { Chart showing the annual SST, core top and plankton locations in } \\
\text { this study. }\end{array}$ & 51 \\
\hline Figure 3.2 & $\begin{array}{l}\text { Selected LA-ICP-MS profiles of Gs. ruber from particular sites in } \\
\text { the Southwest Pacific Ocean. }\end{array}$ & 57 \\
\hline Figure 3.3 & $\begin{array}{l}\text { Scanning Electron Micrograph (SEM) image of broken Gs. ruber } \\
\text { chamber. }\end{array}$ & 59 \\
\hline Figure 3.4 & $\mathrm{Mg} / \mathrm{Ca}$ for each chamber plotted against mean annual SST from & 62 \\
\hline
\end{tabular}




\begin{tabular}{|c|c|c|}
\hline & each sampling site. & \\
\hline Figure 3.5 & $\begin{array}{l}\mathrm{Mg} / \mathrm{Ca} \text { data for each chamber normalised by the mean value for } \\
\text { their temperature and pooled. }\end{array}$ & 65 \\
\hline Figure 3.6 & $\begin{array}{l}\mathrm{Mg} / \mathrm{Ca} \text { data binned by temperature and pooled from the three } \\
\text { chambers. }\end{array}$ & 66 \\
\hline Figure 3.7 & $\mathrm{Mg} / \mathrm{Ca}$ for each individual chamber F-2 and F converted to SST & 71 \\
\hline Figure 3.8 & $\begin{array}{l}\text { Relationship between } \mathrm{SNW} \text { and surface water }\left[\mathrm{CO}_{3}^{2}\right] \text {, temperature } \\
\text { and salinity. }\end{array}$ & 84 \\
\hline Figure 4.1 & $\begin{array}{l}\text { Location chart of the core-top (black circles) and plankton tow } \\
\text { (white circles) samples from the Southwest Pacific Ocean }\end{array}$ & 93 \\
\hline Figure 4.2 & $\begin{array}{l}\text { Illustration adapted from Sadekov et al. [2005] and Reiss [1958] } \\
\text { showing a cross-section of an N. incompta test and chamber wall } \\
\text { construction }\end{array}$ & 97 \\
\hline Figure 4.3 & Morphotypes and ultra-structures of N. incompta from this study. & 98 \\
\hline Figure 4.4 & $\begin{array}{l}\text { Reticulate and crystalline mean test weight and mean test weight } \\
\text { versus depth from each site }\end{array}$ & 100 \\
\hline Figure 4.5 & LA-ICP-MS depth profile for crystalline N. incompta & 101 \\
\hline Figure 4.6 & $\begin{array}{l}\text { LA-ICP-MS depth profiles of } \mathrm{Mg} / \mathrm{Ca} \text { in crystalline and reticulate } \\
\text { tests }\end{array}$ & 102 \\
\hline Figure 4.7 & $\begin{array}{l}\mathrm{Mg} / \mathrm{Ca} \text { ratios from individual chambers of } N \text {. incompta from core } \\
\text { top site } \mathrm{R} 623 .\end{array}$ & 103 \\
\hline Figure 4.8 & $\begin{array}{l}\text { Comparison of } \mathrm{Mg} / \mathrm{Ca} \text { ratios in the final chamber of in } \\
\text { kummerform and normal-forms of reticulate and crystalline } \mathrm{N} \text {. } \\
\text { incompta. }\end{array}$ & 104 \\
\hline Figure 4.9 & $\mathrm{Mg} / \mathrm{Ca}$ ratios versus ocean temperature for $N$. incompta. & 108 \\
\hline Figure 4.10 & $\begin{array}{l}\text { Microprobe elemental maps of three individual N. incompta } \\
\text { samples }\end{array}$ & 111 \\
\hline Figure 5.1 & Orbital parameters during MIS-34 to -29 . & 122 \\
\hline Figure 5.2 & $\begin{array}{l}\text { Chart of the surface ocean currents of offshore New Zealand and } \\
\text { surrounding regions. }\end{array}$ & 124 \\
\hline Figure 5.3 & Age model of ODP Site 1123 & 126 \\
\hline
\end{tabular}




\begin{tabular}{|c|c|c|}
\hline Figure 5.4 & $\begin{array}{l}\text { Variability of } \mathrm{Mg} / \mathrm{Ca} \text { ratios in Gs. ruber and G. bulloides through the } \\
\text { ODP Site } 1123 \text { sediment record. }\end{array}$ & 132 \\
\hline Figure 5.5 & $\begin{array}{l}\text { Orbital parameters, } \mathrm{SST}_{\mathrm{Mg} / \mathrm{Ca}} \mathrm{SST}_{\mathrm{ANN}} \mathrm{SST}_{\mathrm{d} 18 \mathrm{O}} \text { and planktonic } \\
\text { foraminiferal assemblage data. }\end{array}$ & 134 \\
\hline Figure 5.6 & $\begin{array}{l}\text { Summary of all trace elements measured in Gs. ruber and } G \text {. } \\
\text { bulloides }\end{array}$ & 136 \\
\hline Figure 5.7 & The $\delta^{18} \mathrm{O}$ and $\delta^{13} \mathrm{C}$ measured in from Uvigerina and G. bulloides & 138 \\
\hline Figure 5.8 & SST and calculated $\delta^{18} \mathrm{O}_{\mathrm{sw}}$ in G. bulloides & 139 \\
\hline Figure 5.9 & $\begin{array}{l}\text { G. bulloides SST versus actual and predicted size-normalised weight } \\
\text { and other environmental variables. }\end{array}$ & 140 \\
\hline Figure 5.10 & $\begin{array}{l}\text { Comparison between } \mathrm{SST}_{\mathrm{Mg} / \mathrm{Ca}} \text { with orbital precession, obliquity } \\
\text { and insolation. }\end{array}$ & 146 \\
\hline Figure 5.11 & $\begin{array}{l}\text { Changes in SST, } \delta 18 \text { Ocalcite and } \delta 18 \text { Oseawater continental ice } \\
\text { volume and local } \delta 18 \text { Osw measured from Gs. ruber and G. } \\
\text { bulloides. }\end{array}$ & 148 \\
\hline Figure 5.12 & Correlation of ODP Site 1123 palaeomagnetic susceptibility data & 159 \\
\hline Figure 5.13 & $\begin{array}{l}\text { Relationship between temperature and } \delta^{18} \mathrm{O}_{\mathrm{c}}-\delta^{18} \mathrm{O}_{\mathrm{sw}} \text { in } G s . \text { ruber } \\
\text { and G. bulloides }\end{array}$ & 166 \\
\hline
\end{tabular}




\section{List of Abbreviations}

ACC

ANU

Aphelion

Asymbiotic

BP

CTD

DIC

DWBC

Gametogenic (calcite)

G-IG

GNS

ICP-MS

kyr

LA

LA-ICP-MS

Lamellar

Lysocline

$\mathrm{Ma}$

mbsf

mbsl

$\operatorname{mcd}$

$\mu \mathrm{g} / \mathrm{g}$

$\mathrm{mmol} / \mathrm{mol}$

$\mu \mathrm{mol} / \mathrm{mol}$
Antarctic Circumpolar Current

Australian National University

Furthest distance from the sun

An organism that does not have symbionts (see symbionts)

Before Present

Conductivity, Temperature and Density (device)

Dissolved Inorganic Carbon

Deep Western Boundary Current

Calcite formed at the end of the life cycle

Glacial to Inter-glacial (cycles)

Geological and Nuclear Sciences

Inductively Coupled Plasma Mass Spectrometry

Thousand years

Laser Ablation

Laser Ablation Inductively Coupled Plasma Mass Spectrometry

A thin layer (of calcite), or test-wall built of layers of calcite formed at consecutive instars and covering exposed surfaces of previously formed test

Denotes the depth in the ocean below which the rate of dissolution of calcite increases dramatically

Million years

meters below sea floor

meters below sea level

meters composite depth

micro-grams per gram

milli-moles per Mole

micro-moles per Mole 


\begin{tabular}{|c|c|}
\hline MIS & Marine Isotope Stage \\
\hline MS & Mass Spectrometer \\
\hline $\mathrm{n}$ & number of determinations \\
\hline $\mathrm{NH}$ & Northern Hemisphere \\
\hline Non-spinose & Those foraminifera that lack spines \\
\hline NIWA & National Institute of Water \& Atmospheric Research \\
\hline ODP & Ocean Drilling Program \\
\hline Ontogenetic (calcite) & Calcite originally formed as part of the normal life cycle \\
\hline Perihelion & Closest distance to the sun \\
\hline Reticulate & Having ornamental features arranged in a network \\
\hline SAF & Subantarctic Front \\
\hline SAW & Subantarctic Surface Water \\
\hline s.d. & standard deviation \\
\hline s.e. & standard error \\
\hline SEM & Scanning Electron Microscope \\
\hline $\mathrm{SH}$ & Southern Hemisphere \\
\hline SMOW & Standard Mean Ocean Water \\
\hline SNW & Sized-normalised Weight \\
\hline SST & Sea Surface Temperature \\
\hline STF & Subtropical Front \\
\hline STW & Subtropical water \\
\hline Symbiont & An organism in a symbiotic relationship \\
\hline TE & Trace Element (to Ca) \\
\hline VUW & Victoria University of Wellington \\
\hline WOA05 & World Ocean Atlas 2005 \\
\hline WOCE & World Ocean Circulation Experiment \\
\hline
\end{tabular}




\section{Chapter 1}

\section{Introduction}

The study of past interglacial periods warmer than today can provide important perspectives on how Earth's ocean-climate system might respond in a world that may become several degrees Celsius warmer than the present, based on projected future anthropogenic increases of atmospheric carbon dioxide [IPCC, 2007]. This thesis utilises the geochemistry of planktonic foraminifera to establish modern calibrations between the trace element chemistry of their carbonate tests, seawater temperature and chemistry. Subsequently, these calibrations are applied to a high temporal resolution study of foraminifera from Marine Isotope Stage 31 (MIS-31), an interglacial period that occurred ca., $1.1 \mathrm{Ma}$, which has been postulated to have been warmer than the present interglacial [Scherer et al., 2008].

This introductory chapter outlines the objectives and structure of this thesis, and reviews the controls on the global climate system, the use of foraminiferal chemistry as palaeoenvironmental proxies, and the regional oceanography of the Southwest Pacific which is the region of focus in this study.

\subsection{Objectives of this thesis}

This thesis has two main objectives that both primarily involve the trace element analysis of planktonic foraminifera by laser ablation inductively coupled plasma mass spectrometry (LA-ICP-MS). The first part of this study investigates the trace element chemistry of modern individuals of two species of planktic foraminifera (Globigerinoides ruber and Neogloboquadrina incompta) from core top samples taken at various localities in the Southwest Pacific. This part of the thesis was designed to answer the following questions: (a) Can $\mathrm{Mg} / \mathrm{Ca}$ ratios in these species measured by LA-ICP-MS be used to reliably reconstruct sea 
surface temperatures (SST) in the Southwest Pacific?; (b) Assess whether other trace elements (e.g., $\mathrm{Mn}, \mathrm{Zn}$ and $\mathrm{Ba}$ ) measured in the foraminifera tests are potentially useful palaeoclimate and palaeoceanographic proxies in these species of planktonic foraminifera?; (c) What additional information can be gleaned from the in situ LA-ICP-MS analytical method as opposed to traditional bulk solution methods for analysing foraminifera? For example, the extent to which intra- and inter-individual chemical heterogeneity exists in foraminifera from a given core-top and identifying the process(es) responsible for this. (d) To examine the potential relationships between foraminiferal shell weights, size, $\mathrm{Mg} / \mathrm{Ca}$ ratios and environmental variables such as ocean carbonate ion concentration and sea surface temperature.

The second part of this study aimed to utilise the LA-ICP-MS trace element chemistry of three species of planktonic foraminifera (Globigerinoides ruber, Neogloboquadrina incompta and Globigerina bulloides) to reconstruct the ocean-climate conditions of MIS-34 to MIS-29. The modern $\mathrm{Mg} / \mathrm{Ca}$ - ocean temperature calibrations established for Globigerinoides ruber and Neogloboquadrina incompta in the first part of this thesis were used to reconstruct past SSTs from these species, and a comparable study of modern Globigerina bulloides [Marr et al., 2011] was used to reconstruct past SSTs from this species. This work also involved the acquisition of conventional stable oxygen and carbon isotope data.

MIS-34 to mid-MIS-29 occurred 1.00 to $1.15 \mathrm{Ma}$ and during this period global average surface temperatures changed in response to orbitally-driven changes in solar insolation that are modulated by atmospheric composition, oceanic circulation and other factors that reflect the complexities of the Earth system. To date, the MIS-31 interglacial (ca., 1.07 Ma), has received little attention as a key climate event. However, during this period there is sufficient evidence from both low and high latitude records to indicate significant ocean circulation and ice volume changes occurred and that this interglacial may have been considerably warmer than the present interglacial [Naish et al., 2009]. The palaeoenvironmental reconstruction of MIS-31 in this thesis is based on a deep marine sediment core form ODP Site 1123, retrieved on Leg 181 by the Ocean Drilling Program (ODP) offshore of New Zealand (Figure 1.1) [Carter et al., 1999; Carter et al., 2004b].

This palaeo-environmental reconstruction of MIS-31 is aimed to address the following research questions: (a) To compare the $\mathrm{Mg} / \mathrm{Ca}$ derived SST results of this study to other SST data from ODP Site 1123 obtained from other archives or proxies e.g., foraminiferal assemblages (Artificial Neural Networks), Ba/Al ratios from sediments, sortable silt 
fraction. (b) How did the ocean and its planktic foraminiferal assemblages, in the vicinity of the Subtropical Front, respond to a period of peak insolation? (c) Given that this period was the most recent time in the past when Antarctica underwent a major loss of ice [Pollard and DeConto, 2009], what climatic effect resulted in the Southwest Pacific in the New Zealand region? (c) Is MIS-31 suitable as an analogue for projected future climate change and if so, what climatic and oceanographic changes can be expected in the coming centuries?

\subsection{Structure of this thesis}

This thesis comprises six chapters encompassing work from method description, technique development, $\mathrm{Mg} / \mathrm{Ca}$ - ocean temperature core-top calibrations through to palaeoenvironmental reconstruction of MIS-31 as follows:

Chapter 1: An introduction to this thesis, its objectives and background material relevant to this study (Earth's climate system, foraminiferal geochemistry and regional oceanography).

Chapter 2: A description of the materials and analytical methods used in this study.

Chapter 3: The development of the LA-ICP-MS analytical method and application to Gs. ruber from core-top sites from the Southwest Pacific to establish a LA-ICP-MS calibration between $\mathrm{Mg} / \mathrm{Ca}$ and SST. This chapter was submitted for publication to the journal Paleoceanography and accepted for publication on February $22^{\text {nd }} 2011$. AB wrote the paper with contributions from each of the authors, in particular LC and GD commented on the introduction, JB and GD commented on the methods sections, EC contributed to the statistical modelling and all authors contributed to the discussion.

Chapter 4: The development of the LA-ICP-MS analytical method and application to $N$. incompta from core-top sites from the Southwest Pacific to establish a LA-ICP-MS calibration between $\mathrm{Mg} / \mathrm{Ca}$ and SST.

Chapter 5: Application of LA-ICP-MS trace element analyses of Gs. ruber and G. bulloides to reconstructing the palaeo-environmental conditions during MIS-31 (MIS-33 to -29).

Chapter 6: The final chapter closes with a summary of the main conclusions of this thesis and suggestions for further work. 
All of the data in this thesis was produced by me, except for the stable isotope data, which was prepared by myself and analysed at either NIWA or Stanford University. Other contributions were from Kylie Christiansen who worked with me as a summer research assistant under my supervision. Ms. Christiansen contributed to some of the preparation tasks such as weighing samples and measuring lengths and heights of individual foraminifera for the MIS-31 Chapter 5 study.

All of the data reported in this thesis have been copied to a DVD, which is attached to the back cover.

\subsection{Earth's climate - an overview}

Reconstruction of Earth's past climate throughout the Quaternary and Cenozoic can be used to examine natural climate variability, warming and cooling of the oceans and atmosphere, and from the response of Earth's cryosphere to this, at a time when there were no anthropogenic influences. This section reviews the factors that are responsible for driving natural climate variability i.e., without anthropogenic influence.

\subsubsection{What drives Earth's climate system?}

The energy that drives natural climate/ocean variability comes primarily from the sun. Given that Earth is an oblate sphere, different amounts of heat fall on different parts of the planet's surface, less at the poles, and most at the equator. Thus the equator is warmer than the poles, and heat is redistributed from the equator to the poles gives rise to weather, climate and oceanic circulation.

On average, about a quarter of incoming solar radiation is used to evaporate water, which carries with it a large amount of that energy (as latent heat) through the atmosphere. It is effectively this energy, and the pole-equator variation in energy balance, which powers atmospheric circulation and winds, and with it the associated water that is the source of what is characterised as weather. The effect of winds is mostly confined to the upper several hundred metres of the oceans, and these winds redistribute energy and moisture around the globe [Andrews, 2000; Rabmstorf, 2002]. The wind also causes upwelling (referred to as Ekman divergence) near coasts and the Equator, which changes sea surface 
temperatures. This mechanism plays an important role in the El Niño/La Niña Southern Oscillation cycle.

The other way that heat is transported away from the equator is by the oceans. Although oceanic circulation is also influenced by the morphology of the ocean basins, differences in seawater density aided by wind-driven upper ocean currents primarily drives ocean circulation and, in particular, the deep thermohaline circulation system [Munk and Wunsch, 1998]. It is this system that delivers most heat from the equator to high latitude polar regions.

\subsubsection{Thermohaline circulation}

The term thermohaline circulation is often used to describe the movement of temperature and salt (or freshwater) in the ocean. This was further defined by Wunsch [2002] who argued that as both heat and salinity operate in three-dimensions they should be viewed separately and therefore used the definition of ocean circulation as that of its [water] mass, sustained primarily by the wind, and secondarily by tidal forcing. In the Atlantic Ocean, during the winter, this warmer water is transferred to the overlying atmosphere, greatly supplementing that received from the sun. This extra heat results in warmer than expected winters in Europe [Broecker, 1997]. This water loses heat as it cools, and is subsequently converted into cold water that sinks and flows equatorward at depth [Toggweiler and Key, 2001]. The thermohaline circulation system is thought to be a key component in the climatic records that indicate significant changes in the mode of this circulation occurred in this past [Clark and Mix, 2002]. Figure 1.1 shows a highly simplified schematic of the thermohaline circulation system in the modern ocean [Rahmstorf, 2002]. It shows the Pacific equatorial near surface waters, driven westward by atmospheric winds where it slowly moves into the South and then North Atlantic. Here the upper water cools due to ambient temperatures and increases in salinity and density. Initially the dry atmosphere increases evaporation and hence seawater salinity, and then ice formation increases that salinity further. This cold saline dense water then sinks and is pushed south at depth forming one of four main deep-water production regions. In the Southern Hemisphere these are in the Ross Sea and the Weddell Sea. These regions also re-circulate the ocean at depth. Most of this dense, cold water is slowly circulated northward into all three major oceans via the Antarctic Circumpolar Current. This cycling water eventually becomes warmer and less saline, and is upwelled in the Pacific where the cycle continues. 


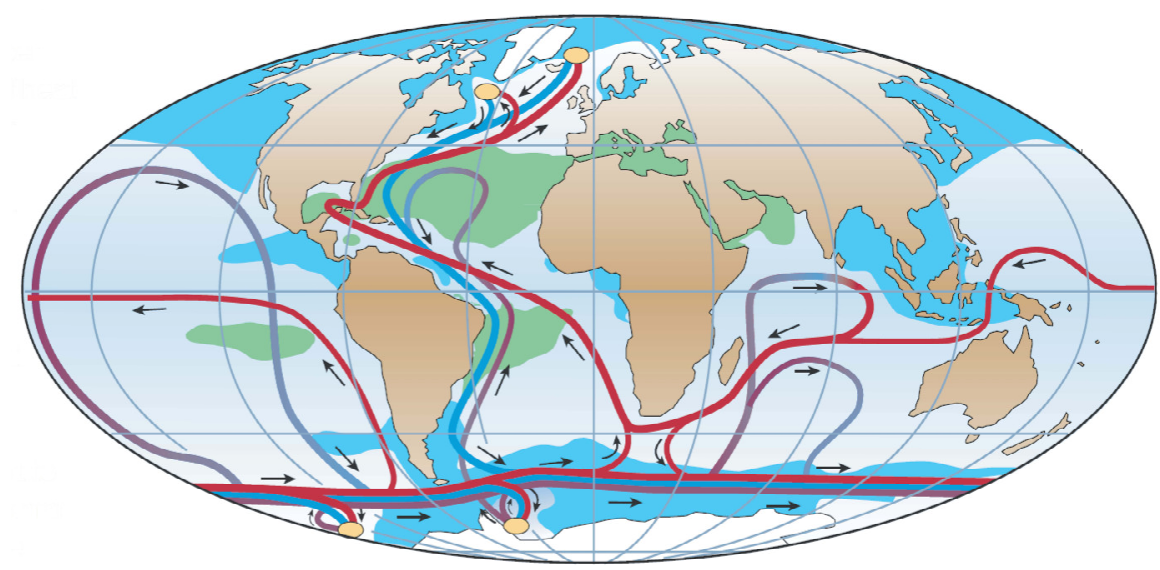

Figure 1.1: Schematic of the global thermohaline circulation system. Red lines $=$ near surface water currents; yellow ovals $=$ main deep-water formation regions; blue lines = deep water currents; purple lines $=$ bottom currents; green shading $=$ salinity above $36 \%$; blue shading $=$ salinity below $34 \%$. Figure from Rahmstorf [2002].

\subsubsection{Why does global climate vary?}

The factors that cause global climate to vary can be divided into two broad types:

- extraterrestrial (orbital variations, solar output) and,

- terrestrial (atmospheric chemistry, tectonics, volcanism and biological factors).

Terrestrial factors are a complex interplay of atmospheric chemistry, ocean-atmosphere circulation, continent-ocean basin configurations, volcanism and life. The latter three are not discussed as they are controlled largely by plate tectonics (with the exception of life), and thus tend to change gradually, and for the most part, uni-directionally, on million-year (My) time scales [Ruddiman, 2003].

In response to external forcing are changes in ice volume and greenhouse gases that interact with the climate system. These variations in ice-volume produce ice-proximal changes in SST, dust fluxes, and deep water flow, and some combination of these responses controls the 41,000-year atmospheric $\mathrm{CO}_{2}$ signal [Ruddiman, 2003]. An increase in $\mathrm{CO}_{2}$ and other greenhouse gases, provides a positive feedback on the size of the ice 
sheets by amplifying ice-volume changes. Atmospheric circulation is also an important component as large-scale anomalies of (SST) induces heating or cooling of the atmosphere, changing wind on the ocean surface (wind stress) and heat exchange between the ocean and the atmosphere (heat fluxes) [Samelson et al., 2006; Wyrtki, 1973], see also Section 1.5.1.

In this section, it is considered that extraterrestrial factors caused by variations in the Earth's orbit are the main driver of climate change; these factors are discussed further below.

Variations in Earth's orbit and attitude were first proposed by scientist James Croll, and later advanced by the Serbian physicist Milutin Milankovitch who identified three modes of variation and predicted that these modes should leave climatic evidence. The three modes are referred to as eccentricity (orbital stretch), obliquity (axial tilt), and precession (axial path wobble) (Figure 1.2). Furthermore, Milankovitch (1941) hypothesised that summer insolation in the northern hemisphere at the periods of obliquity and precession directly forced ice sheets through changes in summer ablation.

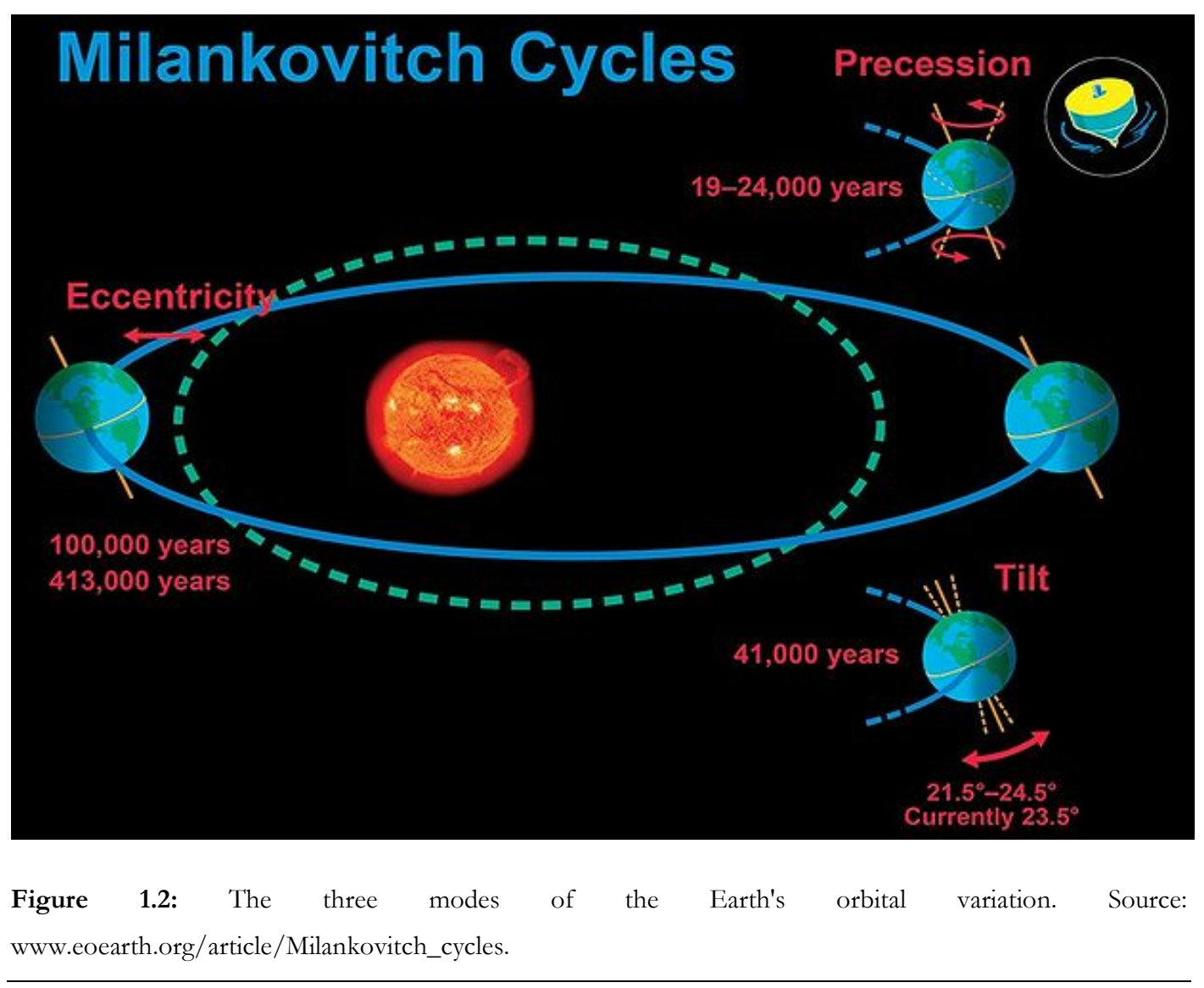


Eccentricity: Earth's orbit about the sun is elliptical and, therefore, the global mean average energy received by the Earth varies with the long axis of its ellipse which is maximal approximately every 100,000 and 400,000 yr [Paillard, 2010]. When the Earth is closest to the Sun, it is called perihelion and when furthest, the aphelion. The difference between the maximum and minimum long axis is about 5 million $\mathrm{km}$. Hence, this 'eccentricity' of Earth's orbit around the Sun leads to regular changes in the amount in solar radiation reaching Earth, which in turn affects global climate.

Precession: The third orbital effect on Earth's climate is that of precession of the equinoxes. Precession is the 'wobble' that occurs on a 19,000 to 24,000 yr cycle in Earth's spin on its rotational axis. It is caused by the gravitational pull of the Sun and Moon on Earth. The amplitude of this cycle is modulated by eccentricity. Changes in precession result in incident changes in intensity of solar radiation at the equator; but this also decreases the length of the summer as the pass around the sun will be shorter. Thus, high precession correlates to hotter, shorter summers.

Tilt/Obliquity: Earth's axis relative to the plane of its orbit has also changed through time between $\left(21.5\right.$ to $\left.24.5^{\circ}\right)$ with a period of about $41,000 \mathrm{yr}$. A change in the axis changes the angle of solar radiation with respect to the poles. The current tilt of $23.5^{\circ}$ is what gives the Earth its seasons where, for example, the northern hemisphere is tilted toward the sun during June, and hence receives more solar energy than the south. At the same time, the southern hemisphere is tilted away from the sun, which results in winter. These changes in tilt produce long-term variations in seasonal solar energy, particularly at the poles. If the axial tilt of the Earth were $0^{\circ}$, then there would be no seasons.

Thus, eccentricity affects climate by modulating the amplitude of precession, influencing the total annual/seasonal solar energy budget, whereas obliquity changes the latitudinal distribution of insolation [Zachos et al., 2001]. Together the combined effect of these parameters are called insolation, which is the amount of solar radiation expressed in $\mathrm{kWh} / \mathrm{m}^{2}$, impinging on the earth in any given region or area.

Evidence of the above external variations is increasingly more apparent in sedimentary archives. For example Zachos et al., [2001], show Earth's climate system last 65 million years 
and beyond, has experienced continuous change, shifting from expansive warmth with icefree poles, to extremes of cold with massive continental ice-sheets and polar ice caps.

\subsection{Foraminifera as archives of palaeoclimate and palaeoceanographic change}

Foraminifera are unicellular marine micro-organisms (single-celled protistids) capable of fossilisation that constitute only a minor percentage of the total living zooplankton [Hemleben et al., 1989]. The name "foram" comes from the 'formamen', which is a tube-like opening that connects all the chambers of the test together. The Class Foraminifera can be separated into groups by their morphology based on wall structure and chemistry [Gupta, 1999]. The first group build their test or outer membrane with organic material. The second group are agglutinated, where the tests are made up of particles from the surrounding environment. The third group are made of calcium carbonate $\left(\mathrm{CaCO}_{3}\right)$. This third group is further separated into two polymorphs, calcite and aragonite. Finally, the fourth group has tests that are composed of opaline silica. Within each of these groups are one or more orders. This study focuses only on those foraminifera that secrete tests made of calcite, of which there are eight orders.

Fossil foraminifer shells or tests preserved in the marine sediment record are important because species assemblage data, test weights and shell chemistry can be used to reconstruct information about past oceanic and climatic conditions such as SST, ocean productivity, global ice volume, and seawater salinity, carbonate ion concentration $\left[\mathrm{CO}_{3}^{2}\right]$ and $\mathrm{pH}$ e.g., [Fischer and Wefer, 1999]. The next section reviews the physico-chemical factors that control foraminifers' ecology, which are pertinent to their use as archives of palaeoenvironmental conditions.

\subsubsection{Modern planktonic foraminifera}

Calcium carbonate tests of foraminifera are either aragonite or calcite, and the shell can be milky white (porcelaneous taxa), grey (microgranualar taxa) or glassy (byaline taxa), [Wilkinson, 1997]. Foraminifera can be separated into two types based on their habitat: planktonic (upper ocean) and benthic (seafloor). Planktonic foraminifera live in the upper surfaces of the oceans passively floating within a depth range of about $0-400 \mathrm{~m}$, but are often found at deeper depths towards the end of their life cycle (e.g., Erez et al., 1991; Huang et al., 2008). Benthic foraminifera are adapted to living in or on the seabed in most water depths. Those 
that live in deep-water can contain information about the abyssal circulation of the ocean [Curry and Lobmann, 1982; Miller et al., 1987]. Benthic foraminifera that are composed of calcite are limited to waters which are thermodynamically supersaturated or near saturation with respect to $\mathrm{CaCO}_{3}$ i.e. above the carbonate compensation depth [Archer, 1996]. This is also true for aragonitic foraminifera and other organisms that precipitate aragonite. In this case, it is the aragonitic depth which controls whether these tests are preserved in sediments [Berger, 1978]. However, most calcium carbonate foraminifera have calcite tests [Todd and Blackmon, 1956].

The lifespan of foraminifera is known to be short, ranging from anything between a few days to several months [Goldstein, 1999]. Foraminifera have been known to reproduce in relation to the lunar calendar and the semi-lunar calendar [Bijma et al., 1990a; Armstrong and Brasier, 2005]. Other researchers have found reproduction (gametogenesis) coinciding with full moons [Erez et al., 1991].

Current available knowledge on the foraminiferal lifespan has mostly been obtained from laboratory culture studies, which have shown variations (e.g., morphology, size, amounts of gametogenic calcite produced) between the same species, thus giving rise to uncertainties and obvious limitations [Bé et al., 1977; Bijma et al., 1990b; Caron et al., 1990; Bijma et al., 1992]. Obtaining reliable data on the lifespan of foraminifera is essential when extrapolating palaeoclimatic data, as such data will represent the duration and depth location in which foraminifera tests record the physico-chemical conditions of seawater in which they were living e.g., temperature, salinity [Nigam et al., 2003].

\subsubsection{Life processes and calcification}

The actual formation of a foraminferal test is thought to reduce biological, physical and chemical stress. For example, providing the organism with protection from predation, provision of shelter from unfavourable physical or chemical conditions, a receptacle for excreted matter, an aid to the reproductive process, control of buoyancy, possible assistance with cell growth and support for pseudopods and the body cell [Marszalek et al., 1969; Armstrong and Brasier, 2005].

The last chamber of the test has one or more openings where protoplasm exudes to engulf the outer test [Goldstein, 1999]. This protoplasm, in the form of pseudopodia, are used to make long filaments that aid movement and trap food particles such as diatoms, algae, 
bacteria and detritus, which after capture are withdrawn and ingested inside the test. The geographical patterns of planktonic foraminiferal abundances generally follow those of nutrient concentrations and plankton productivity, and are closely linked to water circulation patterns [Bé and Hutson, 1977].

The depths habitats of many foraminifera species are not well known and it is believed that some species live at different water depths at different times in their life cycles [Bradley, 1985]. Many forms of planktonic foraminifera, particularly Globorotalia, increase their test densities by forming a calcite crust (secondary calcification); the deepest-dwelling morphotypes having the thickest tests. Thus, planktonic foraminifera control their buoyancy by using the density of the protoplasm, the amount of calcite in the test (by test growth and secondary calcification) and by absolute test size [Kennett, 1982]. Calcification depth has been estimated from depth-stratified plankton tows, sediment traps and stable oxygen isotope ratios $\left(\boldsymbol{\delta}^{18} \mathrm{O}\right)$ (e.g., Mortyn and Charles, 2003; Bé and Ericson 1963; Regenberg et al., 2009). A sediment trap study from the Arabian Sea suggested that the lifecycle of planktonic foraminifera is probably of the order of several months due to periods of nil flux, which could not be explained by practical factors of the experiment [Nigam et al., 2003].

\subsubsection{Geochemistry of foraminiferal tests}

Foraminifera secrete carbonate shells by a biochemical reaction whereby:

$$
\mathrm{Ca}^{2+}+2 \mathrm{HCO}_{3}^{-} \Leftrightarrow \mathrm{CaCO}_{3}+\mathrm{H}_{2} \mathrm{O}+\mathrm{CO}_{2}
$$

The formation of either aragonite or calcite depends on temperature and pressure. Most of the calcium carbonate foraminifera tests are composed of almost pure $\mathrm{CaCO}_{3}(>99 \%)$ with the remaining $1 \%$ consisting of trace elements [Lea, 1999]. It is these trace elements within foraminiferal calcite, which make it a sensitive palaeoclimate indicator via various geochemical proxies. 


\subsubsection{Trace elements in seawater and foraminiferal calcite}

On average, there is about five times more $\mathrm{Mg}$ than $\mathrm{Ca}$ in seawater (Table 1.1). The ratios of conservative elements (e.g., $\mathrm{Mg}, \mathrm{Sr}, \mathrm{B}, \mathrm{Li}, \mathrm{F}, \mathrm{V}, \mathrm{U}$ ) to $\mathrm{Ca}$ are broadly fixed in seawater, whereas those of nutrient (e.g., $\mathrm{Cd}, \mathrm{Ba}, \mathrm{Zn}$ ) or scavenging elements (e.g., $\mathrm{Al}, \mathrm{Mn}$ ) to Ca have much larger and systematic variations [Nozaki, 1997; Bruland and Lohan, 2003]. In inorganic precipitation experiments, calcite is formed only under supersaturated conditions and trace elements such as $\mathrm{Mg}^{2+}$ and $\mathrm{Sr}^{2+}$ can either assist or inhibit nucleation. $\mathrm{Sr}^{2+}$ is a similar size and has similar co-ordination geometry to $\mathrm{Ca}^{2+}$ and will assist nucleation, whereas $\mathrm{Mg}^{2+}$ is much smaller and will hinder nucleation [Williams, 2008]. The Mg content of inorganic calcite was measured as $c a .80 \mathrm{mmol} / \mathrm{mol}$ at $25^{\circ} \mathrm{C}$ whereas it is much lower in aragonite (ca. $4 \mathrm{mmol} / \mathrm{mol}$ ). Foraminifera have a considerable control on the bio-mineralisation of calcite and aragonite because they are able to internally control the $\mathrm{pH}$, concentrations of ions and salts and calcification rate [Erez, 2003; Bentov and Erez, 2006; Kisakürek et al., 2008; Bentov et al., 2009]. Therefore trace element/Ca ratios in foraminiferal tests are influenced by the physiological and/or biological processes of calcification [Elderfield et al., 1996].

The $\mathrm{Ca}^{2+}$ ion can be exchanged for other trace elements (TE) within the calcite lattice [Lea, 1999] whereby:

$$
\mathrm{CaCO}_{3}+\mathrm{TE}^{2+} \Leftrightarrow \mathrm{TECO}_{3}+\mathrm{Ca}^{2+}
$$

Table 1.1: Residence times of trace elements in seawater adapted from [Nozaki, 1997; Bruland and Lohan, 2003].

\begin{tabular}{cccc}
\hline Element & Ion & Average ocean concentration & Ocean residence time (yr) \\
\hline $\mathrm{Mg}$ & $\mathrm{Mg}^{2+}$ & $52.7 \mathrm{mmol} / \mathrm{kg}$ & $13,000,000$ \\
$\mathrm{Sr}$ & $\mathrm{Sr}^{2+}$ & $89 \mu \mathrm{mol} / \mathrm{kg}$ & $5,100,000$ \\
$\mathrm{Ba}$ & $\mathrm{Ba}^{2+}$ & $109 \mathrm{nmol} / \mathrm{kg}$ & 10,000 \\
$\mathrm{Ca}$ & $\mathrm{Ca}^{2+}$ & $10.27 \mathrm{mmol} / \mathrm{kg}$ & $1,100,000$ \\
$\mathrm{Mn}$ & $\mathrm{Mn}^{2+}$ & $360 \mathrm{pmol} / \mathrm{kg}$ & 60 \\
$\mathrm{Al}$ & $\mathrm{Al}^{2+}$ & $1.11 \mathrm{nmol} / \mathrm{kg}$ & 200 \\
$\mathrm{Zn}$ & $\mathrm{Zn}^{2+}$ & $5.4 \mathrm{nmol} / \mathrm{kg}$ & 51,000 \\
\hline
\end{tabular}




\subsubsection{Mg/Ca ratios as a palaeocean thermometer in planktonic foraminifera}

The $\mathrm{Mg} / \mathrm{Ca}$ ratio of planktonic foraminiferal calcite is an important tool for reconstructing past SST. $\mathrm{Ca}^{2+}$ ions in the calcium carbonate test lattice are substituted by $\mathrm{Mg}^{2+}$ ions in an endothermic reaction. Therefore, the higher the temperature at the time of calcification, the higher the carbonate $\mathrm{Mg} / \mathrm{Ca}$ ratio.

This relationship is an exponential one described by the equation:

$$
\mathrm{Mg} / \mathrm{Ca}=\mathrm{B} \exp ^{(\mathrm{A} \times \mathrm{T})}
$$

Where $\mathrm{B}$ is the pre-exponential constant, $\mathrm{A}$ is the exponential constant (intercept) and $\mathrm{T}$ is temperature $\left({ }^{\circ} \mathrm{C}\right)$. Most palaeo-ocean thermometry calibrations are based in specific latitudinal ranges such as equatorial/tropical, subtropical/transitional and polar because of the biogeographical distribution of individual foraminiferal species [Arnold and Parker, 1999]. Calibrations derived to reconstruct SST in polar regions are limited because, as latitude increases, the number of planktonic species decreases with only one planktonic species found at both poles [Pearce, 1991]. Notwithstanding this, calibrations from higher latitudes are important as temperature changes over geological timescales will be more prominent at polar regions, compared to the equatorial regions.

An important aspect of $\mathrm{Mg} / \mathrm{Ca}$ palaeo-ocean thermometry is that the relationship between the $\mathrm{Mg} / \mathrm{Ca}$ ratio and temperature is also modified internally by different species of foraminifera (i.e. A and B in equation 1.3 are species-specific). Some of these differences can be explained by other environmental and biological factors that include salinity, dissolution, test size and seasonality. Some studies have found salinity has little effect on core-top foraminiferal $\mathrm{Mg} / \mathrm{Ca}$ ratios [Sadekov et al., 2008], although it appears to be more pronounced in regions with high salinity gradients such as the Red Sea [Ferguson et al., 2008; Mathien-Blard and Bassinot, 2009]. Others have found that increased test size is coupled with increased $\mathrm{Mg} / \mathrm{Ca}$ ratios in several species [Elderfield et al., 2002]. Dissolution on the other hand, can alter carbonate $\mathrm{Mg} / \mathrm{Ca}$ ratios by the preferential dissolution of high $\mathrm{Mg}$ bands found within the calcite lattice. This is further complicated as some species appear to be 
more susceptible to dissolution than others [Dekens et al., 2002] and, although the majority of dissolution, is related to those fossils that are beneath the calcite compensation depth, there is evidence to suggest that dissolution can also occur at shallower depths [Brown and Elderfield, 1996]. Therefore it is important to exercise caution in the interpretation of foraminiferal $\mathrm{Mg} / \mathrm{Ca}$ ratios from deep marine sediment cores (i.e. > $3000 \mathrm{~m}$ ); as derived temperatures can be erroneously lower than actual calcification temperatures. Seasonality can also affect the $\mathrm{Mg} / \mathrm{Ca}$ ratios where the dominant signal (SST) is biased towards a particular season [Kawahata, 2005; Wilke et al., 2008; Wan et al., 2010]. This could affect the inferred SST, which is usually correlated to annual SST [Fraile et al., 2009].

\subsubsection{Stable Oxygen isotopes ( $\left.\boldsymbol{\delta}^{18} \mathrm{O}\right)$}

The development of high-resolution deep-sea oxygen $\left(\boldsymbol{\delta}^{18} \mathrm{O}\right)$ and carbon $\left(\boldsymbol{\delta}^{13} \mathrm{C}\right)$ isotope records have been pivotal in resolving the rates and scales of Cenozoic climate change [Shackleton, 1987].

There are three stable isotopes of oxygen $\left({ }^{16} \mathrm{O},{ }^{17} \mathrm{O}\right.$ and $\left.{ }^{18} \mathrm{O}\right)$ with relative abundances of $99.76 \% \quad\left({ }^{16} \mathrm{O}\right), \quad 0.04 \% \quad\left({ }^{17} \mathrm{O}\right)$ and $0.20 \% \quad\left({ }^{18} \mathrm{O}\right)$, respectively. Most applications in palaeoclimatology concern only the ${ }^{18} \mathrm{O} /{ }^{16} \mathrm{O}$ ratio. The fractionation of oxygen (and carbon) isotopes results from isotopic exchange reactions and kinetic effects, where the lighter isotope either reacts or evaporates more easily than the heavier one. This temperature-dependent fractionation can be large $\left(0.25 \%{ }^{\circ} /{ }^{\circ} \mathrm{C}\right)$ in biogenic carbonate so that oxygen isotopes can be used to examine past changes in seawater temperature [Ravizza and Zachos, 2003].

However, application of stable oxygen isotopes to palaeo-ocean thermometry is complicated by the fact that the oxygen isotope ratios in seawater $\left(\delta^{18} \mathrm{O}_{\text {sw }}\right)$ have not been constant over relatively short geological timescales. In seawater the lighter isotope ${ }^{16} \mathrm{O}$ is preferentially partitioned into water vapour during evaporation, leaving the heavier ${ }^{18} \mathrm{O}$ isotope in the seawater. Condensation and precipitation result in the reverse, where the heavier ${ }^{18} \mathrm{O}$ condenses into liquid water, and the lighter ${ }^{16} \mathrm{O}$ remains as a vapour. This can result in large differences between global ice sheets and mean seawater $\delta^{18} \mathrm{O}$ values $(-35$ to $40 \%$ versus $0 \%$, respectively). During interglacial periods, the evaporation-precipitation cycle generally maintains an overall balance in oxygen isotope ratios in seawater due to the 
returning of most of the snow and ice to the oceans via summer ice and snow melt [Katz et al., 2010]. During glacial periods, however, the oceans become increasingly depleted in ${ }^{16} \mathrm{O}$ and enriched in ${ }^{18} \mathrm{O}$ as precipitation (snow/rain) on land becomes trapped in ice sheets, and cannot return to the ocean, also resulting in a global fall in sea level. For example, at the last glacial maximum, global sea level fell by ca. $120 \mathrm{~m}$ (e.g., Clark and Mix, 2002; Siddall et al., 2003).

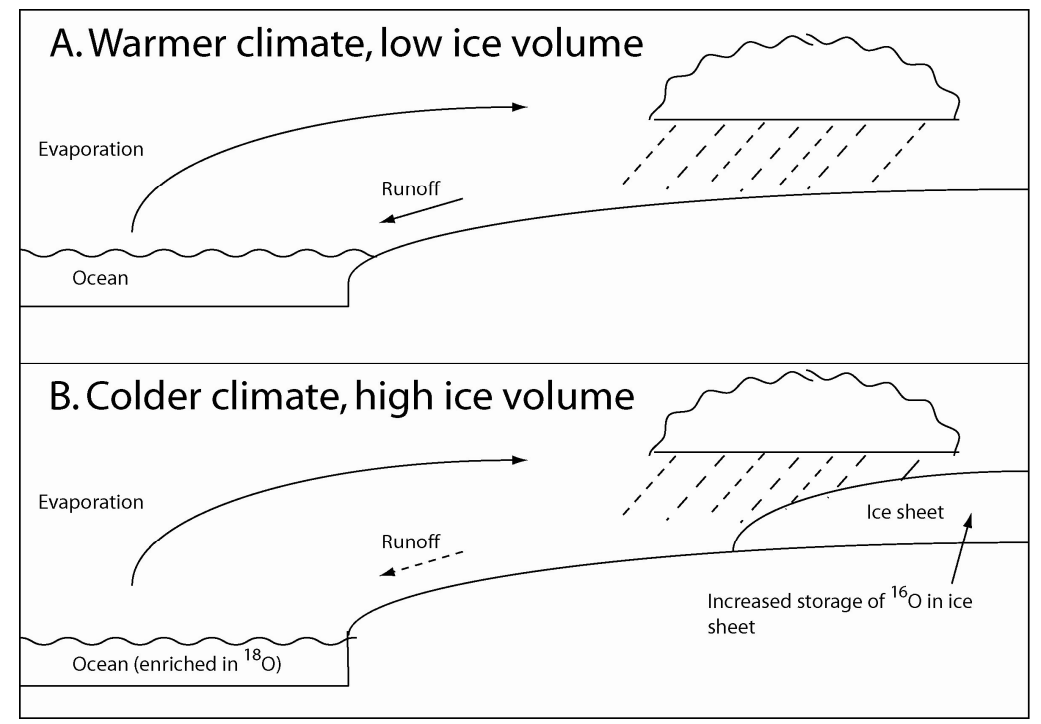

Figure 1.3: Schematic of changes in $\delta^{18} \mathrm{O}$ in oceans during glacial and interglacial periods. (A) Represents a warmer climate with low ice volume. (B) Represents a colder climate with high ice volume. Modified from [Jager and Hunziker, 1979].

Therefore the ${ }^{18} \mathrm{O} /{ }^{16} \mathrm{O}$ ratios can be of importance climatically as they reflect the shifts from glacial (colder climate with high ice volume) and interglacial (warmer climate with low ice volume) periods (Figure 1.3). In foraminiferal tests the ${ }^{18} \mathrm{O} /{ }^{16} \mathrm{O}$ ratios or $\delta^{18} \mathrm{O}$, is a function of the ratio in the seawater in which the foraminifera lived and the temperaturedependent calcification process [Urey, 1947; Epstein et al., 1953]. Individual species of foraminifera have been shown to fractionate oxygen isotopes differently during metabolism [Kennett, 1982], with some species showing differences in isotopic ratios giving lighter than expected (ca., $0.5 \%$ ) values in comparison to non-biological thermodynamic calculations. A $0.5 \%$ lighter value is equivalent to a $c a .2 .5^{\circ} \mathrm{C}$ temperature error [Shackleton et al., 1973] and these differences are species-dependent. 
The oxygen $\left(\delta^{18} \mathrm{O}\right)$ and carbon $\left(\boldsymbol{\delta}^{13} \mathrm{C}\right)$ incorporated into biogenic calcite is quantified by comparison of results to those of a known standard, such as Vienna Pee Dee Belemite (vPDB).

For oxygen isotopes the equation would be:

$$
\delta^{18} \mathrm{O}(\% 0)=1000 \times\left\{\left[\left({ }^{18} \mathrm{O} /{ }^{16} \mathrm{O}\right)_{\text {sample }}-\left({ }^{18} \mathrm{O} /{ }^{16} \mathrm{O}\right)_{\text {standard }}\right] /\left({ }^{18} \mathrm{O} /{ }^{16} \mathrm{O}\right)_{\text {standard }}\right\} \quad[\text { Eq. 1.4 }]
$$

Therefore, foraminiferal tests can be used to examine changes in global hydrological resources e.g., ice volume $\left(\delta^{18} \mathrm{O}_{\text {sw }}\right)$, local changes in evaporation/precipitation, and changes in temperature. An additional complexity lies in the fact that the chemical composition across the oceans is not uniform. When seawater evaporates it also increases in salinity so that empirical relationships within different oceanic regions have been developed in order to derive estimations of palaeosalinity (e.g., LeGrande and Schmidt, 2006). However, changes in $\delta^{18} \mathrm{O}_{\mathrm{sw}}$ also vary seasonally so that one equation may not necessarily define a region [McConnell et al., 2009].

In the deep ocean, changes in temperature recorded in benthic foraminifera over glacial to interglacial timescales are much smaller $\left(c a \cdot 1-2^{\circ} \mathrm{C}\right)$ than the much larger amplitudes recorded in planktonic foraminifera in the upper ocean. In order to unravel the concomitant changes in temperature and ice volume recorded by $\delta^{18} \mathrm{O}$, an independent measurement of temperature (e.g., $\mathrm{Mg} / \mathrm{Ca})$ can be used to remove temperature from the $\delta^{18} \mathrm{O}$ signal. By substitution into a suitable palaeotemperature equation (e.g., Bemis et al. 1998; Shackleton et al. 1973) based on that proposed by Epstein et al., [1953] (Eq. 1.5), the changes in ice volume can be estimated.

$$
\mathrm{T}=16.5-4.3\left(\boldsymbol{\delta}^{18} \mathrm{O}_{\mathrm{c}}-\boldsymbol{\delta}^{18} \mathrm{O}_{\mathrm{sw}}\right)+0.14\left(\boldsymbol{\delta}^{18} \mathrm{O}_{\mathrm{c}}-\boldsymbol{\delta}^{18} \mathrm{O}_{\mathrm{sw}}\right)^{2}
$$




\subsubsection{Complexities of using Oxygen isotopes as a palaeoclimate proxy in foraminiferal calcite}

The estimation of temperature and global ice volume/salinity from foraminiferal $\delta^{18} \mathrm{O}$ is complicated as the $\delta^{18} \mathrm{O}$ in most foraminiferal tests is not in equilibrium with the surrounding seawater. These offsets are referred to as vital effects and can include:

(1) Photosynthetic activity of algal symbionts. Experiments on foraminifera that harbour symbionts have shown that the photosynthetic activity of the algal symbionts can modify test $\delta^{18} \mathrm{O}$ values. For example, they can lower $\mathrm{pH}$ or change the carbonate ion concentration $\left[\mathrm{CO}_{3}{ }^{2}\right]$ of immediately surrounding seawater [Bé et al., 1982; Spero et al., 1997; Wolf-Gladrow et al., 1999; Eggins et al., 2004];

(2) Regional variations, seasonal fluxes or depth habitats of different species that vary regionally [Fairbanks et al., 1980; Reynolds and Thunell, 1986];

(3) Vertical migration of species within the water column where a surface-to-deep temperature gradient may result in different $\delta^{18} \mathrm{O}$ values (e.g., Mortyn and Charles, 2003);

(4) Differences within the test chambers (e.g., the production of gametogenic calcite, (e.g., [Ravelo and Fairbanks, 1992; Kozdon et al., 2009]);

(5) Although not strictly a vital effect, post-depositional diagenesis where deep-burial diagenesis can decrease $\delta^{18} \mathrm{O}$ values due to re-calcification of fossil tests in equilibrium with sediment temperatures [Katz et al., 2010]. Likewise, diagenesis in planktonic foraminifera as opposed benthic foraminifera may result in 'colder overprinting' due to precipitation of calcium carbonate on the foraminiferal tests cold bottom waters.

In considering these issues, careful selection of fossil samples such as those preserved in clay-rich sediments, as well as the study of the species and/or associated vital effects can help overcome these problems.

\subsubsection{Stable Carbon isotopes $\left(\boldsymbol{\delta}^{13} \mathrm{C}\right)$}

There are two stable isotopes of carbon $\left({ }^{12} \mathrm{C}\right.$ and $\left.{ }^{13} \mathrm{C}\right)$, with relative abundances of $98.89 \%$ $\left({ }^{12} \mathrm{C}\right)$ and $1.11 \%\left({ }^{13} \mathrm{C}\right)$, respectively. In the oceans, the distribution of carbon $\left(\delta^{13} \mathrm{C}\right)$ is 
controlled by air to sea gas exchange, biological uptake at the sea surface and organic decomposition at the seafloor [Mackensen et al., 1993]. The oceanic inorganic carbon pool is governed by carbonate reactions such that the dissociation of atmospheric $\mathrm{CO}_{2}$ into the surface oceans produces bicarbonate $\left(\mathrm{HCO}_{3}{ }^{-}\right)$:

$$
\mathrm{H}_{2} \mathrm{O}+\mathrm{CO}_{2(\mathrm{~atm})} \Leftrightarrow \mathrm{H}_{(\mathrm{aq})}^{+}+\mathrm{HCO}_{3(\mathrm{aq})}^{-}
$$

The exact composition of the $\mathrm{HCO}_{3}^{-}$and $\mathrm{CO}_{3}{ }^{2-}$ ions is $\mathrm{pH}$ dependent (Eq. 1.6), but at normal marine $\mathrm{pH}$ (7.8 to 8.3), the $\mathrm{HCO}_{3}{ }^{-}$ion is the dominant species. The sum of $\mathrm{HCO}_{3}{ }^{-}$, $\mathrm{CO}_{3}^{2-}$ and $\mathrm{CO}_{2 \text { (dissolved) }}$ is termed the total dissolved inorganic carbon (DIC).

$$
\mathrm{HCO}_{3}{ }^{-} \Leftrightarrow \mathrm{H}^{+}+\mathrm{CO}_{3}^{2-}
$$

Foraminifera use the $\mathrm{HCO}_{3}^{-}$fraction of the DIC to produce calcium carbonate $\left(\mathrm{CaCO}_{3}\right)$. Planktonic foraminifera use carbon from the DIC in the photic zone to a depth of $c a$., 200 $\mathrm{m}$ in the surface open ocean [Kroopnick, 1985]. However, because photosynthesis strongly favours the lighter ${ }^{12} \mathrm{C}$ isotope, surface waters are isotopically enriched in ${ }^{13} \mathrm{C}$ as marine phytoplankton produces organic matter (Figure 1.4). 


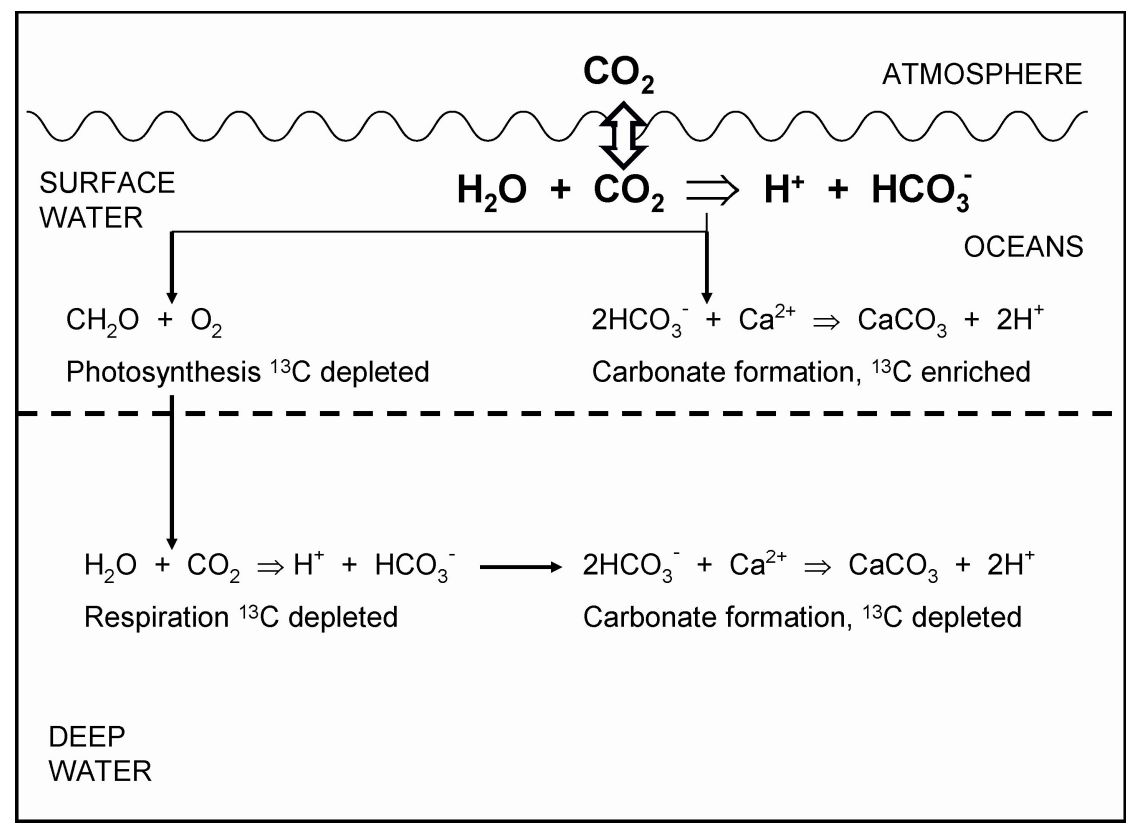

Figure 1.4: Schematic of the generation of a carbon isotope gradient between the sea surface and deep water due to export production and interactions between marine organic and organic cycles. This figure also illustrates the cycling of carbonate species. With foraminifera it is the bicarbonate $\left(\mathrm{HCO}_{3}^{-}\right)$ion that is used to construct tests. Figure modified after Robling and Cooke [2003].

These organic carbon particles eventually sink into deeper water where they become remineralised, causing a gradient in $\delta^{13} \mathrm{C}$ between surface and deep water. The release of the isotopically lighter $\delta^{13} \mathrm{C}$ into deep water equilibrates with $\mathrm{HCO}_{3}^{-}$, and benthic foraminifera use this lighter $\delta^{13} \mathrm{C}$ to construct their tests. Benthic foraminifera tests therefore give a carbon isotope signal that is complicated, affected by the exposure time of decaying organic matter, the amount of organic matter and the rapidity of organic matter delivery (this is temperature-dependent), and basin-to-basin fractionation caused by different source regions and deep water circulation patterns [Kroopnick, 1985; Raymo et al., 1990; Robling and Cooke, 2003].

The $\delta^{13} \mathrm{C}$ in benthic foraminifera has been used to distinguish water masses derived from different sources as the $\delta^{13} \mathrm{C}$ that has sunk from the surface is slowly moved through the ocean basins [Bostock et al., 2004]. This means that as deep waters age, DIC and nutrient contents increase so that the $\delta^{13} \mathrm{C}$ becomes depleted. Over longer timescales, for example Quaternary climate cycles, some of the changes in $\delta^{13} \mathrm{C}$ from glacial to interglacial timescales will also be the result of change in surface ocean productivity. 


\subsubsection{Vital effects}

The 'vital effect' refers to biologically controlled processes that affect the fractionation of trace metal and isotope chemistry in foraminiferal tests away from isotopic and elemental equilibrium [Nürnberg et al., 1996; Eggins et al., 2003; Erez, 2003; Sadekov et al., 2005; Bentov and Erez, 2006].

These vital effects include calcification rate, respiration and photosynthesis (of symbiotic algae) [Duplessey et al., 1970; Spero et al., 1991] and large interspecies, inter-individual and intra-test variability, and deviation of the apparent distribution coefficients from that of inorganic calcite and its variable temperature dependence [Lea, 2003; Bentov and Erez, 2006]. In many cases, the vital effect between species can be avoided by constructing records based on single species.

\subsection{Regional oceanography}

New Zealand and its submerged micro-continent are located midway between the equator and Antarctica at southern mid-latitudes. This section describes the oceanography of this region in the context of the sites of the core top and plankton tow material that were used in this thesis to establish $\mathrm{Mg} / \mathrm{Ca}$ - ocean temperature calibrations for the planktic foraminifera G. ruber and N. incompta. An introduction is also given to ODP Site 1123, which was the sampling site of the sediment core used to establish a palaeoclimate and palaeoceanographic record for Marine Isotope Stage [MIS] 31.

The Southwest Pacific Ocean has three main elements to its circulation:

[i] The South Pacific Gyre (STG) which brings Subtropical surface waters via eastern Australia to northern New Zealand (Figure 1.5);

[ii] The Antarctic Circumpolar Current (ACC) which introduces Subantarctic surface waters to southern New Zealand (Figure 1.6);

[iii] at depth the ACC and Pacific deep western boundary current (DWBC) transport Circumpolar Deep Water from southern sources, with the ACC also carrying Antarctic Intermediate Water and Mode Water (Figure 1.7).

In the New Zealand region, the upper ocean supports several well defined but dynamic fronts that represent the boundaries between these tropical and polar water masses. 


\subsubsection{Surface waters in the Southwest Pacific Ocean}

Surface ocean fronts are zones that are relatively narrow and separate broader zones with marked changes in water mass properties, in particular temperature and salinity, resulting in separate water mass types. In the Southwest Pacific, surface ocean circulation is strongly influenced by the STG which plays a crucial role in the climate system of exporting excess tropical heat and salt polewards [Trenberth and Caron, 2001; Belkin and Cornillon, 2003]. The STG is driven by the combination of low-latitude easterly trade winds and high latitude westerlies and rotates in a counter-clockwise direction. Recent observations have confirmed that the STG is part of a southern 'super-gyre' that connects the South Pacific Ocean with the Indian Ocean and thus creates a pathway for ocean-to-ocean transport of heat, salt and nutrients (Figure 1.5) [Roemmich, 2007; Roemmich et al., 2007]. Recent modelling and observational studies have confirmed a spin-up and southward shift of Southern Hemisphere subtropical ocean circulation forced by wind stress curl intensification associated with a pole-ward shift in the circumpolar westerly winds and a positive Southern Annular Mode [Gillett and Thompson, 2003; Cai et al., 2005; Cai, 2006; Hill et al., 2008]. In the New Zealand region the Subtropical Front (STF) locally approximates the southern limit of the South Pacific STG, and marks the boundary between subtropical water and Subantarctic water of the Southern Ocean.

In the northern reach of the South Pacific STG, the South Equatorial Current moves in an eastern direction where it bifurcates on reaching the Australian continent. There a weaker branch, the Subtropical Counter Current turns north-eastward whereas the main branch turns south to form the East Australian Current (EAC) [Hamon, 1965]. The EAC is a complex seasonal system [Ridgway and Godfrey, 1997] providing the western boundary of the Pacific STG that links with Indian STG [Speich et al., 2002]. Warm core eddies have been observed in the EAC [Boland and Hamon, 1970; Nilsson and Cresswell, 1980; Boland and Church, 1981; Ridgway and Dunn, 2007] and these perturbations can be up to $200-300 \mathrm{~km}$ in diameter with several generated each year. At $35^{\circ} \mathrm{S}$ part of the EAC leaves the coast and continues east as the Tasman Front [Andrews et al., 1980]. 


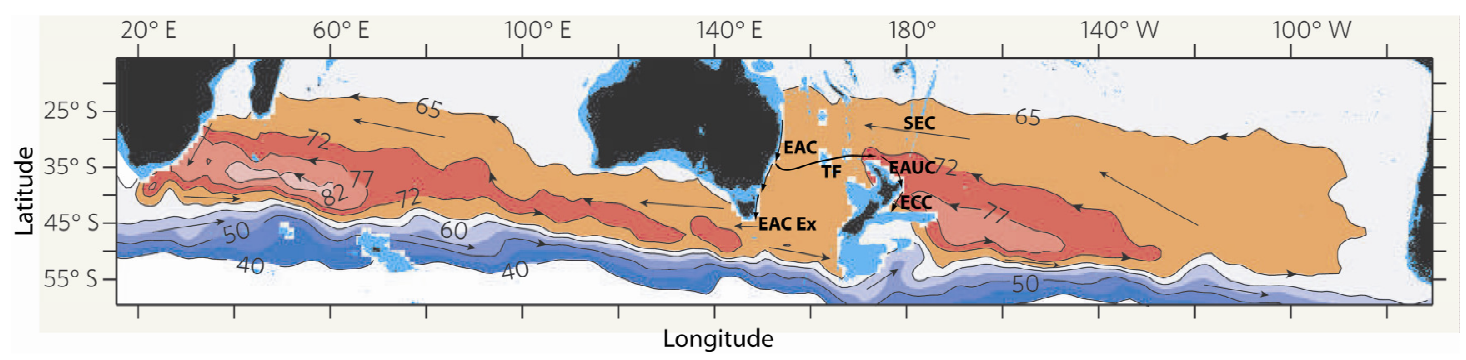

Figure 1.5: Generalised chart of the Southern super-gyre (after Roemmich [2007] and Hill et al., [2008]) showing ocean circulation and heat exchange (black arrows) between the Southern Pacific and Indian Oceans at a depth of $1,000 \mathrm{~m}$. The orange band represents the area of super-gyre circulation, and the pink and red bands show the distinct inner gyres operating north of the ACC (blue band). The contour lines represent dynamic height $\left(\mathrm{m}^{2} \mathrm{~s}^{-2}\right)$, which is generally derived from temperature and salinity profiles. EAC = East Australian Current, SEC $=$ South Equatorial Current, EAC Ex $=$ East Australian Current Extension, EAUC $=$ East Auckland Current, TF $=$ Tasman Front.

On decadal timescales the EAC is strongly influenced by wind stress curl, which has in turn been related to ENSO variability [Ridgway and Hill, 2009]. Increased warmth in the tropical Pacific associates with weaker South Pacific wind stress curl maximum, a weaker extension past Tasmania and a stronger TF [Sasaki et al., 2008]. The eastward flow associated with the TF extends to northern New Zealand, where it part -forms the East Auckland Current (EAUC) together with three semi-permanent eddies- the North Cape Eddy, East Cape Eddy, and Wairarapa Eddy [Roemmich and Sutton, 1998; Stanton, 2001]. The EAUC extends to $\sim 37^{\circ} \mathrm{S}$ before becoming the ECC which continues south to the Chatham Rise where it turns east.

Off western New Zealand, the STF intercepts the southernmost South Island where it is forced northward along the continental margin to eventually continue along the west-east crest of Chatham Rise. The flow associated with the STF along the South Island is locally termed the Southland Current, which carries mainly Subantarctic surface water, some of which passes through Mernoo Saddle onto Cook Straight and the eastern North Island with another branch extending along the southern side of Chatham Rise (Figure 1.6). 


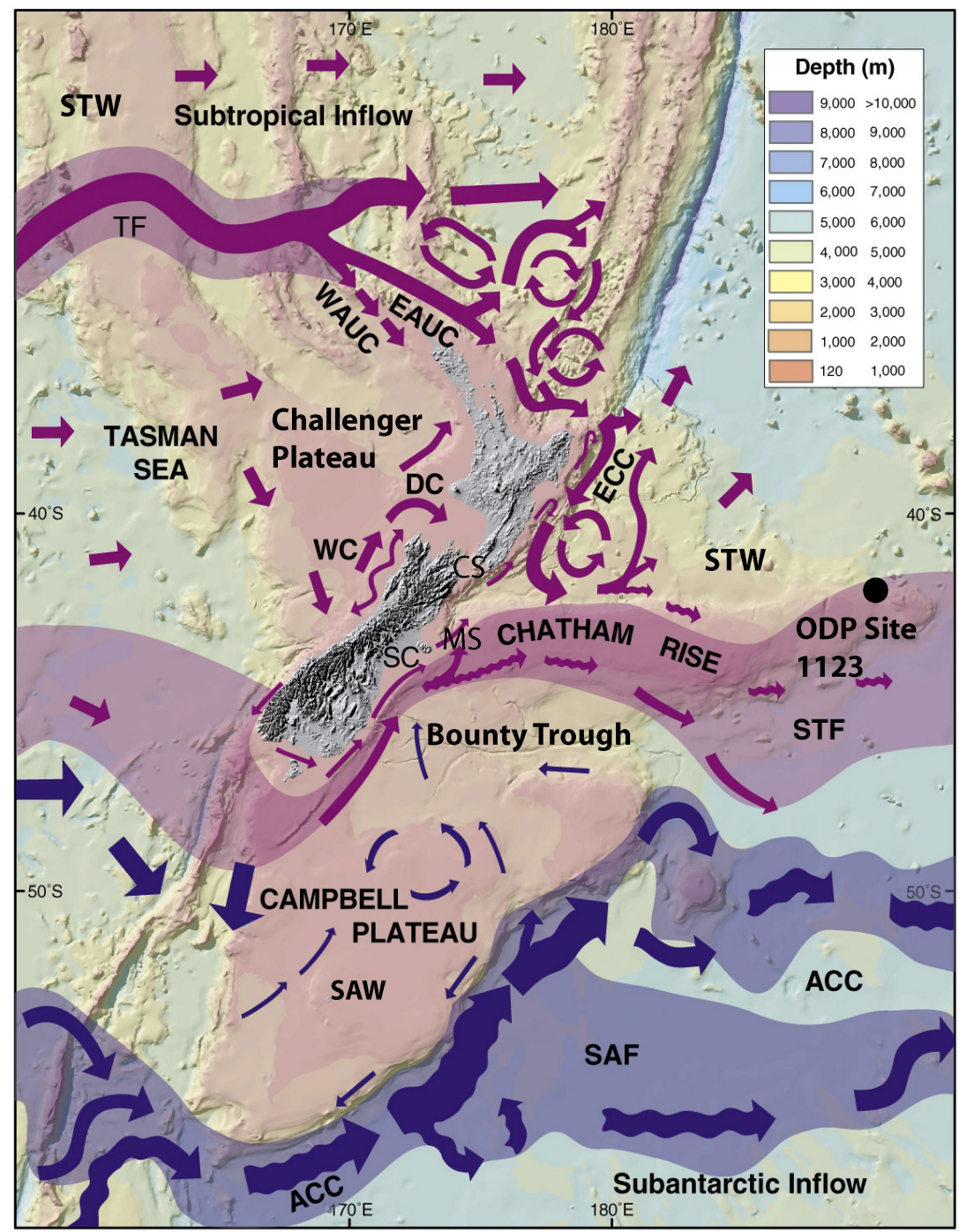

Figure 1.6: Chart of the surface ocean currents of New Zealand and surrounding regions. Blue arrows indicate the cold, fresher Subantarctic front (SAF) within the Antarctic Circumpolar Current (ACC), whilst the purple arrows show warmer, saltier subtropical water that is brought to the west of New Zealand from the East Australian current (EAC) and the Tasman Front (TF), which branches into the East (EAUC) and West Auckland Currents (WAUC). This Subtropical Front (STF) forms part of the South Pacific Subtropical Gyre that moves warm water in a counter -clockwise direction down the east coast of Australia. West of New Zealand the westerly winds force warm water via the Westland Current (WC) and Southland Current. Some of the former flow moves through the Cook Strait as the D'Urville Current (DC). The Southland Current reaches the south of New Zealand, and is diverted by Chatham Rise to the east. AUS = Australia, NZ = New Zealand, ANT = Antarctica. Figure taken and modified from Carter et al., [1998a]. 


\subsubsection{Deep waters in the Southwest Pacific Ocean}

Deep water from the South Indian and South Atlantic Oceans, together with water produced locally around Antarctica, enter the region near Macquarie Ridge entrained within the Pacific deep western boundary current DWBC which, flows in concert with the ACC around southern Campbell Plateau mainly below 49 S [Carter and Wilkin, 1999] but extending up to $\sim 46^{\circ} \mathrm{S}$ (Figure 1.7). North of $\sim 46^{\circ} \mathrm{S}$, the DWBC continues northwards uninterrupted, typically at depths $>2000 \mathrm{~m}$ with most of the transport at depths $>3250 \mathrm{~m}$. Not unexpectedly, for a flow that supplies much of the water filling the Southwest and North Pacific basins, its volume transport is high and variable [Whitworth III et al., 1999].

At Chatham Rise, the DWBC intensifies against the Chatham Rise topography [Warren, 1973; Carter and McCave, 1994] and deposits a sediment drift on the northern Rise flank [Carter and McCave, 1994]. It is this sediment drift that was the target for ODP Site 1123. Because of the water depth, the ocean floor is bathed by lower Circumpolar Deep Water which, on the basis of the salinity and the $\delta^{13} \mathrm{C}$ signatures, contains a marked North Atlantic Deep Water component (e.g., Hall et al., 2001, the DWBC strikes northwest steered by the subdued topography that steepens markedly along the eastern flank of Hikurangi Plateau. From there, the flow turns north-northeast along the Kermadec Ridge and Trench system and is steered onto the central Pacific [McCave and Carter, 1997; Whitworth III et al., 1999]. 


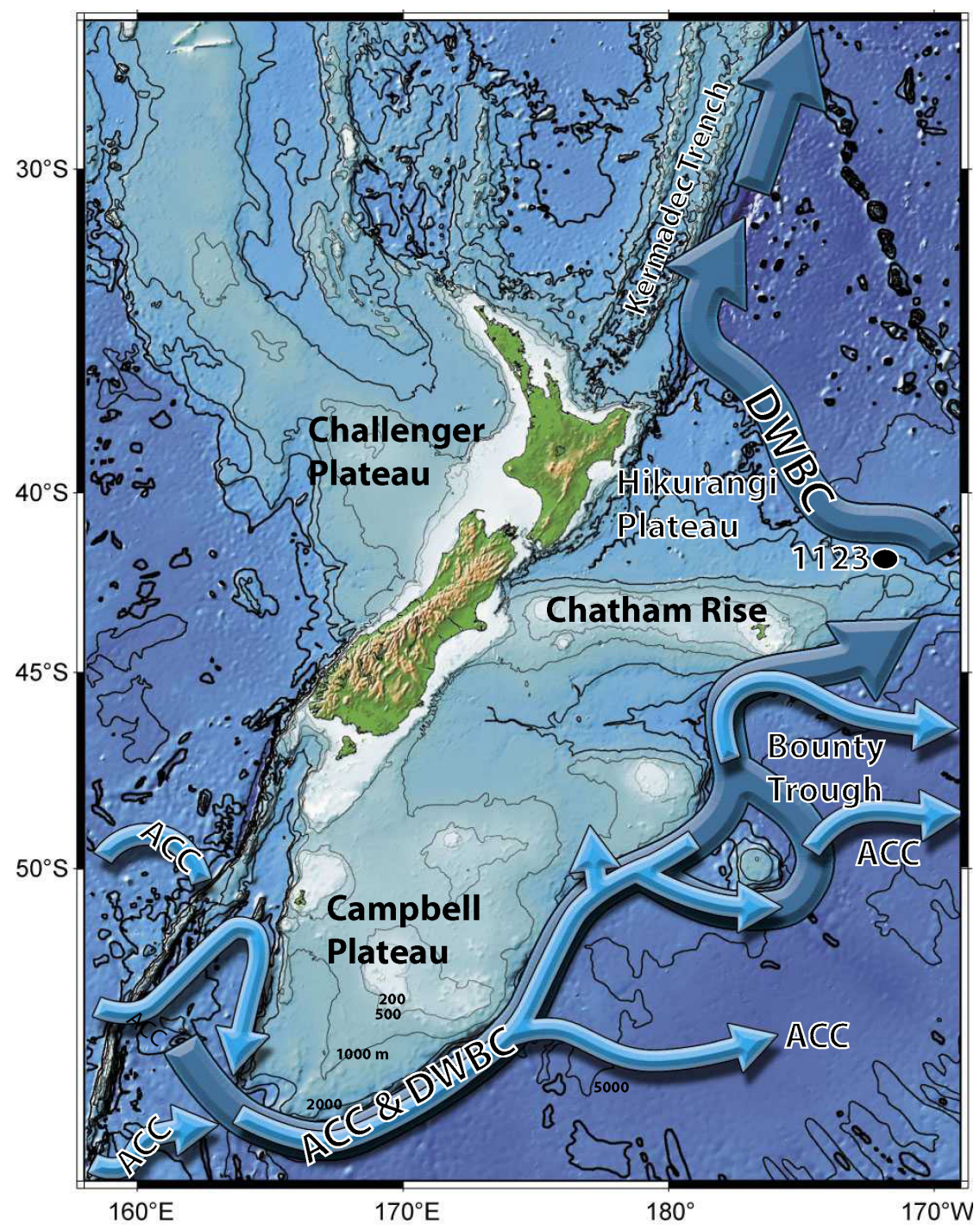

Figure 1.7: Chart of the New Zealand region and the main elements of the abyssal circulation including the deep western boundary current (DWBC), and the overlying but deep-reaching Antarctic Circumpolar Current (ACC). Figure taken and modified from Carter et al., [1998a].

\subsubsection{Oceanography at ODP Site 1123}

One of the main components of this study is analysis of foraminifera from a marine sediment core recovered from ODP Site 1123, which is located east of New Zealand $\left(41^{\circ} 47.2^{\prime} \mathrm{S}, 171^{\circ} 29.9^{\prime} \mathrm{W} ; 3290 \mathrm{~m}\right.$ deep) on the northern flank of a broad, asymmetric submarine high, Chatham Rise, in the Southwest Pacific Ocean (Figure 1.6, 1.7).

Chatham Rise is located below the STF which is geographically locked into a relatively narrow position $(\sim 150 \mathrm{~km})$ and limited vertically by the shallow depths of the uppermost 
bathymetry (250-350 m) [Sutton, 2001] (Figure 1.6). The front is therefore characterised by strong latitudinal (45 to $47^{\circ} \mathrm{S}$ ) temperature and salinity gradients. These gradients correspond to the transition between summer to winter (north to south) surface temperatures and salinities ranging from 15 to $10^{\circ} \mathrm{C}$ and 34.7 to 34.8 psu respectively [Heath, 1985; Chiswell, 2003]. However, at ODP 1123, the STF is relatively unconstrained by the deepening rise topography and the associated currents (ECC and SC) that pass eastward along the north and south rise flanks respectively. Accordingly, the STF has more freedom to migrate as represented by the widening STF zone off eastern Chatham Rise (Figure 1.6). Over glacial to interglacial cycles, these fronts migrate (north or south) and reflect the meridional gradient between STW and SAW. For example, during MIS-11 and MIS-5.5, two exceptionally warm interglacial's in the Late Quaternary, southward migration of the STF occurred, reflecting higher SST [Wilson et al., 2005]. Similarly during glacial periods, shifts in the SAF if the STF was geographically 'locked' [Hayward et al., 2008] would result in an increased temperature gradient between the STF and SAF.

As discussed earlier, the STF separates warm, saline, STW in the north with cooler, fresher SAW in the south. Both STW and SAW have distinct nutrient properties, SAW is high in macronutrients and low in micronutrients and chlorophyll whereas STW has low macronutrients but elevated micronutrients [Bradford-Grieve et al., 1999]. The convergence of these two nutrient complimentary surface waters makes Chatham Rise a highly productive environment [Nodder, 1997; Boyd et al., 1999]. Studies have shown episodic export of particulate material from the surface with distinct differences north and south of the rise [Hawes et al., 1997; Nodder, 1997; Nodder and Northcote, 2001] although the region is also controlled by productivity limiting mechanisms, such as light, grazing pressure, silicate limitation as well as micronutrient supply [Boyd et al., 1999; Boyd et al., 2004].

The samples used in this study all come from above the modern regional calcite lysocline (3600-4000 m) [Berger et al., 1976; Martinez, 1994]. The application of this study's and extant $\mathrm{Mg} / \mathrm{Ca}$ - ocean temperature calibrations to planktonic foraminifera from the ODP Site 1123 core, is used to investigate palaeoceanographic and palaeoclimatic change from MIS29 to 34 [1018-1127 kyr]. The site is close to the northern limit of the modern STF and hence captures the interaction STW and SAW over glacial-interglacial cycles (e.g., Crundwell et al., 2008). In that context, this core provides a record of change in water masses, frontal position and marine productivity [Hall et al., 2001; Crundwell et al., 2008; Hayward et al., 2008]. 
Palaeo-records from the Quaternary indicate that during glacial times, there has been a considerable (up to $8^{\circ}$ ) shift in the STF northwards in open oceanic sites (e.g., Barrows et al., 2000; Weaver et al., 1998). Movement of the STF at Chatham Rise due to forcing from the south during glacial periods has been proposed, [Weaver et al., 1998; King and Howard, 2000; Sikes et al., 2002; Fenner and Di Stefano, 2004; Crundwell et al., 2008] but is disputed in other studies [Schaefer et al., 2005; Wilson et al., 2005]. It may be that some of the disparity between each side of the debate may be explained by location of the southerly control point in one of the studies [Schaefer et al., 2005; Crundwell et al., 2008].

\subsubsection{Application of foraminiferal trace element data from ODP Site 1123 during MIS-31}

The main focus of the thesis is the application of the trace element data to Marine Isotope Stage 31. This 'superwarm' interglacial period is of climatic importance for a number of reasons which are summarised below:

- It lies in the Mid-Pleistocene Transition (MPT), $1.2-0.5 \mathrm{Ma}$, characterised by a shift from low-amplitude 41-kyr obliquity-forced climate cycles typical of the early Pleistocene to high-amplitude 100-kyr cycles, typical of the Late Pleistocene [Head, 2005]. These later cycles are indicative of slow ice build-up and subsequent rapid melting, and imply a transition to a strongly non-linear forced climate system [Head, 2005]. These changes have also been linked to atmospheric $\mathrm{CO}_{2}$ [Medina et al., 2005, Russon et al., 2011], and the scouring of continental regolith hypothesis [Clark et al., 1999], although other theories exist (e.g. Huybers et al., 2007; Tziperman and Gildor, 2003].

- It has unique orbital parameters where eccentricity, precession and obliquity were high, such that insolation in Southern Hemisphere mid to high latitudes were high.

- The benthic $\delta^{18} \mathrm{O}$ record suggests that this period was exceptionally warmer than the present day although much lower in amplitude compared to another earlier 'superwarm interglacial' MIS-11 (Figure 1.8).

- Various proxies suggest sensitivity to the strong precessional forcing in the high and mid latitudes [Tietler et al., 2005; Kupp et al., 2006]. 
- The local insolation has been modelled in Antarctica, with a suggested $5^{\circ} \mathrm{C}$ warming resulting in the collapse of the West Antarctic Ice Sheet [Pollar and DeConto, 2009]. This is also backed by geological evidence suggesting open water in the Ross Sea during this time [Naish et al., 2009].

- Together this evidence points towards higher SST in the mid to high SH and melting of the WAIS.

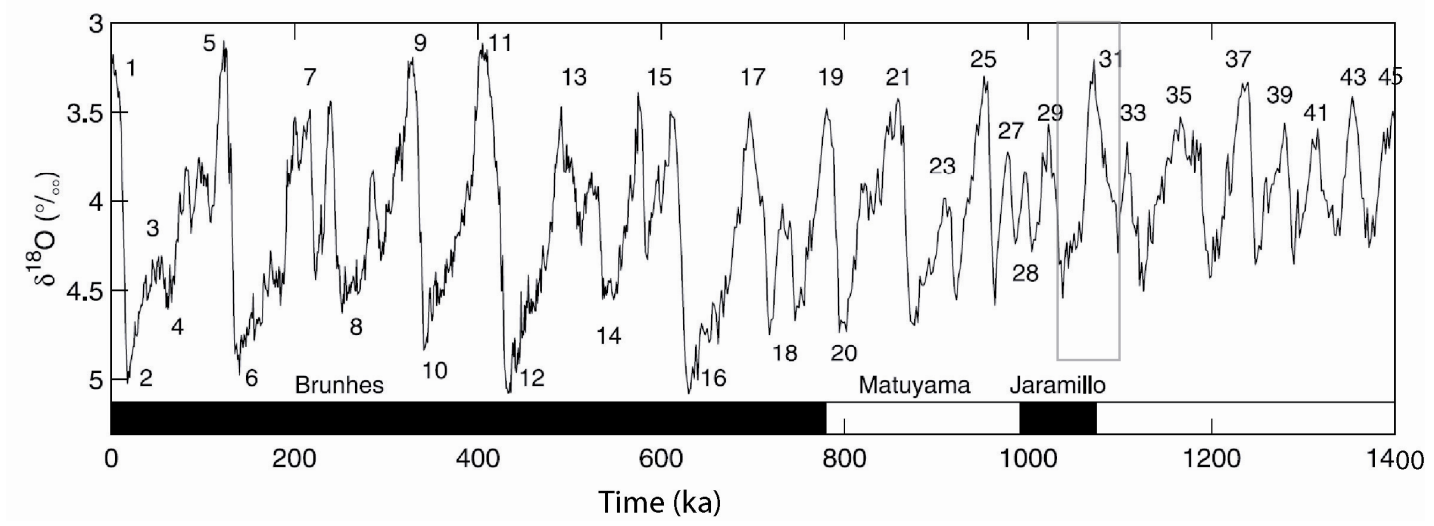

Figure 1.8: The LR04 benthic $\delta^{18} \mathrm{O}$ stack constructed by the graphic correlation of 57 globally distributed benthic $\delta^{18} \mathrm{O}$ records (Lisiecki and Raymo, 2005). MIS-31 is shown in the grey box. 
Chapter 2

\section{Materials and Methods}

\subsection{Fossil and plankton tow material}

The core top and plankton tow material used in this work was provided by the New Zealand National Institute of Water and Atmospheric Research (NIWA), the Australian Institute for Marine Sciences (AIMS) and Geological and Nuclear Sciences (GNS). The details of the core tops and plankton tows are discussed individually in each relevant chapter of this thesis.

\subsubsection{Recovery of foraminifera from marine sediment cores and preparation of foraminifera for LA-ICP-MS analysis}

The core samples used were 1 or $2 \mathrm{~cm}$ sediment sections, which were rehydrated for $24 \mathrm{hr}$. Following this, Calgon ${ }^{\circledR}$ was added and the sample was gently ultrasonicated to disaggregate the mud. The sample was then sieved through a $65 \mu \mathrm{m}$ mesh using deionised, distilled water. The remaining particles were then gently sprayed with deionised, distilled water using a spray bottle to remove remaining clay from the fossil material. This was then transferred into a beaker and placed in an oven at $40^{\circ} \mathrm{C}$ for $24 \mathrm{hr}$. Once the sample was dry, it was subjected to several rinses in ultra-clean water $(>18 \mathrm{M} \Omega)$, followed by ultrasonication in analytical grade methanol for a few seconds, with final rinses in ultraclean water. These procedures are similar to those followed in Eggins et al., [2003] except that ultrasonication times varied depending on the fragility of samples and/or whether or not they were core top or plankton tow samples (see below and section 2.1.2). These procedures differ to solution chemical cleaning which has been shown to reduce the loss of sample material [Boyle and Keigwin, 1985; Barker et al., 2003; Rosenthal et al., 2004; Yu et al., 
2005]. The sample was then oven dried at $40^{\circ} \mathrm{C}$ for $24 \mathrm{hr}$. Once dry, it was sieved through a series of sediment sieves of varying size fractions $(<65,65-125,125-250,250-355,>355$ $\mu \mathrm{m})$.

Organic material was removed from the plankton tow samples using a low temperature oxygen plasma asher [Patterson, 1978]. The samples were pre-rinsed and oven dried at $40^{\circ} \mathrm{C}$ prior to ash removal, rinsed in ultraclean water but not ultrasonically cleaned. This is a method used for preparation of cultured foraminifera (J. Wit, pers. comm., 2008) as ultrasonication was previously found to destroy fragile plankton tow tests. Individual foraminifera $(\mathrm{n}=15-35)$ were then picked from a specific size fraction using a clean dry paint brush under a binocular light microscope. The samples were re-cleaned using the procedure described above, and once dried, a selected number of individuals were examined under both a binocular and scanning electron microscope (SEM) for signs of dissolution, breakage and/or contaminants. For SEM imaging, selected individuals were placed onto carbon tape, gold coated and imaged using a JEOL JSM-5300LV SEM.

Cleaned samples selected for analysis were then individually weighed using a Mettler Toledo UMX2 microbalance, and mounted and photographed prior to analysis. After weighing individual foraminifera were mounted onto a thin strip of double sided cellotape, which was placed on one half of a circular wafer of a NIST610 glass standard, and then placed into the laser ablation cell as shown in Figure 2.1.

\subsubsection{Basis for the adopted foraminifera cleaning technique}

At present, there is no single accepted standard cleaning protocol for ICP-MS solution trace element analysis of foraminifera, with many laboratories following slightly different procedures [Barker et al., 2003; Yu et al., 2007; Bian and Martin, 2010]. Cleaning is an important step because the presence of detrital phases, surface coatings (such as clay minerals and iron and manganese oxyhydroxide coatings), barite crystals, calcareous nannofossils and organic material can significantly affect the measured elemental ratios [Barker et al., 2003; Rollion-Bard et al., 2007]. The steps involved in cleaning typically involve chemical reduction and oxidation steps. In solution work, as the whole test is dissolved, these rigorous cleaning regimes ensure that any contaminants on the surface or inside the test are removed. Hathorne et al. [2003] found that the $\mathrm{Mg} / \mathrm{Ca}$ of tests that had not undergone reductive cleaning had higher $\mathrm{Mg} / \mathrm{Ca}$ ratios than those that had only undergone 
an oxidative cleaning step. Other efforts to examine the effect of cleaning on stable isotopes $\left(\delta^{13} \mathrm{C}\right.$ and $\left.\delta^{18} \mathrm{O}\right)$ revealed that the use of hydrogen peroxide (oxidative cleaning) and ultrasonically cleaned samples produced lower $\delta^{18} \mathrm{O}$ values compared to control samples [Serrano et al., 2008] either due to elimination of inorganic contaminants or partial dissolution of the test [Wierzbowski, 2007; Serrano et al., 2008]. However, it is also likely that the procedure breaks up thinner parts of the test, which are too small to be analysed or become dissolved with further cleaning treatments. The removal of these parts may be the reason that the $\delta^{18} \mathrm{O}$ appears to decrease as the smaller fragments are more likely to be the thinner ontogenetic parts of the test, whereas secondary or gametogenic calcite is thicker and therefore less likely to be broken. In this study, the ultrasonication power was low $(<10 \%)$ so as to prevent breakages of the tests. Where the presence of detrital material was obvious (i.e. after visual inspection under a light microscope), some foraminferal tests were subjected to repeat cleaning.

In this study the same cleaning procedures utilised for previous LA-ICP-MS foraminifera trace element studies were adopted [Hathorne et al., 2003; Eggins et al., 2004], utilising gentle ultrasonication in AR grade methanol to clean tests. This is thought to be gentle and brief enough to prevent significant breakage. There is uncertainty about whether rigorous cleaning, particularly involving reductive steps, is required when preparing foraminifera for LA-ICP-MS trace element analysis [Haley and Klinkhammer, 2002]. The ability of the laser to yield trace element depth profiles of the test as it ablates through the chamber wall allows identification (and exclusion) of zones of the test affected by contaminants. This is particularly apparent on the outer and inner surfaces (beginning and end of profiles) of tests. Bulk sampling requires more rigorous cleaning procedures because the whole test is digested and, therefore, any contaminants on the surface or within the test will give rise to inaccurate trace element/Ca ratios. 
Figure 2.1: (A) Example of individually mounted foraminifera on the NIST610 glass standard. (B) Photograph of the laser ablation sample cell and the well in the middle of it where the NIST 610 standard is placed. Figure 2.1A was taken from Marr [2009]. 


\subsection{LA-ICP-MS analysis of trace elements in foraminiferal calcite}

In this study, LA-ICP-MS was used to analyse trace element/Ca ratios in foraminifera as summarised below.

\subsubsection{Summary of LA-ICP-MS analysis, data accuracy and standardisation, and an inter- laboratory calibration for foraminiferal $\mathrm{Mg} / \mathrm{Ca}$ palaeothermometry}

Foraminifera were analysed at Victoria University of Wellington (VUW) (Gs. ruber core top $\mathrm{Mg} / \mathrm{Ca}$ - temperature calibration) and the Australian National University (ANU) ( $N$. incompta, and all down-core samples). An inter-laboratory comparison between the two laboratories is discussed in Section 2.3. The laser ablation unit at VUW is a New Wave deep UV laser (193 nm solid state) and at ANU is a HELEX ArF Excimer laser (193 nm). Both laboratories use the same Agilent ICP-MS allowing the near-simultaneous measurement of a range of trace elements.

The following isotopes were selected for analysis: ${ }^{24} \mathrm{Mg},{ }^{27} \mathrm{Al},{ }^{43} \mathrm{Ca},{ }^{55} \mathrm{Mn},{ }^{88} \mathrm{Sr},{ }^{66} \mathrm{Zn}$ and ${ }^{138} \mathrm{Ba}$. Before each analysis the ICP-MS was tuned using the NIST SRM 610 standard in raster mode to optimise sensitivity and signal stability at a low mass range $\left({ }^{24} \mathrm{Mg}\right.$ to $\left.{ }^{43} \mathrm{Ca}\right)$. NIST SRM 610 is a synthetically prepared Si-Na-Ca-Al-glass standard reference material spiked with homogeneous amounts of ca., 60 trace elements at the $500 \mu \mathrm{g} / \mathrm{g}$ level [Reed, 1992] and is commonly used as a reference material in in-situ geochemical studies [NBS, 1970; Rocholl et al., 1997]. The working values compiled by Pearce et al. [1996] for this standard [i.e. $\mathrm{Mg} / \mathrm{Ca}$ $=9.38, \mathrm{Al} / \mathrm{Ca}=195.9, \mathrm{Mn} / \mathrm{Ca}=3.86, \mathrm{Zn} / \mathrm{Ca}=3.42, \mathrm{Sr} / \mathrm{Ca}=2.78, \mathrm{Ba} / \mathrm{Ca}=1.51$ $\mathrm{mmol} / \mathrm{mol}$ ] were used for this study. The use of a calcite standard has been investigated by de Nooijer et al. [2007] as a fluence of $<2 \mathrm{~J} / \mathrm{cm}^{2}$ was found to be close to the ablation threshold for the NIST 610 glass standard. However, this method was found to increase the analytical uncertainty in the LA-ICP-MS analyses. Although a matrix matched carbonate standard is theoretically more ideal for in situ foraminiferal trace element analysis, there is currently no suitable standard available. A trial carbonate standard obtained from the University of Utrecht (GJR-carbonate standard) yielded comparable results for $\mathrm{Mg} / \mathrm{Ca}, \mathrm{Al} / \mathrm{Ca}, \mathrm{Mn} / \mathrm{Ca}$ and $\mathrm{Sr} / \mathrm{Ca}$ ratios (Table 2.2). A two tailed t-test at a 95\% confidence interval revealed no significant difference between the analyses performed at 
Victoria University of Wellington and the University of Utrecht suggesting that NIST 610 is a suitable standard for analysis of these elements in carbonate material. However, due to the limited availability of this calcite standard, it was not used throughout this study.

Table 2.1: LA-ICP-MS trace element measurements of the GJR-carbonate standard at VUW compared with data from the University of Utrecht.

\begin{tabular}{|c|c|c|c|c|c|}
\hline & & $\mathrm{Mg} / \mathrm{Ca}$ & $\mathrm{Al} / \mathrm{Ca}$ & $\mathrm{Mn} / \mathrm{Ca}$ & $\mathrm{Sr} / \mathrm{Ca}$ \\
\hline & & $(\mathrm{mmol} / \mathrm{mol})$ & $(\mathrm{mmol} / \mathrm{mol})$ & $(\mathrm{mmol} / \mathrm{mol})$ & $(\mathrm{mmol} / \mathrm{mol})$ \\
\hline \multirow[t]{3}{*}{ VUW } & Mean & 3.310 & 0.026 & 0.199 & 0.278 \\
\hline & $\mathrm{SD}$ & 0.033 & 0.005 & 0.004 & 0.017 \\
\hline & $\% \mathrm{SD}$ & 1.0 & 19.9 & 2.0 & 6.0 \\
\hline \multirow[t]{3}{*}{ Utrecht } & Mean & 3.233 & 0.029 & 0.215 & 0.233 \\
\hline & $\mathrm{SD}$ & 0.285 & 0.008 & 0.010 & 0.012 \\
\hline & $\% \mathrm{SD}$ & 8.8 & 28.3 & 4.8 & 5.1 \\
\hline
\end{tabular}

Following tuning, a background of $60 \mathrm{~s}$ was measured whilst not ablating the sample. This was followed by the measurement of the NIST SRM 610 glass for $60 \mathrm{~s}$ ablated using a 25 $\mu \mathrm{m}$ spot size. Between each standard or sample analysis the ablation cell was allowed to "washout" (purged with He) for 100 s. The NIST SRM 610 standard was measured after every 10-15 analysis of foraminifera to monitor any drift in trace element fractionation produced by the laser and ICP-MS. Typical operating conditions and the range of parameters used during LA-ICP-MS analysis are shown in Tables 2.2 and 2.3. In addition to the analysed elements, $\mathrm{ThO}^{+} / \mathrm{Th}^{+}$was monitored during tuning so that oxide production was $<2 \%$ to reduce potential polyatomic interferences from oxide species [Norman et al., 1996]. 
Table 2.2: Summary of the LA-ICP-MS acquisition protocol during analysis of foraminifera.

\begin{tabular}{lr}
\hline Step & Dwell Time (s) \\
\hline Background 1 (+ 1 repeat) & 120 \\
Washout & 100 \\
Standard 1 (NIST 610) (+ 1 repeat) & 60 \\
Washout & 100 \\
Sample Analysis 1 (10-15 individual spots & \\
separated by 100 s washouts) & 100 \\
Washout & $60-120$ \\
Standard 2 (NIST 610) & 100 \\
Washout & \\
Sample Analysis 2 (10-15 individual spots & 100 \\
separated by 100 s washouts) & \\
Washout & \\
Standard 3 (NIST 610) (+ 1 repeat) & \\
Background 2 (+ 1 repeat) & \\
\hline
\end{tabular}


Table 2.3: Typical operating conditions of the LA-ICP-MS during foraminiferal trace element analysis.

Agilent 7500CS

Forward power

$1400-1500 \mathrm{~W}$

Gas flow rate

Carrier gas (Ar)

$0.80-0.90 \mathrm{~L} / \mathrm{min}$

Ablation gas (He)

$70-90 \%$

New Wave laser ablation system

Wavelength

$193 \mathrm{~nm}$

Energy (2 or $5 \mathrm{~Hz})$

$5 \mathrm{~J} / \mathrm{cm}^{2}$

Trace element analysis of NIST610

Repetition rate

$5 \mathrm{~Hz}$

Spot size

$25 \mu \mathrm{m}$ using a $2 \mu \mathrm{m} / \mathrm{s}$ raster for tuning, $25 \mu \mathrm{m}$ spot for

standardisation

Laser power

$60 \%$

Integration time

$10 \mathrm{~ms}$

Trace element analysis of foraminifera

$\begin{array}{lc}\text { Repetition rate } & 2 \text { or } 5 \mathrm{~Hz} \\ \text { Spot size } & 25 \mu \mathrm{m} \\ \text { Laser power } & 50-60 \% \\ \text { Integration time } & 10 \mathrm{~ms}\end{array}$

Data acquisition

Protocol

time resolved analysis

Scanning mode

peak hopping 


\subsubsection{Data reduction and screening techniques}

Raw data was first screened for outliers, after which the mean background counts were subtracted from the data. The resulting trace element/Ca ratios were then normalised using the measured ratios on the NIST SRM 610 standard relative to the known values for this standard [Craig et al., 2000; Eggins et al., 2003]. Each LA-ICP-MS trace element depth profile was then carefully examined for signs of contamination. A typical depth profile is shown in Figure 2.2A which shows a thin elevated TE/Ca surface veneer, which has also been observed in other laser ablation studies of foraminifera e.g., Sadekov et al. [2008]. This elevated TE/Ca veneer rapidly decreases as the laser ablates towards the inside of the test, where $\mathrm{Mg} / \mathrm{Ca}$ is relatively homogeneous. The other trace elements $\mathrm{Al}$ and $\mathrm{Mn}$, used to infer contamination of the test, remain variable but low $(<1.0 \mathrm{mmol} / \mathrm{mol})$. It is thought that this enriched veneer is of biogenic origin, as it is present in plankton tow samples where it is unlikely to have diagenetic alteration or the addition of surficial contaminant, and was not observed in the NIST 610 standard. Although this could be related to a matrix effect, the calcium carbonate standard (Section 2.2.1) also did not show an elevated TE/Ca enrichment. Furthermore laser ablation work by Hathorne et al., [2008] showed that laser ablation of silicates (e.g. NIST 612 glass) produce microsize particles by hydrodynamic sputtering, while ablation of biogenic carbonates produced them by photomechanical fracturing. The effect of those differences can be minimized using a $193 \mathrm{~nm}$ (i.e. this work) laser as it produces fewer microsize particles. The elevated TE/Ca veneer is further discussed in Chapter 3, Section 3.5.1.

Additionally, each depth profile was examined such that the enriched surface veneer and internal sediment when the laser penetrates the test wall was excluded from the mean $\mathrm{TE} / \mathrm{Ca}$, by selecting and averaging only the data from the middle portion of the test (boxed area, Figure 2.2A). Additionally, the end of each profile can be identified from visual inspection during the analysis or from the sharp reduction of raw Ca counts from the depth profile as these counts decline rapidly once the laser has ablated through each chamber.

A small number of analyses showed high $\mathrm{Al} / \mathrm{Ca}$ ratios and co-varying high $\mathrm{Mg} / \mathrm{Ca}$ ratios throughout the trace element depth profile. Figure 2.2B shows a Gs. ruber analysis (chamber F) from the core top AIMS3703. Although, like all trace element depth profiles, it has an 
elevated TE/Ca surface veneer, in particular, $\mathrm{Al} / \mathrm{Ca}$ and $\mathrm{Mg} / \mathrm{Ca}$ have high ratios and covary throughout the test. Duplicate measurements of the same chamber were used in cases where this was observed. Following this screening step, the individual measurements were compared for co-variation of $\mathrm{Mg}$ with the elements $\mathrm{Mn}$ and $\mathrm{Al}$ and those that did co-vary and/or have anomalously high $\mathrm{Al} / \mathrm{Ca}$ or $\mathrm{Mn} / \mathrm{Ca}$ values were discarded.

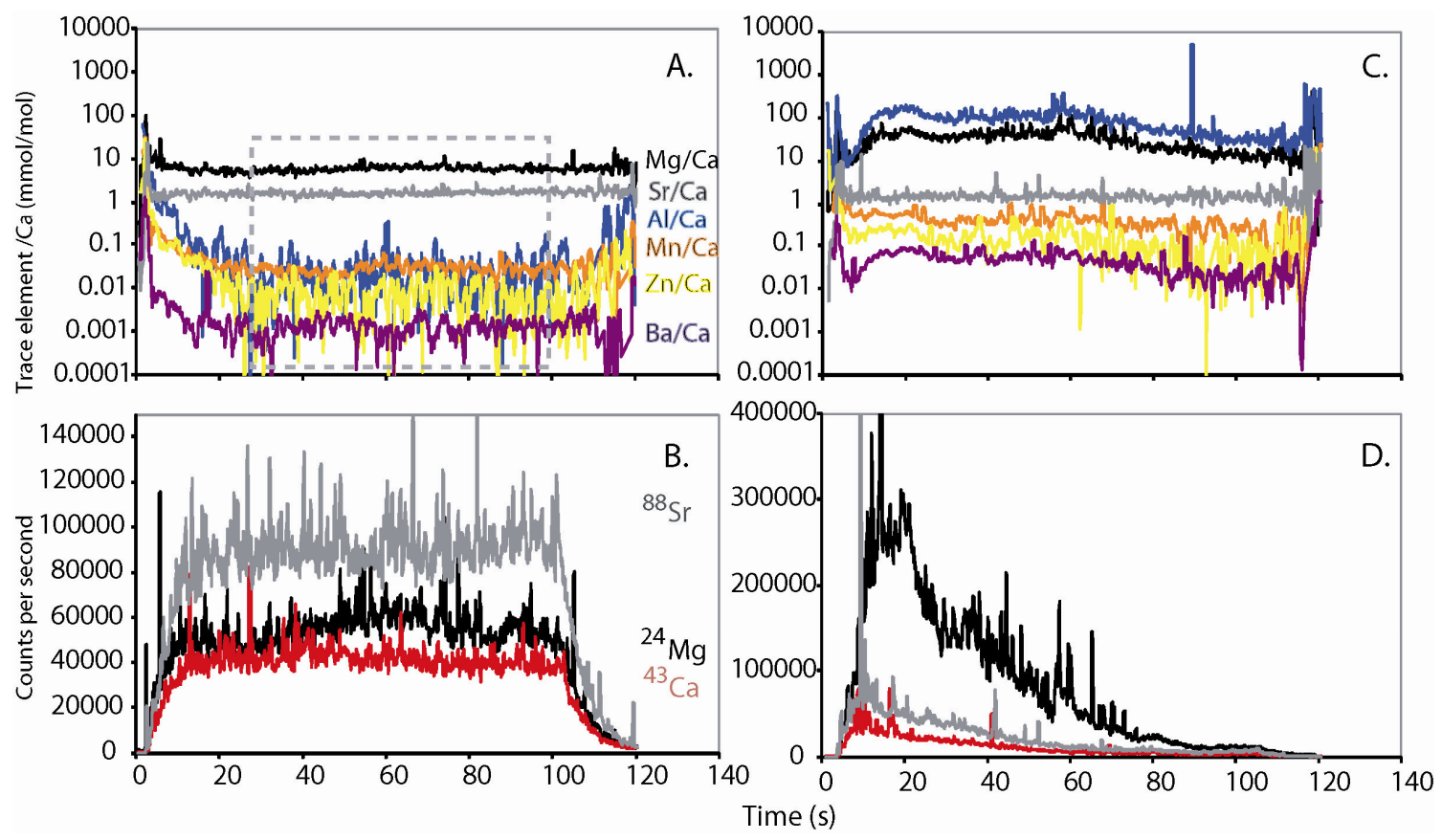

Figure 2.2: (A) Typical laser ablation depth profile of Gs. ruber from the AIMS3703 core top. Dashed grey boxed area represents integrated counts which are used to calculate the mean TE/Ca ratios from such profiles. (B) Shows the raw counts per second for ${ }^{43} \mathrm{Ca},{ }^{24} \mathrm{Mg}$ and ${ }^{88} \mathrm{Sr}$ from the same sample. (C) Example of a discarded foraminiferal trace element analysis from the AIMS3703 core top. (D) Shows the raw counts per second for ${ }^{43} \mathrm{Ca},{ }^{24} \mathrm{Mg}$ and ${ }^{88} \mathrm{Sr}$ for the same sample.

\subsection{An inter-laboratory comparison}

Duplicate analyses on a number of individual foraminifera were used to assess the comparability of LA-ICP-MS trace element analyses between the laboratories at VUW and ANU. The same sample of 17 Gs. ruber and 18 G. bulloides individuals were analysed at each laboratory and their mean trace element ratios compared (Figures 2.3 and 2.4). Both laboratories standardise using the NIST SRM 610 glass standard. The raw data were reduced using the same data reduction process as used at VUW so that the element/Ca ratios should be directly comparable. 
The results are plotted as a change in the measured values between ANU and VUW (yaxis) with the measured values from ANU (x-axis) (Figure 2.3 and 2.4, also Table 2.4). The results scatter around zero and indicate that most element/Ca ratios are comparable. For the ratios $\mathrm{Al} / \mathrm{Ca}, \mathrm{Mn} / \mathrm{Ca}, \mathrm{Zn} / \mathrm{Ca}$ and $\mathrm{Ba} / \mathrm{Ca}$ higher values may indicate presence of a detrital phase. Unsurprisingly, there is some variability even within individual chambers. This is because the analytical technique requires a different site on the chamber for each sample (i.e. the laser profile will incorporate varying amounts of the test structure depending on the plane of the test with respect to the laser spot). This is apart from any spatial heterogeneity of the trace elements within the tests. For example some studies have shown intra-test variation of $\mathrm{Mg} / \mathrm{Ca}$ that cannot be explained by changes in temperature or pH [Raja et al., 2005; Hathorne et al., 2009]. It should also be noted that the values for $\mathrm{Zn} / \mathrm{Ca}$ and $\mathrm{Ba} / \mathrm{Ca}$ are close to the detection limit of the techniques used in both laboratories. To test whether the repeated measurements were statistically different between laboratories, independent t-tests were performed. They show no significant difference between the TE/Ca ratios measured at either laboratory (Table 2.4). 

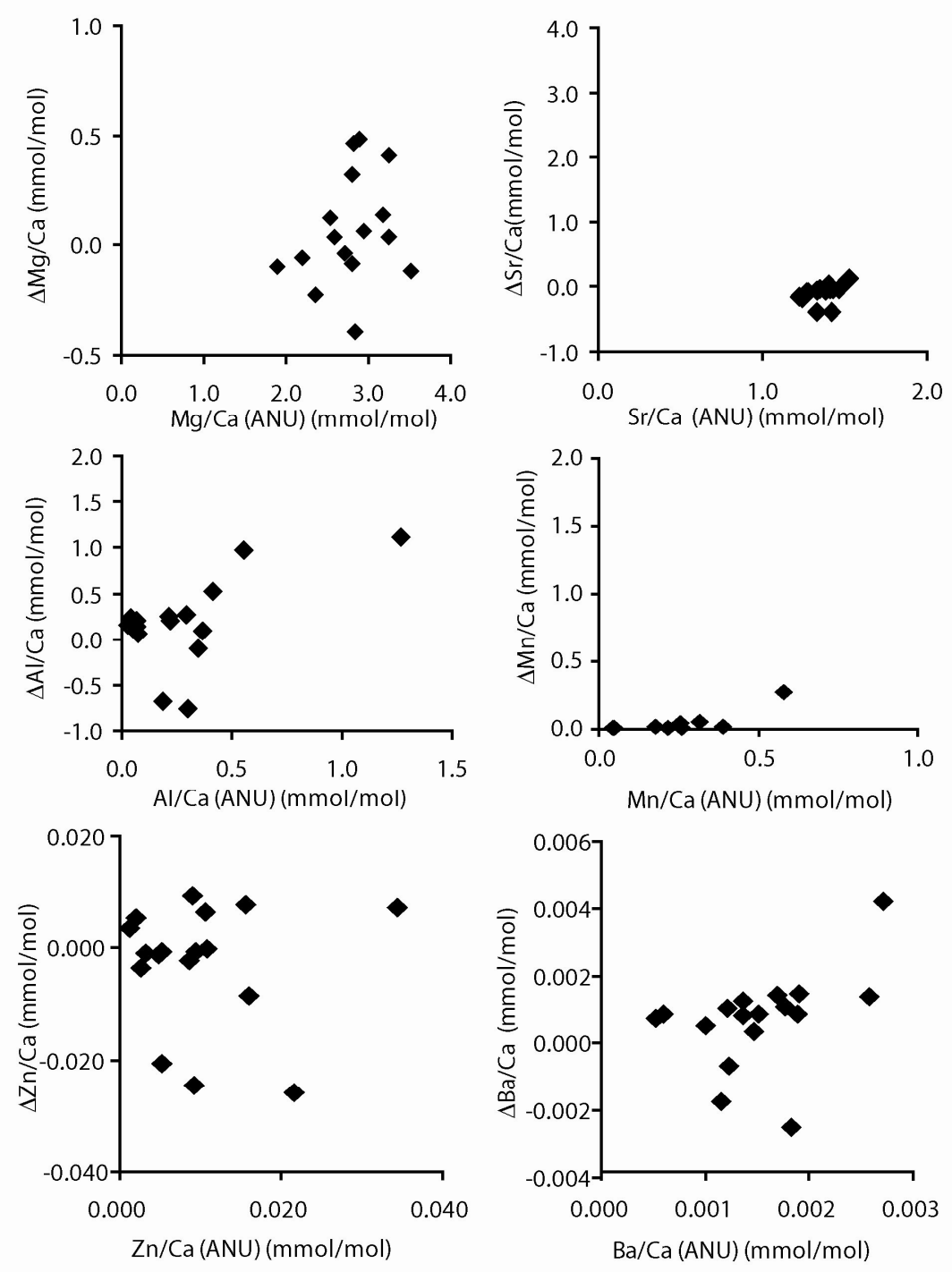

Figure 2.3: Graphs showing duplicate LA-ICP-MS trace element analyses of Gs. ruber (42.46 mbsf, label \#75) carried out at both VUW and ANU. Data are plotted as a change in the measured values between ANU and VUW (y-axis) with the measured values from ANU (x-axis). 

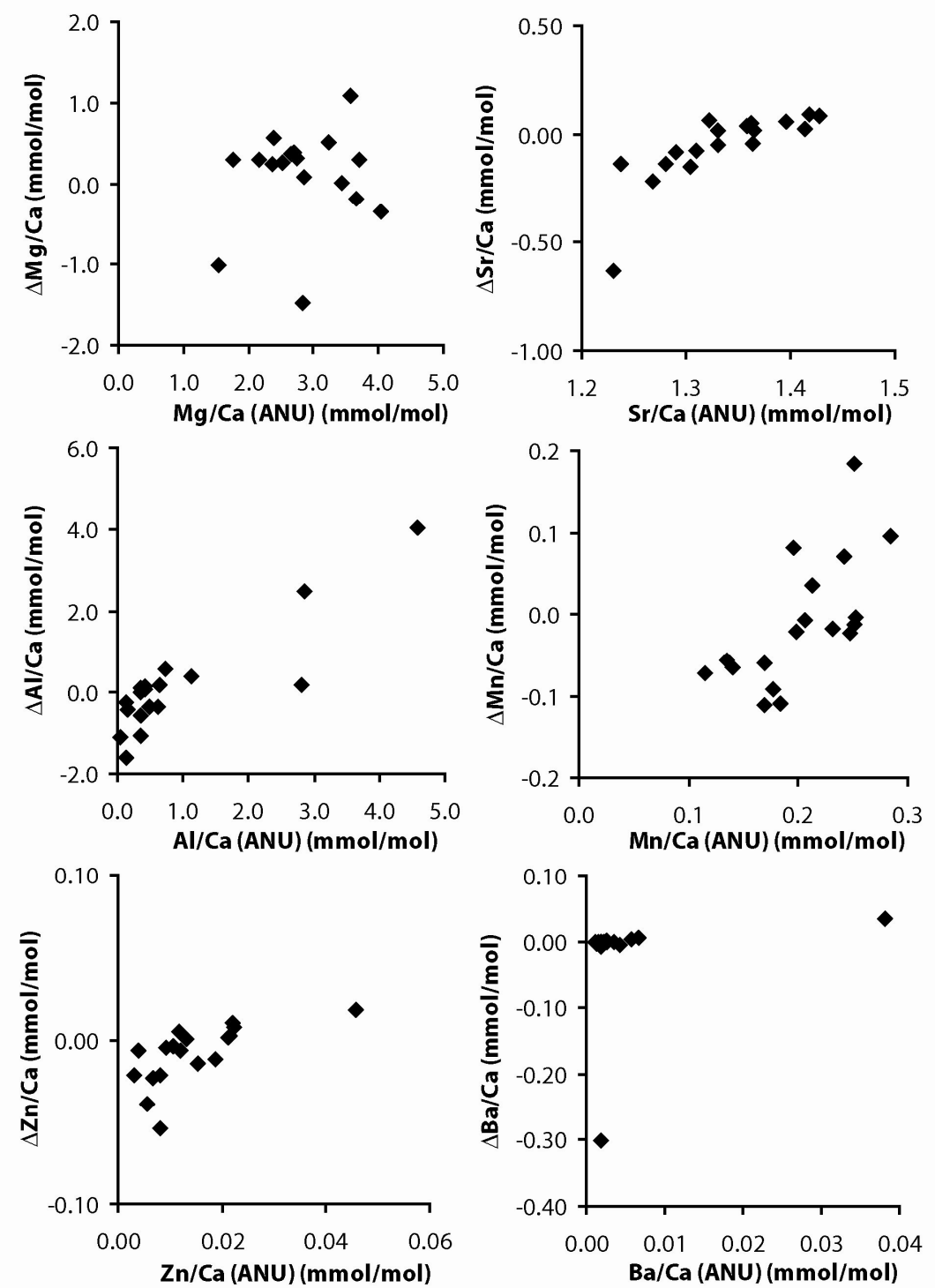

Figure 2.4: Data showing duplicate LA-ICP-MS trace element analyses of G. bulloides (42.64 mbsf, label \#84) carried out at VUW and the ANU. Data are plotted as a change in the measured values between ANU and VUW (Y-axis) with the measured values from ANU (X-axis). 
Table 2.4: Statistical summary of inter-laboratory comparison of TE/Ca ratios measured at VUW and ANU.

\begin{tabular}{|c|c|c|c|c|c|c|c|c|c|}
\hline \multicolumn{10}{|c|}{ Independent Samples Test ${ }^{\mathrm{a}}$} \\
\hline & \multicolumn{3}{|c|}{$\begin{array}{l}\text { Equality of } \\
\text { Variances }\end{array}$} & \multicolumn{4}{|c|}{ t-test for Equality of Means } & \multirow{2}{*}{\multicolumn{2}{|c|}{$\begin{array}{l}95 \% \text { C.I. of the } \\
\text { Difference }\end{array}$}} \\
\hline TE/Ca Pair & \multirow[b]{2}{*}{$\mathrm{F}$} & \multirow[b]{2}{*}{ Sig. } & \multirow[b]{2}{*}{$\mathrm{t}$} & \multirow[b]{2}{*}{ df } & \multirow[b]{2}{*}{$\begin{array}{c}\text { Sig. } \\
(2- \\
\text { tailed) }\end{array}$} & \multirow[b]{2}{*}{$\begin{array}{c}\text { Mean } \\
\text { Difference }\end{array}$} & \multirow[b]{2}{*}{$\begin{array}{l}\text { Std. Error } \\
\text { Difference }\end{array}$} & & \\
\hline ANU versus VUW & & & & & & & & Lower & Upper \\
\hline $\mathrm{Mg} / \mathrm{Ca}-\mathrm{Mg} / \mathrm{Ca}$ & 0.790 & 0.781 & 0.696 & 32 & 0.491 & 0.0982 & 0.141 & -0.1891 & 0.3856 \\
\hline $\mathrm{Al} / \mathrm{Ca}-\mathrm{Al} / \mathrm{Ca}^{\mathrm{b}}$ & 1.956 & 0.175 & -0.643 & 23 & 0.526 & -0.0928 & 0.144 & -0.3911 & 0.2055 \\
\hline $\mathrm{Mn} / \mathrm{Ca}-\mathrm{Mn} / \mathrm{Ca}$ & 0.931 & 0.342 & -0.105 & 32 & 0.917 & -0.0041 & 0.039 & -0.0842 & 0.0759 \\
\hline $\mathrm{Zn} / \mathrm{Ca}-\mathrm{Zn} / \mathrm{Ca}^{\mathrm{b}}$ & 5.767 & 0.023 & -1.556 & 29 & 0.131 & -0.0061 & 0.004 & -0.0142 & 0.0019 \\
\hline $\mathrm{Sr} / \mathrm{Ca}-\mathrm{Sr} / \mathrm{Ca}^{\mathrm{c}}$ & 3.954 & 0.057 & -1.650 & 28 & 0.110 & -0.0456 & 0.028 & -0.1022 & 0.0110 \\
\hline $\mathrm{Ba} / \mathrm{Ca}-\mathrm{Ba} / \mathrm{Ca}^{b}$ & 3.407 & 0.075 & 1.237 & 29 & 0.226 & 0.0004 & 0.000 & -0.0003 & 0.0011 \\
\hline
\end{tabular}

All samples were separated only by lab, with the null hypothesis that there was no significant difference between the TE/Ca analyses between laboratories.

a 2 -tailed significance level, p. Equal variances assumed. All samples show $\mathrm{p}>0.05$, t-test signifying that there is no statistically significant difference between any of the TE/Ca meaurements performed between ANU and VUW.

b Samples where $d f<32$ indicate where some negative values were removed. This is due to higher background levels of the TE/Ca.

c 4 outliers were removed.

In addition to analysing the same foraminifera at the two laboratories, a detailed trace element depth profile was measured from the same fragments of Orbulina universa at each of the laboratories. Trace element/Ca variations and absolute values in these fragments measured in the two laboratories are very similar and demonstrate that comparable data was produced using the two different laser ablation systems (Figure 2.5). The figure shows that both the shape of the trace element depth profiles is reproduced in both laboratories. Furthermore, the average absolute trace element/Ca values from both laboratories (Table 2.5) agree within analytical uncertainty. 


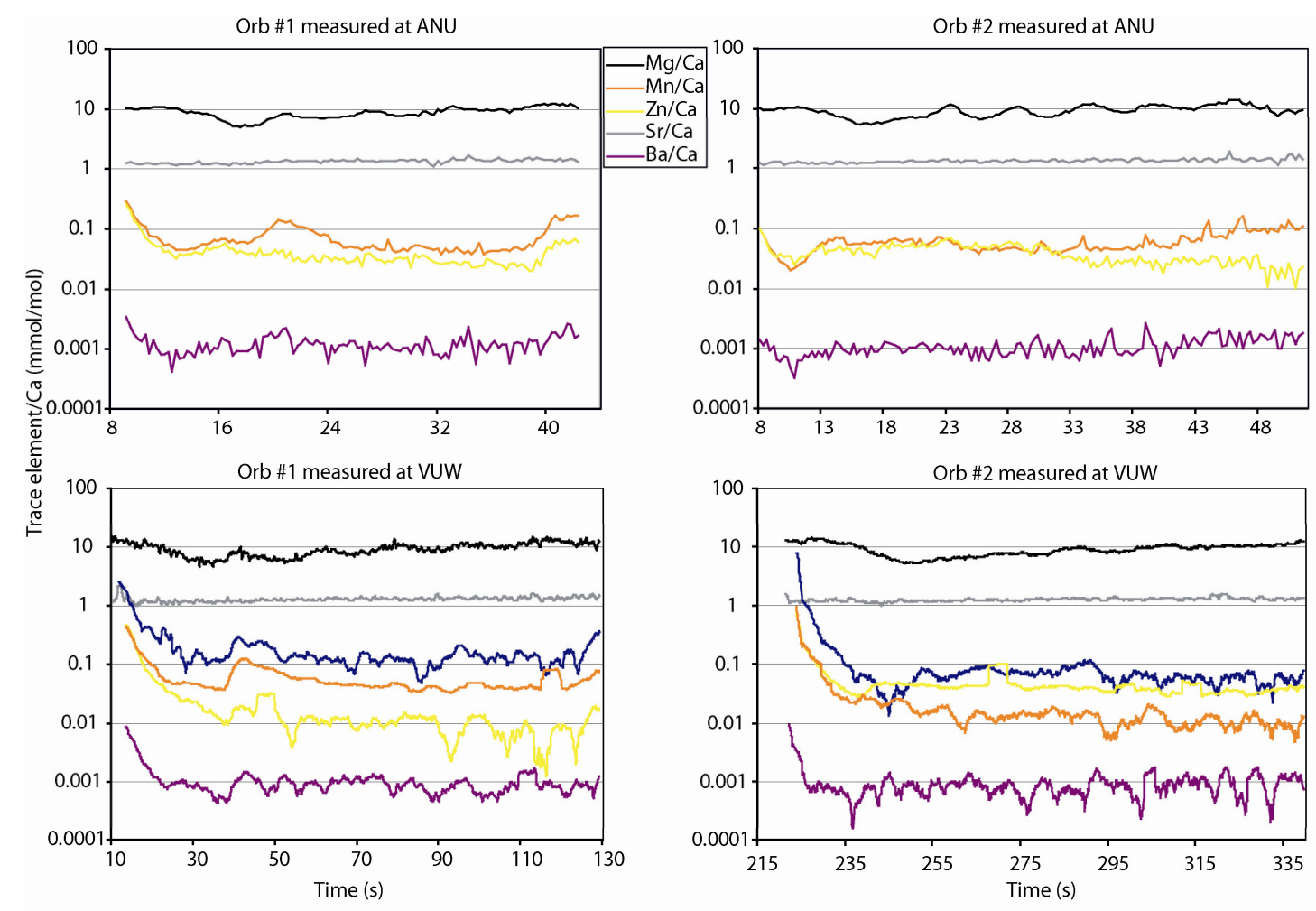

Figure 2.5: Comparison of laser ablation trace element depth profiles analysed in the same fragments of Orbulina universa at VUW and ANU. N.B. Blue line indicates $\mathrm{Al} / \mathrm{Ca}$ which was not measured at ANU. 
Table 2.5: Summary of the mean trace element ratios for the same fragment analysed at VUW and ANU

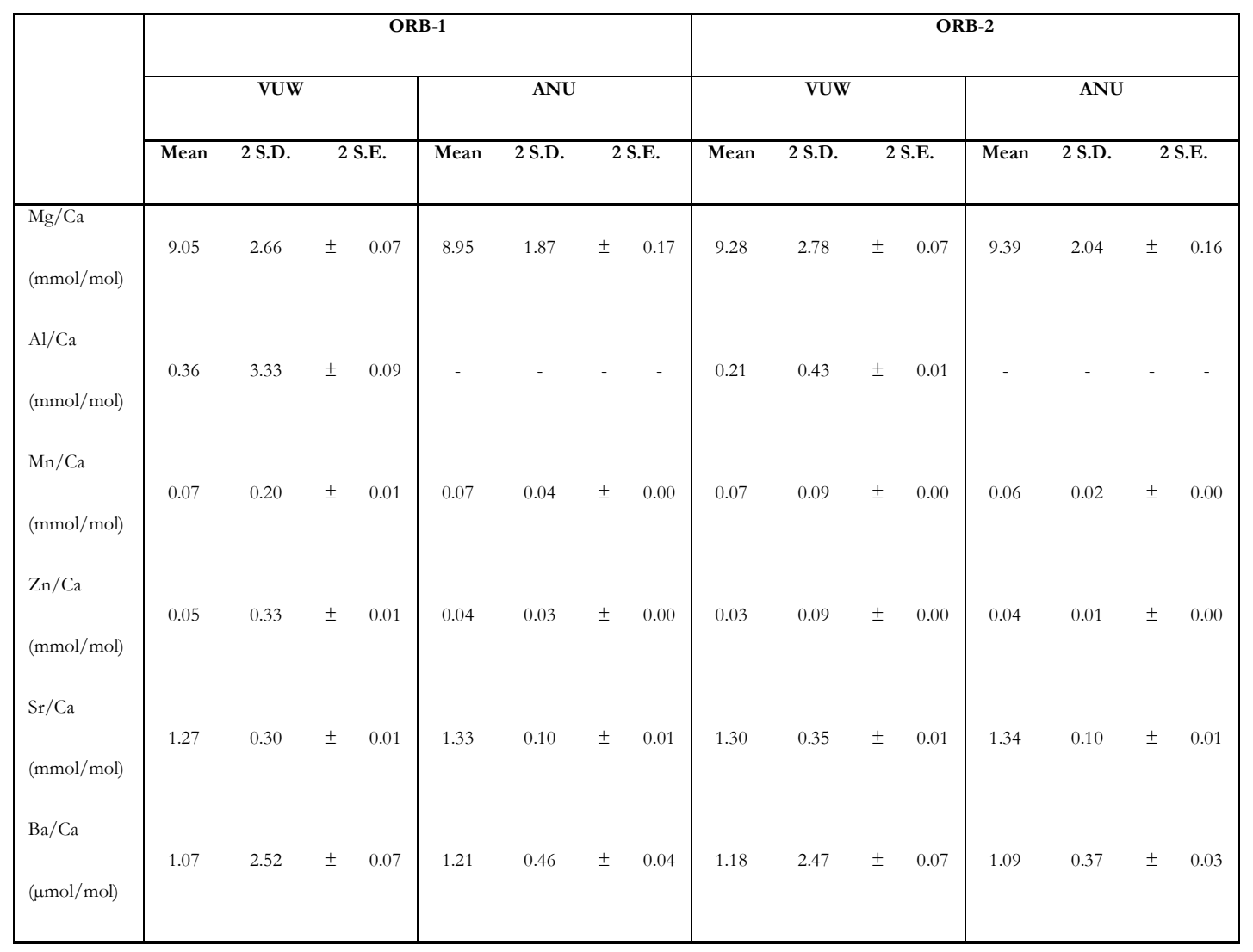

\subsection{Other methods for examining trace element ratios in foraminifera}

In addition to LA-ICP-MS analysis, a number of individual foraminifera were selected for element mapping using a JEOL JXA-8230 Super Probe. These samples were embedded in epoxy, vacuum sealed to remove air bubbles from inside the tests and then transferred to a hot plate and left at $40^{\circ} \mathrm{C}$ for $12 \mathrm{hr}$ to set. Each thin section was then lapped and polished to reveal a cross section of the foraminiferal test wall so that each chamber was exposed. $\mathrm{Mg}, \mathrm{Mn}$ and $\mathrm{Al} \mathrm{X}$-ray intensity maps were generated using an accelerating voltage of $15 \mathrm{kV}$, a beam current of $20 \mathrm{nA}$, a pixel size of $1 \mu \mathrm{m}$ and a dwell time of $1000 \mathrm{~ms}$. All available elements were measured by energy dispersive X-ray spectroscopy, and $\mathrm{Mg}, \mathrm{Mn}, \mathrm{Al}$ and $\mathrm{Ca}$ were also measured with wave-length dispersive spectrometry. Ca intensities below 10,000 counts per second (cps) were at background level. Using this threshold removes background X-ray levels and helps to delineate and remove effects associated with EMP analysis [Pena et al., 2008]. Element/Ca intensity maps were computed from matrix calculations, which were then calibrated to concentrations using the respective LA-ICP-MS trace element data. The intensity in the middle of a test wall was used in the element/Ca 
cps maps with the concentration of what was assumed to be the same part of the wall from the LA-ICP-MS data.

\section{$2.5 \quad \delta^{18} \mathrm{O}$ and $\delta^{13} \mathrm{C}$ stable isotope analyses}

The minimal destruction of foraminferal tests after LA-ICP-MS analysis leaves behind a significant amount of calcite that can be further analysed for stable oxygen and carbon isotopes to provide paired trace element and stable isotopic data on the same individuals. Samples of Gs. ruber (Chapter 3 and 5) and G. bulloides (Chapter 5) were re-cleaned (Section 3.4.2), and reacted with 2 drops of $100 \% \mathrm{H}_{3} \mathrm{PO}_{4}$ at $75^{\circ} \mathrm{C}$ in an automated individualcarbonate reaction (Kiel) device. The device was coupled to a Finnigan MAT252 mass spectrometer at NIWA, Wellington, New Zealand [Neil et al., 2004]. The external reproducibility was estimated by analysing concurrently run carbonate standards (NBS-19). External precision for $\delta^{18} \mathrm{O}_{c}$ and $\delta^{13} \mathrm{C}_{\mathrm{c}}$ was $0.04 \% 0$ and $0.01 \% 0$ respectively. Internal precision for $\delta^{18} \mathrm{O}_{c}$ and $\delta^{13} \mathrm{C}_{\mathrm{c}}$ was $0.03 \%$ and $0.01 \%$ respectively and are reported relative to Vienna Peedee Belemnite (vPDB). 


\section{Chapter 3}

\section{Environmental versus biological controls on $\mathrm{Mg} / \mathrm{Ca}$ variability in Globigerinoides ruber (white) from core- top and plankton tow samples in the Southwest Pacific Ocean}

Bolton, A., Baker, J.A., Carter, L., Dunbar, G., Smith E.C.G. and Neil, H., (2011), Paleoceanography, 26, PA2219, pp. 1-14, DOI: 10.1029/2010PA001924 Minor text modifications have been made to this publication and some additional data has been included and discussed as supplementary material. 


\subsection{Abstract}

Laser ablation inductively coupled plasma mass spectrometry was used to analyse the individual chambers from tests of foraminiferal fossil and plankton tow Globigerinoides ruber from the Southwest Pacific Ocean, from latitudes 3 to $42^{\circ} \mathrm{S}$. The variability of $\mathrm{Mg} / \mathrm{Ca}$ between chambers of an individual (intra) and individuals of the same population (inter), is such that when converted to temperature, the extent of intra- and inter-individual variability appears to exceed that attributable to either calcification or seasonal temperature variability.

The pooled mean chamber $\mathrm{Mg} / \mathrm{Ca}$ from each core top and plankton tow site demonstrate a significant $(\mathrm{p}<0.05)$ positive correlation with temperature. Chamber specific calibrations were derived where: $\mathrm{Mg} / \mathrm{Ca}_{\mathrm{Ch} \_\mathrm{F}-2}=0.798 \exp ^{0.070 \mathrm{~T}}, \mathrm{Mg} / \mathrm{Ca}_{\mathrm{Ch} \_\mathrm{F}-1}=0.891 \exp ^{0.067 \mathrm{~T}}$ and $\mathrm{Mg} / \mathrm{Ca}_{\mathrm{Ch}_{-} \mathrm{F}}=0.590 \exp ^{0.072} \mathrm{~T}$. There was no bias between $\mathrm{Mg} / \mathrm{Ca}$ ratios from the two morphotypes Gs. ruber ruber and Gs. ruber pyramidalis. The chamber specific calibrations potentially offset $\mathrm{Mg} / \mathrm{Ca}$-based temperature reconstructions if used on bulk (whole) test $\mathrm{Mg} / \mathrm{Ca}$ or applied to mis-identified chambers. Nevertheless, these calibrations can be used to reliably estimate past sea surface temperatures.

Although there is a general overriding temperature control on $\mathrm{Mg} / \mathrm{Ca}$, removal of the effect of temperature at each site reveals a log-normal $\mathrm{Mg} / \mathrm{Ca}$ distribution. This suggests that $\mathrm{Mg} / \mathrm{Ca}$ variability at each site is also affected by biological mechanism(s) that may control the distribution of inter-individual $\mathrm{Mg} / \mathrm{Ca}$. In addition, other trace element/Ca data $(\mathrm{Al} / \mathrm{Ca}$ and $\mathrm{Mn} / \mathrm{Ca}$ ) from laser ablation trace element depth profiles can be used to identify detrital or diagenetic phases that may bias the trace element/Ca signal. 


\subsection{Introduction}

The ratio of $\mathrm{Mg} / \mathrm{Ca}$ in planktonic foraminiferal calcite is an important proxy for past sea surface temperatures (SST) [Dekens et al., 2002; Anand and Elderfield, 2003; Barker et al., 2005]. Although there is a strong empirical correlation between calcification temperature and the $\mathrm{Mg} / \mathrm{Ca}$ ratio as bulk samples (comprising $~ 5-50$ individual tests), planktonic foraminifera exert considerable biological control over the incorporation of $\mathrm{Mg}$ (and other trace elements [TE]) into their tests [Elderfield et al., 1996; Zeebe and Sanyal, 2002; Erez, 2003; Eggins et al., 2004]. Furthermore, the TE/Ca ratio measured in foraminiferal tests recovered from deep sea sediments can be complicated by post-depositional digenetic alteration [Dekens et al., 2002; Tachikawa et al., 2008]. Therefore, uncertainties remain over the relative importance of environmental versus biological versus diagenetic factors in determining what controls the $\mathrm{Mg} / \mathrm{Ca}$ ratio of foraminiferal tests.

The development of microprobe and laser ablation inductively coupled plasma mass spectrometry (LA-ICP-MS) micro-analytical techniques now allow researchers to quantify $\mathrm{TE} / \mathrm{Ca}$ ratios in individual foraminifer chambers and along profiles through test walls [Elderfield, 2002; Eggins et al., 2003; Hathorne et al., 2003; Reichart et al., 2003; Sadekov et al., 2005]. For example, in addition to more traditional estimates of sea surface temperature (SST) (e.g., Anand and Elderfield, [2003]), fine scale structural differences such as compositional differences between gametogenic versus ontogenetic calcite can be inferred (e.g., Kozdon et al., [2009]). An additional benefit to using these techniques are the minimal destruction of the test, potentially enabling further paired analyses.

An open question is posed in this study, to what extent does inter-and intra-individual chamber $\mathrm{Mg} / \mathrm{Ca}$ variability reflect environmental conditions relative to biological vital effects and what can this variability tell us about the limitations of $\mathrm{Mg} / \mathrm{Ca}$ for palaeo-ocean temperature reconstruction more generally? To investigate this and other questions, a species of foraminifera commonly used for palaeo-SST reconstruction, Globigerinoides ruber [D'Orbigny, 1839] white variety, Gs. ruber (w) was examined. LA-ICP-MS was used to measure trace element depth profiles from individual chambers of Gs. ruber from core top and plankton tows from the South Pacific Ocean spanning a mean annual SST of 14.7 to $28.8^{\circ} \mathrm{C}$. The data are presented in terms of a LA-ICP-MS derived SST versus $\mathrm{Mg} / \mathrm{Ca}$ calibration for Gs. ruber for the Southwest Pacific Ocean. Following this, the results are considered in terms of potential environmental controls over $\mathrm{Mg} / \mathrm{Ca}$ from which it is 
argued that individual test and chamber measurements point strongly to biological control over $\mathrm{Mg} / \mathrm{Ca}$ on an intra- and inter-individual test basis. These controls are independent of temperature, but the mean $\mathrm{Mg} / \mathrm{Ca}$ of a foraminiferal population is sensitive to temperature in a manner described by solution-based studies.

\subsection{Background}

Gs. ruber is a symbiotic-bearing planktonic foraminifera that is abundant in tropical and Subtropical waters occupying a temperature and salinity range between $14-32^{\circ} \mathrm{C}$ and $22-49$ psu respectively [Bé et al., 1977; Bijma et al., 1990b]. The presence of photosynthetic symbionts [Bé et al., 1977] mean it is restricted to the photic zone that is the upper mixed layer of the ocean [Dekens et al., 2002; Anand and Elderfield, 2003; Huang et al., 2008; Regenberg et al., 2009]. Consequently, SST data obtained from Gs. ruber are thought to largely reflect conditions prevailing in the depth range $\sim 0-50 \mathrm{~m}$, minimising complications from significant temperature changes associated with migration within the water column during the foraminiferal lifecycle. Gs. ruber has been classified into two end-member morphotypes [Steinke et al., 2005] which previous workers have suggested occupy specific ecological niches based on their significantly different $\mathrm{Mg} / \mathrm{Ca}$ and oxygen isotope $\left(\delta^{18} \mathrm{O}_{c}\right)$ values [Kuroyanagi and Kawahata, 2004; Kawahata, 2005; Löwemark et al., 2005; Steinke et al., 2005]. However a separate study [Mobtadi et al., 2009] failed to find geochemical differences between morphotypes whilst Kawahata, [2005] explained the apparent difference as the result of productivity occurring at different times of the year for different morphotypes. Nonetheless, because of its restricted ecological niche in a climatically important part of the water column, it is one of the most widely used planktonic foraminifera for palaeo-ocean thermometry.

\subsection{Materials and Methods}

\subsubsection{Regional Setting and Core Top and Plankton Tow Locations}

The study region is situated in the Southwest Pacific Ocean, and includes 10 core top and 3 plankton tow samples spanning $3.4^{\circ} \mathrm{S}$ to $41.9^{\circ} \mathrm{S}$ latitude. The tropical sites lie within either the Coral Sea or Timor Sea. The Timor Sea moves warm, low salinity, nutrient poor water 
between the Indonesia archipelago and Australia into the Indian Ocean [Gordon et al., 1997]. The site AIMS1631 lies seaward of the north flowing Sepik River that drains largely volcanic and igneous terrain into the Coral Sea [Brunskill, 2004]. Currents from the Coral Sea bring warm nutrient-poor waters down the east coast of Australia to the cool waters of the Tasman Sea. This flow forms a counter-clockwise gyro which includes the East Australian Current (EAC), the largest ocean current off the Australian coast [Ridgway and Godfrey, 1997; Ridgway and Hill, 2009]. Mid-latitude sites are located in subtropical higher salinity waters, which flow south along the Tasman Front (TF) separated at Chatham Rise (CR).

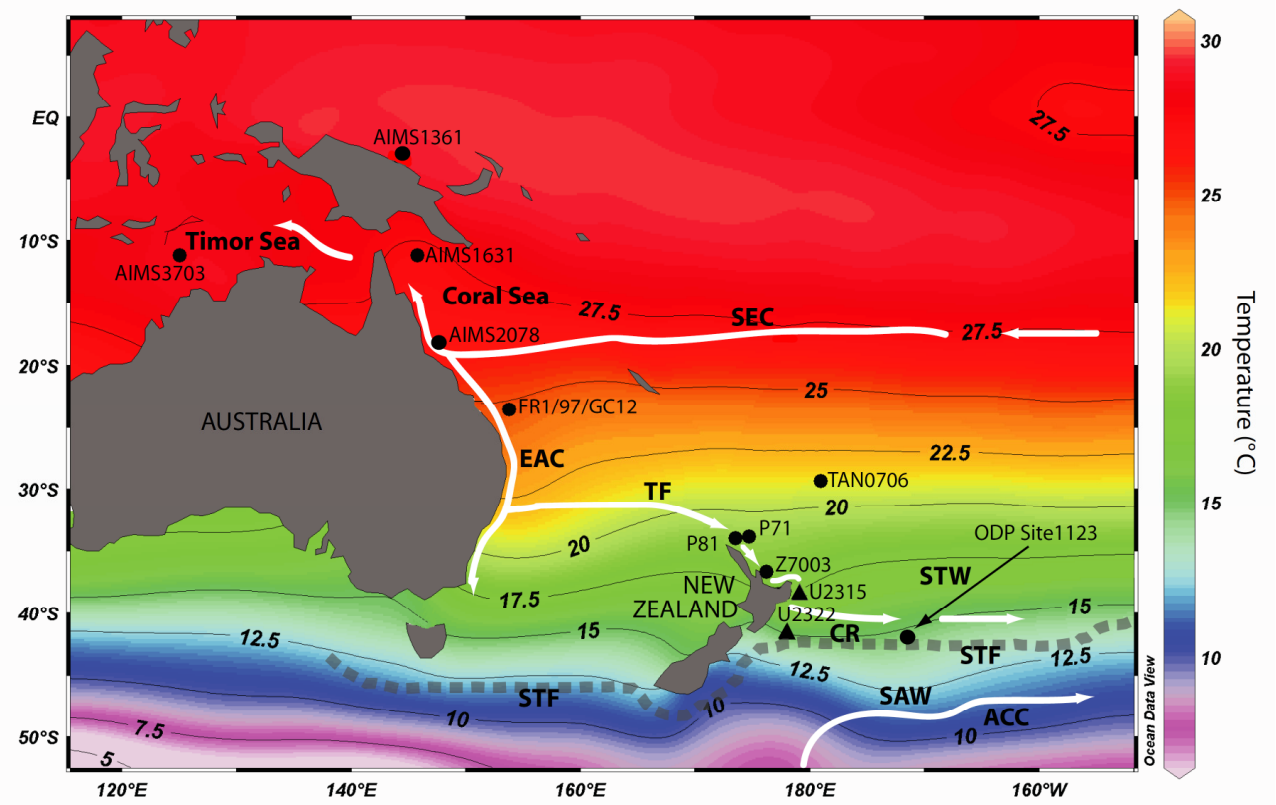

Figure 3.1: Chart showing the annual sea surface temperatures for the Southwest Pacific Ocean [Locarnini et al., 2006] and locations of core top (black dots) and MOCNESS tow (black triangles) samples. Also shown are the East Australian Current (EAC), South Equatorial Current (SEC), Tasman Front (TF) and the Chatham Rise (CR). Major surface water masses shown are Subtropical Water (STW) and Subantarctic Water (SAW). Samples were selected to represent a latitudinal gradient with sea surface temperatures ranging from 14 to $29{ }^{\circ} \mathrm{C}$. Isotherms are in ${ }^{\circ} \mathrm{C}$. Source: Ocean Data Viewer [Schlitzer, 2002].

The Subtropical Front forms the boundary between this Subtropical water (STW) and cold, low salinity and macro-nutrient-rich Subantarctic Surface Water (SAW) from the within the Subantarctic Front of the Antarctic Circumpolar Current [Uddstrom and Oien, 1999; Morris et al., 2001; Neil et al., 2004; McCave et al., 2008] (Figure 3.1). 
The core top samples were selected from archives managed by the National Institute of Water \& Atmospheric Research (NIWA), New Zealand and the Australian Institute of Marine Sciences (AIMS). These sites ranged in depth from $3290 \mathrm{mbsl}$ to $430 \mathrm{mbsl}$ and the mean and seasonal range of SSTs and Sea Surface Salinity (SSS) for each site were taken from the World Ocean Atlas 2005 (WOA05) [Antonov et al., 2006; Locarnini et al., 2006] (Table 3.1). In addition, foraminifera from 3 plankton tow samples were also analysed. They were collected from water depths of 10-50 m (U2322 net 7), 50-100 m (U2322 net 6) and 50-100 m (U2315) using a Multiple Opening-Closing Net and Environmental Sensing System (MOCNESS) [Wiebe et al., 1985] during March and April, 2001 (voyage TAN0103, NIWA). During deployment of the MOCNESS, separate downcast measurements of temperature and salinity data were measured with a conductivity/temperature/depth (CTD) probe. The temperature and salinity data from the CTD agree well with estimates obtained from WOA05.

An important aspect of the suite of samples used in this study is that almost all of the sites are above the present day, regional foraminiferal lysocline $(3600-4000 \mathrm{~m})$ with the exception of ODP Site 1123, which is the deepest site at $3290 \mathrm{~m}$ [Berger et al., 1976; Martinez, 1994]. Other data suggest the modern planktonic foraminifera lysocline in this region is $\sim 3250 \mathrm{~m}$ [Feely et al., 2004]. However, previous studies assessing ratios of benthic to planktonic foraminifera, fragmentation indices, test ultra-structure [Crundwell et al., 2008] and the preservation of associated calcareous nannofossils [Fenner and Di Stefano, 2004] suggest this site has not been adversely affected by dissolution. In addition, a study measuring $\mathrm{Mg} / \mathrm{Ca}$ ratios in the benthic foraminifera Uvigerina spp. at ODP Site 1123, compared the $\mathrm{Mg} / \mathrm{Ca}$ ratio of that species with the shell weights of the planktonic species Globigerina bulloides (G. bulloides) from the same record [Elderfield et al., 2010].

They found that where $\mathrm{Mg} / \mathrm{Ca}$ was high in the Uvigerina spp. record, the corresponding shell weights of $G$. bulloides were low. They also did not find any discernible relationship between $\mathrm{Mg} / \mathrm{Ca}$ and either $\mathrm{Al} / \mathrm{Ca}$ or $\mathrm{Mn} / \mathrm{Ca}$ that may signal a diagenetic overprint. Using these two approaches they concluded that dissolution was unlikely to influence $\mathrm{Mg} / \mathrm{Ca}$ measured in their study. 
Table 3.1: Core top and MOCNESS tow sample locations, seafloor depths, SST (annual and range) and calibrated ${ }^{14} \mathrm{C}$ ages of core tops

\begin{tabular}{|c|c|c|c|c|c|c|c|c|}
\hline Sample & Latitude & Longitude & Depth & $\begin{array}{c}\text { Mean } \\
\text { Annual } \\
\text { SST }^{\mathrm{a}} \\
(0-50 \mathrm{~m})\end{array}$ & $\begin{array}{l}\text { S.D. SST } \\
(0-50 \mathrm{~m})\end{array}$ & $\begin{array}{c}\text { Annual Range } \\
\mathrm{SST}^{\mathrm{a}} \\
(0-50 \mathrm{~m})\end{array}$ & SSS $^{b}$ & Age \\
\hline & (South) & (East) & (metres) & $\left({ }^{\circ} \mathrm{C}\right)$ & $\left({ }^{\circ} \mathrm{C}\right)$ & $\left({ }^{\circ} \mathrm{C}\right)$ & (psu) & $(k . a)^{c}$ \\
\hline AlMS1361 & 3.37 & 144.335 & 1,100 & 28.8 & 0.8 & $27.8-29.6(1.8)$ & 34.5 & \\
\hline AIMS3703 & 11.153 & 125.023 & 504 & 28.4 & 1.6 & $26.3-30.2(3.9)$ & 34.3 & $\begin{array}{r}<100 \text { years (Gregg Brunskill, pers. } \\
\text { comm.) }\end{array}$ \\
\hline AIMS 1631 & 11.158 & 145.79 & 1,468 & 26.8 & 1.7 & $24.8-29.2(4.4)$ & 35.0 & \\
\hline AIMS2078 & 18.212 & 147.597 & 880 & 26.4 & 1.5 & $24.6-28.9(4.3)$ & 35.0 & $\begin{array}{r}2160 \pm 50 \text { based on nearby piston } \\
\text { cores [Dunbar et al., 2000] }\end{array}$ \\
\hline FR1/97/GC12 & 23.577 & 153.793 & 991 & 24.7 & 1.6 & $22.4-27.4(5.0)$ & 35.4 & $8955 \pm 25$ (NIWA, unpublished data) \\
\hline P81 & 34.02 & 173.51 & 2,036 & 18.1 & 2.3 & $15.6-21.2(5.6)$ & 35.6 & $5715 \pm 40^{\mathrm{e}}$ \\
\hline P71 & 33.855 & 174.693 & 1,919 & 18.8 & 1.9 & $16.3-21.9(5.6)$ & 35.6 & $5715 \pm 40$ \\
\hline Z7003 & 36.693 & 176.238 & 430 & 18.1 & 2.4 & $15.8-21.2(5.4)$ & 35.5 & $5932 \pm 55$ \\
\hline U2322 net $7^{d}$ & 41.601 & 178.05 & $50-10$ & 18.8 & - & $18.0-18.6(0.6)$ & 35.6 & Plankton tow - April 2001 \\
\hline U2322 net $6^{d}$ & 41.601 & 178.05 & $100-50$ & 18.3 & - & $18.6(0)$ & 35.6 & Plankton tow - April 2001 \\
\hline $\mathrm{U} 2315^{\mathrm{d}}$ & 38.509 & 179.018 & $100-50$ & 18.7 & - & $17.1-20.2(3.1)$ & 35.6 & Plankton tow - April 2001 \\
\hline TAN0706 C4 & 29.353 & 180.972 & 2,258 & 20.7 & 2.1 & $18.1-24.0(5.9)$ & 35.7 & \\
\hline ODP Site 1123 & 41.942 & 188.501 & 3,290 & 14.7 & 1.9 & $12.1-17.6(5.5)$ & 35.1 & \\
\hline
\end{tabular}

${ }^{a}$ Annual sea surface temperatures (SST), seasonality, and standard deviations (SD) were derived from the World

Ocean Atlas 2005 [ Locarnini et al ., 2006] except for plankton tow samples that used CTD data to infer actual SST and SSS.

${ }^{b}$ Annual sea surface salinities (SSS), were derived from the World Ocean Atlas 2005 [Antonov et al., 2006].

${ }^{\mathrm{C}}$ Ages were calculated using either radiometric dating within the same core or in cores located close by.

Errors are in radiocarbon years.

${ }^{\mathrm{d}}$ Plankton tow temperature data derived from CTD.

${ }^{\mathrm{e}}$ Assumes similar sedimentation rate to $\mathrm{P} 71$

\subsubsection{Sample Preparation}

Foraminiferal samples were dry sieved so that the size fraction 250-355 $\mu \mathrm{m}$ remained.

Previous experiments on Gs. ruber have shown that an increase in size corresponds to an increase in $\mathrm{Mg} / \mathrm{Ca}$ ratios [Elderfield et al., 2002] although not all studies are in agreement [Ni et al., 2007]. In the plankton tow material there were few specimens $>250 \mu \mathrm{m}$ in size, therefore individuals were selected from the $>150 \mu \mathrm{m}$ size fraction. At ODP Site 1123, the morphology of most of the specimens was smaller and more compact than archetypal Subtropical specimens that have large tests and large, well developed, supplementary apertures. In these specimens, the majority had very small supplementary apertures consistent with specimens living at the cold limit of their biogeographic range (M. Crundwell, pers. comm., 2009). 
Following sieving, each individual foraminifer was carefully picked under a binocular microscope resulting in a random sample of 12-30 individuals from each sample set. In order to test for morphotype differences, where possible, the two major morphotypes $G s$. ruber ruber and Gs. ruber pyramidalis were identified prior to LA-ICP-MS analysis using the descriptions from Steinke et al., [2005].

Arbitrary values of $0.1 \mathrm{mmol} / \mathrm{mol}$ have been used by previous workers to reject planktic foraminiferal $\mathrm{TE}$ analyses with suspected high $\mathrm{Al} / \mathrm{Ca}, \mathrm{Fe} / \mathrm{Ca}$ and $\mathrm{Mn} / \mathrm{Ca}$ ratios from samples analysed in solution (e.g., Boyle et al., 1983). This is based on the assumption that high $\mathrm{Al} / \mathrm{Ca}$ and $\mathrm{Mn} / \mathrm{Ca}$ are indicators of contaminants such as clay minerals and surface coatings that also contain $\mathrm{Mg}$, consequently contributing to the $\mathrm{Mg} / \mathrm{Ca}$ that would otherwise be attributed to primary foraminiferal calcite. To ensure detrital contamination was minimised [Rollion-Bard, 2005], three methodologies were employed to identify such specimens:

(i) Specimens were visually inspected and those with obvious adhering sediment were either re-cleaned or discarded (e.g., red/brown coloured tests were avoided);

(ii) All data were analysed for the degree of covariance of $\mathrm{Mg} / \mathrm{Ca}$ with $\mathrm{Al} / \mathrm{Ca}$ and Mn/Ca. A few outliers were discarded. The remaining data did not show a statistically significant correlation $\left(\mathrm{r}^{2}<0.5\right)$.

(iii) Terrigenous clay mineral assemblage data was examined for the Southwest Pacific Ocean and did not suggest major contamination of $\mathrm{Mg}$ from the sediments [Glasby, 1979]. For example, a foraminiferal analysis yielding an $\mathrm{Al} / \mathrm{Ca}$ of 0.2 $\mathrm{mmol} / \mathrm{mol}$ from a mixture of $25 \%$ kaolinite $\left(\mathrm{Al}_{2} \mathrm{Si}_{2} \mathrm{O}_{5}(\mathrm{OH})_{4}\right), 15 \%$ illite $\left(\mathrm{K}_{0.40}\right.$ $\left.\left.\begin{array}{llllllll}\mathrm{Na}_{0.40} & \mathrm{Fe}_{0.24} & \mathrm{Mg}_{0.34} & \mathrm{Al}_{1.50} & \left(\mathrm{Al}_{0.57}\right. & \mathrm{Si}_{3.43} & \mathrm{O}_{10}\end{array}\right)(\mathrm{OH})_{2}\right)$ and $60 \%$ smectite $\left(\mathrm{Na}_{0.165} \mathrm{Ca}_{0.165} \mathrm{Al}_{1.2} \mathrm{Mg}_{0.8} \mathrm{Si}_{4} \mathrm{O}_{10}(\mathrm{OH})_{2} \cdot \mathrm{nH}_{2} \mathrm{O}\right)$ would add $0.06 \mathrm{mmol} / \mathrm{mol} \mathrm{Mg} / \mathrm{Ca}$ to a foraminiferal $\mathrm{Mg} / \mathrm{Ca}$ ratio of $1.35 \mathrm{mmol} / \mathrm{mol}$.

In addition, the laser ablation technique itself yields data that can resolve the contaminants by enabling the analyst to exclude data from certain regions of the test (e.g., Creech et al., 2010) and therefore avoiding the contributions from those deposits - these were the main source of concern for those analysing foraminifera by solution in the work of [Boyle, 1981; 1983] and from other techniques with secondary high Mg-carbonate overgrowths [Hoogakker et al., 2009]. The use of the above methodologies allows some confidence that 
detrital contamination was minimised by the elimination of individual samples. However, samples which were eliminated were done so without using an arbitrary "contaminant" cutoff level.

Following selection of clean foraminifera, each sample was transferred to a clean glass vial. Each core top sample was initially given 3 rinses in ultra-clean water (>18 M $\Omega$ ), followed by 2 rinses in analytical grade methanol, where the first rinse was additionally treated by gentle ultra-sonication (at $10 \%$ power) for $<5$ s. Clearly, the better preserved the specimens or the thicker the tests, the more they will stand up to the rigours of ultrasonication. Ultra-sonication for longer than $5 \mathrm{~s}$ often resulted in partial or complete destruction of tests, particularly those obtained from the plankton tows. Broken tests were discarded from further analyses.

Finally, each sample was rinsed three times with ultra-clean water. Following cleaning, each sample was transferred to an oven and allowed to dry for $24 \mathrm{hrs}$ at $40{ }^{\circ} \mathrm{C}$. These preparation procedures prior to laser ablation are similar to those used in other studies [Eggins et al., 2003; Reichart et al., 2003; Bergami et al., 2008; Sadekov et al., 2008; Hathorne et al., 2009]. Cleaned individual foraminifera were also weighed using a Mettler-Toledo UMX2 microbalance, mounted and photographed prior to LA-ICP-MS analysis.

Organic material was removed from the plankton tow samples using a low temperature oxygen plasma asher. The samples were cleaned using the same procedure as the core top samples but excluding the ultrasonic cleaning step. Other studies have used oxidative cleaning to remove organic material (e.g., buffered hydrogen peroxide or sodium hypochlorite). However, sample loss can be minimised by avoiding the use of these chemicals [Boyle and Keigwin, 1985; Barker et al., 2003; Rosenthal et al., 2004; Yu et al., 2005].

Following cleaning, a selected number of samples were also examined with a scanning electron microscope (SEM) for any signs of dissolution and/or contaminants prior to and post LA-ICP-MS. These individuals were placed onto sticky carbon tape; gold coated and imaged using a JEOL JSM-5300LV SEM.

\subsubsection{Trace elemental analysis of Gs. ruber in the Southwest Pacific Ocean}

Prior to laser ablation analyses, each foraminifera was carefully mounted onto a NIST610 glass standard using very weak adhesive tape and a clean paint brush. The outside to the inside (c.f. Sadekov et al., 2008) of the 3 chambers in the final whorl per individual were 
analysed for the isotopes ${ }^{24} \mathrm{Mg},{ }^{27} \mathrm{Al},{ }^{55} \mathrm{Mn},{ }^{66} \mathrm{Zn},{ }^{88} \mathrm{Sr}$ and ${ }^{138} \mathrm{Ba}$ relative to ${ }^{43} \mathrm{Ca}$, using a New Wave deep UV (193 nm) solid state laser ablation system coupled to an Agilent 7500CS ICP-MS. Gs. ruber chamber formation can be either sinistral or dextral and coiling direction can be identified by examining the dorsal view of the test. Here chamber 'F-2' represents the antepenultimate chamber; ' $\mathrm{F}-1$ ' is the penultimate chamber prior to the ultimate (final) chamber ' $\mathrm{F}$ '. Measurements were standardised using known elemental compositions of the NIST610 standard [Pearce et al., 1996]. The resulting data were processed using a MATLAB script which allowed for initial screening of outliers, background correction, and Cacorrected internal standardisation.

Background and NIST610 measurements were made for 60 seconds at the start and end of each run. For the NIST610 a laser spot size of $35 \mu \mathrm{m}$ and repetition rate of $5 \mathrm{~Hz}$ was used. For foraminiferal measurements a laser spot size of $25 \mu \mathrm{m}$ and repetition rate of 2 or $5 \mathrm{~Hz}$ was used. The washout time between standards and samples was 100 seconds. For individual chambers the measurement profile took a maximum of 120 seconds to penetrate from the outer to inner chamber wall. The LA-ICP-MS depth profiles were used to distinguish between contaminant phases and only include the ontogenetic calcite for calculation of TE/Ca ratios (e.g., Figure 3.2). The end of each profile was identified either visually when the laser had ablated through the test well, or from the sharp reduction of raw $\mathrm{Ca}$ counts from the laser ablation profile which decline rapidly once the laser has ablated through each chamber. The complete ablation of a chamber wall is sometimes observed in conjunction with elevated $\mathrm{Al} / \mathrm{Ca}$ and $\mathrm{Mn} / \mathrm{Ca}$, suggesting the presence of phases containing these metals on the inside of the tests. Using the laser ablation profiles, it is possible to avoid both surface veneers and internal trapped sediment by selecting the middle portion of the test, thus, removing the influence of these contaminants.

Duplicate measurements on sub-samples of individual tests were taken to ensure reproducibility of individual chamber analyses. From these measurements the two standard deviation (2 S.D.) and the median of the 2 S.D. respectively were: 0.72 and $0.25 \mathrm{mmol} / \mathrm{mol}$ for $\mathrm{Mg} / \mathrm{Ca} ; 0.79$ and $0.04 \mathrm{mmol} / \mathrm{mol}$ for $\mathrm{Al} / \mathrm{Ca} ; 0.03$ and $0.01 \mathrm{mmol} / \mathrm{mol}$ for $\mathrm{Mn} / \mathrm{Ca} ; 0.03$ and 0.01 for $\mathrm{Sr} / \mathrm{Ca} ; 0.09$ and $0.03 \mathrm{mmol} / \mathrm{mol}$ for $\mathrm{Zn} / \mathrm{Ca}$ and 4 and $0.83 \mu \mathrm{mol} / \mathrm{mol}$ for $\mathrm{Ba} / \mathrm{Ca}$. 

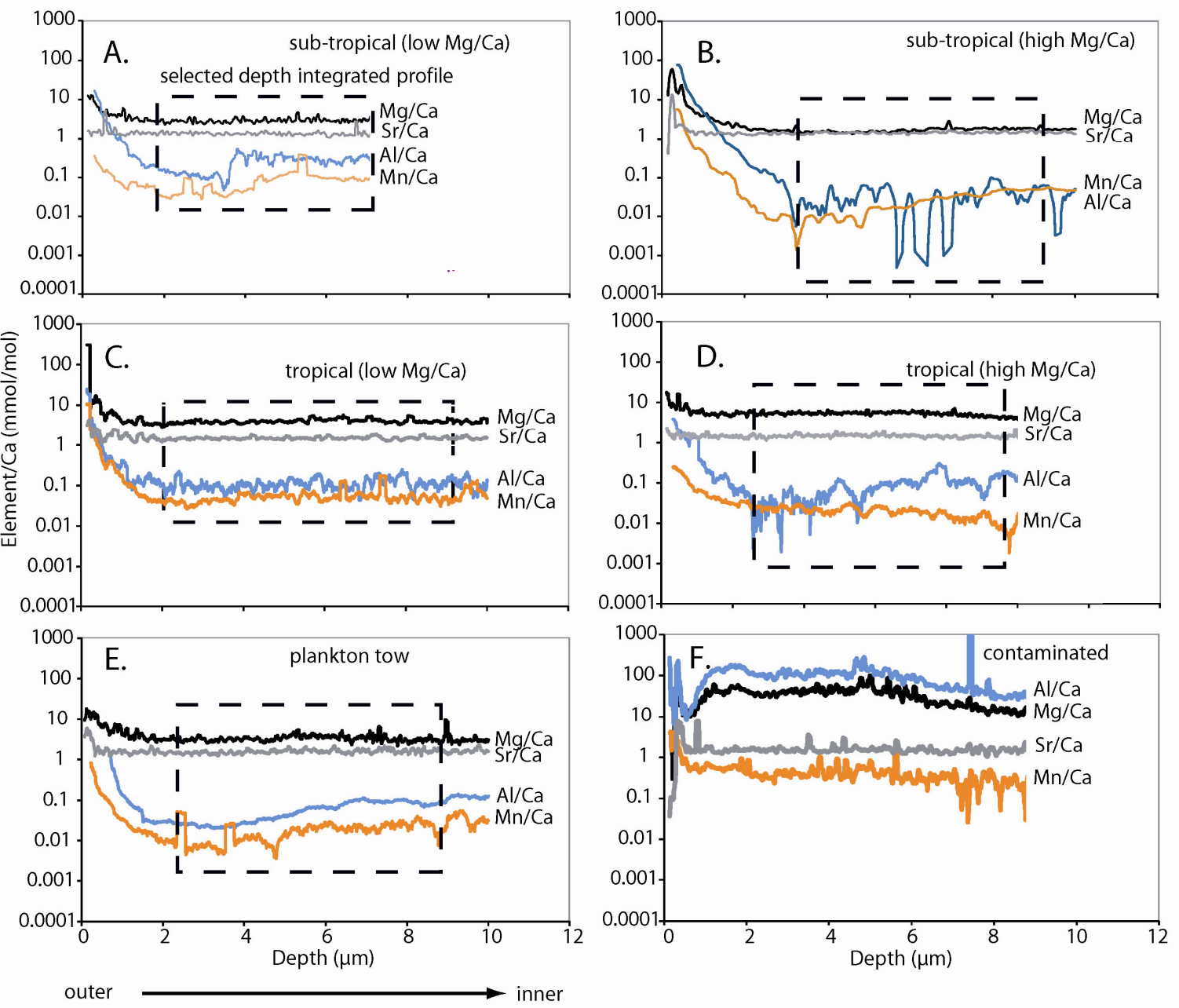

Figure 3.2: Selected LA-ICP-MS profiles of Gs. ruber from particular sites in the Southwest Pacific Ocean (A) Subtropical site core top P71 (low Mg/Ca), and (B) high Mg/Ca, (C) Tropical site AIMS3703 showing low $\mathrm{Mg} / \mathrm{Ca}$ and (D) high Mg/Ca (E) plankton tow U2325 and (F) contaminated sample from AIMS3703. Note how high $\mathrm{Al} / \mathrm{Ca}$ co-varies with $\mathrm{Mg} / \mathrm{Ca}$.

\subsection{Results}

\subsubsection{Elemental profiles through tests of Gs. ruber}

The wall structure of a typical Gs. ruber is illustrated by Scanning Electron Micrograph (Figure 3.3) which shows an outer calcite layer representing $\sim 90 \%$ of the total wall thickness separated by an inner laminar calcite layer representing the remaining $\sim 10 \%$ of the wall thickness by the primary organic membrane (POM). These images are consistent 
with previous work showing that Gs. ruber does not produce a typical gametogenic calcite crust, i.e. thickening and change in crystal structure affecting the mass, thickness and dissolution rate of the test [Hamilton et al., 2008; Williams, 2008]. Furthermore, thin sections of Gs. ruber show chamber specific outer calcite layers that generally follow the model of lamellar wall construction as described in Reiss [1958]. However, these distinct layers do not follow the general globular shape of the chamber but instead follow the shape of the interpore ridges (Figure 3.3).

The SEM images also show pores that are $\sim 3-6 \mu \mathrm{m}$ in diameter at the inner wall, expanding in a funnel-like form to $\sim 10 \mu \mathrm{m}$ in diameter at the outer surface. Pores are typically spaced $\sim 10-20 \mu \mathrm{m}$ apart, regardless of chamber. Consequently, as this study's ablation profiles were measured with a spot size of $25 \mu \mathrm{m}$, each one will typically encompass one or two pores, providing a pathway by which surface material can "appear" in the middle of the profile. It is expected that, because of these funnel shaped pores, the $\mathrm{TE} / \mathrm{Ca}$ ablation profile from the outer to the inner test will reflect, in part, the ratio between the calcite and potentially any adhering contaminants.

With the exception of $\mathrm{Sr} / \mathrm{Ca}$, laser ablation profiles from the outer to inner test walls show a thin $(<1-2 \mu \mathrm{m})$ TE/Ca-enriched (by several orders of magnitude) outer surface veneer compared to the innermost (ontogenetic) calcite. This enriched layer was present in every chamber analysed, regardless of location, (i.e. independent of temperature and depth) and was also present in plankton tow samples (Figure 3.2E) although it is not distinguishable in the SEM images. Apart from the enriched outer veneer, there appears to be relatively uniform $\mathrm{Mg} / \mathrm{Ca}$ and $\mathrm{Sr} / \mathrm{Ca}$ along the inner profile, that is, there is no compositional difference between the inner and outer calcite layers identified in SEM images. Individuals within a core-top or plankton tow population with high $\mathrm{Mg} / \mathrm{Ca}$ values maintain such values throughout the thickness of their tests and vice versa for individuals where $\mathrm{Mg} / \mathrm{Ca}$ ratios were lower. In a number of individuals there were observed changes between low and high $\mathrm{Mg} / \mathrm{Ca}$ ratios in chambers F-2 and F-1 that seemed to have analogues in the SEM images (Figure 3.2). However, the relatively "smoothed" nature of the profiles (caused in part by ablation of an uneven surface, resulting in material being incorporated from various different depths in the profile for each ablation event) meant that the potential presence of sub-micron thick $\mathrm{Mg}$-rich bands inside the tests is difficult to resolve. Improvements to this resolution may involve ablating the test from the smooth inside to the rougher outside [Sadekov et al., 2009], but this greatly increases preparation time and introduces difficulties with identification of specific chambers as they must be individually dismembered from the 
test. These high and low $\mathrm{Mg} / \mathrm{Ca}$ bands are not apparent with $\mathrm{Sr} / \mathrm{Ca}$, that is, there is no significant difference in composition between the outer calcite layers from the inner laminar layers.

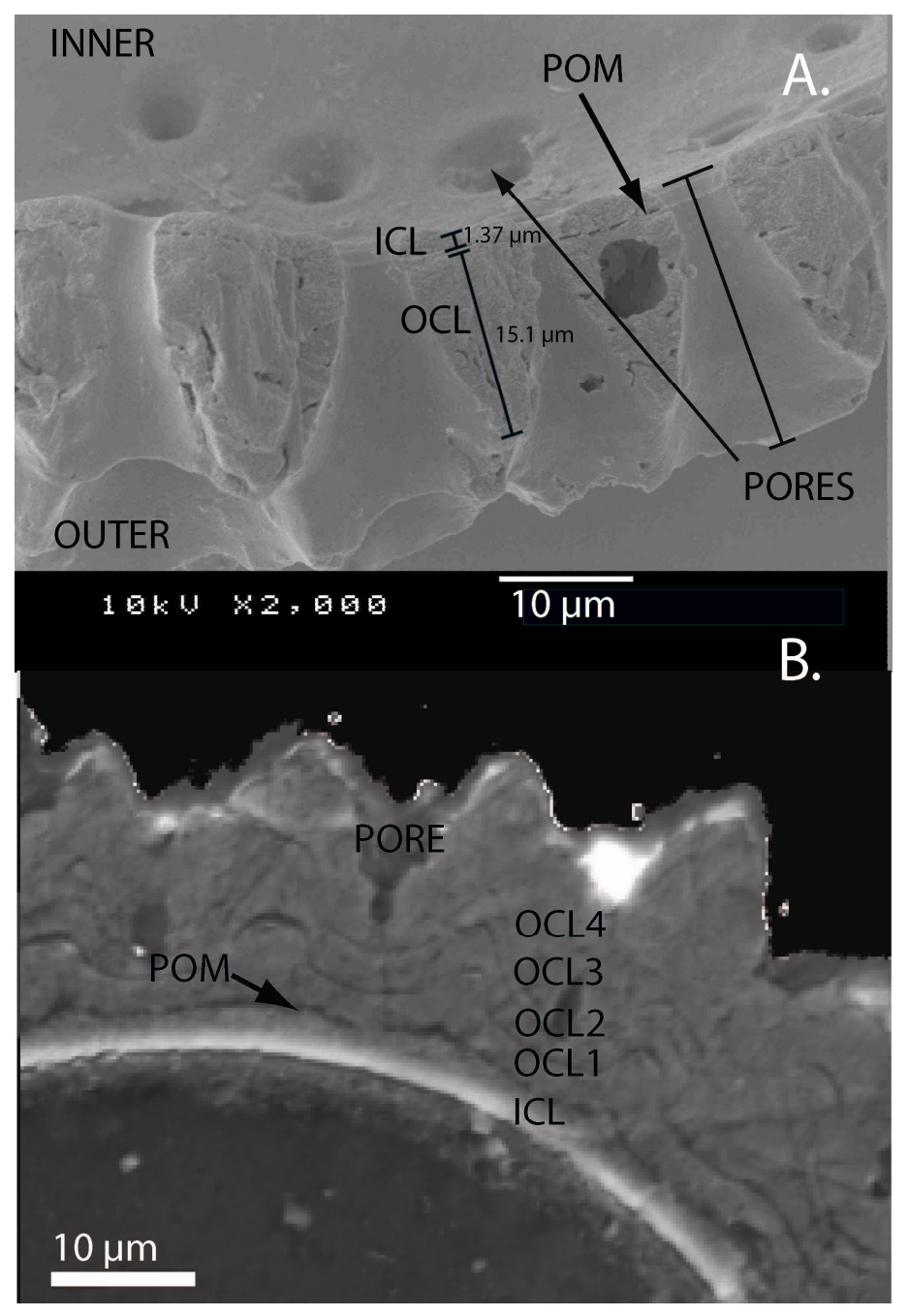

In contrast, for samples that were not obviously contaminated, and where there is no strong co-variation between $\mathrm{Mg} / \mathrm{Ca}$ and $\mathrm{Al} / \mathrm{Ca}$ (e.g., Figure 3.2E) the ratios $\mathrm{Al} / \mathrm{Ca}$ and $\mathrm{Mn} / \mathrm{Ca}$ are more variable, typically low, with a minima occurring about 30\% of the way through the test wall and elevated (by a factor of 1 to 1.5 ) along the inner $50 \%$ of the profile. Note the logarithmic scale enhances that apparent variability for elements occurring in very low concentrations.

Based on this pattern of variability observed in the TE depth profiles, the mid-portion of each test was selected to determine an average $\mathrm{Mg} / \mathrm{Ca}$ value for each chamber as shown in 
Figure 3.2, specifically excluding enhanced values in the outer veneer and inner chamber wall which are particularly vulnerable to surface contamination and/or dissolution (e.g., Pena et al., [2008]). A t-test rejects the null hypothesis (at a confidence interval of 95\%) that there is a significant difference in $\mathrm{Mg} / \mathrm{Ca}$ between the two morphotypes of Gs. ruber where the same chambers were compared. Therefore all data reported are data based on all Gs. ruber.

\subsubsection{The distribution of $M g / C a$ within a population}

Having obtained $\mathrm{Mg} / \mathrm{Ca}$ values for each chamber of each individual and calculated pooled chamber means (i.e. the pooled chamber of mean all F-2, all F-1 or all $\mathrm{F}$ per site) the results are compared against WOA05-derived SST for each sample location (Figure 3.4; Table 3.2).

For each site, the pooled chamber mean $\mathrm{Mg} / \mathrm{Ca}$ ratio from each site is positively correlated with temperature. The chambers F-2 or F-1 show a statistically significant difference in the $\mathrm{Mg} / \mathrm{Ca}$ value when compared to the ultimate chamber F, (paired t-test [2-tailed], $\mathrm{p} \leq 0.05$ ), with the exception of site FR1/97/GC12 where $\mathrm{p}=0.058(\mathrm{~F}-2$ versus $\mathrm{F})$ and $\mathrm{p}=0.110(\mathrm{~F}$ 1 versus $\mathrm{F})$.

Having considered these differences, chamber specific equations were derived, fitted to an exponential relationship, as shown in Figure 3.4. In considering each equation it is observed that the exponential coefficient ' $A$ ' for each chamber is similar ( 0.067 to 0.072$)$ and within the confidence interval of each chamber (i.e. standard error $= \pm 0.005$ to 0.007 ). However, the pre-exponential coefficient 'B' shows a considerable difference between the two earlier chambers F-2 and F-1 (0.798 and 0.891) with the ultimate chamber F (0.590). The standard error of the pre-exponential coefficients for chambers F-2 and F-1 $( \pm 0.091$ and \pm 0.133$)$ are outside the confidence interval for chamber $F( \pm 0.091)$. Therefore, although the gradient for the ultimate chamber $\mathrm{F}$ is comparable to the chamber F-2 and F1 , it is offset to lower $\mathrm{Mg} / \mathrm{Ca}$ between $0.4-2.0 \mathrm{mmol} / \mathrm{mol}$ (Figure 3.4). This would potentially indicate that the ultimate chamber is calcifying in colder temperatures compared to chambers F-2 and F-1. 


\begin{tabular}{|c|c|c|c|c|}
\hline \multirow{2}{*}{ Site } & & \multicolumn{3}{|c|}{ Chamber } \\
\hline & & \multirow{2}{*}{$\frac{\mathrm{F}-2 \mathrm{Mg} / \mathrm{Ca}}{(\mathrm{mmol} / \mathrm{mol})}$} & \multirow{2}{*}{$\frac{\mathrm{F}-1 \mathrm{Mg} / \mathrm{Ca}}{(\mathrm{mmol} / \mathrm{mol})}$} & \multirow{2}{*}{$\frac{\mathrm{FMg} / \mathrm{Ca}}{(\mathrm{mmol} / \mathrm{mol})}$} \\
\hline & & & & \\
\hline AIMS1361 & Mean & 5.33 & 5.15 & 4.17 \\
\hline \multirow[t]{3}{*}{$n=7$} & Minimum & 4.44 & 4.09 & 3.02 \\
\hline & Maximum & 6.11 & 6.06 & 5.89 \\
\hline & S.D. & 0.63 & 0.72 & 0.88 \\
\hline AIMS3703 & Mean & 5.97 & 6.18 & 5.02 \\
\hline \multirow[t]{3}{*}{$n=13$} & Minimum & 3.21 & 4.15 & 2.90 \\
\hline & Maximum & 8.74 & 8.83 & 7.88 \\
\hline & S.D. & 1.47 & 1.46 & 1.28 \\
\hline AIMS2078 & Mean & 5.64 & 5.76 & 3.64 \\
\hline \multirow[t]{3}{*}{$n=10$} & Minimum & 4.34 & 4.17 & 2.33 \\
\hline & Maximum & 7.06 & 7.60 & 4.65 \\
\hline & S.D. & 1.01 & 1.02 & 0.69 \\
\hline AIMS1631 & Mean & 4.69 & 4.82 & 4.12 \\
\hline \multirow[t]{3}{*}{$n=4$} & Minimum & 4.15 & 3.66 & 3.91 \\
\hline & Maximum & 5.13 & 5.98 & 4.62 \\
\hline & S.D. & 0.40 & 0.97 & 0.34 \\
\hline FR1/97/GC12 & Mean & 4.83 & 5.29 & 4.05 \\
\hline \multirow[t]{3}{*}{$n=12$} & Minimum & 3.73 & 2.31 & 2.40 \\
\hline & Maximum & 5.86 & 6.81 & 6.78 \\
\hline & S.D. & 0.64 & 1.20 & 1.23 \\
\hline TAN0706 C4 & Mean & 3.71 & 3.84 & 2.77 \\
\hline \multirow[t]{3}{*}{$n=26$} & Minimum & 2.39 & 2.20 & 1.66 \\
\hline & Maximum & 6.59 & 7.11 & 4.48 \\
\hline & S.D. & 1.20 & 1.22 & 0.81 \\
\hline U2322net7 (PT) & Mean & 2.91 & 2.99 & 2.00 \\
\hline \multirow[t]{3}{*}{$n=8$} & Minimum & 1.78 & 2.21 & 1.30 \\
\hline & Maximum & 4.01 & 3.42 & 2.69 \\
\hline & S.D. & 0.67 & 0.39 & 0.55 \\
\hline U2322net6 (PT) & Mean & 2.89 & 3.38 & 2.77 \\
\hline \multirow[t]{3}{*}{$n=7$} & Minimum & 2.16 & 2.34 & 1.80 \\
\hline & Maximum & 3.93 & 4.60 & 4.24 \\
\hline & S.D. & 0.58 & 0.83 & 0.79 \\
\hline P71 & Mean & 3.26 & 3.08 & 2.46 \\
\hline \multirow[t]{3}{*}{$n=7$} & Minimum & 2.11 & 2.19 & 1.53 \\
\hline & Maximum & 4.37 & 4.21 & 3.29 \\
\hline & S.D. & 0.75 & 0.54 & 0.40 \\
\hline U2315 (PT) & Mean & 3.10 & 3.73 & 2.29 \\
\hline \multirow[t]{3}{*}{$n=13$} & Minimum & 2.09 & 2.80 & 0.91 \\
\hline & Maximum & 5.91 & 6.08 & 3.25 \\
\hline & S.D. & 0.99 & 0.92 & 0.70 \\
\hline Z7003 & Mean & 2.92 & 2.98 & 2.32 \\
\hline \multirow[t]{3}{*}{$n=16$} & Minimum & 1.98 & 0.84 & 1.37 \\
\hline & Maximum & 5.27 & 4.49 & 4.17 \\
\hline & S.D. & 0.76 & 0.94 & 0.86 \\
\hline P81 & Mean & 2.88 & 2.87 & 2.18 \\
\hline \multirow[t]{3}{*}{$n=18$} & Minimum & 1.41 & 1.40 & 1.12 \\
\hline & Maximum & 4.77 & 4.62 & 4.53 \\
\hline & S.D. & 0.91 & 0.84 & 0.94 \\
\hline ODP1123 & Mean & 1.90 & 2.01 & 1.53 \\
\hline \multirow[t]{3}{*}{$n=13$} & Minimum & 1.41 & 1.42 & 1.06 \\
\hline & Maximum & 2.94 & 3.03 & 2.62 \\
\hline & S.D. & 0.53 & 0.46 & 0.43 \\
\hline
\end{tabular}

For comparison, the Gs. ruber $\mathrm{Mg} / \mathrm{Ca}$ versus SST calibration derived by Sadekov et al., [2008] for sites in the Indian Ocean is shown on Figure 3.4. This study's "F" calibration (i.e. $\mathrm{Mg} / \mathrm{Ca}_{\mathrm{Ch}-\mathrm{F}}=0.590[ \pm 0.091] \exp (0.072[ \pm 0.007] * \mathrm{~T})$ is comparable to that of Sadekov et al. [2008] (i.e. $\mathrm{Mg} / \mathrm{Ca}=0.520[ \pm 0.08] \exp (0.076[ \pm 0.002] * \mathrm{~T})$ which was derived using a 
similar LA-ICP-MS technique to measure $\mathrm{Mg} / \mathrm{Ca}$ on the same ultimate chamber (Table 3.3). In addition, Anand et al., [2003] summarised a number of $\mathrm{Mg} / \mathrm{Ca}$ versus temperature calibrations for planktonic foraminifers determined using solution-based analysis, including several specifically for Gs. ruber (w). Their study yielded a widely-used generic (combining data from 10 planktonic species recovered from $\mathrm{N}$. Atlantic sediment traps) $\mathrm{Mg} / \mathrm{Ca}$ versus temperature relationship of $\mathrm{Mg} / \mathrm{Ca}=0.38[ \pm 0.02] \exp (0.09[ \pm 0.003] * \mathrm{SST})$, identical to the Gs. ruber (w) (250-350 $\mu \mathrm{m})$ core top calibration of Dekens et al., [2002]. A similar relationship in Gs. ruber (w) (250-350 $\mu \mathrm{m})$ from sediment traps, revealed a relationship of $\mathrm{Mg} / \mathrm{Ca}=0.34[\underline{ \pm 0.08]} \exp (0.102[\underline{ \pm 0.01]} * \mathrm{~T})$. Therefore, published solution-based $\mathrm{Mg} / \mathrm{Ca}$ versus temperature relationships for Gs. ruber (w) for tests $<350 \mu \mathrm{m}$ in size have yielded a smaller pre-exponential coefficient and a larger exponential co-efficient although the significance of this, if any, remains to be explored.

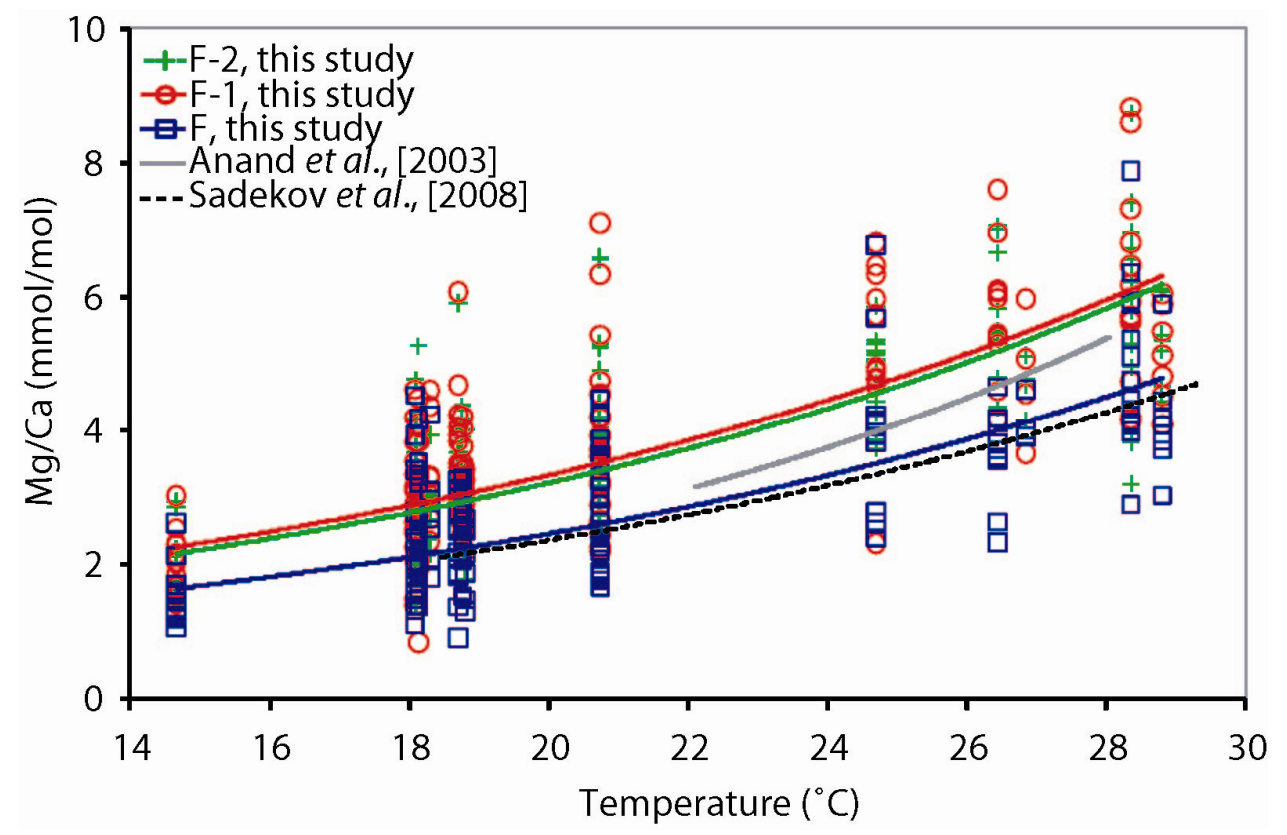

Figure 3.4: $\mathrm{Mg} / \mathrm{Ca}$ for each chamber plotted against mean annual SST from each sampling site. The green crosses represent chamber F-2, red circles F-1 and blue squares F. The exponential regression for each chamber and for the mean test values (i.e. the mean of chambers F-2, F-1 and F) are fitted against the mean $\mathrm{Mg} / \mathrm{Ca}$ : mean annual temperature (WOA05, 0-50 m), where the green line represents the exponential fit for chamber F-2, the red line F-1, the blue line F and the black line the mean. Also shown are the calibrations of Anand et al., [2003], grey line and Sadekov et al., [2008], black dashed line. The equations for each of these calibrations are summarised in Table 3.3 . 
Table 3.3: Summary of this study's $\mathrm{Mg} / \mathrm{Ca}$ chamber specific calibrations and selected existing calibrations for Gs. ruber (white).

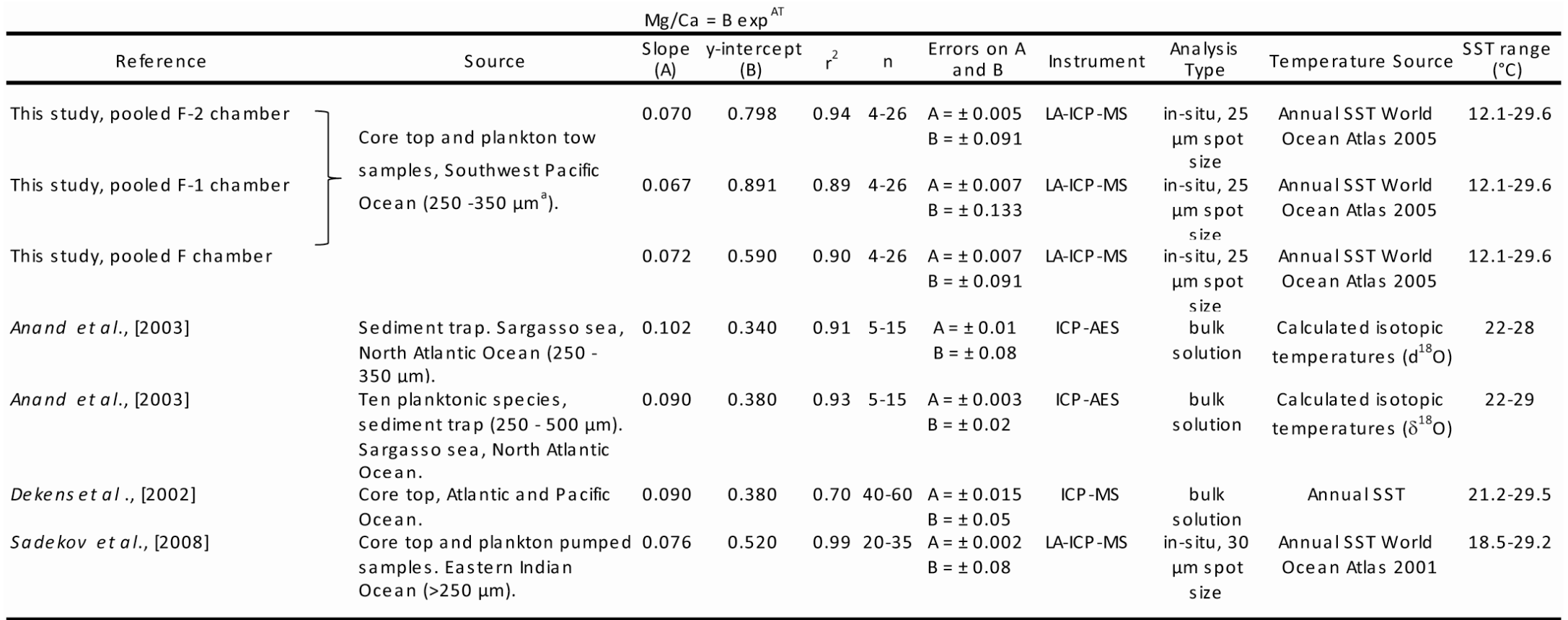

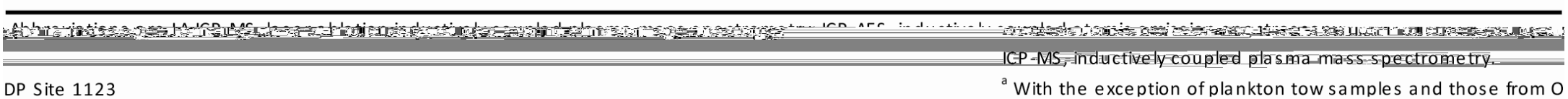




\subsubsection{A log-normal model for the distribution of $\mathrm{Mg} / \mathrm{Ca}$ measurements}

There are currently a limited number of micro-analytical studies that have analysed $\mathrm{Mg} / \mathrm{Ca}$ from individual chambers. Sadekov et al., [2005] produced element maps that show high and low $\mathrm{Mg} / \mathrm{Ca}$ bands in individual chambers from several planktonic foraminiferal species, describing individual measurements across chambers by comparing the arithmetic and harmonic mean. These authors found that the few high $\mathrm{Mg} / \mathrm{Ca}$ ratios skew the data away from the more uniform low Mg/Ca. Similarly Anand et al., [2005] and Sadekov, et al., [2005] fitted individual chamber measurements that gave Gaussian averages smaller than the arithmetic means. This skew was also interpreted to reflect intra-individual $\mathrm{Mg} / \mathrm{Ca}$ variation i.e. the presence of occasional high $\mathrm{Mg} / \mathrm{Ca}$ ratios from within individual chambers. This study contributes to these studies by examining the distribution of $\mathrm{Mg} / \mathrm{Ca}$ measurements at any site (i.e. regardless of temperature) that show a number of large $\mathrm{Mg} / \mathrm{Ca}$ values that exceed those expected from a Gaussian distribution, i.e. the distribution is positively skewed.

From these observations, it is hypothesised that the $\mathrm{Mg} / \mathrm{Ca}$ distribution at any of this study's sites are $\log$-normal; i.e. the distribution of $\log (\mathrm{Mg} / \mathrm{Ca})$ values at any temperature is Gaussian. These log-normal distributions are found regardless of which chamber is examined. To demonstrate this, firstly, the distributions of $\mathrm{Mg} / \mathrm{Ca}$ for each chamber, at different temperatures, were normalised by dividing them by their mean temperatures, (the latter being obtained by simple regression, chamber by chamber, of $\mathrm{Mg} / \mathrm{Ca}$ versus temperature). This method of normalising was used so that log values normalised to 1 can be converted to zero, allowing the data for each chamber to be pooled. Further, maximum likelihood estimates of the parameters of the best fitting log-normal distribution for each of the three chambers were also obtained. Specifically, these are the mean and standard deviations of the logarithms of the pooled data. The results are illustrated in Figure 3.5 and also show that the log-normal model fits the data distinctly better than a Gaussian model.

Secondly, the temperatures were put into seven bins, where the temperatures are within a range of $0.5^{\circ} \mathrm{C}$. For each bin, the normalised $\mathrm{Mg} / \mathrm{Ca}$ data for the three chambers were pooled and their distribution plotted, along with the best-fitting log-normal (Figure 3.6). It is inferred that the log-normal distribution models the data better than the normal distribution at any temperature. 
However, the seven standard deviations (S.D.) of the logs of pooled data in each temperature bin are dissimilar, ranging from 0.19 to 0.32 ( $\mathrm{rms} 0.27$ ). The hypothesis that the seven temperature sets have a common variance of their logs is rejected by a Levene or Bartlett test of homogeneity of variance. But their variability is apparently not due to temperature: the slope of a regression of the S.D. on temperature is not significantly different from zero (95\% C.I).

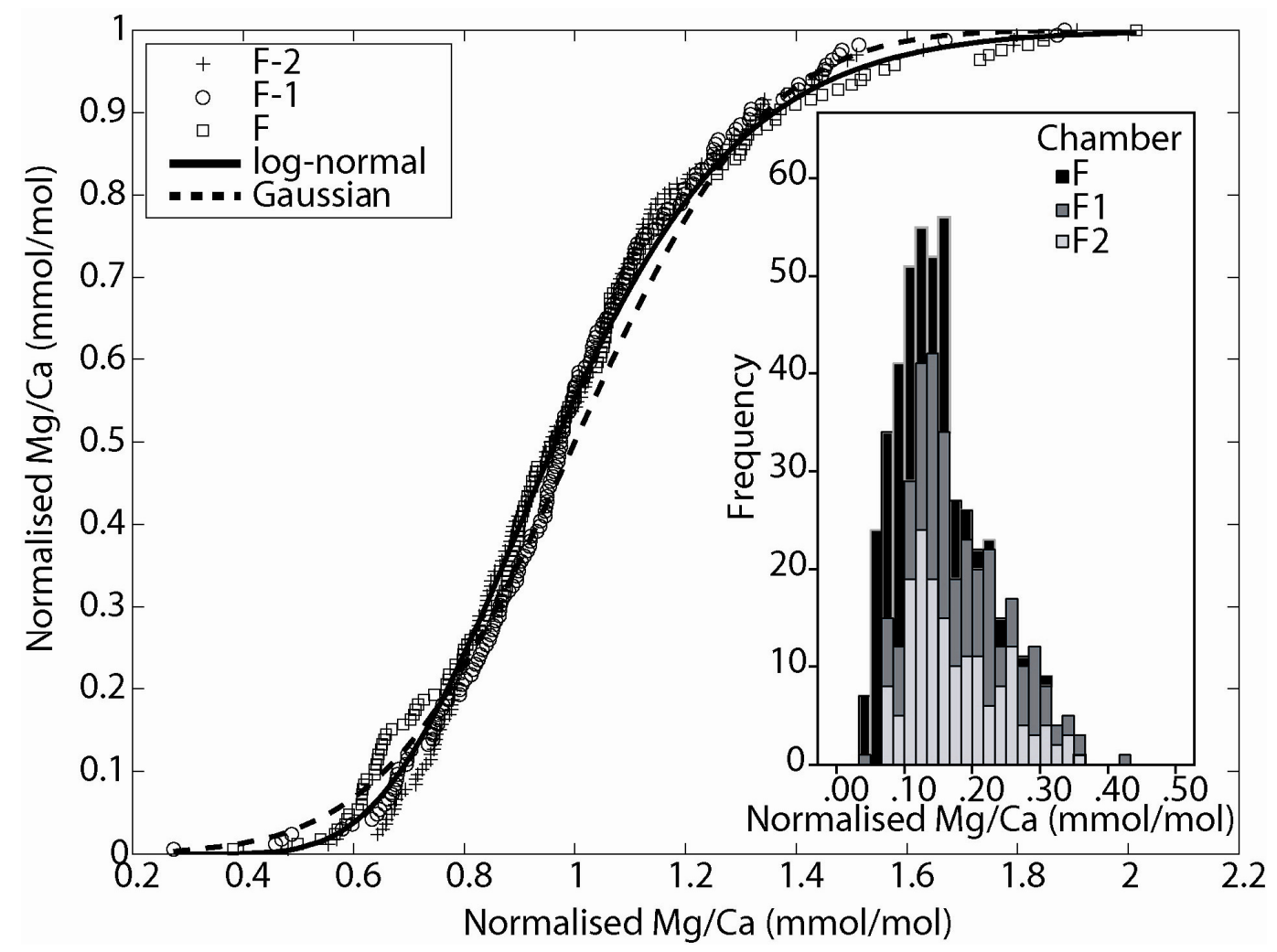

Figure 3.5: $\mathrm{Mg} / \mathrm{Ca}$ data for each chamber $(\mathrm{F}-2$ = crosses, $\mathrm{F}-1=$ circles, $\mathrm{F}=$ squares), normalised by the mean value for their temperature and pooled. Also shown are the overall best fitting log-normal and Gaussian distributions, obtained by pooling the data from the three chambers. Inset in Figure 3.5 shows histogram of lognormalised $\mathrm{Mg} / \mathrm{Ca}$ from pooled chambers (F-2 = black, F-1 = dark grey, F = light grey shaded bars). 


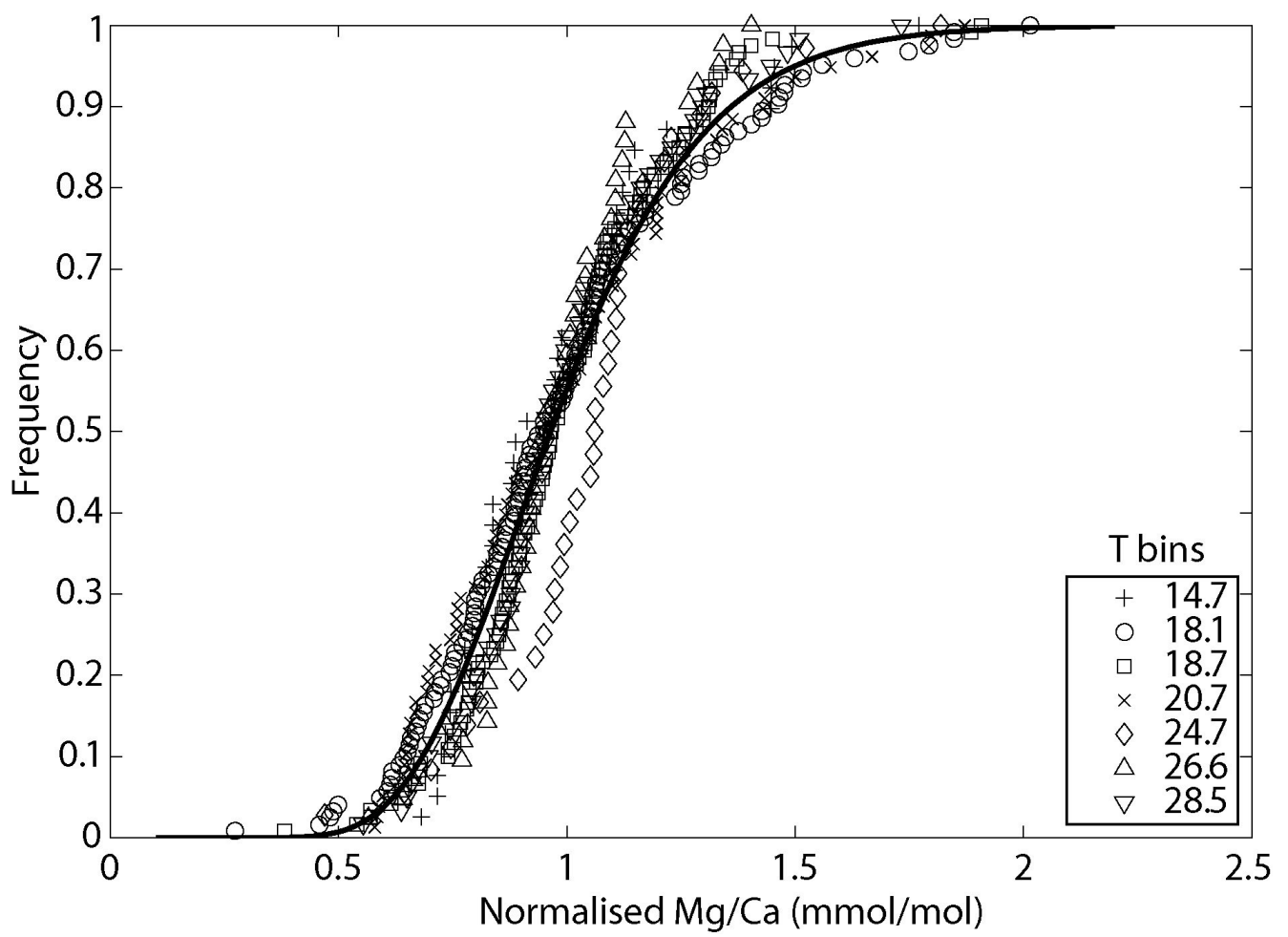

Figure 3.6: $\mathrm{Mg} / \mathrm{Ca}$ data binned by temperature (legend) and pooled from the three chambers. Also shown is the overall best fitting log-normal distribution (as Figure 3.5).

\subsection{Discussion}

\subsubsection{Impacts of dissolution}

All of the sites except ODP Site 1123 are located well above the regional lysocline $(\sim 3250 \mathrm{~m})$ [Feely et al., 2004]. Smaller test sizes and kummerform chambers were observed at ODP Site 1123, indicators of environmental stress [Schmidt et al., 2006]. In addition, this site has highly variable frontal systems that have been demonstrated to result in decreased foraminiferal test size [Hecht, 1974]. Gs. ruber at this latitude are at the cold limit of their temperature tolerance [Bé, 1977; Bijma et al., 1990b] therefore environmental stress is likely to result in decreased growth rates [Bijma et al., 1990b; Caron et al., 1990] and may influence $\mathrm{Mg} / \mathrm{Ca}$ incorporation [Elderfield et al., 1996]. However, the supporting evidence from SEM images [Williams et al., 2007], the benthic to planktic ratios and fragmentation indices from Crundwell et al., [2008], plus the presence of the typical enriched surface veneer found in samples from other locations suggest that at least the outer surface of Mg-rich calcite had not been subject to dissolution. 


\subsubsection{LA-ICP-MS trace element depth profiles}

The test profiles reveal an elevated TE-surface veneer (except $\mathrm{Sr} / \mathrm{Ca}$ ) on all the profiles that were measured. Such TE-rich veneers were also reported in previous LA-ICP-MS studies [Sadekov et al., 2008] although their origin is not clear. Eggins et al., [2003] suggested these are of biogenic origin, formed during the lifetime of the foraminifera, whilst Hathorne et al., [2003] proposed these are of post-depositional diagenetic origin. An open question is whether this high $\mathrm{Mg} / \mathrm{Ca}$ veneer is different to that substituted into the calcite lattice. For example, TE located at grain boundaries and/or dislocations may be higher than the TE in the calcite lattice [Weiner and Dove, 2003]. The data support a biogenic origin, based on the presence of such a veneer on individuals recovered from plankton tow samples where there is no possibility for diagenetic alteration or the addition of surficial contaminant phases on the seafloor, as is the case for core-top samples. The exclusion of these elevated surface veneers offers one explanation for the differences between the chamber specific calibrations and those from bulk solution-derived $\mathrm{Mg} / \mathrm{Ca}$ methods (see section 3.6.4).

\subsubsection{An LA-ICP-MS-derived Mg/Ca versus SST calibration for Gs. ruber in the Southwest Pacific Ocean}

The data support the notion that LA-ICP-MS is a robust method for determining $\mathrm{Mg} / \mathrm{Ca}$ ratios in Gs. ruber for palaeoceanographic studies with the previously noted benefits of rapidity, test preservation (measurements are minimally destructive) and the ability to measure other elements that are useful quality checks for measuring primary foraminiferal $\mathrm{Mg} / \mathrm{Ca}$ ratios.

Regardless of the wide scatter of $\mathrm{Mg} / \mathrm{Ca}$ within individual populations, the mean $\mathrm{Mg} / \mathrm{Ca}$ value for each population shows a positive correlation with SST. On this basis three empirical calibrations between $\mathrm{Mg} / \mathrm{Ca}(\mathrm{mmol} / \mathrm{mol})$ and SST $\left({ }^{\circ} \mathrm{C}\right)$ were generated for the three final chambers of Gs. ruber. The $\mathrm{Mg} / \mathrm{Ca}$ versus SST relationship for chambers F-2 and F-1 is essentially identical, however, although chamber $\mathrm{F}$ has a similar gradient (exponential coefficient " $\mathrm{A}$ "), the mean $\mathrm{Mg} / \mathrm{Ca}$ in chamber $\mathrm{F}$ is 4 to $35 \%$ depleted in $\mathrm{Mg} / \mathrm{Ca}$, thereby resulting in apparently higher $\mathrm{Mg} / \mathrm{Ca}$ derived temperatures (pre-exponential "B") (Table 3.3). Examination of $\mathrm{Mg} / \mathrm{Ca}$ from the final chamber of Gs. ruber in the Indian Ocean measured using a similar LA-ICP-MS technique shows very comparable A and B values, and therefore 
similar Mg/Ca versus SST calibrations [Sadekov et al., 2008]. Interestingly, their study did not find a systematic relationship between a chamber's mean $\mathrm{Mg} / \mathrm{Ca}$ value and its position within the test whorl, i.e. the $\mathrm{Mg} / \mathrm{Ca}$ value for $\mathrm{F}$ was not measurably less than that derived for preceding chambers F-1 or F-2. In contrast to the Sadekov et al., [2008] study, Anand and Elderfield [2003] used Gs. ruber from sediment traps to derive their calibration which lies in between the F-2/1 and F chamber specific calibrations from this study's work (Figure 3.4). This suggests in general terms that $\mathrm{Mg} / \mathrm{Ca}$ from the laser ablation depth profiles are characteristic of the bulk test composition, although other variables such as cleaning techniques [Martin and Lea, 2002; Barker et al., 2003], preservation state [Dekens et al., 2002] and regional and/or site specific oceanography [Barker et al., 2005] may also contribute to these differences. Constraining the relative importance of analytical versus environmental influences on foraminiferal $\mathrm{Mg} / \mathrm{Ca}$ can perhaps best be resolved with paired laser ablation - solution $\mathrm{Mg} / \mathrm{Ca}$ measurements.

For the purposes of determining mean $\mathrm{Mg} / \mathrm{Ca}$ in a sample, it is sufficient to measure one chamber per individual. Whilst the reason(s) for the offset between chambers F-2 and F-1 with F remain unclear (and are discussed in section 4.4), it would appear either calibration is valid for palaeoceanographic purposes. However, it is important that each chamber is identified prior to analysis and that the same chamber is consistently ablated, otherwise, the single chamber calibrations will not yield meaningful palaeo-temperature estimates. Regardless, for Gs. ruber, calibrations are not interchangeable between LA-ICP-MS and solution methods of measuring $\mathrm{Mg} / \mathrm{Ca}$.

\subsubsection{Intra-individual mean $\mathrm{Mg} / \mathrm{Ca}$ variability}

Intra-individual mean $\mathrm{Mg} / \mathrm{Ca}$ compositional measurements show the ultimate chamber " $\mathrm{F}$ " is consistently depleted in $\mathrm{Mg}$ relative to the mean value in chambers "F-2 and F-1", the latter two chambers having no statistical compositional difference. If considering the construction of lamellar walls [Bé and Lott, 1964; Bé and Hemleben, 1970; Hansen, 1999], found in this species, then the lower $\mathrm{Mg} / \mathrm{Ca}$ associated with the formation of chamber $\mathrm{F}$ should also be visible as a low $\mathrm{Mg} / \mathrm{Ca}$ zone in the LA-profiles through F-2 and F-1 chambers. However, there is no evidence of such a zone, implying calcification associated with chamber $\mathrm{F}$ is limited to that chamber. In addition, Gs. ruber does not precipitate a gametogenic calcite crust of any 
significance, [Caron et al., 1990], if it produces one at all [Hamilton et al., 2008]. Although these crusts are also considerably lower in $\mathrm{Mg} / \mathrm{Ca}$ compared to ontogenetic calcite in other planktonic species [Eggins et al., 2003; Klinkhammer et al., 2004; Anand and Elderfield, 2005; Lombard et al., 2010] it is unlikely that the lower $\mathrm{Mg} / \mathrm{Ca}$ in chamber $\mathrm{F}$ is what is considered to be a 'typical' gametogenic crust.

Therefore, potential reasons for this offset include: (1) the mean $\mathrm{Mg} / \mathrm{Ca}$ in the chamber $\mathrm{F}$ represents a systematically lower calcification temperature than for previous chambers, by an amount equivalent to $\sim 2.3$ to $4.4^{\circ} \mathrm{C}$, (2) lower $\mathrm{Mg} / \mathrm{Ca}$ is the product of a biologically mediated "vital" effect that does not directly relate to lower calcification temperature, or (3) some combination of the two.

With respect to (1), the variability between chambers where $\mathrm{Mg} / \mathrm{Ca}$ ratios between $\mathrm{F}-2$ and F-1 are similar could be interpreted as both chambers calcifying at the same water temperature, and hence water depth. By contrast, the relatively lower $\mathrm{Mg} / \mathrm{Ca}$ from chamber $\mathrm{F}$ may represent calcification in cooler, deeper water during the terminal stage of its ontogeny. The interpretation that the $\mathrm{F}$ chamber is formed deeper in the water column than F-1 and F-2 is consistent with known life-cycle of various spinose taxa, as discussed by Bijma et al. [1990a] and references therein. However, the occurrence of a relatively $\mathrm{Mg}$ depleted " $\mathrm{F}$ " in the shallow plankton tows would tend to count against this as the primary reason for the offset.

With respect to (2), internal or genetic controls that are not strongly correlated with the surrounding environment are known to produce variations in skeletal $\mathrm{Mg}$ content, the physical basis of which is not well understood [Williams, 2008; Wang et al., 2009]. These "vital" effects could in turn affect the biologically induced mineralisation (bio-mineralisation) of $\mathrm{Mg}$ between different chambers. Anand and Elderfield [2005] attributed lower $\mathrm{Mg} / \mathrm{Ca}$ in the ultimate chamber of $G$. bulloides from North Atlantic core tops to such a bio-mineralization effect. Similarly, culture experiments on tests of Globigerinoides sacculifer kept at a constant temperature and salinity in the laboratory also show a statistically significant depletion in $\mathrm{Mg}$ in the final gametogenic chamber clearly unrelated to environmental conditions [Dueñas-Bohórquez et al., 2010].

Considering these, in (3) the symbiotic algae of Gs. ruber may, indirectly modulate the calcification process as suggested in other symbiont-bearing species where lower $\mathrm{Mg} / \mathrm{Ca}$ of the 
ultimate chamber may be due to loss of symbiotic activity [Eggins et al., 2003]. Furthermore, symbionts may also alter the calcification rate toward the end of this species' life cycle, in turn influencing the elemental composition of this ultimate chamber [Lohmann, 1995; Nürnberg et al., 1996]. For example in selected globigerinid planktonic foraminifer, Brummer et al., [1987] described the terminal stage of ontogeny with the disappearance (lysis and digestion) of symbionts and regulation of the calcium budget (resorption, calcification) prior to gamete release. However, in Globigerinoides sacculifer the precipitation of the ultimate chamber occurs prior to the expulsion or consumption of algal symbionts [Hemleben et al., 1989]. Moreover, the non-symbiont bearing species G. bulloides was recently demonstrated to have reduced $\mathrm{Mg} / \mathrm{Ca}$ in the final chamber [Anand and Elderfield, 2005; Marr et al., 2011] suggesting that symbionts do not regulate the calcification process, but instead both Gs. ruber and G. bulloides share a similar biological mechanism. Thus, these studies suggest that biological internal regulation plays a more prominent role in the $\mathrm{Mg}$ variability of tests [Bentov and Erez, 2006] and the mechanism(s) which account for low $\mathrm{Mg} / \mathrm{Ca}$ in the final chamber of G. bulloides [Anand and Elderfield, 2005; Marr et al., 2011] and Gs. sacculifer [Sadekov et al., 2008; Dueñas-Bobórquez. et al., 2010] may also be applicable to Gs ruber.

\subsubsection{Inter-individual $\mathrm{Mg} / \mathrm{Ca}$ variability}

A wide range of $\mathrm{Mg} / \mathrm{Ca}$ values between individual foraminifers from each sample site was found that prima facie can be described by a log-normal distribution. An open question is whether or not this is the result of seasonal temperature and productivity variability at the site, or the product of biologically mediated "vital" effects unrelated to temperature. When considering morphotypes, although a significant difference in $\mathrm{Mg} / \mathrm{Ca}$ was not observed it is entirely possible one species had its production peak at a different depth and month to the other which when translated to $\mathrm{Mg} / \mathrm{Ca}$ would appear to record no offset. However, several lines of evidence point towards the "vital" effect explanation. First, if it is assumed that $\mathrm{Mg} / \mathrm{Ca}$ is temperature related, there is a much wider range of values than expected from environmental conditions, particularly if productivity is largely confined to one season (hence narrower range of temperature). Using the chamber specific equations to convert each $\mathrm{Mg} / \mathrm{Ca}$ from chambers F-2 and F to temperature (i.e. Figure 3.4), shows the range of values estimated for each site is much greater than can be explained by the modern seasonal range of SST 
(Figure 3.7). Secondly, although some of this variability may be explained by the age of the core top samples and bioturbation effects, i.e. the mean and seasonal SSTs may have differed (slightly) from today, the spread of $\mathrm{Mg} / \mathrm{Ca}$ in plankton tow samples follows a similarly wide variability (see Figure 3.7). In terms of bioturbation, One would expect that these samples would reflect a narrower range of $\mathrm{Mg} / \mathrm{Ca}$ as the calcification temperature is more or less known for each site (assuming that each chamber calcifies within a few hours) [Bé et al., 1979], however this is not the case in this study. Similar observations from individually pooled chambers from cultured foraminifera kept at constant temperatures also suggest that there is a wide variability in $\mathrm{Mg} / \mathrm{Ca}\left(\sim 2.3 \mathrm{mmol} / \mathrm{mol} @ 25{ }^{\circ} \mathrm{C}\right.$ in G. bulloides $)$ [Lea, 1999]. Thirdly, the observation that the spread between individuals can be described by a common distribution irrespective of site points to a vital effect. Thus, the data suggest that inter-individual variability is most likely caused by a biological vital effect, placing a limit on detailed $\mathrm{Mg} / \mathrm{Ca} \mathrm{SST}$ reconstructions, especially where only a small number of individuals are available from a sample.

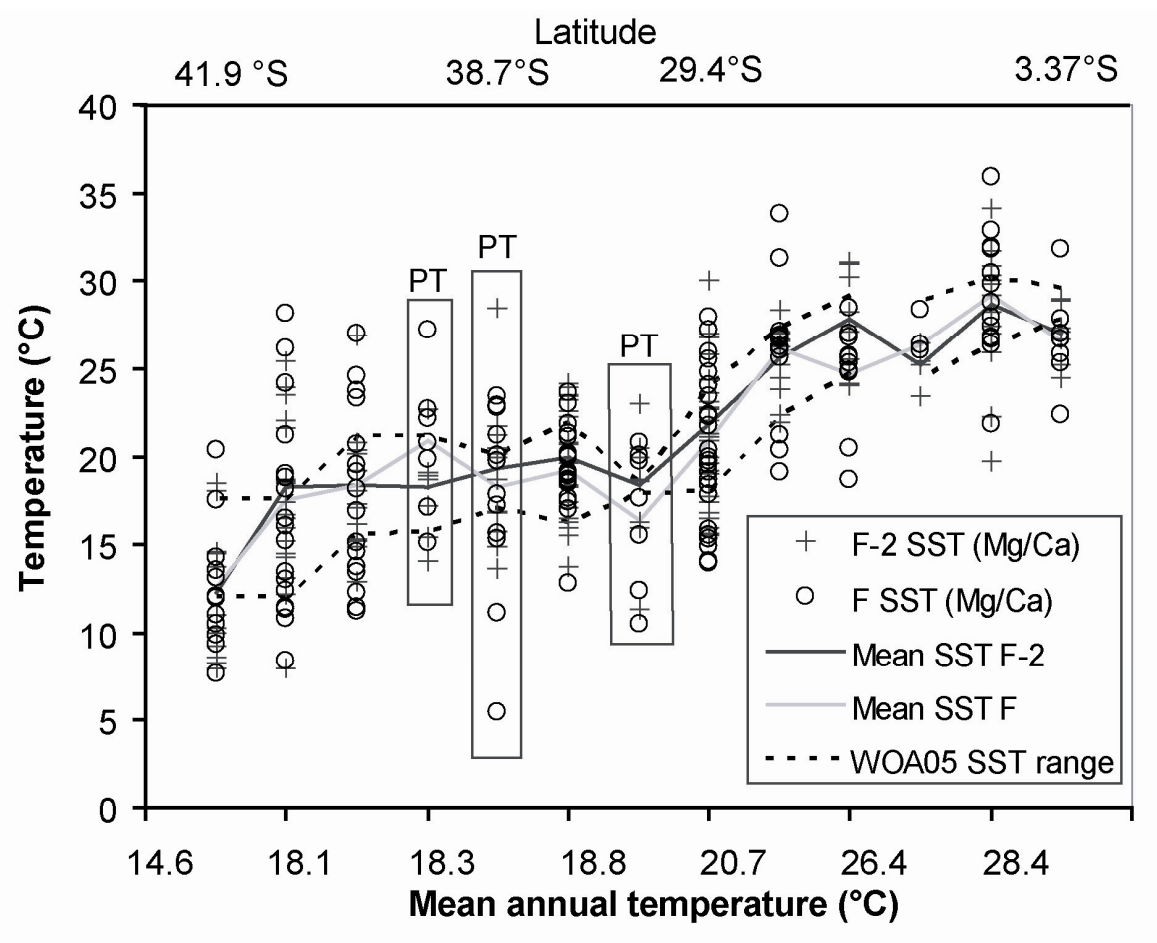

Figure 3.7: $\mathrm{Mg} / \mathrm{Ca}$ for individual chambers $\mathrm{F}-2$ and $\mathrm{F}$ converted to SST using this study's chamber specific equations (see Figure 3.4). Also shown is the seasonal range of SST (WOA05) (black dashed lines) and the mean SST calculated for chambers F-2 (black line) and F (grey line). The boxed samples are plankton tows (PT). 


\subsection{Summary and Conclusions}

In this study LA-ICP-MS was employed to examine the intra- and inter-chamber distribution of $\mathrm{Mg} / \mathrm{Ca}$ within individual tests of Gs. ruber. The LA-ICP-MS profiles showed that this technique can be used to identify areas of secondary calcite crusts, and/or surface contamination and thus, isolate them from ontogenetic calcite by careful screening of profiles. These profiles show a lack of any surface layer on either of the chambers F-2 or F-1 that may typify gametogenetic calcite crusts (i.e. low $\mathrm{Mg} / \mathrm{Ca}$ ). Therefore it was inferred that Gs. ruber does not produce a gametogenic layer over previously precipitated chambers that may bias the $\mathrm{Mg} / \mathrm{Ca}$ signal.

However, the ultimate chamber $\mathrm{F}$ of Gs. ruber is systematically (4- $35 \%$ ) lower in $\mathrm{Mg} / \mathrm{Ca}$ compared to chambers F-1 and F-2. The variability of $\mathrm{Mg} / \mathrm{Ca}$ ratios found between these chambers, could in part, be explained by the ecology of the species. On account of these systematic changes a number of chamber-specific empirical calibrations that reliably estimate SST were derived. These calibrations are comparable to extant calibrations based on LA-ICPMS and demonstrate that chamber-specific calibrations are an alternative to bulk $\mathrm{Mg} / \mathrm{Ca}$ analyses of foraminifera. These single chamber calibrations provide a time efficient method, requiring minimal cleaning, fast analysis time and leave material for use in other analyses.

The inter-individual variability of $\mathrm{TE} / \mathrm{Ca}$ of Gs. ruber within populations suggest the temperatures $(\mathrm{Mg} / \mathrm{Ca})$ recorded from individual foraminifera, including plankton tow samples are often outside the seasonal ranges of the sample sites. Removal of the temperature effect from each site, by dividing by the mean temperature value of each site and normalising the data to a single value reveals a log-normal distribution. The log-normal distribution describes well the variability of $\mathrm{Mg} / \mathrm{Ca}$ values but the spread parameter of this distribution, being the standard deviation of $\log (\mathrm{Mg} / \mathrm{Ca})$ values, is not universal. This variation with temperature is at most weak, suggesting that it is due to some other, unknown, possible vital effect. Microanalytical techniques in other foraminifera may shed more light on this observation. 


\subsection{Supplementary Material}

Chapter 3 is published in the journal Paleoceanography. This supplementary material describes additional research related to that paper, but beyond its scope and the journal's length limitations. Material reported here includes presentation and discussion of: (1) trace element (TE)/Ca ratios (other than $\mathrm{Mg} / \mathrm{Ca}$ ) and $\delta^{18} \mathrm{O}$ data for Gs. ruber, (2) size and weight measurements for Gs. ruber.

\subsubsection{Trace element analysis of $\mathrm{Ba}, \mathrm{Zn}$ and $\mathrm{Sr}$ in Gs. ruber tests}

\section{Introduction}

$\mathrm{Ba} / \mathrm{Ca}$ and $\mathrm{Zn} / \mathrm{Ca}$ ratios are thought to be indicators of ocean nutrient and palaeoproductivity [Lea, 1999a; Yu et al., 2005]. Ba and Si* (see Sarmiento et al., 2004) are strongly correlated in the modern ocean, which has led to the suggestion that $\mathrm{Ba}$ in foraminifera could be used as a tracer of circulation and chemistry of past oceans [Lea and Boyle, 2003]. Further work from laboratory experiments on living planktonic foraminifers (Globigerinoides sacculifer and Orbulina universa) showed that $\mathrm{Ba}$ in tests can provide an accurate record of seawater barium, although others have suggested its application to reconstructing past ocean alkalinity may be limited because $\mathrm{Ba}$ export to the deep ocean is primarily through marine barite formed in decaying organic matter [Katz et al., 2010]. Moreover, in benthic foraminifers, $\Delta \mathrm{Ba}: \Delta \mathrm{Alk}$ relationships may not differ regionally [McManus et al., 1999] and/or may not be constant over time due to decoupled $\mathrm{Ba}$ and Alk biogeochemical cycles [Rubin et al., 2003].

Therefore, these 'nutrient tracers' from Gs. ruber were compared between different core-top sites to see if the foraminifera preserve a trace element fingerprint of the chemistry of the water masses they lived in. Similarly, zinc is a nutrient element required for phytoplankton and, especially, diatom growth [Lynch-Stieglitr, 2003], which results in a strong correlation between oceanic zinc and silicon concentrations.

In both inorganic and biogenically crystallized calcite there is a positive linear correlation between Sr/Ca and Mg/Ca [Mucci and Morse, 1983; Carpenter and Lohmann, 1992]. However the incorporation of Sr into foraminiferal calcitic tests appears to be species-specific [Mortyn et al., 
2005] and is potentially related to different controls on bio-mineralisation [Kisakürek et al., 2008]. Sr/Ca in Gs. ruber shows a dependence on the average growth rate, whereas temperature and salinity have an indirect effect on shell $\mathrm{Sr} / \mathrm{Ca}$ through the biological control of foraminiferal growth rates [Kisakürek et al., 2008]. As such, intra and inter-individual Sr/Ca measurements from Gs. ruber may yield more insights into the mechanisms of Sr incorporation into this species of foraminifera, and the relationships that exist between $\mathrm{Sr} / \mathrm{Ca}$ and temperature, salinity and test size.

\section{Methods}

The method of analysis of trace element data reported in this Supplementary Material for Gs. ruber is the same as reported in Chapter 3. In addition to ${ }^{24} \mathrm{Mg},{ }^{27} \mathrm{Al},{ }^{55} \mathrm{Mn}$, the elemental abundance of ${ }^{66} \mathrm{Zn},{ }^{88} \mathrm{Sr}$ and ${ }^{138} \mathrm{Ba}$ relative to ${ }^{43} \mathrm{Ca}$ were determined by LA-ICP-MS.

\section{Results and discussion}

\section{$\underline{\mathrm{Ba} / \mathrm{Ca} \text { ratios }}$}

When the mean site values are considered, the $\mathrm{Ba} / \mathrm{Ca}$ ratios from the higher latitude tropical sites (AIMS1361, AIMS3703, AIMS1631, AIMS2078 and FR1/97/GC12) range in value from 1.16 to $2.66 \mu \mathrm{mol} / \mathrm{mol}$ which is lower than mean seawater $\mathrm{Ba} / \mathrm{Ca}$ measurements taken from the almost constant surface layer in the Pacific Ocean of $3.5 \mu \mathrm{mol} / \mathrm{mol}$ (c.f. Kunioka et al., [2006]). At the subtropical sites (TAN706, P71, P81, Z7003) the range is more variable (1.20 to $5.69 \mu \mathrm{mol} / \mathrm{mol}$ ). The plankton tow samples consist of the lowest levels of $\mathrm{Ba} / \mathrm{Ca}$ and do not differ greatly between one another or different sites $(0.92$ to $1.12 \mu \mathrm{mol} / \mathrm{mol})$. This may suggest lower $\mathrm{Ba} / \mathrm{Ca}$ in the water column, and/or reflect conditions at the time of the plankton tow collection. ODP Site 1123 shares higher levels of $\mathrm{Ba} / \mathrm{Ca}(5.29 \mu \mathrm{mol} / \mathrm{mol})$ when compared to the tropical sites (Table 3.4). The reasons for these site differences are not clear but may relate to areas of high productivity [von Breymann et al., 1992], upwelling [Kunioka et al., 2006] or reflect different calcification depths. Previous work in a frontal system of the Crozet-Kerguelen Basin in the Southern Ocean has shown that hydrodynamic effects control the dissolved Ba more than biogeochemical processes [Jacquet et al., 2005] and due to increased barite solubility with depth, deeper sites reflect palaeoproductivity better than shallow sites [von Breymann et al., 


\section{Chapter 3: Supplementary Material}

1992]. However, the mean range of $\mathrm{Ba} / \mathrm{Ca}$ for $G$ s. ruber would seem to suggest that $\mathrm{Ba} / \mathrm{Ca}$ recorded in this species may have potential for recording surface $\mathrm{Ba} / \mathrm{Ca}$, although this requires local seawater measurements to confirm.

Table 3.4: Mean $\mathrm{Ba} / \mathrm{Ca}$ and $\mathrm{Zn} / \mathrm{Ca}$ and standard deviation (S.D.) of for each site (sites in bold are plankton tows).

\begin{tabular}{|c|c|c|c|c|}
\hline Sample & $\mathrm{Ba} / \mathrm{Ca}$ & $\mathrm{Ba} / \mathrm{Ca}$ & $\mathrm{Zn} / \mathrm{Ca}$ & $\mathrm{Zn} / \mathrm{Ca}$ \\
\hline & $(\mu \mathrm{mol} / \mathrm{mol})$ & S.D. $(\mu \mathrm{mol} / \mathrm{mol})$ & $(\mu \mathrm{mol} / \mathrm{mol})$ & S.D. $(\mu \mathrm{mol} / \mathrm{mol})$ \\
\hline AIMS1361 & 1.56 & 0.76 & 8.00 & 3.94 \\
\hline AIMS3703 & 2.01 & 1.06 & 24.28 & 23.25 \\
\hline AIMS1631 & 1.16 & 0.30 & 22.55 & 8.80 \\
\hline AIMS2078 & 1.89 & 0.68 & 45.97 & 151.01 \\
\hline FR1/97/GC12 & 2.66 & 1.67 & 8.39 & 26.23 \\
\hline TAN0706 C4 & 1.20 & 1.38 & 30.29 & 17.65 \\
\hline P71 & 2.96 & 3.20 & 30.78 & 16.90 \\
\hline P81 & 5.69 & 3.11 & 94.39 & 74.09 \\
\hline Z7003 & 1.32 & 0.70 & 11.46 & 14.20 \\
\hline U2322 NET7 & 1.01 & 0.42 & 188.54 & 185.72 \\
\hline U2322 NET6 & 0.92 & 0.23 & 105.69 & 113.42 \\
\hline U2315 & 1.12 & 0.42 & 145.77 & 133.11 \\
\hline ODP1123 & 5.29 & 2.56 & 47.33 & 26.81 \\
\hline
\end{tabular}

\section{$\underline{\mathrm{Zn} / \mathrm{Ca} \text { ratios }}$}

Mean $\mathrm{Zn} / \mathrm{Ca}$ ratios from all the core top sites are low $(32 \mu \mathrm{mol} / \mathrm{mol})$ compared to the plankton tows that exhibit considerably higher values $(106-189 \mu \mathrm{mol} / \mathrm{mol})$ (Table 3.4). This 
might reflect a number of factors including Zn contamination during MOCNESS sampling, high zinc in the surface waters where the MOCNESS samples were taken, or difficulty in removing Zn-rich organic material from the captured living foraminifera. $\mathrm{Zn} / \mathrm{Ca}$ data for $G$. bulloides from a core-top site near the MOCNESS plankton tow sites also have elevated $\mathrm{Zn} / \mathrm{Ca}$ ratios (J. Marr, pers. comm., 2009) and potentially indicates that the elevated zinc may be a feature of the surface ocean at this site. Moreover, dissolved $\mathrm{Zn}$ in sub-surface waters close to Site U2322, off the east coast of New Zealand, are also elevated in Zn and Fe, with sub-surface $\mathrm{Zn}$ concentrations at of $c a .1 \mathrm{nmol} / \mathrm{L}$, compared to surface concentrations of 70 to 300 pmol/L (M. Ellwood, unpubl. data). Given these observations and that this region is subject to upwelling [Chiswell, 2003], a nutrient-related origin for the high $\mathrm{Zn} / \mathrm{Ca}$ in Gs. ruber from the plankton tow sites is tentatively favoured.

\section{$\underline{\mathrm{Sr} / \mathrm{Ca} \text { ratios }}$}

Mean Sr/Ca ratios are higher in Gs. ruber from the plankton tow samples compared to the core top samples with average $\mathrm{Sr} / \mathrm{Ca}$ ratios between all sites varying from 1.24 to $1.56 \mathrm{mmol} / \mathrm{mol}$. Unlike $\mathrm{Mg} / \mathrm{Ca}$ ratios which vary from chamber-to-chamber in Gs. ruber individuals, Sr/Ca ratios vary very little (Table 3.5). This implies that $\mathrm{Sr} / \mathrm{Ca}$ is not affected by the same mechanisms that influence $\mathrm{Mg} / \mathrm{Ca}$ chamber variability. This is also apparent in the repeat measurements where the 2 S.D. was extremely low $( \pm 0.04 \mathrm{mmol} / \mathrm{mol})$. However paired t-tests reveal a statistically significant difference between $\mathrm{Sr} / \mathrm{Ca}$ between some chambers at 6 sites (Table 3.6).

It has been previously demonstrated that Sr-rich parts of the test G. tumida are preferentially dissolved with increasing water depth [Brown and Elderfield, 1996]. There appears to be no difference in mean Sr/Ca and depth (Table 3.5). The laser ablation profiles in this study have relatively homogeneous Sr throughout the test suggesting that high and low Sr banding (as found with Mg in G. tumida and other species) [Sadekov et al., 2005; Bentov et al., 2009] and Sr in Globigerinoides sacculifer [Brown and Elderfield, 1996] are not present in Gs. ruber. More detailed analytical studies using NanoSIMS in other planktonic species have shown stronger correlations of $\mathrm{Mg}$ and $\mathrm{Sr}$ that correspond to high organic layers within the test [Kunioka et al., 2006]. 
Other studies [Lea et al., 1999] have linked Sr uptake with calcification rate, which was associated with higher temperature, salinity and $\mathrm{pH}$. It is unclear to what degree these associations are linked to the carbonate ion concentration $\left[\mathrm{CO}_{3}{ }^{2-}\right]$, a driver of calcification rate and growth mechanisms [Lorens, 1981; Paquette and Reeder, 1990]. Moreover, there is no relationship between $\mathrm{Sr} / \mathrm{Ca}$ and temperature suggesting that a large temperature dependence on Sr partitioning [Stoll et al., 1999] is not apparent in Gs. ruber from this study. These results are also consistent with those of Kisakürek et al. [2008] and Cléroux et al. [2008] who found no clear temperature dependence on measured $\mathrm{Sr} / \mathrm{Ca}$ in cultured and fossil Gs. ruber. 
Chamber

\begin{tabular}{|c|c|c|c|c|}
\hline & \\
\hline & & $\mathrm{F}-2 \mathrm{Sr} / \mathrm{Ca}$ & $\mathrm{F}-1 \mathrm{Sr} / \mathrm{Ca}$ & $\mathrm{F} \mathrm{Sr/Ca}$ \\
\hline Site & & \multicolumn{2}{|c|}{$(\mathrm{mmol} / \mathrm{mol})(\mathrm{mmol} / \mathrm{mol})$} & $(\mathrm{mmol} / \mathrm{mol})$ \\
\hline AlMS 1361 & Mean & 1.45 & 1.42 & 1.40 \\
\hline$n=7$ & Minimum & 1.37 & 1.36 & 1.28 \\
\hline \multicolumn{2}{|c|}{ Depth $=1100 \mathrm{~m}$ Maximum } & 1.58 & 1.49 & 1.48 \\
\hline & S.D. & 0.07 & 0.05 & 0.06 \\
\hline AlMS 3703 & Mean & 1.49 & 1.48 & 1.54 \\
\hline$n=13$ & Minimum & 1.41 & 1.40 & 1.41 \\
\hline \multirow[t]{2}{*}{ Depth $=504 \mathrm{~m}$} & Maximum & 1.58 & 1.55 & 1.72 \\
\hline & S.D. & 0.05 & 0.04 & 0.10 \\
\hline AlMS 2078 & Mean & 1.53 & 1.55 & 1.51 \\
\hline$n=10$ & Minimum & 1.42 & 1.38 & 1.33 \\
\hline \multirow[t]{2}{*}{ Depth $=880 \mathrm{~m}$} & Maximum & 1.64 & 1.69 & 1.67 \\
\hline & S.D. & 0.08 & 0.12 & 0.12 \\
\hline AlMS 1631 & Mean & 1.45 & 1.51 & 1.39 \\
\hline$n=4$ & Minimum & 1.39 & 1.42 & 1.30 \\
\hline \multirow{2}{*}{ Depth $=1468 \mathrm{~m}$} & Maximum & 1.49 & 1.64 & 1.46 \\
\hline & S.D. & 0.04 & 0.10 & 0.06 \\
\hline FR1/97/GC12 & Mean & 1.45 & 1.51 & 1.53 \\
\hline$n=12$ & Minimum & 1.36 & 1.36 & 1.37 \\
\hline \multirow[t]{2}{*}{ Depth $=991 \mathrm{~m}$} & Maximum & 1.57 & 1.76 & 1.63 \\
\hline & S.D. & 0.07 & 0.11 & 0.09 \\
\hline TAN0706 C4 & Mean & 1.38 & 1.36 & 1.39 \\
\hline$n=26$ & Minimum & 1.24 & 1.26 & 1.30 \\
\hline \multirow[t]{2}{*}{ Depth $=2258 \mathrm{~m}$} & Maximum & 1.52 & 1.49 & 1.54 \\
\hline & S.D. & 0.07 & 0.06 & 0.06 \\
\hline U2322net7 (PT) & Mean & 1.55 & 1.53 & 1.54 \\
\hline $\mathrm{n}=8$ & Minimum & 1.44 & 1.39 & 1.43 \\
\hline \multirow[t]{2}{*}{ Depth $=50 \mathrm{~m}$} & Maximum & 1.57 & 1.56 & 1.63 \\
\hline & S.D. & 0.07 & 0.09 & 0.10 \\
\hline U2322net6 (PT) & Mean & 1.49 & 1.50 & 1.53 \\
\hline$n=7$ & Minimum & 1.45 & 1.44 & 1.45 \\
\hline \multirow[t]{2}{*}{ Depth $=100 \mathrm{~m}$} & Maximum & 1.57 & 1.56 & 1.63 \\
\hline & S.D. & 0.04 & 0.05 & 0.07 \\
\hline P71 & Mean & 1.46 & 1.47 & 1.48 \\
\hline$n=7$ & Minimum & 1.36 & 1.34 & 1.35 \\
\hline \multirow[t]{2}{*}{ Depth $=1919 \mathrm{~m}$} & Maximum & 1.81 & 1.81 & 1.98 \\
\hline & S.D. & 0.11 & 0.11 & 0.14 \\
\hline U2315 (PT) & Mean & 1.53 & 1.57 & 1.38 \\
\hline$n=13$ & Minimum & 1.47 & 1.45 & 1.24 \\
\hline \multirow[t]{2}{*}{ Depth $=100 \mathrm{~m}$} & Maximum & 1.60 & 1.85 & 1.54 \\
\hline & S.D. & 0.04 & 0.11 & 0.06 \\
\hline Z7003 & Mean & 1.42 & 1.40 & 1.46 \\
\hline$n=16$ & Minimum & 1.31 & 1.28 & 1.32 \\
\hline \multirow[t]{2}{*}{ Depth $=430 \mathrm{~m}$} & Maximum & 1.54 & 1.56 & 1.59 \\
\hline & S.D. & 0.06 & 0.08 & 0.08 \\
\hline P81 & Mean & 1.24 & 1.24 & 1.26 \\
\hline $\mathrm{n}=18$ & Minimum & 0.98 & 1.02 & 1.01 \\
\hline \multicolumn{2}{|c|}{ Depth $=2036 \mathrm{~m}$ Maximum } & 1.42 & 1.47 & 1.49 \\
\hline & S.D. & 0.15 & 0.15 & 0.16 \\
\hline ODP 1123 & Mean & 1.42 & 1.45 & 1.47 \\
\hline$n=13$ & Minimum & 1.35 & 1.33 & 1.35 \\
\hline \multicolumn{2}{|c|}{ Depth $=3290 \mathrm{~m}$ Maximum } & 1.53 & 1.76 & 1.53 \\
\hline & S.D. & 0.06 & 0.11 & 0.05 \\
\hline
\end{tabular}


Table 3.6: Significant differences in Sr/Ca between individual chambers analysed in Gs. ruber at different sites

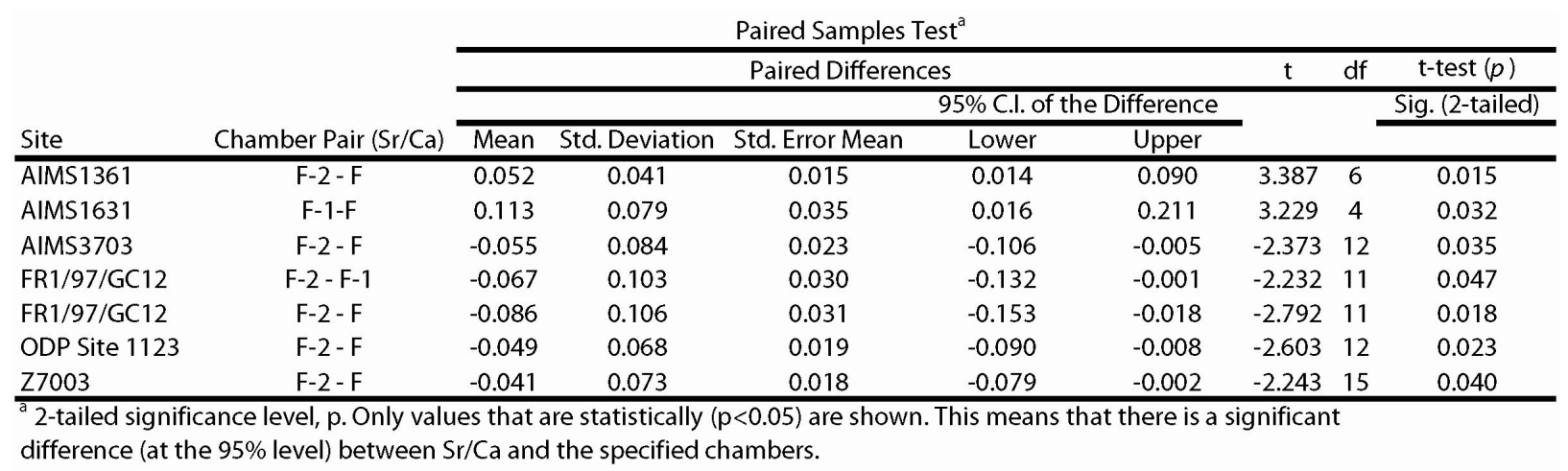

\subsubsection{Oxygen Isotopes}

\section{Introduction}

An alternative method to calibrate the $\mathrm{Mg} / \mathrm{Ca}$ - ocean temperature relationship is the use of calcification temperatures calculated from the $\delta^{18} \mathrm{O}$ composition of planktonic foraminifera, which allows for the varying depth habitat of each species to be incorporated into the temperature calibration [Elderfield and Ganssen, 2000; Anand and Elderfield, 2003; McConnell and Thunell, 2005].

\section{Methods}

Paired oxygen isotope ratios from test calcite $\left(\delta^{18} \mathrm{O}_{c}\right)$ were measured on material selected where $\mathrm{Mg} / \mathrm{Ca}$ ratios varied i.e. individual Gs. ruber were pooled together according to whether $\mathrm{Mg} / \mathrm{Ca}$ was high, low or average. Prior to analysis for $\delta^{18} \mathrm{O}_{\mathrm{c}}$ samples were cleaned (Section 4.2.), and reacted with 2 drops of $100 \% \mathrm{H}_{3} \mathrm{PO}_{4}$ at $75^{\circ} \mathrm{C}$ in an automated individual-carbonate reaction (Kiel) device. The device was coupled to a Finnigan-MAT 252 mass spectrometer at the National Institute of Water and Atmospheric Research, Wellington, New Zealand [Neil et al., 2004]. The internal and external precision of the $\delta^{18} \mathrm{O}_{c}$ measurements is $\pm 0.03 \%$ and $\pm 0.04 \%$, respectively, as determined by analysis of carbonate standards (NBS-19). The $\delta^{18} \mathrm{O}_{c}$ values are 
reported relative to Vienna Peedee Belemnite (vPDB) where $\delta^{18} \mathrm{O}_{c}$ has a value of $-2.20 \%$ for NBS19 calcite.

To derive a temperature, the $\delta^{18} \mathrm{O}$ - temperature equation of Bemis et al. [1998] for Gs. ruber was applied:

$$
\mathrm{T}\left({ }^{\circ} \mathrm{C}\right)=14.9-4.80 \times\left(\boldsymbol{\delta}_{\mathrm{c}}-\boldsymbol{\delta}_{\mathrm{w}}\right)
$$

The $\delta^{18} \mathrm{O}_{\mathrm{c}}$ is the measured $\delta^{18} \mathrm{O}$ of $G$ s. ruber, and $\delta^{18} \mathrm{O}_{\text {sw }}$ the oxygen isotope composition of ambient seawater. The Global Seawater Oxygen-18 Database (http://data.giss.nasa.gov/O18data) lacks $\delta^{18} \mathrm{O}_{\text {sw }}$ data from the Southwest Pacific Ocean. Hence, $\delta^{18} \mathrm{O}_{\text {sw }}$ was calculated using the relationship between $\delta^{18} \mathrm{O}_{\text {sw }}$ and salinity (SSS) determined by Savin et al. [1985] where:

$$
\delta^{18} \mathrm{O}_{\text {sw }}=[0.687 \times \text { site salinity }]-23.74 \quad[\text { Eq. 3.2 }]
$$

\section{Results and discussion}

$\mathrm{Mg} / \mathrm{Ca}$ and stable oxygen isotope data for Gs. ruber tests $\left(\boldsymbol{\delta}^{18} \mathrm{O}_{c}\right)$ are reported in Table 3.7, which includes a comparison with actual measurement of $\delta^{18} \mathrm{O}_{\text {sw }}$ from north of Chatham Rise, (0.57\% , H. Neil, unpubl. data) and from the global seawater oxygen-18 database [Schmidt et al., 1999] and the estimate of $\delta^{18} \mathrm{O}_{\mathrm{sw}}$ using the equation from Savin et al. [1985]. This independent $\delta^{18} \mathrm{O}_{\text {sw }}$ derivation and the measured $\delta^{18} \mathrm{O}_{\mathrm{c}}$ can be substituted into the equation of Epstein, et al. [1953] so that the $\mathrm{Mg} / \mathrm{Ca}$ derived ocean temperatures could be compared to those from the $\delta^{18} \mathrm{O}_{\mathrm{c}}$ :

$$
\mathrm{T}=16.5-4.3\left(\boldsymbol{\delta}^{18} \mathrm{O}_{\mathrm{c}}-\left[\boldsymbol{\delta}^{18} \mathrm{O}_{\mathrm{sw}}-0.27\right]\right)+0.14\left(\boldsymbol{\delta}^{18} \mathrm{O}_{\mathrm{c}}-\left[\boldsymbol{\delta}^{18} \mathrm{O}_{\mathrm{sw}}-0.27\right]\right)^{2}
$$


The relative isotopic abundance of ${ }^{18} \mathrm{O}$ in $\delta^{18} \mathrm{O}_{c}$ increases with decreasing temperature [Urey, 1947; Kim and $\left.O^{\prime} N e i l, 1997\right]$. Shallower dwelling species such as Gs. ruber (w) generally have a more negative $\delta^{18} \mathrm{O}_{\mathrm{c}}$ ratio compared to deeper dwelling species living and calcifying at colder temperatures. This is evident in the warmest subtropical sites where $\delta^{18} \mathrm{O}_{\mathrm{c}}$ is more negative (2.49 to $-2.86 \%$ ), compared to the colder sites that become increasingly more positive ( 0.53 to $0.76 \%$ at ODP Site 1123) (Table 3.7). The conversion of $\boldsymbol{\delta}^{18} \mathrm{O}_{\mathrm{c}}$ to calcification temperatures is comparable to those estimated from $\mathrm{Mg} / \mathrm{Ca}$ although there are some large differences at some sites (AIMS3703, Z7003 and ODP Site 1123). In addition, the variability of $\mathrm{Mg} / \mathrm{Ca}$ at a given site is not comparable to that of $\delta^{18} \mathrm{O}_{\mathrm{c}}$, which instead show comparable measurements (with the exception of P71). These differences suggest that $\mathrm{Mg} / \mathrm{Ca}$ variations between individuals are controlled by other processes such as seasonal changes in salinity and/or carbonate ion concentration (e.g., Wit et al., 2010) when compared to those that govern $\delta^{18} \mathrm{O}_{\text {c. }}$ 
Table 3.7: Gs. ruber $\delta^{18} \mathrm{O}_{c}$ with calculated and measured $\delta^{18} \mathrm{O}_{\text {sw }}$ compared to annual SST (WOA05) and Mg/Ca derived SSTs

\begin{tabular}{|c|c|c|c|c|c|c|c|c|c|c|}
\hline Sample & & Latitude & $\mathrm{SST}^{\mathrm{a}}$ & $\delta^{18} \mathbf{O}_{c}$ & $\delta^{18} \mathbf{O}_{\mathrm{sw}}$ & $\delta^{18} \mathbf{O}_{\text {sw }}{ }^{6}$ & $\mathrm{SST}_{(\mathrm{Mg} / \mathrm{Ca})}{ }^{\mathrm{C}}$ & $\mathrm{SST}_{(180 c)}$ & Pooled $\mathrm{Mg} / \mathrm{Ca}$ & Salinity \\
\hline & $\mathbf{n}$ & ('S) & $\left({ }^{\circ} \mathrm{C}\right)$ & $(\% \circ)$ & $(\%)$ & $(\%)$ & $\left({ }^{\circ} \mathrm{C}\right)$ & $\left({ }^{\circ} \mathrm{C}\right)$ & $(\mathrm{mmol} / \mathrm{mol})$ & $(\%)$ \\
\hline AIMS1361/1/R & 3 & 3.37 & 28.8 & -2.49 & -0.69 (Ashiet al ., 1994) & -0.31 & 30.3 & 26.5 & 6.35 & 34.5 \\
\hline AIMS1361/2/R & 2 & 3.37 & 28.8 & -2.55 & -0.69 (Ashiet al., 1994) & -0.31 & 26.8 & 26.8 & 4.97 & 34.5 \\
\hline AIMS1361/3/R & 3 & 3.37 & 28.8 & -2.73 & -0.69 (Ashiet al., 1994) & -0.31 & 25.4 & 27.7 & 4.51 & 34.5 \\
\hline AIMS3703/22/R & 2 & 11.153 & 28.4 & -2.83 & 0.07 (Craig and Gordon, 1973) & -0.38 & 30.7 & 27.9 & 6.52 & 34.4 \\
\hline AIMS3703/23/R & 3 & 11.153 & 28.4 & -2.85 & 0.07 (Craig and Gordon, 1973) & -0.38 & 22.0 & 28.0 & 3.55 & 34.4 \\
\hline AIMS3703/24/R & 3 & 11.153 & 28.4 & -2.71 & 0.07 (Craig and Gordon, 1973) & -0.38 & 20.2 & 27.3 & 3.12 & 34.4 \\
\hline AIMS3703/25/R & 3 & 11.153 & 28.4 & -2.86 & 0.07 (Craig and Gordon, 1973) & -0.38 & 15.6 & 28.0 & 2.27 & 34.4 \\
\hline TAN0706/15/R & 2 & 29.355 & 20.7 & -0.77 & & 0.52 & 25.8 & 22.3 & 4.64 & 35.7 \\
\hline TAN0706/16/R & 3 & 29.355 & 20.7 & -1.32 & & 0.52 & 23.5 & 24.9 & 3.94 & 35.7 \\
\hline TAN0706/17/R & 3 & 29.355 & 20.7 & -0.95 & & 0.52 & 18.5 & 23.1 & 2.78 & 35.7 \\
\hline $\mathrm{P} 71 / 4 / \mathrm{R}$ & 2 & 33.855 & 18.8 & -1.83 & 0.54 (H. Neil, pers. comm) & 0.45 & 29.1 & 27.0 & 5.84 & 35.6 \\
\hline $\mathrm{P} 71 / 5 \mathrm{a} / \mathrm{R}$ & 3 & 33.855 & 18.8 & -0.71 & 0.54 (H. Neil, pers. comm) & 0.45 & 21.0 & 21.7 & 3.31 & 35.6 \\
\hline $\mathrm{P} 71 / 7 / \mathrm{R}$ & 2 & 33.855 & 18.8 & 1.11 & 0.54 (H. Neil, pers. comm) & 0.45 & 17.0 & 13.7 & 2.50 & 35.6 \\
\hline Z7003/18/R & 2 & 36.69 & 18.1 & -0.32 & 0.54 (H. Neil, pers. comm) & 0.38 & 29.7 & 19.6 & 6.11 & 35.5 \\
\hline Z7003/19/R & 2 & 36.69 & 18.1 & -0.24 & 0.54 (H. Neil, pers. comm) & 0.38 & 21.7 & 19.2 & 3.48 & 35.5 \\
\hline Z7003/20/R & 3 & 36.69 & 18.1 & -0.56 & 0.54 (H. Neil, pers. comm) & 0.38 & 21.7 & 20.7 & 3.47 & 35.5 \\
\hline Z7003/21/R & 2 & 36.69 & 18.1 & -0.19 & 0.54 (H. Neil, pers. comm) & 0.38 & 17.8 & 19.0 & 2.65 & 35.5 \\
\hline $\mathrm{U} 2315 / 11 / \mathrm{R}$ & 4 & 38.509 & 18.7 & -0.95 & 0.54 (H. Neil, pers. comm) & 0.45 & 25.2 & 22.8 & 4.43 & 35.6 \\
\hline $\mathrm{U} 2315 / 12 / \mathrm{R}$ & 4 & 38.509 & 18.7 & -1.02 & 0.54 (H. Neil, pers. comm) & 0.45 & 19.9 & 23.1 & 3.07 & 35.6 \\
\hline $\mathrm{U} 2315 / 13 / \mathrm{R}$ & 3 & 38.509 & 18.7 & -0.90 & 0.54 (H. Neil, pers. comm) & 0.45 & 17.8 & 22.5 & 2.64 & 35.6 \\
\hline ODP1123/8/R & 6 & 41.786 & 14.7 & 0.59 & 0.54 (H. Neil, pers. comm) & 0.86 & 15.6 & 17.7 & 2.26 & 36.2 \\
\hline ODP1123/9/R & 5 & 41.786 & 14.7 & 0.53 & 0.54 (H. Neil, pers. comm) & 0.86 & 11.7 & 17.9 & 1.72 & 36.2 \\
\hline ODP1123/10/R & 6 & 41.786 & 14.7 & 0.76 & 0.54 (H. Neil, pers. comm) & 0.86 & 9.9 & 16.9 & 1.52 & 36.2 \\
\hline
\end{tabular}

${ }^{a} \delta{ }^{18} \mathrm{O}_{w}$ derived using the equation from Savin et al. $(1975)$ where $\delta{ }^{18} \mathrm{O}_{w}=0.687 *$ salinity $(\% o)-23.74$ and converting to PDB by subtracting $0.27 \%$

${ }^{b}$ Annual SST from the World Ocean Atlas (2005), Locarniniet al., (2006).

${ }^{c}$ SST derived using this studies derivation where SST $=\ln (\mathrm{Mg} / \mathrm{Ca} / 0.761) / 0.07$

${ }^{d}$ SST derived using the equation from Epstein et al., (1953) where $T=16.5-4.3\left(\delta^{18} O_{c}-\delta{ }^{18} O_{w}\right)+0.14\left(\delta{ }^{18} O_{c}-\delta{ }^{18} O_{w}\right)^{2}$ 


\subsubsection{Weight and size determinations}

\section{Introduction}

There is a current debate as to the factors that control foraminiferal test weight, such as marine carbonate ion concentration [ $\mathrm{CO}_{3}{ }^{2-}$ ] [Lohmann, 1995; Barker and Elderfield, 2002; Moy et al., 2009] or optimal growth conditions [de Villiers, 2004]. To examine these relationships more carefully Beer et al. [2010] studied Gs. ruber and G. bulloides from plankton net samples and found statistically significant inverse correlations with $\left[\mathrm{CO}_{3}^{2-}\right]$, temperature and salinity but were unable to conclusively decide what parameter primarily controls test weight. Culture studies offer the best way to examine these relationships, and have shown that size-normalised weights (SNW) and growth rates increase with increasing $\left[\mathrm{CO}_{3}{ }^{2}\right]$ [Bijma et al., 1992; Kisakürek et al., 2008].

However post-depositional effects can also change foraminferal test weights upon burial, and transect studies have shown a decrease in $\mathrm{Mg} / \mathrm{Ca}$ with increasing water depth, particularly at deep sites $(>3500 \mathrm{~m})$ below the lysocline [Dekens et al., 2002] implying that bottom water

$\left[\mathrm{CO}_{3}{ }^{2-}\right]$ has more influence over test weights than surface water $\left[\mathrm{CO}_{3}{ }^{2-}\right]$. This is supported by microprobe element maps linking this lower $\mathrm{Mg} / \mathrm{Ca}$ to the selective removal of high $\mathrm{Mg}$ bands within tests [Fehrenbacher et al., 2006]. Therefore test weights may also be useful indicators of dissolution. Gs. ruber $\mathrm{Mg} / \mathrm{Ca}$ ratios were compared with test weight, depth and surface $\left[\mathrm{CO}_{3}{ }^{2}\right]$ from each site. Surface $\left[\mathrm{CO}_{3}{ }^{2}\right]$ was chosen as bottom water $\left[\mathrm{CO}_{3}{ }^{2-}\right]$ data is limited for this region.

\section{Methods}

High precision size and weight measurement data were determined for all the Gs. ruber specimens. First, the mean weights of all tests from each sample were normalised by the mean size to minimise any size effect (equation 3.4). The normalised mean weight was then compared to temperature (calculated from $\mathrm{Mg} / \mathrm{Ca}$ in chamber F-2 $\left[\mathrm{Mg} / \mathrm{Ca}_{\mathrm{ChF}-2}\right]$ ), $\left[\mathrm{CO}_{3}{ }^{2}\right]$ from the surface waters obtained from GEOSECS [Key et al., 2004] and salinity from the World Ocean Atlas [Antonov et al., 2006].

Normalised weight $($ per site $)=\{$ mean weight $(\mu \mathrm{g}) /$ mean width $(\mu \mathrm{m})\}$

x 100 [Eq. 3.4] 


\section{Results and discussion}

The majority of Gs. ruber weights in this study are similar to those found in the South Pacific [de Villiers, 2005] although the distribution at each site is highly variable. There is no obvious relationship between normalised weight and surface $\left[\mathrm{CO}_{3}{ }^{2-}\right]$ contrary to results from plankton tow Gs. ruber samples from a limited surface $\left[\mathrm{CO}_{3}{ }^{2}\right]$ range $(260-300 \mu \mathrm{mol} / \mathrm{kg})$ [Beer et al., 2010] (Figure 3.8). There is a weak relationship between $\mathrm{Mg} / \mathrm{Ca}_{\mathrm{ChF}-2}$ as a proxy for temperature and normalised weight and no relationship with salinity.
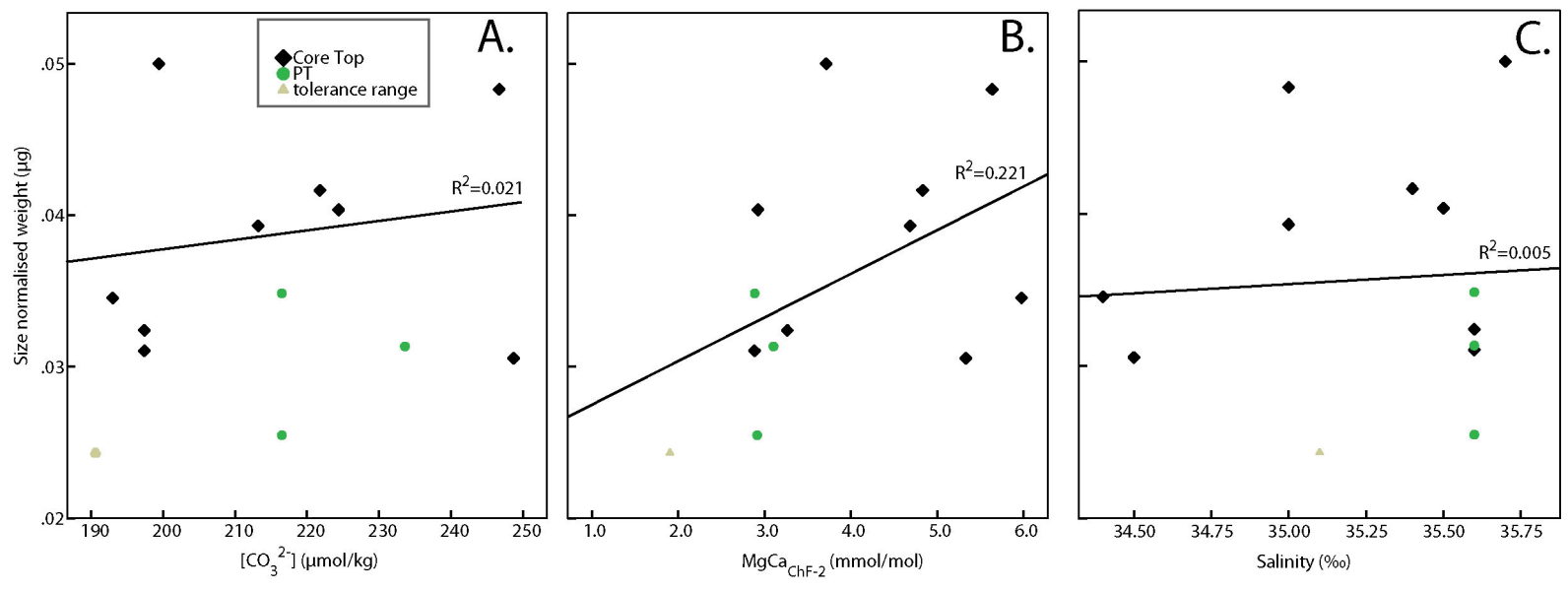

Figure 3.8: Relationship between $\mathrm{SNW}$ and (A) surface water $\left[\mathrm{CO}_{3}{ }^{2}\right]$, (B) temperature $(\mathrm{Mg} / \mathrm{CaChF}-2)$ and $(\mathrm{C})$ salinity. The legend represents mean core top values (black diamonds), plankton tows (PT), green circles and the site where Gs. ruber is at its environmental tolerance limit for temperature (ODP Site 1123).

\subsubsection{Summary and Conclusions}

- Given the above results, there is some further work required to examine relationships between other TE/Ca in foraminifera with other sedimentary and water column measurements.

- The $\delta^{18} \mathrm{O}$ measured in Gs. ruber suggests it is not sensitive to biological or 'vital effects' compared to $\mathrm{Mg} / \mathrm{Ca}$

- Weight and size measurements appear to be correlated with temperature and not $\left[\mathrm{CO}_{3}^{2-}\right]$. 


\section{Chapter 4}

Evaluating complexities in the application of the

$\mathrm{Mg} / \mathrm{Ca}$ palaeo-ocean thermometer to the planktonic foraminifer Neogloboquadrina incompta from the Southwest Pacific Ocean 


\subsection{Abstract}

$\mathrm{Mg} / \mathrm{Ca}$ and $\mathrm{Sr} / \mathrm{Ca}$ ratios are presented for the planktonic foraminifera Neogloboquadrina incompta (N. incompta) from core-top, dredge and plankton tow material from the Southwest Pacific Ocean. The ultra-structure (reticulate or crystalline) of each foraminifera test was determined using a scanning electron microscope, after trace element analysis by laser ablation inductively coupled plasma mass spectrometry (LA-ICP-MS) to examine the variability in $\mathrm{Mg} / \mathrm{Ca}$ and $\mathrm{Sr} / \mathrm{Ca}$ between these two different ultra-structures.

For $\mathrm{Sr} / \mathrm{Ca}$ there was no difference the two ultra-structures studied, nor within individual chambers. N. incompta demonstrate far greater $\mathrm{Mg} / \mathrm{Ca}$ heterogeneity both in individual chambers and between chambers. Comparison of the mean $\mathrm{Mg} / \mathrm{Ca}$ ratios of both reticulate and crystalline $N$. incompta to mean ocean temperatures did not reveal a significant relationship. This lack of correlation between $\mathrm{Mg} / \mathrm{Ca}$ ratios of $\mathrm{N}$. incompta with ocean temperature may suggest that this species does not dwell at the same depths at each core top site and instead may reflect migration within the water column that is not uni-directional, or some other unidentified controls on $\mathrm{Mg}$ incorporation into N. incompta that require further study.

The LA-ICP-MS trace element data reveal differences in $\mathrm{Mg} / \mathrm{Ca}$ between outer calcite crusts in crystalline forms that have an outer layer with very low $\mathrm{Mg} / \mathrm{Ca}$ compared to the inner ontogenetic calcite. In reticulate or non-crystalline forms, this layer is either absent, or is only a thin layer with low $\mathrm{Mg} / \mathrm{Ca}$ ratios. These individuals may represent intermediates of crystalline forms, but this is not obvious with SEM imaging. The majority of reticulate tests without an outer layer with low $\mathrm{Mg} / \mathrm{Ca}$ have high and low $\mathrm{Mg} / \mathrm{Ca}$ bands in the inner ontogenetic calcite layer(s), which are interpreted as reflecting organic layers of ontogenetic calcite. The ablated gametogenic calcite in crystalline forms of $\mathrm{N}$. incompta have similar $\mathrm{Mg} / \mathrm{Ca}$ ratios regardless of the location from which the foraminifera were taken, indicating a possible temperature or vital effect that controls incorporation of $\mathrm{Mg}$. The data also suggest that the ontogenetic calcite in crystalline tests is precipitated in warmer or shallower parts of the water column compared to the low $\mathrm{Mg} / \mathrm{Ca}$ outer calcite layer. Neither reticulate nor crystalline forms of N. incompta from sediments of the Southwest Pacific Ocean appear to be reliable palaeo-ocean thermometers. 


\subsection{Introduction}

This chapter presents results of a study designed to investigate the utility of the planktonic foraminifera Neogloboquadrina incompta ( $N$. incompta) for $\mathrm{Mg} / \mathrm{Ca}$ palaeo-ocean thermometry in the temperate Southern Ocean. Both temperature and non-temperature related controls on the uptake of $\mathrm{Mg} / \mathrm{Ca}$ are considered. This species is of particular interest because it is one of the few that occurs in abundance throughout glacial-interglacial cycles in New Zealand waters [Kennett and Vella, 1975; Crundwell et al., 2008]. More generally, members of the genus Neogloboquadrina tolerate low temperatures in sub-polar and polar regions highlighting their palaeo-oceanographic importance, given most $\mathrm{Mg} / \mathrm{Ca}$ - ocean temperature calibrations for planktonic foraminifera are for water temperatures $>15^{\circ} \mathrm{C}$ [Pak et al., 2004; Barker et al., 2005].

Several solution-derived $\mathrm{Mg} / \mathrm{Ca}$ - ocean temperature calibrations exist for the genus Neogloboquadrina i.e., Neogloboquadrina pachyderma (N. pachyderma) [Nürnberg, 1995] Neogloboquadrina dutertrei (N. dutertrei) and N. incompta [Von Langen et al., 2005]. Other researchers have also utilised these species in generic $\mathrm{Mg} / \mathrm{Ca}$ - ocean temperature calibrations for planktonic foraminifers (e.g., Barker et al., 2005; Table 4.1), suggesting Neogloboquadrind $\mathrm{Mg} / \mathrm{Ca}$ variability with respect to calcification temperature is similar to that found in other planktonic foraminifera. Moreover, most of these calibrations are based on cultured foraminifera and none have been developed from the Pacific Ocean.

However, further studies have highlighted the relatively poor correlation between $\mathrm{Mg} / \mathrm{Ca}$ ratios and ocean temperatures for this genus for the Southern Ocean, which may partly reflect large $\mathrm{Mg} / \mathrm{Ca}$ heterogeneities within the test of this genus [Nürnberg, 1995; Bergami et al., 2008]. 
Table 4.1: N. incompta and N. pachyderma $\mathrm{Mg} / \mathrm{Ca}$ - temperature calibrations adapted from Von Langen et al. [2005].

\begin{tabular}{|c|c|c|c|c|}
\hline \multirow[t]{2}{*}{ Reference } & \multirow[t]{2}{*}{ Sample Type } & \multirow[t]{2}{*}{ Location } & \multicolumn{2}{|c|}{$\mathrm{Mg} / \mathrm{Ca}=\mathrm{B} \exp { }^{(\mathrm{A} \times \mathrm{T})}$} \\
\hline & & & $\mathbf{A}$ & B \\
\hline Nürnberg [1995] & N. pachyderma, core-top & Norwegian Sea & 0.099 & 0.549 \\
\hline Nürnberg [1995] & N. pachyderma, core-top & South Atlantic & 0.083 & 0.406 \\
\hline Von Langen et & cultured N. incompta & Southern California Bight & & \\
\hline al. [2005] & & & 0.101 & 0.510 \\
\hline
\end{tabular}

For example, at high southern latitudes growth of the juvenile phase of $N$. pachyderma may occur in sea ice brine channels which have higher $\mathrm{Mg}$ concentrations and temperatures than ambient seawater [Spindler, 1996; Hendry et al., 2009]. While this cannot be a reason for lack of correlation between ocean temperature and $\mathrm{Mg} / \mathrm{Ca}$ at lower latitudes it highlights potential additional complexity in terms of test growth beyond that identified with shallow dwelling tropical species such as Globigerinoides ruber e.g., Sadekov et al., [2008]. Unlike Gs. ruber, the life cycle of $N$. incompta is thought to be characterised by migration through a depth range up to $100 \mathrm{~m}$ during its life [Schiebel et al., 2001]. Bé [1977] places undifferentiated N. pachyderma (i.e. both N. incompta and pachyderma) in his "polar water" grouping. A particular point of difference between Gs. ruber and N. incompta is the precipitation of gametogenic calcite (absent in Gs. ruber), as part of the reproductive cycle of $N$. incompta as discussed further below.

Neogloboquadrina incompta [Cifelli, 1961] is non-spinose, asymbiotic planktonic foraminifera. This classification was proposed to formally recognise a form previously regarded as the dextral coiling variant of $N$. pachyderma. N. pachyderma is one of the few species of planktonic foraminifera that thrive in cold waters $\left(<8^{\circ} \mathrm{C}\right)$, therefore it is widely used in palaeooceanographic reconstructions involving foraminiferal assemblages [Reynolds and Thunell, 1986]. Earlier workers described N. pachyderma as Globorotalia (Turbototalia) pachyderma [Ehrenberg, 1861; Ehrenberg, 1873]. Later it was re-classified by Cifelli [1961] to Globigerina incompta and the synonym Neogloboquadrina pachyderma based upon scanning electron microscope (SEM) studies of surface features. Subsequent authors considered N. incompta to be a coiling variant of $N$. pachyderma, due to their morphological similarities but opposite coiling directions. Hence, they 
were referred to as N. pachyderma (dextral) and (sinistral) [Bandy, 1972]. The relative abundance of these variants were considered at first to reflect different properties of the mixed layer (temperature), where the left coiling (sinistral) form was more abundant in colder waters or during glacial periods in down-core records and the right coiling variant (dextral) was more abundant in warmer waters or during interglacial periods [Kennett, 1968; Dieckmann et al., 1991]. Sub-unit ribosomal RNA genotyping evidence has since confirmed that the different coiling types are, in fact, genetically distinct [Darling et al., 2006]. Based on this evidence, the dextrallycoiled populations of $N$. pachyderma are now classified as $N$. incompta with the sinistral form remaining as $N$. pachyderma.

Part of the reproductive process of some species of planktonic foraminifera, including $N$. incompta, involves the production of a gametogenic calcite layer that is precipitated over all previous chambers at the time of reproduction and subsequent death. In Globigerinoides sacculifer this layer represented an average of $28 \%$ by weight [Bé, 1980] and in Orbulina universa ranged from $4-20 \%$ of the final shell mass in cultured tests [Hamilton et al., 2008] although comparable data have not been published for $N$. incompta. The formation of these 'crusts', often referred to as 'encrusted' tests or gametogenic calcite, may be related to changes in temperature, illumination, depth, water chemistry or some combination thereof [Bé and Ericson, 1963; Orr, 1967; Srinivasan and Kennett, 1974; Bé et al., 1977; Bé, 1980]. For example, some species of foraminifera, prior to gametogenesis, descend deeper in the water column where they precipitate a gametogenic calcite crust [Duplessy et al., 1981], hence the suggestion that the production of this crust may be stimulated by changes in temperature and/or depth. The amount of light in the photic zone also decreases with increasing depth, although this will primarily affect calcification of symbiont-bearing foraminifera, as opposed to those that are symbiont barren [Bé et al., 1983; Lohmann, 1995] such as this species.

The addition of gametogenic calcite precipitated under temperature conditions different to those found at the ocean surface, and also under different biophysiological conditions (e.g., Barker et al., 2005; Nürnberg et al., 1996) is likely to result in a complex relationship between bulk $\mathrm{Mg} / \mathrm{Ca}$ and SST. For example, stable oxygen isotope compositions $\left(\boldsymbol{\delta}^{18} \mathrm{O}_{c}\right)$ of the different ultra-structures of $N$. pachyderma, that is the arrangement of growth layers of the test wall, as observed by SEM, show that large euhedral crystals dominate gametogenic crusts, and an enrichment in $\delta^{18} \mathrm{O}_{\mathrm{c}}$ in tests that were classified as 'encrusted' as opposed to non-encrusted is 
observed [Kohfield et al., 1996; Sautter, 1998]. Further evidence from Kozdon et al., [2009] and Robling and Cooke, [2003] suggested that the addition of a gametogenic calcite crust in some individuals results in oxygen isotope compositions increasing by $1.5 \%$, equivalent to calcification at $6.5^{\circ} \mathrm{C}$ lower temperatures, in response to changing calcification depths, implying bulk analysis of $\delta^{18} \mathrm{O}_{c}$ could be biased to lower temperatures depending on the proportion of the total test mass that consists of gametogenic calcite.

\subsection{Regional Setting of this Study}

Nine recent marine sediment samples from the Southwest Pacific Ocean (22 to 53 $\mathrm{S}$ ) comprising piston core-top and dredged samples were obtained from the Australian Institute of Marine Sciences (AIMS), National Institute of Water and Atmospheric Research (NIWA), New Zealand, and GNS Science, New Zealand. In addition to these sediment samples, three plankton tows taken from east of New Zealand by NIWA were also used in this study (Table 4.2).

The region over which the samples were taken is variably influenced by atmospheric and oceanic links from both Antarctica and the equatorial Pacific [Carter et al., 2008]. Relatively warm, saline, micro-nutrient rich, macro-nutrient poor waters from the north converge around the south of Chatham Rise with colder, macro-nutrient rich, micro-nutrient poor waters brought northwards from the Subantarctic Front (Figure 4.1). In the Southwest Pacific Ocean, sediments show that both $N$. pachyderma and N. incompta occupy the same water mass and are two of the few species that occur in abundance throughout glacial-interglacial cycles in New Zealand waters [Kennett, 1968; Crundwell et al., 2008].

Calcification temperatures calculated from $\delta^{18} \mathrm{O}_{\mathrm{c}}$ were not used in this study, due to reasons implied in previous work where crystalline parts of tests were shown to be enriched in $\delta^{18} \mathrm{O}_{c}$ compared to ontogenic calcite [Kozdon et al., 2009] and the lack of local $\delta^{18} \mathrm{O}_{\mathrm{sw}}$ measurements. Instead mean annual temperatures for each site were calculated for sub-surface ocean depths (0-100 m) obtained from the World Ocean Atlas (WOA05) [Locarnini et al., 2006]. This depth range was chosen based on previous work linking $N$. incompta abundance to the depth of greatest food availability (e.g., Fairbanks et al., 1980; Ortiz et al., 1995; Darling et al., 2006). This 
depth is usually within a warm, well stratified near surface layer [Reynolds and Tbunell, 1986; Sautter and Sancetta, 1992].

Sediment trap data from east of New Zealand, established the greatest flux of N. incompta occurred during the early austral summer (December) in traps north of Chatham Rise (Subtropical waters), whereas traps located south of the rise (Subantarctic waters) peaked during the late austral summer (March) [King and Howard, 2001]. The peak flux in foraminiferal production was related to moderate thermal stratification with food availability as secondary factor. It is therefore assumed that the majority of $N$. incompta in sediments calcified during spring or summer. 
Table 4.2: Details of core-top and plankton tow samples from the Southwest Pacific Ocean.

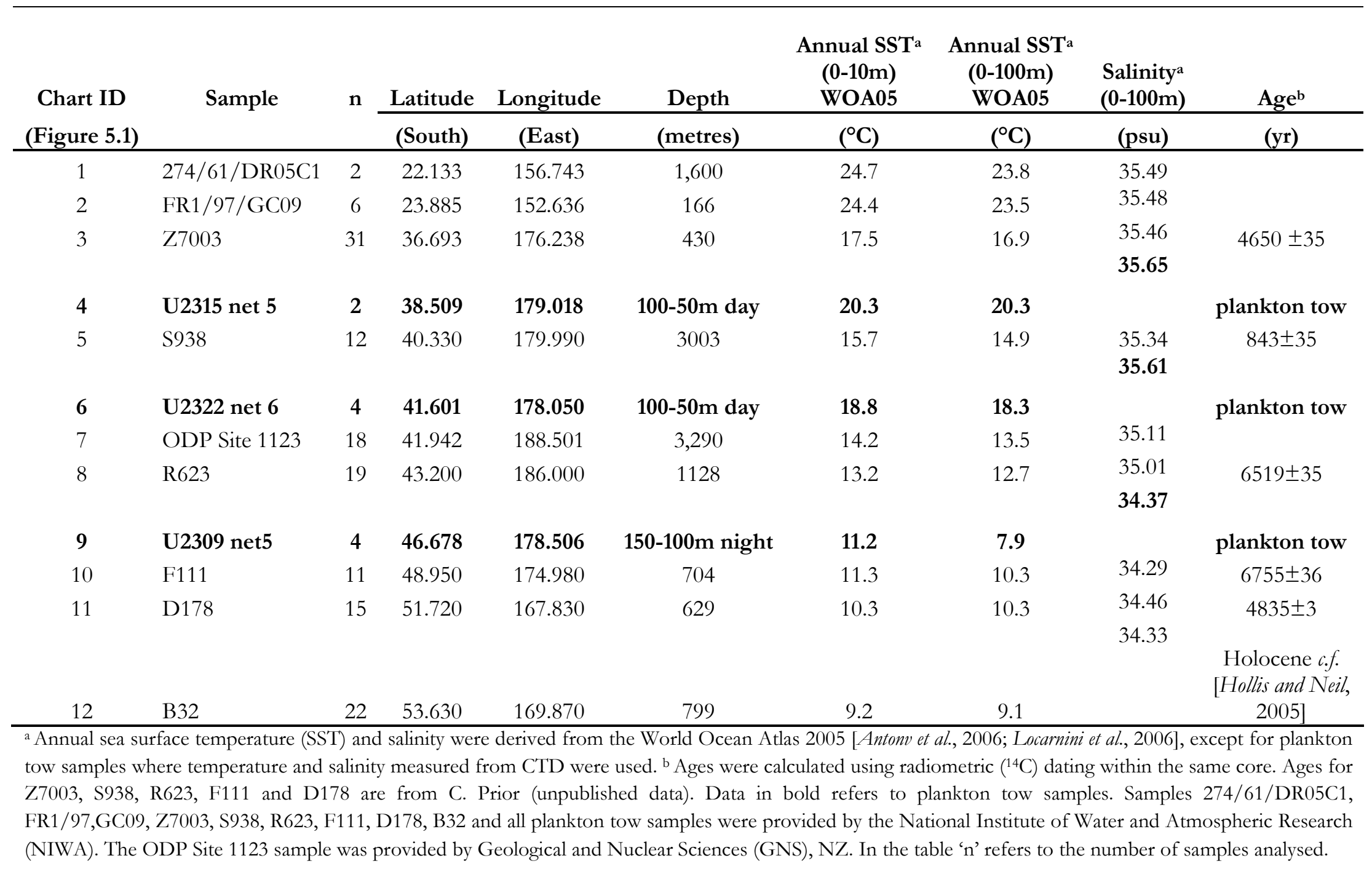



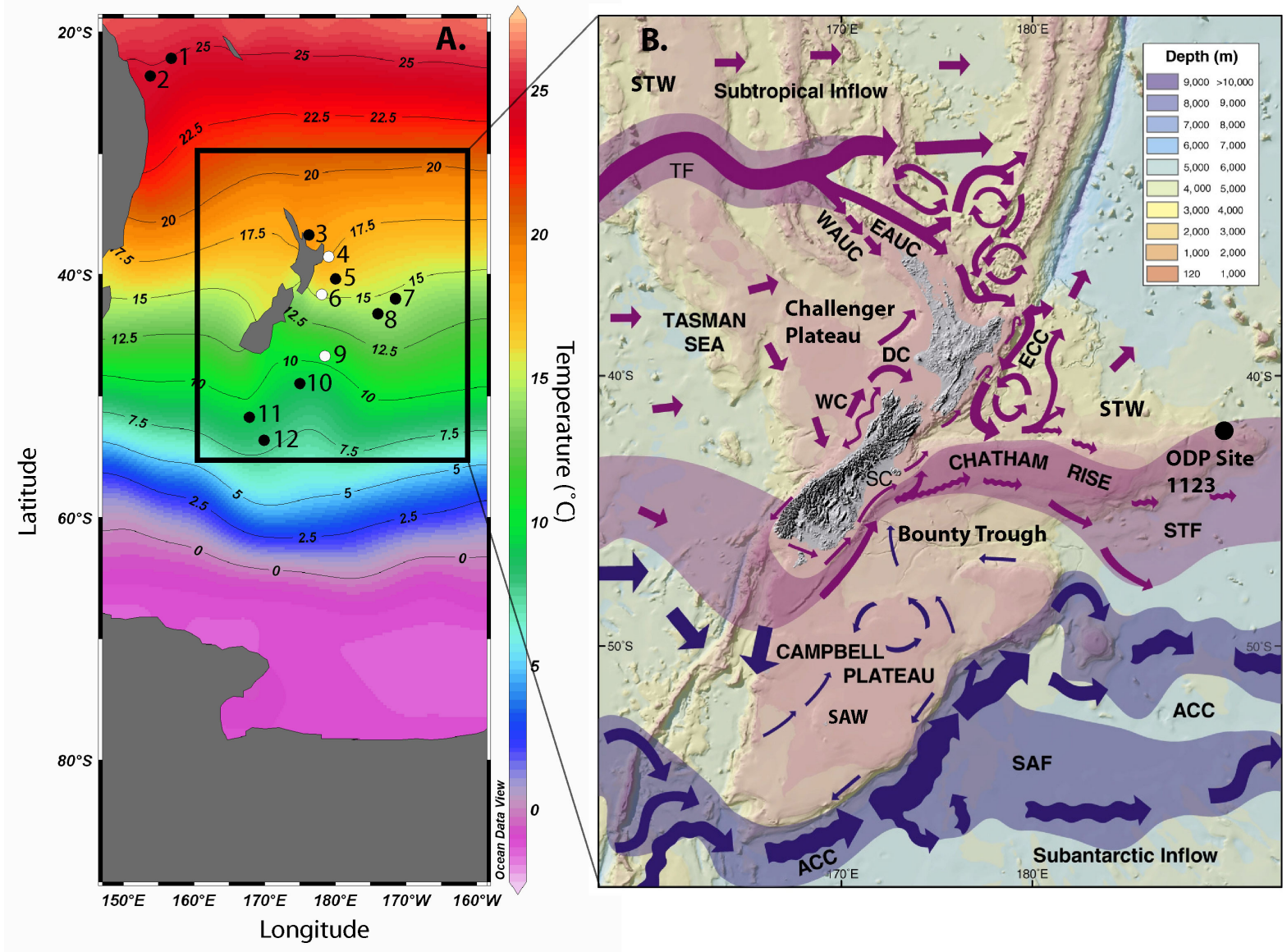

Figure 4.1: (A) Location chart of the core-top (black circles) and plankton tow (white circles) samples from the Southwest Pacific Ocean including annual SST [Locarnini et al., 2006]. The inset (B) shows the surface ocean currents of New Zealand and surrounding regions. Blue arrows indicate the cold, fresher Subantarctic Front (SAF) within the Antarctic Circumpolar Current (ACC), whilst the purple arrows show warmer, saltier subtropical water that is brought to the west of New Zealand from the East Australian Current (EAC) and the Tasman Front (TF), which branches into the East (EAUC) and West Auckland Current (WAUC). The Subtropical Front (STF) forms part of the South Pacific subtropical gyre that moves warm water in a counter-clockwise direction down the east coast of Australia. West of New Zealand, the westerly winds force warm water via the Westland Current (WC) and Southland Current. Some of the former flow moves through Cook Strait as the D’Urville Current (DC). The Southland Current reaches the south of New Zealand and is diverted by Chatham Rise to the east. Figure taken and modified after Carter et al., [1998a]. 


\subsection{Methods}

\subsubsection{Sample Preparation}

Approximately 10-35 N. incompta and Neogloboquadrina pacby-dutertrei (P-D intergrades) were randomly picked from samples. P-D intergrades were chosen as they have been shown to occupy similar ecological niches to N. incompta [Ehrenberg, 1861; Sautter, 1998; Von Langen et al., 2005], implying there is no need to separate them for palaeo-oceanographic studies. Size was limited to the 150-350 $\mu \mathrm{m}$ range because individuals $>350 \mu \mathrm{m}$ are more likely to be $N$. dutertrei [Sautter, 1998]. Each sample was cleaned according to the method outlined in Bolton et al. [2011] with the exception of plankton tows which were cleaned following the procedure in Barker et al., [2003]. The cleaning method for the plankton tows was modified (compared to Chapter 3) due to the presence of much larger amounts of organic material on the tests compared to Gs. ruber plankton material. Large amounts of organic material can contaminate $\mathrm{Mg} / \mathrm{Ca}$ measurements [e.g. Hastings et al., 1996; Barker et al., 2003]. Following the cleaning procedures, individual foraminifera were weighed. All individuals were then mounted onto a glass plate using gum tragacanth and a dry brush.

\subsubsection{Trace element analysis by LA-ICP-MS}

The in situ LA-ICP-MS technique was used so that potential differences within and between individual chambers of each foraminiferal test could be examined. The individual chambers F3 (representing the oldest, thickest visible chamber) and the ultimate or final chamber $\mathrm{F}$ were analysed from each individual.

Each test was ablated from the outside to the inside with a pulsed ArF Excimer laser $(\lambda=193$ $\mathrm{nm}$ ) using a laser beam spot size of $25 \mu \mathrm{m}$. During ablation, the isotopes ${ }^{24} \mathrm{Mg},{ }^{27} \mathrm{Al},{ }^{43} \mathrm{Ca},{ }^{55} \mathrm{Mn}$ ${ }^{88} \mathrm{Sr}$ and $\mathrm{Ba}^{138}$ were measured using an Agilent $7500 \mathrm{CS}$ ICP-MS at The Australian National University (ANU) that was coupled to the laser ablation system.

Each analysis took a maximum of $120 \mathrm{~s}$ to ablate through the chamber walls. Measurements were standardised using interspersed analyses of the glass standard NIST SRM 610, with reference to its known elemental composition [Pearce et al., 1996]. The resulting raw data were processed using MATLAB-developed software which allowed for initial screening of outliers, background correction (washout of $60 \mathrm{~s}$, followed by counts with laser off for $60 \mathrm{~s}$ ), and Ca- 
corrected internal standardisation. Duplicate measurements on sub-samples of individual tests were made to check reproducibility of individual chamber analyses. From these measurements the two standard deviation (2 S.D.) for each element/Ca ratio were: $0.35 \mathrm{mmol} / \mathrm{mol}$ for $\mathrm{Mg} / \mathrm{Ca} ; 0.27 \mathrm{mmol} / \mathrm{mol}$ for $\mathrm{Al} / \mathrm{Ca} ; 0.008 \mathrm{mmol} / \mathrm{mol}$ for $\mathrm{Mn} / \mathrm{Ca} ; 0.08 \mathrm{mmol} / \mathrm{mol}$ for $\mathrm{Sr} / \mathrm{Ca}$; and $0.004 \mathrm{mmol} / \mathrm{mol}$ for Ba/Ca. Following analysis, data were screened for clay contamination using the methods described in Bolton et al. [2011]. Approximately 18\% of analyses with high $\mathrm{Al} / \mathrm{Ca}$ and $\mathrm{Mn} / \mathrm{Ca}$ were eliminated on the basis of this screening.

\subsubsection{Electron Microscopy}

Following LA-ICP-MS trace element analysis each test was imaged by a JEOL JSM-5300LV scanning electron microscope (SEM) under both secondary electron imaging and backscatter electron imaging. These images were used to determine test ultra-structure and identify morphotypes.

To further investigate the distribution of $\mathrm{Mg}, \mathrm{Mn}$ and $\mathrm{Al}$ within the test wall, three individuals were also analysed in cross-section by electron microprobe imaging (EMP). These samples were embedded in epoxy resin, vacuum sealed to evacuate air bubbles from the inside of the tests, and then transferred to a hot plate at $40^{\circ} \mathrm{C}$ for $12 \mathrm{hr}$ to set. Each epoxy mount was thin sectioned, then lapped and polished to reveal cross sections of the test wall. $\mathrm{Mg}$, $\mathrm{Mn}$ and $\mathrm{Al} / \mathrm{Ca} \mathrm{X}$-ray raw intensity maps were generated on a JEOL JXA-8230 Super Probe using an accelerating voltage of $15 \mathrm{kV}$, a beam current of $20 \mathrm{nA}$, a pixel size of $1 \mu \mathrm{m}$ and dwell time of 1000 ms. All available elements (Mg, Mn, Al and Ca) were measured by energy dispersive Xray spectrometers, and these elements were also measured with wavelength dispersive spectrometers. Ca intensities below 10,000 cps were at background level, $\mathrm{Al}>100$ and $\mathrm{Mg}$ or $\mathrm{Mn}>70$ were used to exclude 'hotspots' to maximise the range. Using this threshold removes background X-ray levels that helps to delineate and remove "edge effects" associated with EMP analysis that are produced as a result of the excitation volume of $\mathrm{Mg}$ being larger than $\mathrm{Ca}$ in calcite that can produce artificially high $\mathrm{Mg} / \mathrm{Ca}$ values [Pena et al., 2008; Sadekov et al., 2005]. Element/Ca intensity maps were computed from matrix calculations, which were then converted from cps/cps to $\mathrm{mmol} / \mathrm{mol}$ ratios by calibration with LA-ICP-MS trace element data from the central part of the wall profile from the same chamber. This intensity measured 
in the middle of a test wall was used in the element/Ca cps maps with the concentration of what was assumed to be the same part of the test wall from the LA-ICP-MS data.

\subsection{Results}

\subsubsection{Morphological variation in N. incompta}

SEM images of the outer surface of tests confirm two types of ultra-structure - reticulate and crystalline c.f. Bandy [1972] - were present in the samples (Figure 4.2). Some individuals appeared to have an intermediate structure, particularly some plankton tow individuals and were subsequently classed as crystalline if pore pits were not visible. Both ultra-structures are present at all sites, except those from the two most northerly sites which were solely reticulate. SEM microscope cross-sections of N. incompta in Figure 4.2 show two easily distinguishable layers of calcite i.e., inner ontogenetic calcite and the outer 'gametogenic crust'. This is further illustrated in Figure 4.2F, where sub-micron scale internal banding within the ontogenetic layer can also be distinguished, whereas the crystalline structure is more apparent in SEM images of the outer surface.

Specimens consisting of less than 4 , or more than 5 , chambers visible in umbilical view were extremely rare and the distinction between specimens with 4.5 to 5 chambers and those with 4 was considered arbitrary, consistent with Kennett [1968]. Other morphological differences observed for $N$. incompta include forms that were more quadrate, with an apertural lip (although this was often obscured in some crystalline forms) (see Figure 4.3). Another distinct form observed was more lobular, with increasing chamber sizes, often with a larger ultimate chamber in the final whorl (Figure 4.3). This latter form is commonly referred to as a normal form. A kummerform individual on the other hand refers to a specimen in which the final chamber is smaller than the previously secreted chambers but similar in shape [Bijma and Hemleben, 1994]. For further analyses, these two ultra-structures (reticulate and crystalline) were separated in order to examine the potential inter-individual variability. 

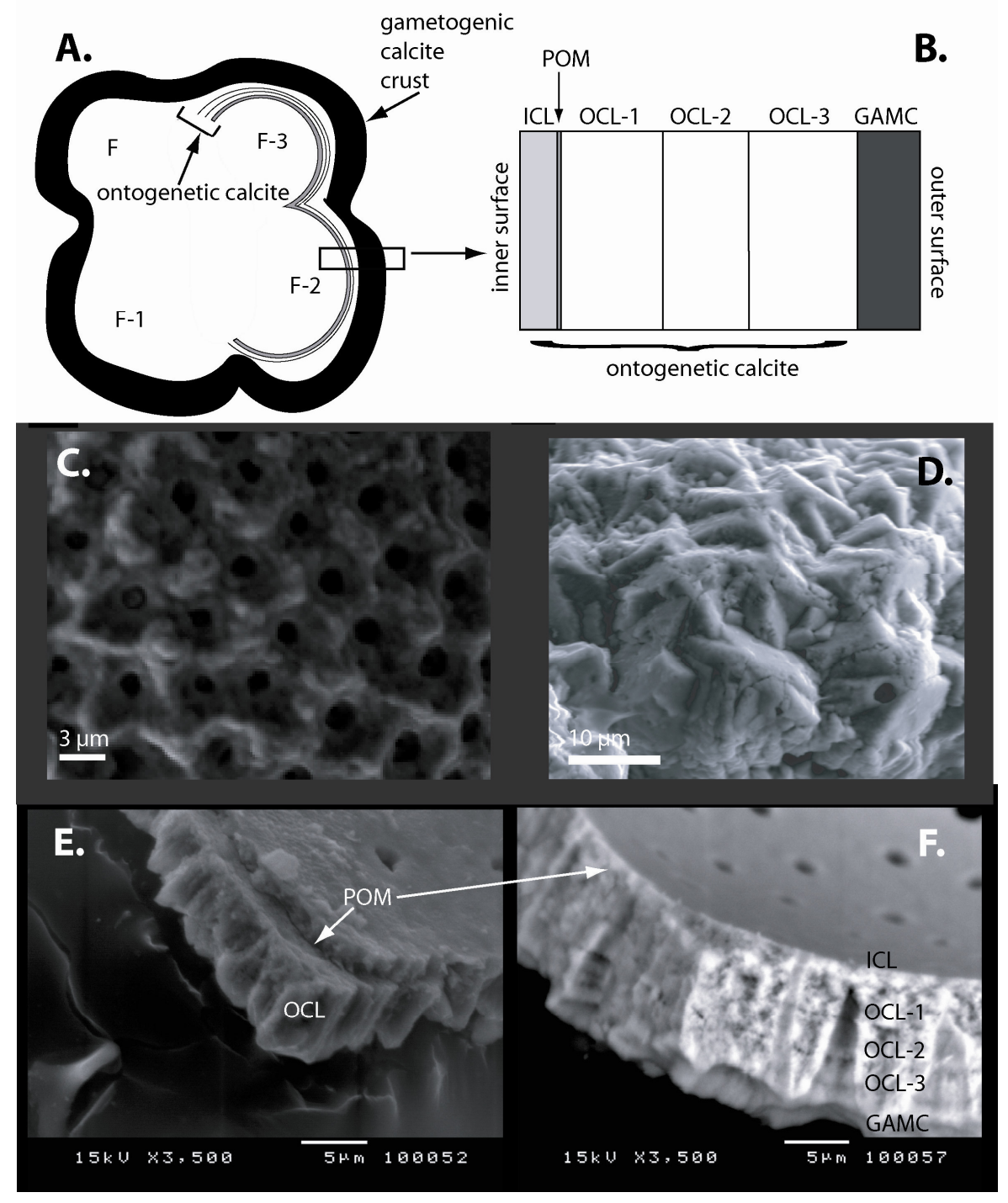

Figure 4.2: (A) Illustration adapted from Sadekov et al. [2005] and Reiss [1958] showing a cross-section of an N. incompta test and chamber wall construction. F-3, F-2, F-1 and F refer to position of the chamber in the final whorl, where $\mathrm{F}$ is the final or ultimate chamber. (B) Cross-section of an N. incompta test showing lamellar wall features. ICL = inner calcite layer; $\mathrm{POM}=$ primary organic membrane; $\mathrm{OCL}=$ outer calcite layer; $\mathrm{GAMC}=$ gametogenic calcite. N.B. As whole tests were broken, it was not possible to differentiate between specific chambers. (C) Example of reticulate ultra-structure on the surface of N. incompta (site F111). (D) Example of crystalline ultra-structure on the surface of N. incompta (site B32). (E) Crystalline fragment showing what is two distinct layers of calcite, an inner and outer calcite layer (Site S938). (F) A crystalline fragment with some visible layers present, possibly from an older chamber (Site S938). Secondary electron imaging mode was used for images $\mathrm{C}, \mathrm{D}$ and $\mathrm{E}$ and backscatter electron imaging mode was used for image $\mathrm{F}$. 


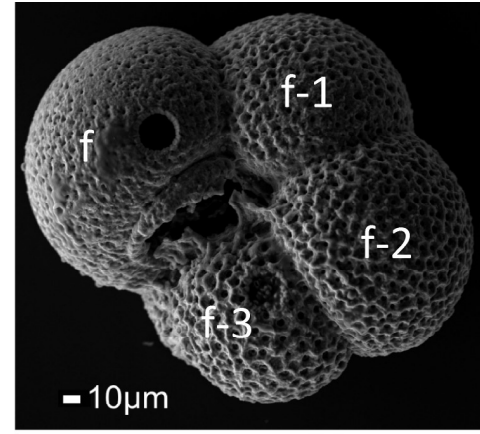

A

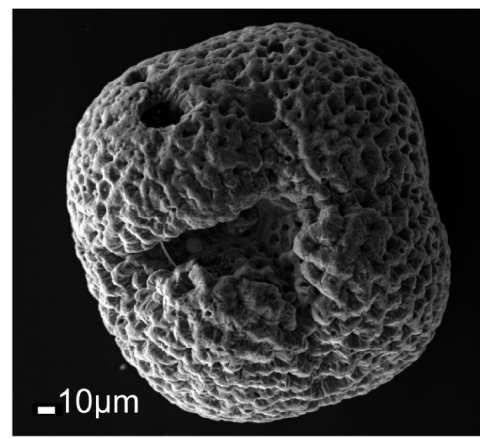

D

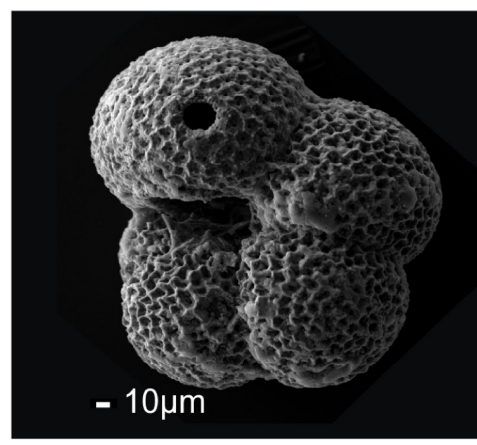

G

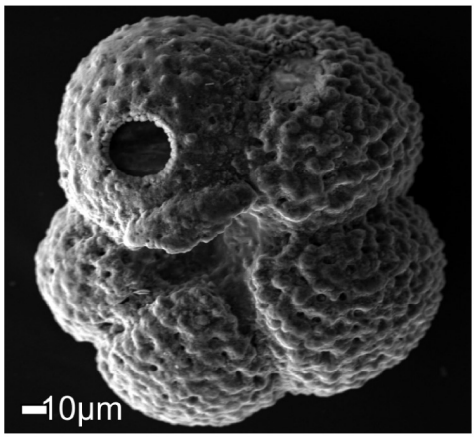

$J$

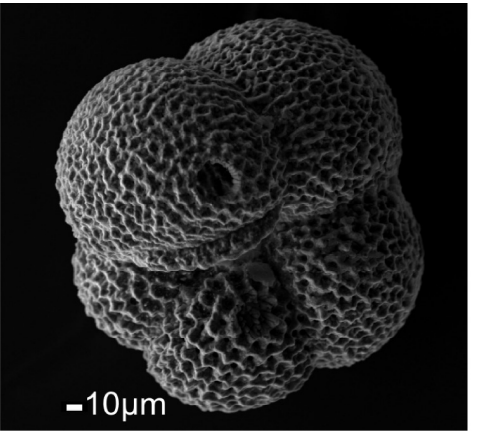

B

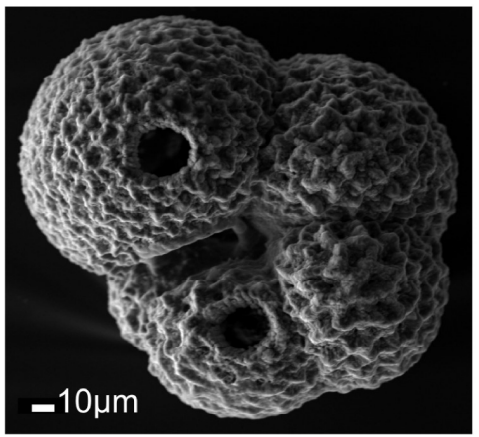

E

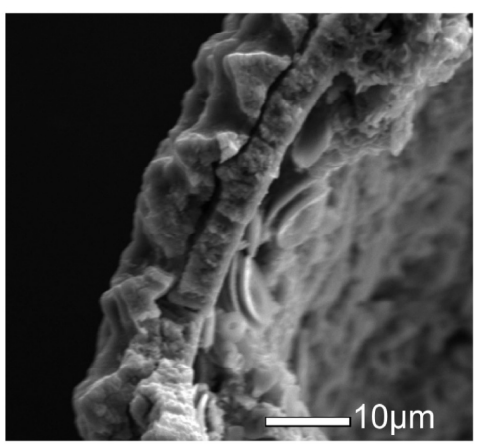

$\mathrm{H}$

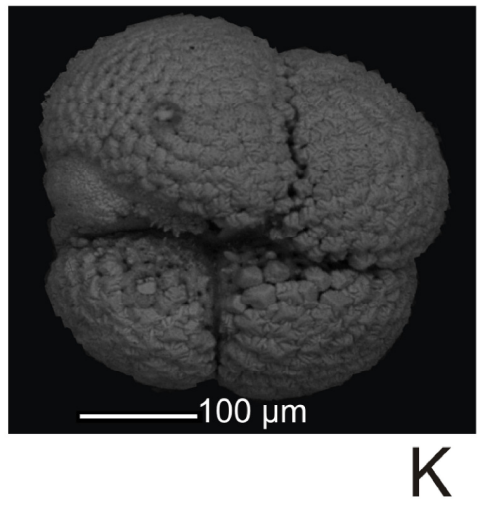

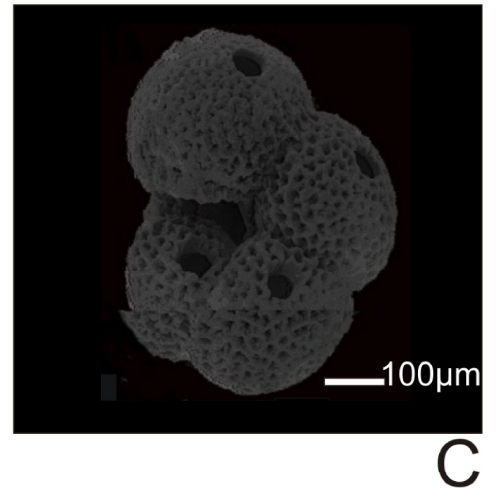

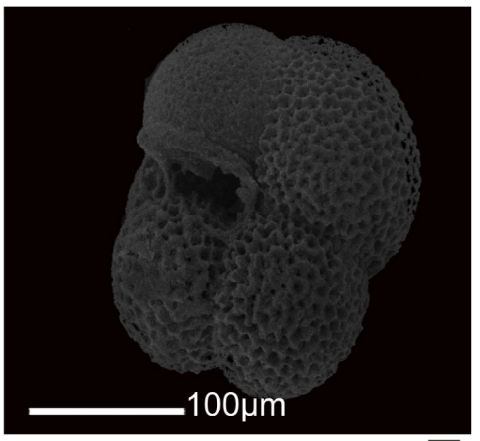

$\mathrm{F}$

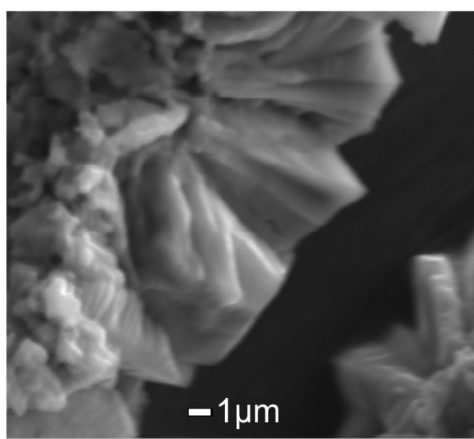

$-1 \mu \mathrm{m}$

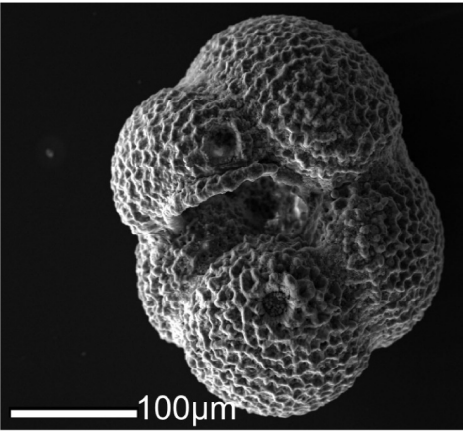

$\mathrm{L}$ 
Figure 4.3: Morphotypes and ultra-structures of N. incompta from this study. (A) P-D intergrade reticulate morphotype from plankton tow TAN0103 U2309 net 5. Note this morphotype is quadrate with a larger final chamber (F) and apertural rim. This is less calcified than crystalline surfaces in images D-E. Chamber formation is shown for reference where $\mathrm{f}$ is the ultimate chamber and F-1, is the penultimate chamber etc. (B) N. incompta reticulate morphotype from core top B32. Note this morphotype has another half chamber in between chambers F-3 and F and is more lobate (C) N. incompta collected by plankton tow sample U2315 showing reticulate surface with calcite ridges surrounding individual pore pits. This surface varies between individuals but in all cases pore pit remain visible. (D) N. incompta crystalline morphotype from core top B32. Note the quadrate and more compact form with all chambers having similar sizes. (E) N. incompta crystalline form from core top B32. This morphotype is quadrate with a larger final chamber, and less than 4.5 chambers in the final whorl. (F) Textural detail of a crystalline surface in individual from core top B32, chamber F-3, where euhedral crystals are visible. (G) N. incompta from plankton tow TAN0103 U2309 net 5. This is a reticulate form showing less calcification than crystalline form. (H) Test section of chamber F-1 in crystalline N. incompta from core top B32 showing thicker outer wall and thin septum. Note the presence of nanno-fossil material on the inner wall. (I) Test section of chamber $\mathrm{F}$ in crystalline $N$. incompta from core top ODP Site 1123 showing calcite rhombohedrons. (J) Crystalline lobulate PD-intergrade from core top B32. (K) Crystalline N. incompta from tropical site 271/61/DR05C1. (L) Reticulate PD-intergrade from core top D178, with a kummerform ultimate chamber.

\subsubsection{Weight variation between reticulate and crystalline forms of N. incompta}

Mean weights from each site were normalised using the mean width of individual N. incompta measurements as per Chapter 3, section 3.8.3. The deepest sites (ODP Site 1123 and S938) share similar mean weights with samples from shallower sites and did not correlate with depth suggesting that carbonate ion concentration and associated partial dissolution is not significantly altering the test weights. The difference in size-normalised weight between the two ultra-structures within the same sites, show that crystalline forms were slightly heavier than

the reticulate forms except at site D178 (Figure 4.4). These differences in weight were not statistically significant (t-test, $\mathrm{p}>0.05)$. 

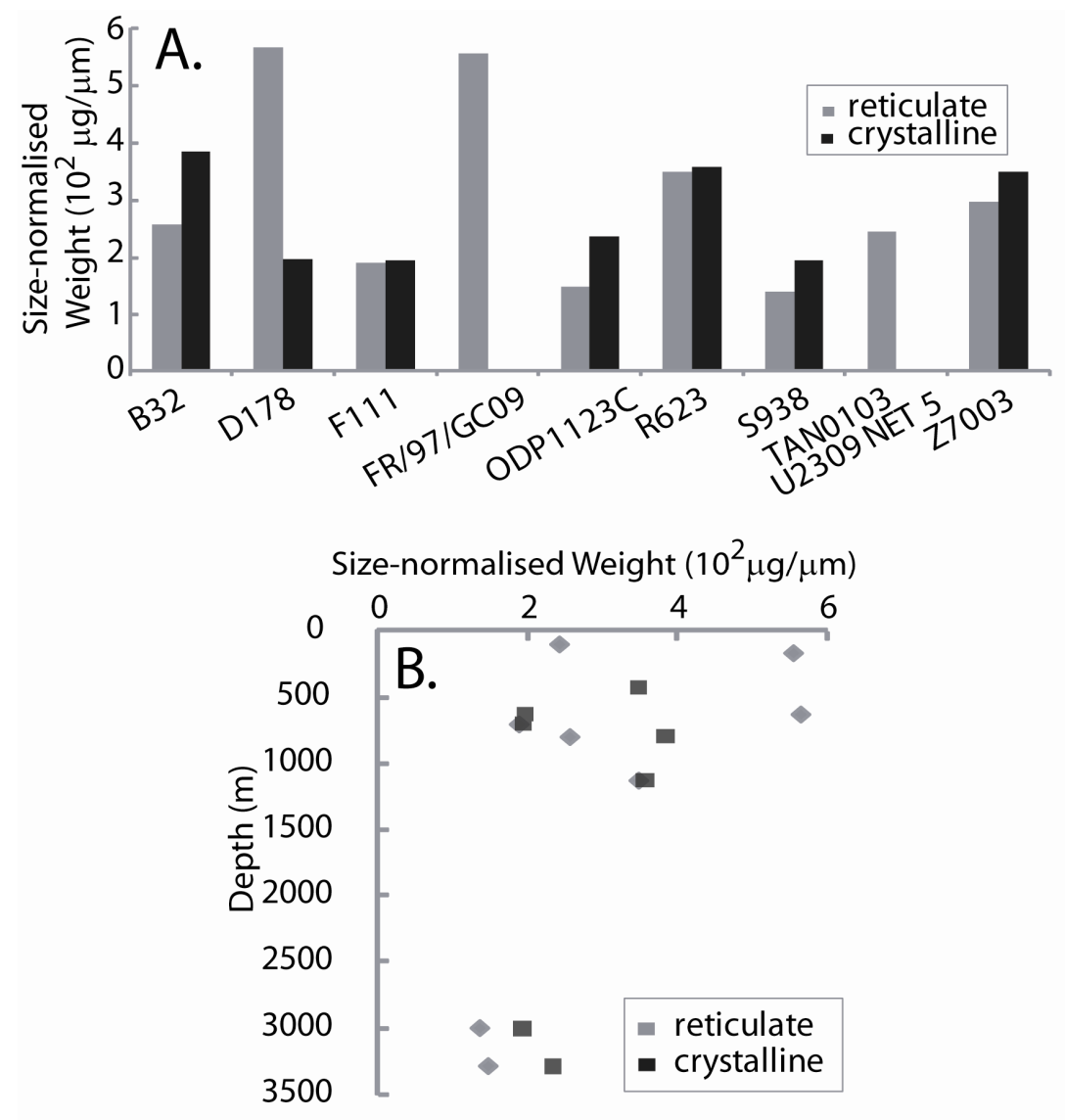

Figure 4.4: (A) Reticulate and crystalline mean test weight from each site. (B) Reticulate and crystalline mean test weight versus depth.

\subsubsection{Trace element depth profiles of N. incompta test}

Previous laser ablation studies of foraminifera have identified an elevated TE/Ca veneer on the surface of tests in other planktonic species [Eggins et al., 2003; Sadekov et al., 2009; Bolton et al., 2011]. This TE-enriched veneer is also present on N. incompta tests, including plankton tow samples and irrespective of test ultra-structure type (Figure 4.5). In Figure 4.5 these elevated TE/Ca veneers were subsequently excluded from the selected profile (dotted box) for calculating the average TE/Ca composition of chambers. Monitoring the TE/Ca depth profiles to screen for potentially contaminated samples (as indicated by co-varying $\mathrm{Mg}$ and $\mathrm{Al}$ or $\mathrm{Mn}$ ) was also combined by detecting the rapid decrease in the raw counts of $\mathrm{Ca}$ when the inner wall of the test had been breached by the laser. Following screening, the remaining mean $\mathrm{Al} / \mathrm{Ca}$ and $\mathrm{Mn} / \mathrm{Ca}$ at all sites was low $(\leq 0.28$ and $\leq 0.0281 \mathrm{mmol} / \mathrm{mol}$, respectively), 
suggesting that samples were not contaminated by clay minerals or diagenetic coatings such as Fe-Mn oxyhydroxides [Boyle, 1983].

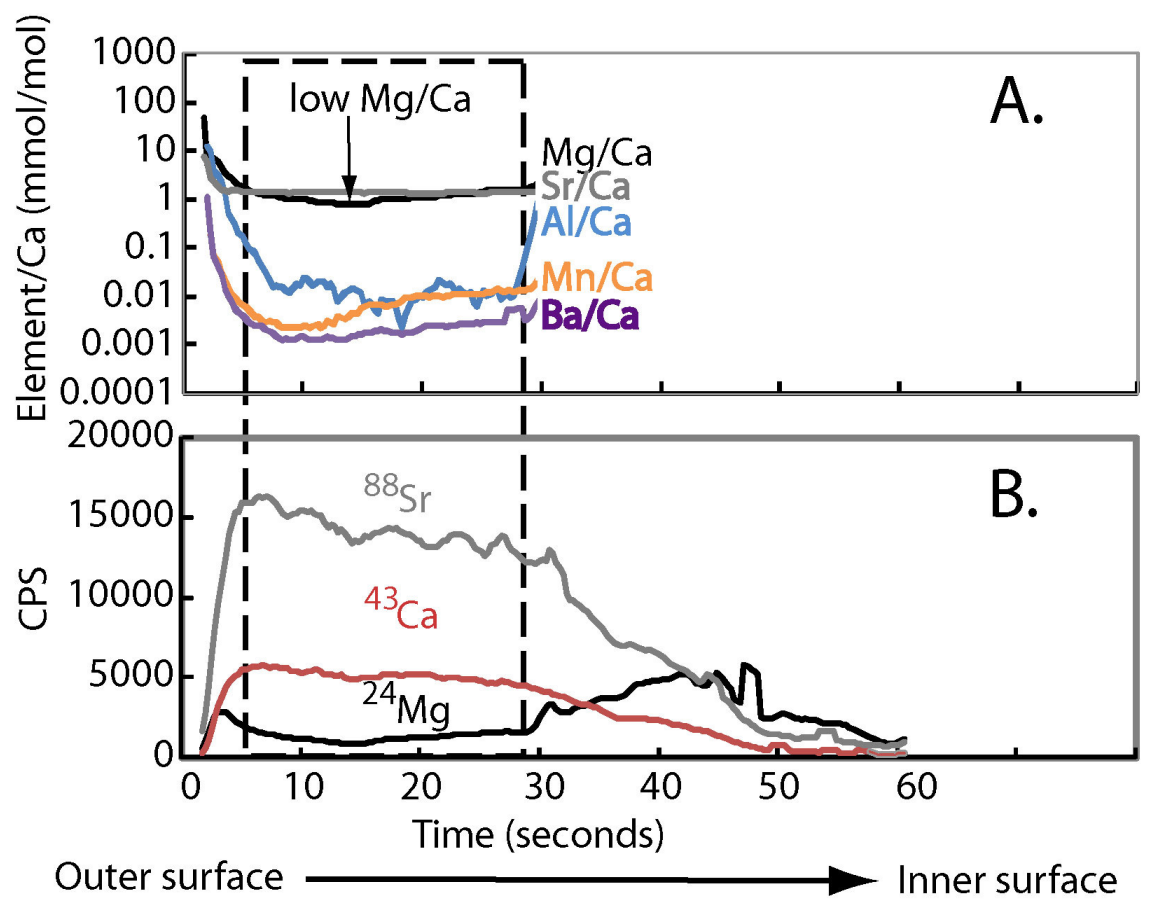

Figure 4.5: (A) LA-ICP-MS depth profile for crystalline N. incompta (chamber F). (B) Shows the raw counts per second (CPS) during the laser ablation profiles for $\mathrm{Ca}, \mathrm{Mg}$ and $\mathrm{Sr}$.

Three typical laser ablation TE/Ca depth profiles in Figure 4.6 show differences in $\mathrm{Mg} / \mathrm{Ca}$ between reticulate and crystalline tests measured in both ( $\mathrm{F}$ and F-3) chambers. The crystalline test (Figure 4.6A), exhibits a lower $\mathrm{Mg} / \mathrm{Ca}$ immediately after the elevated TE/Ca surface veneer and increases in $\mathrm{Mg} / \mathrm{Ca}$ towards the inner profile of the test. These changes between low and high $\mathrm{Mg} / \mathrm{Ca}$ are highly variable between individuals and are apparent from the variable length of the low $\mathrm{Mg} / \mathrm{Ca}$ region from each individual depth profile. In some individuals, there were low and high 'bands' of $\mathrm{Mg} / \mathrm{Ca}$ such as those observed in the reticulate sample shown in Figure 4.6B. Some reticulate individuals also show relatively homogeneous $\mathrm{Mg} / \mathrm{Ca}$ throughout the entire depth profiles (Figure 4.6C), although the initial low $\mathrm{Mg} / \mathrm{Ca}$ could be related to the ablation of surface features such as pore pits. It was also observed that ablation time was longer in crystalline tests compared to the reticulate tests. This suggests that the crystalline test structure were either thicker or of denser structure to the reticulate tests. 
In contrast, where $\mathrm{Mg} / \mathrm{Ca}$ is lower in the crystalline tests (Table 4.3), $\mathrm{Sr} / \mathrm{Ca}$ does not exhibit this pattern and remains relatively homogeneous throughout the entire depth profile (not shown). Both reticulate and crystalline tests of $N$. incompta share similar Sr/Ca with the highest value from one plankton tow (Table 4.4). However, these high values were not coupled with high ratios of other trace elements (Supplementary Table 4.5). It is noteworthy that t-tests did not reveal any statistically significant differences $(\mathrm{P}=0.05)$ in $\mathrm{Sr} / \mathrm{Ca}$ reticulate and crystalline tests from chambers F-3 or F.

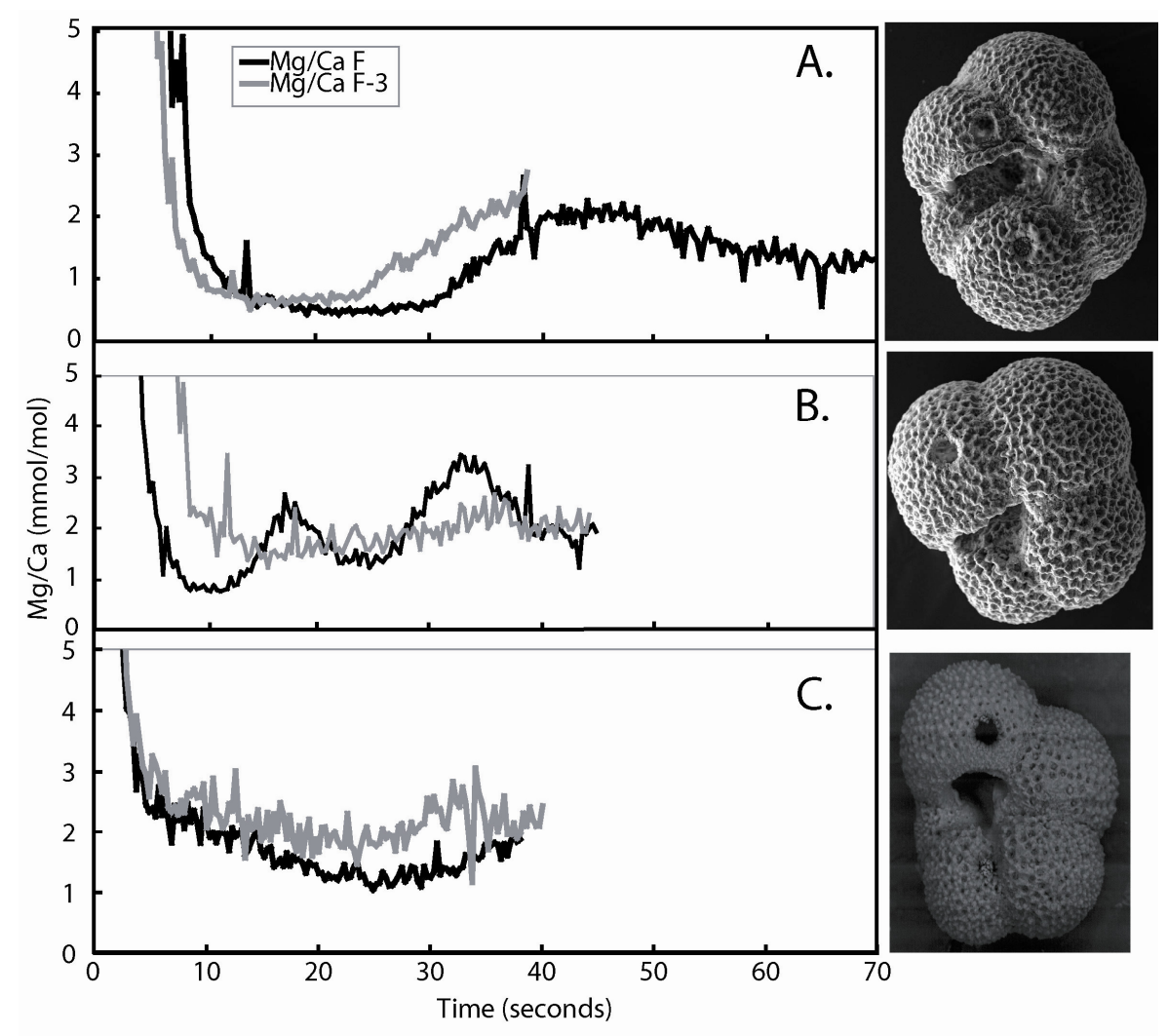

Figure 4.6: (A) $\mathrm{Mg} / \mathrm{Ca}$ for chambers $\mathrm{F}$ and $\mathrm{F}-3$ in a crystalline sample. (B) $\mathrm{Mg} / \mathrm{Ca}$ for chambers $\mathrm{F}$ and $\mathrm{F}-3$ in a reticulate sample. (C) $\mathrm{Mg} / \mathrm{Ca}$ for chambers $\mathrm{F}$ and F-3 in a reticulate sample. Note no log scale.

\subsubsection{Intra-test $\mathrm{Mg} /$ Ca variability}

Initial analysis of chambers F-4 to F in individual reticulate N. incompta from a single core-top (R623) did not reveal any discernable inter-specific differences in $\mathrm{Mg} / \mathrm{Ca}$ ratios, in contrast to those observed earlier in Gs. ruber and other planktonic foraminifera [Marr et al., 2011] (Figure 
4.7). Therefore the oldest chamber (F-3) and the youngest chamber (F) were analysed in the remaining samples.

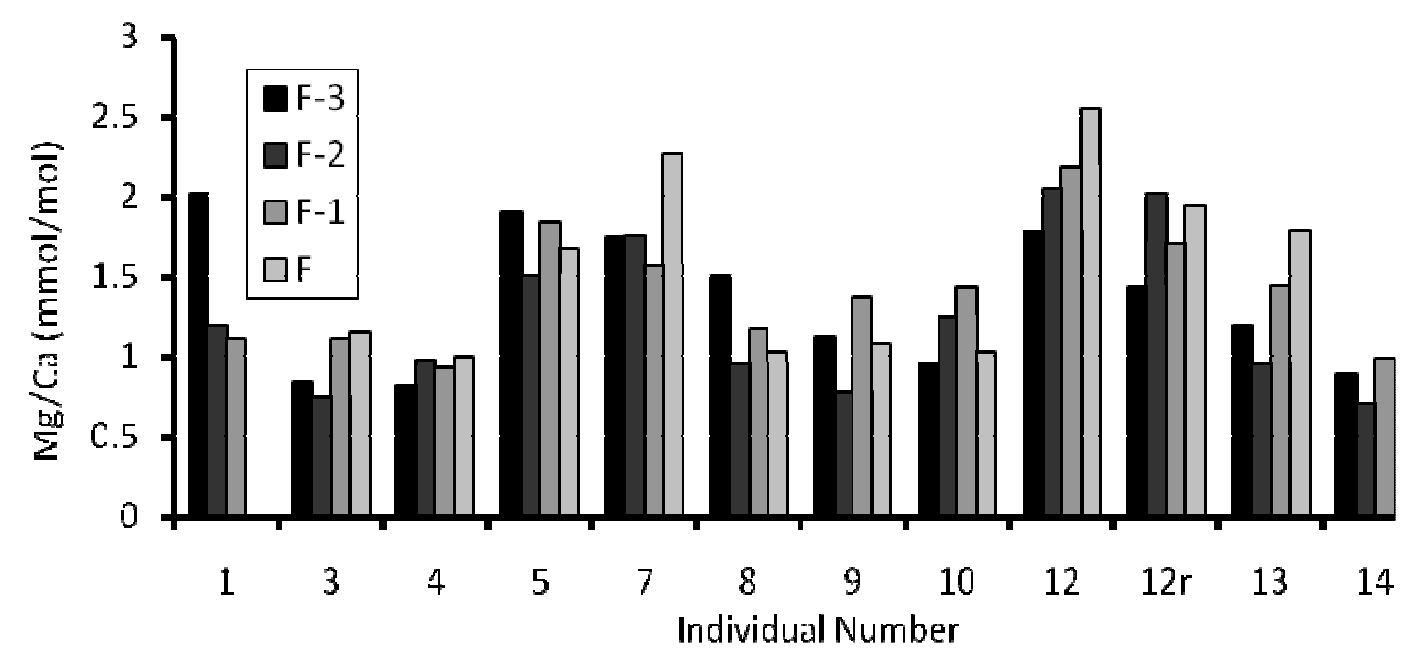

Figure 4.7: $\mathrm{Mg} / \mathrm{Ca}$ from individual chambers of $\mathrm{N}$. incompta from core top site R623.

Additionally, those smaller individuals identified as kummerform (where the ultimate chamber F was smaller or the same size as the penultimate chamber), do not show any significant difference in $\mathrm{Mg} / \mathrm{Ca}$ (Figure 4.8). Some studies have suggested that kummerform chambers are grown in abnormal conditions [Bijma et al., 1990b] but because this was not clearly evident from the $\mathrm{Mg} / \mathrm{Ca}$ ratios measured in this study kummerform chambers were pooled with analyses of the normal morphotypes of $N$. incompta from each site. 

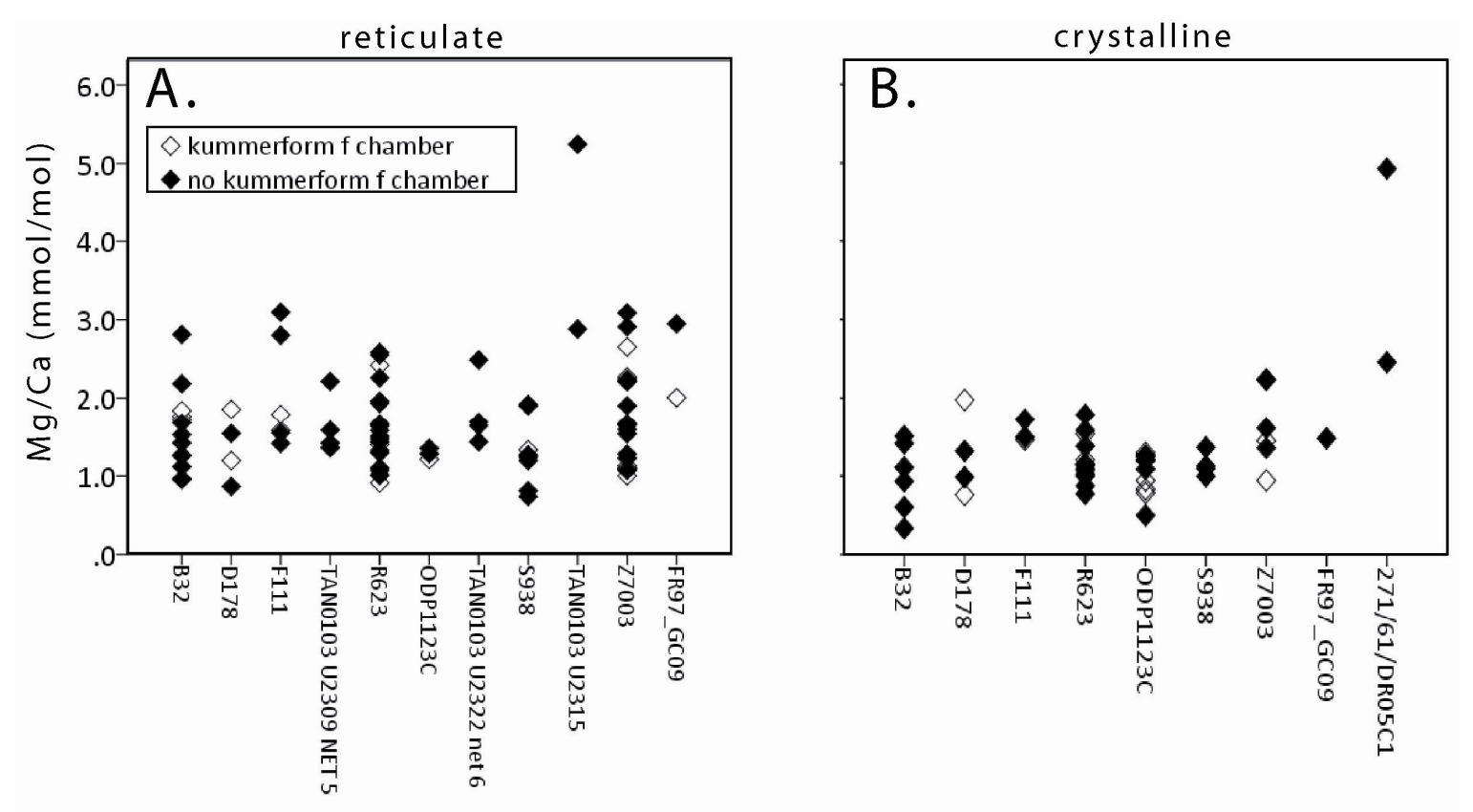

Figure 4.8: (A) Comparison of $\mathrm{Mg} / \mathrm{Ca}$ ratios in the final (F) chamber of in kummerform and normal-forms of reticulate and (B) in crystalline N. incompta.

For all sites, the pooled mean $\mathrm{Mg} / \mathrm{Ca}$ for both $\mathrm{F}-3$ and $\mathrm{F}$ in reticulate forms is higher when compared to inner part of the calcite from the crystalline tests (as determined by the LA-ICPMS where the $\mathrm{Mg} / \mathrm{Ca}$ ratios are higher) except at site S938 (Table 4.4). However, in many cases this difference was marginal, with the largest difference being at site F111 (0.48 $\mathrm{mmol} / \mathrm{mol}$ ). Reticulate forms show variability between individual chambers in some of the sites, whereas other chambers share similar $\mathrm{Mg} / \mathrm{Ca}$ ratios. The variability in the $\mathrm{Mg} / \mathrm{Ca}$ ratios of the ontogenetic calcite is similar but not as clear as that observed in Gs. ruber. While the surface dwelling planktonic foraminifera Gs. ruber was found to have a significantly lower $\mathrm{Mg} / \mathrm{Ca}$ in the final chamber $(\mathrm{F})$ as compared to its other visible chambers, this characteristic is not apparent in $N$. incompta. There is a general decrease in $\mathrm{Mg} / \mathrm{Ca}$ with increasing latitude with divergence from this trend at $38^{\circ} \mathrm{S}, 43^{\circ} \mathrm{S}$ (just north of the Subtropical Front [STF]) and $49^{\circ} \mathrm{S}$ (close to the northern boundary of the Subantarctic front $[\mathrm{SAF}]$ ). 
Table 4.3: Summary of $\mathrm{Mg} / \mathrm{Ca}$ ratios for $\mathrm{N}$. incompta chambers F-3 and F at all study sites. Samples are ordered from high to low SST. PT = plankton tow.

\begin{tabular}{|c|c|c|c|c|c|c|c|}
\hline \multirow[b]{4}{*}{ Site } & & \multirow{2}{*}{\multicolumn{2}{|c|}{ Reticulate }} & \multicolumn{4}{|c|}{ Crystalline } \\
\hline & & & & \multirow{2}{*}{\multicolumn{2}{|c|}{$\begin{array}{c}\text { Ontogenetic } \\
\text { Chamber }\end{array}$}} & \multicolumn{2}{|c|}{ Gametogenic } \\
\hline & & \multicolumn{2}{|c|}{ Chamber } & & & \multicolumn{2}{|c|}{ Chamber } \\
\hline & & $\mathrm{F}-3 \mathrm{Mg} / \mathrm{Ca}$ & $\mathrm{FMg} / \mathrm{Ca}$ & $\mathrm{F}-3 \mathrm{Mg} / \mathrm{Ca}$ & $\mathrm{FMg} / \mathrm{Ca}$ & $\mathrm{F}-3 \mathrm{Mg} / \mathrm{Ca}$ & $\mathrm{FMg} / \mathrm{Ca}$ \\
\hline \multirow[t]{5}{*}{$271 / 61 /$ DR05C1 } & Mean & & & 1.92 & 3.69 & 0.72 & 0.72 \\
\hline & Minimum & & & 1.92 & 2.46 & 0.72 & 0.72 \\
\hline & Maximum & & & 1.92 & 4.93 & . & 0.72 \\
\hline & S.D. & & & . & 1.75 & & - \\
\hline & $\mathrm{n}$ & & & 1 & 2 & 1 & 1 \\
\hline \multirow[t]{5}{*}{ FR09/GC12 } & Mean & 1.16 & 2.48 & & 1.48 & & \\
\hline & Minimum & 0.81 & 2.01 & & 1.48 & & \\
\hline & Maximum & 1.42 & 2.95 & & 1.48 & & \\
\hline & S.D. & 0.31 & 0.67 & & . & & \\
\hline & $\mathrm{n}$ & 3 & 2 & & 1 & & \\
\hline \multirow[t]{5}{*}{ Z7003 } & Mean & 1.76 & 1.74 & & 1.7 & & 1.14 \\
\hline & Minimum & 0.74 & 1 & & 1.2 & & 0.69 \\
\hline & Maximum & 2.72 & 3.09 & & 2.5 & & 1.97 \\
\hline & S.D. & 0.58 & 0.64 & & 0.6 & & 0.56 \\
\hline & $n$ & 12 & 21 & & 4 & & 5 \\
\hline \multirow[t]{5}{*}{ U2315 } & Mean & 1.59 & 4.06 & & & & \\
\hline & Minimum & 1.47 & 2.88 & & & & \\
\hline & Maximum & 1.71 & 5.25 & & & & \\
\hline & S.D. & 0.17 & 1.67 & & & & \\
\hline & $n$ & 2 & 2 & & & & \\
\hline \multirow[t]{5}{*}{ S938 } & Mean & 1.26 & 1.3 & 1.37 & 1.28 & 0.91 & 1.01 \\
\hline & Minimum & 0.69 & 0.74 & 1.33 & 1.17 & 0.91 & 0.82 \\
\hline & Maximum & 1.68 & 1.92 & 1.4 & 1.37 & 0.91 & 1.37 \\
\hline & S.D. & 0.37 & 0.43 & 0.05 & 0.08 & 0 & 0.24 \\
\hline & $\mathrm{n}$ & 6 & 8 & 2 & 4 & 2 & 4 \\
\hline \multirow[t]{5}{*}{ U2322 net 6} & Mean & 2.4 & 1.81 & & & & \\
\hline & Minimum & 1.37 & 1.44 & & & & \\
\hline & Maximum & 3.09 & 2.49 & & & & \\
\hline & S.D. & 0.73 & 0.46 & & & & \\
\hline & $n$ & 4 & 4 & & & & \\
\hline ODP1123 & Mean & 1.16 & 1.32 & 1 & 1.05 & 1.17 & 0.99 \\
\hline & Minimum & 0.92 & 1.28 & 0.82 & 0.5 & 0.54 & 0.5 \\
\hline & Maximum & 1.4 & 1.35 & 1.18 & 1.36 & 2 & 1.25 \\
\hline & S.D. & 0.34 & 0.05 & 0.25 & 0.29 & 0.61 & 0.27 \\
\hline & $n$ & 2 & 2 & 2 & 9 & 5 & 8 \\
\hline R623 & Mean & 1.56 & 1.61 & 1.16 & 1.53 & 0.86 & 1.01 \\
\hline & Minimum & 0.86 & 0.91 & 0.7 & 1.24 & 0.51 & 0.56 \\
\hline & Maximum & 2.02 & 2.58 & 1.48 & 2.05 & 1.57 & 1.79 \\
\hline & S.D. & 0.32 & 0.51 & 0.25 & 0.26 & 0.28 & 0.33 \\
\hline & $\mathrm{n}$ & 14 & 21 & 8 & 11 & 12 & 15 \\
\hline U2309 net 5 & Mean & 1.6 & 1.64 & & & & \\
\hline & Minimum & 1.33 & 1.36 & & & & \\
\hline & Maximum & 1.74 & 2.21 & & & & \\
\hline & S.D. & 0.19 & 0.39 & & & & \\
\hline & $n$ & 4 & 4 & & & & \\
\hline F111 & Mean & 2.35 & 2.04 & 1.87 & 1.91 & 1.57 & 1.21 \\
\hline & Minimum & 2.06 & 1.42 & 1.32 & 1.5 & 0.72 & 0.98 \\
\hline & Maximum & 2.84 & 3.1 & 2.42 & 2.46 & 2.42 & 1.5 \\
\hline & S.D. & 0.34 & 0.72 & 0.78 & 0.5 & 1.21 & 0.26 \\
\hline & $\mathrm{n}$ & 4 & 6 & 2 & 3 & 2 & 3 \\
\hline D178 & Mean & 1.79 & 1.37 & & 1.31 & 0.6 & 0.96 \\
\hline & Minimum & 1.3 & 0.87 & & 0.76 & 0.6 & 0.76 \\
\hline & Maximum & 2.39 & 1.86 & & 1.98 & 0.6 & 1.3 \\
\hline & S.D. & 0.41 & 0.43 & & 0.51 & . & 0.29 \\
\hline & $n$ & 5 & 4 & & 4 & 1 & 3 \\
\hline B32 & Mean & 1.73 & 1.58 & 1.66 & 1.46 & 0.9 & 0.7 \\
\hline & Minimum & 0.72 & 0.95 & 1.41 & 1.25 & 0.29 & 0.33 \\
\hline & Maximum & 2.86 & 2.81 & 1.79 & 1.81 & 1.93 & 1.02 \\
\hline & S.D. & 0.65 & 0.52 & 0.22 & 0.26 & 0.61 & 0.29 \\
\hline & $\mathrm{n}$ & 10 & 13 & 3 & 4 & 6 & 5 \\
\hline
\end{tabular}


Table 4.4: Individual Sr/Ca in chambers F-3 and F from reticulate and crystalline tests of N. incompta

\begin{tabular}{|c|c|c|c|c|c|}
\hline \multirow[b]{2}{*}{ Site } & & \multicolumn{2}{|c|}{ Reticulate } & \multicolumn{2}{|c|}{ Crystalline } \\
\hline & & $\mathrm{FSr} / \mathrm{Ca}$ & $\mathrm{F}-3 \mathrm{Sr} / \mathrm{Ca}$ & $\mathrm{FSr} / \mathrm{Ca}$ & $\mathrm{F}-3 \mathrm{Sr} / \mathrm{Ca}$ \\
\hline & & \multicolumn{4}{|c|}{$(\mathrm{mmol} / \mathrm{mol})(\mathrm{mmol} / \mathrm{mol})(\mathrm{mmol} / \mathrm{mol})(\mathrm{mmol} / \mathrm{mol})$} \\
\hline \multirow[t]{5}{*}{$271 / 61 / \mathrm{DR} 05 \mathrm{C} 1$} & Mean & & & 1.64 & 1.57 \\
\hline & Minimum & & & 1.64 & 1.57 \\
\hline & Maximum & & & 1.64 & 1.57 \\
\hline & S.D. & & & & \\
\hline & $\mathrm{n}$ & & & 1 & 1 \\
\hline \multirow[t]{5}{*}{ FR09/GC12 } & Mean & 1.35 & 1.39 & 1.37 & 1.48 \\
\hline & Minimum & 1.24 & 1.33 & 1.37 & 1.48 \\
\hline & Maximum & 1.56 & 1.45 & 1.37 & 1.48 \\
\hline & S.D. & 0.12 & 0.05 & & \\
\hline & $\mathrm{n}$ & 5 & 5 & 1 & 1 \\
\hline \multirow[t]{5}{*}{ Z7003 } & Mean & 1.45 & 1.41 & 1.43 & 1.38 \\
\hline & Minimum & 1.26 & 1.28 & 1.34 & 1.50 \\
\hline & Maximum & 1.73 & 1.62 & 1.54 & 0.05 \\
\hline & S.D. & 0.09 & 0.09 & 0.08 & \\
\hline & $\mathrm{n}$ & & & 7 & 6 \\
\hline \multirow[t]{5}{*}{ U2315 } & Mean & 1.55 & 1.40 & & \\
\hline & Minimum & 1.53 & 1.37 & & \\
\hline & Maximum & 1.58 & 1.42 & & \\
\hline & S.D. & 0.04 & 0.03 & & \\
\hline & $\mathrm{n}$ & 2 & 2 & & \\
\hline \multirow[t]{5}{*}{ S938 } & Mean & 1.56 & 1.51 & 1.54 & 1.51 \\
\hline & Minimum & 1.38 & 1.39 & 1.49 & 1.49 \\
\hline & Maximum & 1.70 & 1.70 & 1.58 & 1.56 \\
\hline & S.D. & 0.10 & 0.10 & 0.05 & 0.04 \\
\hline & $\mathrm{n}$ & 8 & 8 & 4 & 3 \\
\hline \multirow[t]{5}{*}{ U2322 net 6} & Mean & 1.33 & 1.37 & & \\
\hline & Minimum & 1.29 & 1.31 & & \\
\hline & Maximum & 1.40 & 1.43 & & \\
\hline & S.D. & 0.05 & 0.05 & & \\
\hline & $\mathrm{n}$ & 4 & 4 & & \\
\hline \multirow[t]{5}{*}{ ODP 1123} & Mean & 1.40 & 1.47 & 1.44 & 1.40 \\
\hline & Minimum & 1.30 & 1.36 & 1.28 & 1.30 \\
\hline & Maximum & 1.47 & 1.54 & 1.52 & 1.63 \\
\hline & S.D. & 0.09 & 0.09 & 0.07 & 0.09 \\
\hline & $\mathrm{n}$ & 3 & 3 & 14 & 13 \\
\hline \multirow[t]{5}{*}{ R623 } & Mean & 1.44 & 1.45 & 1.47 & 1.48 \\
\hline & Minimum & 1.24 & 1.26 & 1.33 & 1.35 \\
\hline & Maximum & 1.61 & 1.94 & 1.61 & 1.55 \\
\hline & S.D. & 0.09 & 0.15 & 0.08 & 0.07 \\
\hline & $\mathrm{n}$ & 22 & 20 & 16 & 12 \\
\hline \multirow[t]{5}{*}{ U2309 net5 } & Mean & 1.47 & 1.38 & & \\
\hline & Minimum & 1.42 & 1.35 & & \\
\hline & Maximum & 1.50 & 1.44 & & \\
\hline & S.D. & 0.04 & 0.04 & & \\
\hline & $\mathrm{n}$ & 4 & 4 & & \\
\hline \multirow[t]{5}{*}{ F111 } & Mean & 1.47 & 1.41 & 1.48 & 1.45 \\
\hline & Minimum & 1.37 & 1.29 & 1.45 & 1.39 \\
\hline & Maximum & 1.53 & 1.46 & 1.53 & 1.50 \\
\hline & S.D. & 0.06 & 0.07 & 0.03 & 0.08 \\
\hline & $\mathrm{n}$ & 6 & 5 & 4 & 2 \\
\hline \multirow[t]{5}{*}{ D178 } & Mean & 1.56 & 1.54 & 1.63 & 1.65 \\
\hline & Minimum & 1.46 & 1.46 & 1.56 & 1.55 \\
\hline & Maximum & 1.70 & 1.61 & 1.76 & 1.74 \\
\hline & S.D. & 0.07 & 0.06 & 0.09 & 0.13 \\
\hline & $\mathrm{n}$ & 9 & 6 & 4 & 2 \\
\hline B32 & Mean & 1.40 & 1.40 & 1.48 & 1.45 \\
\hline & Minimum & 1.23 & 1.23 & 1.38 & 1.35 \\
\hline & Maximum & 1.48 & 1.48 & 1.64 & 1.57 \\
\hline & S.D. & 0.07 & 0.07 & 0.09 & 0.09 \\
\hline & $\mathrm{n}$ & 14 & 12 & 6 & 6 \\
\hline
\end{tabular}




\subsubsection{Mg/Ca-ocean temperature calibration for $\mathrm{N}$. incompta from the Southwest Pacific Ocean?}

A calibration was derived for reticulate forms using the mean $\mathrm{Mg} / \mathrm{Ca}$ ratio of all chambers (i.e. the pooled average of chamber F and the pooled average of chamber F-3 from all individuals per site) and compared to the calibration of Von Langen et al. [2005]. Each site was calibrated against seasonal SST at which known $N$. incompta populations are highest across the surface to $100 \mathrm{~m}$ depth [King and Howard, 2001]. For plankton tow samples, calcification temperatures were obtained from conductivity-temperature-density (CTD) measurements collected at the same time of the tow.

In order to compare the data from the reticulate forms with those that were crystalline, the mean $\mathrm{Mg} / \mathrm{Ca}$ of the inner most 'ontogenetic' calcite and the outer, assumed 'gametogenic' crust were calculated separately for the crystalline forms. This allows assessment of whether there is a chemical difference between these two layers of calcite.

The $\mathrm{Mg} / \mathrm{Ca}$ ratios in reticulate forms exhibit a positive significant $\left(\mathrm{r}^{2}=0.38, \mathrm{p}=0.044\right)$ relationship with ocean temperature in the final chamber F. However, in the older chamber F3 there is no significant relationship between $\mathrm{Mg} / \mathrm{Ca}$ and temperature. This is the same for the $\mathrm{Mg} / \mathrm{Ca}$ ratios in chambers $\mathrm{F}$ and F-3 in the ontogenetic and gametogenic calcite of crystalline forms (Figure 4.9, Table 4.5). 


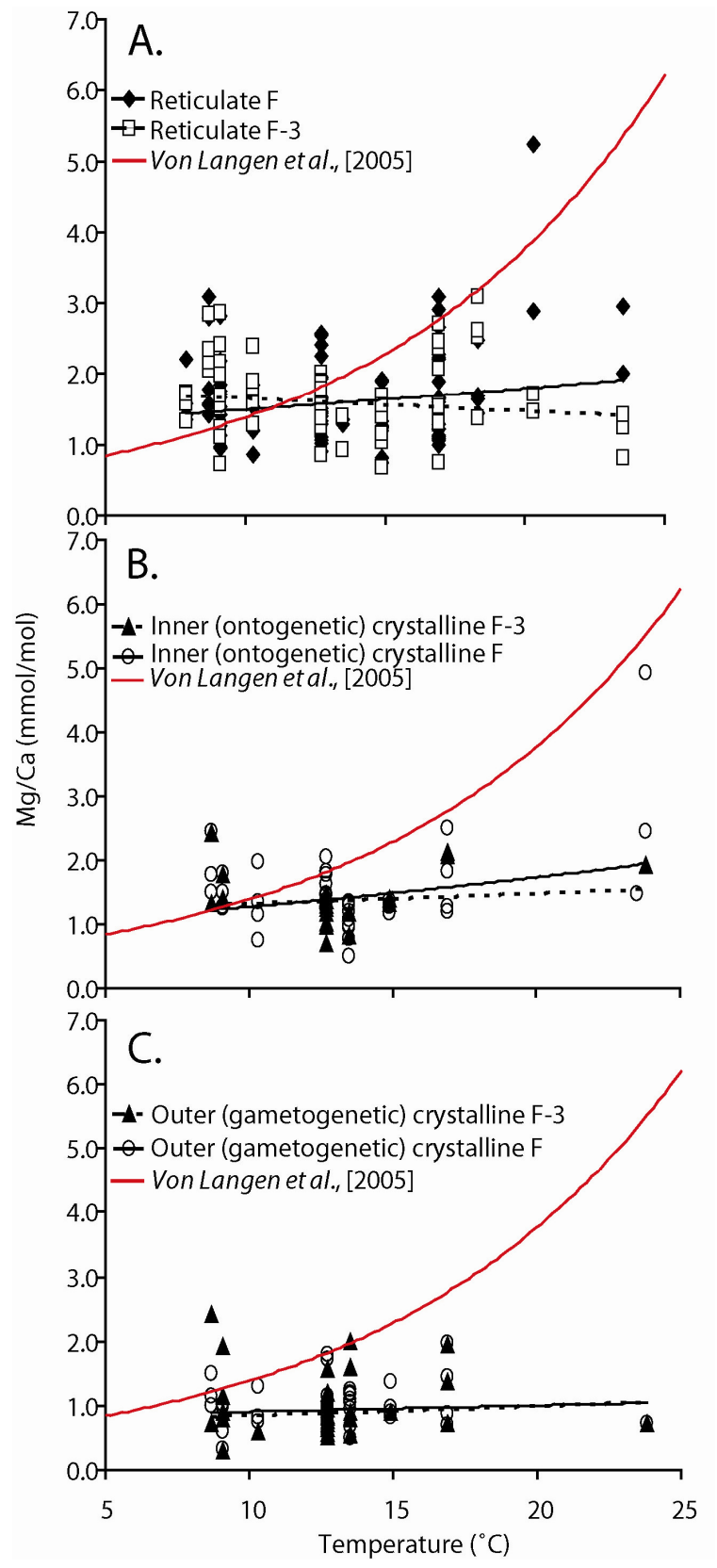


Table 4.5: Summary of $\mathrm{Mg} / \mathrm{Ca}$ chamber specific calibrations and existing calibrations for $\mathrm{N}$. incompta and $\mathrm{N}$. pachyderma

\begin{tabular}{|c|c|c|c|c|c|c|c|c|c|c|c|}
\hline & & $\mathrm{Mg} / \mathrm{Ca}=$ & $B \exp ^{A T}$ & & & & & & & & \\
\hline Reference & Source & Slope (A) & $\begin{array}{c}\mathrm{y}- \\
\text { intercept } \\
\text { (B) }\end{array}$ & $\mathbf{r}^{2}$ & $\mathrm{p}$ & $\mathrm{n}$ & $\begin{array}{l}\text { errors on } A \\
\quad \text { and } B\end{array}$ & Instrument & $\begin{array}{l}\text { Analysis } \\
\text { Type }\end{array}$ & $\begin{array}{l}\text { Temperature } \\
\text { Source }\end{array}$ & $\begin{array}{l}\text { SST } \\
\text { Range } \\
\left({ }^{\circ} \mathrm{C}\right)\end{array}$ \\
\hline $\begin{array}{l}\text { This study, pooled } \mathrm{F} \\
\text { chamber, reticulate forms }\end{array}$ & & 0.032 & 1.102 & 0.38 & $\mathrm{p}=0.044$ & 87 & $\begin{array}{l}A= \pm 0.014 \\
B= \pm 0.227\end{array}$ & LA-ICP-MS & $\begin{array}{l}\text { in-situ, } \\
25 \mu \mathrm{m} \text { spot }\end{array}$ & $\begin{array}{l}\text { Annual SST World } \\
\text { Ocean Atlas } 2005\end{array}$ & $7.9-23.5$ \\
\hline $\begin{array}{l}\text { This study, pooled F-3 } \\
\text { chamber, reticulate forms }\end{array}$ & & -0.014 & 1.975 & -0.026 & $\mathrm{p}=0.409$ & 67 & $\begin{array}{l}\mathrm{A}= \pm 0.016 \\
\mathrm{~B}= \pm 0.471\end{array}$ & LA-ICP-MS & $\begin{array}{l}\text { in-situ, } \\
25 \mu \mathrm{m} \text { spot }\end{array}$ & $\begin{array}{l}\text { Annual SST World } \\
\text { Ocean Atlas } 2005\end{array}$ & $7.9-23.5$ \\
\hline $\begin{array}{l}\text { This study, pooled F } \\
\text { chamber, crystalline } \\
\text { forms, ontogenic calcite }\end{array}$ & & 0.271 & 1.223 & -0.004 & $\mathrm{p}=0.358$ & 41 & $\begin{array}{l}A= \pm 0.014 \\
B= \pm 0.349\end{array}$ & LA-ICP-MS & $\begin{array}{l}\text { in-situ, } \\
25 \mu \mathrm{m} \text { spot }\end{array}$ & $\begin{array}{l}\text { Annual SST World } \\
\text { Ocean Atlas } 2005\end{array}$ & $7.9-23.5$ \\
\hline $\begin{array}{l}\text { This study, pooled F } \\
\text { chamber, crystalline } \\
\text { forms, secondary calcite }\end{array}$ & $\begin{array}{l}\text { tow samples, Southwest } \\
\text { Pacific Ocean } \\
(150-350 \mu \mathrm{m})\end{array}$ & 0 & 0.974 & -0.167 & $\mathrm{p}=0.993$ & 45 & $\begin{array}{l}A= \pm 0.015 \\
B= \pm 0.207\end{array}$ & LA-ICP-MS & $\begin{array}{l}\text { in-situ, } \\
25 \mu \mathrm{m} \text { spot }\end{array}$ & $\begin{array}{l}\text { Annual SST World } \\
\text { Ocean Atlas } 2005\end{array}$ & $7.9-23.5$ \\
\hline $\begin{array}{l}\text { This study, pooled F-3 } \\
\text { chamber, crystalline } \\
\text { forms, ontogenic calcite }\end{array}$ & & 0.004 & 1.365 & -0.196 & $\mathrm{p}=0.904$ & 20 & $\begin{array}{l}A= \pm 0.029 \\
B= \pm 0.599\end{array}$ & LA-ICP-MS & $\begin{array}{l}\text { in-situ, } \\
25 \mu \mathrm{m} \text { spot }\end{array}$ & $\begin{array}{l}\text { Annual SST World } \\
\text { Ocean Atlas } 2005\end{array}$ & $7.9-23.5$ \\
\hline $\begin{array}{l}\text { This study, pooled F-3 } \\
\text { chamber, crystalline } \\
\text { forms, secondary calcite }\end{array}$ & & -0.014 & 1.162 & -0.119 & $\mathrm{p}=0.633$ & 33 & $\begin{array}{l}A= \pm 0.027 \\
B= \pm 0.467\end{array}$ & LA-ICP-MS & $\begin{array}{l}\text { in-situ, } \\
25 \mu \mathrm{m} \text { spot }\end{array}$ & $\begin{array}{l}\text { Annual SST World } \\
\text { Ocean Atlas } 2005\end{array}$ & $7.9-23.5$ \\
\hline Nürnberg [1995] & $\begin{array}{l}\text { Core-top N. pacbyderma } \\
\text { from the Norwegian Sea }\end{array}$ & 0.099 & 0.549 & 0.583 & & & & Electron-microprobe & in-situ & Hydrographic atlas & \\
\hline Nürnberg [1995] & $\begin{array}{l}\text { Core top N. pachyderma } \\
\text { from the South Atlantic }\end{array}$ & 0.083 & 0.406 & 0.892 & & & & Electron-microprobe & in-situ & Hydrographic atlas & \\
\hline Von Langen et al. [2005] & $\begin{array}{c}\text { Cultured N. incompta, } \\
\text { Southern California } \\
\text { Bight }\end{array}$ & 0.101 & 0.51 & 0.9 & $\mathrm{p}<0.001$ & & $\begin{array}{l}A= \pm 0.02 \quad B \\
=-0.15,+0.23\end{array}$ & ICP-MS & solution & & $\begin{array}{c}10.2 \\
\text { (range) }\end{array}$ \\
\hline
\end{tabular}




\subsubsection{Electron Microprobe Element maps of $M g, A l$ and $M n /$ Ca ratios in N. incompta tests}

$\mathrm{Mg}, \mathrm{Al}$ and $\mathrm{Mn} / \mathrm{Ca}$ element ratios maps are presented in Figure 4.10 and are shown as counts per second in order to illustrate the relative intensities of the different elements measured [Pena et al., 2008]. These samples were selected from ODP Site 1123 after laser ablation trace element analysis, and had varying concentrations of trace elements including one sample with relatively high $\mathrm{Al} / \mathrm{Ca}(7.6 \mathrm{mmol} / \mathrm{mol}$, ODP1123_3) and $\mathrm{Mn} / \mathrm{Ca} \quad(0.17 \mathrm{mmol} / \mathrm{mol}$, ODP1123_3) (Table 4.6).

Table 4.6: N. incompta samples from ODP Site 1123 selected for trace element mapping post LA-ICP-MS

Average TE/Ca (LA-ICP-MS)

\begin{tabular}{|c|c|c|c|c|c|}
\hline \multirow[b]{2}{*}{ Sample } & \multirow[b]{3}{*}{ Shell ultra-structure } & \multirow[b]{3}{*}{ Depth } & \multicolumn{3}{|c|}{ Average TE/Ca (LA-ICP-MS) } \\
\hline & & & & & \\
\hline Number & & & $\mathrm{Mg} / \mathrm{Ca}$ & $\mathrm{Al} / \mathrm{Ca}$ & $\mathrm{Mn} / \mathrm{Ca}$ \\
\hline & & (mbsf) & $(\mathrm{mmol} / \mathrm{mol})$ & $(\mathrm{mmol} / \mathrm{mol})$ & $(\mathrm{mmol} / \mathrm{mol})$ \\
\hline ODP1123_2 & crystalline & 3290 & 0.80 & 0.35 & 0.03 \\
\hline ODP1123_3 & crystalline & 3290 & 1.98 & 7.63 & 0.17 \\
\hline ODP1123_5 & crystalline & 3290 & 1.19 & 0.08 & 0.01 \\
\hline
\end{tabular}

These element maps do not show any clear differences in $\mathrm{Mg} / \mathrm{Ca}$ between the ontogenetic calcite and gametogenic crusts in the selected samples. Sample ODP1123_3 with high Al/Ca ratios had higher $\mathrm{Al} / \mathrm{Ca}$ ratios showed the highest $\mathrm{Al} / \mathrm{Ca}$ were concentrated around pores. ODP1123_2 and ODP1123_5 also show similar, but smaller spots of high Al/Ca although these do not appear to have influenced the $\mathrm{Mg} / \mathrm{Ca}$ ratios during laser ablation. 

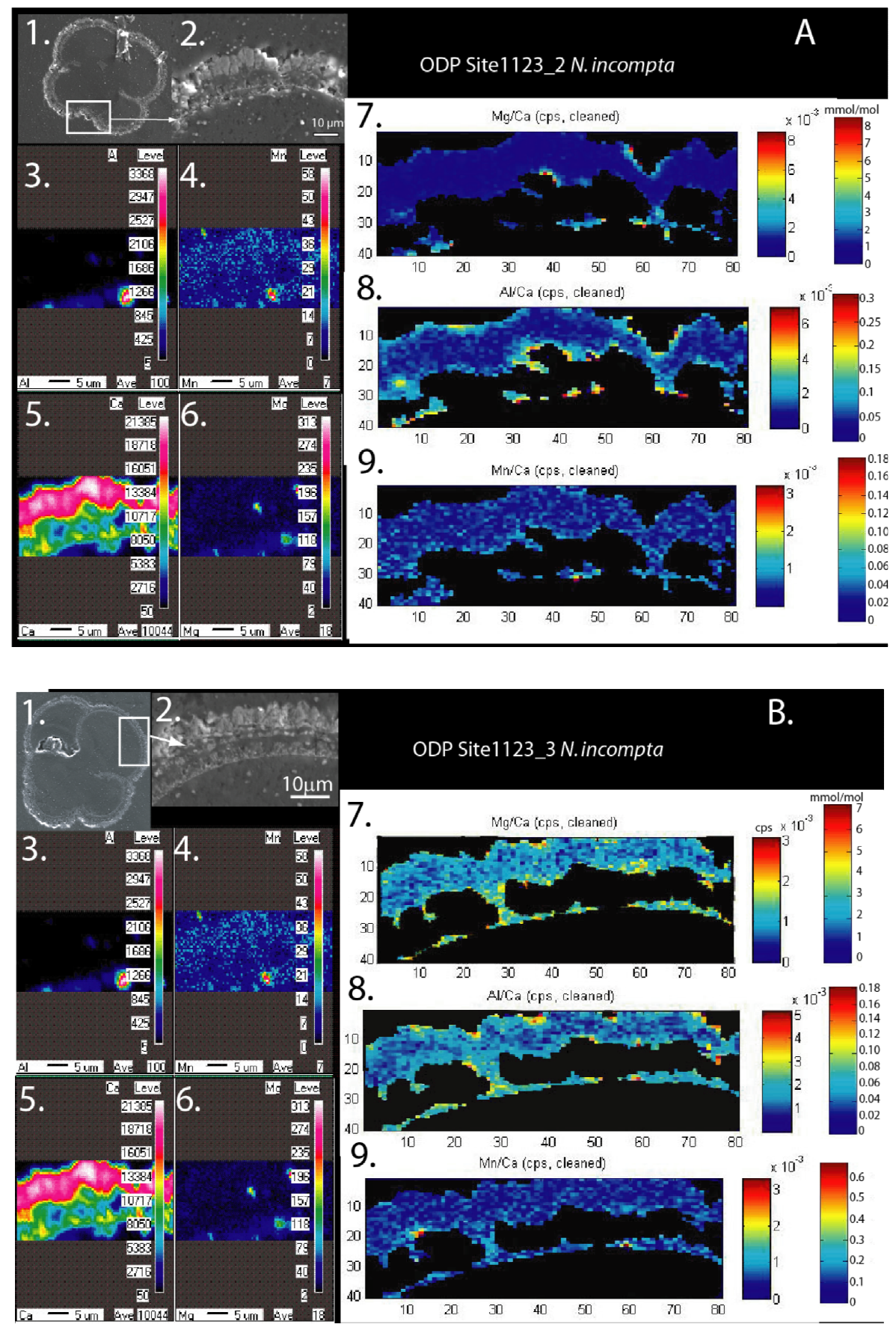


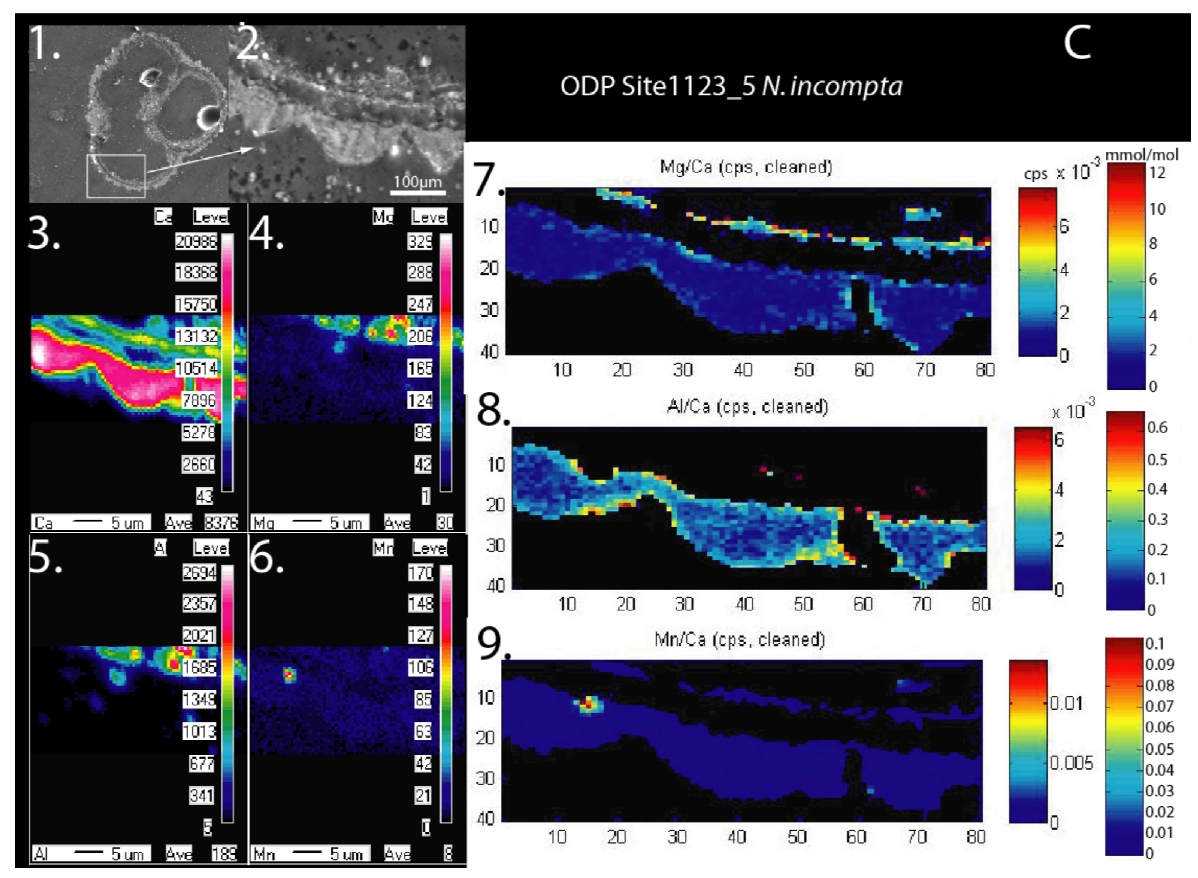

Figure 4.10: (A, B and C) Electron microprobe elemental maps of three $N$. incompta individuals (ODP1123_numbers 2, 3 and 5; Table 4.6) on exposed cross sections of foraminifera tests. Images 1 and 2 on all figures show the SEM images the cross-section of $N$. incompta tests with the highlighted area where the element maps were made. Images 3 to 6 on all figures show intensity values are expressed as counts per second (cps) of $\mathrm{Ca}, \mathrm{Mg}, \mathrm{Al}$ and $\mathrm{Mn}$ as shown in the colour bars. Images 7 to 9 all figures show the $\mathrm{Mg} / \mathrm{Ca}, \mathrm{Al} / \mathrm{Ca}$ and $\mathrm{Mn} / \mathrm{Ca}$ expressed as cps converted to $\mathrm{mmol} / \mathrm{mol}$ (see section 4.3.3).

\subsection{Discussion}

\subsection{1 $\mathrm{Mg} /$ Ca variability within test walls of $\mathrm{N}$. incompta}

Of the crystalline forms, the innermost ontogenetic calcite (ICL) is characterised by a moderately higher $\mathrm{Mg} / \mathrm{Ca}$ layer whereas the outer calcite layer (OCL) or gametogenic crust in many samples is usually has a lower $\mathrm{Mg} / \mathrm{Ca}$. The ratio of high to low $\mathrm{Mg} / \mathrm{Ca}$ between these layers is variable but it appears, in general, that the lower $\mathrm{Mg} / \mathrm{Ca}$ is often denser than the inner, higher $\mathrm{Mg} / \mathrm{Ca}$ layer(s). Mean $\mathrm{Mg} / \mathrm{Ca}$ between ICL in reticulate and crystalline forms varies from 16 to $63 \%$ lower (compared to reticulate) in chamber F-3 and 6 to $80 \%$ lower in chamber F. Other micro-analytical studies have established in many planktonic species that the OCL typically has lower $\mathrm{Mg} / \mathrm{Ca}$ ratios (by up to a factor of 3) than the ICL of the test [Duplessy et al., 
1981; Klinkhammer et al., 2004; Anand and Elderfield, 2005; Schmidt et al., 2006; Hamilton et al., 2008; Lombard et al., 2010], which is consistent with the findings of this study. Element maps of $N$. dutertrei and $N$. incompta specimens have previously shown only limited $\mathrm{Mg} / \mathrm{Ca}$ variation across chamber walls, with two distinct layers [Sadekov et al., 2005]. In that study, the ICL was characterized by a moderately high $\mathrm{Mg} / \mathrm{Ca}(4 \pm 1 \mathrm{mmol} / \mathrm{mol})$, compared to the equally thick or thicker OCL that has significantly lower $\mathrm{Mg} / \mathrm{Ca}(1.5 \pm 1 \mathrm{mmol} / \mathrm{mol})$. Similar variations were found in $N$. dutertrei and occasionally in N. pachyderma analysed by LA-ICP-MS [Eggins et al., 2003; Bergami et al., 2008]. N. pachyderma, in particular, showed a considerable range of $\mathrm{Mg} / \mathrm{Ca}$ that extended well beyond plausible calcification temperatures [Eggins et al., 2003]. These authors suggested that this may be due to variation in calcification kinetics, or other factors not related to temperature, such as salinity. However, salinity was not considered to be a significant factor in controlling the chemistry of $N$. pachyderma from the Southern Ocean [Nürnberg, 1995]. Although the salinity range from this study's sample sites is considerably larger than that of Nürmberg, [1995], the results suggest no significant relationship with salinity.

Furthermore, the $\mathrm{Mg} / \mathrm{Ca}$ data presented in this study are consistent with all ICL forming in warmer or shallower depths than the OCL, which is typically precipitated in deeper water in other Neogloquadrinid species [Orr, 1967; Erez and Honjo, 1981; Lohmann, 1995; Sadekov et al., 2008]. This is a characteristic observed in other planktonic foraminifera, including $N$. pachyderma, which is thought to add a final, often thick outer ("gametogenic") crust in deeper colder waters immediately prior to gametogenesis, and ensuing death [Brown and Elderfield, 1996; Elderfield and Ganssen, 2000; Jha and Elderfield, 2000; Hathorne et al., 2003]. Based on these observations, it is reasonable to propose that reticulate forms are pre-gametogenic variants of the same species. The $\delta^{18} \mathrm{O}_{c}$ of reticulate and crystalline ultra-structures of $N$. incompta in a study by Kozdon et al., [2009] found distinctly more negative $\delta^{18} \mathrm{O}_{c}$ in reticulate forms, indicating a least some of the test in crystalline forms is precipitated at greater (colder) depths than reticulate forms from the same location. Alternatively, the difference between OCL and ICL may be the result of a biological mechanism that results in a different chemical composition between these layers [Bé, 1980; Hemleben et al., 1989]. The magnitude of these effects will depend on factors such as the temperature gradient in the water column, the amount of calcite secreted at these various depths, and any additional effects from dissolution (c.f. Duplessy, et al. 1981). 
For all sites, the mean $\mathrm{Mg} / \mathrm{Ca}$ in reticulate forms is higher when compared to crystalline forms, suggesting that these tests grow in warmer water or during warmer seasons when compared to the crystalline forms. This is consistent with the results of a study using $N$. pachyderma from the Southern Ocean, which recognised two different morphotypes [Bergami et al., 2008]. One morphotype is described as having a "thin and lobate walled test" (assumed to be equivalent to "reticulate" forms described in this study), which had much higher $\mathrm{Mg} / \mathrm{Ca}$ ratios compared to the morphotype with "subspheric and heavily encrusted tests", assumed here to be crystalline forms.

The $\mathrm{Mg} / \mathrm{Ca}$ of the OCL between each site does not vary greatly and may indicate a particular temperature where this layer is secreted. Assuming that $\mathrm{Mg} / \mathrm{Ca}$ variability is the result of differences in calcification temperature, applying the generic planktic species calibration of Elderfield and Ganssen [2000] and that from Von Langen et al., [2005] reveals a temperature range for the OCL (all chambers) that varies from -9.4 to $15.47^{\circ} \mathrm{C}$ and -5.5 to $15.4^{\circ} \mathrm{C}$ respectively. There are a number of possible explanations for these large ranges:

(1) The current calibrations do not include individuals collected from colder sampling sites, thus the regressions used to calculate temperatures are based on the extrapolation of current data;

(2) The range reported in this study are from all sites, and the maximum range found within an individual site is much smaller e.g., Table 4.2;

(3) That temperature is not the primary reason for these observed ranges in $\mathrm{Mg} / \mathrm{Ca}$. Instead, there may be a specific biological mechanism that favours the precipitation of a chemically (in terms of $\mathrm{Mg}$ ) uniform calcite.

\subsubsection{Comparison with other calibrations}

The $\mathrm{Mg} / \mathrm{Ca}$ - ocean temperature calibrations derived in this study do not show a significant relationship with temperature. The best correlation is for the final chamber in reticulate forms $\left(\mathrm{r}^{2}=0.33\right)$ although this is still not statistically significant $(\mathrm{p}=0.09)$ in contrast to the results of Von Langen et al. [2005] who show a strong $\left(\mathrm{r}^{2}=0.90\right)$ positive correlation between $\mathrm{Mg} / \mathrm{Ca}$ and temperature that is similar to trends reported for other planktonic species. The Von Langen et al. [2005] calibration was based on N. incompta, PD-intergrades and N. dutertrei cultured under 
known temperature conditions. The main disadvantage of culturing lies in the controlled environment that cannot fully replicate the complexities captured in samples recovered from the sea floor, in terms of factors including but not exclusive to nutrient availability, ontogenic migration through the water column and diagenesis. Hilbrect [1997] suggested that N. incompta is more likely to be showing variable ontogenic cycles where conditions in the water column do not depend strictly on depth but also other factors such as nutrient availability (see also Hemleben et al., 1989), depth of the thermocline, the deep chlorophyll maximum and upwelling conditions [Fairbanks et al., 1980; Ravelo et al., 1990; Brock et al., 1992; Ravelo and Fairbanks, 1992]. The above conditions cannot be replicated in under culture but these different factors may explain the lack of correlation between $\mathrm{Mg} / \mathrm{Ca}$ and ocean temperatures in this $\mathrm{N}$. incompta from the Southwest Pacific Ocean.

Apart from these factors, the samples in the Von Langen et al., [2005] study were based on individuals that had been collected at shallower depths $(0-50 \mathrm{~m})$ although previous plankton tows had noted that specimens were considerably more encrusted in deeper tows $(300 \mathrm{~m})$. It could be that those shallower specimens did not undergo gametogenesis, as this process is rarely observed in cultured specimens [Bé, 1980].

The implications for palaeoceanographic studies would be that calibrations from cultured conditions are less representative of the actual ocean conditions than those from core-tops. As pointed out in earlier studies, when measured by solution, a prerequisite for palaeoceanographic applications is the demonstration that the temperature sensitivity of foraminiferal calcite is retained from the initial chamber formation through to the development of gametogenic calcite crusts, with the additional effects of dissolution, to residence at the sea bed [Elderfield and Ganssen, 2000]. Although, this does not explain why N. incompta measured from the Southwest Pacific do not display a significant positive Mg:temperature relationship, other studies have also found inconsistencies in Neogloboquadrinids. For example, covariance of magnesium concentrations and water temperature in N. pachyderma from both northern and southern high latitudes showed similar regression lines and inclination, however the relationship was much weaker in the southern high latitudes (Southern Ocean) [Nürnberg, 1995]. In the latter study, the author speculates that the hemispheric discrepancies must be associated, in addition to temperature effects, to differences in plankton biosynthesis and metabolism. Additionally, Bergami et al., [2008] could not find a clear relationship between the 
distribution of dextral coiling specimens of $N$. pachyderma and water temperature. This leads towards the conclusion that perhaps this species is not a good (geochemical) palaeothermometer.

\subsubsection{Vital Effects}

In this study, the low $\mathrm{Mg} / \mathrm{Ca}$ ratios in crystalline forms were less variable compared to that considered to be ontogenetic calcite. Kennett, [1968] found no temperature dependence in gametogenic calcite in the same species. This would mean, however, that because this study's sites span both Subtropical and Subantarctic sites, for each site the depth at which gametogenesis occurred would be different. A different possibility is that the composition of gametogenic calcite is entirely determined by a biological mechanism which is unrelated to seawater temperature (or depth). As the thickness of the gametogenic crust varies between individuals, it may be related to the calcium budget of the individual at the time of gametogenesis such that the $\mathrm{Ca}^{2+}$ or alkalinity (carbon pool) volume of cytoplasm inside a sphere, increases the calcite saturation state in the microenvironment prior to gametogenesis [Hemleben and Spindler, 1983; Hamilton et al., 2008].

\subsubsection{Palaeoceanographic implications}

The two different ultra-structures of $N$. incompta clearly have variable intra and inter-test $\mathrm{Mg} / \mathrm{Ca}$ values and this will bias temperature values derived from fossil samples, if one form is more dominant than the other. For example, it has been shown that crystalline forms have lower $\mathrm{Mg} / \mathrm{Ca}$ ratios (if gametogenic calcite is considered) compared to the reticulate forms (Table 4.3). Given that most studies use bulk $\mathrm{Mg} / \mathrm{Ca}$ ratios, it is important to discriminate between reticulate and crystalline ultra-structures before analysis. This may explain some large variations found in temperature and salinity from down-core records [Came et al., 2007; Benway et al., 2010], particularly if the production of gametogenic forms is stimulated by specific environmental conditions. In other studies, dissolution appears to discriminate between different calcite structures so that crystalline tests can appear to be well preserved on the outer surface when in fact the inner calcite has been preferentially dissolved [Barker et al., 2005; Johnstone et al., 2010]. This could also bias the inferred temperature signal to much lower 
temperatures, however the presence of high and low $\mathrm{Mg}$ in this study does not suggest a dissolution effect.

The application of LA-ICP-MS this study has shown varying layers of $\mathrm{Mg} / \mathrm{Ca}$ within $\mathrm{N}$. incompta that may be related to the presence of gametogenic and various ontogenetic layers of calcite of varying thickness. The $\mathrm{Mg} / \mathrm{Ca}$ profile increases towards the inner (ontogenetic) calcite, and the signal appears to be mixed, probably because the test surface is lobate but also due to varying organic layers of ontogenetic calcite. In addition, the crystalline tests required more laser power and it was noted that once the entire crystalline layer has been fully ablated, the thinner primary calcite layer requires less laser power to ablate. These settings need to be considered in future analyses in order to resolve the two calcite types more confidently. In addition, the non-destructive nature of LA-ICP-MS allows SEM images to be taken of each individual, allowing accurate analyses of test ultra-structure.

\subsection{Conclusions}

An electron microscopy and LA-ICP-MS trace element study of modern N. incompta from a range of ocean temperatures $\left(9\right.$ to $\left.24^{\circ} \mathrm{C}\right)$ has shown that:

(a) Only a weak positive relationship exists between ocean temperature and $\mathrm{Mg} / \mathrm{Ca}$ ratios in reticulate forms of $N$. incompta from the Southwest Pacific Ocean, although this was not statistically significant. What was tentatively identified to be ontogenetic calcite in crystalline forms of $N$. incompta also shows a general increase of $\mathrm{Mg} / \mathrm{Ca}$ with increasing ocean temperature, but again this relationship is not statistically significant.

(b) Gametogenic calcite in crystalline forms of $\mathrm{N}$. incompta is lower in $\mathrm{Mg} / \mathrm{Ca}$ compared to the ontogenetic calcite.

(c) In crystalline forms of $N$. incompta, based on the laser ablation depth profiles, the gametogenic calcite crust (rather than the ontogenetic calcite) typically appears to be either thicker or denser. The similarity of $\mathrm{Mg} / \mathrm{Ca}$ in the outer crusts of all chambers suggests that this crust was deposited at the same temperature or is controlled biologically. 
(d) The presence of inter-gradational surface ultra-microstructures between reticulate and crystalline forms suggests that they are the same phenotypic variant.

(e) There does not appear to be a difference in weight between the two ultra-structures.

In summary, it can be concluded that $\mathrm{Mg} / \mathrm{Ca}$ ratios from $\mathrm{N}$. incompta in the studied specimens from core-top sediments and plankton tows from the Southwest Pacific Ocean do not appear to suggest this species will be a reliable archive of past ocean temperatures in this region. 
Chapter 5

Southwest Pacific Ocean response to Marine Isotope Stage 31 as recorded at ODP Site 1123 


\subsection{Abstract}

Marine Isotope Stage (MIS) 31 occurred from 1.081-1.061 Ma and coincided with one of the phases of highest mid- to high latitude insolation and warm temperatures of the past $5 \mathrm{Ma}$. A high-resolution foraminiferal trace element and stable isotope chemistry record from Ocean Drilling Program Site (ODP) 1123, offshore of eastern New Zealand, was produced here to investigate the palaeoceanographic and palaeoclimatic history of the Southwest Pacific Ocean during the 'super-warm' MIS-31.

$\mathrm{Mg} / \mathrm{Ca}$ ratios measured by laser ablation inductively coupled plasma mass spectrometry on planktonic foraminifera reveal distinct shifts during glacial-interglacial (G-IG) cycles encompassing MIS 34-29 (1.14 to $1.00 \mathrm{Ma}$ ). During interglacials, the planktonic species Globigerinoides ruber (Gs. ruber) and Globigerina bulloides (G. bulloides) record elevated sea surface temperatures (SSTs) that reached $19^{\circ} \mathrm{C}$ in MIS31 - ca. $4^{\circ} \mathrm{C}$ warmer than the present interglacial. Coolest climatic conditions occurred during MIS-30 when SSTs fell to $c a .10^{\circ} \mathrm{C}$.

Paired $\mathrm{Mg} / \mathrm{Ca}$ and $\delta^{18} \mathrm{O}$ data reveal significant changes in ice volume over the sampling period, with increases in SSTs recorded by the planktonic foraminifera leading the seawater stable isotope record by up to $10 \mathrm{kyr}$ suggesting a significant influence from changes in Northern Hemisphere ice sheet volume during MIS-31. Other trace element data ( $\mathrm{Mn}, \mathrm{Ba}$ and $\mathrm{Zn})$ in the planktonic foraminifera reveal somewhat systematic changes on G-IG cycles. In particular, $\mathrm{Mn} / \mathrm{Ca}$ appears to co-vary with SSTs and increases in $\mathrm{Ba}$ and $\mathrm{Zn} / \mathrm{Ca}$ ratios proceed the peak MIS-31 interglacial that may reflect enhanced southward transport of micro-nutrient rich Subtropical Surface Waters and/or increased productivity. The fact that the patchy distribution of Gs. ruber increases during interglacial periods and signals a southward shift or strengthening of the South Pacific Subtropical Gyre potentially supports interpretation of the changing foraminifera $\mathrm{Mn}, \mathrm{Ba}$ and $\mathrm{Zn} / \mathrm{Ca}$ ratios as reflecting meridional changes in the surface water masses.

Size-normalised weights (SNW) of G. bulloides tests show systematic variations over G-IG cycles. For much of the record, SNW anti-correlate with SST in a manner similar to the modern relationship between SNW and SST in the Southwest Pacific Ocean. However, in the warm period marked by high SST during and immediately prior to MIS-31 during the Southern 
Hemisphere insolation maxima, SNW correlate with SST suggesting a fundamental change in surface ocean carbonate ion chemistry occurred that is unique to this warm event.

\subsection{Introduction}

Reconstructed records of past climatic conditions can provide important constraints on the potential environmental responses to projected changes in the Earth's climate system [Berger and Loutre, 2002; Skinner, 2010]. Global wind- and the thermohaline-driven circulation system is the primary means by which heat is transported globally. Two key parameters that can be used to define past climate are ocean temperatures and other oceanographic changes, such as the reorganisation of major ocean currents, water masses and the position of ocean fronts between these.

MIS-31 occurred from 1.081 - 1.061 Ma [Lisiecki and Raymo, 2005] during the Mid-Pleistocene Transition (MPT) that took place from ca. 0.5 to $1.2 \mathrm{Ma}$ [Head and Gibbard, 2005]. The MPT represents a period from the 41-kyr world of the late Pliocene/early Pleistocene to the emergence of the 100-kyr world of the late Pleistocene, in the absence of any change in the orbital forcing [Clark et al., 2006]. Several indirect and direct lines of evidence suggest that MIS-31 was one of the warmest periods during the Quaternary within the MPT. As well as being a particularly long and warm interglacial, it was also characterised by an orbital configuration unique in the last $5 \mathrm{Ma}$ [Scherer et al., 2008]. The orbital configuration at this time consisted of high obliquity and precession combined with a January perihelion early in the interglacial. Combined, these caused extreme southern mid-high latitude insolation (Figure 5.1). Additionally, the stable oxygen isotope compositions of benthic foraminiferal calcite $\left(\delta^{18} \mathrm{O}_{c}\right)$ at this time reflect the dominant $40 \mathrm{kyr}$ periodicity that represents Earth's obliquity (tilt) e.g. Raymo and Nisancioglu [2003], Liu and Herbert [2004] and, Kupp [2006].

There are two recently proposed explanations to explain this periodicity: (1) The ice sheets responded to obliquity (tilt), which determined the duration of the high latitude summer at the expense of mid- and low-latitude summer insolation, and its effect was synchronous in the northern and southern hemispheres (e.g. Huybers, 2006). In this scenario, ice sheets expand and contract with a 40 kyr period. (2) Alternatively, the ice sheets are more sensitive to precession which affects the intensity at all latitudes by altering the Earth-Sun distance during each season 
and are out-of-phase between the hemispheres [Raymo et al., 2006; Scherer et al., 2008]. In this model, ice sheets expand and contract with a $\sim 19$ to $23 \mathrm{kyr}$ period. The effect of ice growth in one hemisphere on sea level may thus be cancelled by melting in the other hemisphere, so the weaker $40 \mathrm{kyr}$ obliquity period is recorded by globally integrated proxies such as foraminiferal stable oxygen isotopes $\left(\boldsymbol{\delta}^{18} \mathrm{O}_{c}\right)$.

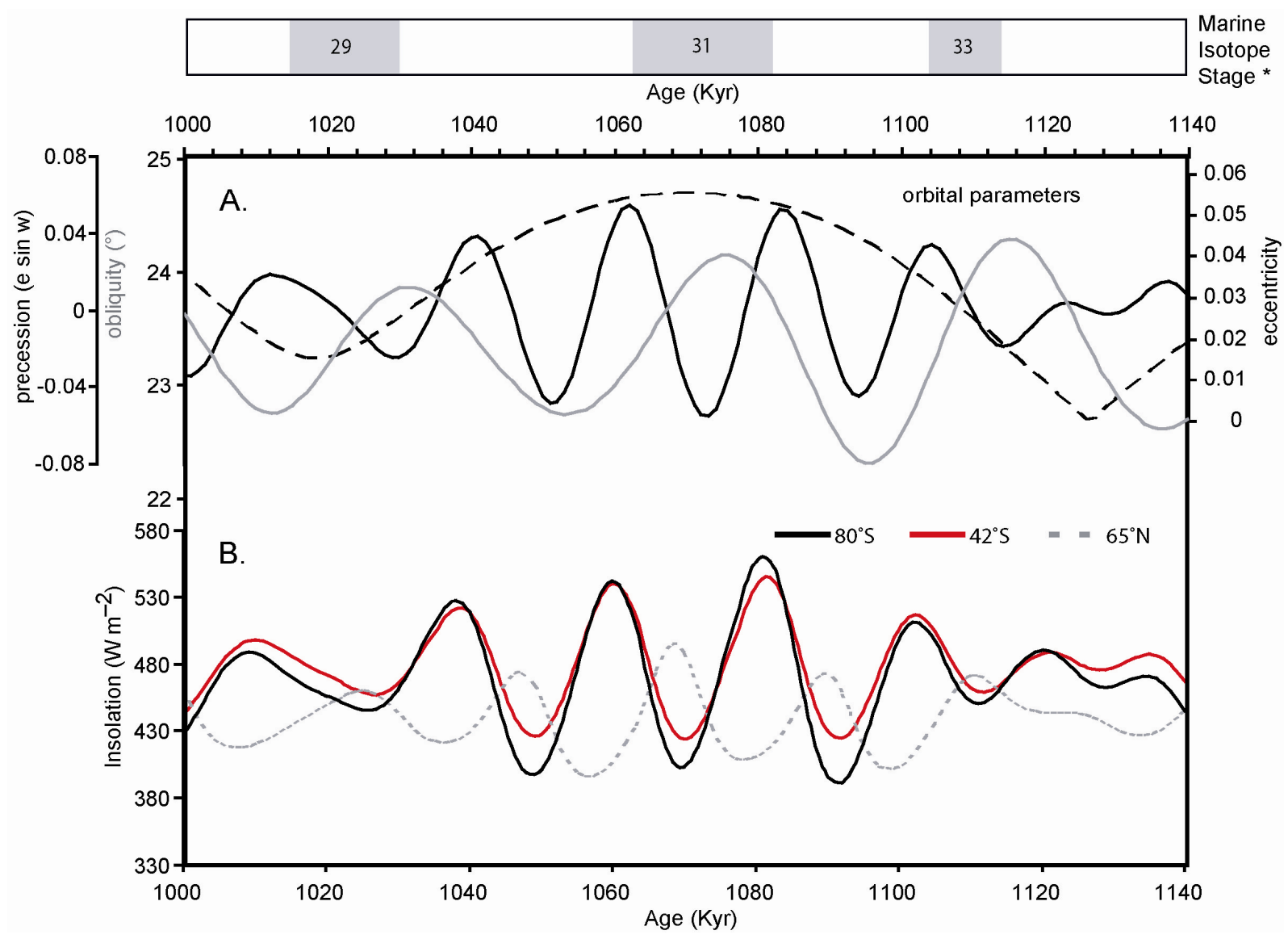

Figure 5.1: (A) Orbital parameters during MIS 34-29. For units of precession $\varepsilon$ is the eccentricity of the Earth's orbit and $\omega$ is the Earth's angular velocity. (B) Mean daily insolation at perihelion for latitudes $80^{\circ} \mathrm{S}, 42^{\circ} \mathrm{S}$ and $65^{\circ} \mathrm{N}$ [Laskar, 2004]. Extreme high southern latitude insolation is evident at ca. $1082 \mathrm{Kyr}$. Pollard et al. [2009] used the insolation at $80^{\circ} \mathrm{S}$ to model West Antarctic Ice Sheet (WAIS) variations in the same time period as this study. Insolation at $65^{\circ} \mathrm{N}$ represents the summer insolation records for the Northern Hemisphere $(\mathrm{NH})$ used in the Raymo and Huybers [2008] models of global ice volume change. The peak NH insolation maximum also coincides with the Jaramillo palaeomagnetic reversal at $1.07 \mathrm{Ma}$. The insolation at $42^{\circ} \mathrm{S}$ represents that received at the latitude of this study's site (ODP Site 1123). The shaded gray bars (top of figure) indicate the MIS age boundaries as defined in the Lisiecki and Raymo [2005] global benthic stack (LR04). 
During MIS-31 ice-rafted debris is abundant in sediment cores from ODP Sites 1090 and 1165 suggesting that Antarctic ice sheets generated icebergs capable of at least reaching the subpolar South Atlantic [Becquey and Gersonde, 2002; Kupp, 2006]. Furthermore, a 5 Myr simulation from the early Pliocene to present, suggests the East Antarctica Ice Sheet (EAIS) was relatively stable with nearly all of the ice-volume variability being due to the West Antarctic Ice Sheet (WAIS) [Pollard and DeConto, 2009]. During MIS-31, their model simulates a partial retreat to collapse of the WAIS, which is consistent with geological evidence from a coastal Antarctic sediment core (AND-1B) [Naish et al., 2007]. This sediment core from the Ross Sea sector of the Southern Ocean suggests that MIS-31 was indeed characterised by a prolonged retreat or collapse of the Ross Ice Shelf and likely led to a substantial reduction in the volume of the WAIS and a contribution to sea level rise of 3 to $6 \mathrm{~m}$ [Bamber et al., 2009; Villa et al., 2010]. The Pollard and DeConto [2009] model suggests that retreat/collapse of the WAIS occurred when nearby ocean temperatures warmed by $\sim 5^{\circ} \mathrm{C}$.

Given the substantial changes in the Antarctic cryosphere and climate predicted from models and inferred from sedimentary evidence during MIS-31, this study uses the geochemistry (trace element and stable isotope data) and shell weights of planktonic foraminifera to investigate the palaeoceanographic and palaeoclimatic history of the Southwest Pacific Ocean at this time. The foraminifera were sampled from a high resolution sediment core from ODP Site 1123, located at southern mid-latitude, east of New Zealand and directly downstream of the Antarctic Circumpolar Current (ACC) and directly above the Pacific Deep Western Boundary Current (DWBC) (Figure 5.2). This site also lies close to the northern limit of the modern Subtropical Front (STF) and hence captures the interaction between Subtropical Water (STW) from the north and Subantarctic Water (SAW) from the south.

\subsection{Materials and Methods}

\subsubsection{Regional Setting of ODP Site 1123}

ODP Site $1123\left(41^{\circ} 47.2^{\prime} \mathrm{S}, 171^{\circ} 29.9 \mathrm{~W}\right)$ is located at $3290 \mathrm{~m}$ depth on the northeastern flank of Chatham Rise, east of New Zealand [Carter et al., 1998b]. The site is immediately north of the STF that separates warm, saline macro-nutrient poor and micro-nutrient rich STW in part 
carried by the South Pacific Subtropical Gyre (SPSG) from cold, low salinity and macronutrient rich, micro-nutrient poor SAW within the Subantarctic Front (SAF) of the ACC [Heath, 1985; Boyd et al., 1999; Uddstrom and Oien, 1999; Morris et al., 2001; Murphy et al., 2001; Neil et al., 2004; McCave et al., 2008]. This site also lies beneath the Pacific DWBC, which flows northwards east of New Zealand (Figure 5.2). Modern SSTs at this site have a seasonal range from 12.3 to $17.6^{\circ} \mathrm{C}(0-50 \mathrm{~m})$, with a mean annual value of $14.6^{\circ} \mathrm{C}$ [Schlitzer, 2002; Locarnini et al., 2006]. Salinity ranges from 35 to 35.2 psu with an annual average of 35.1 psu [Antonov et al., 2006].
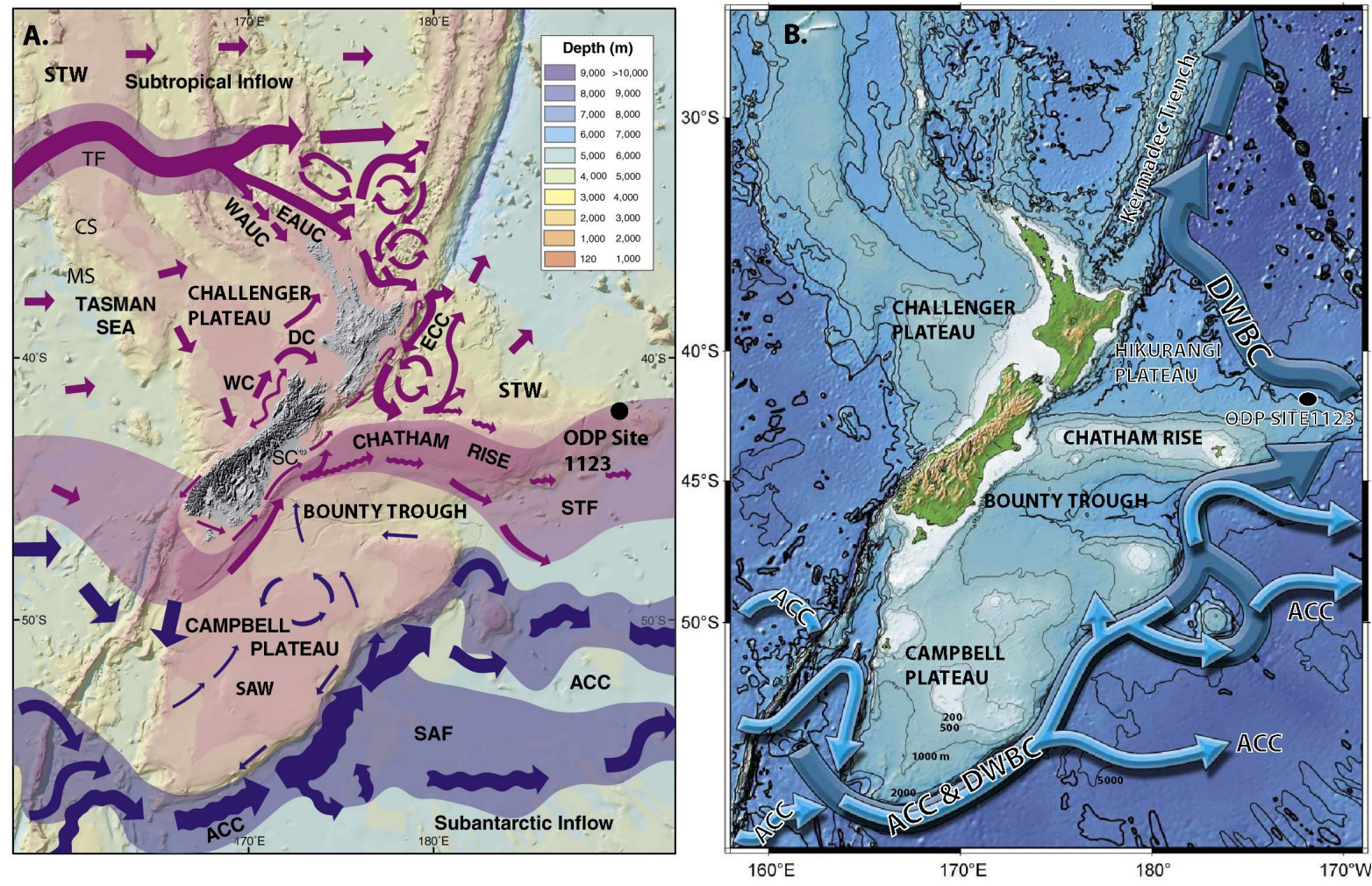

Figure 5.2: (A) Chart of the surface ocean currents of offshore New Zealand and surrounding regions. Blue arrows indicate the transport of Subantarctic and circumpolar surface waters mainly within the Subantarctic Front (SAF) of the Antarctic Circumpolar Current (ACC), while the purple arrows show warmer, saltier Subtropical Water (STW) carried to New Zealand via the South Pacific Subtropical Gyre (SPSG) that is locally represented by the Tasman Front (TF). That frontal flow branches mainly into the East Auckland Current (EAUC) with some water also contributing to an ephemeral West Auckland Current (WAUC). The eastern surface flow continues as the East Cape Current (ECC) that contributes to the Subtropical Front (STF). West of New Zealand the westerly zonal winds force the Westland Current (WC) and its offshoot the D'Urville Current (DC) into Cook Strait whereas to the east of the South Island, the Southland Current (SC) moves mainly Subantarctic surface water northward where some continues north to central New Zealand, and the remainder is diverted east along Chatham Rise and help form the southern boundary of the STF. (B) Chart of the New Zealand region and the main elements of the abyssal circulation system including the Pacific Deep Western Boundary Current (DWBC), and the overlying but deep-reaching Antarctic Circumpolar Current (ACC). Both charts taken and modified from Carter et al., [1998a]. 


\subsubsection{Age Model}

Stable oxygen isotopes $\left(\boldsymbol{\delta}^{18} \mathrm{O}_{c}\right)$ of the benthic foraminifera species Uvigerina spp. were used to complement the first isotope-based age model of Hall et al. [2001], which was tuned to an icevolume model using boreal summer (July) insolation values at $65^{\circ} \mathrm{N}$ [Imbrie and Imbrie, 1980]. An average of 10-15 samples of Uvigerina spp. from the 250 to $355 \mu \mathrm{m}$ size fraction were pooled and analysed from $5 \mathrm{~cm}$ sections of the ODP Site 1123 'C' core. In some sections, there were too few individuals available for analysis and, although smaller individuals were present, these were not analysed due to potential size specific isotopic fractionation effects [Schumacher et al., 2010]. In addition, other workers using this core (e.g. Crundwell et al., 2008) use a similar age model that is modified and supported by the ODP 1123 palaeomagnetostratigraphy [Carter et al., 1998b], ages of interbedded tephra [Alloway et al., 1995; Carter et al., 2004a] and microfossil biostratigraphy [Carter and Wilkin, 1999].

This original age model was initially based on shipboard palaeomagnetic and micro faunal data but further work on palaeomagnetic U-channel samples revealed that the palaeomagnetic reversal at the base of the Jaramillo subchron (C1r.1n) in core 'C' of ODP 1123 (1123C) was 41.68 meters below sea level (G. Wilson, personal communication). This is an important age control dated at 1.072 Ma and coincides with the NH insolation peak during MIS-31. Based on this new information a modified age model was derived from this study's benthic oxygen isotope data, the new U-channel palaeomagnetic data and correlation to the stacked benthic oxygen isotope stratigraphy model of Lisieki and Raymo [2005] (LR04) using Analyseries v.2.0.3. Previous age models were also adjusted so that other proxy data could be incorporated into this study (see Supplementary Material 5.8.1). The LR04 age model is a global PliocenePleistocene stack that contains benthic $\delta^{18} \mathrm{O}$ data from 57 globally distributed sites and has an average standard error of only $0.06 \%$. The LR04 age model is designed to minimize changes in global sedimentation rates such that the uncertainty including all sources of error is estimated 4 kyr from 1-0 Ma. 


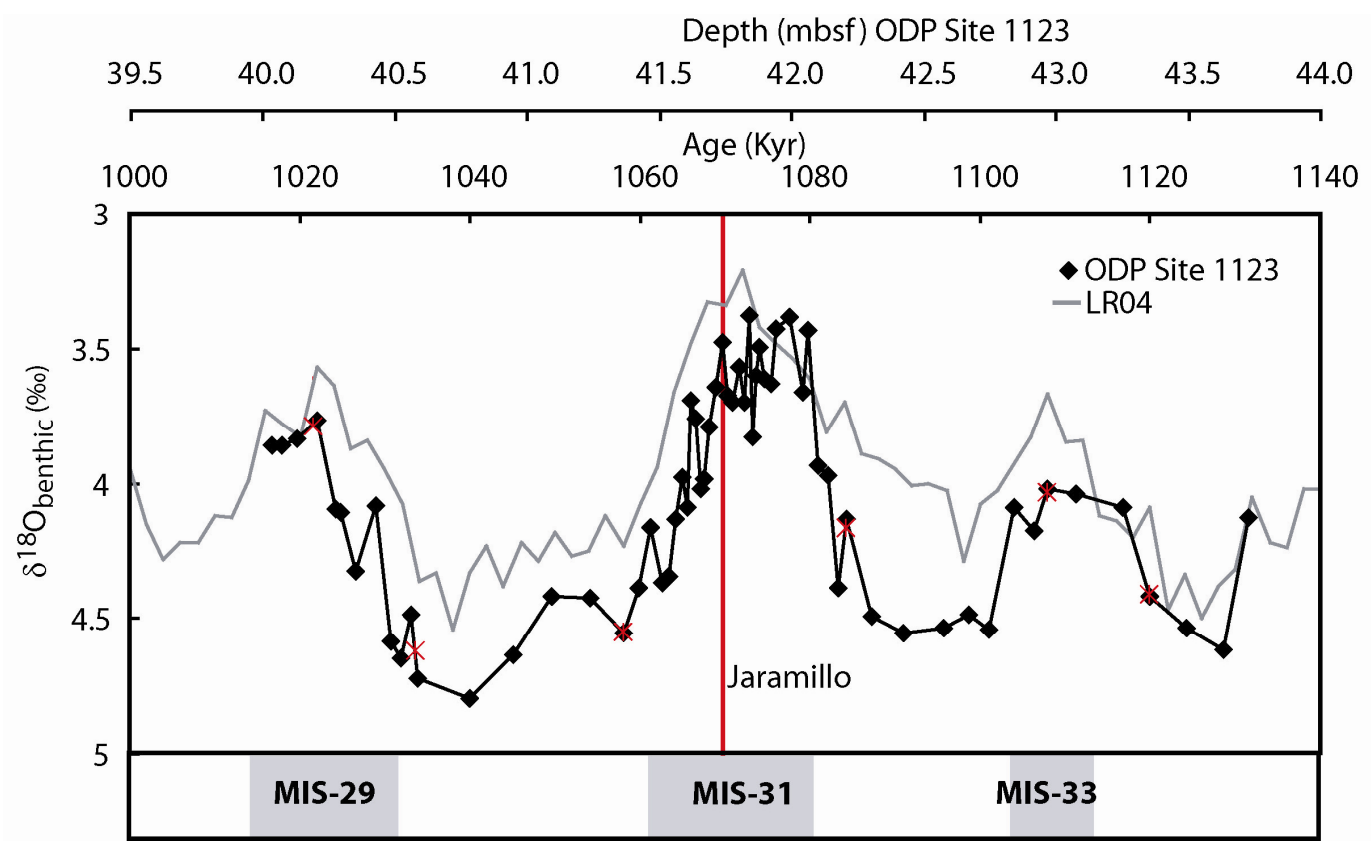

Figure 5.3: Age model of ODP Site 1123, which was derived by correlating this study's benthic oxygen isotope record (Uvigerina spp.; black filled diamonds and black curve), to the global stacked benthic oxygen isotope record of Lisiecki and Raymo [2005] (LR04; grey curve). The U-channel palaeomagnetic susceptibility data were used to tie the base of the Jaramillo subchron (C1r.1n) at $41.68 \mathrm{mbsf}$ to $1.072 \mathrm{Ma}$ (red solid line). The red stars indicate the age tie-points used to align the benthic $\delta^{18} \mathrm{O}$ sections (see Supplementary Table 5.1.). MIS boundaries, taken from Lisiecki and Raymo, [2005], are shown at the bottom of the figure.

\subsubsection{Foraminifera}

This study utilises 110 sediment samples from ODP Site 1123, core 'C', from 39.9 to 43.34 mbsf totalling a $3.44 \mathrm{~m}$ section of the core (see Supplementary Material for further details). Samples of $\sim 1 \mathrm{~cm}$ intervals, were collected at $\sim 5 \mathrm{~cm}$ intervals (an average resolution of $1.9 \mathrm{kyr}$ ) and record the glacial to interglacial MIS-34 to MIS-29 ( 1140 to $1000 \mathrm{kyr}$ ). The materials from this study were collected by hydropiston coring [Carter et al., 1998b].

Two planktonic foraminiferal species were studied. Globigerinoides ruber white (Gs. ruber) which is a subtropical to tropical species [Anand and Elderfield, 2003] and records surface water temperatures $(0-50 \mathrm{~m})$ equivalent to a spring/summer signal of 13.0 to $17.6^{\circ} \mathrm{C}$ at ODP Site 1123. At mid-latitudes Gs. ruber becomes less dominant within the foraminiferal assemblage, particularly during glacial periods [Crundwell et al., 2008], therefore Globigerina bulloides ( $G$. bulloides) was also studied as is it common throughout the record. G. bulloides is a non-symbiotic 
species and typically a transitional species. High abundances of this species are often associated with enhanced nutrient supply and a spring/summer flux as determined by sediment traps [King and Howard, 2001; Nürnberg and Groeneveld, 2006; Crundwell et al., 2008]. Although this species lives in the surface mixed layer, its ontogeny means it migrates within it and hence records a wider temperature range than Gs. ruber at water depths of 50-150 m [Hemleben et al., 1989]. Moreover, recent work on G. bulloides from core-tops in the Southwest Pacific calibrated the $\mathrm{Mg} / \mathrm{Ca}$ ratios of this species to calcification depths of 75 to $150 \mathrm{~m}$ equivalent to spring/summer temperatures of $\sim 11.7$ to $13.5^{\circ} \mathrm{C}$ at ODP Site 1123 [Marr et al., 2011].

\subsubsection{Sample preparation}

From ODP Site 1123 core 'C', approximately 10-35 individual foraminifera (Gs. ruber, G. bulloides, and Uvigerina spp.) were selected and cleaned according to the methods outlined in Bolton et al., [2011]. Specimens of Gs. ruber and G. bulloides were randomly picked from the 250$355 \mu \mathrm{m}$ size fractions. Both Gs. ruber and G. bulloides are not considered to produce gametogenic calcite of any significance [Caron et al., 1990; Hamilton et al., 2008], therefore prior to geochemical analysis, the mean shell weights of $c a$. 10-15 individuals from each sample were measured with an ultra-microbalance. The shell or test area has been previously used to normalise weights [Elderfield et al., 2002], whereas other studies have used the mean diameter of G. bulloides as opposed to the height as it is less sensitive to variations in shape of the highly variable final chamber [Malmgren and Kennett, 1978]. Given test diameter is highly correlated with test area [Beer et al., 2010]; each mean weight in this study was used to calculate sizenormalised weight (SNW) as follows [Equation 1]:

$$
\mathrm{SNW}=\{\text { mean weight }(\mu \mathrm{g}) / \text { mean diameter }(\mu \mathrm{m})\} * 100 \quad \text { [Eqn. 5.1] }
$$

In addition, during the picking of Gs. ruber, its morphotype was noted where possible. High spired and normal forms were assigned the morphotype of Gs. ruber senso stricto (s.s) and smaller forms similar to those described as type b "platys" in Numberger et al. [2009] were defined as Gs. ruber sensu lato (s.l.) [e.g. Wang, 2000]. Following geochemical analysis, photographs of all samples were taken to scale using an Olympus DP70 camera attached to a 
binocular light microscope. Although morphotypes of $G$. bulloides exist, they are not as morphologically distinguishable as Gs. ruber (K. Darling, pers. comm., 2010) and were not identified separately in this study.

\subsubsection{Trace element analysis}

The ratios of $\mathrm{Mg}, \mathrm{Al}, \mathrm{Mn}, \mathrm{Zn}, \mathrm{Sr}$ and $\mathrm{Ba}$ to $\mathrm{Ca}$ were analysed by laser ablation inductively coupled plasma mass spectrometry (LA-ICP-MS) on Gs. ruber and G. bulloides as described in Chapter 3. To estimate ocean temperatures, the $\mathrm{Mg} / \mathrm{Ca}$ ratio of the oldest chamber (F-2) $\left(\mathrm{Mg} / \mathrm{Ca}_{\mathrm{chF}-2}\right)$ was analysed and converted to temperature using locally derived, chamber-specific core-top calibrations from the Southwest Pacific [Bolton et al., 2011; Marr et al., 2011] where:

For Gs. ruber:

$$
\frac{M g}{C a_{c h F-2}}=0.798 \times \exp ^{0.070 \times S S T}
$$

For G. bulloides:

$$
\frac{M g}{C a_{c h F-2}}=0.983 \times \exp ^{0.067 \times S S T}
$$

\subsubsection{Stable oxygen and carbon isotope analyses}

LA-ICP-MS is a non-destructive method and allows samples to be subsequently analysed for other geochemical proxies such as stable oxygen and carbon isotope ratios $\left(\delta^{18} \mathrm{O}\right.$ and $\left.\delta^{13} \mathrm{C}\right)$. Following trace element analysis, the same specimens of Gs. mber and G. bulloides, as well as the Uvigerina spp., were pooled and analysed for $\delta^{18} \mathrm{O}$ and $\delta^{13} \mathrm{C}$. The methods for stable isotope analysis are outlined in Chapter 3, Section 3.8.2. Analyses were performed using a Finnigan stable isotope mass spectrometer at Stanford University, California. 


\subsubsection{Estimation of the $\delta^{18} O_{s w}$ 'salinity proxy' from G. bulloides}

Over geological timescales, the $\delta^{18} \mathrm{O}_{\text {sw }}$ reflects two components. The major component of the planktonic foraminifera signal over periods greater than a few thousands years [Charles et al., 1996] are changes in continental ice volume. The second component is the $\delta^{18} \mathrm{O}_{\text {sw }}$ of the regional water mass (and/or local salinity). The two equations that were applied for Gs. ruber and $G$. bulloides are based on culturing experiments on the symbiotic foraminifera Orbulina universa (O. universa) and G. bulloides [Bemis et al., 1998] where:

For O. universa/Gs. ruber:

$\delta^{18} \mathrm{O}_{\mathrm{sw}}=\left[\mathrm{T}\left({ }^{\circ} \mathrm{C}\right)-14.9+4.8 * \delta^{18} \mathrm{O}_{\mathrm{c}}\right] / 4.8+0.27$

[Eqn. 5.4]

For G. bulloides:

$\delta^{18} \mathrm{O}_{\mathrm{sw}}=\left[\mathrm{T}\left({ }^{\circ} \mathrm{C}\right)-16.5+4.8 * \delta^{18} \mathrm{O}_{\mathrm{c}}\right] / 4.8+0.27$

[Eqn. 5.5]

Only G. bulloides is considered in the discussion due to the intermittent record of Gs. ruber. However, because both species calcify in the mixed layer, their $\delta^{18} \mathrm{O}_{\mathrm{sw}}$ should be similar. A factor of $0.27 \%$ was used to convert $\delta^{18} \mathrm{O}_{\mathrm{c}}$ of calcite measured and reported on the vPee Dee Belemite (vPDB) scale to water on the standard mean ocean water scale (SMOW).

For comparison, the global sea-level curve of Raymo et al., [2006] was converted into $\delta^{18} \mathrm{O}_{\mathrm{sw}}$ (\%) using the assumption that a relative sea level drop of $-130 \mathrm{~m}$ corresponded to a global mean $\delta^{18} \mathrm{O}_{\text {sw }}$ enrichment of $1.1 \%$ [Yokoyama et al., 2000]. Independent constraints on ice volume-sea level changes before the Late Pleistocene using shallow-marine continental margins have indicated that the sea level $\delta^{18} \mathrm{O}$ calibration may have been the same over the last $2.6 \mathrm{Ma}$ e.g. [Pekar and DeConto, 2006; Pollard and DeConto, 2009]. The component of $\delta^{18} \mathrm{O}_{\mathrm{sw}}$ that is due to changes in regional hydrology over MIS-34 -29 was then calculated by subtracting the influence of continental ice volume [Yokoyama et al., 2000; Raymo et al., 2006] and subtracting the modern surface $\delta^{18} \mathrm{O}_{\mathrm{sw}}$ value based on a local measurement close the ODP Site 1123 (H. 
Neil, pers. comm., 2009) to produce an ice-volume-free residual, $\Delta \delta^{18} \mathrm{O}_{\text {IVF-Sw }}[$ Schmidt et al., 2004]. Removing the influence of ice volume [Waelbroeck et al., 2002] and subtracting the modern surface $\delta^{18} \mathrm{O}_{\text {sw }}$ value of $0.40 \%$ for $G$. bulloides yields $\Delta \delta^{18} \mathrm{O}_{\text {IVF-sw }}$. Positive values indicate increased surface salinity due to the excess removal of $\mathrm{H}_{2}{ }^{16} \mathrm{O}$ during evaporation [Schmidt et al., 2004].

There are a number of limitations surrounding the estimation of $\delta^{18} \mathrm{O}_{\mathrm{sw}}$ and the ice-volumefree residual, which are discussed in more detail in the Supplementary Material (Section 5.8.2).

\subsection{Results}

\subsubsection{Morphotypes of Gs. ruber}

Two main morphotypes of Gs. ruber were classified; although there are some inter-gradational forms also present. Morphotypes of Gs. ruber have previously been used to indicate habitat preferences, where the normal form (senso stricto) occupies the upper water column, and the smaller form commonly referred to as sensu lato (s.l.) preferring slightly deeper waters (e.g. Steinke et al., 2003; Löwemark et al., 2005). However, throughout the glacial to interglacial cycles of MIS-34 to MIS-29, the abundance of the individual morphotypes did not vary considerably. It appears that the normal form of Gs. ruber is rare, only appearing during peak SST's (particularly MIS-31) and therefore the samples had insufficient specimens of each morphotype for a statistical comparison. However, the record suggests that the s.l. form is dominant and may be adapted to this unique setting, which is colder and more nutrient-rich than typical tropical to sub-tropical environments more common for Gs. ruber normal forms. The s.l. type is thought to be adapted to colder conditions; and has been found consistently more abundant at the margin of the distribution of Gs. ruber (M. Kucera, pers. comm., 2011).

\subsubsection{Mg/Ca ratios and ocean palaeotemperatures recorded by Gs. ruber and G. bulloides}

The pooled mean $\mathrm{Mg} / \mathrm{Ca}$ ratios measured in Gs. ruber and G. bulloides are presented in Figure 5.4 and Appendix C, Tables $\mathrm{C} 1$ and $\mathrm{C} 2$. Individually, the $\mathrm{Mg} / \mathrm{Ca}$ analyses for each sample scatter around the mean with the highest variability is found in Gs. ruber as it appears sporadically during MIS-33 and MIS-29, and prominently in MIS-31. It is absent throughout 
the remainder of the record, except in very low numbers (i.e. $\mathrm{n}<9$ ). To reflect more reliable temperatures, $\mathrm{Mg} / \mathrm{Ca}$ or SST for Gs. ruber are subsequently shown where n $>9$ as red triangles and where $n<9$ as a black line. This was an arbitrary number but examination of the more larger datasets e.g. where $\mathrm{n}=22$, a two-sample t-test did not show any significant difference between using the mean of 9 samples with the overall mean (see Supplementary Material 5.8.1, Tables 5.2a and b). This assumes that other samples share a similar relationship.

The pooled mean $\mathrm{Mg} / \mathrm{Ca}$ was chosen to estimate SST as this is the traditional method with both solution and LA-ICP-MS e.g. Anand et al., [2003]; Sadekov et al., [2008]. It also minimises error in the prediction of any one value in the data set, such that it produces the lowest amount of error from all other values in the data set. Furthermore, all of the data can be included in the estimation. One of the issues with using the mean is that it is particularly susceptible to the influence of outliers. Outliers are values that are unusual compared to the rest of the data set by being especially small or large in numerical value. However, outliers can be statistically identified (see section 5.5.1).

It should be noted that $\mathrm{Mg} / \mathrm{Ca}$ and subsequent temperatures that relate to lower numbers will be less reliable and should be interpreted with caution. Gaps between any Gs. ruber points indicate samples that did not have any Gs. ruber specimens present (Appendix C, Table C1). Also shown in Figure 5.4 are the 95\% confidence intervals for the mean of each species (grey lines in $\mathrm{A}$ and $\mathrm{B})$. 


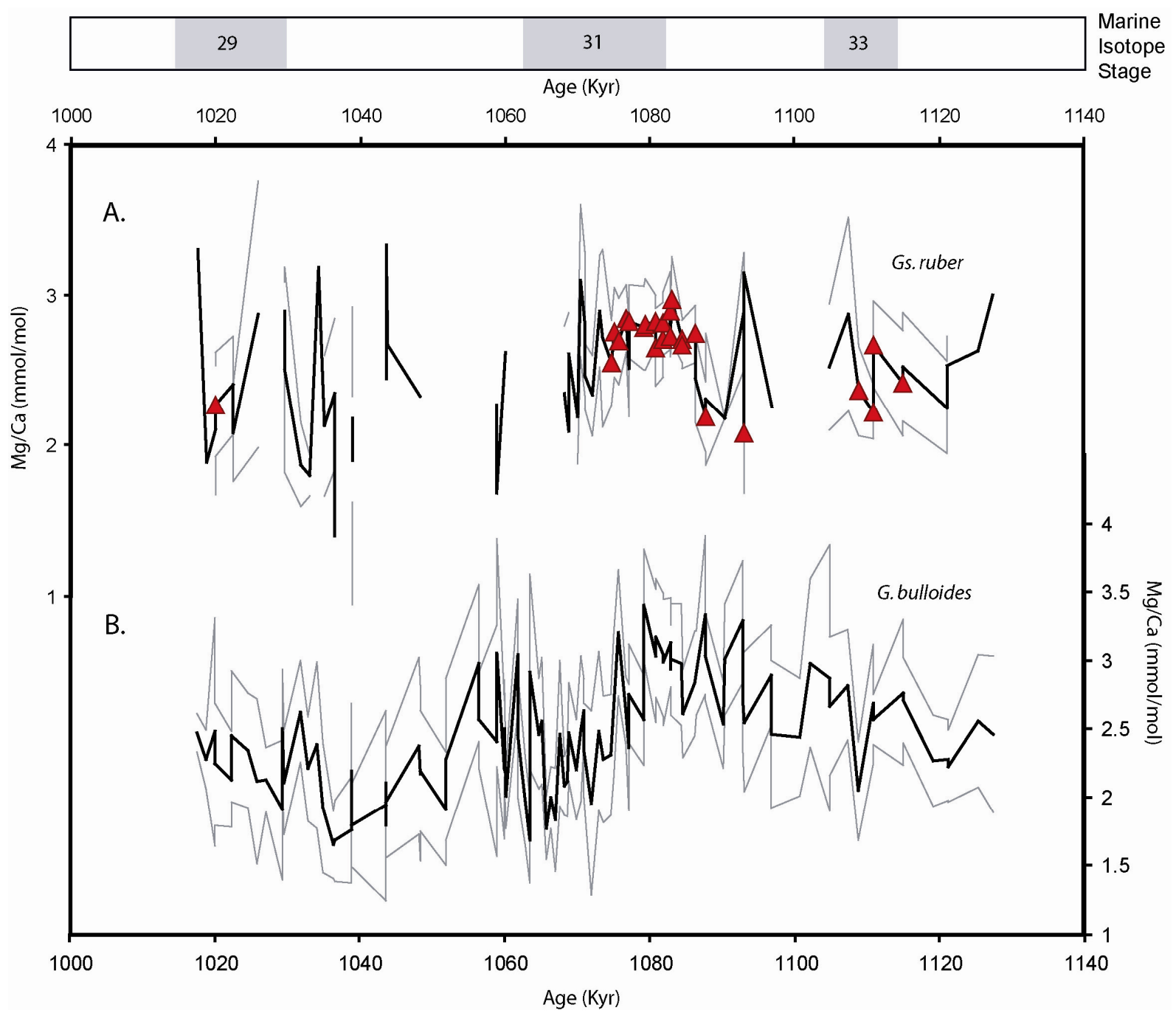

Figure 5.4: (A) Variability of mean $\mathrm{Mg} / \mathrm{Ca}$ ratios in Gs. ruber (black line), red stars indicate where the number of samples (n) >9. (B) G. bulloides (black line) through the ODP Site 1123 sediment record. The grey lines represent the $95 \%$ confidence interval of the mean. For Gs. ruber, in some samples there were no individuals, although there were sporadic amounts within the deglacial and glacial intervals. For reference the grey shaded bars (top of figure) represents the MIS interglacial stages according to the Lisiecki and Raymo, [2005] global benthic stack.

G. bulloides was present during the entire sampling interval and generally records colder SSTs than Gs. ruber (where present) (Figure 5.5), except during the SH insolation maxima of MIS-31 (1080 kyr) where both species record the highest SSTs of $\sim 18^{\circ} \mathrm{C}$ (G. bulloides) and $\sim 19^{\circ} \mathrm{C}(\mathrm{Gs}$. ruber), which are 4 to $5{ }^{\circ} \mathrm{C}$ warmer than the present (annual) SSTs at the core site. While $\mathrm{SST}_{\mathrm{Mg} / \mathrm{Ca}}$ from both species vary, they record a rapid warming of up to $\sim 19^{\circ} \mathrm{C}$ at $1080 \mathrm{kyr}$ in phase with the peak Southern Hemisphere insolation maxima. G. bulloides is the first to show 
this warming, which from $\sim 1100 \mathrm{kyr}$ onwards increases from 9.2 to $16.2^{\circ} \mathrm{C}$, although the warming appears to begin before the onset of local insolation. This is followed by a marked increase of subtropical taxa including Gs. ruber, which occurs at the expense of the Subantarctic taxa such as N. pachyderma and the eutrophic taxa G. bulloides [e.g. Crundwell et al., 2008] (Fig 5.5). The appearance of Gs. ruber generally marks a change in SSTs to those at $>14^{\circ} \mathrm{C}$, (or greater), which is the minimum temperature tolerated for this species [Bé, 1977]. Throughout the record, G. bulloides gives mean glacial and interglacial temperatures of $\sim 10.6$ and $16^{\circ} \mathrm{C}$ respectively and during mid-glacial MIS-30 records temperatures up to $6.2^{\circ} \mathrm{C}$ lower than the modern temperature at this site. For comparison, SST data calculated using Artificial Neural Networks (ANN25) from the same core are shown [Crundwell et al., 2008] and also temperature estimates using only the $\delta^{18} \mathrm{O}$ compositions from the same samples. For the latter, the Bemis et al., [1998] equation [Eq. 5.5] was used where $\mathrm{T}=16.5-4.8\left(\delta^{18} \mathrm{O}_{\mathrm{c}}-\delta^{18} \mathrm{O}_{\text {sw }}\right)$. The values of $\delta^{18} \mathrm{O}_{\mathrm{c}}$ were calculated by subtracting the modern mean ocean water reconstruction by Waelboeck et al., [2002] from the foraminiferal $\delta^{18} \mathrm{O}_{c}$. For the $\delta{ }^{18} \mathrm{O}_{\mathrm{sw}}$ modern measurements close to this studies core site were used averaging the values from $0-75 \mathrm{~m}$ (Table 5.3). 


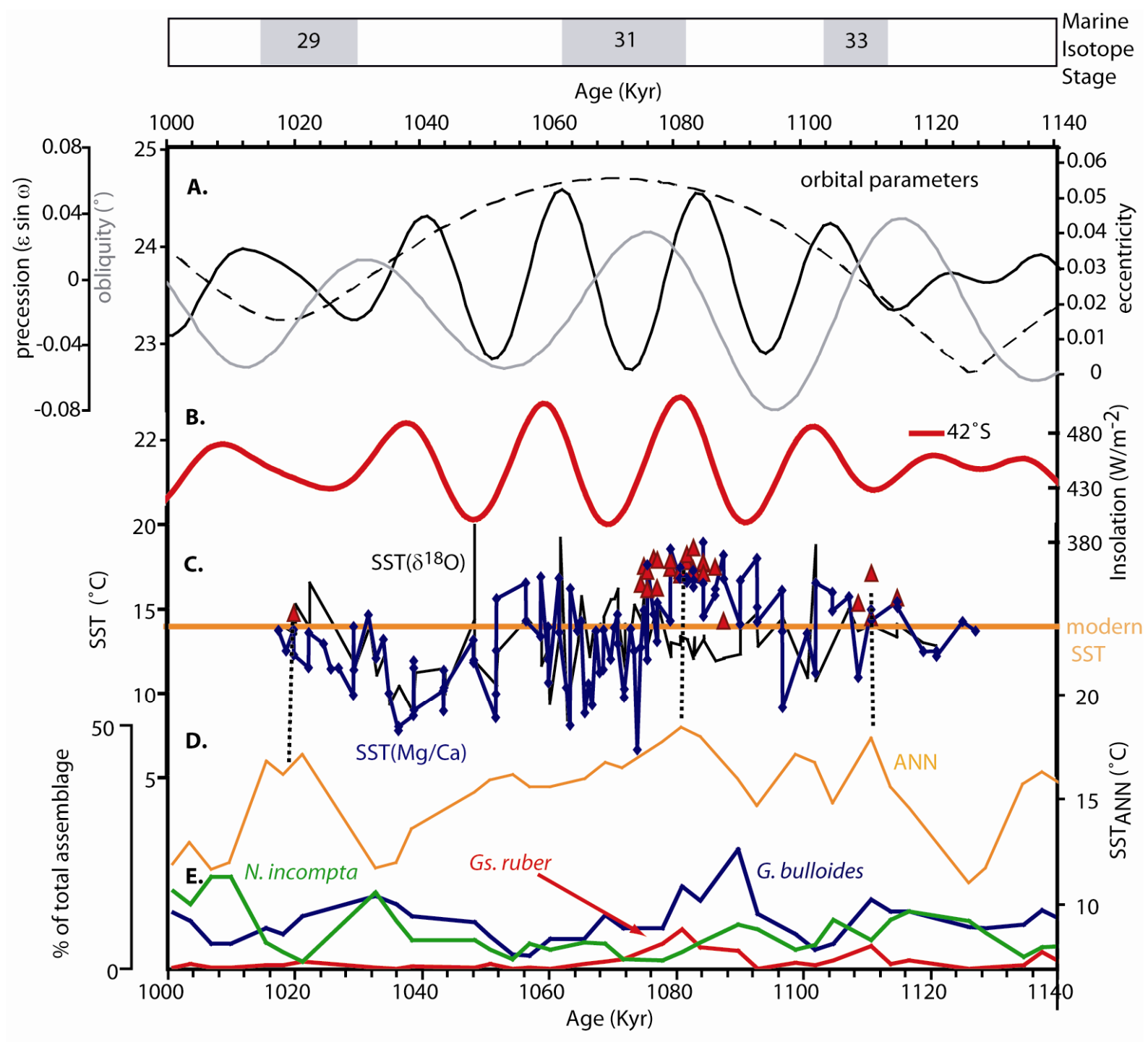

Figure 5.5: (A) Orbital parameters eccentricity, precession and obliquity [Laskar et al., 2004]. (B) Insolation at $42^{\circ} \mathrm{S}$ Laskar et al., [2004]. (C) SST derived from $\mathrm{Mg} / \mathrm{Ca}$ of Gs. ruber where $\mathrm{n}>9$ (red triangles) and G. bulloides (blue diamonds) and $\delta^{18} \mathrm{O}$ (black line) using the equation of Bemis et al., [1998] where $\mathrm{T}=16.5-4.8\left(\boldsymbol{\delta}^{18} \mathrm{O}_{\mathrm{c}}-\boldsymbol{\delta}^{18} \mathrm{O}_{\mathrm{sw}}\right)$ for G. bulloides. The standard mean ocean water reconstruction of Waelbroeck et al., [2002] and modern estimates of $\delta^{18} \mathrm{O}_{\text {sw }}$ from the Southwest Pacific Ocean (Helen Neil, unpublished data, Table 5.3) were used. (D) SST calculated from artificial neural network data in Crundwell et al., [2008] re-calibrated onto this studies new age model. (E) Planktonic foraminiferal assemblage data also from Crundwell et al. [2008] showing the percentage abundance of Gs. ruber, G. bulloides and N. incompta. The horizontal orange line in B is the modern mean SST $\left(14.7^{\circ} \mathrm{C}\right)$ at ODP Site 1123. Dotted lines indicate where peak SST(ANN) coincide with Gs. ruber maxima. For reference the grey shaded bars (top of figure) represents the MIS interglacial stages according to the Lisiecki and Raymo, [2005] global benthic stack. 


\subsubsection{Other trace element data (Al, Mn, Sr, Ba and $\mathrm{Zn} / \mathrm{Ca})$ in $\mathrm{Gs}$. ruber and G. bulloides}

Figure 5.6 shows the $\mathrm{Mn}, \mathrm{Sr}, \mathrm{Ba}$ and $\mathrm{Zn} / \mathrm{Ca}$ ratios measured in Gs. ruber and G. bulloides. $\mathrm{Al} / \mathrm{Ca}$ ratios can be used to screen for silicate contamination of foraminiferal tests, which may also affect $\mathrm{Mg} / \mathrm{Ca}$ ratios. The average $\mathrm{Al} / \mathrm{Ca}$ ratios for $\mathrm{Gs}$. ruber and $\mathrm{G}$. bulloides were 0.35 and 0.49 $\mathrm{mmol} / \mathrm{mol}$ respectively and did not significantly co-vary with $\mathrm{Mg} / \mathrm{Ca}$ suggesting that samples were unaffected by silicate/clay contamination. The $\mathrm{Mg} / \mathrm{Ca}$ and $\mathrm{Mn} / \mathrm{Ca}$ ratios in G. bulloides positively co-vary to some extent over the sampling period with $\mathrm{Mn} / \mathrm{Ca}$ varying between $\sim 0.1$ and $0.4 \mathrm{mmol} / \mathrm{mol}$ (Figure 5.6). A similar relationship between $\mathrm{Mg} / \mathrm{Ca}$ and $\mathrm{Mn} / \mathrm{Ca}$ ratios is observed in the raw Gs. ruber data (not shown in Figure 5.6), although this is less clear compared to with $G$. bulloides, perhaps due to the smaller number of analysed Gs. ruber samples. 


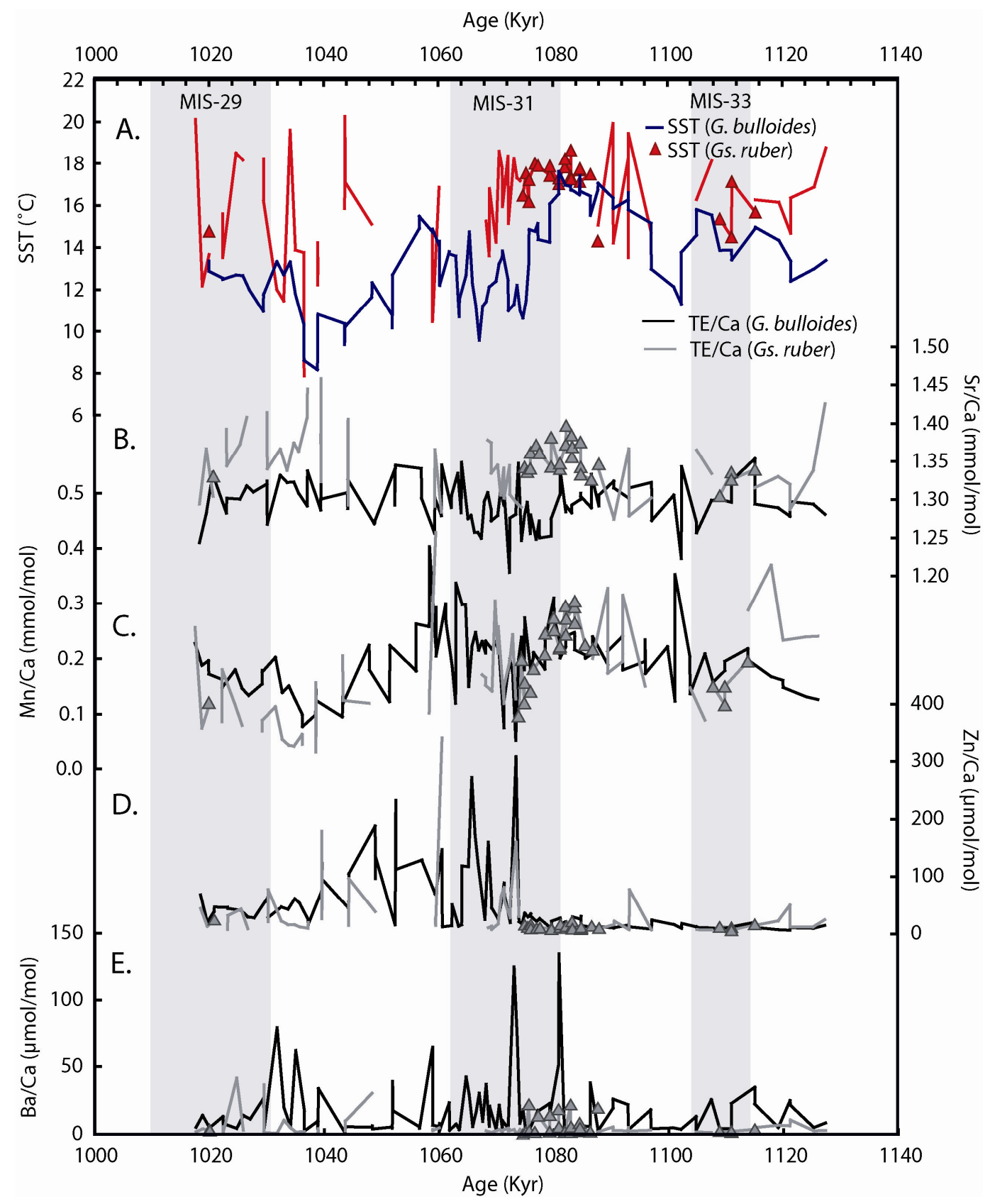

Figure 5.6 (previous page): (A) SST derived from $\mathrm{Mg} / \mathrm{Ca}$ ratios of Gs. ruber (red triangles/line) and G. bulloides (blue line) (B) Sr/Ca ratios in Gs. ruber (grey triangles/line) and G. bulloides (black line) (C) $\mathrm{Mn} / \mathrm{Ca}$ ratios in Gs. ruber (grey triangles/line) and G. bulloides (grey triangles/line) (D) $\mathrm{Zn} / \mathrm{Ca}$ ratios measured in Gs. ruber (grey triangles/line) and G. bulloides (black line) and (E) Ba/Ca ratios measured in Gs. ruber (grey triangles/line) and G. bulloides (black line). For reference the grey shaded bars represent the MIS interglacial stages according to the Lisiecki and Raymo, [2005] global benthic stack. All samples are 3 -point moving averages. 
In G. bulloides, Sr/Ca ratios throughout the entire record do not deviate from 1.20 to 1.35 $\mathrm{mmol} / \mathrm{mol}$. Similarly, Sr/Ca ratios for Gs. ruber show a restricted range from 1.24 to 1.56 $\mathrm{mmol} / \mathrm{mol} \mathrm{Zn} / \mathrm{Ca}$ ratios are low throughout the record with values typically $<400 \mu \mathrm{mol} / \mathrm{mol}$. However, after $1070 \mathrm{kyr}, \mathrm{Zn} / \mathrm{Ca}$ ratios show consistently higher values than the remainder of the record. Correspondingly, the $\mathrm{Ba} / \mathrm{Ca}$ ratios throughout the record are low, typically $<50$ $\mu \mathrm{mol} / \mathrm{mol}$. There are however, a number of excursions where the $\mathrm{Ba} / \mathrm{Ca}$ is approximately three times higher during MIS-31 and throughout the glacial period of MIS-30 there are three excursions between $\sim 50-100 \mu \mathrm{mol} / \mathrm{mol}$.

\subsubsection{Stable isotope data and the $\delta^{18} \mathrm{O}_{\text {sw }}$ 'salinity proxy' from $G$. bulloides}

The estimated duration of MIS-31 from the planktic $\delta^{18} \mathrm{O}_{\mathrm{c}}$ record is $\sim 20 \mathrm{kyr}$ (1094 to 1074 kyr), as compared to 10-15 kyr in the benthic curve (1082 to $1067 \mathrm{kyr}$ ) (Figure 5.7). The G. bulloides $\delta^{18} \mathrm{O}_{\mathrm{c}}$ record over MIS32/31 displays a glacial-interglacial change from $\sim-1.5$ to $0.5 \%$. The $\delta^{18} \mathrm{O}_{\mathrm{c}}$ record from G. bulloides is similar to its paired $\mathrm{SST}_{\mathrm{Mg} / \mathrm{Ca}}$ record except that the $\delta^{18} \mathrm{O}_{\mathrm{c}}$ data are offset during the interglacial of MIS-31 when $\delta^{18} \mathrm{O}_{\mathrm{c}}$ lags the $\mathrm{SST}_{\mathrm{Mg} / \mathrm{Ca}}$ record by $\sim 10$ kyr (Figure 5.8).

The $\delta^{13} \mathrm{C}_{\mathrm{c}}$ data for Gs. ruber are sparse and not plotted on Figure 5.7 but are generally in phase with $\delta^{18} \mathrm{O}_{\mathrm{c}}$ i.e. where $\delta^{18} \mathrm{O}_{\mathrm{c}}$ is depleted, $\delta^{13} \mathrm{C}_{\mathrm{c}}$ is enriched. This pattern is not observed for $G$. bulloides, which during MIS-33 and from MIS-30 onwards has antiphased $\delta^{18} \mathrm{O}_{c}$ and $\delta^{13} \mathrm{C}_{c}$. During the MIS-31 peak, the planktic $\delta^{13} \mathrm{C}_{\mathrm{c}}$ and $\delta^{18} \mathrm{O}_{\mathrm{c}}$ are comparable to the benthic record, i.e. depleted in $\delta^{18} \mathrm{O}_{\mathrm{c}}$ and enriched $\delta^{13} \mathrm{C}_{\mathrm{c}}$ but are not in phase with the SST. The peak of MIS-31 is more prolonged than the benthic record, with the highest SST at $\sim 1080 \mathrm{kyr}$, coincident with the peak summer hemisphere $(\mathrm{SH})$ insolation maxima. The most depleted $\delta^{18} \mathrm{O}_{\mathrm{c}}$ indicates to an extent, the warmest temperatures are some $8 \mathrm{kyr}$ later (1088 kyr). In Gs. ruber, the pattern prevalent in G. bulloides is not similar. The concurrent SSTs from both Gs. ruber and G. bulloides suggest a change in the upper surface waters during the peak of MIS-31 when these species record almost identical SST. However, at $1078 \mathrm{kyr}$, whilst the inferred SST's by Gs. ruber remain high, G. bulloides SST decrease until $1073 \mathrm{kyr}$ when Gs. ruber disappears from the sediment record. By examining the difference in $\delta^{13} \mathrm{C}_{\mathrm{c}}$ from planktonic and benthic carbon isotopes measured i.e. $\Delta \delta^{13} \mathrm{C}_{\mathrm{plk} \text {-ben }}$ (Figure 5.7), a qualitative interpretation can be made. Large 
changes in $\Delta \delta^{13} \mathrm{C}_{\text {plk-ben }}$ could indicate increased strength of export production and meridional overturning in the global ocean [Oliver et al., 2009]. The $\Delta \delta^{13} \mathrm{C}_{\text {plk-ben }}$ is enriched at the MIS-33/32 boundary and the glacial of MIS-29. However, from MIS-32/31 there is a general gradual increase in the $\Delta \delta^{13} \mathrm{C}_{\text {plk-ben. }}$

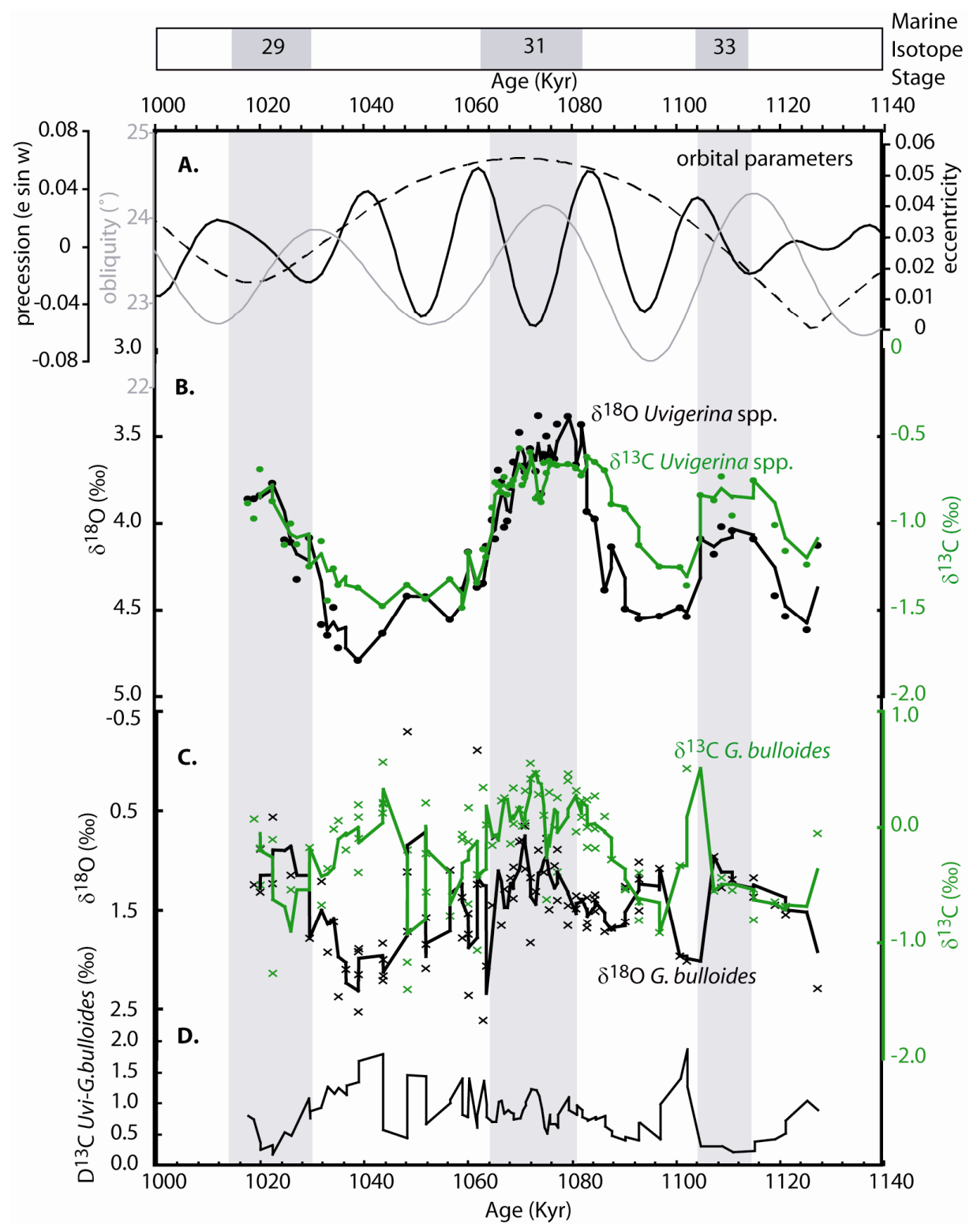

Figure 5.7: (A) Orbital parameters [Laskar et al., 2005]. (B) $\delta^{18} \mathrm{O}$ (black curve) and $\delta^{13} \mathrm{C}$ (green curve) from Uvigerina species along with (C) $\delta^{18} \mathrm{O}$ (black) and $\delta^{13} \mathrm{C}$ (green) for G. bulloides (3-pt mean). (D) The surface to deep water carbon isotope gradient as inferred from the $\Delta^{13} \mathrm{C}$ from Uvigerina - G. bulloides. For reference the grey shaded bars (top of figure) represents the MIS interglacial stages according to the Lisiecki and Raymo, [2005] global benthic stack. 
At the time of peak SH insolation at MIS-31 similar values of $\delta^{18} \mathrm{O}_{\text {sw }}$ are obtained, 1.71 and $1.80 \%$ for Gs. ruber and G. bulloides respectively (Figure 5.8, Tables C4 and 5, Appendix C). The $\delta^{18} \mathrm{O}_{\text {sw }}$ for both species are more enriched compared to modern annual $\delta^{18} \mathrm{O}_{\text {sw }}$ values of $0.57 \%$ for $0.40 \%$ respectively (Supplementary Table 5.3). Following the SH insolation maxima (1080 kyr), the $\delta^{18} \mathrm{O}_{\text {sw }}$ in $G$. bulloides rapidly depletes reaching its minima during the $\mathrm{NH}$ insolation maxima to $\sim 0.15 \%$ o. This depletion in $\delta^{18} \mathrm{O}_{\text {sw }}$ also occurs concurrently with a decrease in SST recorded in G. bulloides. Following the $\mathrm{NH}$ insolation maxima, the $\delta^{18} \mathrm{O}_{\text {sw }}$ becomes more enriched, in concert with rapidly increasing SST. Depletion in $\delta^{18} \mathrm{O}_{\text {sw }}$ occurs at $1058 \mathrm{kyr}, \mathrm{G}$. bulloides also show an increase in SST to $15^{\circ} \mathrm{C}$. The general trend of $\boldsymbol{\delta}^{18} \mathrm{O}_{\mathrm{sw}}$ is less variable, despite the overall decrease in SST. There is another brief depletion in $\delta^{18} \mathrm{O}_{\text {sw }}$ MIS-29 which is also in phase with a small increase in $\mathrm{NH}$ insolation.

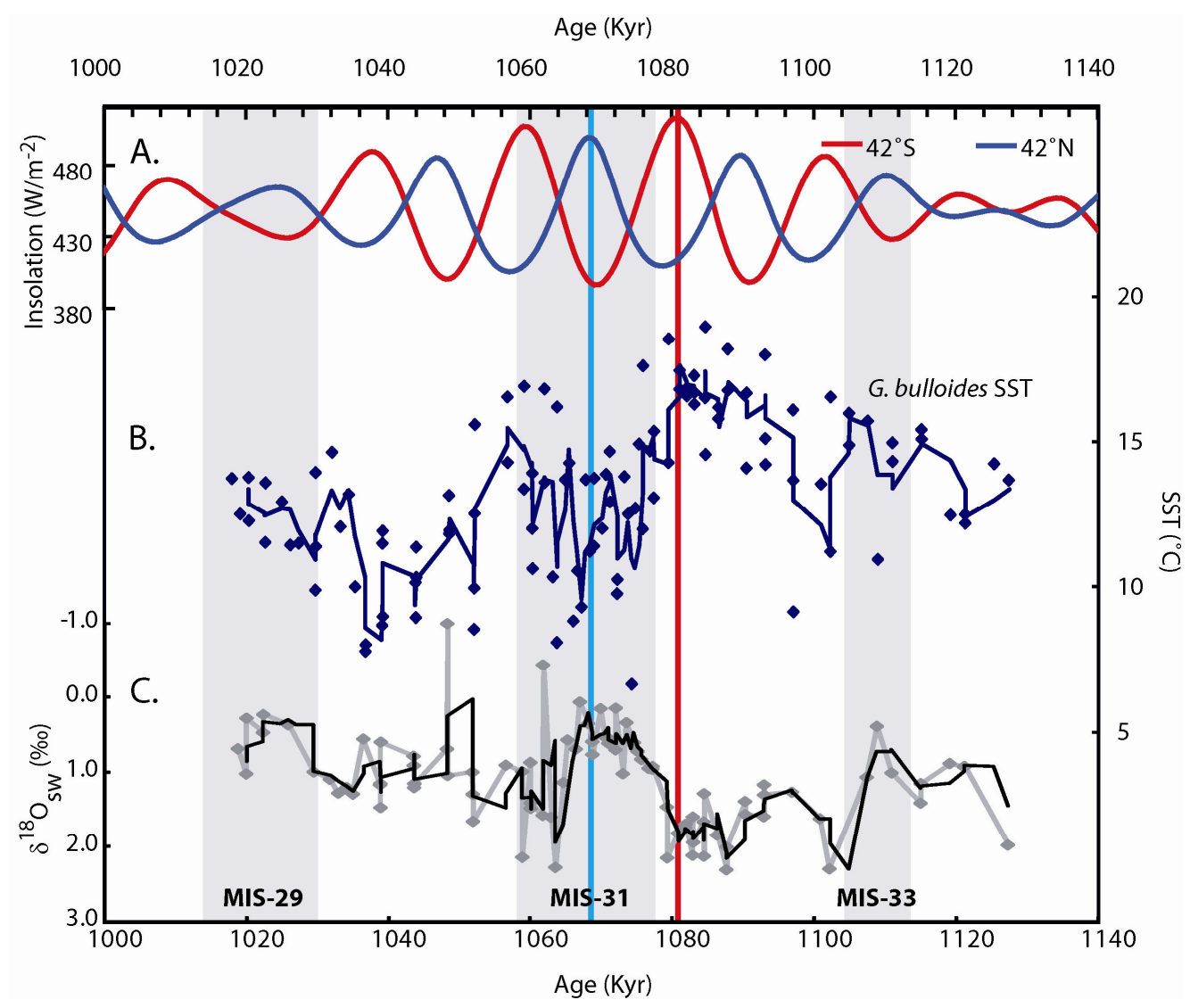

Figure 5.8: (A) Insolation at $42^{\circ} \mathrm{S}$ (red) and $42^{\circ} \mathrm{N}$ (blue) [Laskar et al., 2004]. (B) SST calculated from $\mathrm{Mg} / \mathrm{Ca}$ ratios in G. bulloides. (C) Calculated $\boldsymbol{\delta}^{18} \mathrm{O}_{\text {sw }}$ using the palaeotemperature equations from Bemis et al, [1998] where: $\mathrm{T}$ $=16.5-4.8\left(\boldsymbol{\delta}^{18} \mathrm{O}_{\mathrm{c}}-\boldsymbol{\delta}^{18} \mathrm{O}_{\mathrm{sw}}\right)$ for G. bulloides. Blue solid line indicates 3-pt running mean G. bulloides and grey solid line show raw data. Blue and red lines indicate $\mathrm{NH}$ and $\mathrm{SH}$ insolation maxima. For reference the grey shaded vertical bars represent the MIS interglacial stages according to the Lisiecki and Raymo, [2005] global benthic stack. 


\subsubsection{Changes in size and weight of $G$. bulloides}

The mean measurements of the width and height of each foraminiferal individual reveals a normal distribution with an average width (the normalisation parameter for weight), of $315 \mu \mathrm{m}$ for Gs. ruber and $343 \mu \mathrm{m}$ for G. bulloides (Appendix C, Table C6). Only G. bulloides weights are considered here as this species is present throughout the sampling interval.

Size-normalised weights (SNW) are heavier in glacial periods with lighter SNW in inter-glacial periods ranging from 2.1 to $5.7\left(10^{2} \mu \mathrm{g} / \mu \mathrm{m}\right.$ ) (Figure 5.9). The trend is more prominent during interglacial terminations, when decreasing SST coincides with increasing weight. However, from $\sim 1100-1070 \mathrm{kyr}$ the opposite trend is observed. The predicted SNW of G. bulloides, were derived from local core top data where predicted weight $=\left[\left(\ln \left(\mathrm{SST}_{\mathrm{Mg} / \mathrm{Ca}} / 31.8\right)\right] /-30.5[\right.$ Marr et al., 2011] [Eqn. 5.6], confirm the deviation observed during the study interval. The predicted SNW are generally in-phase with the actual SNW throughout the record, but as described above become significantly offset at $\sim 1100$ until $\sim 1070 \mathrm{kyr}$.

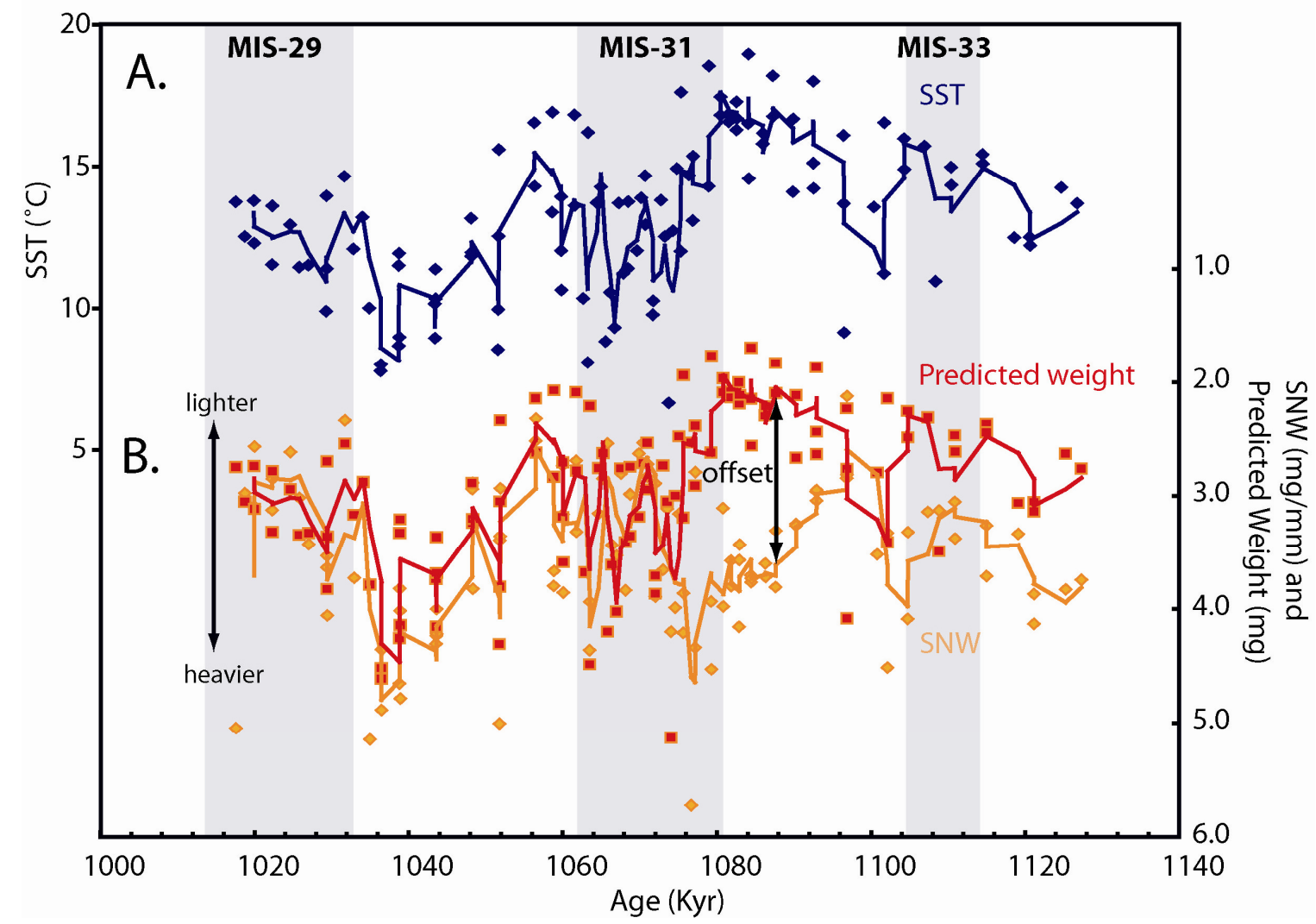

Figure 5.9: (A) G. bulloides derived SST versus (B) actual SNW and predicted SNW. Note that the (B) scale is reversed. 


\subsection{Discussion}

\subsubsection{Errors associated with the estimate}

The uncertainties of average foraminiferal $\mathrm{Mg} / \mathrm{Ca}$ ratios obtained by solution and LA-ICP-MS methods are not necessarily the same. LA-ICP-MS analysis of individual foraminifera allows examination of the components of mean $\mathrm{Mg} / \mathrm{Ca}$ ratios. At first glance, the uncertainties of $\mathrm{Mg} / \mathrm{Ca}$ ratios obtained from LA-ICP-MS methods appear to be larger than those from solution work. However, the reality is that unlike those obtained by LA-ICP-MS, the means obtained from solution work only contain analytical error, and do not give any information about variability. To compare the variances or 'errors' obtained from the two methods is therefore not appropriate. This issue highlights some key points:

(1) The scatter from both species in this study is not attributable to analytical error as multiple analyses from a single chamber as measurement of $\mathrm{Mg} / \mathrm{Ca}$ is typically $\left(\sim \pm 0.5^{\circ} \mathrm{C}\right)$. Larger 'errors' associated with each individual analysis largely reflect the environmental or biological variability within individual (intra) samples.

(b) For down-core work, results from both solution and LA-ICP-MS methodologies are limited by the provenance of individual foraminifera down the core. Often, there is a trade-off between resolution and quantity. This is a problem shared by both methodologies, and it is often simply not possible to use more foraminifera, because simply there are none. Furthermore, in Sadekov et al., [2008], a sample size of 15 Gs. ruber tests corresponded to an uncertainty of $2^{\circ} \mathrm{C},\left( \pm 1^{\circ} \mathrm{C}\right)$ which was almost identical to the sample size predicted by power analysis for an SST of $28^{\circ} \mathrm{C}$ (in that particular study location) and a target uncertainty of $2^{\circ} \mathrm{C}$. Increasing the uncertainty to discern a $1^{\circ} \mathrm{C}$ difference in SST with $95 \%$ confidence, required the analysis of $\sim 250$ tests at a SST of $18^{\circ} \mathrm{C}$ and $\sim 60$ tests at $28^{\circ} \mathrm{C}$.

(c) 'Error' estimates from solution work are invariably smaller because these only contain measurement error - i.e. from repeated measurements of the same solution. They do not contain any information about the variability (environmental or biological) of the individual foraminifera that make up the sample. It is currently not possible to analyse 
individual foraminifera by solution. However more recent studies are now using flow through techniques to clean tests followed by solution analysis on Gs. ruber using a smaller number of pooled specimens (e.g. 10 individuals) [Haarman et al., 2011]. The latter study showed the $\mathrm{Mg} / \mathrm{Ca}$ ratios from the same sample ranged between the lowest $(2.20 \mathrm{mmol} / \mathrm{mol})$ and highest $(4.94 \mathrm{mmol} / \mathrm{mol})$. These $\mathrm{Mg} / \mathrm{Ca}$ ratios are similar to those by Sadekov et al. [2008] for G. ruber from Sargasso Sea that ranged from 1.75 $\mathrm{mmol} / \mathrm{mol}$ to $5.53 \mathrm{mmol} / \mathrm{mol}$. This compares with a range of $1.29 \mathrm{mmol} / \mathrm{mol}$ to 3.79 $\mathrm{mmol} / \mathrm{mol}$ (maximum range of $2.51 \mathrm{mmol} / \mathrm{mol}$ ), from the down core measurements of Gs. ruber in this study (MIS-34 to 29). For G. bulloides the largest range through the MIS-29 to 34 was $3.86 \mathrm{mmol} / \mathrm{mol}(1.01 \mathrm{mmol} / \mathrm{mol}$ to $4.87 \mathrm{mmol} / \mathrm{mol})$ compared to core top and plankton tow (some measured by LA-ICP-MS) which exhibited ranges of $4.3 \mathrm{mmol} / \mathrm{mol}$ [Ferguson et al., 2008] and $3.6 \mathrm{mmol} / \mathrm{mol}$ [Van Raden et al., 2011]. Although these comparisons are from different oceanographic settings they show reasonable variability between other samples that appear comparable to those in during the MIS-34 to 29 intervals. Similar comparisons with G. bulloides from other temperate regions will help reveal whether the variability down core is a reasonable representation compared to core top studies.

(d) Calibrations should be based on assemblages of means rather than individuals, because the mean is the value most common, and produces the lowest amount of error from all other values in the data set. Given the inability to increase the numbers of foraminifera that make up each average, (see above), the other approach is to establish whether the sample mean is a reasonable estimate of the population mean. For this to be true, the sample mean should not contain outliers.

(e) Examination of the individual measurements does not reveal any outliers. For example, if the highest and lowest $5 \%$ of the samples are removed from the mean, the value does not change by more than $\sim 0.1 \mathrm{mmol} / \mathrm{mol}$. A Dixon's Q test [Miller and Miller, 1984] can be performed to test this hypothesis. The test identifies rogue samples, which then should be eliminated from the rest of the sample as it would significantly bias the mean value. However application of this test on the dataset does not reveal any significant outliers. Therefore the variability of the individuals reflects the mean value (see Supplementary material 5.8.1, Table 5.6). 
(f) Additionally, the relationships found in Bolton et al., [2011] and Marr et al., [2011] that show significant differences between the older (e.g. F-2) chambers with the final chamber (F), still pertains (Appendix C, Tables C7 and C8).

(g) It has been previously suggested that mean $\mathrm{Mg} / \mathrm{Ca}$ variability of any given sample is partly controlled by biological factors [e.g. Bentov et al., 2005; 2006; Lea et al., 1999]. However, calibrations using the mean value still show a statistically significant relationship with temperature.

(h) The $\mathrm{Mg} / \mathrm{Ca}$ derived SST values compared to those measured by artificial neural networks (ANN) in the same core [Crundwell et al., 2008] and calculated only from $\delta^{18} \mathrm{O}_{\mathrm{c}}$ show reasonably comparable trends (Figure 5.5). The main differences lie in the lower resolution of the ANN study, and the fact that their SST estimates are recording mean surface annual SST, and is thus more comparable to SST estimates of Gs. ruber. This can be seen particularly where the local solar insolation is high, as Gs. ruber numbers increase and are in phase with the peak SST recorded by ANN (Figure 5.5). The ANN-SST estimates were calibrated to surface temperatures where as Gs. ruber is calibrated at $(0-50 \mathrm{~m})$, hence peak SST from ANN data appear to be more in phase with G. ruber SST. The $\delta^{18} \mathrm{O}_{\mathrm{c}}$ data however, show that the magnitudes between the two temperature proxies are comparable, except for the excursion during 1090-1080 (see below).

\subsubsection{Palaeo-SSTs during MIS-34 to 29}

During the cooling of MIS 33-32 (1110 to $1095 \mathrm{kyr}$ ) the lower $\mathrm{SST}_{\mathrm{Mg} / \mathrm{Ca}}$ suggest the northward encroachment of SAW across the eastern end of Chatham Rise, where the absence of bathymetric constraints permit more water mass exchange compared to the main body of the Rise [Chiswell and Sutton, 1998] and with northward migration of SAW and a reduced Subtropical inflow [Hayward et al., 2008]. During glacial stages movement of SAW northward is likely to occur with jetting of cold SAW across Mernoo Saddle where presently some exchange between northern STW and SAW occurs [Nelson et al., 2000]. It was proposed that intensified current flows south of the Chatham Rise during the last glaciation, were a consequence of 
more compressed SAW, lowered sea level, bathymetry, and expanded and stronger westerly winds [Nelson et al., 2000; Carter et al., 2004a]. These studies suggested that this system led to accelerated leakage to the north of Australasian SAW and upwelled Antarctic Intermediate Water (AIW) over Mernoo Saddle in a modified and intensified Southland Current with the expanded cold water masses displacing the south-flowing warm East Cape Current off the South-eastern North Island. Other possible movement may have occurred at the deep eastern end of Chatham Rise (c.f. Chiswell and Sutton, 1998). Additionally, Ba/Ca and $\mathrm{Zn} / \mathrm{Ca}$ ratios at this time remain low, suggesting the presence of micro-nutrient low SAW. Microfaunal assemblage data from ODP Site 1123 show a comparable increase in the Subantarctic species N. pachyderma and eutrophic taxa whereas with a small decrease in Subtropical taxa [Crundwell et al., 2008].

Warming of $\mathrm{SST}_{\mathrm{Mg} / \mathrm{Ca}}$ during MIS32/31 is concurrent with an increase in SH insolation, small (equivalent to $\sim 3 \mathrm{~m}$ ) increases in modelled sea level [Raymo et al., 2006; Pollard and DeConto, 2009], and perhaps precessional forcing of the SPSG [Villanueva et al., 1998; Herbert et al., 2001]. The increase in SST could also be reflecting changes in obliquity as the warming appears to begin at the onset of the increase in the obliquity phase (Figure 5.10). The near-identical SSTs of $18-19{ }^{\circ} \mathrm{C}$ recorded by Gs. ruber and G. bulloides during peak MIS-31 at $\sim 1080 \mathrm{kyr}$ are similar but slightly higher than those measured using artificial neural networks that estimate peak SST of $18-18.5^{\circ} \mathrm{C}$ [Crundwell et al., 2008]. In comparison, the temperature estimates from $\delta^{18} \mathrm{O}$ at the same time do not suggest a significant warming. This could be related to local regional hydrography and/or ice volume effects. For example local changes may also strongly influence the $\delta^{18} \mathrm{O}$ water — salinity relationships [Dekens et al., 2001].

As modern G. bulloides in the modern Southwest Pacific Ocean calcifies at $\sim 75-150 \mathrm{~m}$ water depth and modern Gs. ruber at 0-50 m depth, one could surmise that the surface mixed layer was deeper or that $G$. bulloides calcified at similar (shallower) depths to Gs. ruber at this time. During the Antarctic Cold Reversal and Younger Dryas ( 13.5 to $12 \mathrm{kyr}$ ), the range of planktic $\delta^{18} \mathrm{O}$ from Gs. ruber, G. bulloides and G. inflata at Site MD2121, north of Chatham Rise $\left(40^{\circ} 22.935^{\prime} \mathrm{S} ; 177^{\circ} 59.68^{\prime} \mathrm{E}, 2314 \mathrm{~m}\right)$ had converged into a narrow band. This has been related to deeper mixed surface waters that were characteristic of the cooling trend driven from Antarctica, forcing a northward expansion of cold atmospheric and oceanic temperatures 
[Carter et al., 2008]. Combined with the three fold increase in $\mathrm{Zn} / \mathrm{Ca}$ and $\mathrm{Ba} / \mathrm{Ca}$ (Figure 5.6), the data suggest an intensification of the micro-nutrient rich STW as a result of increased forcing at the pole (precession), such that the South Pacific Subtropical gyre [Roemmich, 2007] shifted southward. This shift in the water mass with increasing SST could explain the similar SST in both Gs. ruber and G. bulloides as a potential permanent shift in ENSO also occurred during this time in the Western tropical Pacific [Russon et al., 2011]. It has been suggested that STW mass movement to the south is advected across from the East Cape Current and over Mernoo Saddle via the Southland Current (SC) (Figure 5.2). During other significantly warmer interglacials, such as MIS-11, the SC passed around the south end of New Zealand during MIS-11, 3 and 1 [Hayward et al., 2008].

Other Southern Hemisphere studies from the same latitude to ODP Site 1123 located in the open ocean e.g. ODP Site 1090 in the SE Atlantic, (42 ${ }^{\circ} 54.8$ 'S, $8^{\circ} 53.9^{`} \mathrm{E}, 3700 \mathrm{~m}$ ) [Becquey and Gersonde, 2002; Maiorano et al., 2009] or further south at ODP Site 704 (46 $52.766^{\prime}$, $0^{\circ} 25.23^{\prime} \mathrm{E}$, $2350 \mathrm{~m}$ ) [Allen and Warnke, 1991] and ODP Site 1094 (53.2 ${ }^{\circ} \mathrm{S}, 5.1^{\circ} \mathrm{E}, 2818 \mathrm{~m}$ ) [Kanfoush et al., 2002] suggest a southward migration of the STF during MIS-31 that may have resulted from either modification of poleward heat transport and/associated zonal winds or polar amplification of an orbitally induced climate. During the Late Pleistocene, Howard and Prell [1992] in their reconstruction of the Southern Indian Ocean, found that the STF was north of its present position in the open ocean $\left(40^{\circ} \mathrm{S}\right)$ for most of the past $500 \mathrm{kyr}$ and south only during four major interglacial periods including MIS-11.

The warmest SSTs recorded during MIS-31 are also concomitant with a sudden increase in subtropical taxa that also suggest an enhanced subtropical inflow via SPSG, which is manifested by a small local increase in salinity (Figure 5.11). Following the peak SH insolation maxima, between 1080 and $1070 \mathrm{kyr}$, the SSTs recorded by Gs. ruber and G. bulloides slowly decrease. The minimum temperature recorded during MIS-30 is $6.7^{\circ} \mathrm{C}\left(6.3^{\circ} \mathrm{C}\right.$ colder than modern interglacial temperatures). At the SH insolation minima, Gs. ruber disappears from the record. A second peak in planktic SSTs from G. bulloides occurs in conjunction with the precession maxima again suggesting an intensification of the SPSG accompanied by a southward movement of the STF (Fig 5.10). It can be argued that a third, but much lower amplitude SST warming occurred around $1040 \mathrm{kyr}$ thus confirming precessional forcing of the warming at ODP 1123. 


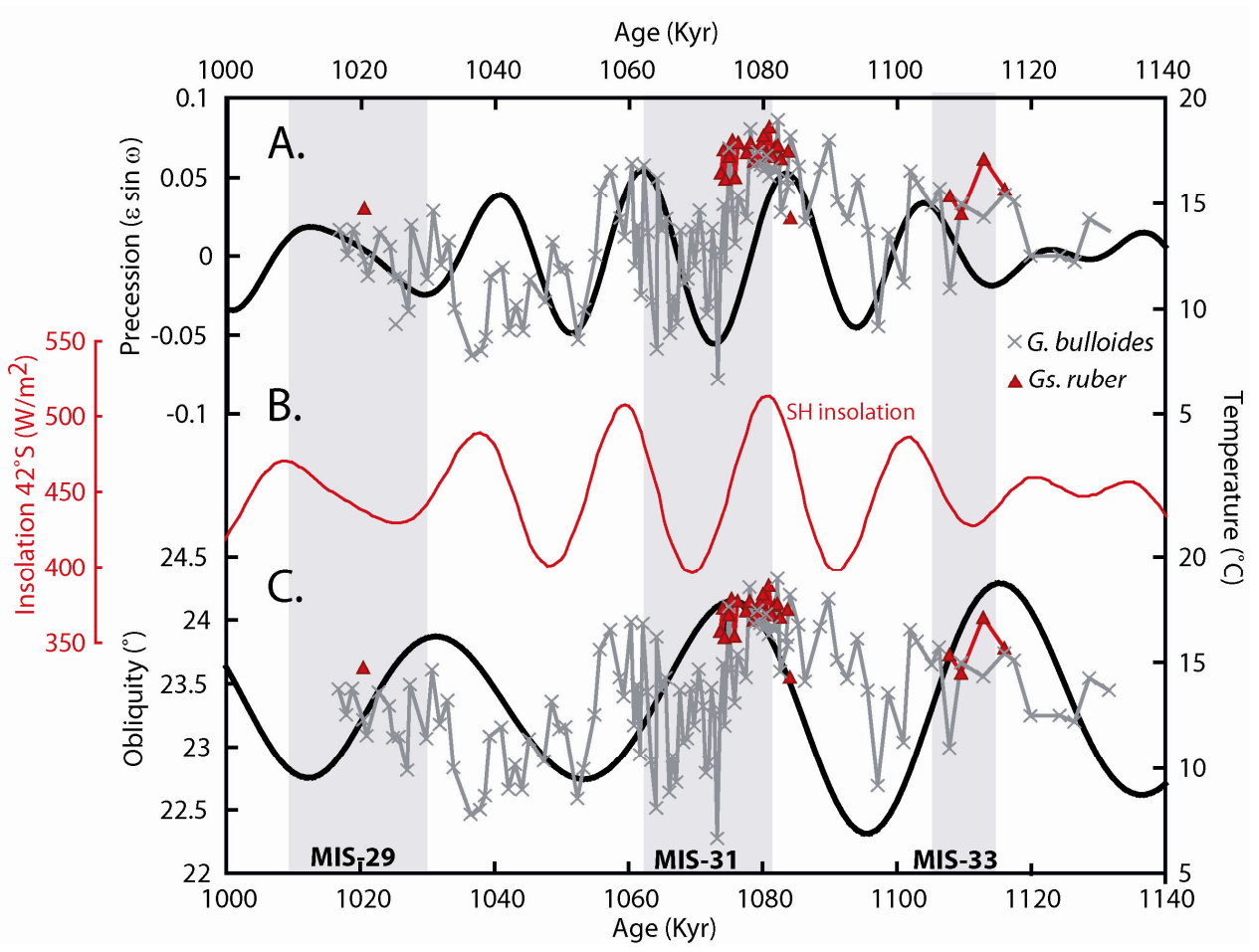

Figure 5.10: (A) Comparison between $\mathrm{SST}_{\mathrm{Mg} / \mathrm{Ca}}$ with orbital precession. (B) Insolation values for $42^{\circ} \mathrm{S}$ and (C) comparison between $\mathrm{SST}_{\mathrm{Mg} / \mathrm{Ca}}$ orbital obliquity over 1140 to $1000 \mathrm{kyr}$. Grey crosses and profile show G. bulloides SSTs, and black filled triangles show Gs. ruber SSTs where n $>9$. Gs. ruber appears during obliquity peaks whereas G. bulloides SSTs appear to be in phase partially with precession.

\subsection{3 $\delta^{18} \mathrm{O}$ and palaeo-salinity during MIS-33 to 29}

The changes in SST lead the changes in $\delta^{18} \mathrm{O}$ by as much as $10 \mathrm{kyr}$, suggesting that temperature changed before global ice volume and/or local hydrology [Lea et al., 2000]. The paired measurements avoid any possible chronological offset due to seasonal or temporal bias, offsets in water column production depth, or from bioturbation. The main restriction lies in the accuracy of the absolute timing of events, which relies on the quality of the absolute chronology, of the $\delta^{18} \mathrm{O}$ record to the benthic curve of Lisiecki and Raymo [2005].

Following conversion to an ice free residual, $\Delta \delta^{18} \mathrm{O}_{\mathrm{IVF}-\mathrm{sw},}$, at $\mathrm{ODP}$ Site 1123 in G. bulloides, appears to record more positive values throughout the study period, thus indicating more saline conditions in this region than present day. During MIS-31, where the SST is highest, there is a concurrent increase in salinity, and Southern Hemisphere sea-level. This would indicate that any freshwater signal from melting Antarctica ice sheets is not observed at ODP 
Site 1123. However, a decrease in $\Delta \delta^{18} \mathrm{O}_{\text {IVF-sw }}$, related to a large freshening from global $\delta^{18} \mathrm{O}_{\text {sw }}$ is observed during 1080 to $1076 \mathrm{kyr}$, which coincides with peak NH insolation maxima (Figure 5.11). This suggests a significant contribution in freshwater from retreat of the NH ice sheets, with a concurrent shift to negative (fresher) conditions. There is strong evidence from other marine records that the timing of temperature and $\delta^{18} \mathrm{O}_{\mathrm{sw}}$ (ice volume) changes are not necessarily in phase, and that the phasing varies from place to place in the ocean [Hays et al., 1976; Ruddiman and McIntyre, 1979; Lea et al., 2000].

The uncertainties in using these methods are much greater than those for calculating $\mathrm{Mg} / \mathrm{Ca}$ as there is limited data on local $\delta^{18} \mathrm{O}_{\text {sw }}$ e.g. [Schmidt et al., 1999] with the implicit assumption that this relationship between salinity and $\delta^{18} \mathrm{O}_{\mathrm{sw}}$ remains constant through geologic time (e.g. Robling and Bigg, 1998). In the absence of these data, the equations chosen appear to match reasonably well with core top data where independent equations using salinity and $\delta^{18} \mathrm{O}_{\mathrm{c}}$ were generated and compared (Supplementary Material, Figure 5.12).

In a core south of Chatham Rise (MD-2120) Pabnke et al., [2003] found similar albeit weaker $\delta^{18} \mathrm{O}_{\mathrm{c}}$ and $\mathrm{SST}_{\mathrm{Mg} / \mathrm{Ca}}$ from planktonic foraminifera reminiscent of the glacial climatic oscillations of Dansgaard-Oeschger and in the GISP2 ice core recorded in NH records. These oscillations coincided with orbital precession minima, analogous to this study's paired record and hence suggest that forcing from the $\mathrm{NH}$ is the cause of the large enrichment in $\delta^{18} \mathrm{O}_{\text {sw }}$ following the SH insolation maxima. Similar oscillations to the timing of $\mathrm{NH}$ records have been found in other SH records, with the ocean conveyor as the most logical explanation [Charles et al., 1996]. Prior to the MPT the continental ice sheets were of limited size, and therefore more susceptible to rapid deglaciations [Maslin and Ridgwell, 2005]. Following the $\mathrm{NH}$ insolation maxima, a second $\mathrm{SH}$ insolation peak occurs at $1060 \mathrm{Kyr}$ and marks a global shift in $\delta^{18} \mathrm{O}_{\mathrm{sw}}$ to more saline water, coinciding with a small SH sea level increase with a short reappearance in Gs. ruber that signal a brief excursion in STW. The duration of this is relatively short compared to the SH insolation maxima; G. bulloides records an increase in SST from $\sim 10$ to $15^{\circ} \mathrm{C}$ although the conditions were clearly not optimal for Gs. ruber which is either absent or present in small numbers. G. bulloides records the coldest temperatures during the glacial MIS-30 and appears to respond to small changes in $\mathrm{NH}$ insolation $(1050 \mathrm{kyr})$ where both SST and $\delta^{18} \mathrm{O}_{\mathrm{c}}$ increase. 


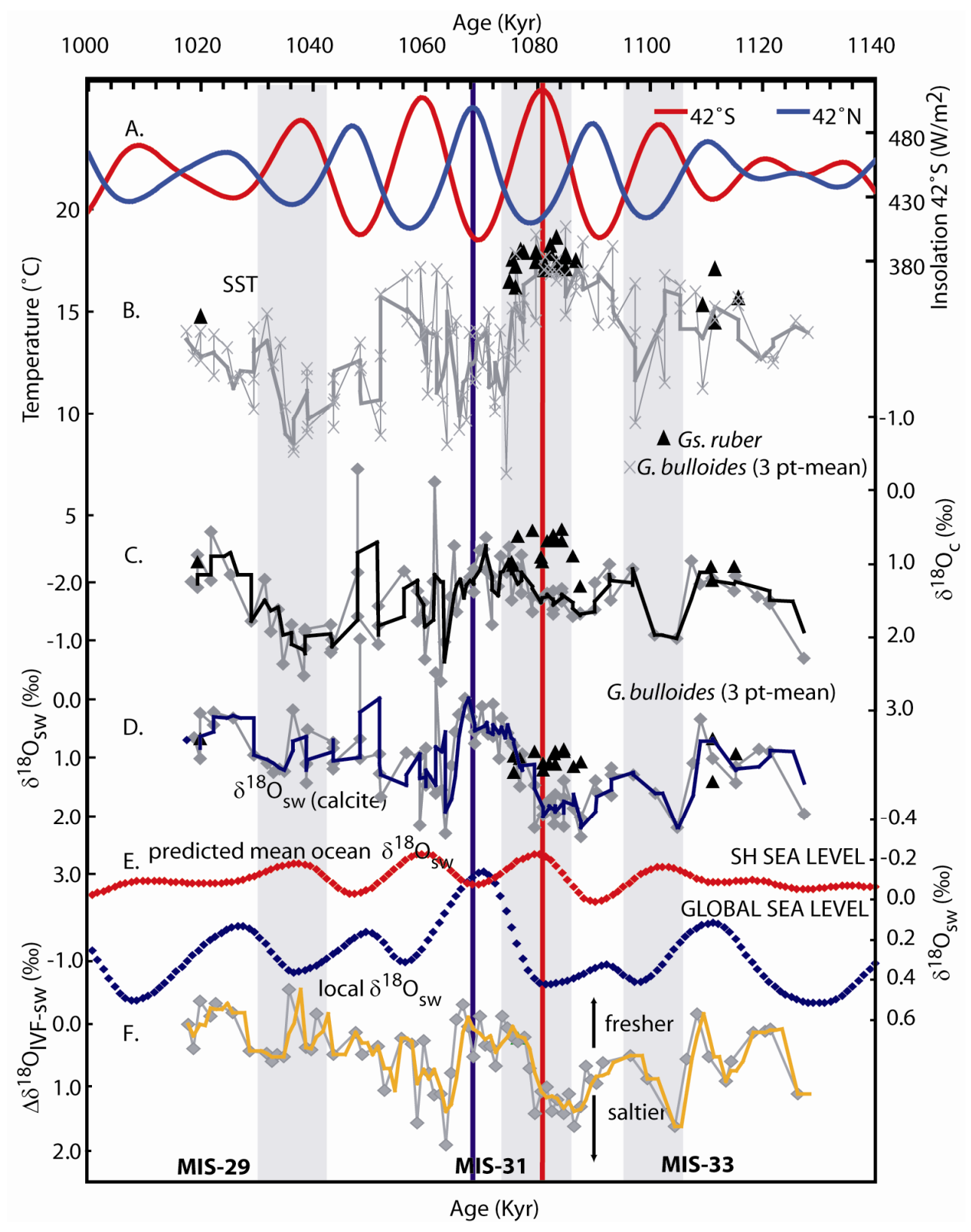

Figure 5.11: Changes in SST, $\delta^{18} \mathrm{O}_{\text {calcite }}$ and $\delta^{18} \mathrm{O}_{\text {seawater }}$ continental ice volume and local $\delta^{18} \mathrm{O}_{\text {sw }}$ measured from Gs. ruber and G. bulloides. (A) Insolation at $42^{\circ} \mathrm{N}$ and $42^{\circ} \mathrm{S}$. (B) SST converted from $\mathrm{Mg} / \mathrm{Ca}$ ratios in G. bulloides (grey) and Gs. ruber (black triangles). Grey solid line indicates 3-pt running mean for G. bulloides. (C) The $\delta^{18} \mathrm{O}_{\mathrm{c}}$ measured in G. bulloides (black line) and Gs. ruber (black triangles). Black solid line indicates 3-pt running mean for G. bulloides. (D) Calculated $\delta^{18} \mathrm{O}_{\mathrm{sw}}$ using the palaeotemperature equations from Bemis [1998] where: $\mathrm{T}=14.9-$ $4.8\left(\delta^{18} \mathrm{O}_{\mathrm{c}}-\delta^{18} \mathrm{O}_{\mathrm{sw}}\right)$ for Gs. ruber and $\mathrm{T}=13.4-4.48\left(\delta^{18} \mathrm{O}_{\mathrm{c}}-\delta^{18} \mathrm{O}_{\mathrm{sw}}\right)$ for G. bulloides. Blue solid line indicates 3-pt running mean G. bulloides. (E) The predicted $\delta^{18} \mathrm{O}_{\mathrm{sw}}$ from sea level from the Southern Hemisphere (red) and global sea level (blue) which was derived using the Raymo et al., [2006] global sea level and converted to $\delta^{18} \mathrm{O}_{\text {sw }}$ using the relationship from Yokoyama et al., [2000] where $\delta^{18} \mathrm{O}_{\text {sw }}=$ Sea Level $*(1.1 /-130 \mathrm{~m})$. (F) $\Delta \delta^{18} \mathrm{O}_{\text {IVF-sw }}$ (salinity excess), which represents regional hydrologic changes at ODP Site 1123 through MIS-34 to 29. Orange solid line indicates 3-pt running mean for G. bulloides. The red and blue vertical lines represent peak insolation at $42^{\circ} \mathrm{S}$ and $42^{\circ} \mathrm{N}$ respectively. 
This significant amplitude in the planktic $\delta^{18} \mathrm{O}_{\mathrm{sw}}$ record provides evidence that the magnitude of millennial scale climatic oscillations is dependent on the state of the global climate. This study links the $\mathrm{NH}$ and $\mathrm{SH}$ and is consistent with a Late Pleistocene record to the south of ODP Site 1123 [Pahnke et al., 2003]. This implies that although insolation was high in the SH, it did not have a significant effect (compared to the $\mathrm{NH}$ ) to changes in global ice volume.

\subsection{4 $\delta^{13} \mathrm{C}$ during MIS-33 to 29}

In $G$. bulloides the $\delta^{13} \mathrm{C}_{\mathrm{c}}$ is most enriched during the deglacial of MIS33/32, MIS-31 and during MIS-30 and was slightly more enriched than modern values of $0.27 \%$ (A. Bolton, unpubl. data). Over MIS-31 the $\delta^{13} \mathrm{C}_{\mathrm{c}}$ increases in concert with SST. These high $\delta^{13} \mathrm{C}_{\mathrm{c}}$ values are interpreted to indicate increased marine productivity from increases in photosynthesis at the surface. The events that show negative $\delta^{13} \mathrm{C}_{\mathrm{c}}$ excursions indicate the installation of a different regime dominated by more oligotrophic conditions. The largest $\Delta \delta^{13} \mathrm{C}_{\mathrm{plk} \text {-ben }}$ changes are observed at $1102 \mathrm{kyr}$ (MIS33/32 transition), 1051 and $1043 \mathrm{kyr}$ (MIS-32) kyr. These differences are partly due to a small lag between the planktic and the benthic signal, indicating an influence of older bottom water $\delta^{13} \mathrm{C}$ but may also represent the merging of both STW and SAW above the core site. Weaker gradients on the other hand could indicate decreased export production, mixing between the deep and surface ocean, or a shift in downwelling [Oliver et al., 2009]. In addition to changes in the $\delta^{13} C_{\text {DIC }}$ the benthic record can also be affected from secondary overprints of extra ${ }^{12} \mathrm{C}$ from areas of high productivity or shallow waters producing 'benthic fluff productivity signal. High productivity at this site has occurred with frontal shifts as indicated by the changes in foraminiferal assemblages [Crundwell et al., 2008] and therefore needs to be taken into consideration.

\subsubsection{Other trace elements (Ba, Mn, $\mathrm{Zn}$ and $\mathrm{Sr} / \mathrm{Ca}$ )}

$\mathrm{Sr} / \mathrm{Ca}$ ratios remain relatively constant in all species throughout the entire record indicting that there is no detectable temperature dependence of this ratio in Gs. ruber or G. bulloides. Ba/Ca and $\mathrm{Zn} / \mathrm{Ca}$ are low throughout the entire record. In the planktonic foraminifera of this thesis, there are 3 significant excursions of $\mathrm{Ba} / \mathrm{Ca}$ to values $>100 \mu \mathrm{mol} / \mathrm{mol}$. These changes occur 
shortly after the $1080 \mathrm{kyr}$ in Gs. ruber and G. bulloides prior to the SH summer insolation minima and indicate increased fluxes in productivity [Hönisch et al., 2011] (Figure 5.6). Increased productivity is supported by the marked increase in eutrophic mixed-layer taxa, especially $G$. bulloides (e.g. Schiebel et al., 2001) and as shown in Crundwell et al., [2008]. Assuming that Ba/Ca is a productivity indicator these changes would suggest a significant increase in productivity from 1060 and 1042 kyr. As the core site is north of Chatham Rise, presently a highly productive area, changes in productivity may be related to the intermixing of micro-nutrient poor and macro nutrient rich SAW with macro-nutrient poor but micro-nutrient rich STW [Boyd et al., 2004]. Thus their mixing enhances productivity, as shown by present day chlorophyll concentrations [Murphy et al., 2001].

The ratios of $\mathrm{Zn} / \mathrm{Ca}$ have been suggested to correlate with silicic acid [Lea, 2003]. During the largest increase in $\mathrm{Ba} / \mathrm{Ca}$, the $\mathrm{Zn} / \mathrm{Ca}$ ratio also increases from 1 to $25 \mu \mathrm{mol} / \mathrm{mol}$, although this excursion is much shorter. However, apart from this excursion the $\mathrm{Zn} / \mathrm{Ca}$ does not appear to vary with other trace elements or stable isotopes from this study. Although $\mathrm{Zn}$ concentrations are highest in surface waters they are not thought to be a limiting micronutrient for phytoplankton [Ellwood, 2004]. However, changes in $\mathrm{Zn}$ concentration may reflect shifts in surface water masses, which bring other limiting micro-nutrients such as iron [Ellwood, 2004]. Marr et al., [2011] suggested changes in concentration of $\mathrm{Zn}$ in G. bulloides could be used to infer different water masses with elevated $\mathrm{Zn} / \mathrm{Ca}$ ratios found in STW. If this interpretation is used, the $\mathrm{Zn}$ increases over MIS-30 it may imply that surface water mass exchange with the STF shifted south.

In Gs. ruber and G. bulloides the variation of $\mathrm{Mn} / \mathrm{Ca}$ ratios is similar to that of $\mathrm{Mg} / \mathrm{Ca}$ and to some extent $\delta^{18} \mathrm{O}_{\mathrm{c}}$ and this pattern is analogous to other studies. Wei et al., [2009] showed climatic variations at ODP Site 1144 (South China Sea), where Mn/Ca ratios were roughly in phase with SST $(\mathrm{Mg} / \mathrm{Ca})$ and $\delta^{18} \mathrm{O}_{\mathrm{c}}$ in the planktonic foraminifer Globigerinoides sacculifer. Their $\mathrm{Mn} / \mathrm{Ca}$ ratios varied from 0.02 to $0.49 \mathrm{mmol} / \mathrm{mol}$ (comparable to this work of 0.05 to 0.40 $\mathrm{mmol} / \mathrm{mol}$ ). Klinkhammer et al., [2009] found co-variance of water column $\mathrm{Mn}$ and core top Mn/Ca from ODP Site 1242 (Panama Basin) and suggest that the partition coefficients for Mn $\left(\mathrm{K}_{\mathrm{Mn}}\right)$ of the three species they studied were similar. However, there are a priori two potential sources of $\mathrm{Mn}$ to the tests, and hence two possible reasons for $\mathrm{Mn}-\mathrm{Mg}$ correlations. Either the Mn was acquired in the upper oceans, hence potentially could be a tracer of ocean chemistry. 
Or, it was acquired from the sediments, in which case it is post vivo and could be viewed as contamination, albeit tracking changes in bottom water chemistry and potentially redox conditions.

LA-ICP-MS studies [Eggins et al., 2003; Reichart et al., 2003] have shown distinct enrichment of trace elements including $\mathrm{Mn}$ on outer and inner surfaces of selected foraminifera. These surface enrichments are often high in $\mathrm{Cd}$ and $\mathrm{Ba}$ as first observed by Boyle [1983]. The microanalytic results of Pena et al., [2008] report contamination of tests of G. ruber and N. dutertrei with Fe-Mn oxides and Mn-Mg carbonates. That work proposes that those species with more pores and spine holes (e.g. G. ruber) will carry more contamination, and that contamination is difficult to remove except by "reductive" cleaning. Unfortunately, this cleaning technique also induces partial dissolution of the actual foraminiferal calcite and thereby can cause a decrease in measured Mg/Ca ratios [Boyle, 1981; Brown and Elderfield, 1996; Rosenthal et al., 2000; Martin and Lea, 2002]. It may be that the results of Pena et al., [2008] represent a "worst case" scenario - that work was carried out in a basin that is characterized by sediments that are somewhat anoxic and particularly rich in manganese minerals [Pedersen and Price, 1982; Reimers, 1987], conditions that promote manganese reduction reactions.

In this work, LA-ICP-MS was used to identify and exclude surface coatings such that the trace element ratios presented are those from the innermost biogenic calcite. Therefore the Mn/Ca ratios in this study are not likely to be Mn oxides or manganese carbonate overgrowths because LA-ICP-MS analyses were made on the internal layers of the foraminferal chamber and the external surfaces were excluded.

However, this is not to say that the foraminiferal $\mathrm{Mn} / \mathrm{Ca}$ ratios reported in this work are unambiguously a signature of the surface oceans. Other data from plankton tow samples in Gs. ruber, report low $\mathrm{Mn} / \mathrm{Ca}$ (e.g. Chapter 3). If there are sedimentary processes that can insert $\mathrm{Mn}$ into the calcite lattice, then the results reported here could be a diagenetic overprint. However, the generally low $\mathrm{Mn} / \mathrm{Ca}$ ratios overall suggest this is not happening in this core. 


\subsubsection{Size-normalised weights - changes in carbonate chemistry during early MIS-31?}

With regards to the size $/ \delta^{13} \mathrm{C}$ relationship, the $\delta^{13} \mathrm{C}$ difference for $G$. bulloides between the 250300 and $300-350 \mu \mathrm{m}$ size fractions was only $0.04 \%$ suggesting that size is unlikely to significantly influence the $\delta^{13} \mathrm{C}$. Culturing work on G. bulloides attributed changes in $\delta^{13} \mathrm{C}$ to carbonate ion concentration $\left[\mathrm{CO}_{3}{ }^{2}\right]$ [Spero et al., 1997]. This could explain the apparent relationship between size-normalised weight (SNW) and $\delta^{13} \mathrm{C}$. However, recent work on cultured G. bulloides did not find a significant relationship with test weight and $\left[\mathrm{CO}_{3}{ }^{2-}\right][$ Beer et al., 2010]. The predicted weight relationship suggests a shift from the general trend indicating a significant change in the carbonate chemistry at this time.

SNW also generally correlate with SST in G. bulloides over glacial-interglacial cycles (Figure 5.8). The effect of SST on carbonate chemistry may be manifested from dissolution of tests although dissolution may also be a feature of post depositional change in $\mathrm{pH}$ brought about by organic material in the sediments. Evidence of dissolution was observed around $1096 \mathrm{kyr}$ at the MIS-32 glacial maximum as evinced by fewer specimens, plus a minor increase in the planktic to benthic fragmentation ratios $(\sim 5)$ [Crundwell et al., 2008]. Increased dissolution generally coincides with warm interglacial episodes [Farrell and Prell, 1989; Le and Shackleton, 1992] so that increasing dissolution lowers the $\mathrm{Mg} / \mathrm{Ca}$ [Brown and Elderfield, 1996; Rosenthal et al., 2000; Dekens et al., 2002]. The SNW matches well with those from the predicted weights of Marr et al., [2011] and although the apparent offset during early MIS-31 may indicate a dissolution artifact, the weights show a general increase towards MIS-31, converse to a dissolution effect.

SNW of planktic foraminifera have been previously linked to changes in surface ocean carbonate ion concentration $\left[\mathrm{CO}_{3}{ }^{2}\right.$ ] [Barker and Elderfield, 2002; Moy et al., 2009]. Different species may have different primary factors that govern changes in weight over glacial to interglacial cycles [Gonzalez-Mora et al., 2008]. Reductions in shell weights are thought to be related to changes in calcium carbonate $\left(\mathrm{CaCO}_{3}\right)$ export in the surface ocean and changes in atmospheric $\mathrm{pCO}_{2}$ [Barker and Elderfield, 2002]. Increased $\mathrm{pCO}_{2}$ results in the drawdown into the oceans, which in turn modifies the carbonate chemistry in the upper oceans [Petit et al., 1999]. The change in $\mathrm{CO}_{2}$ results in the decrease of $\mathrm{pH}$ and $\left[\mathrm{CO}_{3}{ }^{2}\right]$ which has been linked to reduction of calcification rates in planktonic foraminifera [Moy et al., 2009]. Therefore the 
weights of planktonic foraminifera may be indicative of changes to the carbonate system equilibrium related to atmospheric carbon released from greenhouse gases.

Recent culturing experiments on Gs. ruber and G. bulloides concluded that environmental influences other than $\left[\mathrm{CO}_{3}{ }^{2}\right]$ were most likely the dominant control on foraminifera calcification rate [Beer et al., 2010]. In the culturing study by Beer et al., [2010] Gs. ruber showed a statistically significant inverse correlation with $\left[\mathrm{CO}_{3}{ }^{2-}\right]$, temperature, salinity and the SWN. $\left[\mathrm{CO}_{3}^{2}{ }^{2}\right]$ relationships observed were not necessarily indicative of causal relationships. Gs. ruber is a symbiotic species and therefore thought to be less sensitive to changes in $\left[\mathrm{CO}_{3}{ }^{2-}\right]$ than those that do not harbour symbionts [Lombard et al., 2010]. In this study, as with G. bulloides, changes with increased SST affected shell weights where the peak SH insolation maxima of MIS-31 coincided with lower shell weights of approx $30 \mu \mathrm{g}$. A number of alternative factors may be the results of these lower weights including $\mathrm{pCO}_{2}$ [Gonzalez-Mora et al., 2008]. Previous data from core tops in the Southwest Pacific show the weights of Gs. ruber is weakly correlated to SST $\left(\mathrm{r}^{2}=0.26\right)$ (Chapter 4, Supplementary Material) where SNW is strongly inversely correlated in G. bulloides [Marr et al., 2011].

Gametogenic calcite may bias the weights as traditionally the onset of gametogenesis occurs in colder waters [Caron et al., 1990]. For example, although typically inhabiting the mixed-layer, during their life cycle, Gs. ruber, G. sacculifer, G. bulloides and N. pachyderma may produce gametogenic calcite, formed at greater depths [Erez and Lu₹, 1983; Niebler et al., 1999]. Given that Gs. ruber disappears during glacial to early deglacial periods, G. bulloides is the only reliable indicator of weights throughout the entire glacial to interglacial cycles studied. G. bulloides produced gametogenic calcite in specimens larger than $150 \mu \mathrm{m}$ in a study by Schiebel et al., [1997] although this is converse to similar studies that claim this species (neither Gs. ruber) does not add a gametogenic calcite layer of significance [Hamilton et al., 2008]. The presence or absence may be related to chemical changes i.e. movement to colder waters. Therefore the changes in weights may be related to changes within the mixed layer (i.e. increased nutrients, or changes to $\left[\mathrm{CO}_{3}{ }^{2}\right]$ or a combination of both). However, during these colder temperatures, although the laser ablation profiles appear to record a small number of individuals with a lower initial $\mathrm{Mg} / \mathrm{Ca}$ ratio which may indicate the presence of a gametogenic layer, it was generally thin, and therefore is unlikely to control the variability of weights. 
This study has shown that the application of weights as a proxy for changing calcium carbonate chemistry may be limited and complicated by additional environmental factors (e.g., temperature, nutrient availability, $\delta^{18} \mathrm{O}_{\mathrm{sw}}$ that appear to partially co-vary). Interestingly, size may also provide an alternative to weights as it is not affected by gametogenic calcite (typical thicknesses of this crust is negligible) and will not be affected by weight loss from potential dissolution (Appendix C, Table C6).

\subsection{Summary and Implications for future global warming scenarios}

Temperatures at ODP Site 1123 during MIS-31 were 4 to $4.5^{\circ} \mathrm{C}$ warmer than present day. Given the distribution of modern ocean temperatures under the present phase of global warming, it is likely that SSTs around Antarctica also increased and caused substantial melting. Indeed, Pollard and DeConto [2009] modelled a retreat and possible collapse of the WAIS with a $5^{\circ} \mathrm{C}$ warming of nearby seas. At ODP 1123 , peak SSTs led ice volume changes by $10 \mathrm{kyr}$.

Insights into potential causes of warming at MIS-31 are suggested from observations of the modern and past ocean/climate system. In light of ODP 1123's proximity to the South Pacific Subtropical Gyre (SPSG), warm pulses are likely to be related to the strength of the gyre as well as to a general atmospheric warming of the ocean from increased precessional forcing. In the present phase of warming, the SPSG has spun-up mainly in response to an increase in the zonal westerly winds [Roemmich et al., 2007]. A more energetic gyre would affect transport within the East Australian Current (EAC) and its outflows to New Zealand (Tasman Front) and Tasmania (EAC extension) [Ridgway and Dunn, 2007; Hill et al., 2008]. Between 1944 and 2002 the intensification of the SPSG has indeed enhanced the EAC but transport has been focused on the EAC extension, which has shifted $\sim 350 \mathrm{~km}$ poleward (Figure 5.2). In contrast, transport in the Tasman Front has declined although continues to maintain warm seas [Sasaki et al., 2008; Ridgway and Hill, 2009]. I suggest that during the MIS 32-31 deglaciation, the zonal westerly winds and SPSG migrated south from latitudes lower than present (e.g. Martinez, 1994) and during the course of this migration the Tasman Front inflow to New Zealand increased, perhaps in response to the finding of gaps in the Norfolk Ridge, to enhance its input to ODP 1123. With migration further south the Tasman Front inflow may have reduced although high insolation would have still maintained warmth in the overall ocean. Accompanying the 
warmth was a possible change in the surface ocean thermal structure where by Gs. ruber and $G$. bulloides either calcified at a similar depth implying a change from these species usual habitat depths, or that there was a change to the depth of the mixed layer from an intensified SPSG.

Glacial periods either side of MIS-31 show more intense forcing from the Southern Ocean, as the STF shifted further north. This is shown by the disappearance of Gs. ruber, decrease in $\delta^{18} \mathrm{O}_{\text {sw }}$ and SSTs that were lower than $14^{\circ} \mathrm{C}$ reaching a minimum $7^{\circ} \mathrm{C}$ during MIS-30 as recorded by $G$. bulloides. Other studies also show that SSTs led benthic foraminiferal $\delta^{18} \mathrm{O}_{\mathrm{c}}$ by several thousand years during the Late Pleistocene [Lin and Herbert, 2004; Medina-Elizalde and Lea, 2005; Herbert et al., 2010]. These studies infer the lead of SST over continental ice volume was not controlled by the direct radiative influence of Northern Hemisphere continental ice sheets. These studies show phasing of SSTs with SH precession in G. bulloides and suggest perhaps that the NH was out of phase, in agreement with Raymo, et al. [2006] and Scherer, et al. [2008].

\subsection{Conclusions}

$\mathrm{Mg} / \mathrm{Ca}$ data for planktic foraminifera generated from the southern mid-latitude ODP Site 1123, on the Chatham Rise, east of New Zealand, indicates that MIS 31 was $4-5^{\circ} \mathrm{C}$ warmer than modern interglacial SST. As calculated from the $\mathrm{Mg} / \mathrm{Ca}$ data measured in Gs. ruber and $G$. bulloides using available calibrations, SSTs reach up to $19^{\circ} \mathrm{C}$ compared to typical temperatures of $\sim 14$ to $13^{\circ} \mathrm{C}$ for each species, respectively. The timing of the SST peak in MIS 31, 1081 kyr on the LR04 time scale [Lisiecki and Raymo, 2005], appears to precede the minimum in ice volume, as indicated by the $\delta^{18} \mathrm{O}$ record, by $\sim 10 \mathrm{kyr}$. MIS 31 as inferred from the benthic $\delta^{18} \mathrm{O}$ lasts for $15 \mathrm{kyr}$ compared to $20 \mathrm{kyr}$ from the planktonic record. A warm subtropical intensification of the SPTG during MIS 31 is supported by elevated foraminiferal $\mathrm{Zn} / \mathrm{Ca}$ and $\mathrm{Ba} / \mathrm{Ca}$ ratios. To summarise, the SST and stable isotope recorded in foraminifera at ODP Site 1123 suggest that:

(1) During the peak MIS-31 interglacial, G. bulloides and Gs. ruber SSTs converged but outside this peak G. bulloides recorded lower temperatures than Gs. ruber. This implies a 
change in the calcification habitat such that they both calcified close to the surface or a deeper mixed layer.

(2) The increase in subtropical taxa and SST recorded at MIS-31 suggest a southward shift of the SPSG.

(3) The ocean temperatures inferred from Gs. ruber appear to be in phase with obliquity but the lack of continuous data make the relationship between either orbital parameter difficult. G. bulloides appears to be in phase with precession which indicates a shift in the SPTG (and STF) to the south.

(5) The SNW of G. bulloides correlate with SST, $\delta^{18} \mathrm{O}$ and $\delta^{13} \mathrm{C}$. The general relationship with temperature is such that warmer temperatures result in lower SNW, except from early MIS-31. It is unclear as to which environmental variable(s) are the causes of these relationships but the data suggest that there is a significant shift in the carbonate chemistry in early MIS-31.

(6) $\mathrm{Mn} / \mathrm{Ca}$ ratios appear to co-vary with $\mathrm{Mg} / \mathrm{Ca}$. This is interpreted to reflect, in part, a change in surface ocean chemistry, although there is also a possibility of a diagenetic overprint.

(7) Stable isotope records in planktonic foraminifera are partially in phase with $\mathrm{Mg} / \mathrm{Ca}$ ratios. The SST in planktonic foraminifera lead the benthic stable isotope by $10 \mathrm{kyr}$ inferring that SST variability is not controlled by continental ice sheets but local/regional changes in hydrography. The enriched $\delta^{13} \mathrm{C}_{\mathrm{c}}$ values during MIS-31 are interpreted to indicate higher marine productivity from increases in photosynthesis at the surface. 


\section{Supplementary Material}

Table 5.1: Age control points for core ODP Site 1123

\begin{tabular}{|c|c|c|c|}
\hline Depth & Age & Age Control Points & Calibration and references \\
\hline \multirow[t]{2}{*}{ (mbsf) } & (Kyr) & & \\
\hline & & $\delta^{18} \mathrm{O}_{\mathrm{b}}$ tuned to $\delta^{18} \mathrm{O}_{\mathrm{b}}$ of Lisiecki and & $\delta^{18} \mathrm{O}_{\mathrm{b}}$ tuned to $\delta^{18} \mathrm{O}_{\mathrm{b}}$ of Lisiecki and \\
\hline \multirow[t]{2}{*}{40.073} & 1021.7720 & Raymo [2005] & Raymo [2005] \\
\hline & & $\delta^{18} \mathrm{O}_{\mathrm{b}}$ tuned to $\delta^{18} \mathrm{O}_{\mathrm{b}}$ of Lisiecki and & $\delta^{18} \mathrm{O}_{\mathrm{b}}$ tuned to $\delta^{18} \mathrm{O}_{\mathrm{b}}$ of Lisiecki and \\
\hline \multirow[t]{3}{*}{40.490} & 1033.8754 & Raymo [2005] & Raymo [2005] \\
\hline & & Palaeomagnetic reversal (base of & \\
\hline & & Jaramillo subchron @ 41.68 mbsf) & \\
\hline \multirow[t]{2}{*}{41.247} & 1058.2485 & interpolated at $1070 \mathrm{Kyr}$ & Prof. G. Wilson, pers. comm. \\
\hline & & $\delta^{18} \mathrm{O}_{\mathrm{b}}$ tuned to $\delta^{18} \mathrm{O}_{\mathrm{b}}$ of Lisiecki and & $\delta^{18} \mathrm{O}_{\mathrm{b}}$ tuned to $\delta^{18} \mathrm{O}_{\mathrm{b}}$ of Lisiecki and \\
\hline \multirow[t]{2}{*}{41.688} & 1069.9759 & Raymo [2005] & Raymo [2005] \\
\hline & & $\delta^{18} \mathrm{O}_{\mathrm{b}}$ tuned to $\delta^{18} \mathrm{O}_{\mathrm{b}}$ of Lisiecki and & $\delta^{18} \mathrm{O}_{\mathrm{b}}$ tuned to $\delta^{18} \mathrm{O}_{\mathrm{b}}$ of Lisiecki and \\
\hline \multirow[t]{2}{*}{42.366} & 1084.4456 & Raymo [2005] & Raymo [2005] \\
\hline & & $\delta^{18} \mathrm{O}_{\mathrm{b}}$ tuned to $\delta^{18} \mathrm{O}_{\mathrm{b}}$ of Lisiecki and & $\delta^{18} \mathrm{O}_{\mathrm{b}}$ tuned to $\delta^{18} \mathrm{O}_{\mathrm{b}}$ of Lisiecki and \\
\hline \multirow[t]{2}{*}{42.989} & 1108.1658 & Raymo [2005] & Raymo [2005] \\
\hline & & $\delta^{18} \mathrm{O}_{\mathrm{b}}$ tuned to $\delta^{18} \mathrm{O}_{\mathrm{b}}$ of Lisiecki and & $\delta^{18} \mathrm{O}_{\mathrm{b}}$ tuned to $\delta^{18} \mathrm{O}_{\mathrm{b}}$ of Lisiecki and \\
\hline \multirow[t]{2}{*}{43.184} & 1120.1347 & Raymo [2005] & Raymo [2005] \\
\hline & & $\delta^{18} \mathrm{O}_{\mathrm{b}}$ tuned to $\delta^{18} \mathrm{O}_{\mathrm{b}}$ of Lisiecki and & $\delta^{18} \mathrm{O}_{\mathrm{b}}$ tuned to $\delta^{18} \mathrm{O}_{\mathrm{b}}$ of Lisiecki and \\
\hline 43.294 & 1128.1865 & Raymo [2005] & Raymo [2005] \\
\hline
\end{tabular}

\subsubsection{Complementary data from ODP Site 1123}

The original Hall et al., [2001] and subsequent Crundwell et al., [2008] age models were based on a spliced composite section where holes $1123 \mathrm{~B}$ and $1123 \mathrm{C}$ were used. As this study uses only 
data from the 1123C hole, data from hole 1123B was converted to the hole 1123C age model using the palaeomagnetic susceptibility data from both cores (Supplementary Figure 5.12). This then allows the other proxy data from Crundwell et al., [2008] to be incorporated into this study.

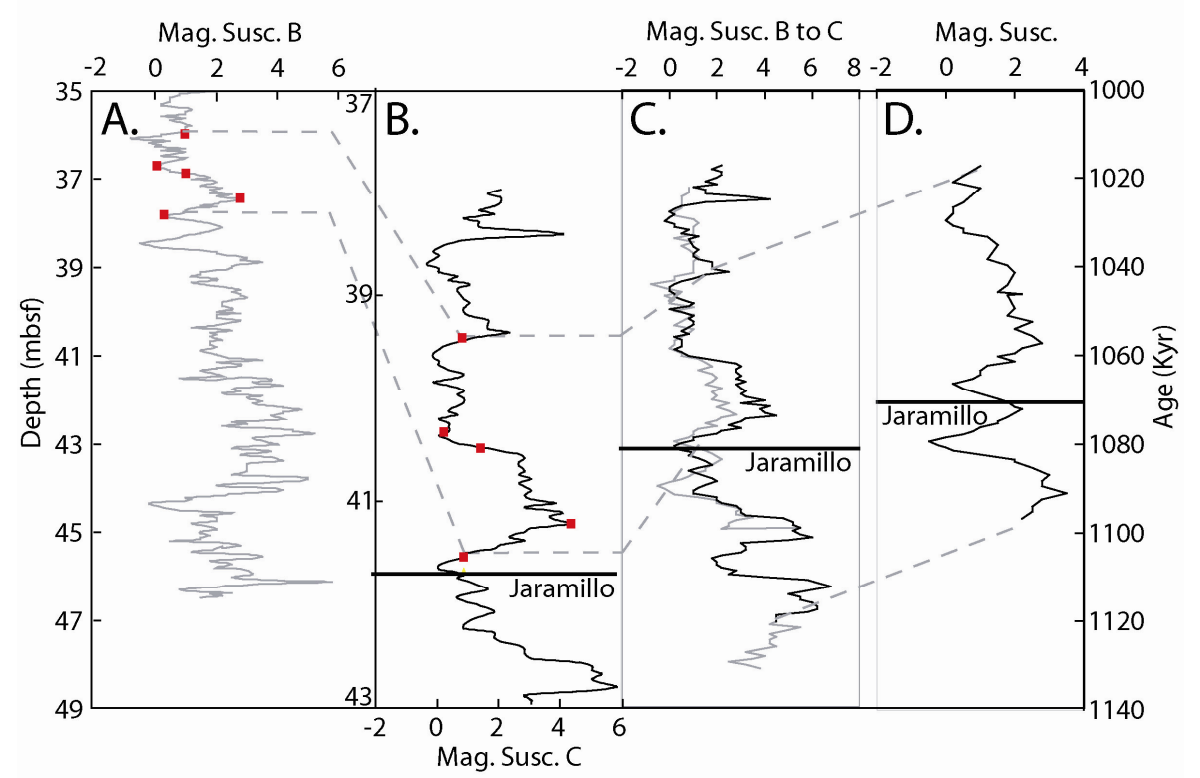

Figure 5.12: Correlation of ODP Site 1123 palaeomagnetic susceptibility data from hole 'B' (grey curve) (A) to hole $1123^{\circ} \mathrm{C}$ ' (black curve) (B) which was derived using Analyseries resulting in (C) which shows the palaeomagnetic data from both cores on the same scale (mbsf). The new age model derived was then correlated using the depths from the in $1123 \mathrm{C}$ core to give the age in (D). The U-channel palaeomagnetic susceptibility data from core $1123 \mathrm{C}$ was used to tie the base of the Jaramillo subchron (C1r.1n) at $41.68 \mathrm{mbsf}$ to $1.072 \mathrm{Ma}$, black line in (B). Red squares represent visual tie points from 1123B to 1123C.

\subsubsection{Estimation of $\delta^{18} O_{s w}$ from salinity relationships}

The oxygen isotopic composition of seawater $\left(\delta^{18} \mathrm{O}_{\mathrm{sw}}\right)$ has a demonstrated linear relationship with sea surface salinity and therefore has been used to reconstruct palaeosalinity [Schmidt et al., 2006]. In some oceanographic regions these relationships are well established, particularly with the increased measurements of $\delta^{18} \mathrm{O}_{\mathrm{sw}}$ from studies such as GEOSECS [Schmidt et al., 1999]. In the Southwest Pacific Ocean, local $\delta^{18} \mathrm{O}_{\mathrm{sw}}$ measurements are however more scarce. Therefore $\delta^{18} \mathrm{O}_{c}$ in the foraminiferal tests of Gs. ruber and G. bulloides (A. Bolton, unpubl. data) were used in conjunction with estimated $\delta^{18} \mathrm{O}_{\mathrm{sw}}$ in order examine the palaeo-seawater equations available 
for $G$ s. ruber and G. bulloides. The derived $\delta^{18} \mathrm{O}_{\mathrm{sw}}$ values estimated from the salinity relationships were also compared to local measurements from north of Chatham Rise (Table 5.3) and some locations that were located close to GEOSECS stations [LeGrande and Schmidt, 2006].

The measured $\delta^{18} \mathrm{O}_{\mathrm{c}}$ coupled with estimated $\mathrm{SST}_{\mathrm{Mg} / \mathrm{Ca}}$ and salinity measurements which were used to calculate $\delta^{18} \mathrm{O}_{\text {sw }}$ using the following equations:

$\delta^{18} \mathrm{O}_{\mathrm{sw}}=0.687 *$ site salinity -23.74 [Savin et al., 1985]

$\delta^{18} \mathrm{O}_{\mathrm{sw}}($ South Pacific $)=-0.45 *$ site salinity $-15.29 \quad$ [LeGrande and Schmidt, 2006]

$\delta^{18} \mathrm{O}_{\text {sw }}=0.5 *$ site salinity - 35 [Craig and Gordon, 1965]

[Eq. 5.9]

$\delta^{18} \mathrm{O}_{\text {sw }}=$ site salinity $-34 / 1.465$ [Schmidt et al., 1999]

[Eq. 5.10]

The averaged depth preference for Gs. ruber is assumed to be $0-50 \mathrm{~m}$ and 75 to $150 \mathrm{~m}$ for $G$. bulloides and the range of $\delta^{18} \mathrm{O}_{\text {sw }}$ over this depth range is 0.57 to $0.39 \%$ (Table 5.6, Dr. H. Neil, unpubl. data). The $\delta^{18} \mathrm{O}_{\text {sw }}$ estimates are shown in Tables 5.3 and 5.4 for Gs. ruber and for G. bulloides, respectively. Given the lack of $\delta^{18} \mathrm{O}_{\mathrm{sw}}$ measurements close to Chatham Rise, the equations by Le Grande and Schmidt [2006] and Savin et al., [1985] appear to match well to those north of Chatham Rise. However for G. bulloides the estimated $\delta^{18} \mathrm{O}_{\text {sw }}$ is much closer to $\delta^{18} \mathrm{O}_{\text {sw }}$ values from the sea surface (Table 5.3).

Other GEOSECS $\delta^{18} \mathrm{O}_{\text {sw }}$ measurements that lie close to tropical core tops show $\delta^{18} \mathrm{O}_{\text {sw }}$ of $0.69 \%$ (AIMS1361) and $0.07 \%$ (AIMS3703) and highlight potential regional differences (i.e. local precipitation and evaporation processes in the tropics). Given this information the salinity 
equations of Le Grande and Schmidt [2006] were chosen to estimate $\delta^{18} \mathrm{O}_{\mathrm{sw}}$ in Gs. ruber and Savin et al., [1985] for G. bulloides.

Table 5.2a: Two sample t-test (two-tailed) for $\mathrm{Mg} / \mathrm{Ca}$ ratios from sample age 1081.8383 and $\mathrm{n}=19$.

\begin{tabular}{cccccc}
\hline $\begin{array}{c}\text { n vs. all } \\
\text { data }\end{array}$ & t stat & t-crit & df & $p$ & different? \\
\hline 8 & 0.290 & 2.131 & 15.000 & 0.776 & no \\
9 & -0.112 & 2.120 & 16.000 & 0.912 & no \\
10 & -0.330 & 2.093 & 19.000 & 0.745 & no \\
15 & -0.066 & 2.045 & 29.000 & 0.948 & no \\
18 & -0.479 & 2.030 & 35.000 & 0.635 & no \\
\hline
\end{tabular}

* Unequal variances were assumed.

Table 5.2b: Two sample t-test (two-tailed) for $\mathrm{Mg} / \mathrm{Ca}$ ratios from sample age 1110.8879 and $\mathrm{n}=22$.

\begin{tabular}{cccccc}
\hline $\begin{array}{c}\text { n vs. all } \\
\text { data }\end{array}$ & t stat & t-crit & df & p & different? \\
\hline 8 & 1.454 & 2.145 & 14 & 0.168 & no \\
9 & 1.235 & 2.120 & 9 & 0.235 & no \\
10 & 1.316 & 2.086 & 20 & 0.203 & no \\
15 & -0.132 & 2.045 & 29 & 0.896 & no \\
20 & -0.022 & 2.021 & 40 & 0.983 & no \\
\hline
\end{tabular}

* Unequal variances were assumed.

For both Tables 5.2a and $\mathrm{b}$ if $\mathrm{t}$ stat is $>\mathrm{t}$-crit then there is a significant difference between the means (n versus all the data). The data show that there is no significant difference between using 9 as a sample mean versus using all of the data. 
Table 5.3: $\delta^{18} \mathrm{O}_{\text {sw }}$ from north of Chatham Rise (courtesy of H. Neil, unpubl. data).

\begin{tabular}{|c|c|}
\hline Depth & Measured $\delta^{18} \mathbf{O}_{\mathrm{sw}}(\% 0)$ \\
\hline 10 & 0.57 \\
\hline 20 & 0.55 \\
\hline 30 & 0.51 \\
\hline 50 & 0.52 \\
\hline 75 & 0.46 \\
\hline 100 & 0.4 \\
\hline 150 & 0.39 \\
\hline 200 & 0.33 \\
\hline 300 & 0.23 \\
\hline 500 & -0.1 \\
\hline 750 & -0.28 \\
\hline 1000 & -0.36 \\
\hline 1500 & 0.21 \\
\hline 2000 & 0.13 \\
\hline 2500 & 0.11 \\
\hline 3085 & 0.14 \\
\hline
\end{tabular}


Table 5.4: Estimation of $\delta^{18} \mathrm{O}_{\mathrm{sw}}$ using existing calibrations for Gs. ruber

\begin{tabular}{|c|c|c|c|c|c|c|c|c|}
\hline Sample & Latitude & $\delta^{18} \mathrm{O}$ & $\begin{array}{l}\text { Modern Annual } \\
\text { SST (75-150 m) }\end{array}$ & $\begin{array}{l}\text { Modern } \\
\text { Salinity }\end{array}$ & $\begin{array}{l}\text { Savin } \\
\text { et al., } \\
\text { [1985] }\end{array}$ & $\begin{array}{c}\text { Le } \\
\text { Grande } \\
\text { and } \\
\text { Scmidt } \\
\text { [2006] }\end{array}$ & $\begin{array}{c}\text { Craig } \\
\text { and } \\
\text { Gordon } \\
{[1965]}\end{array}$ & $\begin{array}{c}\text { Schmidt } \\
\text { et al., } \\
\text { [1999] }\end{array}$ \\
\hline & ${ }^{\circ} \mathrm{S}$ & $\left({ }^{\circ} \mathrm{C}\right)$ & $(\% 0)$ & $(\% 0)$ & $\begin{array}{c}\delta^{18} \mathrm{O}_{\mathrm{sw}} \\
(\% 0)\end{array}$ & $\begin{array}{c}\delta^{18} \mathrm{O}_{\mathrm{sw}} \\
(\%)\end{array}$ & $\begin{array}{c}\delta^{18} \mathrm{O}_{\mathrm{sw}} \\
(\%)\end{array}$ & $\begin{array}{c}\delta^{18} \mathrm{O}_{\mathrm{sw}} \\
(\% 0)\end{array}$ \\
\hline AIMS1361 & 3.37 & -2.59 & 27.62 & 34.5 & -0.04 & 0.24 & -0.25 & 0.34 \\
\hline AIMS3703 & 11.153 & -2.81 & 22.16 & 34.4 & -0.11 & 0.19 & -0.30 & 0.27 \\
\hline TAN0706 & 29.355 & -1.01 & 22.65 & 35.7 & 0.79 & 0.78 & 0.35 & 1.16 \\
\hline P71 & 33.855 & -0.48 & 22.40 & 35.6 & 0.72 & 0.73 & 0.30 & 1.09 \\
\hline Z7003 & 36.69 & -0.33 & 22.79 & 35.5 & 0.65 & 0.69 & 0.25 & 1.02 \\
\hline U2315 & 38.509 & -0.96 & 20.97 & 35.6 & 0.72 & 0.73 & 0.30 & 1.09 \\
\hline ODP1123 & 41.786 & 0.63 & 12.28 & 35.1 & 0.37 & 0.51 & 0.05 & 0.75 \\
\hline
\end{tabular}


Table 5.5: Estimation of $\delta^{18} \mathrm{O}_{\text {sw }}$ using existing calibrations for $G$. bulloides

\begin{tabular}{|c|c|c|c|c|c|c|c|c|}
\hline Sample & Latitude & $\delta^{18} \mathrm{O}$ & $\operatorname{SST}_{(\mathrm{Mg} / \mathrm{Ca})}$ & Salinity & $\begin{array}{l}\text { Savin } \\
\text { et al., } \\
(1985)\end{array}$ & $\begin{array}{c}\text { Le } \\
\text { Grande } \\
\text { and } \\
\text { Scmidt } \\
(2006)\end{array}$ & $\begin{array}{c}\text { Craig and } \\
\text { Gordon } \\
(1965)\end{array}$ & $\begin{array}{c}\text { Schmidt } \\
\text { et al., } \\
\text { [1999] }\end{array}$ \\
\hline & ${ }^{\circ} \mathrm{S}$ & $\left({ }^{\circ} \mathrm{C}\right)$ & $(\% 0)$ & $(\%)$ & $\begin{array}{c}\delta^{18} \mathbf{O}_{\mathrm{sw}} \\
(\% 0)\end{array}$ & $\begin{array}{c}\delta^{18} \mathbf{O}_{\text {sw }} \\
(\% 0)\end{array}$ & $\begin{array}{c}\delta^{18} \mathbf{O}_{\mathrm{sw}} \\
(\% 0)\end{array}$ & $\begin{array}{c}\delta^{18} \mathbf{O}_{\mathrm{sw}} \\
(\%)\end{array}$ \\
\hline P71 & 33.855 & -0.26 & 17.40 & 35.64 & 0.74 & 0.75 & 0.32 & 1.11 \\
\hline P81 & 34.02 & 0.07 & 16.10 & 35.47 & 0.63 & 0.67 & 0.23 & 1.00 \\
\hline S793 & 36.3 & 0.32 & 15.40 & 35.42 & 0.59 & 0.65 & 0.21 & 0.99 \\
\hline S938 & 40.03 & 1.27 & 18.80 & 35.53 & 0.67 & 0.70 & 0.27 & 1.04 \\
\hline P69 & 40.4 & 0.75 & 19.10 & 35.57 & 0.70 & 0.72 & 0.29 & 1.07 \\
\hline R623 & 43.2 & 1.89 & 12.00 & 35.04 & 0.33 & 0.48 & 0.02 & 0.70 \\
\hline ODP1123 & 41.786 & 0.92 & 13.79 & 35.38 & 0.57 & 0.63 & 0.19 & 0.94 \\
\hline Q220 & 44.29 & 2.41 & 9.20 & 34.55 & 0.00 & 0.26 & -0.23 & 0.37 \\
\hline D178 & 51.72 & 2.57 & 7.20 & 34.40 & -0.11 & 0.19 & -0.30 & 0.27 \\
\hline F111 & 48.95 & 2.22 & 7.30 & 34.45 & -0.07 & 0.21 & -0.27 & 0.30 \\
\hline B32 & 53.63 & 2.65 & 7.50 & 34.4 & -0.11 & 0.19 & -0.30 & 0.27 \\
\hline
\end{tabular}

This study's independent estimate of temperature $\left(\mathrm{SST}_{\mathrm{Mg} / \mathrm{Ca}}\right)$ allows the substitution into a number of equations to rearrange for $\delta^{18} \mathrm{O}_{\mathrm{sw}}$ so as to compare previously established temperature relationships. Bemis et al., [1998] in experiments on cultured G. bulloides developed a number of equations based on the test size (number of final chambers), showing a small enrichment of $\delta^{18} \mathrm{O}_{c}$ with increasing ontogenetic calcite. However these experiments are limited to the culturing parameters, in this case their temperatures were set between 15 to 
$24^{\circ} \mathrm{C}$. The variability of SSTs from ODP Site 1123 ranges from 9 to $19^{\circ} \mathrm{C}$, and would therefore mean that extrapolation of these relationships would be required to estimate the $\delta^{18} \mathrm{O}$ relationships at the colder end of the dataset. For colder oceanic temperatures, discrepancies can occur e.g. For Bemis et al. [1998] these were as much as $5^{\circ} \mathrm{C}$.

G. bulloides 12-chambered shell [Bemis et al., 1998]:

$$
\mathrm{T}\left({ }^{\circ} \mathrm{C}\right)=13.2-4.89\left(\delta^{18} \mathrm{O}_{\mathrm{c}}-\delta^{18} \mathrm{O}_{\text {sw }}\right) \quad[\text { Eq. 5.11] }
$$

G. bulloides (cultured) [Bemis et al., 2002]:

$$
\mathrm{T}\left({ }^{\circ} \mathrm{C}\right)=14.2-4.44\left(\delta^{18} \mathrm{O}_{\mathrm{c}}-\delta^{18} \mathrm{O}_{\mathrm{sw}}\right) \quad[\text { Eq. 5.12] }
$$

G. bulloides [Mulitza et al., 2003]:

$$
\mathrm{T}\left({ }^{\circ} \mathrm{C}\right)=13.4-4.48\left(\delta^{18} \mathrm{O}_{\mathrm{c}}-\delta^{18} \mathrm{O}_{\mathrm{sw}}\right) \quad[\text { Eq. 5.13] }
$$

Orbulina universa (high-light) used for Gs. ruber [Bemis et al., 1998]:

$$
\mathrm{T}=14.9-4.8\left(\delta^{18} \mathrm{O}_{\mathrm{c}}-\delta^{18} \mathrm{O}_{\mathrm{sw}}\right) \quad[\text { Eq. 5.14] }
$$


The Orbulina universa equation was selected as it is a symbiotic foraminifera, as is Gs. ruber. So far no other suitable equations exist because Gs. ruber is difficult to sustain in culture. Figure 5.13 shows the derived equations for Gs. ruber from core top samples closely match those for O. universa [Bemis et al., 1998] and for G. bulloides the [Bemis et al., 2002].

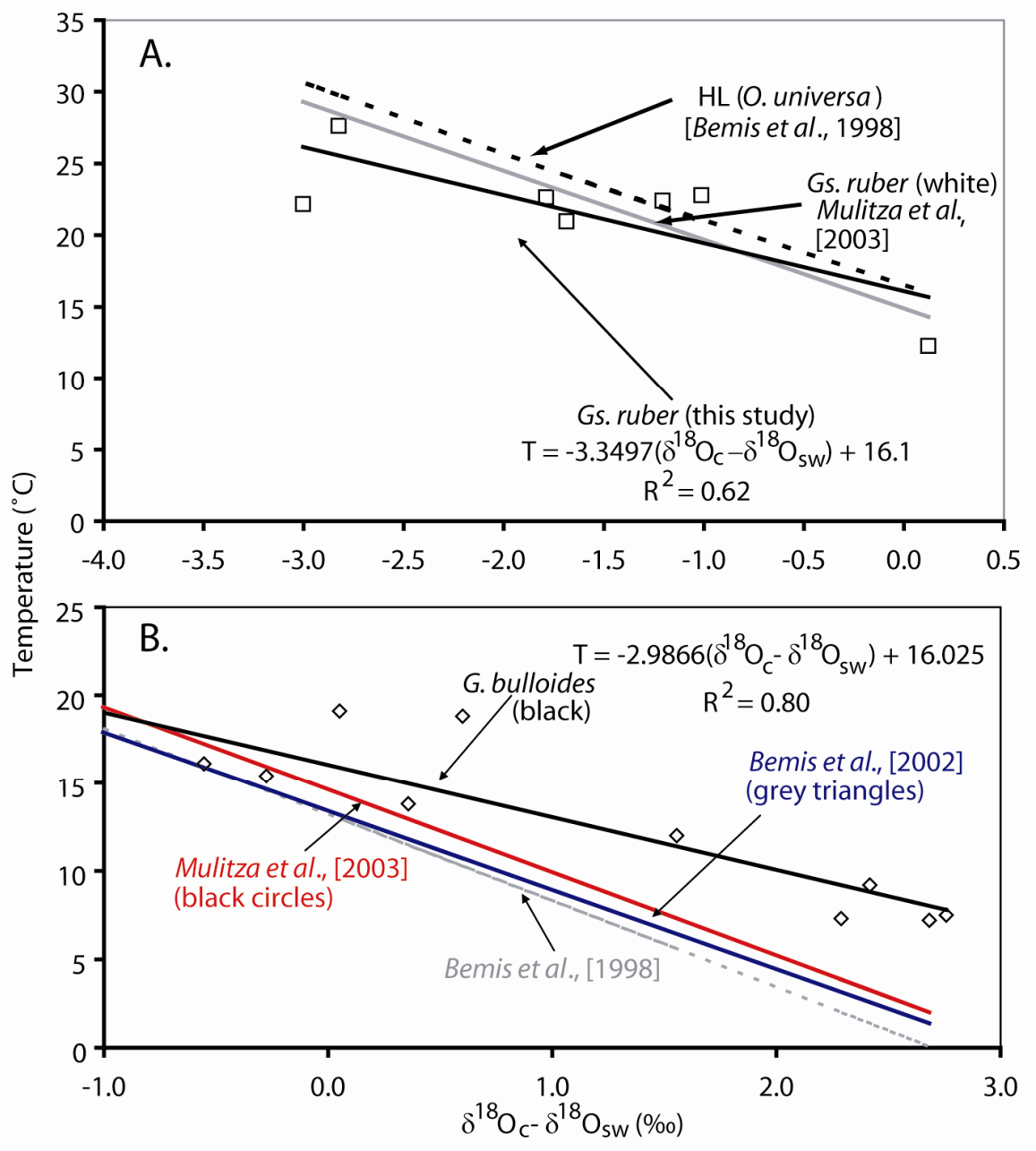

Figure 5.13: Relationships between temperature and $\left(\delta^{18} \mathrm{O}_{\mathrm{c}}-\delta^{18} \mathrm{O}_{\mathrm{sw}}\right)$ in (A) Gs. ruber and (B) G. bulloides core top derived data (Chapter 4) and unpublished $\delta^{18} \mathrm{O}_{\mathrm{c}}$ data (A. Bolton, 2009) from G. bulloides core tops (in addition to data from Marr et al., [2011] with other extant calibrations. 
Table 5.6: Dixons's Q test of outliers in the sample means

\begin{tabular}{|c|c|c|c|c|c|c|c|c|}
\hline & age $(\mathbf{k y r})$ & $\begin{array}{c}\text { extreme } \\
\text { low }\end{array}$ & $\begin{array}{l}\text { next } \\
\text { low }\end{array}$ & $\begin{array}{l}\text { next } \\
\text { high }\end{array}$ & $\begin{array}{c}\text { extreme } \\
\text { high }\end{array}$ & $\mathbf{Q}$ & Qcrit & Outliers? \\
\hline 1 & 1017.6033 & 2.17 & 2.44 & 2.45 & 2.73 & 0.51 & 0.83 & no \\
\hline 2 & 1018.7824 & 1.66 & 2.18 & 2.62 & 2.80 & 0.45 & 0.83 & no \\
\hline 3 & 1019.9615 & 1.60 & 1.72 & 3.06 & 4.28 & 0.45 & 0.83 & no \\
\hline 4 & 1020.0015 & 1.55 & 1.83 & 2.50 & 3.52 & 0.52 & 0.83 & no \\
\hline 5 & 1022.3198 & 1.55 & 1.76 & 2.35 & 3.00 & 0.45 & 0.83 & no \\
\hline 6 & 1022.3598 & 1.23 & 1.23 & 2.75 & 3.22 & 0.24 & 0.83 & no \\
\hline 7 & 1024.6781 & 1.76 & 1.89 & 2.48 & 3.08 & 0.45 & 0.83 & no \\
\hline 8 & 1025.8572 & 1.19 & 1.56 & 2.00 & 3.24 & 0.60 & 0.83 & no \\
\hline 9 & 1027.0363 & 1.71 & 2.06 & 2.23 & 2.78 & 0.51 & 0.83 & no \\
\hline 10 & 1029.3946 & 1.36 & 1.64 & 2.35 & 2.70 & 0.26 & 0.83 & no \\
\hline 11 & 1029.4346 & 1.32 & 3.07 & 3.07 & 3.60 & 0.77 & 0.83 & no \\
\hline 12 & 1029.4746 & 1.11 & 2.36 & 2.72 & 2.72 & 0.78 & 0.83 & no \\
\hline 13 & 1031.7529 & 1.05 & 2.25 & 3.44 & 3.65 & 0.46 & 0.83 & no \\
\hline 14 & 1032.9320 & 2.74 & 2.89 & 3.31 & 3.31 & 0.27 & 0.83 & no \\
\hline 15 & 1034.1111 & 1.35 & 2.16 & 2.16 & 3.22 & 0.57 & 0.83 & no \\
\hline 16 & 1034.9955 & 0.72 & 1.53 & 2.60 & 2.89 & 0.37 & 0.83 & no \\
\hline 17 & 1036.4694 & 1.03 & 1.52 & 1.76 & 2.62 & 0.54 & 0.83 & no \\
\hline 18 & 1036.5033 & 0.87 & 0.87 & 1.94 & 2.40 & 0.30 & 0.83 & no \\
\hline 19 & 1038.8276 & 1.02 & 1.23 & 1.56 & 3.03 & 0.73 & 0.83 & no \\
\hline 20 & 1038.8616 & 1.45 & 1.45 & 2.35 & 3.57 & 0.57 & 0.83 & no \\
\hline 21 & 1038.8955 & 1.02 & 2.07 & 4.31 & 4.31 & 0.32 & 0.83 & no \\
\hline 22 & 1038.9294 & 1.12 & 1.39 & 2.25 & 2.86 & 0.35 & 0.83 & no \\
\hline 23 & 1043.5442 & 1.26 & 1.41 & 4.65 & 4.65 & 0.04 & 0.83 & no \\
\hline 24 & 1043.5842 & 1.17 & 1.86 & 2.31 & 2.40 & 0.56 & 0.83 & no \\
\hline 25 & 1043.6242 & 1.14 & 1.43 & 2.67 & 3.09 & 0.22 & 0.83 & no \\
\hline 26 & 1043.6642 & 1.23 & 1.40 & 2.01 & 3.06 & 0.57 & 0.83 & no \\
\hline 27 & 1048.2607 & 1.32 & 1.63 & 2.17 & 4.70 & 0.75 & 0.83 & no \\
\hline 28 & 1048.3007 & 1.88 & 1.88 & 2.28 & 2.93 & 0.62 & 0.83 & no \\
\hline 29 & 1048.3407 & 1.50 & 2.20 & 2.60 & 3.28 & 0.39 & 0.83 & no \\
\hline 30 & 1051.7981 & 1.25 & 2.41 & & & & 0.83 & \\
\hline 31 & 1051.8381 & 1.23 & 1.24 & 1.90 & 1.90 & 0.01 & 0.83 & no \\
\hline 32 & 1051.8781 & 1.16 & 2.06 & 2.88 & 3.98 & 0.39 & 0.83 & no \\
\hline 33 & 1051.9181 & 1.01 & 2.37 & 3.19 & 4.87 & 0.44 & 0.83 & no \\
\hline 34 & 1056.5146 & 2.17 & 2.17 & 2.81 & 3.99 & 0.65 & 0.83 & no \\
\hline 35 & 1056.5490 & 1.58 & 2.10 & 2.45 & 4.88 & 0.74 & 0.83 & no \\
\hline 36 & 1058.8435 & 1.63 & 2.48 & 3.12 & & & 0.83 & \\
\hline
\end{tabular}




\begin{tabular}{|c|c|c|c|c|c|c|c|c|}
\hline & age $(\mathrm{kyr})$ & $\begin{array}{c}\text { extreme } \\
\text { low }\end{array}$ & $\begin{array}{l}\text { next } \\
\text { low }\end{array}$ & $\begin{array}{l}\text { next } \\
\text { high }\end{array}$ & $\begin{array}{l}\text { extreme } \\
\text { high }\end{array}$ & $\mathbf{Q}$ & Qcrit & Outliers? \\
\hline 37 & 1058.8778 & 1.92 & 2.02 & 3.51 & 4.70 & 0.43 & 0.83 & no \\
\hline 38 & 1060.0068 & 1.18 & 1.18 & 3.41 & 4.45 & 0.32 & 0.83 & no \\
\hline 39 & 1060.0412 & 1.63 & 2.83 & 3.13 & 3.71 & 0.57 & 0.83 & no \\
\hline 40 & 1060.0756 & 1.19 & 1.86 & 2.61 & 3.01 & 0.37 & 0.83 & no \\
\hline 41 & 1061.7518 & 1.45 & 2.12 & 3.12 & 5.15 & 0.55 & 0.83 & no \\
\hline 42 & 1061.7862 & 1.72 & 1.78 & 3.00 & 3.12 & 0.09 & 0.83 & no \\
\hline 43 & 1062.9152 & 1.25 & 2.61 & 2.61 & 4.08 & 0.52 & 0.83 & no \\
\hline 44 & 1063.4968 & 1.21 & 1.21 & 1.84 & 1.87 & 0.04 & 0.83 & no \\
\hline 45 & 1063.5312 & 1.91 & 3.05 & 3.05 & 3.64 & 0.66 & 0.83 & no \\
\hline 46 & 1064.6602 & 1.29 & 1.77 & 2.41 & 3.69 & 0.53 & 0.83 & no \\
\hline 47 & 1065.2419 & 1.74 & 1.81 & 2.83 & 3.41 & 0.35 & 0.83 & no \\
\hline 48 & 1065.8235 & 1.32 & 1.75 & 2.21 & 2.21 & 0.48 & 0.83 & no \\
\hline 49 & 1066.4052 & 2.05 & 2.05 & 2.44 & 2.44 & 0.01 & 0.83 & no \\
\hline 50 & 1066.9869 & 0.92 & 1.46 & 1.46 & 2.08 & 0.53 & 0.83 & no \\
\hline 51 & 1067.5685 & 1.84 & 2.07 & 2.84 & 3.60 & 0.43 & 0.83 & no \\
\hline 52 & 1068.1502 & 2.26 & 2.46 & 1.56 & 1.99 & -0.74 & 0.83 & no \\
\hline 53 & 1068.7319 & 1.13 & 2.11 & 1.72 & 3.17 & 0.71 & 0.83 & no \\
\hline 54 & 1068.7663 & 2.07 & 1.57 & 3.03 & 4.59 & 0.62 & 0.83 & no \\
\hline 55 & 1069.8952 & 1.24 & 1.50 & 1.86 & 3.38 & 0.71 & 0.83 & no \\
\hline 56 & 1070.4452 & 1.65 & 1.33 & 5.02 & 2.25 & -0.53 & 0.83 & no \\
\hline 57 & 1070.9630 & 1.89 & 1.99 & 3.05 & 3.06 & 0.09 & 0.83 & no \\
\hline 58 & 1071.0017 & 1.60 & 1.63 & 2.54 & 3.24 & 0.43 & 0.83 & no \\
\hline 59 & 1071.9988 & 2.41 & 1.37 & & & & 0.83 & \\
\hline 60 & 1072.0374 & 3.15 & 2.20 & 0.98 & 1.16 & 0.48 & 0.83 & no \\
\hline 61 & 1073.0345 & 1.49 & 1.88 & 2.79 & 4.17 & 0.51 & 0.83 & no \\
\hline 62 & 1073.5524 & 1.41 & 1.84 & 3.02 & 3.09 & 0.26 & 0.83 & no \\
\hline 63 & 1074.0702 & 1.04 & 2.03 & & & & 0.83 & \\
\hline 64 & 1074.5881 & 1.72 & 1.73 & 3.31 & 3.53 & 0.12 & 0.83 & no \\
\hline 65 & 1075.1060 & 1.19 & 2.18 & 3.61 & 4.35 & 0.31 & 0.83 & no \\
\hline 66 & 1075.6238 & 2.94 & 0.85 & & & & 0.83 & \\
\hline 67 & 1075.6625 & 3.65 & 2.07 & 3.83 & 4.10 & 0.61 & 0.83 & no \\
\hline 68 & 1076.6596 & 1.48 & 2.33 & 3.02 & 3.58 & 0.40 & 0.83 & no \\
\hline 69 & 1077.1774 & 0.15 & 2.81 & 1.15 & 3.54 & 0.79 & 0.83 & no \\
\hline 70 & 1077.2161 & 1.54 & 2.43 & 3.23 & 4.19 & 0.36 & 0.83 & no \\
\hline 71 & 1079.2489 & 1.69 & 1.88 & 3.12 & 3.76 & 0.31 & 0.83 & no \\
\hline 72 & 1079.2875 & 2.17 & 4.03 & 4.36 & 4.54 & 0.78 & 0.83 & no \\
\hline 73 & 1080.8025 & 1.69 & 2.35 & 2.58 & 5.10 & 0.74 & 0.83 & no \\
\hline 74 & 1080.8411 & 1.47 & 1.81 & 4.59 & 4.76 & 0.10 & 0.83 & no \\
\hline
\end{tabular}




\begin{tabular}{|c|c|c|c|c|c|c|c|c|}
\hline & age (kyr) & $\begin{array}{c}\text { extreme } \\
\text { low }\end{array}$ & $\begin{array}{l}\text { next } \\
\text { low }\end{array}$ & $\begin{array}{l}\text { next } \\
\text { high }\end{array}$ & $\begin{array}{c}\text { extreme } \\
\text { high }\end{array}$ & $\mathbf{Q}$ & Qcrit & Outliers? \\
\hline 75 & 1081.8383 & 1.57 & 2.46 & 3.67 & 4.92 & 0.37 & 0.83 & no \\
\hline 76 & 1081.8769 & 1.90 & 2.11 & 4.59 & 5.03 & 0.14 & 0.83 & no \\
\hline 77 & 1082.8740 & 1.52 & 1.91 & 3.96 & 4.04 & 0.15 & 0.83 & no \\
\hline 78 & 1082.9126 & 1.74 & 2.05 & 4.01 & 4.31 & 0.12 & 0.83 & no \\
\hline 79 & 1082.9512 & 1.48 & 2.23 & 4.50 & 4.67 & 0.24 & 0.83 & no \\
\hline 80 & 1084.4276 & 1.87 & 2.48 & 3.55 & 5.00 & 0.46 & 0.83 & no \\
\hline 81 & 1084.4579 & 1.56 & 3.40 & 4.75 & 5.23 & 0.50 & 0.83 & no \\
\hline 82 & 1084.4883 & 1.42 & 2.07 & 2.63 & 3.83 & 0.50 & 0.83 & no \\
\hline 83 & 1086.3078 & 1.51 & 1.91 & 3.33 & 4.53 & 0.40 & 0.83 & no \\
\hline 84 & 1086.3382 & 1.53 & 2.74 & 2.55 & 4.47 & 0.65 & 0.83 & no \\
\hline 85 & 1087.6259 & 2.36 & 2.40 & 4.73 & 5.55 & 0.26 & 0.83 & no \\
\hline 86 & 1087.6562 & 1.62 & 3.34 & 3.34 & 4.41 & 0.62 & 0.83 & no \\
\hline 87 & 1090.2619 & 1.47 & 1.87 & 3.12 & 4.46 & 0.45 & 0.83 & no \\
\hline 88 & 1090.2923 & 1.74 & 2.08 & 2.70 & 4.73 & 0.68 & 0.83 & no \\
\hline 89 & 1092.8980 & 2.20 & 2.38 & 3.41 & 4.53 & 0.48 & 0.83 & no \\
\hline 90 & 1092.9284 & 1.26 & 2.66 & 3.51 & 4.01 & 0.51 & 0.83 & no \\
\hline 91 & 1092.9587 & 1.54 & 2.07 & 3.41 & 4.01 & 0.24 & 0.83 & no \\
\hline 92 & 1096.8521 & 1.24 & 3.01 & 3.41 & 4.06 & 0.63 & 0.83 & no \\
\hline 93 & 1096.8825 & 1.51 & 1.64 & 2.85 & 3.62 & 0.36 & 0.83 & no \\
\hline 94 & 1096.9128 & 1.34 & 2.29 & & & & 0.83 & \\
\hline 95 & 1100.8062 & 1.46 & 1.82 & 2.95 & 3.91 & 0.39 & 0.83 & no \\
\hline 96 & 1102.1242 & 1.41 & 2.91 & & & & 0.83 & \\
\hline 97 & 1102.1546 & 1.00 & 2.54 & 3.50 & 3.72 & 0.57 & 0.83 & no \\
\hline 98 & 1104.7603 & 1.24 & 2.78 & 3.24 & 4.33 & 0.50 & 0.83 & no \\
\hline 99 & 1104.7907 & 1.69 & 1.75 & 3.10 & 4.17 & 0.43 & 0.83 & no \\
\hline 100 & 1107.3964 & 1.26 & 1.77 & 2.52 & 3.78 & 0.50 & 0.83 & no \\
\hline 101 & 1108.8353 & 1.07 & 1.48 & 2.27 & 3.84 & 0.57 & 0.83 & no \\
\hline 102 & 1110.8879 & 1.27 & 1.27 & 3.27 & 4.85 & 0.44 & 0.83 & no \\
\hline 103 & 1110.9074 & 2.16 & 2.49 & 2.49 & 3.52 & 0.76 & 0.83 & no \\
\hline 104 & 1114.9930 & 1.57 & 2.17 & 2.84 & 4.53 & 0.57 & 0.83 & no \\
\hline 105 & 1115.0125 & 1.61 & 1.61 & 2.92 & 4.15 & 0.48 & 0.83 & no \\
\hline 106 & 1119.0982 & 1.07 & 1.07 & 2.63 & 3.63 & 0.39 & 0.83 & no \\
\hline 107 & 1121.1507 & 1.54 & 1.83 & 3.06 & 3.30 & 0.17 & 0.83 & no \\
\hline 108 & 1121.1702 & 1.46 & 1.48 & 3.15 & 3.28 & 0.07 & 0.83 & no \\
\hline 109 & 1125.2558 & 1.53 & 2.18 & 4.08 & 5.28 & 0.32 & 0.83 & no \\
\hline 110 & 1127.3084 & 0.87 & 2.94 & 4.35 & 4.35 & 0.60 & 0.83 & no \\
\hline
\end{tabular}




\subsubsection{Analysis of means to identify outliers}

In common with the bulk of other work in the field (e.g. Sadekov et al, [2008]; Anand et al., [2003]), means have been used to construct the calibration curve. In addition, the data was examined to identify potential outliers that may influence the mean value.

Each sample mean comprises of between 2 and 22 individual tests. There is no guarantee, especially in those means comprised of few data, that the sample means themselves are not affected by outliers, i.e. that these sample means are good estimates of the population sample means. Hence, each of the sample means (that were used in the calibration) was screened for outliers. If they contained no outliers, it might be reasonable to assume that they were appropriate estimates of the population sample means.

A Dixon's Q test was used to screen for outliers, employing a confidence interval of 95\% $(\mathrm{P}=0.05)$. This means that there is a $95 \%$ certainty that average does not contain outliers, i.e. that the sample means are good estimates of the population sample means. If the $\mathrm{Q}$ statistic is less than the critical $Q$ value $\left(Q_{\text {crit }}\right)$, then with $95 \%$ confidence, there are no outliers. The Dixon Q statistic is defined as:

$Q=\frac{(\text { suspect value }- \text { nearest value) }}{\text { (largest value - smallest value) }}$

For each sample mean, four of the data were chosen, comprising of the highest, next highest, and lowest, next lowest, thus allowing the full variation to be represented. A conservative approach was adopted by using the $Q_{\text {crit }}$ value for $n=4$. Seven samples did not contain four points and hence could not be tested. The data are shown in Table 5.6. (N.B. the seven samples unable to be tested are in bold).

This analysis shows that the sample means tested did not (at the 95\% CI) contain outliers, and hence they are good estimates of the population sample means. 
Chapter 6

\section{Conclusions and Suggestions for Future Work}

The two main objectives of this thesis were to: (a) determine whether LA-ICP-MS is a useful analytical tool for the measurement of trace elements in foraminiferal calcite of Gs. ruber and $N$. incompta and can be used for reliable reconstruction of past ocean temperatures and, having demonstrated this, (b) reconstruct the ocean-climate conditions of MIS-34 to MIS-29 using these techniques. Trace element/Ca ratios were analysed in modern and fossil Gs. ruber, N. incompta and G. bulloides from core top, plankton tow and down-core material, which included the 'super-warm' interglacial period MIS-31 from sites in the Southwest Pacific Ocean.

\subsection{Trace element determination in "modern" planktonic foraminifera (Gs. ruber and $N$. incompta) by LA-ICP-MS}

Trace element/Ca ratios were measured by LA-ICP-MS in Gs. ruber and N. incompta from a wide range of core top and plankton tow samples in the Southwest Pacific Ocean with particular focus on linking measured $\mathrm{Mg} / \mathrm{Ca}$ ratios to observed (near-) surface ocean temperatures.

\subsubsection{Gs. ruber}

The variability of $\mathrm{Mg} / \mathrm{Ca}$ ratios within an individual Gs. ruber test show statistically significantly lower $\mathrm{Mg} / \mathrm{Ca}$ ratios in the final chamber $(\mathrm{F})$ compared to the two older final chambers $(\mathrm{F}-2$ and F-1). Although the lower $\mathrm{Mg} / \mathrm{Ca}$ in the final chamber could reflect a change in depth 
habitat, such as that typical during gametogenesis, data from plankton tow and other culturing studies also find lower $\mathrm{Mg} / \mathrm{Ca}$ ratios in the final chamber of other planktonic foraminiferal species, which suggests that this may also be a biological or 'vital effect'. These vital effects could affect the incorporation of $\mathrm{Mg}$ between different chambers and suggests that biological internal regulation plays a more prominent role in the $\mathrm{Mg} / \mathrm{Ca}$ intra-individual variability of foraminiferal tests than previously thought.

Inter-individual variability of $\mathrm{Mg} / \mathrm{Ca}$ ratios between $G$ s. ruber from the same core top sites and plankton tows reveals a wide range of $\mathrm{Mg} / \mathrm{Ca}$ values than cannot be explained by environmental conditions such as changes in seasonal near-surface ocean temperature or depth habitat, or reworking of modern and fossil foraminifera in core top samples. This variability requires that ocean temperature is not the only control on the incorporation of $\mathrm{Mg}$ into the tests of individual Gs. ruber and an as yet important control on $\mathrm{Mg}$ incorporation into Gs. ruber living under similar environmental conditions exists. Removal of the temperature effect on $\mathrm{Mg} / \mathrm{Ca}$ ratios on Gs. ruber individuals from the same sample reveals a log-normal distribution that describes the variability of $\mathrm{Mg} / \mathrm{Ca}$ ratios. However, the spread parameter of this distribution (i.e. the standard deviation of $\log [\mathrm{Mg} / \mathrm{Ca}]$ values) is not universal.

Regardless of this wide range of $\mathrm{Mg} / \mathrm{Ca}$ within individual Gs. ruber populations, the mean site $\mathrm{Mg} / \mathrm{Ca}$ value from each of the pooled final 3 chambers for each sample shows a positive correlation with annual SST at 0-50 m depth described by the following relationships:

$$
\begin{array}{ll}
\frac{M g}{C a_{c h F-2}}=0.798 \times \exp ^{0.070 \times S S T} & \\
& \left(\mathrm{r}^{2}=0.94\right) \\
\frac{M g}{C a_{c h F-1}}=0.891 \times \exp ^{0.067 \times S S T} & \left(\mathrm{r}^{2}=0.89\right)
\end{array}
$$


$\frac{M g}{C a_{c h F}}=0.798 \times \exp ^{0.070 \times S S T} \quad\left(\mathrm{r}^{2}=0.90\right)$

[Eqn. 6.3]

These chamber-specific calibrations can be used as an alternative to bulk, solution-based, $\mathrm{Mg} / \mathrm{Ca}$ analyses of foraminifera when analyses are performed by LA-ICP-MS. However, when LA-ICP-MS derived calibrations are compared to those derived from bulk solution ICP-MS studies, they are intermediate between the single chamber calibrations derived from F-2/F-1 and $\mathrm{F}$ from this study.

In summary, despite the intra-individual and inter-individual complexity observed in the $\mathrm{Mg}$ incorporation into Gs. ruber, LA-ICP-MS trace element analysis of this species of planktonic foraminifera can be used as a robust palaeocean thermometer provided the same chamber is analysed from each individual foraminifera.

\subsubsection{N. incompta}

In contrast to the LA-ICP-MS study of Gs ruber, individual N. incompta demonstrate far greater $\mathrm{Mg} / \mathrm{Ca}$ heterogeneity that contrasts with previous work on this species. For example, outer calcite crusts in crystalline forms have an outer layer with very low $\mathrm{Mg} / \mathrm{Ca}$ compared to the inner ontogenetic calcite. In reticulate or non-crystalline forms, this layer is either absent, or is only a thin layer with low $\mathrm{Mg} / \mathrm{Ca}$ ratios. These individuals may represent intermediates of crystalline forms, but this is not obvious with SEM imaging. The majority of reticulate tests without an outer layer with low $\mathrm{Mg} / \mathrm{Ca}$ have high and low $\mathrm{Mg} / \mathrm{Ca}$ bands in the inner ontogenetic calcite layer(s), which are interpreted as reflecting organic layers of ontogenetic calcite.

The lack of correlation between $\mathrm{Mg} / \mathrm{Ca}$ ratios of $\mathrm{N}$. incompta with ocean temperature may suggest that this species does not dwell at the same depths at each core top site. Additionally, unlike Gs ruber there was no systematic difference in $\mathrm{Mg} / \mathrm{Ca}$ found between the final four visible chambers at one core top site, nor between the F-3 and F chambers at any sites. This 
may reflect migration within the water column that is not uni-directional, or points towards further unidentified controls on $\mathrm{Mg}$ incorporation into N. incompta that require further study.

In summary, trace element/Ca ratios measured by LA-ICP-MS on N. incompta from the Southwest Pacific Ocean cannot be used to extract reliable past-ocean temperatures and, as such, this species was not used in the reconstruction of the ocean-climate conditions of MIS34 to MIS-29 in the second part of this thesis study.

\subsection{Ocean-climate response at ODP Site 1123 during MIS-34 to 29}

The trace element chemistry of Gs. ruber and G. bulloides, as well as size-normalised weights and the stable isotope composition $\left(\delta^{18} \mathrm{O}, \delta^{13} \mathrm{C}\right)$ of $G$. bulloides were determined from Marine Isotope Stages 33 to 29 at ODP Site 1123. Palaeo-ocean temperatures were constructed using the calibration developed in the first part of this study (Gs. ruber) and using a calibration developed using the same techniques for G. bulloides [Marr et al., 2011].

A new age model was generated for MIS-31 based on alignment of benthic $\delta^{18} \mathrm{O}$ to the LR04 age model. The age model includes the revised position of the base of the Jaramillo palaeomagnetic sub-chron (C1r.1n).

G. bulloides is present throughout the sediment record and records the warmest SST at the peak of SH insolation maxima in concert with SST recorded by Gs. ruber. When compared to the $\delta^{18} \mathrm{O}$ record, however, there is a $10 \mathrm{kyr}$ offset that cannot be an artefact of a chronological offset as both $\mathrm{Mg} / \mathrm{Ca}$ and stable isotope measurements were made on the same material. The lag between SST and $\delta^{18} \mathrm{O}$ may indicate that these records are not in phase. The lead of the Southwest Pacific Ocean planktic SST's $\left(\mathrm{Mg} / \mathrm{Ca}\right.$ ) over local (benthic $\delta^{18} \mathrm{O}_{c}$ ) ice volume change and a global $\left(\boldsymbol{\delta}^{18} \mathrm{O}_{\text {sw }}\right)$ change is consistent with other southern hemisphere SST records and infers that SST variability is not controlled by continental ice sheets.

The palaeo-SST from ODP Site 1123 show that during MIS-31 SST recorded by both Gs. ruber and $G$. bulloides reached a maximum of $c a .19^{\circ} \mathrm{C}$, which is ca. $4-7^{\circ} \mathrm{C}$ warmer than the modern 
spring/summer SST for each species, respectively, and in phase with the SH insolation maxima. As such, SST at southern mid-latitudes during MIS-31 in this "super-warm" interglacial were considerably higher than the present interglacial and consistent with sedimentary records that show a significant change in the Antarctic cryosphere at this time [Naish et al., 2007b; Scherer et al., 2008]. Modelled SST from Antarctica [Pollard and DeConto, 2009] predicts a SST increase of $5^{\circ} \mathrm{C}$ would be required to significantly melt the WAIS. The cause of this warming is suggested to be in part related to increased precessional forcing of the tropics, intensifying the SPTG and migration of STW to the south, as indicated by the increase in local salinity, and $\mathrm{Zn} / \mathrm{Ca}$ and $\mathrm{Ba} / \mathrm{Ca}$ ratios at ODP Site 1123. Additionally MIS-31 is characterised by high obliquity, which will have affected ice sheet expansion and contraction with a $40 \mathrm{kyr}$ periodicity. Although the effect of ice growth in one hemisphere on sea level may thus be cancelled by melting in the other hemisphere through precessional forcing, the large depletion in $\delta^{18} \mathrm{O}_{\text {sw }}$ and minimal SST recorded by G. bulloides that coincide with $\mathrm{NH}$ insolation maxima, suggest that $\mathrm{NH}$ ice sheets were more responsive to high latitude insolation than those in the SH.

Size-normalised weights of G. bulloides are generally lightest during interglacial periods and heaviest during glacial periods, and consistent with the temperature effect on size-normalised weights for modern G. bulloides from the Southwest Pacific [Marr et al., 2011], but this relationship is not consistent throughout the record. During early MIS-31 the size-normalised test weights are consistently heavier than would be expected given the warm SST. This indicates that dissolution during this interglacial period is not the reason for this offset. This offset may be related to changes in ocean $\left[\mathrm{CO}_{3}{ }^{2}\right]$ or other changes in water mass chemistry $\left(\delta^{13} \mathrm{C}\right.$, nutrient availability). Clearly, size-normalised weights of $G$. bulloides in the Southwest Pacific reflect a complex interplay of SST [e.g. Marr et al., 2011], and other factors such as ocean $\left[\mathrm{CO}_{3}^{2-}\right]$ and, in particular, during early MIS-31 the oceanographic and ocean chemistry of the Southwest Pacific was significantly perturbed compared to the present day when nontemperature controls became the dominant control on size-normalised weights of G. bulloides. 


\subsection{Suggestions for future work}

This thesis has potentially identified a number of research directions that would be useful in improving the use of foraminiferal trace element chemistry as a proxy of palaeo-climatic and oceanographic change both generally and in the Southwest Pacific.

(1) As LA-ICP-MS is a relatively new analytical technique in terms of its application to foraminifera, the comparison of LA-ICP-MS results versus those obtained by traditional solution-based ICP-MS techniques would be a useful avenue for further study to examine the comparability of the two techniques. This could be achieved by first analysing the same foraminifer's by LA-ICP-MS, which is essentially a non-destructive technique, followed by traditional solution-based ICP-MS analysis of the same individuals. In addition, it would be interesting to apply the cleaning techniques used during foraminifera preparation for solution-based methods and then analyse the foraminifera by LA-ICP-MS to critically assess the effects that various cleaning methods (oxidative, reductive and acid polishing) have on foraminiferal test chemistry.

(2) While the incorporation of $\mathrm{Mg}$ into planktic foraminifer tests as a palaeo-ocean thermometer has been the focus of this study, a wide range of other trace element/Ca ratios remain to be fully utilised for palaeo-climatic and-oceanographic reconstructions. For example, preliminary work in this study suggests that $\mathrm{Mn}$ and $\mathrm{Zn} / \mathrm{Ca}$ ratios vary systematically between interglacial and glacial periods and work by others [Yu et al., 2007; Foster, 2008] appear to show that B/Ca ratios may be able to be used to reconstruct past ocean $\left[\mathrm{CO}_{3}{ }^{2-}\right]$ and $\mathrm{pH}$. Application of new generation sector-field ICP-MS instruments which have much greater sensitivity than the analytical system used here, coupled to a laser ablation system, may result in significant advances in the application of other trace elements in foraminifera as palaeoenvironmental proxies.

(3) Finally, there is a lack of $\delta^{18} \mathrm{O}_{\text {sw }}$ measurements in the Southwest Pacific, and therefore it is difficult to examine regional $\delta^{18} \mathrm{O}_{\mathrm{sw}}$-salinity relationships with certainty and reconstruct past changes in $\delta^{18} \mathrm{O}_{\text {sw }}$ that might be then linked to changes in global ice volume. As such, and assuming that modern relationships are maintained in the past, measurements of $\delta^{18} \mathrm{O}_{\text {sw }}$ in the water column at different depths within the mixed layer and across a N-S transect of the Chatham Rise would be an important suite of data. 


\subsection{References}

Allen, C. P., and D. A. Warnke (1991), History of ice rafting at Leg 114 sites, Subantarctic/South Atlantic, in Proceedings of the Ocean Drilling Program Scientific Results, edited by P. F. Ciesielski, et al., pp. 599607.

Alloway, B. V., V. E. Neall, and C. G. Vucetich (1995), Late Quaternary tephrostratigraphy of northeast and central Taranaki, New Zealand, Journal of the Royal Society New Zealand, 25, 385-458.

Anand, P., and H. Elderfield (2003), Calibration of $\mathrm{Mg} / \mathrm{Ca}$ thermometry in planktonic foraminifera from a sediment trap time series, Paleoceanography, 18(2), 1-15, DOI: 10.1029/2002PA000846

Anand, P., and H. Elderfield (2005), Variability of $\mathrm{Mg} / \mathrm{Ca}$ and $\mathrm{Sr} / \mathrm{Ca}$ between and within the planktonic foraminifers Globigerina bulloides and Globorotalia truncatulinoides, Geochemistry, Geophysics, Geosystems, 6, DOI: 10.1029/2004GC000811.

Andrews, D. G. (2000), An Introduction to Atmospheric Physics, 1 ed., Cambridge University Press, Cambridge, New York, Melbourne, Madrid, Cape Town, Singapore, São Paulo, Delhi, Dubai, Tokyo.

Andrews, J. C., M. W. Lawrence, and C. S. Nilsson (1980), Observations of the Tasman Front, Journal of Physical Oceanography, 10(11), 1854-1869.

Antonov, J. I., R. A. Locarnini, T. P. Boyer, A. V. Mishonov, and H. E. Garcia (2006), World Ocean Atlas 2005, Volume 2: Salinity, in NOAA Atlas NESDIS, vol. 62, edited by p. N. S. Levitus, Silver Spring, Md.

Archer, D. E. (1996), An atlas of the distribution of calcium carbonate in sediments of the deep sea, Global Biogeochemical Cycles, 10(1), 159-174, DOI: 10.1029/95gb03016.

Armstrong, H. A., and M. D. Brasier (Eds.) (2005), Microfossils, 2nd ed., pp.296, Blackwell Publishing, Oxford, United Kingdom.

Arnold, A. J., and W. C. Parker (Eds.) (1999), Biogeography of planktonic Foraminifera, 103-122 pp., Kluwer Academic Publishers, Great Britain.

Bamber, J. L., R. E. M. Riva, B. L. A. Vermeersen, and A. M. LeBrocq (2009), Reassessment of the Potential Sea-Level Rise from a Collapse of the West Antarctic Ice Sheet, Science, 324(5929), 901-903.

Bandy, O. L. (1972), Origin and Development of Globorotalia (Turborotalia) pachyderma (Ehrenberg), Micropaleontology, 18(3), DOI: http://www.jstor.org/stable/1485010.

Barker, S., and H. Elderfield (2002), Foraminiferal calcification response to glacial-interglacial changes in atmospheric $\mathrm{CO}_{2}$, Science, 297, 833-836, DOI: 10.1126/science.1072815.

Barker, S., M. Greaves, and H. Elderfield (2003), A study of cleaning procedures used for foraminiferal $\mathrm{Mg} / \mathrm{Ca}$ paleothermometry, Geochemistry, Geophysics, Geosystems, 4(9), DOI: 8407, DOI:10.1029/2003GC000559. 
Barker, S., I. Cacho, H. Benway, and K. Tachikawa (2005), Planktonic foraminiferal Mg/Ca as a proxy for past oceanic temperatures: a methodological overview and data compilation for the Last Glacial Maximum, Quaternary Science Reviews, 24(7-9), 821-834, DOI: 10.1016/j.quascirev.2004.07.016.

Barrows, T. T., S. Juggins, P. De Deckker, J. Thiede, and J. I. Martinez (2000), Sea surface temperatures of the Southwest Pacific Ocean during the Last Glacial Maximum, Paleoceanography, 15(1), 95-109.

Bé, A. W. H., and D. B. Ericson (1963), Aspects of calcification in planktonic foraminifera (Sarcodina). In: Comparative biology of calcified tissues, Annals of the New York. Academy of Science, 109(1), 65-81.

Bé, A. W. H., and L. Lott (1964), Shell growth and structure of planktonic foraminifera, Science, (145), 823-824, DOI: $10.1126 /$ science.145.3634.823

Bé, A. W. H., and C. Hemleben (1970), Calcification in a living planktonic foraminifer, Globigerinoides sacculifer (Brady), Nenes Jabrb. Geol. Paläontol, 134(3), 221-234.

Bé, A. W. H. (Ed.) (1977), An ecological, zoogeographic and taxonomic review of recent planktonic foraminifera, 1100 pp., Academic Press, San Diego.

Bé, A. W. H., C. Hemleben, O. R. Anderson, M. Spindler, J. Hacunda, and S. Tuntivate-Choy (1977), Laboratory and field observations of living planktonic foraminifera, Micropaleontology, 23, 155-179.

Bé, A. W. H., and W. H. Hutson (1977), Ecology of planktonic foraminifera and biogeographic patterns of life and fossil assemblages in the Indian Ocean, Micropaleontology, 23(4), 369-414.

Bé, A. W. H., C. Hemleben, O. R. Anderson, and M. Spindler (1979), Chamber formation in planktonic foraminifera, Micropaleontology, 25(3), 294-307.

Bé, A. W. H. (1980), Gametogenic calcification in a spinose planktonic foraminifera Globigerinoides sacculifer using ${ }^{45} \mathrm{Ca}$ as a tracer: A recommended procedure for improved accuracy, Journal of Foraminiferal Research, 14(4), 303-308.

Bé, A. W. H., H. J. Spero, and O. R. Anderson (1982), Effects of symbiont elimination and reinfection on the life processes of the planktonic foraminifer Globigerinoides sacculifer, Marine Biology, 70, 73-86.

Bé, A. W. H., O. R. Anderson, and W. W. Faber, Jr. (1983), Sequence of morphological and cytoplasmic changes during gametogenesis in the planktonic foraminifer Globigerinoides sacculifer (Brady), Micropaleontology, 29(3), 310-325.

Becquey, S., and R. Gersonde (2002), Past hydrographic and climatic changes in the Subantarctic Zone of the South Atlantic - The Pleistocene record from ODP Site 1090, Palaeogeography, Palaeoclimatology, Palaeoecology, 182(3-4), 221-239.

Beer, C. J., R. Schiebel, and P. A. Wilson (2010), Testing planktic foraminiferal shell weight as a surface water [ $\left.\mathrm{CO}_{3}{ }^{2-}\right]$ proxy using plankton net samples, Geology, 38(2), 103-106, DOI: 10.1130/G30150.1.

Belkin, I., and P. Cornillon (2003), SST fronts of the Pacific coastal and marginal seas, Pacific Oceanography, 1(2), 90-113. 
Bemis, B. E., H. J. Spero, J. Bijma, and D. W. Lea (1998), Re-evaluation of the oxygen isotopic composition of planktonic foraminifera; experimental results and revised paleotemperature equations, Paleoceanography, 13, 150-160, DOI: 10.1029/98PA00070

Bemis, B. E., H. J. Spero, and R. C. Thunell (2002), Using species-specific paleotemperature equations with foraminifera: a case study in the Southern California Bight, Marine Micropaleontology, 46(3-4), 405430 .

Bentov, S., and J. Erez (2006), Impact of biomineralization processes on the Mg content of foraminiferal shells: A biological perspective, Geochemistry, Geophysics, Geosystems, 7, DOI: 10.1029/2005GC001015.

Bentov, S., C. Brownlee, and J. Erez (2009), The role of seawater endocytosis in the biomineralisation process in calcareous foraminifera, Proceedings of the National Academy of Sciences of the United States of America, 106(51), 21500-21504.

Benway, H. M., J. F. McManus, D. W. Oppo, and J. L. Cullen (2010), Hydrographic changes in the eastern subpolar North Atlantic during the last deglaciation, Quaternary Science Reviews, 29(23-24), 33363345, DOI: 10.1016/j.quascirev.2010.08.013.

Bergami, C., L. Capotondi, M. Sprovieri, M. Tiepolo, L. Langone, F. Giglio, and M. Ravaioli (2008), $\mathrm{Mg} / \mathrm{Ca}$ ratios in the planktonic foraminifer Neogloboquadrina pachyderma (sinistral) from plankton tows in the Ross Sea and the Pacific sector of the Southern Ocean (Antarctica): comparison of different methodological approaches, Chemistry and Ecology, 24(S1), 39-46.

Berger, A., and M. F. Loutre (2002), An exceptionally long interglacial ahead?, Science, 297, 1287-1288, DOI: $10.1126 /$ science.1076120.

Berger, W. H., C. G. Adelseck Jr., and A. L. Mayer (1976), Distribution of carbonate in surface sediments of the Pacific Ocean, Journal of Geophysical Research, 81, 2617-2627.

Berger, W. H. (1978), Deep-sea carbonate: pteropod distribution and the aragonite compensation depth, Deep Sea Research, 25(5), 447-452.

Bian, N., and P. A. Martin (2010), Investigating the fidelity of $\mathrm{Mg} / \mathrm{Ca}$ and other elemental data from reductively cleaned planktonic foraminifera, Paleoceanography, 25(2), PA2215, DOI: 10.1029/2009pa001796.

Bijma, J., J. Erez, and C. Hemleben (1990a), Lunar and semi-lunar reproductive cycles in some spinose planktonic foraminifers, Journal of Foraminiferal Research, 20, 117-127.

Bijma, J., W. W. J. Faber, and C. Hemleben (1990b), Temperature and salinity limits for growth and survival of some planktonic foraminifers in laboratory cultures, Journal of Foraminiferal Research, 20, 95116. 
Bijma, J., C. Hemleben, H. Oberhänsli, and M. Spindler (1992), The effects of increased water fertility on tropical spinose planktonic foraminifera in laboratory cultures, Journal of Foraminiferal Research, 22(3), 242-256.

Bijma, J., and C. Hemleben (1994), Population dynamics of the planktic foraminifer Globigerinoides sacculifer (Brady) from the central Red Sea, Deep-Sea Research, 41, 485-510.

Boland, F. M., and B. V. Hamon (1970), The East Australian Current, 1965-1968, Deep Sea Research, 17, 777-794.

Boland, F. M., and J. A. Church (1981), The East Australian Current 1978, Deep Sea Research, 28, $937-$ 957.

Bolton, A., J. A. Baker, G. Dunbar, L. Carter, E. G. C. Smith, and H. L. Neil (2011), Environmental versus biological controls on $\mathrm{Mg} / \mathrm{Ca}$ variability in Globigerinoides ruber (white) from core top and plankton tow samples in the Southwest Pacific Ocean, Paleoceanography, 26(PA2219), pp 1-14, DOI: 10.1029/2010PA001924.

Bostock, H. C., B. N. Opdyke, M. K. Gagan, and L. K. Fifield (2004), Carbon isotope evidence for changes in Antarctic Intermediate Water circulation and ocean ventilation in the southwest Pacific during the last deglaciation, Paleoceanography, 19(4), 1-15, DOI: 10.1029/2004PA001047.

Boyd, P., M. LaRoche, M. Gall, R. Frew, and R. M. L. McKay (1999), Role of iron, light, and silicate in controlling algal biomass in subantarctic waters SE of New Zealand, Journal of Geophysical Research, 104(13), 13,395-313,408, DOI: 10.1029/1999JC900009.

Boyd, P. W., G. McTainsh, V. Sherlock, K. Richardson, S. Nichol, M. Ellwood, and R. Frew (2004), Episodic enhancement of phytoplankton stocks in New Zealand subantarctic waters: Contribution of atmospheric and oceanic iron supply, Global Biogeochemical Cycles, 18(1), 1-23, DOI: 10.1029/2002GB002020.

Boyle, E. A. (1981), Cadmium, zinc, copper and barium in foraminifera tests, Earth and Planetary Science Letters, 53, 11-35.

Boyle, E. A. (1983), Manganese carbonate overgrowths on foraminifera tests, Geochimica et Cosmochimica Acta, 47, 1815-1819.

Boyle, E. A., and L. D. Keigwin (1985), Comparison of Atlantic and Pacific paleochemical records for the last 215,000 years: changes in deep ocean circulation and chemical inventories, Earth and Planetary Science Letters, 76, 135-150.

Bradford-Grieve, J. M., P. W. Boyd, F. H. Chang, S. Chiswell, M. Hadfield, J. A. Hall, M. R. James, S. D. Nodder, and E. A. Shushkina (1999), Pelagic ecosystem structure and functioning in the Subtropical Front region east of New Zealand in austral winter and spring 1993, Journal of Plankton Research, 21, 405428, DOI: $10.1093 /$ plankt/21.3.405. 
Bradley, R. S. (1985), Quaternary Paleoclimatology: Methods of Paleoclimatic Reconstruction, Allen \& Unwin, USA.

Brock, J. C., C. R. McClain, D. M. Anderson, W. L. Prell, and W. W. Hay (1992), Southwest monsoon circulation and environments of recent planktonic foraminifera in the Northwestern Arabian Sea, Paleoceanography, 7(6), 799-813, DOI: 10.1029/92PA01267.

Broecker, W. S. (1997), Thermohaline circulation, the Achilles Heel of our climate system: Will manmade $\mathrm{CO}_{2}$ upset the current balance?, Science, 278(5343), 1582-1588, DOI: 10.1126/science.278.5343.1582.

Brown, S. J., and H. Elderfield (1996), Variations in $\mathrm{Mg} / \mathrm{Ca}$ and $\mathrm{Sr} / \mathrm{Ca}$ ratios of planktonic foraminifera caused by postdepositional dissolution: Evidence of shallow Mg-dependent dissolution, Paleoceanography, 11, 543-551, DOI: 10.1029/96PA01491

Bruland, K. W., and M. C. Lohan (2003), Controls of trace metals in seawater, Treatise on Geochemistry, 6, 23-47.

Brummer, G.-J. A., C. Hemleben, and M. Spindler (1987), Ontogeny of extant spinose planktonic foraminifera (Globigerinidae): A concept exemplified by Globigerinoides sacculifer (Brady) and G. ruber (D'Orbigny), Marine Micropaleontology, 12, 357-381.

Brunskill, G. J. (2004), New Guinea and its coastal seas, a testable model of wet tropical coastal processes: an introduction to Project TROPICS, Continental Shelf Research, 24(19), 2273-2295.

Cai, W., G. Shi, T. Cowan, D. Bi, and J. Ribbe (2005), The response of the Southern Annual Mode, the East Australian Current and the southern mid-latitude circulation to global warming, Geophysical Research Letters, 32, L23706, DOI: 10.1029/2005GL024701.

Cai, W. (2006), Antarctic ozone depletion causes an intensification of the Southern Ocean super-gyre circulation, Geophysical Research Letters, 33, L03712, DOI: 10.1029/2005GL024911.

Came, R. E., D. W. Oppo, and J. F. McManus (2007), Amplitude and timing of temperature and salinity variability in the subpolar North Atlantic over the past 10 k.y, Geology, 35(4), 315-318.

Caron, D. A., O. R. Anderson, J. L. Lindsey, W. W. J. R. Faber, and E. E. L. Lim (1990), Effects of gametogenesis on test structure and dissolution of some spinose planktonic foraminifera and implications for test preservation, Marine Micropaleontology, 16, 93-116, DOI: 10.1016/03778398(90)90031-G.

Carpenter, S. J., and K. C. Lohmann (1992), Sr/Mg Ratios of modern marine calcite - empirical indicators of ocean chemistry and precipitation rate, Geochimica et Cosmochimica Acta, 56(5), 1837-1849.

Carter, L., and I. N. McCave (1994), Development of sediment drifts approaching an active plate margin under the SW Pacific Deep Western Boundary Current, Paleoceanography, 9, 1061-1085.

Carter, L., R. D. Garlick, and P. Sutton (1998a), Ocean Circulation New Zealand, NIWA Chart Miscellaneous Series, 76. 
Carter, L., and J. Wilkin (1999), Abyssal circulation around New Zealand: A comparison between observations and a global circulation model, Marine Geology, 159, 221-239.

Carter, L., B. Manighetti, G. Ganssen, and L. Northcote (2008), Southwest Pacific modulation of abrupt climate change during the Antarctic Cold Reversal-Younger Dryas, Palaeogeography, Palaeoclimatology, Palaeoecology, 260(1-2), 284-298.

Carter, R. M., I. N. McCave, and C. Richter (1998b), Ocean Drilling Program Leg 181 scientific prospectus Southwest Pacific gateways, Scientific Prospectus No. 81, 1-61.

Carter, R. M., L. Carter, and I. N. a. t. L. S. S. P. McCave (1999), The DWBC sediment drift record from Leg 181: drilling in the Pacific gateway for the global thermohaline circulation, JOIDES Journal, 25(1), 8-13.

Carter, R. M., P. R. Gammon, and L. Millwood (2004a), Glacial-interglacial (MIS 1-10) migrations of the Subtropical Front across ODP Site 1119, Canterbury Bight, Southwest Pacific Ocean, Marine Geology, 205(1-4), 29-58.

Carter, R. M., I. N. McCave, and L. Carter (Eds.) (2004b), Leg 181 synthesis: fronts, flows, drifts, volcanoes, and the evolution of the southwestern gateway to the Pacific Ocean, eastern New Zealand, 1-111 pp., TX (Ocean Drilling Program), 181: College Station.

Charles, C. D., J. Lynch-Stieglitz, U. S. Ninnemann, and R. G. Fairbanks (1996), Climate connections between the hemisphere revealed by deep sea sediment core/ice core correlations, Earth and Planetary Science Letters, 142(1-2), 19-27.

Chiswell, S. M., and P. J. H. Sutton (1998), A Deep Eddy in the Antarctic Intermediate Water North of the Chatham Rise, Journal of Physical Oceanography, 28(3), 535-540.

Chiswell, S. M. (2003), Circulation within the Wairarapa Eddy, New Zealand, New Zealand Journal of Marine Freshwater Research, 37, 691-704.

Cifelli, R. (1961), Globigerina incompta, a new species of pelagic foraminifera from the North Atlantic, Cushman Foundation for Foraminiferal Research, 12(3), 83-86, pl. 84. .

Clark, P. U., and A. C. Mix (2002), Ice sheets and sea level of the Last Glacial Maximum, Quaternary Science Reviews, 21(1-3), 1-7, DOI: 10.1016/S0277-3791(01)00118-4.

Cléroux, C., E. Cortijo, P. Anand, L. Labeyrie, F. Bassinot, N. Caillon, and J.-C. Duplessy (2008), $\mathrm{Mg} / \mathrm{Ca}$ and $\mathrm{Sr} / \mathrm{Ca}$ ratios in planktonic foraminifera: Proxies for upper water column temperature reconstruction, Paleoceanography, 23(PA3214), 1-12, DOI: 10.1029/2007PA001505.

Craig, C.-A., K. E. Jarvis, and L. J. Clarke (2000), An assessment of calibration strategies for the quantitative and semi-quantitative analysis of calcium carbonate matrices by laser ablation-inductively coupled plasma-mass spectrometry (LA-ICP-MS), Journal of Analytical Atomic Spectrometry, 15, 1001-1008, DOI: 10.1039/B002097O. 
Craig, H., and L. I. Gordon (1965), Isotope oceanography: Deuterium and oxygen 18 variations in the ocean and the marine atmosphere, Symposium on Marine Geochemistry, University of Rhode Island Occasional Publications, 3, 277-374.

Creech, J. B., J. A. Baker, C. J. Hollis, H. E. G. Morgans, and E. G. C. Smith (2010), Eocene sea temperatures for the mid-latitude southwest Pacific from $\mathrm{Mg} / \mathrm{Ca}$ ratios in planktonic and benthic foraminifera, Earth and Planetary Science Letters, 299(3-4), 483-495, DOI: 10.1016/j.epsl.2010.09.039.

Crundwell, M., G. Scott, T. Naish, and L. Carter (2008), Glacial-interglacial ocean climate variability from planktonic foraminifera during the Mid-Pleistocene transition in the temperate Southwest Pacific, ODP Site 1123, Paleogeography, Paleoclimatology, Paleoecology, 260, 202-229, DOI: 10.1016/j.palaeo.2007.08.023.

Curry, W. B., and G. P. Lohmann (1982), Carbon isotopic changes in benthic foraminifera from the western South Atlantic: Reconstruction of glacial abyssal circulation patterns, Quaternary Research, 18(2), 218-235.

D'Orbigny, A. D. (1839), Foraminifères, In: de la Sagra, R. (Ed.), Histoire physique, politique et naturelle d l'Ile de Cuba, 8, 1-224.

Darling, K. F., M. Kucera, D. Kroon, and C. M. Wade (2006), A resolution for the coiling direction paradox in Neogloboquadrina pachyderma, Paleoceanography, 21(PA2011), DOI: 10.1029/2005PA001189.

de Nooijer, L. J., G. J. Reichart, A. Dueñas-Bohórquez, M. Wolthers, S. R. Ernst, P. R. D. Mason, and G. J. van der Zwaan (2007), Copper incorporation in foraminiferal calcite: results from culturing experiments, Biogeosciences Discussions, 4, 961-991, DOI: 10.5194/bg-4-493-2007.

de Villiers, S. (2004), Optimum growth conditions as opposed to calcite saturation as a control on the calcification rate and shell-weight of marine foraminifera, Marine Biology, 144, 45-49, DOI: 10.1007/s00227-003-1183-8.

de Villiers, S. (2005), Foraminiferal shell-weight evidence for sedimentary calcite dissolution above the lysocline, Deep Sea Research, Part 1(52), 671-680, DOI: 10.1016/j.dsr.2004.11.014.

Dekens, P. S., D. W. Lea, D. K. Pak, and H. J. Spero (2002), Core top calibration of Mg/Ca in tropical foraminifera: Refining paleotemperature estimation, Geochemistry, Geophysics, Geosystems, 3(4), 1-29, DOI: 10.1029/2001GC000200.

Dieckmann, G. S., M. Spindler, M. A. Lange, S. F. Ackley, and H. Eicken (1991), Antarctic sea ice: A habitat for the foraminifer Neogloboquadrina pachyderma Journal of Foraminiferal Research, 21(2), 182-189, DOI: 10.2113/gsjfr.21.2.182.

Dueñas-Bohórquez, A., R. E. da Rocha, A. Kuroyanagi, L. J. de Nooijer, J. Bijma, and G.-J. Reichart (2010), Interindividual variability and ontogenetic effects on $\mathrm{Mg}$ and $\mathrm{Sr}$ incorporation in the planktonic foraminifer Globigerinoides sacculifer, Geochimica et Cosmochimica Acta, 75(2), 520-532, DOI: 10.1016/j.gca.2010.10.006. 
Dunbar, G., Dickens, G.R., and Carter, R.M., 2000, Sediment flux across the Great Barrier Reef Shelf to the Queensland Trough over the last 300 ky:, Sedimentary Geology, 13: 49-92.

Duplessey, J. C., C. Lalou, and A. C. Vinot (1970), Differential isotopic fractionation in benthic foraminifera and paleotemperatures reassessed Science, 168(3928), 250 - 251, DOI: $10.1126 /$ science. 168.3928 .250

Duplessy, J. C., P.-L. Blanc, and A. W. H. Bé (1981), Oxygen-18 enrichment of planktonic foraminifera due to gametogenic calcification below the euphotic zone, Science, 213(4513), 1247-1250, DOI: 10.1126/science.213.4513.1247.

Eggins, S., P. De Deckker, and J. Marshall (2003), Mg/Ca variation in planktonic foraminifera tests: implications for reconstructing palaeo-seawater temperature and habitat migration, Earth and Planetary Science Letters, 212, 291-306, DOI: 10.1016/S0012-821X(03)00283-8.

Eggins, S. M., A. Sadekov, and P. De Deckker (2004), Modulation and daily banding of $\mathrm{Mg} / \mathrm{Ca}$ in Orbulina universa tests by symbiont photosynthesis and respiration: a complication for seawater thermometry?, Earth and Planetary Science Letters, 225, 411-419, DOI: 10.1016/j.epsl.2004.06.019.

Ehrenberg, C. (1861), Uberd ie Tiefgrund - Verhaltnissed es Oceans am Eingange der Davisstrasse und bei Island, in G K. Preuss. Akad. Wiss., edited, pp. 275-315, Monatsber., Jahr 1861 (1862), Berlin.

Ehrenberg, C. (1873), Mikrogeologische Studien Ober das kleinste Leben der Meeres -Tiefgrunde aller Zonen und dessen geologischen Einfluss, in K. Akad. Wiss., edited, pp. 131- 397, Abh., Jahr 1872, Berlin.

Elderfield, H., C. J. Bertram, and J. Erez (1996), A biomineralization model for the incorporation of trace elements into foraminiferal calcium carbonate, Earth and Planetary Science Letters, 142, 409-423, DOI: 10.1016/0012-821X(96)00105-7.

Elderfield, H., and G. Ganssen (2000), Past temperature and $\delta^{18} \mathrm{O}$ of surface ocean waters inferred from foraminiferal Mg/Ca ratios, Nature, 405, 442-445, DOI: 10.1038/35013033.

Elderfield, H. (2002), Foraminiferal $\mathrm{Mg} / \mathrm{Ca}$ paleothermometry: expected advances and unexpected consequences, Geochimica et Cosmochimica Acta, 66, A213.

Elderfield, H., M. Vautravers, and M. Cooper (2002), The relationship between shell size and $\mathrm{Mg} / \mathrm{Ca}$, $\mathrm{Sr} / \mathrm{Ca}, \delta^{18} \mathrm{O}$ and $\delta^{13} \mathrm{C}$ of species of planktonic foraminifera, Geochemistry, Geophysics, Geosystems, 3(8), DOI: $10.1029 / 2001 \mathrm{GC000194.}$

Elderfield, H., M. Greaves, S. Barker, I. R. Hall, A. Tripati, P. Ferretti, S. Crowhurst, L. Booth, and C. Daunt (2010), A record of bottom water temperature and seawater $\delta^{18} \mathrm{O}$ for the Southern Ocean over the past $440 \mathrm{kyr}$ based on $\mathrm{Mg} / \mathrm{Ca}$ of benthic foraminiferal Uvigerina spp. , Quaternary Science Reviews, 29, 160-169, DOI: 10.1016/j.quascirev.2009.07.013.

Ellwood, M. (2004), Zinc and cadmium speciation in subantarctic waters east of New Zealand, Marine Chemistry, 87, 37-58. 
Epstein, S., R. Buchsbaum, H. A. Lowenstam, and H. C. Urey (1953), Revised carbonate-water isotopic temperature scale, Bulletin of the Geological Society of America, 64, 1315-1326.

Erez, J., and S. Honjo (1981), Comparison of isotopic composition of planktonic foraminifera in plankton tows, sediment traps and sediments, Palaeogeography, Palaeoclimatology, Palaeoecology, 33(1-3), 129156.

Erez, J., and B. Luz (1983), Experimental palaeotemperature equation for planktonic foraminifera, Geochimica et Cosmochimica Acta, 47, 1025-1031.

Erez, J., A. Almogi-Labin, and S. Avraham (1991), On the life history of planktonic foraminifera: Lunar reproduction cycle in Globigerinoides sacculifer (Brady), Paleoceanography, 6(3), 295-306, DOI: 10.1029/90pa02731.

Erez, J. (2003), The source of ions for biomineralization in foraminifera and their implications for paleoceanographic proxies, Reviews in Mineralogy and Geochemistry, 54, 115-149.

Fairbanks, R. G., P. H. Wiebe, and A. W. H. Be (1980), Vertical distribution and isotopic composition of living planktonic foraminifera in the western North Atlantic, Science, 201, 61-63, DOI: 10.1126/science.207.4426.61.

Farrell, J. W., and W. L. Prell (1989), Climatic change and $\mathrm{CaCO}_{3}$ preservation: an 800,000 year bathymetric reconstruction from the central equatorial Pacific ocean, Paleoceanography, 4, 447-466.

Feely, R. A., C. L. Sabine, K. Lee, W. Berelson, J. Kleypas, V. J. Fabry, and F. J. Millero (2004), Impact of anthropogenic $\mathrm{CO}_{2}$ on the $\mathrm{CaCO}_{3}$ system in the oceans, Science, 305(5682), 362-366, DOI: 10.1126/science.1097329.

Fehrenbacher, J., P. A. Martin, and G. Eshel (2006), Glacial deep water carbonate chemistry inferred from foraminiferal $\mathrm{Mg} / \mathrm{Ca}$ : A case study from the western tropical Atlantic, Geochemistry, Geophysics, Geosystems, 7(9), Q09P16, DOI: 10.1029/2005gc001156.

Fenner, J., and A. Di Stefano (2004), Late Quaternary oceanic fronts along Chatham Rise indicated by phytoplankton assemblages, and refined calcareous nannofossil stratigraphy for the mid-latitude SW Pacific, Marine Geology, 205, 59-86, DOI: 10.1016/0025-3227(92)90206-W.

Ferguson, J. E., G. M. Henderson, M. Kucera, and R. E. M. Rickaby (2008), Systematic change of foraminiferal $\mathrm{Mg} / \mathrm{Ca}$ ratios across a strong salinity gradient, Earth and Planetary Science Letters, 265, 153166, DOI: $10.1016 /$ j.epsl.2007.10.011.

Fischer, G., and G. Wefer (Eds.) (1999), Use of proxies in paleoceanography: Examples from the South Atlantic, Springer-Verlag, Berlin, Heidelberg, New York.

Foster, G. L. (2008), Seawater pH, pCO2 and [CO2-3] variations in the Caribbean Sea over the last 130 kyr: A boron isotope and B/Ca study of planktic foraminifera, Earth and Planetary Science Letters, 271(1-4), 254-266. 
Fraile, I., M. Schilz, S. Mulitza, U. Merkel, M. Prange, and A. Paul (2009), Modelling the seasonal distribution of planktonic foraminifera during the Last Glacial Maximum, Paleoceanography, DOI: 10.1029/2008PA001686.

Gillett, N. P., and D. W. J. Thompson (2003), Simulation of recent southern hemisphere climate change, Science, 302(273-275), DOI: 10.1126/science.1087440.

Glasby, G. P. (1979), Major element analyses of marine sediments from the southwest Pacific, New Zealand Soil Bureau scientific report.

Goldstein, S. T. (Ed.) (1999), Foraminifera: A biological overview, 37-55 pp., Kluwer Academic Publishers, Great Britain.

Gonzalez-Mora, B., F. J. Sierro, and J. A. Flores (2008), Controls of shell calcification in planktonic foraminifers, Quaternary Science Reviews, 27, 956-961, DOI: 10.1016/j.quascirev.2008.01.008

Gordon, A. L., S. Ma, D. B. Olson, P. Hacker, A. Ffield, L. D. Talley, D. Wilson, and M. Baringer (1997), Advection and diffusion of Indonesian throughflow water within the Indian Ocean South Equatorial Current, Geophysical Research Letters, 24(21), 2573-2576, DOI: 10.1029/97GL01061.

Gupta, B. K. S. (Ed.) (1999), Systematics of modern Foraminifera, 7-36 pp., Kluwer Academic Publishers, Great Britain.

Haarmann, T., Hathorne, E.C., Mohtadi, M., Groeneveld, J., Kölling, M., Bickert, T., (2011), Mg/Ca ratios of single planktonic foraminifer shells and the potential to reconstruct the thermal seasonality of the water column, Paleoceanography, DOI: 10.1029/2010PA002091, in press.

Haley, B. A., and G. P. Klinkhammer (2002), Development of a flow-through system for cleaning and dissolving foraminiferal tests, Chemical Geology, 185(1-2), 51-69, DOI: 10.1016/S0009-2541(01)00399-0.

Hall, I. R., I. N. McCave, N. J. Shackleton, G. P. Weedon, and S. E. Harris (2001), Intensified deep Pacific inflow and ventilation in Pleistocene glacial times, Nature, 412(6849), 809-812, DOI: $10.1038 / 35090552$.

Hamilton, C. P., H. J. Spero, J. Bijma, and D. W. Lea (2008), Geochemical investigation of gametogenic calcite addition in the planktonic foraminifera Orbulina universa, Marine Micropaleontology, 68, 256-267.

Hamon, B. V. (1965), The East Australian Current, 1960-1964, Deep Sea Research, 12(6), 899-921.

Hansen, H. J. (1999), Shell construction in modern calcareous Foraminifera, in Modern Foraminifera, edited by B. K. S. Gupta, pp. 57-70, Kluwer Academic Publishers, Great Britain.

Hathorne, E. C., O. Alard, R. H. James, and N. W. Rogers (2003), Determination of intratest variability of trace elements in foraminifera by laser ablation inductively coupled plasma-mass spectrometry, Geochemistry, Geophysics, Geosystems, 4(12), DOI: 10.1029/2003GC000539.

Hathorne, E.C., James, R.H., Savage, P. and Alard, O., Physical and chemical characteristics of particles produced by laser ablation of biogenic calcium carbonate, (2008), Journal of Analytical Atomic Spectrometry, 23: 240-243, DOI: 10.1039/b706727e. 
Hathorne, E. C., R. H. James, and R. S. Lampitt (2009), Environmental versus biomineralization controls on the intratest variation in the trace element composition of the planktonic foraminifera $G$. inflata and G. scitula, Paleoceanography, 24, 1-14, DOI: 10.1029/2009PA001742.

Hawes, I., M. Gall, and M. Weatherfield (1997), Photosynthetic parameters in water masses in the vicinity of the Chatham Rise, South Pacific Ocean, during late summer, New Zealand Journal of Marine Freshwater Research, 31, 25-38.

Hays, J. D., J. Imbrie, and N. J. Shackleton (1976), Variations in the earth's orbit: pacemaker of the ice ages, Science, 194, 1121-1132, DOI: 10.1126/science.194.4270.1121.

Hayward, B. W., G. Scott, M. P. Crundwell, J. P. Kennett, L. Carter, H. L. Neil, A. T. Sabaa, K. Wilson, J. S. Rodger, G. Schaefer, H. R. Grenfell, and Q. Li (2008), The effect of submerged plateaux on Pleistocene gyral circulation and sea-surface temperatures in the Southwest Pacific, Global and Planetary Change, 63, 309-316, DOI: 10.1016/j.gloplacha.2008.07.003.

Head, M. J., and P. L. Gibbard (Eds.) (2005), Early middle Pleistocene transitions: An overview and recommendation for the defining boundary, in Early Middle Pleistocene transitions, 1-18 pp., Geological Society, London.

Heath, R. A. (1985), A review of the physical oceanography of the seas around New Zealand — 1982, New Zealand Journal of Marine and Freshwater Research, 19(79-124).

Hecht, A. D. (1974), Intraspecific variation in recent population of Globigerinoides ruber and Globigerinoides trilobus and their application to paleoenvironmental analysis Journal of Paleontology, 48(6), 1217-1234.

Hemleben, C., and M. Spindler (1983), Recent advances in research on living planktonic foraminifera, Utrecht Micropaleontology Bulletin, 30, 141-171.

Hemleben, C., M. Spindler, and O. R. Anderson (1989), Modern planktonic foraminifera, Springer-Verlag, New York.

Hendry, K. R., R. E. M. Rickaby, M. P. Meredith, and H. Elderfield (2009), Controls on stable isotope and trace metal uptake in Neogloboquadrina pachyderma (sinistral) from an Antarctic sea-ice environment, Earth and Planetary Science Letters, 278(1-2), 67-77, DOI: 10.1016/j.epsl.2008.11.026.

Herbert, T. D., J. D. Schuffert, D. Andreasen, L. Heusser, M. Lyle, A. Mix, A. C. Ravelo, L. D. Stott, and J. C. Herguera (2001), Collapse of the California Current During Glacial Maxima Linked to Climate Change on Land, Science, 293(5527), 71-76.

Herbert, T. D., L. C. Peterson, K. T. Lawrence, and Z. Liu (2010), Tropical Ocean Temperatures Over the Past 3.5 Million Years, Science, 328(5985), 1530-1534.

Hilbrecht, H. (1997), Morphologic gradation and ecology in Neogloboquadrina pachyderma and Neogloboquadrina dutertrei (planktic foraminifera) from core top sediments, Marine Micropaleontology, 31, 143. 
Hill, K. L., S. R. Rintoul, R. Coleman, and K. R. Ridgway (2008), Wind forced low frequency variability of the East Australia Current, Geophysical Research Letters, 35(8), L08602, DOI: 10.1029/2007gl032912.

Hollis, C. J., and H. L. Neil (2005), Sedimentary record of radiolarian biogeography, offshore eastern New Zealand, New Zealand Journal of Marine Freshwater Research, 39, 165-192.

Hönisch, B., K. A. Allen, A. D. Russell, S. M. Eggins, J. Bijma, H. J. Spero, D. W. Lea, and J. Yu (2011), Planktic foraminifers as recorders of seawater Ba/Ca, Marine Micropaleontology, 79(1-2), 52-57, DOI: 10.1016/j.marmicro.2011.01.003.

Hoogakker, B. A. A., G. P. Klinkhammer, H. Elderfield, E. J. Rohling, and C. Hayward (2009), Mg/Ca Paleothermometry in high salinity environments, Earth and Planetary Science Letters, 284, 583-589, DOI: 10.1016/j.epsl.2009.05.027.

Howard, W. R., and W. L. Prell (1992), Late Quaternary Surface Circulation of the Southern Indian Ocean and its Relationship to Orbital Variations, Paleoceanography, 7(1), 79-117.

Huang, K., C. You, H. Lin, and Y. Shieh (2008), In situ calibration of Mg/Ca ratio in planktonic foraminiferal shell using time series sediment trap: A case study of intense dissolution artefact in the South China Sea, Geochemistry, Geophysics, Geosystems, 9(4), 1-20, DOI: 10.1029/2007GC001660.

Huybers, P. (2006), Early Pleistocene Glacial Cycles and the Integrated Summer Insolation Forcing, Science, 313(5786), 508-511.

Imbrie, J., and J. Z. Imbrie (1980), Modelling the climatic response to orbital variations, Science, 207, 943-953.

IPCC (Ed.) (2007), Climate Change 2007: The Physical Science Basis, Cambridge University Press, Cambridge, United Kingdom and New York, NY, USA.

Jacquet, S. H. M., F. Dehairs, D. Cardinal, J. Navez, and B. Delille (2005), Barium distribution across the Southern Ocean frontal system in the Crozet-Kerguelen Basin, Marine Chemistry, 95(3-4), 149-162.

Jager, E., and J. C. Hunziker (Eds.) (1979), Lectures in Isotopic Geology, 266 pp., Springer-Verlag, Heidelberg, Germany.

Jha, P., and H. Elderfield (2000), Variation of $\mathrm{Mg} / \mathrm{Ca}$ and $\mathrm{Sr} / \mathrm{Ca}$ in planktonic and benthic foraminifera from single test chemistry, Eos Trans, $A G U(81), \mathrm{F} 705$.

Johnstone, H. J. H., M. Schulz, S. Barker, and H. Elderfield (2010), Inside story: An X-ray computed tomography method for assessing dissolution in the tests of planktonic foraminifera, Marine Micropaleontology, 77(1-2), 58-70, DOI: 10.1016/j.marmicro.2010.07.004.

Kanfoush, S. L., D. A. Hodell, C. D. Charles, T. R. Janecek, and F. R. Rack (2002), Comparison of icerafted debris and physical properties in ODP Site 1094 (South Atlantic) with the Vostok ice core over the last four climatic cycles, Palaeogeography, Palaeoclimatology, Palaeoecology, 182(3-4), 329-349. 
Katz, M. E., B. S. Cramer, A. Franzese, B. Hönisch, K. G. Miller, Y. Rosenthal, and J. D. Wright (2010), Traditional and emerging geochemical proxies in foraminifera, Journal of Foraminiferal Research, 40(2), 165-192.

Kawahata, H. (2005), Stable isotope composition of two morphotypes of Globigerinoides ruber (white) in the subtropical gyre in the North Pacific, Paleontological Research, 9(1), 27-35.

Kennett, J. P. (1968), Latitudinal variation in Globigerina pachyderma (Ehrenberg) in surface sediments of the Southwest Pacific Ocean, Micropaleontology, 14(3), 305-318.

Kennett, J. P., and P. Vella (Eds.) (1975), Late Cenozoic planktonic foraminifera and paleoceanography at DSDP site 284 in the cool subtropical South Pacific, 769-799 pp., U.S. Government Printing Office Washington, D.C.

Kennett, J. P. (1982), Marine Geology, Prentice-Hall, New Jersey.

Key, R. M., A. Kozyr, C. L. Sabine, K. Lee, R. Wanninkhof, J. L. Bullister, R. A. Feely, F. J. Millero, C. Mordy, and T.-H. Peng (2004), A global ocean carbon climatology: Results from GLODAP, Global Biogeochemical Cycles, 18(4).

Kim, S.-T., and J. R. O'Neil (1997), Equilibrium and nonequilibrium oxygen isotope effects in synthetic carbonates, Geochemica et Cosmochimica Acta, 61(16), 3461-3475.

King, A. L., and W. R. Howard (2000), Middle Pleistocene sea-surface temperature change in the southwest Pacific Ocean on orbital and suborbital time scales, Geology, 28(7), 659-662.

King, A. L., and W. R. Howard (2001), Seasonality of foraminiferal flux in sediment traps at Chatham Rise, SW Pacific: implications for paleotemperature estimates, Deep Sea Research, I(48), 1687-1708, DOI: 10.1016/S0967-0637(00)00106-0.

Kisakürek, B., A. Eisenhauer, F. Böhm, D. Garbe-Schönberg, and J. Erez (2008), Controls on shell $\mathrm{Mg} / \mathrm{Ca}$ and $\mathrm{Sr} / \mathrm{Ca}$ in cultured planktonic foraminiferan, Globigerinoides ruber (white), Earth and Planetary Science Letters, 273, 260-269, DOI: 10.1016/j.eps1.2008.06.026.

Klinkhammer, G. P., B. A. Haley, A. C. Mix, H. M. Benway, and M. Cheseby (2004), Further evaluation of flow-through as a method for cleaning and dissolving shells of planktonic foraminifera for $\mathrm{Mg} / \mathrm{Ca}$ paleothermometry, Geochimica et Cosmochimica Acta, 68(11), A335-A335.

Klinkhammer, G. P., A. C. Mix, and B. A. Haley (2009), Increased dissolved terrestrial input to the coastal ocean during the last deglaciation, Geochemistry, Geophysics, Geosystems, 10(3), Q03009, DOI: 10.1029/2008GC002219.

Kohfield, K. E., R. G. Fairbanks, S. L. Smith, and I. D. Walsh (1996), Neogloboquadrina pachyderma (sinistral coiling) as paleoceanographic tracers in polar oceans: Evidence from Northeast Water Polynya plankton tows, sediment traps, and surface sediments, Paleoceanography, 11(6), 679-699. 
Kozdon, R., T. Ushikubo, N. T. Kita, M. Spicuzza, and J. W. Valley (2009), Intratest oxygen isotope variability in the planktonic foraminifer $N$. pachyderma: Real vs. apparent vital effects by ion microprobe, Chemical Geology, 258, 327-337, DOI: 10.1016/j.chemgeo.2008.10.032.

Kroopnick, P. M. (1985), The distribution of ${ }^{13} \mathrm{C}$ of $\Sigma \mathrm{CO}_{2}$ in the world oceans, Deep Sea Research Part A. Oceanographic Research Papers, 32(1), 57-84.

Kunioka, D., K. Shirai, N. Takahata, Y. Sano, T. Toyofuku, and Y. Ujiie (2006), Microdistribution of $\mathrm{Mg} / \mathrm{Ca}, \mathrm{Sr} / \mathrm{Ca}$, and $\mathrm{Ba} / \mathrm{Ca}$ ratios in Pulleniatina obliquiloculata test by using a NanoSIMS: Implication for the vital effect mechanism, Geochemistry, Geophysics, Geosystems, 7, DOI: Q12P20, DOI:10.1029/2006GC001280.

Kupp, G. (2006), Analysis of ice-rafted debris from Ocean Drilling Program Site 1165, Hole B indicates occasional warm-water intrusions during the last 5 million years, Unpublished Master's thesis, CSU East Bay, Hayward, CA.

Kuroyanagi, A., and H. Kawahata (2004), Vertical distribution of living planktonic foraminifera in the seas around Japan, Marine Micropaleontology, 53, 173-196.

Laskar, J., P. Robutel, F. F. Joutel, M. M. Gastineau, A. C. M. Correia, and B. Levrard (2004), A long term numerical solution for the insolation quantities of the Earth, Astronomy \& Astrophysics, 1-26.

Le, J., and N. J. Shackleton (1992), Carbonate dissolution fluctuations in the western equatorial Pacific during the late Quaternary, Paleoceanography, 7, 21-42.

Lea, D. W. (1999), Trace elements in foraminiferal calcite, in Modern Foraminifera, edited by B. K. S. Gupta, pp. 259-277, Kluwer Academic.

Lea, D. W., T. A. Mashiotta, and H. J. Spero (1999), Controls on magnesium and strontium uptake in planktonic foraminifera determined by live culturing, Geochimica et Cosmochimica Acta, 62(16), 2369-2379.

Lea, D. W., D. K. Pak, and H. J. Spero (2000), Climate impact of late Quaternary equatorial Pacific sea surface temperature variations, Science, 289, 1719-1724, DOI: 10.1126/science.289.5485.1719.

Lea, D. W. (2003), Elemental and Isotopic Proxies of Past Ocean Temperatures, Treatise on Geochemistry, 6, 365-390.

Lea, D. W., and E. A. Boyle (2003), Reply to the Comment by N.E. Pingitore Jr. on "Barium in planktonic foraminifera". Geochemica Cosmochimica Acta, 57, 471-473.

LeGrande, A. N., and G. A. Schmidt (2006), Global gridded data set of the oxygen isotopic composition in seawater, Geophysical Research Letters, 33(12), L12604.

Lisiecki, L. E., and M. E. Raymo (2005), A Pliocene-Pleistocene stack of 57 globally distributed benthic $\delta^{18} \mathrm{O}$ records, Paleoceanography, 20(PA1003), DOI: 10.1029/2004PA001071.

Liu, Z., and T. D. Herbert (2004), High-latitude influence on the eastern equatorial Pacific climate in the early Pleistocene epoch, Nature, 427(6976), 720-723. 
Locarnini, R. A., A. V. Mishonov, J. I. Antonov, T. P. Boyer, and H. E. Garcia (2006), World Ocean Atlas 2005, Volume 1: Temperature, U.S. Government Printing Office, Washington, D.C.

Lohmann, G. P. (1995), A Model for Variation in the Chemistry of Planktonic Foraminifera Due to Secondary Calcification and Selective Dissolution, Paleoceanography, 10(3), 445-457, DOI: 10.1029/95PA00059.

Lombard, F., R. E. da Rocha, J. Bijma, and J.-P. Gattuso (2010), Effect of carbonate ion concentration and irradiance on calcification in planktonic foraminifera, Biogeosciences, 7, 247-255.

Lorens, R. B. (1981), Sr, Cd, Mn, and Co distribution coefficients in calcite as a function of calcite precipitation rate, Geochemica et Cosmochimica Acta, 45, 553-561.

Löwemark, L., W.-L. Hong, T.-F. Yui, and G.-W. Hung (2005), A test of different factors influencing the isotopic signal of planktonic foraminifera in surface sediments from the northern South China Sea, Marine Micropaleontology, 55, 49-62, DOI: 10.1016/j.marmicro.2005.02.004.

Lynch-Stieglitz, J. (2003), Tracers of Past Ocean Circulation, Treatise on Geochemistry, 6, 433-451.

Mackensen, A., H.-W. Hubberten, T. Bickert, G. Fischer, and D. K. Fütterer (1993), The $\delta^{13} \mathrm{C}$ in benthic foraminiferal tests of Fontbotia wuellerstorfi (Schwager) relative to the $\delta^{13} \mathrm{C}$ of dissolved inorganic carbon in Southern Ocean deep water: Implications for glacial ocean circulation models, Paleoceanography, 8(5), 587-610.

Maiorano, P., M. Marino, and J.-A. Flores (2009), The warm interglacial Marine Isotope Stage 31: Evidences from the calcareous nannofossil assemblages at Site 1090 (Southern Ocean), Marine Micropaleontology, 71(3-4), 166-175.

Malmgren, B. A., and J. P. Kennett (1978), Late Quaternary Paleoclimatic Applications of Mean Size Variations in Globigerina bulloides d'Orbigny in the Southern Indian Ocean, Journal of Paleontology, 52(6), 1195-1207.

Marr, J. (2009), Ecological, Oceanographic and Temperature Controls on the Incorporation of Trace Elements into Globigerina bulloides and Globoconella inflata in the Southwest Pacific Ocean, MSc thesis, Victoria University of Wellington, Wellington.

Marr, J., J. Baker, L. Carter, A. Allen, G. Dunbar, and H. Bostock (2011), Ecological and temperature controls on $\mathrm{Mg} / \mathrm{Ca}$ ratios of Globigerina bulloides from the southwest Pacific Ocean, Paleoceanography, 26(2), 1-15, DOI: 10.1029/2010PA002059

Marszalek, D. S., R. C. Wright, and W. W. Hay (1969), Function of the test in foraminifera, Transactions of the Gulf Coast Association of Geological Societies, 19, 341-352.

Martin, P. A., and D. W. Lea (2002), A simple evaluation of cleaning procedures on fossil benthic foraminiferal Mg/Ca, Geochemistry, Geophysics, Geosystems, 3(10), DOI: 10.1029/2001GC000280.

Martínez, J. I. (1994), Late Pleistocene palaeoceanography of the Tasman Sea: Implications for the dynamics of the warm pool in the western Pacific, Paleogeography, Paleoclimatology, Paleoecology, 112, 19-62. 
Maslin, M. A., and A. J. Ridgwell (2005), Mid-Pleistocene revolution and the 'eccentricity myth', Geological Society, London, Special Publications, 247(1), 19-34, DOI: 10.1144/gsl.sp.2005.247.01.02.

Mathien-Blard, E., and F. Bassinot (2009), Salinity bias on the foraminifera $\mathrm{Mg} / \mathrm{Ca}$ thermometry: Correction procedure and implications for past ocean hydrographic reconstructions, Geochemistry, Geophysics, Geosystems, 10(12), 1-17, DOI: 10.1029/2008GC002353.

McCave, I. N., and L. Carter (1997), Recent sedimentation beneath the Deep Western Boundary Current off Northern New Zealand, Deep-Sea Res., 44, 1203-1237.

McCave, I. N., L. Carter, and I. R. Hall (2008), Glacial-interglacial changes in water mass structure and flow in the S.W. Pacific Ocean, Quaternary Science Reviews 27(19-20), 1886-1908.

McConnell, M. C., and R. C. Thunell (2005), Calibration of the planktonic foraminiferal Mg/Ca paleothermometer: sediment trap results from the Guaymas Basin, Gulf of California, Paleoceanography, 20(2), DOI: 10.1029/2004PA001077.

McConnell, M. C., R. C. Thunell, L. Lorenzoni, Y. Astor, J. D. Wright, and R. Fairbanks (2009), Seasonal variability in the salinity and oxygen isotopic composition of seawater from the Cariaco Basin, Venezuela: Implications for paleosalinity reconstructions, Geochemistry, Geophysics, Geosystems, 10(6), Q06019, DOI: 10.1029/2008gc002035.

McManus, J., W. M. Berelson, D. E. Hammond, and G. P. Klinkhammer (1999), Barium cycling in the North Pacific: Implications for the utility of $\mathrm{Ba}$ as a paleoproductivity and paleoalkalinity proxy, Paleoceanography, 14(1), 53-61, DOI: 10.1029/1998pa900007.

Medina-Elizalde, M., and D. W. Lea (2005), The Mid-Pleistocene Transition in the Tropical Pacific, Science, 310(5750), 1009-1012.

Milankovitch, M., (1941), Kanon der Erdbestrahlung und seine Andwendung auf das Eiszeitenproblem,. Royal Serbian Academy Special Publication, (English translation published in 1969 by Israel Program for Scientific translations, US Dept. Comm.), 133: 633, Belgrade.

Miller, K. G., T. R. Janecek, M. E. Katz, and D. J. Keil (1987), Abyssal circulation and benthic foraminiferal changes near the Paleocene/Eocene Oligocene to Miocene benthic foraminiferal and abyssal circulation changes in the North Atlantic, Paleoceanography, 2(6), 741-761.

Miller, J.C. and Miller, J.N., (1984), Statistics for analytical chemistry, in King, E.P., (1958), Journal of the American statistical association, 48 , pp. 531

Mohtadi, M., S. Steinke, J. Groeneveld, H. G. Fink, T. Rixen, D. Hebbeln, B. Donner, and B. Herunadi (2009), Low-latitude control on seasonal and interannual changes in planktonic foraminiferal flux and shell geochemistry off south Java: A sediment trap study, Paleoceanography, 24, DOI: 10.1029/2008PA001636.

Morris, M., B. Stanton, and H. L. Neil (2001), Subantarctic oceanography around New Zealand: preliminary results from an ongoing survey, New Zealand Journal of Marine and Freshwater Research, 35, 499519. 
Mortyn, P. G., and C. D. Charles (2003), Planktonic foraminiferal depth habitat and $\delta^{18} \mathrm{O}$ calibrations: Plankton tow results from the Atlantic sector of the Southern Ocean, Paleoceanography, 18(2), 1037, DOI: $1010.1029 / 2001$ PA000637.

Mortyn, P. G., H. Elderfield, P. Anand, and M. Greaves (2005), An evaluation of controls on planktonic foraminiferal Sr/Ca: Comparison of water column and core-top data from a North Atlantic transect, Geochemistry, Geophysics, Geosystems, 6, DOI: 10.1029/2005GC001047.

Moy, A. D., W. R. Howard, S. G. Bray, and T. W. Trull (2009), Reduced calcification in modern Southern Ocean planktonic foraminifera, Nature Geoscience, 2, 276-280, DOI: 10.1038/ngeo460.

Mucci, A., and J. W. Morse (1983), The incorporation of $\mathrm{Mg}^{2+}$ and $\mathrm{S}^{\mathrm{r} 2+}$ into calcite overgrowthsinfluences of growth-rate and solution composition, Geochimica et Cosmochimica Acta, 47(2), 217-233.

Mulitza, S., D. Boltovskoy, B. Donner, H. Meggers, A. Paul, and G. Wefer (2003), Temperature: $\delta^{18} \mathrm{O}$ relationships of planktonic foraminifera collected from surface waters, Palaeogeography, Palaeoclimatology, Palaeoecology, 202(1-2), 143-152.

Munk, W., and C. Wunsch (1998), Abyssal recipes II: energetics of wind and tidal mixing, Deep Sea Research, 45, 1977-2010.

Murphy, R. J., M. H. Pinkerton, K. M. Richardson, and J. M. Bradford-Grieve (2001), Phytoplankton distributions around New Zealand derived from SeaWiFS remotely-sensed ocean colour data, New Zealand Journal of Marine Freshwater Research, 35, 343-362.

Naish, T., R. D. Powell, S. A. Henrys, G. Wilson, L. A. Krissek, F. Niessen, M. Pompilio, R. Scherer, F. Talarico, R. H. Levy, and A. R. Pyne (2007), Late Neogene climate history of the Ross Embayment: Initial results from the ANDRILL McMurdo Ice Shelf Project, in 10th International Symposium on Antarctic Earth Sciences, edited, University of California, Santa Barbara.

Naish, T., Powell, R., Levy, R., Wilson, G., Scherer, R., Talarico, F., Krissek, L.' Niessen, F., Pompilio, M., Wilson, T., Carter, L., DeConto, R., Huybers, P., McKay, R., Pollard D., Ross, J., Winter, D., Barrett, P., Browne, G., Cody, R., Cowan, E., Crampton, J, Dunbar, G., Dunbar, N., Florindo, F., Gebhardt, C., Graham, I., Hannah, M., Hansaraj, D., Harwood, D., Helling, D., Henrys, S, Hinnov, L., Kuhn, G., Kyle, P., Läufer, A., Maffioli, P., Magens, D., Mandernack, K., McIntosh, W., Millan, C., Morin, R., Ohneiser, C., Paulsen, T., Persico, D., Raine, I., Reed, J., Riesselman, C., Sagnotti, L., Schmitt, D., Sjunneskog, C., Strong, P., Taviani, M., Vogel, S., Wilch, T., \& Williams, T., (2009), Obliquity-paced Pliocene West Antarctic ice sheet oscillations, Nature, 458:322-328, DOI: 10.1038/nature07867

NBS (1970), Trace elements in glass SRMs: SRM 610 through 619, inclusive, National Bureau of Standards (Certificate), 1-4.

Neil, H. L., L. Carter, and M. Y. Morris (2004), Thermal isolation of Campbell Plateau, New Zealand, by the Antarctic Circumpolar Current over the past 130 kyr, Paleoceanography, 19, PA4008, DOI:10.1029/2003PA000975. 
Nelson, C. S., I. L. Hendy, H. L. Neil, C. H. Hendy, and P. P. E. Weaver (2000), Last glacial jetting of cold waters through the Subtropical Convergence zone in the Southwest Pacific off eastern New Zealand, and some geological implications, Palaeogeography, Palaeoclimatology, Palaeoecology, 156(1-2), 103121.

Ni, Y., G. L. Foster, T. Bailey, T. Elliot, D. N. Schmidt, P. Pearson, B. Haley, and C. Coath (2007), A core top assessment of proxies for the ocean carbonate system in surface-dwelling foraminifers, Paleoceanography, 22, 1-14, DOI: 10.1029/2006PA001337.

Niebler, H.-S., H.-W. Hubberton, and R. Gersonde (1999), Oxygen isotope values of planktic foraminifera: a tool for the reconstruction of surface water stratification, in Use of Proxies in Paleoceanography: examples from the South Atlantic, edited by G. Fischer, et al., pp. 165-189, Springer-Verlag, Berlin, Heidelberg.

Nigam, R., R. Saraswat, and A. Mazumder (2003), Life spans of planktonic foraminifers: New insight through sediment traps, Journal of the palaeontological society of India, 48, 129-133.

Nilsson, C. S., and G. R. Cresswell (1980), The formation and evolution of East Australian Current warm-core eddies, Progress in Oceanography, 9(3), 133-183.

Nodder, S. D. (1997), Short-term sediment trap fluxes from Chatham Rise, Southwest Pacific Ocean, Limnology and Oceanography, 42(4), 777-783.

Nodder, S. D., and L. C. Northcote (2001), Episodic particulate fluxes at southern temperate midlatitudes $\left(42-45^{\circ} \mathrm{S}\right)$ in the Subtropical Front region, east of New Zealand, Deep Sea Research Part I: Oceanographic Research Papers, 48(3), 833-864.

Norman, M. D., N. J. Pearson, A. Sharma, and W. L. Griffin (1996), Quantitative analysis of trace elements in geological materials by laser ablation ICP-MS: Instrumental operating and calibration values of NIST glasses, Geostandards Newsletter, 20(2), 247-261.

Nozaki, Y. (1997), Supplementary material to "A fresh look at element distribution in the North Pacific", Eos Trans.

Numberger, L., C. Hemleben, R. Hoffman, A. Mackensen, H. Schulz, J.-M. Wunderlich, and M. Kucera (2009), Habitats, abundance patterns and isotopic signals of morphotypes of the planktonic foraminifer Globigerinoides ruber (d'Orbigny) in the eastern Mediterranean Sea since the Marine Isotopic Stage 12, Marine Micropaleontology, 73, 90-104, DOI: 10.1016/j.marmicro.2009.07.004.

Nürnberg, D. (1995), Magnesium in tests of Neogloboquadrina pachyderma sinistral from high northern and southern latitudes, Journal of Foraminiferal Research, 25(4), 350-368.

Nürnberg, D., J. Bijma, and C. Hemleben (1996), Assessing the reliability of magnesium in foraminiferal calcite as a proxy for water mass temperature, Geochimica et Cosmochimica Acta, 60(5), 803814. 
Nürnberg, D., and J. Groeneveld (2006), Pleistocene variability of the Subtropical Convergence at East Tasman Plateau: Evidence from planktonic foraminiferal $\mathrm{Mg} / \mathrm{Ca}$ (ODP Site 1172A), Geochemistry Geophysics Geosystems, 7, DOI: Q04P11, DOI:10.1029/2005GC000984.

Oliver, K. I. C., B. A. A. Hoogakker, S. Crowhurst, G. M. Henderson, R. E. M. Rickaby, N. R. Edwards, and H. Elderfield (2009), A synthesis of marine sediment core $\delta^{13} \mathrm{C}$ data over the last 150000 years, Climate of the Past Discussions, 5(6), 2497-2554, DOI: 10.5194/cpd-5-2497-2009.

Orr, W. M. (1967), Secondary calcification in the foraminiferal genus Globorotalia Science, 157(3796), 1554-1555.

Ortiz, J.D., Mix, A.C., and Collier, R.W., (1995), Environmental control of living symbiotic ad asymbiotic foraminifera of the California Current, Paleoceanography, 10(6):987-1009.

Pahnke, K., R. Zahn, H. Elderfield, and M. Schulz (2003), 340,000-year centennial-scale marine record of Southern hemisphere climatic oscillation, Science, 301, 948-952, DOI: 10.1126/science.1084451.

Paillard, D. (2010), Climate and the orbital parameters of the Earth, Comptes Rendus Geoscience, 342(4-5), 273-285.

Pak, D. K., D. W. Lea, and J. P. Kennett (2004), Seasonal and interannual variation in Santa Barbara Basin water temperatures observed in sediment trap foraminiferal $\mathrm{Mg} / \mathrm{Ca}$, Geochemistry, Geophysics, Geosystems, 5(12), Q12008, DOI: 10.1029/2004GC000760.

Paquette, J., and R. J. Reeder (1990), New type of compositional zoning in calcite - insights in to crystal growth mechanisms, Geology, 18, 1244-1247.

Patterson, J. E. (1978), Oxygen Plasma Asher, Analytical Chemistry, 51, 1087-1089.

Pearce, N. J. G., W. T. Perkins, J. A. Westgate, M. P. Gorton, S. E. Jackson, C. R. Neal, and S. P. Chenery (1996), A Compilation of New and Published Major and Trace Element Data for NIST SRM 610 and NIST SRM 612 Glass Reference Materials, Geostandards Newsletter, The Journal of Geostandards and Geoanalysis, 21(1), 115-144.

Pearce, R. B. (1991), Ocean chemistry and deep-sea sediments, 2 ed., Pergamon Press, Open University, Oxford.

Pedersen, T. F., and N. B. Price (1982), The geochemistry of manganese carbonate in Panama Basin sediments, Geochimica et Cosmochimica Acta, 46, 59-74.

Pekar, S. F., and R. M. DeConto (2006), High-resolution ice-volume estimates for the early Miocene: evidence for a dynamic ice sheet in Antarctica, Palaeogeography, Palaeoclimatology, Palaeoecology, 231, 101 109, DOI: $10.1016 /$ j.palaeo.2005.07.027.

Pena, L. D., I. Cacho, E. Calvo, C. Pelejero, S. Eggins, and A. Sadekov (2008), Characterization of contaminant phases in foraminifera carbonates by electron microprobe mapping, Geochemistry, Geophysics, Geosystems, 9(7), 1-12, DOI: 10.1029/2008GC002018. 
Petit, J. R., J. Jouzel, D. Raynaud, N. I. Barkov, J. M. Barnola, I. Basile, M. Bender, J. Chappellaz, M. Davis, G. Delaygue, M. Delmotte, V. M. Kotlyakov, M. Legrand, V. Y. Lipenkov, C. Lorius, L. Pepin, C. Ritz, E. Saltzman, and M. Stievenard (1999), Climate and atmospheric history of the past 420,000 years from the Vostok ice core, Antarctica, Nature, 399(6735), 429-436, DOI: 10.1038/20859.

Pollard, D., and R. M. DeConto (2009), Modelling West Antarctic ice sheet growth and collapse through the past five million years, Nature, 458(19), DOI: 10.1038/nature07809.

Rahmstorf, S. (2002), Ocean circulation and climate during the past 120,000 years, Nature, 419(6903), 207-214, DOI: 10.1038/nature01090.

Raja, R., P. K. Saraswati, K. Rogers, and K. Iwao (2005), Magnesium and strontium compositions of recent symbiont-bearing benthic foraminifera, Marine Micropaleontology, 58(1), 31-44, DOI: 10.1016/j.marmicro.2005.08.001.

Ravelo, A. C., R. G. Fairbanks, and S. G. H. Philander (1990), Reconstructing tropical Atlantic hydrography using planktonic foraminifera and an ocean model, Paleoceanography, 5, 409-431.

Ravelo, A. C., and R. G. Fairbanks (1992), Oxygen isotopic composition of multiple species of planktonic foraminifera: Recorders of the modern photic zone temperature gradient, Paleoceanography, 7(6), 815-831, DOI: 10.1029/92PA02092

Ravizza, G. E., and J. C. Zachos (2003), Records of Cenozoic Ocean Chemistry, Treatise on Geochemistry, 6, 551-581.

Raymo, M. E., W. F. Ruddiman, N. J. Shackleton, and D. W. Oppo (1990), Evolution of AtlanticPacific $\delta^{13} \mathrm{C}$ gradients over the last $2.5 \mathrm{~m} . \mathrm{y}$, Earth and Planetary Science Letters, 97(3-4), 353-368.

Raymo, M. E., and K. Nisancioglu (2003), The 41 kyr world: Milankovitch's other unsolved mystery, Paleoceanography, 18(1), 1011, DOI: 10.1029/2002PA000791.

Raymo, M. E., (1997), The timing of major climate terminations, Paleoceanography, 12(4): 577-585; DOI: 10.1029/97PA01169.

Raymo, M. E., L. E. Lisiecki, and K. H. Nisancioglu (2006), Plio-Pleistocene Ice Volume, Antarctic Climate, and the Global $\delta^{18}$ O Records, Sciencexpress, DOI: 10.1126/science.1123296.

Raymo, M. E., and P. Huybers (2008), Unlocking the mysteries of the ice ages, Nature, 451(7176), 284285, DOI: $10.1038 /$ nature06589.

Reed, W. P. (1992), Certificate of Analysis: Standard Reference Materials 610 and 611, National Institute of Standards and Technology, 1-3.

Regenberg, M., S. Steph, D. Nürnberg, R. Tiedemann, and D. Garbe-Schönberg (2009), Calibrating $\mathrm{Mg} / \mathrm{Ca}$ ratios of multiple planktonic foraminiferal species with $\delta^{18} \mathrm{O}$ calcification temperatures: Paleothermometry for the upper water column, Earth and Planetary Science Letters, 278, 324-336, DOI: 10.1016/j.epsl.2008.12.019. 
Reichart, G. J., F. Jorissen, P. Anschutz, and P. R. D. Mason (2003), Single foraminiferal test chemistry records the marine environment, Geology, 31(4), 355-358.

Reimers, C. E. (1987), An in situ microprofiling instrument for measuring interfacial pore water gradients: Methods and oxygen profiles from the North Pacific Ocean, Deep Sea Research Part A, 34, 2019-2035.

Reiss, Z. (1958), Classification of lamellar foraminifera, Micropaleontology, 4(1), 51-70.

Reynolds, L. A., and R. C. Thunell (1986), Seasonal production and morphologic variation of Neogloboquadrina pachyderma (Ehrenberg) in the northeast Pacific, Micropaleontology, 32(1), 1-18.

Ridgway, K. R., and J. S. Godfrey (1997), Seasonal cycle of the East Australian Current, Journal of Geophysical Research, 102(C10), 22921-22936, DOI: 10.1029/97jc00227.

Ridgway, K. R., and J. R. Dunn (2007), Observational evidence for a Southern Hemisphere oceanic supergyre, Geophysical Research Letters, 34(13), L13612, DOI: 10.1029/2007GL030392.

Ridgway, K. R., and K. Hill (2009), The East Australian Current, in A Marine Climate Change Impacts and Adaptation Report Card for Australia 2009, edited by E. S. Poloczanska, et al., NCCARF Publication 05/09.

Rocholl, A. B. E., K. Simon, K. P. Jochum, F. Bruhn, R. Gehann, U. Kramar, W. Luecke, M. Molzahn, E. Pernicka, M. Seufert, B. Spettel, and J. Stummeier (1997), Chemical characterisation of NIST silicate glass certified reference material SRM 610 by ICP-MS, TIMS, LIMS, SSMS, INAA, AAS and PIXE, Geostandards Newsletter, 21(1), 101-114.

Roemmich, D., and P. Sutton (1998), The mean and variability of ocean circulation past northern New Zealand: determining the representativeness of hydrographic climatologies, Journal of Geophysical Research, 103(C6), 13041-13054, DOI: 10.1029/98JC00583.

Roemmich, D. (2007), Physical oceanography: Super spin in the southern seas, Nature, 449(7158), 3435, DOI: 10.1038/449034a.

Roemmich, D., J. Gilson, R. Davis, P. Sutton, S. Wijffels, and S. Riser (2007), Decadal spinup of the South Pacific Subtropical Gyre, Journal of Physical Oceanography, 37(2), 162-173, DOI: 10.1175/JPO3004.1.

Rohling, E. J., and G. R. Bigg (1998), Paleosalinity and $\delta^{18} \mathrm{O}$ : A critical assessment, Journal of Geophysical Research, 103(C1), 1307-1318, DOI: 10.1029/97JC01047.

Rohling, E. J., and S. Cooke (Eds.) (2003), Stable oxygen and carbon isotope ratios in foraminiferal carbonate shells, 239-258 pp., Kluwer Academic, Dordrecht, The Netherlands.

Rollion-Bard, C. (2005), Microanalysis by ion microprobe of oxygen isotopic compositions in foraminifera, Geophysical Research Abstracts, 7, 1607-7962. 
Rollion-Bard, C., D. Mangin, and M. Champenois (2007), Development and applications of oxygen and carbon isotopic measurements of biogenic carbonates by ion microprobe, Geostandards and Geoanalytical Research, 31, 39-50, DOI: 10.1111/j.1751-908X.2007.00834.x.

Rosenthal, Y., G. P. Lohmann, K. C. Lohmann, and R. M. Sherrell (2000), Incorporation and preservation of $\mathrm{Mg}$ in Globigerinoides sacculifer: Implications for reconstructing the temperature and ${ }^{18} \mathrm{O} /{ }^{16} \mathrm{O}$ of seawater, Paleoceanography, 15(1), 135-145.

Rosenthal, Y., S. Perron-Cashman, C. H. Lear, E. Bard, S. Barker, K. Billups, M. Bryan, M. L. Delaney, P. B. deMenocal, G. S. Dwyer, H. Elderfield, C. R. German, M. Greaves, D. W. Lea, T. M. Marchitto, D. K. Pak, G. L. Paradis, A. D. Russell, R. R. Schneider, K. Scheiderich, L. Stott, K. Tachikawa, E. Tappa, R. Thunell, M. Wara, S. Weldeab, and P. A. Wilson (2004), Interlaboratory comparison study of $\mathrm{Mg} / \mathrm{Ca}$ and $\mathrm{Sr} / \mathrm{Ca}$ measurements in planktonic foraminifera for paleoceanographic research, Geochemistry, Geophysics, Geosystems, 5, DOI: 10.1029/2003GC000650.

Rubin, S. I., S. L. King, R. A. Jahnke, and P. N. Froelich (2003), Benthic barium and alkalinity fluxes: Is $\mathrm{Ba}$ an oceanic paleo-alkalinity proxy for glacial atmospheric $\mathrm{CO}_{2}$ ?, Geophysical Research Letters, 30(17), 1885, DOI: $10.1029 / 2003 g 1017339$.

Ruddiman, W. F., and A. McIntyre (1979), Warmth of the subpolar North Atlantic Ocean during northern hemisphere ice-sheet growth, Science, 204, 173-175, DOI: 10.1126/science.204.4389.173.

Ruddiman, W. F., (2003), Orbital insolation, ice volume, and greenhouse gases, Quaternary Science Reviews, 22, 1597-1629, DOI: 10.1016/S0277-3791(03)00087-8.

Russon, T., Elliot, M., Sadekov, A., Cabioch, G., Corrège, T., De Deckker, P. (2011), The midPleistocene transition in the subtropical southwest Pacific, Paleoceanography, 26(1), (PA1211), 1-12, DOI: $10.1029 / 2010$ PA002019

Sadekov, A., S. M. Eggins, and P. De Deckker (2005), Characterization of $\mathrm{Mg} / \mathrm{Ca}$ distributions in planktonic foraminifera species by electron microprobe mapping, Geochemistry, Geophysics, Geosystems, 6(12), 1-14, DOI: 10.1029/2005GC000973.

Sadekov, A., S. M. Eggins, P. De Deckker, and D. Kroon (2008), Uncertainties in seawater thermometry deriving from intratest and intertest $\mathrm{Mg} / \mathrm{Ca}$ variability in Globigerinoides ruber, Paleoceanography, 23(PA1215), 1-12, DOI: 10.1029/2007/PA001452.

Sadekov, A., S. M. Eggins, P. De Deckker, U. Ninnemann, W. Kuhnt, and F. Bassinot (2009), Surface and subsurface seawater temperature reconstruction using $\mathrm{Mg} / \mathrm{Ca}$ microanalysis of planktonic foraminifera Globigerinoides ruber, Globigerinoides sacculifer, and Pulleniatina obliquiloculata, Paleoceanography, 24, DOI: $10.1029 / 2008 \mathrm{PA} 001664$.

Samelson, R.M., Skyllingstad, E.D., Chelton, D.B., Esbensen, S.K.,. O'Neill, L.W., and Thum, N., (2006), On the Coupling of Wind Stress and Sea Surface Temperature, Journal of Climate, 19: 1557-1566, DOI: 10.1175/JCLI3682.1. 
Sarmiento, J. L., N. Gruber, M. A. Brzezinski, and J. P. Dunne (2004), High-latitude controls of thermocline nutrients and low latitude biological productivity, Nature, 427(6969), 56-60, DOI: $10.1038 /$ nature 02127 .

Sasaki, Y., S. Minobe, T. Kagimoto, M. Nonaka, and H. Sasaki (2008), Decadal sea level variability in the South Pacific in a global eddy resolving model, Journal of Physical Oceanography, 38, 1731-1747.

Sautter, L. R., and C. Sancetta (1992), Seasonal associations of phytoplankton and planktic foraminifera in an upwelling region and their contribution to the seafloor, Marine Micropaleontology, 18, 263-278.

Sautter, L. R. (1998), Morphologic and stable isotopic variability within the planktic foraminiferal genus Neogloboquadrina, Journal of Foraminiferal Research, 28(3), 220-232.

Savin, S. M., L. Abel, E. Barrera, D. Hodell, G. Keller, J. P. Kennett, J. Killingley, M. Murphy, and E. Vincent (1985), The evolution of Miocene surface and near-surface marine temperature: oxygen isotopic evidence. In: Kennett JP (ed.) The Miocene ocean: paleoceanography and biogeography, GSA memoir 163, Geological Society of America, Boulder, pp 49-82.

Schaefer, G., J. S. Rodger, B. W. Hayward, J. P. Kennett, A. T. Sabaa, and G. H. Scott (2005), Planktic foraminiferal and sea surface temperature record during the last $1 \mathrm{Myr}$ across the Subtropical Front, Southwest Pacific, Marine Micropaleontology, 54(3-4), 191-212, DOI: 10.1016/j.marmicro.2004.12.001

Scherer, R., S. Bohaty, R. B. Dunbar, O. Esper, J. A. Flores, R. Gersonde, D. M. Harwood, A. P. Roberts, and M. Taviani (2008), Antarctic records of precession-paced insolation-driven warming during early Pleistocene Marine Isotope Stage 31, Geophysical Research Letters, 35(L03505), DOI: 10.1029/2007GL032254

Schiebel, R., J. Bijma, and C. Hemleben (1997), Population dynamics of the planktic foraminifer Globigerina bulloides from the eastern North Atlantic, Deep Sea Research Part II, 44, 1701-1713.

Schiebel, R., J. Waniek, M. Bork, and C. Hemleben (2001), Planktic foraminiferal production stimulated by chlorophyll redistribution and entrainment of nutrients, Deep Sea Research, 1(48), 721-470

Schlitzer, R. (2002), Ocean Data View, http://www.awi-bremerhaven.de/GEO/ODV, edited.

Schmidt, G. A., G. R. Bigg, and E. J. Rohling (1999), Global Seawater Oxygen-18 Database, http://data.giss.nasa.gov/o18data/, edited.

Schmidt, M. W., H. J. Spero, and D. W. Lea (2004), Links between salinity variation in the Caribbean and North Atlantic thermohaline circulation, Nature, 428(6979), 160-163, DOI: 10.1038/nature02346.

Schmidt, M. W., M. J. Vautravers, and H. J. Spero (2006), Rapid subtropical North Atlantic salinity oscillations across Dansgaard-Oeschger cycles, Nature, 443(7111), 561-564, DOI: 10.1038/nature05121.

Schumacher, S., F. J. Jorissen, A. Mackensen, A. J. Gooday, and O. Pays (2010), Ontogenetic effects on stable carbon and oxygen isotopes in tests of live (Rose Bengal stained) benthic foraminifera from the Pakistan continental margin, Marine Micropaleontology, 76(3-4), 92-103. 
Serrano, O., L. Serrano, and M. A. Mateo (2008), Effects of sample pre-treatment on the delta ${ }^{13} \mathrm{C}$ and delta $^{18} \mathrm{O}$ values of living benthic foraminifera, Chemical Geology, 257, 221-223.

Shackleton, N.J., (1987), The carbon isotope record of the Cenozoic: history of organic carbon burial and of oxygen in the ocean and atmosphere, Geological Society Special Publication, 26, 423-434, DOI: 10.1144/GSL.SP.1987.026.01.27

Shackleton, N. J., D. H. Wiseman, and H. A. Buckley (1973), Non-equilibrium isotopic fractionation between sea-water and planktonic foraminiferal tests, Nature, 242, 177-179.

Siddall, M., E. J. Rohling, A. Almogi-Labin, C. Hemleben, D. Meischner, I. Schmelzer, and D. A. Smeed (2003), Sea-level fluctuations during the last glacial cycle, Nature, 423(6942), 853-858, DOI: 10.1038 / nature01690.

Sikes, E. L., W. R. Howard, H. L. Neil, and J. K. Volkman (2002), Glacial-interglacial sea surface temperature changes across the subtropical front east of New Zealand based on alkenone unsaturation ratios and foraminiferal assemblages, Paleoceanography, 17(2), 1012, DOI: 10.1029/2001PA000640

Skinner, L. (2010), Facing future climate change: is the past relevant?, Philosophical Transactions of The Royal Society A, 366, 4627-4645, DOI: 10.1098/rsta.2008.0228.

Speich, S., B. Blanke, P. de Vries, K. Doos, S. Drijfhout, A. Ganachaud, and R. Marsh (2002), Tasman leakage: a new route in the global ocean conveyor belt, Geophysical Research Letters, 29(10), 1416-1420, DOI: $10.1029 / 2001$ GL014586

Spero, H. J., I. Lerche, and D. F. Williams (1991), Opening the carbon isotope "Vital effect" black box, 2, Quantitative model for interpreting foraminiferal carbon isotope data, Paleoceanography, 6(6), 639-655, DOI: $10.1029 / 91$ PA02022

Spero, H. J., J. Bijma, D. W. Lea, and B. E. Bemis (1997), Effect of seawater carbonate concentration on foraminiferal carbon and oxygen isotopes, Nature, 390(6659), 497-500, DOI: 10.1038/37333.

Spindler, M. (1996), On the salinity tolerance of the planktonic foraminifer Neogloboquadrina pachyderma from the Antarctic sea ice, Proceedings of the NIPR symposium on polar biology, 9, 85-91.

Srinivasan, M. S., and J. P. Kennett (1974), Secondary calcification of the planktonic foraminifer Neogloboquadrina pachyderma as a climatic index, Science, 186(186), 630-632, DOI: 10.1126/science.186.4164.630

Stanton, B. R. (2001), Estimating the East Auckland Current transport from model winds and the Island Rule, New Zealand Journal of Marine and Freshwater Research, 35(531-540).

Steinke, S., H. Y. Chiu, P. S. Yu, C. C. Shen, L. Lowemark, H. S. Mii, and M. T. Chen (2005), Mg/Ca ratios of two Globigerinoides ruber (white) morphotypes: Implications for reconstructing past tropical/ subtropical surface water conditions, Geochemistry, Geophysics, Geosystems, 6, 1-12. 
Stoll, H. M., D. P. Schrag, and S. C. Clemens (1999), Are seawater Sr/Ca variations preserved in Quaternary foraminifera?, Geochimica et Cosmochimica Acta, 63(21), 3535-3547, DOI: 10.1016/S00167037(99)00129-5.

Sutton, P. (2001), Detailed structure of the Subtropical Front over Chatham Rise, east of New Zealand, Journal of Geophysical Research, 106(C12), 31045-31056, DOI: 10.1029/2000JC000562

Tachikawa, K., S. Sépulcre, and T. Toyofuku (2008), Assessing influence of diagenetic carbonate dissolution on planktonic foraminiferal $\mathrm{Mg} / \mathrm{Ca}$ in the southeastern Arabian Sea over the past $450 \mathrm{ka}$ Comparison between Globigerinoides ruber and Globigerinoides sacculifer, Geochemistry, Geophysics, Geosystems, 9(4), DOI: 10.1029/2007GC001904.

Todd, R., and P. Blackmon (1956), Calcite and Aragonite in Foraminifera, Journal of Paleontology, 30(1), 217-219.

Toggweiler, J. R., and R. M. Key (Eds.) (2001), Ocean Circulation: Thermohaline circulation, 2941-2947 pp., Academic Press, Ltd, London.

Trenberth, K., and J. Caron (2001), Estimates of meridional atmosphere and ocean heat transports, Journal of Geophysical Research, 14, 3433-3443.

Tziperman, E., and Gildor, H., (2003), On the mid-Pleistocene transition to 100-kyr glacial cycles and the asymmetry between glaciation and deglaciation times, Paleoceanography, 18(1), 1001, DOI:10.1029/2001PA000627, 2003.

Uddstrom, M. J., and N. A. Oien (1999), On the use of high resolution satellite data to describe the spatial and temporal variability of sea surface temperatures in the New Zealand region, Journal of Geophysical Research, 104(20), 729-720.

Urey, H. C. (1947), The Thermodynamic Properties of Isotopic Substances, Journal of Chemical Society $1947,562-581$.

van Raden, U.J., Groeneveld, J., Raitzsch, M., Kucera, M., (2011), Mg/Ca in the planktonic foraminifera Globorotalia inflata and Globigerinoides bulloides from Western Mediterranean plankton tow and core top samples, Marine Micropaleontology, 78:101-112, DOI:10.1016/j.marmicro.2010.11.002

Villa, G., D. Persico, S. W. Wise, and A. Gadaleta (2010), Calcareous nannofossil evidence for Marine Isotope Stage 31 (1 Ma) in the AND-1B Core, ANDRILL (Antarctica), Global and Planetary Change, article in press, DOI: 10.1016/j.gloplacha.2009.12.003.

Villanueva, J., J. O. Grimalt, E. Cortijo, L. Vidal, and L. Labeyrie (1998), Assessment of sea surface temperature variations in the central North Atlantic using the alkenone unsaturation index (U37k'), Geochimica et Cosmochimica Acta, 62(14), 2421-2427.

von Breymann, M. T., K.-C. Emeis, and E. Suess (1992), Water depth and diagenetic constraints on the use of barium as a palaeoproductivity indicator (in Upwelling systems; evolution since the early Miocene), Geological Society Special Publications, 64, 273-284 
Von Langen, P. J., D. K. Pak, H. J. Spero, and D. W. Lea (2005), Effects of temperature on Mg/Ca in Neogloboquadrinid shells determined by live culturing, Geochemistry, Geophysics, Geosystems, 6(10), 1-11, DOI: $10.1029 / 2005$ GC000989.

Waelbroeck, C., L. Labeyrie, E. Michel, J. C. Duplessey, J. F. McManus, K. Lambeck, E. Balbon, and M. Labracherie (2002), Sea-level and deep water temperature changes derived from benthic foraminifera isotopic records, Quaternary Science Reviews, 21, 295-305.

Wan, S., Z. M. Jian, X. R. Cheng, P. J. Qiao, and R. Wang (2010), Seasonal variation in planktonic foraminiferal flux and the chemical properties of their shells in the South China Sea, Science China Earth Sciences, 53(8), 1176-1187, DOI: 10.1007/s11430-010-4039-3.

Wang, D., A. F. Wallace, J. J. De Yoreo, and P. M. Dove (2009), Carboxylated molecules regulate magnesium content of amorphous calcium carbonates during calcification, Proceedings of the national academy of sciences of the United States of America, 106(51), 21511-21516.

Wang, L. (2000), Isotopic signals in two morphotypes of Globigerinoides ruber (white) from the South China Sea: implications for monsoon climate change during the last glacial cycle, Palaeogeography, Palaeoclimatology, Palaeoecology, 161(3-4), 381-394.

Warren, B. A. (1973), Transpacific hydrographic sections at Lats. $43^{\circ} \mathrm{S}$ and $28^{\circ} \mathrm{S}$ : The SCORPIO Expedition - II. Deep Water, Deep Sea Research, 20, 9-38.

Weaver, P. P. E., L. Carter, and H. L. Neil (1998), Response of surface water masses and circulation to late Quaternary climate change east of New Zealand, Paleoceanography, 13, 70-83, DOI: 10.1029/97PA02982

Wei, G.-J., L. Zou, W.-F. Deng, X.-H. Li, Y. Liu, and J.-F. Chen (2009), Mn/Ca ratio in planktonic foraminifer from ODP Site 1144, the northern South China Sea: A possible paleoclimate indicator, Geochemical Journal, 43(4), 235-246.

Weiner, S., and P. M. Dove (2003), An overview of biomineralization processes and the problem of the vital effect, Reviews in Mineralogy and Geochemistry, 54, 1-29.

Whitworth III, T., B. A. Warren, J. W. D. Nowlin, S. B. Rutz, R. D. Pillsbury, and M. I. Moore (1999), On the deep western-boundary current in the Southwest Pacific Basin, Progress In Oceanography, 43(1), 154 .

Wiebe, P. H., A. W. Morton, A. M. Bradley, R. H. Backus, J. E. Craddock, V. Barber, T. J. Cowles, and G. R. Flierl (1985), New developments in the MOCNESS, an apparatus for sampling zooplankton and micronekton, Marine Biology, 87, 313-323, DOI: 10.1016/j.dsr.2008.08.001.

Wierzbowski, H. (2007), Effects of pre-treatments and organic matter on oxygen and carbon isotope analyses of skeletal and inorganic calcium carbonate, International Journal of Mass Spectrometry, 268(1), 1629. 
Wilke, I., H. Meggers, and T. Bickert (2008), Depth habitats and seasonal distributions of recent planktic foraminifers in the Canary Islands region $\left(29^{\circ} \mathrm{N}\right)$ based on oxygen isotopes, Deep Sea Research, 1 (check internet as this was an article in press version).

Wilkinson, I. (1997), Fossil Focus: Foraminifera (Discovering Geology), edited, Earthwise Publications UK.

Williams, M., A. M. Haywood, M. Vautravers, B. W. Sellwood, C.-D. Hillenbrand, I. P. Wilkinson, and C. G. Miller (2007), Relative effect of taphonomy on calcification temperature estimates from fossil planktonic foraminifera, Geobios, 40, 861-874.

Williams, R. J. P. (2008), Some fundamental features of biomineralization, Geological Society, Special Publications, 303, 33-44.

Wilson, K., B. W. Hayward, A. T. Sabaa, G. Scott, and J. P. Kennett (2005), A one-million year history of a north-south segment of the Subtropical Front, east of New Zealand, Paleoceanography, 20(PA2004,), DOI: $10.1029 / 2004 \mathrm{PA} 001080$.

Wit, J. C., G. J. Reichart, S. J. A Jung, and D. Kroon (2010), Approaches to unravel seasonality in sea surface temperatures using paired single-specimen foraminiferal $\delta^{18} \mathrm{O}$ and $\mathrm{Mg} / \mathrm{Ca}$ analyses, Paleoceanography, 25(4), PA4220, DOI: 10.1029/2009PA001857.

Wolf-Gladrow, D. A., J. Bijma, and R. E. Zeebe (1999), Model simulation of the carbonate chemistry in the microenvironment of symbiont bearing foraminifera, Marine Chemistry, 64, 181-198.

Wunsch, C. (2002), What is the thermohaline circulation?, Science, 298(5596), 1179-1181, DOI: 10.1126/science.1079329.

Wyrtki, K. (1973), Teleconnections in the Equatorial Pacific Ocean, Science, 180:66-68, DOI: 10.1126/science.180.4081.66.

Yokoyama, Y., K. Lambeck, P. De Deckker, P. Johnston, and L. K. Fifield (2000), Timing of the Last Glacial Maximum from observed sea-level minima, Nature, 406(6797), 713-716, DOI: $10.1038 / 35021035$.

Yu, J., H. Elderfield, M. Greaves, and J. Day (2007a), Preferential dissolution of benthic foraminiferal calcite during laboratory reductive cleaning, Geochemistry, Geophysics, Geosystems, 8(6), Q06016, DOI: $10.1029 / 2006 \mathrm{gc} 001571$.

Yu, J., H. Elderfield, and B. Hönisch (2007b), B/Ca in planktonic foraminifera as a proxy for surface seawater $\mathrm{pH}$, Paleoceanography, 22(2), PA2202.

Yu, J. M., J. Day, M. Greaves, and H. Elderfield (2005), Determination of multiple element/calcium ratios in foraminiferal calcite by quadrupole ICP-MS, Geochemistry, Geophysics, Geosystems, 6, DOI: 10.1029/2005GC000964.

Zeebe, R. E., and A. Sanyal (2002), Comparison of two potential strategies of planktonic foraminifera for house building: $\mathrm{Mg}^{2+}$ or $\mathrm{H}^{+}$removal?, Geochemica et Cosmochimica Acta, 66(7), 1159-1169. 
Appendices 
Appendix A. Chapter 3 
Table A1: Core top and plankton tow $\mathrm{Mg} / \mathrm{Ca}$ ratios for individual Globigernoides ruber $(250-355 \mu \mathrm{m})$ from sites in the Southwest Pacific Ocean

\begin{tabular}{|c|c|c|c|c|c|c|c|c|c|c|c|}
\hline Site & $\begin{array}{l}\text { Latitud } \\
\mathrm{e}\end{array}$ & $\begin{array}{l}\text { Longitu } \\
\text { de }\end{array}$ & Core Type & Depth & Age & $\begin{array}{l}\text { Individu } \\
\text { al } \\
\text { Number }\end{array}$ & $\begin{array}{c}\mathrm{F}-2 \\
\mathrm{Mg} / \mathrm{Ca}\end{array}$ & $\begin{array}{c}\mathrm{F}-1 \\
\mathrm{Mg} / \mathrm{Ca}\end{array}$ & $\begin{array}{c}\mathrm{F} \\
\mathrm{Mg} / \mathrm{Ca}\end{array}$ & $\begin{array}{c}\text { WOA } \\
\text { 05 SST } \\
(0-50 \mathrm{~m})\end{array}$ & Salinity \\
\hline & $\begin{array}{c}\text { (degree } \\
\text { s) }\end{array}$ & $\begin{array}{c}\text { (degrees } \\
)\end{array}$ & & (m) & (yr) & & $\begin{array}{c}(\mathrm{mmol} / \\
\mathrm{mol})\end{array}$ & $\begin{array}{c}(\mathrm{mmol} / \\
\mathrm{mol})\end{array}$ & $\begin{array}{c}(\mathrm{mmol} / \\
\mathrm{mol})\end{array}$ & $\left({ }^{\circ} \mathrm{C}\right)$ & (psu) \\
\hline AIMS1361 & 3.370 & 144.34 & grab & 1100 & & 1 & 5.21 & 4.09 & 4.08 & 28.8 & 34.5 \\
\hline AIMS1361 & 3.370 & 144.34 & grab & 1100 & & 2 & 5.44 & 5.90 & 5.89 & 28.8 & 34.5 \\
\hline AIMS1361 & 3.370 & 144.34 & grab & 1100 & & 4 & 6.11 & 4.53 & 3.85 & 28.8 & 34.5 \\
\hline AIMS1361 & 3.370 & 144.34 & grab & 1100 & & 6 & 5.36 & 6.06 & 4.18 & 28.8 & 34.5 \\
\hline AIMS1361 & 3.370 & 144.34 & grab & 1100 & & 11 & 4.68 & 4.81 & 3.71 & 28.8 & 34.5 \\
\hline AIMS1361 & 3.370 & 144.34 & grab & 1100 & & 12 & 4.44 & 5.14 & 4.44 & 28.8 & 34.5 \\
\hline AIMS1361 & 3.370 & 144.34 & grab & 1100 & & 14 & 6.08 & 5.49 & 3.02 & 28.8 & 34.5 \\
\hline AIMS3703 & 11.153 & 125.02 & grab & 504 & $<100$ & 1 & 5.30 & 4.74 & 4.08 & 28.4 & 34.4 \\
\hline AIMS3703 & 11.153 & 125.02 & grab & 504 & $<100$ & 3 & 3.82 & 4.15 & 2.90 & 28.4 & 34.4 \\
\hline AIMS3703 & 11.153 & 125.02 & grab & 504 & $<100$ & 4 & 6.48 & 5.63 & 4.76 & 28.4 & 34.4 \\
\hline AIMS3703 & 11.153 & 125.02 & grab & 504 & $<100$ & 5 & 8.74 & 8.61 & 6.36 & 28.4 & 34.4 \\
\hline AIMS3703 & 11.153 & 125.02 & grab & 504 & $<100$ & 6 & 4.95 & 5.72 & 4.13 & 28.4 & 34.4 \\
\hline AIMS3703 & 11.153 & 125.02 & grab & 504 & $<100$ & 7 & 6.97 & 6.19 & 4.32 & 28.4 & 34.4 \\
\hline AIMS3703 & 11.153 & 125.02 & grab & 504 & $<100$ & 8 & 3.21 & 4.19 & 4.48 & 28.4 & 34.4 \\
\hline AIMS3703 & 11.153 & 125.02 & grab & 504 & $<100$ & 13 & 6.22 & 6.82 & 5.90 & 28.4 & 34.4 \\
\hline AIMS3703 & 11.153 & 125.02 & grab & 504 & $<100$ & 14 & 7.41 & 7.32 & 7.88 & 28.4 & 34.4 \\
\hline AIMS3703 & 11.153 & 125.02 & grab & 504 & $<100$ & 16 & 5.48 & 5.68 & 5.12 & 28.4 & 34.4 \\
\hline AIMS3703 & 11.153 & 125.02 & grab & 504 & $<100$ & 17 & 6.56 & 5.93 & 3.99 & 28.4 & 34.4 \\
\hline AIMS3703 & 11.153 & 125.02 & grab & 504 & $<100$ & 18 & 6.73 & 8.83 & 5.94 & 28.4 & 34.4 \\
\hline AIMS3703 & 11.153 & 125.02 & grab & 504 & $<100$ & 19 & 5.80 & 6.47 & 5.37 & 28.4 & 34.4 \\
\hline AIMS1631 & 11.158 & 145.79 & grab & 1468 & & 1 & 4.15 & 3.66 & 4.01 & 26.8 & 35.0 \\
\hline AIMS1631 & 11.158 & 145.79 & grab & 1468 & & 4 & 5.13 & 5.98 & 4.62 & 26.8 & 35.0 \\
\hline AIMS1631 & 11.158 & 145.79 & grab & 1468 & & 5 & 4.69 & 5.08 & 3.92 & 26.8 & 35.0 \\
\hline AIMS1631 & 11.158 & 145.79 & grab & 1468 & 2160 & 7 & 4.77 & 4.56 & 3.91 & 26.8 & 35.0 \\
\hline AIMS2078 & 18.212 & 147.60 & grab & 880 & $\begin{array}{l} \pm 50 \\
2160\end{array}$ & 1 & 5.36 & 4.59 & 3.57 & 26.4 & 35.0 \\
\hline AIMS2078 & 18.212 & 147.60 & grab & 880 & $\begin{array}{l} \pm 50 \\
2160\end{array}$ & 2 & 6.66 & 6.96 & 4.12 & 26.4 & 35.0 \\
\hline AIMS2078 & 18.212 & 147.60 & grab & 880 & $\begin{array}{l} \pm 50 \\
2160\end{array}$ & 3 & 7.01 & 5.30 & 3.80 & 26.4 & 35.0 \\
\hline AIMS2078 & 18.212 & 147.60 & grab & 880 & $\begin{array}{l} \pm 50 \\
2160\end{array}$ & 4 & 4.34 & 6.10 & 4.65 & 26.4 & 35.0 \\
\hline AIMS2078 & 18.212 & 147.60 & grab & 880 & $\begin{array}{l} \pm 50 \\
2160\end{array}$ & 6 & 5.82 & 6.07 & 2.33 & 26.4 & 35.0 \\
\hline AIMS2078 & 18.212 & 147.60 & grab & 880 & $\begin{array}{l} \pm 50 \\
2160\end{array}$ & 8 & 5.47 & 5.41 & 3.71 & 26.4 & 35.0 \\
\hline AIMS2078 & 18.212 & 147.60 & grab & 880 & $\begin{array}{l} \pm 50 \\
2160\end{array}$ & 9 & 5.49 & 5.99 & 3.60 & 26.4 & 35.0 \\
\hline AIMS2078 & 18.212 & 147.60 & grab & 880 & $\begin{array}{l} \pm 50 \\
2160\end{array}$ & 14 & 4.79 & 5.45 & 4.19 & 26.4 & 35.0 \\
\hline AIMS2078 & 18.212 & 147.60 & grab & 880 & $\begin{array}{l} \pm 50 \\
2160\end{array}$ & 16 & 7.06 & 7.60 & 2.64 & 26.4 & 35.0 \\
\hline $\begin{array}{c}\text { AIMS2078 } \\
\text { FR1/97/GC }\end{array}$ & 18.212 & 147.60 & grab & 880 & $\begin{array}{l} \pm 50 \\
8995\end{array}$ & 17 & 4.35 & 4.17 & 3.82 & 26.4 & 35.0 \\
\hline $\begin{array}{c}12 \\
\text { FR1/97/GC }\end{array}$ & 23.577 & 153.79 & core top & 991 & $\begin{array}{l} \pm 25 \\
8995\end{array}$ & 1 & 5.30 & 5.74 & 2.40 & 24.7 & 35.4 \\
\hline $\begin{array}{c}12 \\
\text { FR1/97/GC }\end{array}$ & 23.577 & 153.79 & core top & 991 & $\begin{array}{l} \pm 25 \\
8995\end{array}$ & 2 & 4.26 & 4.77 & 3.81 & 24.7 & 35.4 \\
\hline $\begin{array}{c}12 \\
\text { FR1/97/GC }\end{array}$ & 23.577 & 153.79 & core top & 991 & $\begin{array}{l} \pm 25 \\
8995\end{array}$ & 3 & 5.15 & 6.35 & 3.96 & 24.7 & 35.4 \\
\hline $\begin{array}{c}12 \\
\text { FR1/97/GC }\end{array}$ & 23.577 & 153.79 & core top & 991 & $\begin{array}{l} \pm 25 \\
8995\end{array}$ & 5 & 5.86 & 5.97 & 4.22 & 24.7 & 35.4 \\
\hline $\begin{array}{c}12 \\
\text { FR1/97/GC }\end{array}$ & 23.577 & 153.79 & core top & 991 & $\begin{array}{l} \pm 25 \\
8995\end{array}$ & 7 & 4.44 & 4.95 & 4.15 & 24.7 & 35.4 \\
\hline 12 & 23.577 & 153.79 & core top & 991 & \pm 25 & 10 & 3.86 & 6.81 & 4.13 & 24.7 & 35.4 \\
\hline
\end{tabular}




\begin{tabular}{|c|c|c|c|c|c|c|c|c|c|c|c|}
\hline Site & $\begin{array}{c}\text { Latitud } \\
\text { e }\end{array}$ & $\begin{array}{c}\begin{array}{c}\text { Longitu } \\
\text { de }\end{array} \\
\end{array}$ & Core Type & Depth & Age & $\begin{array}{c}\text { Individu } \\
\text { al } \\
\text { Number }\end{array}$ & $\begin{array}{c}\mathrm{F}-2 \\
\mathrm{Mg} / \mathrm{Ca}\end{array}$ & $\begin{array}{c}\mathrm{F}-1 \\
\mathrm{Mg} / \mathrm{Ca}\end{array}$ & $\begin{array}{c}\mathrm{F} \\
\mathrm{Mg} / \mathrm{Ca} \\
\end{array}$ & $\begin{array}{l}\text { WOA } \\
\text { 05 SST } \\
(0-50 \mathrm{~m}) \\
\end{array}$ & Salinity \\
\hline & $\begin{array}{c}\text { (degree } \\
\mathrm{s})\end{array}$ & $\begin{array}{c}\text { (degrees } \\
\text { ) }\end{array}$ & & (m) & $(\mathrm{yr})$ & & $\begin{array}{c}(\mathrm{mmol} / \\
\mathrm{mol})\end{array}$ & $\begin{array}{c}\left(\begin{array}{c}\mathrm{mmol} / \\
\mathrm{mol})\end{array}\right. \\
\text { (a) }\end{array}$ & $\begin{array}{c}(\mathrm{mmol} / \\
\mathrm{mol})\end{array}$ & $\left({ }^{\circ} \mathrm{C}\right)$ & (psu) \\
\hline $\begin{array}{c}\text { FR1/97/GC } \\
12\end{array}$ & 23.577 & 153.79 & core top & 991 & $\begin{array}{l}8995 \\
\pm 25\end{array}$ & 11 & 4.70 & 4.89 & 2.62 & 24.7 & 35.4 \\
\hline FR1/97/GC & & & & & 8995 & & & & & & \\
\hline $\begin{array}{c}12 \\
\text { FR1/97/GC }\end{array}$ & 23.577 & 153.79 & core top & 991 & $\begin{array}{l} \pm 25 \\
8995\end{array}$ & 12 & 5.35 & 5.71 & 5.68 & 24.7 & 35.4 \\
\hline $\begin{array}{c}12 \\
\text { FR1/97/GC }\end{array}$ & 23.577 & 153.79 & core top & 991 & $\begin{array}{l} \pm 25 \\
8995\end{array}$ & 13 & 5.06 & 4.79 & 3.92 & 24.7 & 35.4 \\
\hline $\begin{array}{c}12 \\
\text { FR1/97/GC }\end{array}$ & 23.577 & 153.79 & core top & 991 & $\begin{array}{r} \pm 25 \\
8995\end{array}$ & 14 & 5.20 & 6.48 & 4.09 & 24.7 & 35.4 \\
\hline $\begin{array}{c}12 \\
\text { FR } 1 / 97 / G C\end{array}$ & 23.577 & 153.79 & core top & 991 & $\begin{array}{r} \pm 25 \\
8995\end{array}$ & 15 & 3.73 & 2.31 & 6.78 & 24.7 & 35.4 \\
\hline $\begin{array}{c}12 \\
\text { TAN0706 }\end{array}$ & 23.577 & 153.79 & core top & 991 & \pm 25 & 16 & 5.05 & 4.67 & 2.78 & 24.7 & 35.4 \\
\hline $\begin{array}{c}\text { C4 } \\
\text { TAN0706 }\end{array}$ & 29.353 & 180.97 & core top & 2258 & & 1 & 3.92 & 4.75 & 3.57 & 20.7 & 35.7 \\
\hline $\begin{array}{c}\text { C4 } \\
\text { TAN0706 }\end{array}$ & 29.353 & 180.97 & core top & 2258 & & 2 & 6.57 & 7.11 & 4.48 & 20.7 & 35.7 \\
\hline $\begin{array}{c}\text { C4 } \\
\text { TAN0706 }\end{array}$ & 29.353 & 180.97 & core top & 2258 & & 5 & 3.77 & 3.70 & 1.83 & 20.7 & 35.7 \\
\hline $\begin{array}{c}\text { C4 } \\
\text { TAN0706 }\end{array}$ & 29.353 & 180.97 & core top & 2258 & & 6 & 4.05 & 4.55 & 2.50 & 20.7 & 35.7 \\
\hline $\begin{array}{c}\text { C4 } \\
\text { TAN0706 }\end{array}$ & 29.353 & 180.97 & core top & 2258 & & 8 & 3.25 & 3.63 & 2.53 & 20.7 & 35.7 \\
\hline $\begin{array}{c}\text { C4 } \\
\text { TAN0706 }\end{array}$ & 29.353 & 180.97 & core top & 2258 & & 9 & 2.73 & 3.19 & 1.90 & 20.7 & 35.7 \\
\hline $\begin{array}{c}\text { C4 } \\
\text { TAN0706 }\end{array}$ & 29.353 & 180.97 & core top & 2258 & & 10 & 4.20 & 4.55 & 3.40 & 20.7 & 35.7 \\
\hline $\begin{array}{c}\text { C4 } \\
\text { TAN0706 }\end{array}$ & 29.353 & 180.97 & core top & 2258 & & 11 & 4.42 & 4.18 & 3.02 & 20.7 & 35.7 \\
\hline $\begin{array}{c}\text { C4 } \\
\text { TAN0706 }\end{array}$ & 29.353 & 180.97 & core top & 2258 & & 12 & 5.30 & 4.54 & 2.88 & 20.7 & 35.7 \\
\hline $\begin{array}{c}\text { C4 } \\
\text { TAN0706 }\end{array}$ & 29.353 & 180.97 & core top & 2258 & & 13 & 2.78 & 3.24 & 2.62 & 20.7 & 35.7 \\
\hline $\begin{array}{c}\text { C4 } \\
\text { TAN0706 }\end{array}$ & 29.353 & 180.97 & core top & 2258 & & 14 & 2.41 & 2.89 & 2.33 & 20.7 & 35.7 \\
\hline $\begin{array}{c}\text { C4 } \\
\text { TAN0706 }\end{array}$ & 29.353 & 180.97 & core top & 2258 & & 15 & 5.25 & 5.43 & 3.00 & 20.7 & 35.7 \\
\hline $\begin{array}{c}\text { C4 } \\
\text { TAN0706 }\end{array}$ & 29.353 & 180.97 & core top & 2258 & & 16 & 3.58 & 2.64 & 2.47 & 20.7 & 35.7 \\
\hline $\begin{array}{c}\text { C4 } \\
\text { TAN0706 }\end{array}$ & 29.353 & 180.97 & core top & 2258 & & 17 & 3.96 & 3.72 & 3.57 & 20.7 & 35.7 \\
\hline $\begin{array}{c}\text { C4 } \\
\text { TAN0706 }\end{array}$ & 29.353 & 180.97 & core top & 2258 & & 18 & 3.53 & 4.75 & 2.99 & 20.7 & 35.7 \\
\hline $\begin{array}{c}\text { C4 } \\
\text { TAN0706 }\end{array}$ & 29.353 & 180.97 & core top & 2258 & & 19 & 2.45 & 2.20 & 1.66 & 20.7 & 35.7 \\
\hline $\begin{array}{c}\text { C4 } \\
\text { TAN0706 }\end{array}$ & 29.353 & 180.97 & core top & 2258 & & 20 & 3.17 & 3.91 & 2.40 & 20.7 & 35.7 \\
\hline $\begin{array}{c}\text { C4 } \\
\text { TAN0706 }\end{array}$ & 29.353 & 180.97 & core top & 2258 & & 21 & 6.59 & 6.34 & 3.87 & 20.7 & 35.7 \\
\hline $\begin{array}{c}\text { C4 } \\
\text { TAN0706 }\end{array}$ & 29.353 & 180.97 & core top & 2258 & & 22 & 2.54 & 2.44 & 1.67 & 20.7 & 35.7 \\
\hline $\begin{array}{c}\text { C4 } \\
\text { TAN0706 }\end{array}$ & 29.353 & 180.97 & core top & 2258 & & 23 & 2.39 & 2.46 & 1.77 & 20.7 & 35.7 \\
\hline $\begin{array}{c}\text { C4 } \\
\text { TAN0706 }\end{array}$ & 29.353 & 180.97 & core top & 2258 & & 24 & 2.61 & 2.88 & 4.26 & 20.7 & 35.7 \\
\hline $\begin{array}{c}\text { C4 } \\
\text { TAN0706 }\end{array}$ & 29.353 & 180.97 & core top & 2258 & & 25 & 2.61 & 2.27 & 1.86 & 20.7 & 35.7 \\
\hline $\begin{array}{c}\text { C4 } \\
\text { TAN0706 }\end{array}$ & 29.353 & 180.97 & core top & 2258 & & 26 & 4.91 & 3.93 & 3.24 & 20.7 & 35.7 \\
\hline $\begin{array}{c}\text { C4 } \\
\text { TAN0706 }\end{array}$ & 29.353 & 180.97 & core top & 2258 & & 27 & 3.47 & 4.21 & 3.77 & 20.7 & 35.7 \\
\hline $\begin{array}{c}\text { C4 } \\
\text { TAN0706 }\end{array}$ & 29.353 & 180.97 & core top & 2258 & & 28 & 3.03 & 2.65 & 2.18 & 20.7 & 35.7 \\
\hline $\mathrm{C} 4$ & 29.353 & 180.97 & core top & 2258 & & 29 & 3.08 & 3.60 & 2.27 & 20.7 & 35.7 \\
\hline P71 & 33.855 & 174.69 & core top & 1919 & $\begin{array}{c}5715 \pm \\
40 \\
5715 \pm\end{array}$ & 1 & 2.45 & 2.80 & 2.06 & 18.8 & 35.6 \\
\hline P71 & 33.855 & 174.69 & core top & 1919 & $\begin{array}{c}40 \\
5715 \pm\end{array}$ & 2 & 2.72 & 2.78 & 2.31 & 18.8 & 35.6 \\
\hline P71 & 33.855 & 174.69 & core top & 1919 & $\begin{array}{c}40 \\
5715 \pm\end{array}$ & 2 & 2.66 & 3.18 & 2.28 & 18.8 & 35.6 \\
\hline P71 & 33.855 & 174.69 & core top & 1919 & 40 & 3 & 4.16 & 4.04 & 2.90 & 18.8 & 35.6 \\
\hline
\end{tabular}




\begin{tabular}{|c|c|c|c|c|c|c|c|c|c|c|c|}
\hline Site & $\begin{array}{c}\text { Latitud } \\
\text { e }\end{array}$ & $\begin{array}{c}\text { Longitu } \\
\text { de }\end{array}$ & Core Type & Depth & Age & $\begin{array}{c}\text { Individu } \\
\text { al } \\
\text { Number }\end{array}$ & $\begin{array}{c}\mathrm{F}-2 \\
\mathrm{Mg} / \mathrm{Ca}\end{array}$ & $\begin{array}{c}\mathrm{F}-1 \\
\mathrm{Mg} / \mathrm{Ca}\end{array}$ & $\begin{array}{c}\mathrm{F} \\
\mathrm{Mg} / \mathrm{Ca}\end{array}$ & $\begin{array}{l}\text { WOA } \\
\text { 05 SST } \\
(0-50 \mathrm{~m}) \\
\end{array}$ & Salinity \\
\hline & $\begin{array}{c}\text { (degree } \\
\text { s) }\end{array}$ & $\begin{array}{c}\text { (degrees } \\
\text { ) }\end{array}$ & & $(\mathrm{m})$ & $(\mathrm{yr})$ & & $\begin{array}{c}(\mathrm{mmol} / \\
\mathrm{mol})\end{array}$ & $\begin{array}{c}(\mathrm{mmol} / \\
\mathrm{mol})\end{array}$ & $\begin{array}{c}(\mathrm{mmol} / \\
\mathrm{mol})\end{array}$ & $\left({ }^{\circ} \mathrm{C}\right)$ & (psu) \\
\hline P71 & 33.855 & 174.69 & core top & 1919 & $\begin{array}{c}5715 \pm \\
40\end{array}$ & 3 & 4.13 & 3.76 & 2.36 & 18.8 & 35.6 \\
\hline P71 & 33.855 & 174.69 & core top & 1919 & $\begin{array}{c}5715 \pm \\
40 \\
\mathbf{5 7 1 5} \pm\end{array}$ & 4 & 2.89 & 2.76 & 2.39 & 18.8 & 35.6 \\
\hline P71 & 33.855 & 174.69 & core top & 1919 & $\begin{array}{c}\mathbf{4 0} \\
5715 \pm\end{array}$ & 4 & 2.54 & 2.83 & 2.55 & 18.8 & 35.6 \\
\hline P71 & 33.855 & 174.69 & core top & 1919 & $\begin{array}{c}40 \\
5715 \pm\end{array}$ & 5 & 4.29 & 3.40 & 2.35 & 18.8 & 35.6 \\
\hline P71 & 33.855 & 174.69 & core top & 1919 & $\begin{array}{c}40 \\
5715 \pm\end{array}$ & 7 & 3.41 & 2.44 & 3.14 & 18.8 & 35.6 \\
\hline P71 & 33.855 & 174.69 & core top & 1919 & $\begin{array}{c}40 \\
5715 \pm\end{array}$ & 8 & 2.38 & 3.02 & 3.29 & 18.8 & 35.6 \\
\hline P71 & 33.855 & 174.69 & core top & 1919 & $\begin{array}{c}40 \\
5715 \pm\end{array}$ & 9 & 2.51 & 2.60 & 1.53 & 18.8 & 35.6 \\
\hline P71 & 33.855 & 174.69 & core top & 1919 & $\begin{array}{c}40 \\
5715 \pm\end{array}$ & 9 & 2.92 & 2.44 & 2.32 & 18.8 & 35.6 \\
\hline P71 & 33.855 & 174.69 & core top & 1919 & $\begin{array}{c}40 \\
5715 \pm\end{array}$ & 10 & 3.44 & 3.33 & 2.13 & 18.8 & 35.6 \\
\hline P71 & 33.855 & 174.69 & core top & 1919 & $\begin{array}{c}40 \\
5715 \pm\end{array}$ & 11 & 3.91 & 3.51 & 2.53 & 18.8 & 35.6 \\
\hline P71 & 33.855 & 174.69 & core top & 1919 & $\begin{array}{c}40 \\
5715 \pm\end{array}$ & 13 & 3.18 & 4.21 & 2.80 & 18.8 & 35.6 \\
\hline P71 & 33.855 & 174.69 & core top & 1919 & $\begin{array}{c}40 \\
5715 \pm\end{array}$ & 13 & 4.37 & 3.13 & 2.58 & 18.8 & 35.6 \\
\hline P71 & 33.855 & 174.69 & core top & 1919 & $\begin{array}{c}40 \\
5715 \pm\end{array}$ & 14 & 3.82 & 3.12 & 2.38 & 18.8 & 35.6 \\
\hline P71 & 33.855 & 174.69 & core top & 1919 & $\begin{array}{c}40 \\
5715 \pm\end{array}$ & 14 & 4.09 & 2.91 & 2.76 & 18.8 & 35.6 \\
\hline P71 & 33.855 & 174.69 & core top & 1919 & $\begin{array}{c}40 \\
5715 \pm\end{array}$ & 16 & 2.11 & 2.19 & 2.15 & 18.8 & 35.6 \\
\hline P81 & 34.020 & 173.51 & core top & 2036 & $\begin{array}{c}40 \\
5715 \pm\end{array}$ & 1 & 2.54 & 2.90 & 1.55 & 18.1 & 35.6 \\
\hline P81 & 34.020 & 173.51 & core top & 2036 & $\begin{array}{c}40 \\
5715 \pm\end{array}$ & 2 & 2.98 & 2.64 & 2.34 & 18.1 & 35.6 \\
\hline P81 & 34.020 & 173.51 & core top & 2036 & $\begin{array}{c}40 \\
5715 \pm\end{array}$ & 3 & 4.77 & 4.20 & 4.53 & 18.1 & 35.6 \\
\hline P81 & 34.020 & 173.51 & core top & 2036 & $\begin{array}{c}40 \\
5715 \pm\end{array}$ & 5 & 2.21 & 2.48 & 1.99 & 18.1 & 35.6 \\
\hline P81 & 34.020 & 173.51 & core top & 2036 & $\begin{array}{c}40 \\
5715 \pm\end{array}$ & 6 & 2.96 & 3.54 & 2.24 & 18.1 & 35.6 \\
\hline P81 & 34.020 & 173.51 & core top & 2036 & $\begin{array}{c}40 \\
5715 \pm\end{array}$ & 7 & 4.28 & 4.62 & 3.93 & 18.1 & 35.6 \\
\hline P81 & 34.020 & 173.51 & core top & 2036 & $\begin{array}{c}40 \\
5715 \pm\end{array}$ & 10 & 3.77 & 3.11 & 2.78 & 18.1 & 35.6 \\
\hline P81 & 34.020 & 173.51 & core top & 2036 & $\begin{array}{c}40 \\
5715 \pm\end{array}$ & 12 & 4.18 & 3.83 & 3.41 & 18.1 & 35.6 \\
\hline P81 & 34.020 & 173.51 & core top & 2036 & $\begin{array}{c}40 \\
5715 \pm\end{array}$ & 14 & 2.59 & 3.34 & 1.48 & 18.1 & 35.6 \\
\hline P81 & 34.020 & 173.51 & core top & 2036 & $\begin{array}{c}40 \\
5715 \pm\end{array}$ & 15 & 2.01 & 2.07 & 1.60 & 18.1 & 35.6 \\
\hline P81 & 34.020 & 173.51 & core top & 2036 & $\begin{array}{c}40 \\
5715 \pm\end{array}$ & 16 & 2.19 & 2.49 & 1.39 & 18.1 & 35.6 \\
\hline P81 & 34.020 & 173.51 & core top & 2036 & $\begin{array}{c}40 \\
5715 \pm\end{array}$ & 17 & 2.94 & 2.53 & 1.81 & 18.1 & 35.6 \\
\hline P81 & 34.020 & 173.51 & core top & 2036 & $\begin{array}{c}40 \\
5715 \pm\end{array}$ & 18 & 2.46 & 2.73 & 1.99 & 18.1 & 35.6 \\
\hline P81 & 34.020 & 173.51 & core top & 2036 & $\begin{array}{c}40 \\
5715 \pm\end{array}$ & 20 & 1.88 & 1.40 & 1.33 & 18.1 & 35.6 \\
\hline P81 & 34.020 & 173.51 & core top & 2036 & 40 & 21 & 2.34 & 2.27 & 1.38 & 18.1 & 35.6 \\
\hline P81 & 34.020 & 173.51 & core top & 2036 & $\begin{array}{c}5715 \pm \\
40 \\
5715 \pm\end{array}$ & 25 & 3.66 & 3.15 & 2.38 & 18.1 & 35.6 \\
\hline P81 & 34.020 & 173.51 & core top & 2036 & $\begin{array}{c}40 \\
5715 \pm\end{array}$ & 26 & 1.41 & 1.49 & 1.12 & 18.1 & 35.6 \\
\hline P81 & 34.020 & 173.51 & core top & 2036 & $\begin{array}{c}40 \\
5932\end{array}$ & 27 & 2.73 & 2.90 & 1.93 & 18.1 & 35.6 \\
\hline Z7003 & 36.693 & 176.24 & core top & 430 & \pm 55 & 2 & 1.98 & 2.82 & 3.33 & 18.1 & 35.5 \\
\hline
\end{tabular}




\begin{tabular}{|c|c|c|c|c|c|c|c|c|c|c|c|}
\hline Site & $\begin{array}{c}\text { Latitud } \\
\text { e }\end{array}$ & $\begin{array}{c}\text { Longitu } \\
\text { de }\end{array}$ & Core Type & Depth & Age & $\begin{array}{c}\text { Individu } \\
\text { al } \\
\text { Number }\end{array}$ & $\begin{array}{c}\mathrm{F}-2 \\
\mathrm{Mg} / \mathrm{Ca}\end{array}$ & $\begin{array}{c}\mathrm{F}-1 \\
\mathrm{Mg} / \mathrm{Ca}\end{array}$ & $\begin{array}{c}\mathrm{F} \\
\mathrm{Mg} / \mathrm{Ca}\end{array}$ & $\begin{array}{l}\text { WOA } \\
\text { 05 SST } \\
(0-50 \mathrm{~m}) \\
\end{array}$ & Salinity \\
\hline & $\begin{array}{c}\text { (degree } \\
\mathrm{s})\end{array}$ & $\begin{array}{c}\text { (degrees } \\
\text { ) }\end{array}$ & & (m) & (yr) & & $\begin{array}{c}(\mathrm{mmol} / \\
\mathrm{mol})\end{array}$ & $\begin{array}{c}\left(\begin{array}{c}\mathrm{mmol} / \\
\mathrm{mol})\end{array}\right. \\
\text { (a) }\end{array}$ & $\begin{array}{c}(\mathrm{mmol} / \\
\mathrm{mol})\end{array}$ & $\left({ }^{\circ} \mathrm{C}\right)$ & (psu) \\
\hline Z7003 & 36.693 & 176.24 & core top & 430 & $\begin{array}{l}5932 \\
\pm 55 \\
5932\end{array}$ & 4 & 2.49 & 2.05 & 3.22 & 18.1 & 35.5 \\
\hline Z7003 & 36.693 & 176.24 & core top & 430 & $\begin{array}{l} \pm 55 \\
5932\end{array}$ & 6 & 2.34 & 3.41 & 3.52 & 18.1 & 35.5 \\
\hline Z7003 & 36.693 & 176.24 & core top & 430 & $\begin{array}{l} \pm 55 \\
5932\end{array}$ & 8 & 3.30 & 0.84 & 2.40 & 18.1 & 35.5 \\
\hline Z7003 & 36.693 & 176.24 & core top & 430 & $\begin{array}{l} \pm 55 \\
5932\end{array}$ & 10 & 2.84 & 3.83 & 2.67 & 18.1 & 35.5 \\
\hline Z7003 & 36.693 & 176.24 & core top & 430 & $\begin{array}{l} \pm 55 \\
5932\end{array}$ & 15 & 3.09 & 4.10 & 4.17 & 18.1 & 35.5 \\
\hline Z7003 & 36.693 & 176.24 & core top & 430 & $\begin{array}{l} \pm 55 \\
5932\end{array}$ & 16 & 2.49 & 2.01 & 1.74 & 18.1 & 35.5 \\
\hline Z7003 & 36.693 & 176.24 & core top & 430 & $\begin{array}{l} \pm 55 \\
5932\end{array}$ & 17 & 3.34 & 3.26 & 1.39 & 18.1 & 35.5 \\
\hline Z7003 & 36.693 & 176.24 & core top & 430 & $\begin{array}{l} \pm 55 \\
5932\end{array}$ & 18 & 2.29 & 1.94 & 1.37 & 18.1 & 35.5 \\
\hline Z7003 & 36.693 & 176.24 & core top & 430 & $\begin{array}{l} \pm 55 \\
5932\end{array}$ & 19 & 2.35 & 2.75 & 2.04 & 18.1 & 35.5 \\
\hline Z7003 & 36.693 & 176.24 & core top & 430 & $\begin{array}{l} \pm 55 \\
5932\end{array}$ & 20 & 2.67 & 2.80 & 1.60 & 18.1 & 35.5 \\
\hline Z7003 & 36.693 & 176.24 & core top & 430 & $\begin{array}{l} \pm 55 \\
5932\end{array}$ & 21 & 5.27 & 4.49 & 2.46 & 18.1 & 35.5 \\
\hline Z7003 & 36.693 & 176.24 & core top & 430 & $\begin{array}{l} \pm 55 \\
5932\end{array}$ & 22 & 3.09 & 3.30 & 1.64 & 18.1 & 35.5 \\
\hline Z7003 & 36.693 & 176.24 & core top & 430 & $\begin{array}{l} \pm 55 \\
5932\end{array}$ & 23 & 3.09 & 2.87 & 1.47 & 18.1 & 35.5 \\
\hline Z7003 & 36.693 & 176.24 & core top & 430 & $\begin{array}{l} \pm 55 \\
5932\end{array}$ & 24 & 2.70 & 3.18 & 1.80 & 18.1 & 35.5 \\
\hline Z7003 & 36.693 & 176.24 & $\begin{array}{l}\text { core top } \\
\text { plankton }\end{array}$ & 430 & $\begin{array}{l} \pm 55 \\
\text { April }\end{array}$ & 25 & 3.44 & 4.04 & 2.23 & 18.1 & 35.5 \\
\hline U2315 & 38.509 & 179.02 & $\begin{array}{c}\text { tow } \\
\text { plankton }\end{array}$ & $100-50$ & $\begin{array}{l}2001 \\
\text { April }\end{array}$ & 2 & 2.42 & 4.06 & 1.36 & 18.7 & 35.6 \\
\hline U2315 & 38.509 & 179.02 & $\begin{array}{l}\text { tow } \\
\text { plankton }\end{array}$ & $100-50$ & $\begin{array}{l}2001 \\
\text { April }\end{array}$ & 3 & 5.91 & 6.08 & 3.10 & 18.7 & 35.6 \\
\hline U2315 & 38.509 & 179.02 & $\begin{array}{c}\text { tow } \\
\text { plankton }\end{array}$ & $100-50$ & $\begin{array}{l}2001 \\
\text { April }\end{array}$ & 4 & 3.26 & 4.68 & 2.50 & 18.7 & 35.6 \\
\hline U2315 & 38.509 & 179.02 & $\begin{array}{l}\text { tow } \\
\text { plankton }\end{array}$ & $100-50$ & $\begin{array}{l}2001 \\
\text { April }\end{array}$ & 5 & 2.29 & 3.16 & 2.18 & 18.7 & 35.6 \\
\hline U2315 & 38.509 & 179.02 & $\begin{array}{l}\text { tow } \\
\text { plankton }\end{array}$ & $100-50$ & $\begin{array}{l}2001 \\
\text { April }\end{array}$ & 6 & 3.67 & 3.44 & 2.77 & 18.7 & 35.6 \\
\hline U2315 & 38.509 & 179.02 & $\begin{array}{l}\text { tow } \\
\text { plankton }\end{array}$ & $100-50$ & $\begin{array}{l}2001 \\
\text { April }\end{array}$ & 9 & 2.62 & 2.96 & 1.87 & 18.7 & 35.6 \\
\hline U2315 & 38.509 & 179.02 & $\begin{array}{l}\text { tow } \\
\text { plankton }\end{array}$ & $100-50$ & $\begin{array}{l}2001 \\
\text { April }\end{array}$ & 10 & 3.56 & 3.51 & 3.13 & 18.7 & 35.6 \\
\hline U2315 & 38.509 & 179.02 & $\begin{array}{l}\text { tow } \\
\text { plankton }\end{array}$ & $100-50$ & $\begin{array}{l}2001 \\
\text { April }\end{array}$ & 11 & 2.29 & 2.93 & 0.91 & 18.7 & 35.6 \\
\hline U2315 & 38.509 & 179.02 & $\begin{array}{l}\text { tow } \\
\text { plankton }\end{array}$ & $100-50$ & $\begin{array}{l}2001 \\
\text { April }\end{array}$ & 12 & 3.30 & 3.93 & 2.19 & 18.7 & 35.6 \\
\hline U2315 & 38.509 & 179.02 & $\begin{array}{l}\text { tow } \\
\text { plankton }\end{array}$ & $100-50$ & $\begin{array}{l}2001 \\
\text { April }\end{array}$ & 13 & 3.36 & 2.80 & 2.55 & 18.7 & 35.6 \\
\hline U2315 & 38.509 & 179.02 & $\begin{array}{l}\text { tow } \\
\text { plankton }\end{array}$ & $100-50$ & $\begin{array}{l}2001 \\
\text { April }\end{array}$ & 14 & 2.97 & 4.24 & 1.83 & 18.7 & 35.6 \\
\hline U2315 & 38.509 & 179.02 & $\begin{array}{l}\text { tow } \\
\text { plankton }\end{array}$ & $100-50$ & $\begin{array}{l}2001 \\
\text { April }\end{array}$ & 15 & 2.09 & 3.84 & 3.25 & 18.7 & 35.6 \\
\hline U2315 & 38.509 & 179.02 & $\begin{array}{l}\text { tow } \\
\text { plankton }\end{array}$ & $100-50$ & $\begin{array}{l}2001 \\
\text { April }\end{array}$ & 16 & 2.60 & 2.84 & 2.09 & 18.7 & 35.6 \\
\hline U2322net6 & 41.601 & 178.05 & $\begin{array}{l}\text { tow } \\
\text { plankton }\end{array}$ & $100-50$ & $\begin{array}{l}2001 \\
\text { April }\end{array}$ & 1 & 3.93 & 4.60 & 2.69 & 18.3 & 35.6 \\
\hline U2322net6 & 41.601 & 178.05 & $\begin{array}{l}\text { tow } \\
\text { plankton }\end{array}$ & $100-50$ & $\begin{array}{l}2001 \\
\text { April }\end{array}$ & 3 & 2.16 & 2.69 & 2.08 & 18.3 & 35.6 \\
\hline U2322net6 & 41.601 & 178.05 & $\begin{array}{l}\text { tow } \\
\text { plankton }\end{array}$ & $100-50$ & $\begin{array}{l}2001 \\
\text { April }\end{array}$ & 4 & 2.97 & 4.37 & 4.24 & 18.3 & 35.6 \\
\hline U2322net6 & 41.601 & 178.05 & $\begin{array}{l}\text { tow } \\
\text { plankton }\end{array}$ & $100-50$ & $\begin{array}{l}2001 \\
\text { April }\end{array}$ & 5 & 2.68 & 3.02 & 1.80 & 18.3 & 35.6 \\
\hline U2322net6 & 41.601 & 178.05 & $\begin{array}{l}\text { tow } \\
\text { plankton }\end{array}$ & $100-50$ & $\begin{array}{l}2001 \\
\text { April }\end{array}$ & 6 & 3.02 & 3.29 & 2.96 & 18.3 & 35.6 \\
\hline U2322net6 & 41.601 & 178.05 & $\begin{array}{l}\text { tow } \\
\text { plankton }\end{array}$ & $100-50$ & $\begin{array}{l}2001 \\
\text { April }\end{array}$ & 8 & 3.07 & 2.34 & 3.09 & 18.3 & 35.6 \\
\hline U2322net6 & 41.601 & 178.05 & $\begin{array}{l}\text { tow } \\
\text { plankton }\end{array}$ & $100-50$ & $\begin{array}{l}2001 \\
\text { April }\end{array}$ & 9 & 2.37 & 3.33 & 2.52 & 18.3 & 35.6 \\
\hline U2322net7 & 41.601 & 178.05 & tow & $50-10$ & 2001 & 1 & 3.37 & 3.05 & 2.16 & 18.8 & 35.6 \\
\hline
\end{tabular}




\begin{tabular}{|c|c|c|c|c|c|c|c|c|c|c|c|}
\hline Site & $\begin{array}{l}\text { Latitud } \\
\mathrm{e}\end{array}$ & $\begin{array}{l}\text { Longitu } \\
\text { de }\end{array}$ & Core Type & Depth & Age & $\begin{array}{c}\text { Individu } \\
\text { al } \\
\text { Number }\end{array}$ & $\begin{array}{c}\mathrm{F}-2 \\
\mathrm{Mg} / \mathrm{Ca}\end{array}$ & $\begin{array}{c}\mathrm{F}-1 \\
\mathrm{Mg} / \mathrm{Ca}\end{array}$ & $\begin{array}{c}\mathrm{F} \\
\mathrm{Mg} / \mathrm{Ca}\end{array}$ & $\begin{array}{c}\text { WOA } \\
\text { 05 SST } \\
(0-50 \mathrm{~m})\end{array}$ & Salinity \\
\hline & $\begin{array}{c}\text { (degree } \\
\mathrm{s})\end{array}$ & $\begin{array}{c}\text { (degrees } \\
\text { ) }\end{array}$ & & (m) & (yr) & & $\begin{array}{c}(\mathrm{mmol} / \\
\mathrm{mol})\end{array}$ & $\begin{array}{c}(\mathrm{mmol} / \\
\mathrm{mol})\end{array}$ & $\begin{array}{c}(\mathrm{mmol} / \\
\mathrm{mol})\end{array}$ & $\left({ }^{\circ} \mathrm{C}\right)$ & (psu) \\
\hline U2322net7 & 41.601 & 178.05 & $\begin{array}{l}\text { plankton } \\
\text { tow } \\
\text { plankton }\end{array}$ & $50-10$ & $\begin{array}{l}\text { April } \\
2001 \\
\text { April }\end{array}$ & 5 & 4.01 & 3.25 & 2.55 & 18.8 & 35.6 \\
\hline U2322net7 & 41.601 & 178.05 & $\begin{array}{l}\text { tow } \\
\text { plankton }\end{array}$ & 50-10 & $\begin{array}{l}2001 \\
\text { April }\end{array}$ & 2 & 2.96 & 3.08 & 1.48 & 18.8 & 35.6 \\
\hline U2322net7 & 41.601 & 178.05 & $\begin{array}{l}\text { tow } \\
\text { plankton }\end{array}$ & $50-10$ & $\begin{array}{l}2001 \\
\text { April }\end{array}$ & 6 & 2.46 & 2.91 & 1.48 & 18.8 & 35.6 \\
\hline U2322net7 & 41.601 & 178.05 & $\begin{array}{l}\text { tow } \\
\text { plankton }\end{array}$ & $50-10$ & $\begin{array}{l}2001 \\
\text { April }\end{array}$ & 3 & 1.78 & 2.21 & 1.86 & 18.8 & 35.6 \\
\hline U2322net7 & 41.601 & 178.05 & $\begin{array}{l}\text { tow } \\
\text { plankton }\end{array}$ & $50-10$ & $\begin{array}{l}2001 \\
\text { April }\end{array}$ & 7 & 2.98 & 3.27 & 2.69 & 18.8 & 35.6 \\
\hline U2322net7 & 41.601 & 178.05 & $\begin{array}{c}\text { tow } \\
\text { plankton }\end{array}$ & $50-10$ & $\begin{array}{l}2001 \\
\text { April }\end{array}$ & 4 & 3.25 & 3.42 & 2.50 & 18.8 & 35.6 \\
\hline U2322net7 & 41.601 & 178.05 & tow & 50-10 & 2001 & 8 & 2.51 & 2.71 & 1.30 & 18.8 & 35.6 \\
\hline ODP1123 & 41.942 & 188.50 & core top & 3290 & & 1 & 2.24 & 2.31 & 1.24 & 14.7 & 36.2 \\
\hline ODP1123 & 41.942 & 188.50 & core top & 3290 & & 2 & 1.53 & 2.15 & 1.06 & 14.7 & 36.2 \\
\hline ODP1123 & 41.942 & 188.50 & core top & 3290 & & 3 & 2.94 & 2.54 & 2.62 & 14.7 & 36.2 \\
\hline ODP1123 & 41.942 & 188.50 & core top & 3290 & & 5 & 1.47 & 1.53 & 1.44 & 14.7 & 36.2 \\
\hline ODP1123 & 41.942 & 188.50 & core top & 3290 & & 7 & 1.53 & 1.85 & 1.45 & 14.7 & 36.2 \\
\hline ODP1123 & 41.942 & 188.50 & core top & 3290 & & 9 & 1.44 & 1.42 & 1.35 & 14.7 & 36.2 \\
\hline ODP1123 & 41.942 & 188.50 & core top & 3290 & & 11 & 1.41 & 2.03 & 1.30 & 14.7 & 36.2 \\
\hline ODP1123 & 41.942 & 188.50 & core top & 3290 & & 12 & 1.62 & 1.65 & 1.24 & 14.7 & 36.2 \\
\hline ODP1123 & 41.942 & 188.50 & core top & 3290 & & 13 & 2.21 & 2.29 & 1.70 & 14.7 & 36.2 \\
\hline ODP1123 & 41.942 & 188.50 & core top & 3290 & & 14 & 2.11 & 2.06 & 1.56 & 14.7 & 36.2 \\
\hline ODP1123 & 41.942 & 188.50 & core top & 3290 & & 15 & 1.65 & 1.55 & 1.20 & 14.7 & 36.2 \\
\hline ODP1123 & 41.942 & 188.50 & core top & 3290 & & 18 & 2.85 & 3.03 & 2.14 & 14.7 & 36.2 \\
\hline
\end{tabular}

N.B. In order to perform paired t-tests, those individuals where 1 or more chambers were excluded post-analysis, were not included in the above table.

Table A2: Core top and plankton tow morphotypes, height, length and weight data for individual Globigernoides ruber $(250-355 \mu \mathrm{m})$ from sites in the Southwest Pacific Ocean

\begin{tabular}{|c|c|c|c|c|c|c|c|c|c|}
\hline Site & Latitude & Longitude & Depth & Age & $\begin{array}{c}\text { Individual } \\
\text { Number }\end{array}$ & Morphotype & $\mathrm{X}$ & $\mathrm{Y}$ & Weight \\
\hline & (degrees) & (degrees) & (metres) & (yr) & & & $(\mu \mathrm{m})$ & $(\mu \mathrm{m})$ & $(\mu \mathrm{g})$ \\
\hline AIMS1361 & 3.370 & 144.34 & 1100 & & 1 & s.s. & 251 & 280 & 5.7 \\
\hline AIMS1361 & 3.370 & 144.34 & 1100 & & 2 & s.s. & 214 & 249 & 6.9 \\
\hline AIMS1361 & 3.370 & 144.34 & 1100 & & 4 & s.s. & 259 & 290 & 7.5 \\
\hline AIMS1361 & 3.370 & 144.34 & 1100 & & 6 & s.l. & 277 & 294 & 6.8 \\
\hline AIMS1361 & 3.370 & 144.34 & 1100 & & 11 & s.l. & 280 & 270 & 9.9 \\
\hline AIMS1361 & 3.370 & 144.34 & 1100 & & 12 & s.s. & 215 & 266 & 8.5 \\
\hline AIMS1361 & 3.370 & 144.34 & 1100 & & 14 & s.l. & 279 & 283 & 9.0 \\
\hline AIMS3703 & 11.153 & 125.02 & 504 & $<100$ & 1 & s.s. & 343 & 384 & 11.6 \\
\hline AIMS3703 & 11.153 & 125.02 & 504 & $<100$ & 3 & s.l. & 414 & 410 & 18.5 \\
\hline AIMS3703 & 11.153 & 125.02 & 504 & $<100$ & 4 & s.s. & 341 & 381 & 13.7 \\
\hline AIMS3703 & 11.153 & 125.02 & 504 & $<100$ & 5 & s.s. & 254 & 321 & 11.6 \\
\hline AIMS3703 & 11.153 & 125.02 & 504 & $<100$ & 6 & s.s. & 369 & 421 & 16.3 \\
\hline AIMS3703 & 11.153 & 125.02 & 504 & $<100$ & 7 & s.l. & 336 & 352 & 10.3 \\
\hline AIMS3703 & 11.153 & 125.02 & 504 & $<100$ & 8 & s.s. & 261 & 308 & 7.5 \\
\hline AIMS3703 & 11.153 & 125.02 & 504 & $<100$ & 13 & s.l. & 283 & 317 & 5.8 \\
\hline AIMS3703 & 11.153 & 125.02 & 504 & $<100$ & 14 & s.s. & 397 & 408 & 5.8 \\
\hline AIMS3703 & 11.153 & 125.02 & 504 & $<100$ & 16 & s.s. & 273 & 338 & 7.5 \\
\hline
\end{tabular}




\begin{tabular}{|c|c|c|c|c|c|c|c|c|c|}
\hline Site & Latitude & Longitude & Depth & Age & $\begin{array}{c}\text { Individual } \\
\text { Number }\end{array}$ & Morphotype & $\mathrm{X}$ & $\mathrm{Y}$ & Weight \\
\hline & (degrees) & (degrees) & (metres) & (yr) & & & $(\mu \mathrm{m})$ & $(\mu \mathrm{m})$ & $(\mu \mathrm{g})$ \\
\hline AIMS3703 & 11.153 & 125.02 & 504 & $<100$ & 17 & s.l. & 308 & 303 & 9.8 \\
\hline AIMS3703 & 11.153 & 125.02 & 504 & $<100$ & 18 & s.l. & 335 & 253 & 13.0 \\
\hline AIMS3703 & 11.153 & 125.02 & 504 & $<100$ & 19 & s.l. & 288 & 283 & 11.0 \\
\hline AIMS1631 & 11.158 & 145.79 & 1468 & & 1 & s.s. & 344 & 350 & 25.1 \\
\hline AIMS1631 & 11.158 & 145.79 & 1468 & & 4 & s.s. & 320 & 353 & 15.0 \\
\hline AIMS1631 & 11.158 & 145.79 & 1468 & & 5 & s.s. & 283 & 318 & 10.0 \\
\hline AIMS1631 & 11.158 & 145.79 & 1468 & & 7 & s.s. & 257 & 264 & 5.5 \\
\hline AIMS2078 & 18.212 & 147.60 & 880 & $2160 \pm 50$ & 1 & s.l. & 307 & 295 & 10.3 \\
\hline AIMS2078 & 18.212 & 147.60 & 880 & $2160 \pm 50$ & 2 & s.s. & 336 & 353 & 8.7 \\
\hline AIMS2078 & 18.212 & 147.60 & 880 & $2160 \pm 50$ & 3 & s.l. & 270 & 291 & 10.6 \\
\hline AIMS2078 & 18.212 & 147.60 & 880 & $2160 \pm 50$ & 4 & s.l. & 263 & 301 & 7.8 \\
\hline AIMS2078 & 18.212 & 147.60 & 880 & $2160 \pm 50$ & 6 & s.l. & 242 & 256 & 9.6 \\
\hline AIMS2078 & 18.212 & 147.60 & 880 & $2160 \pm 50$ & 8 & s.s. & 302 & 328 & 8.8 \\
\hline AIMS2078 & 18.212 & 147.60 & 880 & $2160 \pm 50$ & 9 & s.l. & 322 & 290 & 7.7 \\
\hline AIMS2078 & 18.212 & 147.60 & 880 & $2160 \pm 50$ & 14 & s.s. & 275 & 289 & 5.3 \\
\hline AIMS2078 & 18.212 & 147.60 & 880 & $2160 \pm 50$ & 16 & s.l. & 249 & 267 & 5.2 \\
\hline AIMS2078 & 18.212 & 147.60 & 880 & $2160 \pm 50$ & 17 & s.l. & 230 & 233 & 6.2 \\
\hline FR1/97/GC12 & 23.577 & 153.79 & 991 & $8995 \pm 25$ & 1 & s.s. & 211 & 255 & 8.8 \\
\hline FR1/97/GC12 & 23.577 & 153.79 & 991 & $8995 \pm 25$ & 2 & s.l. & 224 & 244 & 9.8 \\
\hline FR1/97/GC12 & 23.577 & 153.79 & 991 & $8995 \pm 25$ & 3 & s.l. & 260 & 273 & 7.4 \\
\hline FR1/97/GC12 & 23.577 & 153.79 & 991 & $8995 \pm 25$ & 5 & s.l. & 251 & 294 & 11.3 \\
\hline FR1/97/GC12 & 23.577 & 153.79 & 991 & $8995 \pm 25$ & 7 & s.l. & 256 & 284 & 10.3 \\
\hline FR1/97/GC12 & 23.577 & 153.79 & 991 & $8995 \pm 25$ & 10 & s.l. & 268 & 222 & 7.2 \\
\hline FR1/97/GC12 & 23.577 & 153.79 & 991 & $8995 \pm 25$ & 11 & s.l. & 218 & 252 & 13.3 \\
\hline FR1/97/GC12 & 23.577 & 153.79 & 991 & $8995 \pm 25$ & 12 & s.l. & 244 & 261 & 10.1 \\
\hline FR1/97/GC12 & 23.577 & 153.79 & 991 & $8995 \pm 25$ & 13 & s.l. & 208 & 232 & 6.5 \\
\hline FR1/97/GC12 & 23.577 & 153.79 & 991 & $8995 \pm 25$ & 14 & s.l. & 189 & 232 & 10.4 \\
\hline FR1/97/GC12 & 23.577 & 153.79 & 991 & $8995 \pm 25$ & 15 & s.l. & 194 & 237 & 10.1 \\
\hline FR1/97/GC12 & 23.577 & 153.79 & 991 & $8995 \pm 25$ & 16 & s.l. & 180 & 194 & 7.5 \\
\hline TAN0706 C4 & 29.353 & 180.97 & 2258 & & 1 & s.s. & 260 & 294 & 13.0 \\
\hline TAN0706 C4 & 29.353 & 180.97 & 2258 & & 2 & s.s. & 272 & 315 & 22.4 \\
\hline TAN0706 C4 & 29.353 & 180.97 & 2258 & & 5 & s.l. & 344 & 377 & 10.1 \\
\hline TAN0706 C4 & 29.353 & 180.97 & 2258 & & 6 & s.l. & 273 & 270 & 12.1 \\
\hline TAN0706 C4 & 29.353 & 180.97 & 2258 & & 8 & s.l. & 246 & 248 & 10.9 \\
\hline TAN0706 C4 & 29.353 & 180.97 & 2258 & & 9 & s.s. & 203 & 227 & 6.0 \\
\hline TAN0706 C4 & 29.353 & 180.97 & 2258 & & 10 & s.s. & 224 & 245 & 7.9 \\
\hline TAN0706 C4 & 29.353 & 180.97 & 2258 & & 11 & s.l. & & & 24.4 \\
\hline TAN0706 C4 & 29.353 & 180.97 & 2258 & & 12 & s.l. & & & 12.3 \\
\hline TAN0706 C4 & 29.353 & 180.97 & 2258 & & 13 & s.l. & & & 13.8 \\
\hline TAN0706 C4 & 29.353 & 180.97 & 2258 & & 14 & s.l. & & & 12.3 \\
\hline TAN0706 C4 & 29.353 & 180.97 & 2258 & & 15 & s.l. & & & 16.7 \\
\hline TAN0706 C4 & 29.353 & 180.97 & 2258 & & 16 & s.s. & & & 15.0 \\
\hline TAN0706 C4 & 29.353 & 180.97 & 2258 & & 17 & s.l. & & & 16.2 \\
\hline TAN0706 C4 & 29.353 & 180.97 & 2258 & & 18 & s.s. & & & 22.4 \\
\hline TAN0706 C4 & 29.353 & 180.97 & 2258 & & 19 & s.l. & & & 7.6 \\
\hline TAN0706 C4 & 29.353 & 180.97 & 2258 & & 20 & s.l. & & & 16.1 \\
\hline TAN0706 C4 & 29.353 & 180.97 & 2258 & & 21 & s.l. & & & 14.7 \\
\hline TAN0706 C4 & 29.353 & 180.97 & 2258 & & 22 & s.s. & & & 8.9 \\
\hline TAN0706 C4 & 29.353 & 180.97 & 2258 & & 23 & s.s. & & & 10.2 \\
\hline TAN0706 C4 & 29.353 & 180.97 & 2258 & & 24 & s.l. & & & 15.5 \\
\hline TAN0706 C4 & 29.353 & 180.97 & 2258 & & 25 & s.l. & & & 12.3 \\
\hline
\end{tabular}




\begin{tabular}{|c|c|c|c|c|c|c|c|c|c|}
\hline Site & Latitude & Longitude & Depth & Age & $\begin{array}{c}\text { Individual } \\
\text { Number }\end{array}$ & Morphotype & $\mathrm{X}$ & $\mathrm{Y}$ & Weight \\
\hline & (degrees) & (degrees) & (metres) & (yr) & & & $(\mu \mathrm{m})$ & $(\mu \mathrm{m})$ & $(\mu g)$ \\
\hline TAN0706 C4 & 29.353 & 180.97 & 2258 & & 26 & s.l. & & & 14.5 \\
\hline TAN0706 C4 & 29.353 & 180.97 & 2258 & & 27 & s.s. & & & 7.0 \\
\hline TAN0706 C4 & 29.353 & 180.97 & 2258 & & 28 & s.s. & & & 8.5 \\
\hline TAN0706 C4 & 29.353 & 180.97 & 2258 & & 29 & s.s. & & & 7.7 \\
\hline P71 & 33.855 & 174.69 & 1919 & $5715 \pm 40$ & 1 & & 368 & 396 & 10.4 \\
\hline P71 & 33.855 & 174.69 & 1919 & $5715 \pm 40$ & 2 & & 271 & 300 & 9.0 \\
\hline P71 & 33.855 & 174.69 & 1919 & $5715 \pm 40$ & 2 & & 271 & 300 & 9.0 \\
\hline P71 & 33.855 & 174.69 & 1919 & $5715 \pm 40$ & 3 & & 257 & 296 & 8.4 \\
\hline P71 & 33.855 & 174.69 & 1919 & $5715 \pm 40$ & 3 & & 257 & 296 & 8.4 \\
\hline P71 & 33.855 & 174.69 & 1919 & $5715 \pm 40$ & 4 & & 311 & 327 & 14.2 \\
\hline P71 & 33.855 & 174.69 & 1919 & $5715 \pm 40$ & 4 & & 311 & 327 & 14.2 \\
\hline P71 & 33.855 & 174.69 & 1919 & $5715 \pm 40$ & 5 & & 270 & 299 & 6.3 \\
\hline P71 & 33.855 & 174.69 & 1919 & $5715 \pm 40$ & 7 & & 268 & 315 & 9.0 \\
\hline P71 & 33.855 & 174.69 & 1919 & $5715 \pm 40$ & 8 & & 210 & 223 & 4.4 \\
\hline P71 & 33.855 & 174.69 & 1919 & $5715 \pm 40$ & 9 & & 353 & 340 & 8.7 \\
\hline P71 & 33.855 & 174.69 & 1919 & $5715 \pm 40$ & 9 & & 353 & 340 & 8.7 \\
\hline P71 & 33.855 & 174.69 & 1919 & $5715 \pm 40$ & 10 & & 297 & 338 & 10.3 \\
\hline P71 & 33.855 & 174.69 & 1919 & $5715 \pm 40$ & 11 & & 253 & 286 & 9.2 \\
\hline P71 & 33.855 & 174.69 & 1919 & $5715 \pm 40$ & 13 & & 254 & 250 & 4.9 \\
\hline P71 & 33.855 & 174.69 & 1919 & $5715 \pm 40$ & 13 & & 254 & 250 & 4.9 \\
\hline P71 & 33.855 & 174.69 & 1919 & $5715 \pm 40$ & 14 & & 192 & 233 & 8.4 \\
\hline P71 & 33.855 & 174.69 & 1919 & $5715 \pm 40$ & 14 & & 192 & 233 & 8.4 \\
\hline P71 & 33.855 & 174.69 & 1919 & $5715 \pm 40$ & 16 & & 299 & 321 & 4.1 \\
\hline P81 & 34.020 & 173.51 & 2036 & $5715 \pm 40$ & 1 & s.l. & 309 & 305 & 2.3 \\
\hline P81 & 34.020 & 173.51 & 2036 & $5715 \pm 40$ & 2 & s.l. & 293 & 291 & 3.3 \\
\hline P81 & 34.020 & 173.51 & 2036 & $5715 \pm 40$ & 3 & & 289 & 294 & 3.5 \\
\hline P81 & 34.020 & 173.51 & 2036 & $5715 \pm 40$ & 5 & & 296 & 344 & 4.3 \\
\hline P81 & 34.020 & 173.51 & 2036 & $5715 \pm 40$ & 6 & & 282 & 272 & 3.1 \\
\hline P81 & 34.020 & 173.51 & 2036 & $5715 \pm 40$ & 7 & s.s. & 211 & 243 & 3.4 \\
\hline P81 & 34.020 & 173.51 & 2036 & $5715 \pm 40$ & 10 & s.l. & 188 & 234 & 2.6 \\
\hline P81 & 34.020 & 173.51 & 2036 & $5715 \pm 40$ & 12 & s.s. & 225 & 245 & 3.1 \\
\hline P81 & 34.020 & 173.51 & 2036 & $5715 \pm 40$ & 14 & s.s. & & & 2.1 \\
\hline P81 & 34.020 & 173.51 & 2036 & $5715 \pm 40$ & 15 & s.l. & & & \\
\hline P81 & 34.020 & 173.51 & 2036 & $5715 \pm 40$ & 16 & s.l. & & & \\
\hline P81 & 34.020 & 173.51 & 2036 & $5715 \pm 40$ & 17 & s.l. & & & \\
\hline P81 & 34.020 & 173.51 & 2036 & $5715 \pm 40$ & 18 & s.s. & & & \\
\hline P81 & 34.020 & 173.51 & 2036 & $5715 \pm 40$ & 20 & s.l. & & & \\
\hline P81 & 34.020 & 173.51 & 2036 & $5715 \pm 40$ & 21 & s.l. & & & \\
\hline P81 & 34.020 & 173.51 & 2036 & $5715 \pm 40$ & 25 & s.l. & & & \\
\hline P81 & 34.020 & 173.51 & 2036 & $5715 \pm 40$ & 26 & & & & \\
\hline P81 & 34.020 & 173.51 & 2036 & $5715 \pm 40$ & 27 & & & & \\
\hline Z7003 & 36.693 & 176.24 & 430 & $5932 \pm 55$ & 2 & s.l. & 265 & 281 & 9.9 \\
\hline Z7003 & 36.693 & 176.24 & 430 & $5932 \pm 55$ & 4 & s.l. & 319 & 315 & 16.1 \\
\hline Z7003 & 36.693 & 176.24 & 430 & $5932 \pm 55$ & 6 & s.l. & 294 & 301 & 13.7 \\
\hline Z7003 & 36.693 & 176.24 & 430 & $5932 \pm 55$ & 8 & s.s. & 261 & 296 & 10.1 \\
\hline Z7003 & 36.693 & 176.24 & 430 & $5932 \pm 55$ & 10 & s.l. & 279 & 328 & 13.1 \\
\hline Z7003 & 36.693 & 176.24 & 430 & $5932 \pm 55$ & 15 & s.s. & 246 & 279 & 9.6 \\
\hline Z7003 & 36.693 & 176.24 & 430 & $5932 \pm 55$ & 16 & s.s. & & & 8.3 \\
\hline Z7003 & 36.693 & 176.24 & 430 & $5932 \pm 55$ & 17 & s.l. & & & 6.8 \\
\hline Z7003 & 36.693 & 176.24 & 430 & $5932 \pm 55$ & 18 & s.l. & & & 5.7 \\
\hline Z7003 & 36.693 & 176.24 & 430 & $5932 \pm 55$ & 19 & s.l. & & & 10.0 \\
\hline
\end{tabular}




\begin{tabular}{|c|c|c|c|c|c|c|c|c|c|}
\hline Site & Latitude & Longitude & Depth & Age & $\begin{array}{c}\text { Individual } \\
\text { Number }\end{array}$ & Morphotype & $\mathrm{X}$ & $\mathrm{Y}$ & Weight \\
\hline & (degrees) & (degrees) & (metres) & (yr) & & & $(\mu \mathrm{m})$ & $(\mu \mathrm{m})$ & $(\mu \mathrm{g})$ \\
\hline Z7003 & 36.693 & 176.24 & 430 & $5932 \pm 55$ & 20 & s.s. & & & crushed \\
\hline Z7003 & 36.693 & 176.24 & 430 & $5932 \pm 55$ & 21 & s.s. & & & crushed \\
\hline Z7003 & 36.693 & 176.24 & 430 & $5932 \pm 55$ & 22 & s.s. & & & 15.8 \\
\hline Z7003 & 36.693 & 176.24 & 430 & $5932 \pm 55$ & 23 & s.s. & & & 11.2 \\
\hline Z7003 & 36.693 & 176.24 & 430 & $5932 \pm 55$ & 24 & s.s. & & & 12.0 \\
\hline Z7003 & 36.693 & 176.24 & 430 & $5932 \pm 55$ & 25 & s.s. & & & 9.1 \\
\hline U2315 & 38.509 & 179.02 & $100-50$ & April 2001 & 2 & s.l. & 263 & 255 & 9.7 \\
\hline $\mathrm{U} 2315$ & 38.509 & 179.02 & $100-50$ & April 2001 & 3 & s.l. & 216 & 225 & 8.0 \\
\hline U2315 & 38.509 & 179.02 & $100-50$ & April 2001 & 4 & s.l. & 214 & 228 & 6.2 \\
\hline $\mathrm{U} 2315$ & 38.509 & 179.02 & $100-50$ & April 2001 & 5 & s.l. & 235 & 257 & 8.7 \\
\hline $\mathrm{U} 2315$ & 38.509 & 179.02 & $100-50$ & April 2001 & 6 & s.s. & 174 & 216 & 4.3 \\
\hline $\mathrm{U} 2315$ & 38.509 & 179.02 & $100-50$ & April 2001 & 9 & s.s. & 171 & 188 & 4.4 \\
\hline U2315 & 38.509 & 179.02 & $100-50$ & April 2001 & 10 & s.s. & 180 & 224 & 4.8 \\
\hline U2315 & 38.509 & 179.02 & $100-50$ & April 2001 & 11 & s.l. & 230 & 264 & 7.1 \\
\hline $\mathrm{U} 2315$ & 38.509 & 179.02 & $100-50$ & April 2001 & 12 & s.s. & 206 & 237 & 5.9 \\
\hline U2315 & 38.509 & 179.02 & $100-50$ & April 2001 & 13 & s.s. & 198 & 208 & 6.0 \\
\hline U2315 & 38.509 & 179.02 & $100-50$ & April 2001 & 14 & s.s. & 274 & 307 & 10.9 \\
\hline U2315 & 38.509 & 179.02 & $100-50$ & April 2001 & 15 & s.l. & 187 & 216 & 5.7 \\
\hline U2315 & 38.509 & 179.02 & $100-50$ & April 2001 & 16 & s.s. & 140 & 160 & 2.6 \\
\hline U2322net6 & 41.601 & 178.05 & $100-50$ & April 2001 & 1 & s.l. & 206 & 197 & 4.4 \\
\hline U2322net6 & 41.601 & 178.05 & $100-50$ & April 2001 & 3 & s.l. & 239 & 272 & 5.4 \\
\hline U2322net6 & 41.601 & 178.05 & $100-50$ & April 2001 & 4 & s.s. & 191 & 219 & 3.7 \\
\hline U2322net6 & 41.601 & 178.05 & $100-50$ & April 2001 & 5 & s.s. & 201 & 209 & 2.6 \\
\hline U2322net6 & 41.601 & 178.05 & $100-50$ & April 2001 & 6 & s.s. & 190 & 231 & 4.5 \\
\hline U2322net6 & 41.601 & 178.05 & $100-50$ & April 2001 & 8 & s.s. & 107 & 158 & 1.1 \\
\hline U2322net6 & 41.601 & 178.05 & $100-50$ & April 2001 & 9 & s.s. & 207 & 199 & 4.7 \\
\hline U2322net7 & 41.601 & 178.05 & $50-10$ & April 2001 & 1 & s.s. & 243 & 269 & 5.3 \\
\hline U2322net7 & 41.601 & 178.05 & $50-10$ & April 2001 & 2 & s.s. & 200 & 225 & 5.5 \\
\hline U2322net7 & 41.601 & 178.05 & $50-10$ & April 2001 & 3 & s.s. & 216 & 245 & 4.0 \\
\hline U2322net7 & 41.601 & 178.05 & $50-10$ & April 2001 & 4 & s.l. & 216 & 203 & n.d. \\
\hline ODP1123 & 41.942 & 188.50 & 3290 & & 1 & s.l. & 250 & 261 & 6.8 \\
\hline ODP1123 & 41.942 & 188.50 & 3290 & & 2 & s.s. & 180 & 174 & 3.8 \\
\hline ODP1123 & 41.942 & 188.50 & 3290 & & 3 & s.l. & 190 & 188 & 4.8 \\
\hline ODP1123 & 41.942 & 188.50 & 3290 & & 5 & s.l. & 179 & 216 & 2.7 \\
\hline ODP1123 & 41.942 & 188.50 & 3290 & & 7 & s.s. & 188 & 217 & 2.5 \\
\hline ODP1123 & 41.942 & 188.50 & 3290 & & 9 & s.l. & 189 & 232 & 6.3 \\
\hline ODP1123 & 41.942 & 188.50 & 3290 & & 11 & s.l. & 180 & 194 & 4.4 \\
\hline ODP1123 & 41.942 & 188.50 & 3290 & & 12 & s.l. & 194 & 218 & 5.9 \\
\hline ODP1123 & 41.942 & 188.50 & 3290 & & 13 & s.s. & 150 & 203 & 4.4 \\
\hline ODP1123 & 41.942 & 188.50 & 3290 & & 14 & s.l. & 125 & 200 & 3.5 \\
\hline ODP1123 & 41.942 & 188.50 & 3290 & & 15 & s.l. & 171 & 195 & 2.2 \\
\hline ODP1123 & 41.942 & 188.50 & 3290 & & 18 & s.l. & 148 & 193 & 2.2 \\
\hline
\end{tabular}

N.B. In order to perform paired t-tests, those individuals where 1 or more chambers were excluded post-analysis, were not included in the above table. Cells in bold 
Table A3: Other trace element data for Globigernoides ruber $(250-355 \mu \mathrm{m})$ for core top and plankton tow sites in the Southwest Pacific Ocean

\begin{tabular}{|c|c|c|c|c|c|c|c|c|}
\hline$\overline{\text { Site }}$ & $\begin{array}{c}\text { Individual } \\
\text { Number }\end{array}$ & Chamber & $\mathrm{Mg} / \mathrm{Ca}$ & $\mathrm{Al} / \mathrm{Ca}$ & $\mathrm{Mn} / \mathrm{Ca}$ & $\mathrm{Sr} / \mathrm{Ca}$ & $\mathrm{Zn} / \mathrm{Ca}$ & $\mathrm{Ba} / \mathrm{Ca}$ \\
\hline & & & $(\mathrm{mmol} / \mathrm{mol})$ & $(\mu \mathrm{mol} / \mathrm{mol})$ & $(\mu \mathrm{mol} / \mathrm{mol})$ & $(\mathrm{mmol} / \mathrm{mol})$ & $(\mu \mathrm{mol} / \mathrm{mol})$ & $(\mu \mathrm{mol} / \mathrm{mol})$ \\
\hline$\overline{\text { AIMS1361 }}$ & 1 & $\mathrm{~F}$ & 4.076 & -0.4 & 32.4 & 1.429 & 10.7 & 1.1 \\
\hline AIMS1361 & 1 & $\mathrm{~F}-1$ & 4.086 & 27.2 & 28.2 & 1.356 & 2.1 & 1.0 \\
\hline AIMS1361 & 1 & $\mathrm{~F}-2$ & 5.213 & 54.1 & 42.2 & 1.477 & 2.4 & 1.1 \\
\hline AIMS1361 & 2 & $\mathrm{~F}$ & 5.888 & 126.1 & 60.6 & 1.383 & 11.0 & 3.4 \\
\hline AIMS1361 & 2 & F-1 & 5.905 & 479.5 & 64.6 & 1.424 & 12.0 & 1.9 \\
\hline AIMS1361 & 2 & $\mathrm{~F}-2$ & 5.443 & 161.7 & 67.4 & 1.400 & 11.0 & 2.9 \\
\hline AIMS1361 & 3 & $\mathrm{~F}$ & 4.695 & 2.1 & 56.3 & 1.458 & 2.9 & 1.0 \\
\hline AIMS1361 & 3 & F-1 & 4.711 & 438.7 & 49.5 & 1.377 & 8.1 & 1.3 \\
\hline AIMS1361 & 4 & $\mathrm{~F}$ & 3.849 & 33.3 & 51.3 & 1.411 & 14.7 & 1.1 \\
\hline AIMS1361 & 4 & F-1 & 4.531 & 9.3 & 64.8 & 1.365 & 16.9 & 1.1 \\
\hline AIMS1361 & 4 & $\mathrm{~F}-2$ & 6.111 & 328.1 & 53.7 & 1.403 & 13.2 & 1.5 \\
\hline AIMS1361 & 5 & $\mathrm{~F}$ & 3.210 & 66.1 & 24.8 & 1.435 & 9.3 & 1.8 \\
\hline AIMS1361 & 5 & F-1 & 5.487 & 370.4 & 34.7 & 1.406 & 9.9 & 3.4 \\
\hline AIMS1361 & 6 & $\mathrm{~F}$ & 4.183 & 99.3 & 40.1 & 1.277 & 9.3 & 1.6 \\
\hline AIMS1361 & 6 & F-1 & 6.057 & 580.1 & 70.2 & 1.375 & 5.2 & 3.6 \\
\hline AIMS1361 & 6 & F-2 & 5.360 & 177.2 & 59.2 & 1.368 & 4.3 & 2.0 \\
\hline AIMS1361 & 7 & $\mathrm{~F}$ & 4.241 & 148.7 & 2.7 & 1.422 & 6.7 & 0.9 \\
\hline AIMS1361 & 7 & F-1 & 6.145 & 676.4 & 14.0 & 1.510 & 5.1 & 1.0 \\
\hline AIMS1361 & 8 & $\mathrm{~F}$ & 3.474 & 148.9 & 55.9 & 1.346 & 12.7 & 1.8 \\
\hline AIMS1361 & 9 & $\mathrm{~F}$ & 4.652 & 450.7 & 40.2 & 1.591 & 4.4 & 2.0 \\
\hline AIMS1361 & 10 & $\mathrm{~F}$ & 4.435 & 9.6 & 27.7 & 1.435 & 7.0 & 1.2 \\
\hline AIMS1361 & 10 & $\mathrm{~F}-2$ & 4.514 & 14.4 & 21.9 & 1.464 & 7.3 & 1.4 \\
\hline AIMS1361 & 11 & $\mathrm{~F}$ & 3.708 & 74.8 & 5.9 & 1.415 & 3.3 & 0.7 \\
\hline AIMS1361 & 11 & F-1 & 4.814 & 158.1 & 7.1 & 1.465 & 3.4 & 0.8 \\
\hline AIMS1361 & 11 & F-2 & 4.680 & 73.3 & 6.8 & 1.494 & 2.8 & 1.1 \\
\hline AIMS1361 & 12 & $\mathrm{~F}$ & 4.444 & 1.3 & 23.6 & 1.385 & 12.7 & 1.2 \\
\hline AIMS1361 & 12 & F-1 & 5.140 & 150.1 & 26.9 & 1.487 & 11.9 & 1.4 \\
\hline AIMS1361 & 12 & $\mathrm{~F}-2$ & 4.445 & 57.1 & 21.5 & 1.421 & 7.2 & 1.3 \\
\hline AIMS1361 & 13 & $\mathrm{~F}$ & 3.508 & 399.4 & 37.3 & 1.348 & 8.4 & 1.3 \\
\hline AIMS1361 & 14 & $\mathrm{~F}$ & 3.022 & 22.8 & 9.1 & 1.476 & 8.6 & 0.8 \\
\hline AIMS1361 & 14 & F-1 & 5.489 & 35.1 & 18.6 & 1.459 & 4.6 & 1.4 \\
\hline AIMS1361 & 14 & $\mathrm{~F}-2$ & 6.085 & 303.3 & 17.2 & 1.578 & 7.1 & 1.6 \\
\hline AIMS1631 & 1 & $\mathrm{~F}$ & 4.008 & 29.9 & 23.4 & 1.463 & 13.3 & 1.1 \\
\hline AIMS1631 & 1 & F-1 & 3.663 & -7.3 & 24.1 & 1.645 & 19.8 & 1.1 \\
\hline AIMS1631 & 1 & $\mathrm{~F}-2$ & 4.148 & 0.6 & 54.9 & 1.489 & 36.8 & 1.6 \\
\hline AIMS1631 & 2 & $\mathrm{~F}$ & 3.059 & 36.7 & 13.5 & 1.432 & 15.2 & 1.4 \\
\hline AIMS1631 & 2 & $\mathrm{~F}-2$ & 3.834 & 81.6 & 13.4 & 1.406 & 11.4 & 1.1 \\
\hline AIMS1631 & 3 & $\mathrm{~F}$ & 3.458 & 12.7 & 20.8 & 1.415 & 16.3 & 1.1 \\
\hline AIMS1631 & 3 & F-2 & 5.948 & 5.3 & 22.9 & 1.652 & 15.4 & 1.6 \\
\hline AIMS1631 & 4 & $\mathrm{~F}$ & 4.624 & 17.5 & 6.2 & 1.400 & 42.1 & 0.8 \\
\hline AIMS1631 & 4 & F-1 & 5.981 & 16.6 & 8.6 & 1.586 & 20.4 & 1.2 \\
\hline AIMS1631 & 4 & $\mathrm{~F}-2$ & 5.130 & 23.9 & 4.6 & 1.482 & 16.3 & 0.9 \\
\hline AIMS1631 & 5 & $\mathrm{~F}$ & 3.925 & 10.4 & 11.3 & 1.387 & 27.7 & 1.1 \\
\hline AIMS1631 & 5 & F-1 & 5.078 & 8.3 & 16.8 & 1.456 & 34.9 & 1.1 \\
\hline AIMS1631 & 5 & F-2 & 4.687 & 9.6 & 15.4 & 1.466 & 26.3 & 1.1 \\
\hline AIMS1631 & 6 & $\mathrm{~F}$ & 4.069 & 10.3 & 13.7 & 1.407 & 13.1 & 0.8 \\
\hline AIMS1631 & 6 & F-1 & 5.107 & 26.2 & 19.1 & 1.323 & 32.5 & 1.0 \\
\hline AIMS1631 & 7 & $\mathrm{~F}$ & 3.909 & 1.5 & 72.1 & 1.418 & 22.7 & 1.0 \\
\hline AIMS1631 & 7 & F-1 & 4.562 & -1.7 & 64.9 & 1.419 & 24.8 & 1.1 \\
\hline AIMS1631 & 7 & $\mathrm{~F}-2$ & 4.773 & 3.7 & 99.6 & 1.393 & 19.2 & 2.0 \\
\hline AIMS1631 & 8 & F-2 & 4.011 & 9.2 & 25.1 & 1.428 & 20.3 & 0.9 \\
\hline AIMS2078 & 1 & $\mathrm{~F}$ & 3.571 & 197.1 & 2.2 & 1.675 & 2.4 & 1.3 \\
\hline AIMS2078 & 1 & F-1 & 4.591 & 385.3 & 9.6 & 1.692 & 5.7 & 2.3 \\
\hline AIMS2078 & 1 & $\mathrm{~F}-2$ & 5.361 & 1263.0 & 34.9 & 1.585 & 5.6 & 3.4 \\
\hline AIMS2078 & 2 & $\mathrm{~F}$ & 4.116 & 134.2 & 5.4 & 1.663 & 6.1 & 1.8 \\
\hline
\end{tabular}




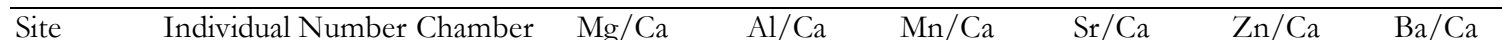

\begin{tabular}{|c|c|c|c|c|c|c|c|c|}
\hline & & & $(\mathrm{mmol} / \mathrm{mol})$ & $\mu \mathrm{mol} / \mathrm{mol})$ & $\mathrm{imol} / \mathrm{mol})$ & $(\mathrm{mmol} / \mathrm{mol})$ & $(\mu \mathrm{mol} / \mathrm{mol})$ & $\overline{(\mu \mathrm{mol} / \mathrm{mol})}$ \\
\hline AIMS2078 & 2 & F-1 & 6.960 & 216.1 & 24.5 & 1.651 & 7.1 & 2.7 \\
\hline AIMS2078 & 2 & $\mathrm{~F}-2$ & 6.655 & 174.3 & 7.8 & 1.642 & 6.0 & 1.4 \\
\hline AIMS2078 & 3 & $\mathrm{~F}$ & 3.798 & 917.0 & 13.0 & 1.571 & 668.0 & 2.0 \\
\hline AIMS2078 & 3 & F-1 & 5.296 & 959.9 & 3.8 & 1.661 & 27.3 & 2.1 \\
\hline AIMS2078 & 3 & $\mathrm{~F}-2$ & 7.007 & 740.4 & 5.5 & 1.612 & 6.0 & 2.6 \\
\hline AIMS2078 & 4 & $\mathrm{~F}$ & 4.655 & 1150.2 & 41.0 & 1.511 & 13.1 & 2.4 \\
\hline AIMS2078 & 4 & F-1 & 6.103 & 599.2 & 32.8 & 1.557 & 9.7 & 2.6 \\
\hline AIMS2078 & 4 & $\mathrm{~F}-2$ & 4.340 & 922.4 & 45.9 & 1.521 & 33.9 & 3.0 \\
\hline AIMS2078 & 5 & F-1 & 6.790 & 1194.8 & 19.0 & 1.466 & 6.7 & 1.4 \\
\hline AIMS2078 & 6 & $\mathrm{~F}$ & 2.333 & 290.0 & 8.1 & 1.517 & 7.4 & 1.1 \\
\hline AIMS2078 & 6 & F-1 & 6.067 & 507.0 & 23.4 & 1.531 & 5.7 & 3.1 \\
\hline AIMS2078 & 6 & $\mathrm{~F}-2$ & 5.821 & 680.2 & 12.0 & 1.504 & 8.4 & 2.0 \\
\hline AIMS2078 & 7 & $\mathrm{~F}-1$ & 6.563 & 1104.4 & 9.5 & 1.660 & 28.9 & 2.2 \\
\hline AIMS2078 & 7 & F-2 & 6.645 & 141.8 & 8.7 & 1.594 & 3.9 & 1.4 \\
\hline AIMS2078 & 8 & $\mathrm{~F}$ & 3.708 & 151.1 & 5.7 & 1.528 & 5.7 & 1.4 \\
\hline AIMS2078 & 8 & F-1 & 5.413 & 340.8 & 17.0 & 1.393 & 19.1 & 2.4 \\
\hline AIMS2078 & 8 & F-2 & 5.469 & 440.6 & 12.0 & 1.505 & 7.8 & 1.5 \\
\hline AIMS2078 & 9 & $\mathrm{~F}$ & 3.604 & 330.2 & 5.9 & 1.403 & 5.1 & 1.0 \\
\hline AIMS2078 & 9 & F-1 & 5.987 & 208.3 & 6.2 & 1.432 & 5.6 & 1.5 \\
\hline AIMS2078 & 9 & F-2 & 5.488 & 93.8 & 5.3 & 1.498 & 1.8 & 1.1 \\
\hline AIMS2078 & 14 & $\mathrm{~F}$ & 4.190 & 57.3 & 7.8 & 1.415 & 5.4 & 1.3 \\
\hline AIMS2078 & 14 & F-1 & 5.452 & 140.7 & 15.6 & 1.469 & 14.0 & 2.8 \\
\hline AIMS2078 & 14 & $\mathrm{~F}-2$ & 4.794 & 140.5 & 0.2 & 1.419 & 13.5 & 1.7 \\
\hline AIMS2078 & 15 & $\mathrm{~F}$ & 4.661 & 455.7 & 9.3 & 1.464 & 38.3 & 1.4 \\
\hline AIMS2078 & 15 & F-2 & 6.601 & 737.6 & 2.7 & 1.578 & 11.8 & 2.7 \\
\hline AIMS2078 & 16 & $\mathrm{~F}$ & 2.642 & 29.6 & 4.0 & 1.332 & 9.2 & 1.1 \\
\hline AIMS2078 & 16 & F-1 & 7.605 & 37.2 & 2.2 & 1.473 & 10.5 & 1.1 \\
\hline AIMS2078 & 16 & F-2 & 7.064 & 150.0 & 4.9 & 1.435 & 7.5 & 1.7 \\
\hline AIMS2078 & 17 & $\mathrm{~F}$ & 3.823 & 64.3 & 5.7 & 1.451 & 7.1 & 1.5 \\
\hline AIMS2078 & 17 & F-1 & 4.167 & 184.9 & 3.7 & 1.380 & 5.4 & 1.4 \\
\hline AIMS2078 & 17 & $\mathrm{~F}-2$ & 4.347 & 699.1 & 9.7 & 1.466 & 5.4 & 1.6 \\
\hline AIMS2078 & & F-3 & 3.799 & 917.5 & 13.4 & 1.568 & 668.2 & 1.3 \\
\hline AIMS2078 & & F-3 & 3.926 & 183.8 & 21.2 & 1.572 & 7.6 & 2.9 \\
\hline AIMS3703 & 1 & $\mathrm{~F}$ & 4.085 & 432.2 & 66.9 & 1.534 & 36.9 & 3.1 \\
\hline AIMS3703 & 1 & F-1 & 4.740 & 526.0 & 65.3 & 1.494 & 19.7 & 2.8 \\
\hline AIMS3703 & 1 & F-2 & 5.302 & 187.3 & 50.2 & 1.507 & 14.6 & 2.4 \\
\hline AIMS3703 & 2 & $\mathrm{~F}$ & 4.240 & 332.8 & 53.2 & 1.464 & 8.6 & 1.7 \\
\hline AIMS3703 & 2 & F-1 & 5.298 & 429.7 & 71.5 & 1.516 & 10.3 & 2.2 \\
\hline AIMS3703 & 3 & $\mathrm{~F}$ & 2.897 & 155.3 & 51.1 & 1.424 & 18.2 & 1.3 \\
\hline AIMS3703 & 3 & F-1 & 4.153 & 587.9 & 42.6 & 1.397 & 12.0 & 1.7 \\
\hline AIMS3703 & 3 & F-2 & 3.821 & 25.8 & 28.7 & 1.413 & 5.8 & 0.9 \\
\hline AIMS3703 & 4 & $\mathrm{~F}$ & 4.758 & 253.9 & 53.7 & 1.415 & 10.2 & 1.3 \\
\hline AIMS3703 & 4 & F-2 & 6.476 & 636.2 & 56.3 & 1.439 & 12.5 & 1.5 \\
\hline AIMS3703 & 5 & $\mathrm{~F}$ & 6.363 & 1789.2 & 79.7 & 1.439 & 21.6 & 2.9 \\
\hline AIMS3703 & 5 & F-2 & 8.741 & 1419.0 & 118.7 & 1.455 & 16.3 & 2.8 \\
\hline AIMS3703 & 6 & $\mathrm{~F}$ & 4.131 & 681.2 & 111.1 & 1.622 & 127.9 & 6.0 \\
\hline AIMS3703 & 6 & F-1 & 5.715 & 851.3 & 87.6 & 1.468 & 25.3 & 3.0 \\
\hline AIMS3703 & 6 & F-2 & 4.946 & 228.4 & 49.4 & 1.493 & 19.3 & 1.8 \\
\hline AIMS3703 & 7 & $\mathrm{~F}$ & 4.322 & 58.2 & 19.0 & 1.544 & 10.7 & 1.0 \\
\hline AIMS3703 & 7 & F-1 & 6.194 & 15.2 & 58.9 & 1.503 & 16.3 & 2.0 \\
\hline AIMS3703 & 7 & $\mathrm{~F}-2$ & 6.969 & 38.7 & 21.9 & 1.583 & 8.9 & 1.5 \\
\hline AIMS3703 & 8 & $\mathrm{~F}$ & 4.484 & 874.5 & 58.1 & 1.460 & 22.7 & 2.7 \\
\hline AIMS3703 & 8 & F-1 & 4.191 & 477.8 & 53.4 & 1.548 & 19.9 & 2.0 \\
\hline AIMS3703 & 8 & F-2 & 3.208 & -2523.9 & 58.1 & 1.504 & -0.6 & 0.7 \\
\hline AIMS3703 & 11 & $\mathrm{~F}$ & 4.719 & 224.4 & 79.0 & 1.460 & 29.0 & 2.5 \\
\hline AIMS3703 & 13 & $\mathrm{~F}$ & 5.899 & 16.2 & 29.0 & 1.626 & 9.0 & 1.5 \\
\hline AIMS3703 & 13 & F-1 & 6.822 & 252.7 & 80.2 & 1.444 & 12.6 & 1.6 \\
\hline AIMS3703 & 13 & $\mathrm{~F}-2$ & 6.221 & 74.6 & 54.7 & 1.444 & 9.3 & 1.4 \\
\hline
\end{tabular}




\begin{tabular}{|c|c|c|c|c|c|c|c|c|}
\hline Site & $\begin{array}{c}\text { Individual } \\
\text { Number }\end{array}$ & Chamber & $\mathrm{Mg} / \mathrm{Ca}$ & $\mathrm{Al} / \mathrm{Ca}$ & $\mathrm{Mn} / \mathrm{Ca}$ & $\mathrm{Sr} / \mathrm{Ca}$ & $\mathrm{Zn} / \mathrm{Ca}$ & $\mathrm{Ba} / \mathrm{Ca}$ \\
\hline & & & $(\mathrm{mmol} / \mathrm{mo}$ & $\mu \mathrm{mol} / \mathrm{mo}$ & $(\mu \mathrm{mol} / \mathrm{mol}$ & $\mathrm{nmol} / \mathrm{mc}$ & $\mathrm{umol} / \mathrm{mc}$ & $\mathrm{imol} / \mathrm{mol})$ \\
\hline AIMS3703 & 14 & $F$ & 7.875 & 479.0 & 71.0 & 1.677 & 84.0 & 3.0 \\
\hline AIMS3703 & 14 & F-1 & 7.319 & 949.1 & 93.3 & 1.497 & 47.5 & 4.4 \\
\hline AIMS3703 & 14 & $\mathrm{~F}-2$ & 7.412 & 517.4 & 46.1 & 1.507 & 24.4 & 2.2 \\
\hline AIMS3703 & 15 & $\mathrm{~F}$ & 4.849 & 108.8 & 30.7 & 1.480 & 12.6 & 1.7 \\
\hline AIMS3703 & 15 & F-1 & 6.323 & 1030.9 & 41.6 & 1.552 & 18.7 & 2.2 \\
\hline AIMS3703 & 16 & $\mathrm{~F}$ & 5.117 & 840.5 & 21.6 & 1.468 & 26.4 & 1.5 \\
\hline AIMS3703 & 16 & F-1 & 5.678 & 1459.1 & 42.5 & 1.428 & 32.4 & 2.5 \\
\hline AIMS3703 & 16 & F-2 & 5.476 & 80.8 & 21.5 & 1.448 & 45.4 & 1.7 \\
\hline AIMS3703 & 17 & $\mathrm{~F}$ & 3.990 & 139.9 & 13.3 & 1.717 & 25.9 & 0.9 \\
\hline AIMS3703 & 17 & F-1 & 5.934 & 240.6 & 51.3 & 1.465 & 65.7 & 2.5 \\
\hline AIMS3703 & 17 & F-2 & 6.560 & 148.9 & 27.8 & 1.545 & 35.6 & 2.3 \\
\hline AIMS3703 & 18 & $\mathrm{~F}$ & 5.940 & -502.2 & 47.2 & 1.560 & 24.9 & -0.8 \\
\hline AIMS3703 & 18 & F-1 & 8.827 & -9.3 & 65.3 & 1.541 & 10.4 & 1.8 \\
\hline AIMS3703 & 18 & F-2 & 6.726 & -19.1 & 39.7 & 1.525 & 6.7 & 1.4 \\
\hline AIMS3703 & 19 & $\mathrm{~F}$ & 5.375 & 1668.2 & 62.3 & 1.579 & 44.2 & 2.2 \\
\hline AIMS3703 & 19 & F-1 & 6.472 & 610.1 & 94.9 & 1.519 & 11.2 & 1.4 \\
\hline AIMS3703 & 19 & F-2 & 5.804 & 2.6 & 39.6 & 1.486 & 6.8 & 1.1 \\
\hline FR1/97/GC12 & 1 & $\mathrm{~F}$ & 2.398 & 121.7 & 36.6 & 1.425 & 6.2 & 1.2 \\
\hline FR1/97/GC12 & 1 & F-1 & 5.738 & 1799.5 & 63.5 & 1.436 & 4.0 & 5.2 \\
\hline FR1/97/GC12 & 1 & F-2 & 5.302 & 1716.8 & 83.6 & 1.411 & 4.3 & 4.3 \\
\hline FR1/97/GC12 & 2 & $\mathrm{~F}$ & 3.811 & 861.6 & 47.1 & 1.575 & 88.5 & 3.2 \\
\hline FR1/97/GC12 & 2 & F-2 & 4.256 & 460.5 & 28.3 & 1.500 & 5.6 & 1.5 \\
\hline FR1/97/GC12 & 3 & $\mathrm{~F}$ & 3.958 & 230.5 & 15.4 & 1.571 & 8.3 & 2.4 \\
\hline FR1/97/GC12 & 3 & F-1 & 6.348 & 653.5 & 11.6 & 1.545 & 4.8 & 2.0 \\
\hline FR1/97/GC12 & 3 & F-2 & 5.151 & 74.0 & 36.5 & 1.482 & 4.2 & 1.6 \\
\hline FR1/97/GC12 & 4 & $\mathrm{~F}$ & 4.318 & 566.1 & 17.0 & 1.529 & 5.1 & 1.3 \\
\hline FR1/97/GC12 & 5 & $\mathrm{~F}$ & 4.216 & 33.2 & 21.5 & 1.583 & 1.7 & 3.0 \\
\hline FR1/97/GC12 & 5 & F-1 & 5.969 & 416.8 & 16.4 & 1.554 & 2.7 & 2.8 \\
\hline FR1/97/GC12 & 5 & F-2 & 5.860 & 373.3 & 50.8 & 1.379 & 2.7 & 1.5 \\
\hline FR1/97/GC12 & 6 & $\mathrm{~F}$ & 2.957 & 1192.7 & 41.1 & 1.533 & 3.4 & 2.2 \\
\hline FR1/97/GC12 & 6 & F-2 & 6.455 & 1562.7 & 41.1 & 1.489 & 3.4 & 1.8 \\
\hline FR1/97/GC12 & 7 & $\mathrm{~F}$ & 4.146 & 479.3 & 26.8 & 1.608 & 3.8 & 5.8 \\
\hline FR1/97/GC12 & 7 & F-1 & 4.954 & 696.1 & 21.5 & 1.452 & 2.0 & 8.1 \\
\hline FR1/97/GC12 & 7 & $\mathrm{~F}-2$ & 4.439 & 799.7 & 37.4 & 1.375 & 9.8 & 1.7 \\
\hline FR1/97/GC12 & 9 & F-1 & 5.086 & 1269.2 & 31.2 & 1.464 & 5.8 & 3.7 \\
\hline FR1/97/GC12 & 10 & $\mathrm{~F}$ & 4.129 & 1023.8 & 54.5 & 1.448 & 133.2 & 2.0 \\
\hline FR1/97/GC12 & 10 & F-2 & 3.863 & 1078.4 & 46.0 & 1.487 & 5.5 & 2.5 \\
\hline FR1/97/GC12 & 11 & $\mathrm{~F}$ & 2.625 & 69.8 & 16.2 & 1.445 & 2.6 & 1.4 \\
\hline FR1/97/GC12 & 11 & F-2 & 4.703 & 1744.8 & 33.7 & 1.359 & 8.0 & 1.7 \\
\hline FR1/97/GC12 & 12 & $\mathrm{~F}$ & 5.684 & 1660.7 & 27.4 & 1.625 & 3.3 & 1.5 \\
\hline FR1/97/GC12 & 12 & F-2 & 5.353 & 831.1 & 48.7 & 1.435 & 4.9 & 1.9 \\
\hline FR1/97/GC12 & 13 & $\mathrm{~F}$ & 3.921 & -40.6 & 52.2 & 1.368 & 3.2 & 1.5 \\
\hline FR1/97/GC12 & 13 & F-1 & 4.788 & -3586.4 & 0.0 & 1.365 & -12.1 & 3.7 \\
\hline FR1/97/GC12 & 13 & F-2 & 5.064 & 288.5 & 33.4 & 1.506 & -0.9 & 3.3 \\
\hline FR1/97/GC12 & 14 & $\mathrm{~F}$ & 4.090 & 63.5 & 23.9 & 1.614 & 2.0 & 1.6 \\
\hline FR1/97/GC12 & 14 & F-1 & 6.477 & -454.6 & 0.0 & 1.625 & -1.4 & 1.6 \\
\hline FR1/97/GC12 & 14 & F-2 & 5.205 & 1912.1 & 19.7 & 1.491 & -8.4 & 1.8 \\
\hline FR1/97/GC12 & 15 & $\mathrm{~F}$ & 6.784 & -20.7 & 46.2 & 1.621 & 2.5 & 1.9 \\
\hline FR1/97/GC12 & 15 & F-1 & 2.314 & -6700.4 & 0.0 & 1.534 & -14.4 & 1.9 \\
\hline FR1/97/GC12 & 15 & F-2 & 3.728 & 685.0 & 44.8 & 1.574 & 2.4 & 2.1 \\
\hline FR1/97/GC12 & 16 & $\mathrm{~F}$ & 2.779 & 462.0 & 26.1 & 1.508 & -1.3 & 2.1 \\
\hline FR1/97/GC12 & 16 & F-1 & 4.673 & 726.0 & 7.7 & 1.463 & 2.7 & 7.5 \\
\hline FR1/97/GC12 & 16 & F-2 & 5.046 & 682.2 & 55.2 & 1.362 & 4.4 & 2.6 \\
\hline ODP1123 & 1 & $\mathrm{~F}$ & 1.241 & 105.0 & 48.3 & 1.490 & 43.8 & 4.2 \\
\hline ODP1123 & 1 & F-1 & 2.314 & 959.4 & 46.8 & 1.357 & 34.6 & 7.6 \\
\hline ODP1123 & 1 & F-2 & 2.235 & 771.6 & 57.3 & 1.388 & 40.2 & 6.5 \\
\hline ODP1123 & 2 & $\mathrm{~F}$ & 1.059 & 294.7 & 26.5 & 1.454 & 41.8 & 3.3 \\
\hline ODP1123 & 2 & F-1 & 2.145 & 259.1 & 100.8 & 1.453 & 44.9 & 4.1 \\
\hline
\end{tabular}




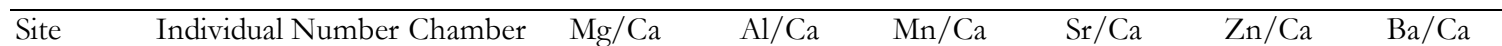

\begin{tabular}{|c|c|c|c|c|c|c|c|c|}
\hline & & & $(\mathrm{mmol} / \mathrm{mol})$ & $(\mu \mathrm{mol} / \mathrm{mol})$ & $(\mu \mathrm{mol} / \mathrm{mol})$ & $(\mathrm{mmol} / \mathrm{mol})$ & $(\mu \mathrm{mol} / \mathrm{mol})$ & $\overline{(\mu \mathrm{mol} / \mathrm{mol})}$ \\
\hline ODP1123 & 2 & F-2 & 1.533 & 132.6 & 31.1 & 1.414 & 47.1 & 3.3 \\
\hline ODP1123 & 3 & $\mathrm{~F}$ & 2.618 & 310.1 & 12.4 & 1.418 & 23.4 & 2.9 \\
\hline ODP1123 & 3 & F-1 & 2.541 & 95.6 & 9.7 & 1.475 & 15.7 & 2.7 \\
\hline ODP1123 & 3 & $\mathrm{~F}-2$ & 2.938 & 236.2 & 9.2 & 1.425 & 17.3 & 2.7 \\
\hline ODP1123 & 4 & $\mathrm{~F}$ & 1.176 & 653.2 & 108.5 & 1.479 & 51.6 & 6.6 \\
\hline ODP1123 & 4 & F-2 & 1.806 & 597.6 & 68.6 & 1.424 & 83.3 & 6.4 \\
\hline ODP1123 & 5 & $\mathrm{~F}$ & 1.435 & 382.3 & 17.5 & 1.493 & 51.8 & 2.9 \\
\hline ODP1123 & 5 & F-1 & 1.525 & 825.1 & 11.9 & 1.468 & 36.5 & 8.9 \\
\hline ODP1123 & 5 & $\mathrm{~F}-2$ & 1.473 & 464.7 & 7.7 & 1.501 & 33.4 & 2.0 \\
\hline ODP1123 & 7 & $\mathrm{~F}$ & 1.448 & 254.9 & 162.9 & 1.484 & 64.0 & 8.3 \\
\hline ODP1123 & 7 & $\mathrm{~F}-2$ & 1.528 & 322.7 & 126.1 & 1.533 & 71.5 & 6.9 \\
\hline ODP1123 & 8 & $\mathrm{~F}$ & 1.612 & 69.2 & 18.2 & 1.497 & 9.0 & 4.3 \\
\hline ODP1123 & 9 & $\mathrm{~F}$ & 1.350 & 745.7 & 41.9 & 1.398 & 54.9 & 7.8 \\
\hline ODP1123 & 9 & F-1 & 1.417 & 180.2 & 17.9 & 1.370 & 33.3 & 4.5 \\
\hline ODP1123 & 9 & $\mathrm{~F}-2$ & 1.442 & 274.9 & 14.7 & 1.384 & 26.1 & 3.7 \\
\hline ODP1123 & 10 & $\mathrm{~F}$ & 1.463 & 299.6 & 47.3 & 1.433 & 65.5 & 8.2 \\
\hline ODP1123 & 10 & F-1 & 1.556 & 374.7 & 27.0 & 1.453 & 44.1 & 7.3 \\
\hline ODP1123 & 11 & $\mathrm{~F}$ & 1.300 & 154.9 & 43.0 & 1.533 & 46.2 & 5.0 \\
\hline ODP1123 & 11 & F-1 & 2.032 & 468.9 & 69.5 & 1.346 & 105.3 & 7.2 \\
\hline ODP1123 & 11 & $\mathrm{~F}-2$ & 1.413 & 272.4 & 45.6 & 1.383 & 92.2 & 6.8 \\
\hline ODP1123 & 12 & $\mathrm{~F}$ & 1.239 & 1271.0 & 55.1 & 1.528 & 37.2 & 9.3 \\
\hline ODP1123 & 12 & F-1 & 1.648 & 729.4 & 38.1 & 1.499 & 31.9 & 7.6 \\
\hline ODP1123 & 13 & $\mathrm{~F}$ & 1.699 & 89.8 & 59.8 & 1.350 & 57.0 & 6.3 \\
\hline ODP1123 & 13 & F-1 & 2.295 & 347.4 & 241.1 & 1.330 & 68.5 & 9.9 \\
\hline ODP1123 & 14 & $\mathrm{~F}$ & 1.556 & 120.4 & 14.0 & 1.471 & 29.6 & 2.6 \\
\hline ODP1123 & 14 & F-1 & 2.061 & 859.1 & 37.6 & 1.437 & 34.9 & 4.3 \\
\hline ODP1123 & 14 & $\mathrm{~F}-2$ & 2.113 & 238.3 & 17.5 & 1.419 & 31.8 & 2.9 \\
\hline ODP1123 & 15 & $\mathrm{~F}$ & 1.201 & 6.2 & 5.0 & 1.504 & 14.1 & 1.3 \\
\hline ODP1123 & 15 & F-1 & 1.549 & 23.4 & 8.9 & 1.423 & 19.0 & 1.3 \\
\hline ODP1123 & 15 & $\mathrm{~F}-2$ & 1.645 & 11.9 & 11.5 & 1.347 & 24.1 & 1.8 \\
\hline ODP1123 & 17 & $\mathrm{~F}-1$ & 1.512 & 337.3 & 50.1 & 1.440 & 130.5 & 8.4 \\
\hline ODP1123 & 17 & F-2 & 1.734 & 335.7 & 111.4 & 1.422 & 90.6 & 7.6 \\
\hline ODP1123 & 18 & $\mathrm{~F}$ & 2.135 & 39.3 & 10.2 & 1.502 & 29.2 & 2.4 \\
\hline ODP1123 & 18 & F-1 & 3.032 & 294.9 & 29.0 & 1.495 & 33.9 & 3.3 \\
\hline ODP1123 & 18 & $\mathrm{~F}-2$ & 2.850 & 182.8 & 21.6 & 1.507 & 36.9 & 3.9 \\
\hline ODP1123 & 19 & $\mathrm{~F}$ & 1.511 & 456.6 & 140.6 & 1.372 & 93.9 & 9.9 \\
\hline P71 & 1 & F & 2.056 & 62.1 & 27.4 & 1.347 & 23.5 & 2.0 \\
\hline P71 & 1 & F-1 & 2.798 & 19.9 & 14.6 & 1.482 & 16.2 & 0.9 \\
\hline P71 & 1 & F-2 & 2.446 & 40.5 & 24.1 & 1.405 & 19.3 & 1.8 \\
\hline P71 & 2 & $\mathrm{~F}$ & 2.372 & 45.2 & 34.9 & 1.446 & 55.2 & 1.4 \\
\hline P71 & 2 & $\mathrm{~F}$ & 2.256 & 43.6 & 44.6 & 1.449 & 45.0 & 1.4 \\
\hline P71 & 2 & F-1 & 2.777 & 76.1 & 33.7 & 1.345 & 64.4 & 1.5 \\
\hline P71 & 2 rep & F-1 & 3.185 & 42.5 & 35.8 & 1.391 & 90.6 & 1.7 \\
\hline P71 & 2 & $\mathrm{~F}-2$ & 2.716 & 27.6 & 31.4 & 1.374 & 48.3 & 1.5 \\
\hline P71 & 2 rep & F-2 & 2.658 & 1.2 & 28.2 & 1.380 & 44.5 & 2.4 \\
\hline P71 & 3 & $\mathrm{~F}$ & 2.283 & -2.2 & 5.7 & 1.533 & 16.7 & 1.1 \\
\hline P71 & 3 rep & $\mathbf{F}$ & 2.901 & 73.7 & 17.9 & 1.572 & 54.9 & 1.4 \\
\hline P71 & 3 & F-1 & 4.040 & 65.9 & 21.3 & 1.598 & 43.5 & 1.3 \\
\hline P71 & 3 rep & F-1 & 3.757 & 23.1 & 16.5 & 1.553 & 35.3 & 11.1 \\
\hline P71 & 3 & F-2 & 4.165 & 21.0 & 25.4 & 1.513 & 47.2 & 8.5 \\
\hline P71 & 3 rep & F-2 & 4.127 & 38.0 & 40.3 & 1.467 & 37.2 & 3.9 \\
\hline P71 & 4 & $\mathrm{~F}$ & 2.356 & 123.1 & 30.0 & 1.375 & 40.2 & 3.4 \\
\hline P71 & 4 rep & F & 2.394 & 170.9 & 82.6 & 1.384 & 27.2 & 5.1 \\
\hline P71 & 4 & F-1 & 2.764 & 674.2 & 26.0 & 1.438 & 20.9 & 5.5 \\
\hline P71 & 4 rep & F-1 & 2.830 & 58.5 & 29.7 & 1.413 & 20.4 & 5.8 \\
\hline P71 & 4 & F-2 & 2.887 & 300.7 & 32.9 & 1.385 & 34.1 & 1.9 \\
\hline P71 & 4 rep & F-2 & 2.539 & 52.1 & 29.7 & 1.366 & 33.1 & -1.5 \\
\hline P71 & 5 & $\mathrm{~F}$ & 2.551 & 65.8 & 9.2 & 1.981 & 82.7 & 1.4 \\
\hline
\end{tabular}




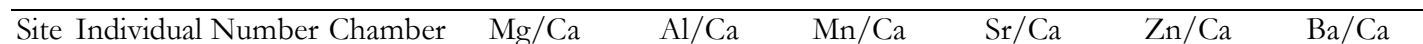

\begin{tabular}{|c|c|c|c|c|c|c|c|c|}
\hline & & & $(\mathrm{mmol} / \mathrm{mol})$ & $(\mu \mathrm{mol} / \mathrm{mol})$ & $(\mu \mathrm{mol} / \mathrm{mol})$ & $(\mathrm{mmol} / \mathrm{mol})$ & $(\mu \mathrm{mol} / \mathrm{mol})$ & $(\mu \mathrm{mol} / \mathrm{mol})$ \\
\hline$\overline{\text { P71 }}$ & 5 rep & $\mathbf{F}$ & 2.352 & 196.7 & 68.4 & 1.877 & 70.8 & 1.6 \\
\hline P71 & 5 & F-1 & 3.404 & 30.6 & 14.7 & 1.805 & 47.8 & 1.6 \\
\hline P71 & 5 rep & F-1 & 3.129 & 74.6 & 13.4 & 1.797 & 40.3 & 2.4 \\
\hline P71 & 5 & $\mathrm{~F}-2$ & 3.994 & 125.9 & 42.3 & 1.719 & 56.9 & 2.7 \\
\hline P71 & 6 & F-1 & 3.121 & 19.3 & 55.9 & 1.394 & 31.3 & 1.6 \\
\hline P71 & 6 & $\mathrm{~F}-2$ & 2.405 & 42.6 & 20.2 & 1.367 & 25.6 & 4.0 \\
\hline P71 & 6 rep & F-2 & 3.139 & 911.6 & 71.2 & 1.389 & 26.2 & 1.6 \\
\hline P71 & 7 & $\mathrm{~F}$ & 2.988 & 72.1 & 14.9 & 1.393 & 33.8 & 1.5 \\
\hline P71 & 7 rep & $\mathbf{F}$ & 3.137 & 1469.9 & 41.1 & 1.405 & 44.5 & 1.6 \\
\hline P71 & 7 & F-1 & 2.442 & 70.2 & 8.0 & 1.451 & 16.2 & 1.9 \\
\hline P71 & 7 rep & F-1 & 3.021 & 672.0 & 34.5 & 1.391 & 21.0 & 6.9 \\
\hline P71 & 7 & F-2 & 2.016 & 13.2 & 4.1 & 1.479 & 7.4 & 5.5 \\
\hline P71 & 7 rep & F-2 & 3.414 & 241.4 & 50.4 & 1.359 & 18.8 & 4.2 \\
\hline P71 & 8 & $\mathrm{~F}$ & 3.291 & 37.5 & 52.9 & 1.488 & 33.9 & 5.4 \\
\hline P71 & 8 rep & $\mathbf{F}$ & 1.388 & 98.3 & 26.0 & 1.440 & 15.6 & 1.4 \\
\hline P71 & 8 & F-1 & 2.208 & 158.5 & 47.1 & 1.405 & 12.6 & 2.3 \\
\hline P71 & 8 & F-2 & 2.377 & 10.5 & 34.0 & 1.417 & 21.5 & 1.4 \\
\hline P71 & 8 rep & F-2 & 3.258 & 46.4 & 65.4 & 1.336 & 12.4 & 15.3 \\
\hline P71 & 9 & $\mathrm{~F}$ & 1.530 & 1297.4 & 29.9 & 1.418 & 19.3 & 1.0 \\
\hline P71 & 9 rep & F & 2.320 & 112.6 & 46.3 & 1.443 & 25.3 & 0.8 \\
\hline P71 & 9 & F-1 & 2.596 & 71.3 & 61.4 & 1.338 & 31.8 & 1.0 \\
\hline P71 & 9 rep & F-1 & 2.436 & 24.5 & 15.6 & 1.419 & 18.2 & 2.0 \\
\hline P71 & 9 & F-2 & 2.511 & 61.6 & 20.2 & 1.423 & 30.7 & 9.7 \\
\hline P71 & 9 rep & F-2 & 2.924 & 89.3 & 18.5 & 1.623 & 10.7 & 2.7 \\
\hline P71 & 10 & $\mathrm{~F}$ & 2.131 & 890.9 & 15.1 & 1.523 & 23.4 & 1.4 \\
\hline P71 & 10 rep & $\mathbf{F}$ & 2.078 & 443.9 & 16.4 & 1.565 & 22.5 & 3.0 \\
\hline P71 & 10 rep & F & 2.411 & 116.5 & 70.5 & 1.360 & 42.1 & 1.2 \\
\hline P71 & 10 & F-1 & 3.327 & 22.9 & 15.2 & 1.493 & 17.9 & 3.9 \\
\hline P71 & 10 rep & F-1 & 3.390 & 29.8 & 14.0 & 1.514 & 14.1 & 3.2 \\
\hline P71 & 10 rep & F-1 & 2.535 & 202.5 & 62.7 & 1.382 & 32.2 & 3.5 \\
\hline P71 & 10 & F-2 & 3.443 & 46.1 & 16.6 & 1.498 & 16.9 & 1.5 \\
\hline P71 & 11 & $\mathrm{~F}$ & 2.527 & 308.3 & 15.2 & 1.442 & 17.4 & 2.4 \\
\hline P71 & 11 & F-1 & 3.512 & 724.8 & 55.7 & 1.480 & 21.0 & 2.9 \\
\hline P71 & 11 & $\mathrm{~F}-2$ & 3.911 & 422.4 & 166.1 & 1.498 & 24.1 & 5.0 \\
\hline P71 & 12 & $\mathrm{~F}$ & 1.241 & 43.5 & 8.3 & 1.602 & 3.0 & 0.5 \\
\hline P71 & 12 & F-1 & 1.832 & 158.1 & 34.4 & 1.437 & 7.2 & 0.6 \\
\hline P71 & 13 & $\mathrm{~F}$ & 2.803 & 41.3 & 25.4 & 1.547 & 27.1 & 1.3 \\
\hline P71 & 13 rep & F & 2.577 & 24.9 & 11.5 & 1.421 & 16.6 & 1.0 \\
\hline P71 & 13 & F-1 & 4.212 & 60.1 & 45.1 & 1.450 & 37.7 & 1.7 \\
\hline P71 & 13 rep & F-1 & 3.131 & 57.4 & 24.5 & 1.392 & 15.6 & 1.2 \\
\hline P71 & 13 & F-2 & 3.176 & 28.1 & 23.5 & 1.465 & 15.0 & 1.3 \\
\hline P71 & 13 rep & F-2 & 4.371 & 106.4 & 53.8 & 1.424 & 34.7 & 1.5 \\
\hline P71 & 14 & $\mathrm{~F}$ & 2.384 & 17.5 & 56.4 & 1.472 & 22.8 & 3.8 \\
\hline P71 & 14 rep & $\mathbf{F}$ & 2.757 & 23.2 & 38.9 & 1.448 & 25.3 & 18.1 \\
\hline P71 & 14 & F-1 & 3.123 & 219.0 & 79.0 & 1.419 & 37.6 & 0.9 \\
\hline P71 & 14 rep & F-1 & 2.915 & 44.1 & 61.1 & 1.535 & 30.9 & -3.3 \\
\hline P71 & $14^{1}$ & $\mathrm{~F}-2$ & 3.818 & 25.9 & 49.9 & 1.429 & 24.6 & 1.5 \\
\hline P71 & 14 rep & F-2 & 4.090 & 44.2 & 55.6 & 1.490 & 30.8 & 5.3 \\
\hline P71 & $15^{1}$ & $\mathrm{~F}$ & 2.813 & 119.2 & 43.7 & 1.355 & 48.5 & 4.6 \\
\hline P71 & 15 & F-1 & 2.706 & 377.4 & 91.3 & 1.408 & 55.1 & 4.6 \\
\hline P71 & 16 & $\mathrm{~F}$ & 2.154 & 87.8 & 43.5 & 1.399 & 37.9 & 3.4 \\
\hline P71 & 16 & F-1 & 2.193 & 114.8 & 15.4 & 1.514 & 19.4 & 1.5 \\
\hline P71 & 16 & F-2 & 2.107 & 922.9 & 16.0 & 1.389 & 14.3 & 1.7 \\
\hline P81 & 1 & $\mathrm{~F}$ & 1.550 & 136.9 & 116.2 & 1.491 & 68.9 & 5.1 \\
\hline P81 & 1 & F-1 & 2.903 & 135.9 & 97.9 & 1.470 & 37.4 & 6.5 \\
\hline P81 & 1 & F-2 & 2.540 & 48.2 & 113.7 & 1.401 & 46.3 & 6.5 \\
\hline P81 & 2 & $\mathrm{~F}$ & 2.342 & 230.6 & 30.0 & 1.462 & 62.0 & 3.6 \\
\hline P81 & 2 & F-1 & 2.644 & 57.5 & 36.4 & 1.386 & 52.0 & 4.0 \\
\hline
\end{tabular}


\begin{tabular}{lllllll}
\hline Site Individual Number Chamber & $\mathrm{Mg} / \mathrm{Ca}$ & $\mathrm{Al} / \mathrm{Ca}$ & $\mathrm{Mn} / \mathrm{Ca}$ & $\mathrm{Sr} / \mathrm{Ca}$ & $\mathrm{Zn} / \mathrm{Ca}$ & $\mathrm{Ba} / \mathrm{Ca}$
\end{tabular}

\begin{tabular}{|c|c|c|c|c|c|c|c|c|}
\hline & & & $(\mathrm{mmol} / \mathrm{mol})$ & $(\mu \mathrm{mol} / \mathrm{mol})$ & $(\mu \mathrm{mol} / \mathrm{mol})$ & $(\mathrm{mmol} / \mathrm{mol})$ & $(\mu \mathrm{mol} / \mathrm{mol})$ & $(\mu \mathrm{mol} / \mathrm{mol})$ \\
\hline$\overline{\text { P81 }}$ & 2 & F-2 & 2.985 & 129.5 & 53.1 & 1.415 & 45.1 & 5.6 \\
\hline P81 & 3 & $\mathrm{~F}$ & 4.535 & 311.8 & 75.2 & 1.425 & 137.2 & 5.3 \\
\hline P81 & 3 & F-1 & 4.196 & 635.9 & 240.7 & 1.416 & 116.3 & 10.1 \\
\hline P81 & 3 & F-2 & 4.774 & 765.4 & 222.7 & 1.347 & 118.5 & 12.5 \\
\hline P81 & 5 & $\mathrm{~F}$ & 1.994 & 379.7 & 118.6 & 1.332 & 64.2 & 8.0 \\
\hline P81 & 5 & F-1 & 2.485 & 623.0 & 144.7 & 1.364 & 91.4 & 12.2 \\
\hline P81 & 5 & $\mathrm{~F}-2$ & 2.214 & 230.5 & 159.2 & 1.346 & 130.9 & 10.8 \\
\hline P81 & 6 & $\mathrm{~F}$ & 2.238 & 73.4 & 64.4 & 1.421 & 36.7 & 3.1 \\
\hline P81 & 6 & F-1 & 3.543 & 68.6 & 94.0 & 1.320 & 19.7 & 4.3 \\
\hline P81 & 6 & F-2 & 2.956 & 36.0 & 90.5 & 1.361 & 36.5 & 4.0 \\
\hline P81 & 7 & $\mathrm{~F}$ & 3.928 & 103.4 & 43.1 & 1.439 & 39.4 & 4.1 \\
\hline P81 & 7 & F-1 & 4.621 & 48.0 & 103.4 & 1.355 & 34.5 & 4.6 \\
\hline P81 & 7 & F-2 & 4.282 & 52.4 & 52.5 & 1.366 & 40.4 & 5.2 \\
\hline P81 & 8 & $\mathrm{~F}$ & 1.796 & 43.9 & 26.3 & 1.437 & 11.2 & 1.9 \\
\hline P81 & 8 & F-1 & 2.439 & 37.0 & 34.0 & 1.365 & 11.7 & 2.8 \\
\hline P81 & 9 & F-1 & 3.533 & 258.3 & 240.2 & 1.301 & 37.1 & 1.0 \\
\hline P81 & 10 & $\mathrm{~F}$ & 2.781 & 34.1 & 45.0 & 1.382 & 29.4 & 2.8 \\
\hline P81 & 10 & F-1 & 3.107 & 43.7 & 168.0 & 1.423 & 36.5 & 4.7 \\
\hline P81 & 10 & F-2 & 3.775 & 90.1 & 128.6 & 1.416 & 272.8 & 5.6 \\
\hline P81 & 11 & $\mathrm{~F}$ & 2.573 & 19.9 & 16.2 & 1.483 & 10.4 & 1.3 \\
\hline P81 & 11 & F-1 & 3.924 & 30.0 & 70.7 & 1.403 & 8.4 & 1.9 \\
\hline P81 & 12 & $\mathrm{~F}$ & 3.406 & 71.5 & 148.3 & 1.364 & 115.8 & 5.7 \\
\hline P81 & 12 & F-1 & 3.834 & 355.3 & 53.9 & 1.378 & 43.1 & 5.1 \\
\hline P81 & 12 & F-2 & 4.179 & 65.0 & 79.9 & 1.402 & 57.3 & 8.1 \\
\hline P81 & 13 & F-1 & 4.313 & 591.6 & 271.6 & 1.332 & 39.5 & 9.8 \\
\hline P81 & 13 & F-2 & 3.146 & 91.9 & 118.0 & 1.377 & 25.2 & 5.3 \\
\hline P81 & 14 & $\mathrm{~F}$ & 1.480 & 368.0 & 209.0 & 1.128 & 242.0 & 9.0 \\
\hline P81 & 14 & F-2 & 2.592 & 242.0 & 60.0 & 1.214 & 93.0 & 3.0 \\
\hline P81 & 14 & F-1 & 3.337 & 234.0 & 44.0 & 1.271 & 66.0 & 3.0 \\
\hline P81 & 15 & $\mathrm{~F}$ & 1.598 & 311.0 & 304.0 & 1.118 & 140.0 & 10.0 \\
\hline P81 & 15 & F-2 & 2.013 & 219.0 & 111.0 & 1.199 & 46.0 & 7.0 \\
\hline P81 & 15 & F-1 & 2.073 & 400.0 & 485.0 & 1.052 & 72.0 & 17.0 \\
\hline P81 & 16 & $\mathrm{~F}$ & 1.385 & 226.0 & 33.0 & 1.154 & 24.0 & 2.0 \\
\hline P81 & 16 & F-2 & 2.194 & 413.0 & 166.0 & 1.091 & 103.0 & 6.0 \\
\hline P81 & 16 & F-1 & 2.493 & 349.0 & 121.0 & 1.146 & 64.0 & 5.0 \\
\hline P81 & 17 & $\mathrm{~F}$ & 1.807 & 384.0 & 22.0 & 1.246 & 79.0 & 3.0 \\
\hline P81 & 17 & F-2 & 2.938 & 321.0 & 34.0 & 1.133 & 124.0 & 4.0 \\
\hline P81 & 17 & F-1 & 2.534 & 378.0 & 24.0 & 1.235 & 69.0 & 3.0 \\
\hline P81 & 18 & $\mathrm{~F}$ & 1.991 & 203.0 & 98.0 & 1.067 & 135.0 & 4.0 \\
\hline P81 & 18 & F-2 & 2.460 & 205.0 & 83.0 & 1.091 & 287.0 & 5.0 \\
\hline P81 & 18 & F-1 & 2.731 & 357.0 & 55.0 & 1.067 & 235.0 & 6.0 \\
\hline P81 & 19 & F-2 & 2.477 & 439.0 & 37.0 & 1.160 & 117.0 & 6.0 \\
\hline P81 & 19 & F-1 & 2.371 & 325.0 & 43.0 & 1.149 & 121.0 & 6.0 \\
\hline P81 & 20 & $\mathrm{~F}$ & 1.330 & 267.0 & 51.0 & 1.159 & 133.0 & 6.0 \\
\hline P81 & 20 & F-2 & 1.877 & 298.0 & 88.0 & 1.122 & 87.0 & 8.0 \\
\hline P81 & 20 & F-1 & 1.404 & 360.0 & 435.0 & 1.111 & 74.0 & 16.0 \\
\hline P81 & 21 & $\mathrm{~F}$ & 1.377 & 184.0 & 65.0 & 1.192 & 74.0 & 3.0 \\
\hline P81 & 21 & F-2 & 2.344 & 231.0 & 98.0 & 1.051 & 325.0 & 6.0 \\
\hline P81 & 21 & F-1 & 2.269 & 328.0 & 61.0 & 1.069 & 173.0 & 7.0 \\
\hline P81 & 22 & $\mathrm{~F}$ & 1.179 & 363.0 & 98.0 & 1.192 & 191.0 & 5.0 \\
\hline P81 & 23 & $\mathrm{~F}$ & 2.455 & 147.0 & 24.0 & 1.256 & 20.0 & 3.0 \\
\hline P81 & 23 & F-2 & 3.578 & 440.0 & 63.0 & 1.125 & 106.0 & 7.0 \\
\hline P81 & 24 & $\mathrm{~F}$ & 2.449 & 300.0 & 36.0 & 1.274 & 207.0 & 3.0 \\
\hline P81 & 24 & F-2 & 2.768 & 291.0 & 72.0 & 1.142 & 224.0 & 4.0 \\
\hline P81 & 25 & $\mathrm{~F}$ & 2.380 & 270.0 & 44.0 & 1.233 & 55.0 & 4.0 \\
\hline P81 & 25 & F-2 & 3.663 & 260.0 & 48.0 & 1.304 & 50.0 & 7.0 \\
\hline P81 & 25 & F-1 & 3.153 & 545.0 & 33.0 & 1.207 & 126.0 & 6.0 \\
\hline P81 & 26 & $\mathrm{~F}$ & 1.122 & 167.0 & 43.0 & 1.013 & 159.0 & 6.0 \\
\hline
\end{tabular}




\begin{tabular}{|c|c|c|c|c|c|c|c|c|}
\hline Site & $\begin{array}{c}\text { Individual } \\
\text { Number }\end{array}$ & Chamber & $\mathrm{Mg} / \mathrm{Ca}$ & $\mathrm{Al} / \mathrm{Ca}$ & $\mathrm{Mn} / \mathrm{Ca}$ & $\mathrm{Sr} / \mathrm{Ca}$ & $\mathrm{Zn} / \mathrm{Ca}$ & $\mathrm{Ba} / \mathrm{Ca}$ \\
\hline & & & $(\mathrm{mmol} / \mathrm{mol})$ & $(\mu \mathrm{mol} / \mathrm{mol}$ & $(\mu \mathrm{mol} / \mathrm{mol})$ & $(\mathrm{mmol} / \mathrm{mo}$ & $(\mu \mathrm{mol} / \mathrm{mo}$ & $(\mu \mathrm{mol} / \mathrm{mol})$ \\
\hline$\overline{\text { P81 }}$ & 26 & F-2 & 1.405 & 222.0 & 52.0 & 0.984 & 161.0 & 5.0 \\
\hline P81 & 26 & F-1 & 1.486 & 308.0 & 142.0 & 1.070 & 221.0 & 7.0 \\
\hline P81 & 27 & F & 1.925 & 294.0 & 54.0 & 1.005 & 18.0 & 3.0 \\
\hline P81 & 27 & F-2 & 2.727 & 420.0 & 60.0 & 1.021 & 27.0 & 5.0 \\
\hline $\begin{array}{l}\text { TAN0706 } \\
\text { C4 }\end{array}$ & 1 & $\mathrm{~F}$ & 3.573 & 11.7 & 6.1 & 1.340 & 13.5 & 0.9 \\
\hline $\begin{array}{l}\text { TAN0706 } \\
\text { C4 }\end{array}$ & 1 & F-1 & 4.746 & 13.2 & 7.7 & 1.331 & 16.9 & 1.1 \\
\hline $\begin{array}{l}\text { TAN0706 } \\
\text { C4 }\end{array}$ & 1 & F-2 & 3.917 & 10.0 & 4.7 & 1.331 & 10.0 & 1.1 \\
\hline $\begin{array}{l}\text { TAN0706 } \\
\text { C4 }\end{array}$ & 2 & $\mathrm{~F}$ & 4.483 & 35.2 & 10.2 & 1.388 & 38.1 & 1.7 \\
\hline $\begin{array}{l}\text { TAN0706 } \\
\text { C4 }\end{array}$ & 2 & F-1 & 7.107 & 14.7 & 7.6 & 1.424 & 50.4 & 0.9 \\
\hline $\begin{array}{l}\text { TAN0706 } \\
\text { C4 }\end{array}$ & 2 & $\mathrm{~F}-2$ & 6.575 & 50.3 & 6.2 & 1.464 & 10.9 & 0.9 \\
\hline $\begin{array}{l}\text { TAN0706 } \\
\text { C4 }\end{array}$ & 3 & $\mathrm{~F}$ & 3.474 & 5.1 & 3.0 & 1.346 & 9.4 & 0.7 \\
\hline $\begin{array}{l}\text { TAN0706 } \\
\text { C4 }\end{array}$ & 3 & F-2 & 5.260 & 34.4 & 16.9 & 1.306 & 25.7 & 1.2 \\
\hline $\begin{array}{l}\text { TAN0706 } \\
\text { C4 }\end{array}$ & 4 & F & 3.255 & 28.2 & 6.2 & 1.378 & 54.4 & 0.9 \\
\hline $\begin{array}{l}\text { TAN0706 } \\
\text { C4 }\end{array}$ & 4 & F-2 & 5.623 & 22.7 & 12.9 & 1.605 & 23.0 & 1.2 \\
\hline $\begin{array}{l}\text { TAN0706 } \\
\text { C4 }\end{array}$ & 5 & $\mathrm{~F}$ & 1.825 & 4.8 & 0.4 & 1.467 & 16.4 & 0.9 \\
\hline $\begin{array}{l}\text { TAN0706 } \\
\text { C4 }\end{array}$ & 5 & F-1 & 3.699 & 7.5 & 4.2 & 1.387 & 18.4 & 0.9 \\
\hline $\begin{array}{l}\text { TAN0706 } \\
\text { C4 }\end{array}$ & 5 & F-2 & 3.766 & 7.3 & 5.7 & 1.361 & 38.0 & 1.1 \\
\hline $\begin{array}{l}\text { TAN0706 } \\
\text { C4 }\end{array}$ & 6 & F & 2.498 & 7.8 & 1.2 & 1.403 & 9.9 & 0.5 \\
\hline $\begin{array}{l}\text { TAN0706 } \\
\text { C4 }\end{array}$ & 6 & F-1 & 4.547 & 6.9 & 4.0 & 1.378 & 21.1 & 0.8 \\
\hline $\begin{array}{l}\text { TAN0706 } \\
\text { C4 }\end{array}$ & 6 & F-2 & 4.054 & 6.1 & 2.3 & 1.409 & 31.2 & 0.8 \\
\hline $\begin{array}{l}\text { TAN0706 } \\
\text { C4 }\end{array}$ & 7 & $\mathrm{~F}$ & 2.266 & 5.3 & 6.1 & 1.349 & 6.7 & 0.8 \\
\hline $\begin{array}{l}\text { TAN0706 } \\
\text { C4 }\end{array}$ & 7 & F-1 & 3.067 & 22.7 & 13.8 & 1.324 & 37.4 & 1.2 \\
\hline $\begin{array}{l}\text { TAN0706 } \\
\text { C4 }\end{array}$ & 8 & $\mathrm{~F}$ & 2.528 & 6.5 & 2.2 & 1.408 & 31.2 & 0.7 \\
\hline $\begin{array}{l}\text { TAN0706 } \\
\text { C4 }\end{array}$ & 8 & F-1 & 3.631 & 5.3 & 6.0 & 1.326 & 49.9 & 0.8 \\
\hline $\begin{array}{l}\text { TAN0706 } \\
\text { C4 }\end{array}$ & 8 & F-2 & 3.245 & 3.9 & 2.4 & 1.359 & 40.9 & 0.7 \\
\hline $\begin{array}{l}\text { TAN0706 } \\
\text { C4 }\end{array}$ & 9 & F & 1.903 & 6.9 & 3.1 & 1.357 & 53.7 & 0.8 \\
\hline $\begin{array}{l}\text { TAN0706 } \\
\text { C4 }\end{array}$ & 9 & F-1 & 3.186 & 17.4 & 8.6 & 1.362 & 70.6 & 1.0 \\
\hline $\begin{array}{l}\text { TAN0706 } \\
\text { C4 }\end{array}$ & 9 & F-2 & 2.735 & 11.9 & 8.2 & 1.407 & 45.5 & 1.0 \\
\hline $\begin{array}{l}\text { TAN0706 } \\
\text { C4 }\end{array}$ & 10 & F & 3.401 & 15.0 & 5.4 & 1.351 & 56.1 & 0.9 \\
\hline $\begin{array}{l}\text { TAN0706 } \\
\text { C4 }\end{array}$ & 10 & F-1 & 4.548 & 12.7 & 8.0 & 1.494 & 20.2 & 1.2 \\
\hline $\begin{array}{l}\text { TAN0706 } \\
\text { C4 }\end{array}$ & 10 & F-2 & 4.200 & 13.1 & 4.8 & 1.406 & 18.7 & 1.0 \\
\hline
\end{tabular}


Appendix A

\begin{tabular}{|c|c|c|c|c|c|c|c|c|}
\hline Site & $\begin{array}{c}\text { Individual } \\
\text { Number }\end{array}$ & Chamber & $\mathrm{Mg} / \mathrm{Ca}$ & $\mathrm{Al} / \mathrm{Ca}$ & $\mathrm{Mn} / \mathrm{Ca}$ & $\mathrm{Sr} / \mathrm{Ca}$ & $\mathrm{Zn} / \mathrm{Ca}$ & $\mathrm{Ba} / \mathrm{Ca}$ \\
\hline & & & $(\mathrm{mmol} / \mathrm{mol})$ & $(\mu \mathrm{mol} / \mathrm{mol})$ & $(\mu \mathrm{mol} / \mathrm{mol})$ & $(\mathrm{mmol} / \mathrm{mol})$ & $(\mu \mathrm{mol} / \mathrm{mol})$ & $(\mu \mathrm{mol} / \mathrm{mol})$ \\
\hline $\begin{array}{l}\text { TAN0706 } \\
\text { C4 }\end{array}$ & 11 & $\mathrm{~F}-2$ & 4.420 & 55.0 & 7.4 & 1.408 & & 1.0 \\
\hline $\begin{array}{l}\text { TAN0706 } \\
\text { C4 }\end{array}$ & 11 & $\mathrm{~F}$ & 3.019 & 20.8 & 8.6 & 1.479 & & 0.8 \\
\hline $\begin{array}{l}\text { TAN0706 } \\
\text { C4 }\end{array}$ & 11 & F-1 & 4.178 & 579.0 & 89.5 & 1.420 & & 2.2 \\
\hline $\begin{array}{l}\text { TAN0706 } \\
\text { C4 }\end{array}$ & 12 & $\mathrm{~F}-2$ & 5.304 & 58.8 & 5.4 & 1.439 & & 1.3 \\
\hline $\begin{array}{l}\text { TAN0706 } \\
\text { C4 }\end{array}$ & 12 & F-1 & 4.542 & 35.5 & 13.5 & 1.417 & & 3.8 \\
\hline $\begin{array}{l}\text { TAN0706 } \\
\text { C4 }\end{array}$ & 12 & $\mathrm{~F}$ & 2.882 & 74.1 & 18.8 & 1.311 & & 0.9 \\
\hline $\begin{array}{l}\text { TAN0706 } \\
\text { C4 }\end{array}$ & 13 & $\mathrm{~F}$ & 2.617 & 15.8 & 4.3 & 1.297 & & 0.8 \\
\hline $\begin{array}{l}\text { TAN0706 } \\
\text { C4 }\end{array}$ & 13 & F-2 & 2.776 & 40.6 & 8.6 & 1.307 & & 1.0 \\
\hline $\begin{array}{l}\text { TAN0706 } \\
\text { C4 }\end{array}$ & 13 & F-1 & 3.244 & 80.6 & 14.3 & 1.335 & & 1.2 \\
\hline $\begin{array}{l}\text { TAN0706 } \\
\text { C4 }\end{array}$ & 14 & $\mathrm{~F}$ & 2.326 & 23.3 & 3.1 & 1.541 & & 0.8 \\
\hline $\begin{array}{l}\text { TAN0706 } \\
\text { C4 }\end{array}$ & 14 & F-2 & 2.410 & 43.2 & 12.0 & 1.461 & & 1.7 \\
\hline $\begin{array}{l}\text { TAN0706 } \\
\text { C4 }\end{array}$ & 14 & F-1 & 2.892 & 129.7 & 16.0 & 1.330 & & 1.0 \\
\hline $\begin{array}{l}\text { TAN0706 } \\
\text { C4 }\end{array}$ & 15 & $\mathrm{~F}$ & 2.996 & 16.6 & 2.0 & 1.404 & & 0.7 \\
\hline $\begin{array}{l}\text { TAN0706 } \\
\text { C4 }\end{array}$ & 15 & F-1 & 5.426 & 65.2 & 7.1 & 1.378 & & 1.1 \\
\hline $\begin{array}{l}\text { TAN0706 } \\
\text { C4 }\end{array}$ & 15 & F-2 & 5.251 & 37.7 & 13.1 & 1.429 & & 1.1 \\
\hline $\begin{array}{l}\text { TAN0706 } \\
\text { C4 }\end{array}$ & 16 & $\mathrm{~F}$ & 2.473 & 9.3 & 1.1 & 1.344 & & 0.5 \\
\hline $\begin{array}{l}\text { TAN0706 } \\
\text { C4 }\end{array}$ & 16 & F-1 & 2.643 & 21.1 & 6.9 & 1.296 & & 0.6 \\
\hline $\begin{array}{l}\text { TAN0706 } \\
\text { C4 }\end{array}$ & 17 & F-1 & 3.717 & 14.3 & 2.7 & 1.347 & & 0.7 \\
\hline $\begin{array}{l}\text { TAN0706 } \\
\text { C4 }\end{array}$ & 17 & $\mathrm{~F}-2$ & 3.965 & 34.1 & 6.4 & 1.303 & & 0.9 \\
\hline $\begin{array}{l}\text { TAN0706 } \\
\text { C4 }\end{array}$ & 17 & $\mathrm{~F}$ & 3.573 & 348.9 & 121.6 & 1.477 & & 12.6 \\
\hline $\begin{array}{l}\text { TAN0706 } \\
\text { C4 }\end{array}$ & 18 & F-2 & 3.531 & 66.5 & 3.5 & 1.412 & & 1.4 \\
\hline $\begin{array}{l}\text { TAN0706 } \\
\text { C4 }\end{array}$ & 18 & F-1 & 4.754 & 6.3 & 8.0 & 1.466 & & 0.7 \\
\hline $\begin{array}{l}\text { TAN0706 } \\
\text { C4 }\end{array}$ & 18 & F & 2.985 & 8.2 & 8.6 & 1.416 & & 0.7 \\
\hline $\begin{array}{l}\text { TAN0706 } \\
\text { C4 }\end{array}$ & 19 & $\mathrm{~F}$ & 1.656 & 38.1 & 3.2 & 1.349 & & 0.9 \\
\hline $\begin{array}{l}\text { TAN0706 } \\
\text { C4 }\end{array}$ & 19 & $\mathrm{~F}-2$ & 2.450 & 31.5 & 6.6 & 1.333 & & 1.0 \\
\hline $\begin{array}{l}\text { TAN0706 } \\
\text { C4 }\end{array}$ & 19 & F-1 & 2.200 & 29.9 & 19.4 & 1.306 & & 1.0 \\
\hline $\begin{array}{l}\text { TAN0706 } \\
\text { C4 }\end{array}$ & 20 & $\mathrm{~F}$ & 2.396 & 8.1 & 1.8 & 1.463 & & 0.5 \\
\hline $\begin{array}{l}\text { TAN0706 } \\
\text { C4 }\end{array}$ & 20 & F-2 & 3.166 & 329.4 & 8.8 & 1.473 & & 0.9 \\
\hline $\begin{array}{l}\text { TAN0706 } \\
\text { C4 }\end{array}$ & 20 & F-1 & 3.913 & 355.5 & 12.3 & 1.390 & & 3.8 \\
\hline
\end{tabular}


Appendix A

\begin{tabular}{|c|c|c|c|c|c|c|c|c|}
\hline Site & $\begin{array}{c}\text { Individual } \\
\text { Number }\end{array}$ & Chamber & $\mathrm{Mg} / \mathrm{Ca}$ & $\mathrm{Al} / \mathrm{Ca}$ & $\mathrm{Mn} / \mathrm{Ca}$ & $\mathrm{Sr} / \mathrm{Ca}$ & $\mathrm{Zn} / \mathrm{Ca}$ & $\mathrm{Ba} / \mathrm{Ca}$ \\
\hline & & & $(\mathrm{mmol} / \mathrm{mol})$ & $(\mu \mathrm{mol} / \mathrm{mol})$ & $(\mu \mathrm{mol} / \mathrm{mol})$ & $(\mathrm{mmol} / \mathrm{mol})$ & $(\mu \mathrm{mol} / \mathrm{mol})$ & $(\mu \mathrm{mol} / \mathrm{mol})$ \\
\hline $\begin{array}{l}\text { TAN0706 } \\
\text { C4 }\end{array}$ & 21 & $\mathrm{~F}$ & 3.869 & 13.9 & 2.2 & 1.441 & & 0.6 \\
\hline $\begin{array}{l}\text { TAN0706 } \\
\text { C4 }\end{array}$ & 21 & F-1 & 6.335 & 16.9 & 3.9 & 1.439 & & 1.3 \\
\hline $\begin{array}{l}\text { TAN0706 } \\
\text { C4 }\end{array}$ & 21 & F-2 & 6.588 & 38.5 & 7.0 & 1.459 & & 0.9 \\
\hline $\begin{array}{l}\text { TAN0706 } \\
\text { C4 }\end{array}$ & 22 & $\mathrm{~F}$ & 1.666 & 22.4 & 2.8 & 1.330 & & 0.7 \\
\hline $\begin{array}{l}\text { TAN0706 } \\
\text { C4 }\end{array}$ & 22 & F-2 & 2.537 & 27.2 & 3.3 & 1.329 & & 3.2 \\
\hline $\begin{array}{l}\text { TAN0706 } \\
\text { C4 }\end{array}$ & 22 & F-1 & 2.441 & 36.6 & 5.8 & 1.355 & & 0.8 \\
\hline $\begin{array}{l}\text { TAN0706 } \\
\text { C4 }\end{array}$ & 23 & $\mathrm{~F}$ & 1.774 & 6.8 & 1.6 & 1.335 & & 0.5 \\
\hline $\begin{array}{l}\text { TAN0706 } \\
\text { C4 }\end{array}$ & 23 & F-1 & 2.462 & 45.8 & 10.2 & 1.261 & & 0.9 \\
\hline $\begin{array}{l}\text { TAN0706 } \\
\text { C4 }\end{array}$ & 23 & F-2 & 2.391 & 87.0 & 23.2 & 1.289 & & 0.8 \\
\hline $\begin{array}{l}\text { TAN0706 } \\
\text { C4 }\end{array}$ & 24 & F-1 & 2.876 & 36.8 & 6.5 & 1.429 & & 1.6 \\
\hline $\begin{array}{l}\text { TAN0706 } \\
\text { C4 }\end{array}$ & 24 & F-2 & 2.606 & 23.9 & 18.0 & 1.516 & & 1.2 \\
\hline $\begin{array}{l}\text { TAN0706 } \\
\text { C4 }\end{array}$ & 24 & $\mathrm{~F}$ & 4.263 & 69.9 & 38.0 & 1.386 & & 1.2 \\
\hline $\begin{array}{l}\text { TAN0706 } \\
\text { C4 }\end{array}$ & 25 & F-2 & 2.612 & 24.4 & 2.5 & 1.333 & & 1.0 \\
\hline $\begin{array}{l}\text { TAN0706 } \\
\text { C4 }\end{array}$ & 25 & $\mathrm{~F}$ & 1.860 & 18.3 & 3.0 & 1.339 & & 0.5 \\
\hline $\begin{array}{l}\text { TAN0706 } \\
\text { C4 }\end{array}$ & 25 & F-1 & 2.271 & 20.5 & 4.1 & 1.314 & & 2.0 \\
\hline $\begin{array}{l}\text { TAN0706 } \\
\text { C4 }\end{array}$ & 26 & F-2 & 4.908 & 34.8 & 3.0 & 1.274 & & 1.3 \\
\hline $\begin{array}{l}\text { TAN0706 } \\
\text { C4 }\end{array}$ & 26 & $\mathrm{~F}$ & 3.235 & 13.0 & 4.3 & 1.399 & & 0.6 \\
\hline $\begin{array}{l}\text { TAN0706 } \\
\text { C4 }\end{array}$ & 26 & F-1 & 3.931 & 18.9 & 5.7 & 1.299 & & 1.1 \\
\hline $\begin{array}{l}\text { TAN0706 } \\
\text { C4 }\end{array}$ & 27 & $\mathrm{~F}-2$ & 3.468 & 37.4 & 18.0 & 1.396 & & 0.9 \\
\hline $\begin{array}{l}\text { TAN0706 } \\
\text { C4 }\end{array}$ & 27 & $\mathrm{~F}$ & 3.774 & 38.8 & 32.7 & 1.429 & & 1.0 \\
\hline $\begin{array}{l}\text { TAN0706 } \\
\text { C4 }\end{array}$ & 27 & F-1 & 4.213 & 71.6 & 38.4 & 1.384 & & 1.2 \\
\hline $\begin{array}{l}\text { TAN0706 } \\
\text { C4 }\end{array}$ & 28 & F-1 & 2.650 & 21.5 & 5.2 & 1.305 & & 0.8 \\
\hline $\begin{array}{l}\text { TAN0706 } \\
\text { C4 }\end{array}$ & 28 & F-2 & 3.033 & 30.1 & 9.4 & 1.244 & & 0.9 \\
\hline $\begin{array}{l}\text { TAN0706 } \\
\text { C4 }\end{array}$ & 28 & $\mathrm{~F}$ & 2.181 & 159.0 & 27.4 & 1.368 & & 1.4 \\
\hline $\begin{array}{l}\text { TAN0706 } \\
\text { C4 }\end{array}$ & 29 & $\mathrm{~F}$ & 2.267 & 15.5 & 12.8 & 1.378 & & 0.8 \\
\hline $\begin{array}{l}\text { TAN0706 } \\
\text { C4 }\end{array}$ & 29 & F-2 & 3.077 & 32.9 & 42.3 & 1.347 & & 1.0 \\
\hline $\begin{array}{l}\text { TAN0706 } \\
\text { C4 }\end{array}$ & 29 & F-1 & 3.604 & 31.4 & 65.6 & 1.313 & & 1.2 \\
\hline $\begin{array}{l}\text { TAN0706 } \\
\text { C4 }\end{array}$ & 30 & $\mathrm{~F}$ & 2.132 & 10.1 & 4.6 & 1.324 & & 0.7 \\
\hline $\begin{array}{l}\text { TAN0706 } \\
\text { C4 }\end{array}$ & 30 & F-2 & 2.600 & 71.4 & 59.5 & 1.300 & & 0.9 \\
\hline
\end{tabular}




\begin{tabular}{|c|c|c|c|c|c|c|c|c|}
\hline Site & $\begin{array}{c}\text { Individual } \\
\text { Number }\end{array}$ & Chamber & $\mathrm{Mg} / \mathrm{Ca}$ & $\mathrm{Al} / \mathrm{Ca}$ & $\mathrm{Mn} / \mathrm{Ca}$ & $\mathrm{Sr} / \mathrm{Ca}$ & $\mathrm{Zn} / \mathrm{Ca}$ & $\mathrm{Ba} / \mathrm{Ca}$ \\
\hline & & & $(\mathrm{mmol} / \mathrm{mol})$ & $(\mu \mathrm{mol} / \mathrm{mol})$ & $(\mu \mathrm{mol} / \mathrm{mol})$ & $(\mathrm{mmol} / \mathrm{mol})$ & $(\mu \mathrm{mol} / \mathrm{mol})$ & $(\mu \mathrm{mol} / \mathrm{mol})$ \\
\hline $\mathrm{U} 2315$ & 1 & F-1 & 4.095 & 7.1 & 9.3 & 1.577 & 134.8 & 1.4 \\
\hline U2315 & 1 & F-2 & 3.289 & 20.5 & 9.1 & 1.670 & 153.3 & 1.6 \\
\hline $\mathrm{U} 2315$ & 2 & F & 1.361 & -2.3 & 6.8 & 1.650 & 291.4 & 0.8 \\
\hline $\mathrm{U} 2315$ & 2 & F-1 & 4.064 & 1.8 & 4.6 & 1.564 & 92.4 & 0.8 \\
\hline $\mathrm{U} 2315$ & 2 & F-2 & 2.424 & -9.7 & 1.5 & 1.384 & 44.4 & 0.7 \\
\hline $\mathrm{U} 2315$ & 3 & $\mathrm{~F}$ & 3.102 & -0.9 & 2.2 & 1.454 & 32.3 & 0.6 \\
\hline $\mathrm{U} 2315$ & 3 & F-1 & 6.082 & 7.6 & 4.2 & 1.521 & 43.5 & 1.0 \\
\hline $\mathrm{U} 2315$ & 3 & F-2 & 5.909 & 1.6 & 0.9 & 1.551 & 35.5 & 0.9 \\
\hline $\mathrm{U} 2315$ & 4 & $\mathrm{~F}$ & 2.497 & -6.8 & 3.8 & 1.505 & 268.9 & 0.7 \\
\hline U2315 & 4.1 & $\mathrm{~F}$ & 3.207 & 6.2 & 6.8 & 1.501 & 134.8 & 1.0 \\
\hline U2315 & 4 & F-1 & 4.680 & 5.5 & 7.4 & 1.529 & 77.1 & 1.2 \\
\hline $\mathrm{U} 2315$ & 4 & F-2 & 3.261 & 5.6 & 9.6 & 1.520 & 63.9 & 1.3 \\
\hline $\mathrm{U} 2315$ & 5 & $\mathrm{~F}$ & 2.178 & 3.9 & 5.8 & 1.466 & 93.4 & 0.9 \\
\hline $\mathrm{U} 2315$ & 5 & F-1 & 3.160 & 0.9 & 5.9 & 1.526 & 69.7 & 1.2 \\
\hline $\mathrm{U} 2315$ & 5 & F-2 & 2.294 & 3.7 & 2.9 & 1.443 & 27.2 & 0.7 \\
\hline $\mathrm{U} 2315$ & 6 & $\mathrm{~F}$ & 2.775 & 12.1 & 17.5 & 1.618 & 300.2 & 1.8 \\
\hline U2315 & 6 & F-1 & 3.444 & 30.2 & 25.2 & 1.601 & 303.0 & 2.2 \\
\hline $\mathrm{U} 2315$ & 6 & F-2 & 3.673 & 19.6 & 25.4 & 1.609 & 285.0 & 1.9 \\
\hline $\mathrm{U} 2315$ & 7 & F-1 & 3.047 & 2.7 & 4.1 & 1.560 & 70.9 & 0.8 \\
\hline $\mathrm{U} 2315$ & 7 & F-2 & 4.317 & 4.4 & 2.9 & 1.457 & 71.2 & 0.9 \\
\hline $\mathrm{U} 2315$ & 9 & $\mathrm{~F}$ & 1.873 & 25.2 & 11.0 & 1.485 & 190.1 & 1.5 \\
\hline $\mathrm{U} 2315$ & 9 & F-1 & 2.964 & 8.1 & 30.5 & 1.482 & 55.3 & 0.9 \\
\hline $\mathrm{U} 2315$ & 9 & F-2 & 2.624 & 3.8 & 7.3 & 1.496 & 69.9 & 0.8 \\
\hline U2315 & 10 & F & 3.125 & 21.0 & 17.0 & 1.624 & 255.0 & 2.0 \\
\hline U2315 & 10 & F-1 & 3.514 & 9.6 & 8.2 & 1.529 & 161.1 & 1.3 \\
\hline $\mathrm{U} 2315$ & 10 & F-2 & 3.564 & 14.1 & 8.2 & 1.618 & 146.9 & 1.5 \\
\hline U2315 & 11 & $\mathrm{~F}$ & 0.913 & 3.4 & 2.5 & 1.531 & 54.8 & 0.6 \\
\hline U2315 & 11 & F-1 & 2.932 & 0.1 & 3.1 & 1.501 & 27.0 & 0.8 \\
\hline U2315 & 11 & F-2 & 2.294 & -4.4 & 2.0 & 1.427 & 15.1 & 0.7 \\
\hline $\mathrm{U} 2315$ & 12 & $\mathrm{~F}$ & 2.188 & 15.1 & 21.3 & 1.665 & 597.0 & 2.0 \\
\hline U2315 & 12 & F-1 & 3.929 & 0.8 & 14.4 & 1.604 & 253.2 & 1.7 \\
\hline $\mathrm{U} 2315$ & 12 & F-2 & 3.304 & -2.5 & 7.9 & 1.480 & 133.8 & 0.9 \\
\hline $\mathrm{U} 2315$ & 13 & $\mathrm{~F}$ & 2.551 & 1.9 & 4.7 & 1.480 & 88.6 & 0.9 \\
\hline $\mathrm{U} 2315$ & 13 & F-1 & 2.798 & 6.2 & 8.2 & 1.486 & 115.7 & 1.3 \\
\hline U2315 & 13 & F-2 & 3.364 & 1.3 & 13.4 & 1.481 & 137.9 & 1.2 \\
\hline $\mathrm{U} 2315$ & 14 & $\mathrm{~F}$ & 1.826 & 1.3 & 2.3 & 1.554 & 47.3 & 0.7 \\
\hline $\mathrm{U} 2315$ & 14 & F-1 & 4.241 & -1.6 & 5.3 & 1.557 & 62.7 & 1.0 \\
\hline $\mathrm{U} 2315$ & 14 & F-2 & 2.975 & 1.0 & 7.4 & 1.445 & 94.6 & 1.0 \\
\hline U2315 & 15 & $\mathrm{~F}$ & 3.253 & 36.6 & 19.1 & 1.847 & 638.8 & 1.8 \\
\hline $\mathrm{U} 2315$ & 15 & F-1 & 3.841 & 10.5 & 4.0 & 1.474 & 133.7 & 1.0 \\
\hline $\mathrm{U} 2315$ & 15 & F-2 & 2.090 & 10.9 & 5.4 & 1.552 & 170.6 & 0.9 \\
\hline $\mathrm{U} 2315$ & 16 & $\mathrm{~F}$ & 2.090 & 5.8 & 8.7 & 1.494 & 212.6 & 0.9 \\
\hline $\mathrm{U} 2315$ & 16 & F-1 & 2.845 & 3.6 & 5.7 & 1.514 & 88.7 & 0.9 \\
\hline U2315 & 16 & F-2 & 2.600 & 5.3 & 2.6 & 1.537 & 70.9 & 0.7 \\
\hline U2322 & 1 & $\mathrm{~F}$ & 2.695 & 28.3 & 10.0 & 1.469 & 105.9 & 0.9 \\
\hline \multicolumn{9}{|l|}{ NET6 } \\
\hline $\mathrm{U} 2322$ & 1 & F-1 & 4.602 & 82.8 & 8.8 & 1.448 & 152.5 & 1.3 \\
\hline \multicolumn{9}{|l|}{ NET6 } \\
\hline U2322 & 1 & F-2 & 3.934 & 10.5 & 8.5 & 1.472 & 129.8 & 1.1 \\
\hline \multicolumn{9}{|l|}{ NET6 } \\
\hline $\mathrm{U} 2322$ & 2 & $\mathrm{~F}$ & 2.387 & 16.2 & 2.7 & 1.635 & 16.3 & 0.8 \\
\hline \multicolumn{9}{|l|}{ NET6 } \\
\hline U2322 & 2 & F-2 & 3.739 & 26.2 & 1.5 & 1.509 & 25.3 & 0.6 \\
\hline \multicolumn{9}{|l|}{ NET6 } \\
\hline U2322 & 3 & F-1 & 2.694 & 24.2 & 8.3 & 1.524 & 369.3 & 1.0 \\
\hline \multicolumn{9}{|l|}{ NET6 } \\
\hline U2322 & 3 & F-2 & 2.165 & 6.9 & 4.0 & 1.575 & 300.6 & 0.8 \\
\hline
\end{tabular}


Appendix A

\begin{tabular}{|c|c|c|c|c|c|c|c|c|}
\hline Site & $\begin{array}{l}\text { Individual } \\
\text { Number }\end{array}$ & Chamber & $\mathrm{Mg} / \mathrm{Ca}$ & $\mathrm{Al} / \mathrm{Ca}$ & $\mathrm{Mn} / \mathrm{Ca}$ & $\mathrm{Sr} / \mathrm{Ca}$ & $\mathrm{Zn} / \mathrm{Ca}$ & $\mathrm{Ba} / \mathrm{Ca}$ \\
\hline & & & $(\mathrm{mmol} / \mathrm{mo}$ & $\mathrm{mol} / \mathrm{mc}$ & $\mathrm{umol} / \mathrm{mo}$ & $\mathrm{amol} / \mathrm{m}$ & $\mathrm{mol} / \mathrm{mo}$ & $\mathrm{emol} / \mathrm{mol})$ \\
\hline U2322 & 3 & $\mathrm{~F}$ & 2.083 & 29.8 & 7.7 & 1.588 & 453.8 & 0.9 \\
\hline NET6 & & & & & & & & \\
\hline U2322 & 4 & $\mathrm{~F}$ & 4.236 & 3.4 & 4.1 & 1.627 & 49.8 & 1.0 \\
\hline NET6 & & & & & & & & \\
\hline $\begin{array}{l}\text { U2322 } \\
\text { NET6 }\end{array}$ & 4 & F-1 & 4.365 & -8.9 & 5.6 & 1.561 & 26.6 & 0.8 \\
\hline U2322 & 4 & F-2 & 2.968 & -3.2 & 3.7 & 1.504 & 20.1 & 0.7 \\
\hline $\begin{array}{l}\text { NET6 } \\
\text { U2322 }\end{array}$ & 5 & $\mathrm{~F}$ & 1.804 & 8.0 & 6.5 & 1.563 & 158.3 & 1.2 \\
\hline NET6 & & & & & & & & \\
\hline $\begin{array}{l}\text { U2322 } \\
\text { NET6 }\end{array}$ & 5 & F-1 & 3.021 & 20.3 & 6.0 & 1.463 & 123.8 & 1.3 \\
\hline $\begin{array}{l}\text { U2322 } \\
\text { NET6 }\end{array}$ & 5 & F-2 & 2.685 & 53.9 & 6.7 & 1.466 & 127.1 & 1.3 \\
\hline $\begin{array}{l}\text { U2322 } \\
\text { NET6 }\end{array}$ & 6 & $\mathrm{~F}$ & 2.960 & 28.2 & 4.1 & 1.527 & 136.7 & 1.3 \\
\hline $\begin{array}{l}\text { U2322 } \\
\text { NET6 }\end{array}$ & 6 & F-1 & 3.291 & 15.0 & 0.0 & 1.532 & 79.2 & 0.8 \\
\hline $\begin{array}{l}\text { U2322 } \\
\text { NET6 }\end{array}$ & 6 & F-2 & 3.018 & 98.0 & 4.3 & 1.494 & 42.4 & 0.6 \\
\hline $\begin{array}{l}\text { U2322 } \\
\text { NET6 }\end{array}$ & 7 & $\mathrm{~F}$ & 1.842 & 57.1 & 2.6 & 1.539 & 23.3 & 0.8 \\
\hline $\begin{array}{l}\text { U2322 } \\
\text { NET6 }\end{array}$ & 7 & F-1 & 3.549 & 46.1 & 6.9 & 1.522 & 88.7 & 1.1 \\
\hline $\begin{array}{l}\text { U2322 } \\
\text { NET6 }\end{array}$ & 8 & $\mathrm{~F}$ & 3.089 & 4.3 & 5.9 & 1.472 & 39.2 & 0.8 \\
\hline $\begin{array}{l}\text { U2322 } \\
\text { NET6 }\end{array}$ & 8 & F-1 & 2.338 & -0.2 & 3.9 & 1.440 & 38.1 & 0.7 \\
\hline $\begin{array}{l}\text { U2322 } \\
\text { NET6 }\end{array}$ & 8 & F-2 & 3.072 & 22.9 & 4.0 & 1.450 & 47.4 & 0.9 \\
\hline $\begin{array}{l}\text { U2322 } \\
\text { NET6 }\end{array}$ & 9 & $\mathrm{~F}$ & 2.522 & 22.4 & 3.8 & 1.454 & 35.4 & 0.7 \\
\hline $\begin{array}{l}\text { U2322 } \\
\text { NET6 }\end{array}$ & 9 & F-1 & 3.335 & 25.3 & 5.2 & 1.542 & 24.3 & 0.8 \\
\hline $\begin{array}{l}\text { U2322 } \\
\text { NET6 }\end{array}$ & 9 & F-2 & 2.374 & 104.4 & 4.0 & 1.482 & 28.6 & 0.6 \\
\hline $\begin{array}{l}\text { U2322 } \\
\text { NET7 }\end{array}$ & 5 & F-1 & 3.250 & 9.8 & 10.1 & 1.556 & & 1.3 \\
\hline $\begin{array}{l}\text { U2322 } \\
\text { NET7 }\end{array}$ & 5 & $\mathrm{~F}$ & 2.551 & 17.5 & 12.6 & 1.454 & & 0.9 \\
\hline $\begin{array}{l}\text { U2322 } \\
\text { NET7 }\end{array}$ & 5 & F-2 & 4.007 & 21.7 & 25.0 & 1.626 & & 1.8 \\
\hline $\begin{array}{l}\text { U2322 } \\
\text { NET7 }\end{array}$ & 6 & $\mathrm{~F}$ & 1.484 & 18.0 & 3.2 & 1.491 & & 0.7 \\
\hline $\begin{array}{l}\text { U2322 } \\
\text { NET7 }\end{array}$ & 6 & F-2 & 2.464 & 9.7 & 6.4 & 1.496 & & 1.0 \\
\hline $\begin{array}{l}\text { U2322 } \\
\text { NET7 }\end{array}$ & 6 & F-1 & 2.909 & 6.8 & 6.6 & 1.471 & & 0.9 \\
\hline $\begin{array}{l}\text { U2322 } \\
\text { NET7 }\end{array}$ & 7 & $\mathrm{~F}$ & 2.686 & 20.6 & 3.2 & 1.546 & & 0.7 \\
\hline $\begin{array}{l}\text { U2322 } \\
\text { NET7 }\end{array}$ & 7 & F-2 & 2.978 & 7.3 & 9.1 & 1.631 & & 1.0 \\
\hline $\begin{array}{l}\text { U2322 } \\
\text { NET7 }\end{array}$ & 7 & F-1 & 3.274 & 7.4 & 15.1 & 1.470 & & 1.2 \\
\hline $\begin{array}{l}\text { U2322 } \\
\text { NET7 }\end{array}$ & 8 & F-2 & 2.509 & 10.1 & 2.7 & 1.483 & & 0.7 \\
\hline $\begin{array}{l}\text { U2322 } \\
\text { NET7 }\end{array}$ & 8 & $\mathrm{~F}$ & 1.299 & 19.6 & 5.4 & 1.433 & & 0.8 \\
\hline
\end{tabular}




\begin{tabular}{|c|c|c|c|c|c|c|c|c|}
\hline Site & $\begin{array}{c}\text { Individual } \\
\text { Number }\end{array}$ & Chamber & $\mathrm{Mg} / \mathrm{Ca}$ & $\mathrm{Al} / \mathrm{Ca}$ & $\mathrm{Mn} / \mathrm{Ca}$ & $\mathrm{Sr} / \mathrm{Ca}$ & $\mathrm{Zn} / \mathrm{Ca}$ & $\mathrm{Ba} / \mathrm{Ca}$ \\
\hline & & & \multicolumn{3}{|c|}{$(\mathrm{mmol} / \mathrm{mol})(\mu \mathrm{mol} / \mathrm{mol})(\mu \mathrm{mol} / \mathrm{mol})$} & $\mathrm{nmol} / \mathrm{m}$ & $\mu \mathrm{mol} / \mathrm{mc}$ & $\mathrm{mol} / \mathrm{mol}$ \\
\hline$\overline{\mathrm{U} 2322}$ & 8 & F-1 & 2.710 & 14.5 & 5.8 & 1.387 & & 1.0 \\
\hline NET7 & & & & & & & & \\
\hline U2322 & 1 & $\mathrm{~F}$ & 2.165 & -13.7 & 1.0 & 1.499 & 26.1 & 0.5 \\
\hline NET7 & & & & & & & & \\
\hline $\mathrm{U} 2322$ & 1 & $\mathrm{~F}-1$ & 3.054 & 1.0 & 3.5 & 1.559 & 88.4 & 2.4 \\
\hline NET7 & & & & & & & & \\
\hline $\mathrm{U} 2322$ & 1 & $\mathrm{~F}-2$ & 3.368 & 2.6 & 2.7 & 1.565 & 86.5 & 1.0 \\
\hline NET7 & & & & & & & & \\
\hline $\mathrm{U} 2322$ & 2 & $\mathrm{~F}$ & 1.481 & 124.0 & 17.3 & 1.736 & 484.3 & 1.6 \\
\hline NET7 & & & & & & & & \\
\hline U2322 & 2 & F-1 & 3.075 & 26.0 & 4.4 & 1.588 & 120.0 & 0.9 \\
\hline NET7 & & & & & & & & \\
\hline U2322 & 2 & F-2 & 2.960 & -0.4 & 4.8 & 1.443 & 77.1 & 0.9 \\
\hline NET7 & & & & & & & & \\
\hline U2322 & 3 & $\mathrm{~F}$ & 1.858 & 23.2 & 5.5 & 1.588 & 589.3 & 0.9 \\
\hline NET7 & & & & & & & & \\
\hline U2322 & 3 & F-1 & 2.207 & 1.0 & 1.8 & 1.566 & 173.6 & 0.6 \\
\hline NET7 & & & & & & & & \\
\hline U2322 & 3 & F-2 & 1.782 & 41.5 & 5.8 & 1.565 & 369.2 & 0.7 \\
\hline NET7 & & & & & & & & \\
\hline U2322 & 4 & $\mathrm{~F}$ & 2.503 & 6.2 & 1.8 & 1.606 & 57.9 & 0.6 \\
\hline NET7 & & & & & & & & \\
\hline U2322 & 4 & F-1 & 3.421 & 9.3 & 4.8 & 1.683 & 91.9 & 1.1 \\
\hline NET7 & & & & & & & & \\
\hline U2322 & 4 & $\mathrm{~F}-2$ & 3.249 & 109.2 & 5.8 & 1.627 & 98.3 & 1.2 \\
\hline NET7 & & & & & & & & \\
\hline Z7003 & 1 & $\mathrm{~F}$ & 3.326 & -27.4 & 31.4 & 1.312 & 1.4 & 1.0 \\
\hline Z7003 & 2 & $\mathrm{~F}$ & 2.874 & 145.5 & 45.7 & 1.412 & 11.2 & 1.1 \\
\hline Z7003 & 2 & F-1 & 2.822 & 210.8 & 40.8 & 1.446 & 31.2 & 2.2 \\
\hline Z7003 & 2 & F-2 & 1.979 & 77.7 & 38.1 & 1.426 & 7.1 & 1.2 \\
\hline Z7003 & 3 & $\mathrm{~F}$ & 3.222 & 627.5 & 25.7 & 1.483 & 4.1 & 1.3 \\
\hline Z7003 & 3 & F-1 & 2.692 & 275.0 & 65.6 & 1.558 & 10.3 & 1.7 \\
\hline Z7003 & 4 & $\mathrm{~F}$ & 3.516 & 172.8 & 19.7 & 1.580 & 6.1 & 0.9 \\
\hline Z7003 & 4 & F-2 & 2.487 & 37.7 & 50.0 & 1.543 & 15.8 & 1.7 \\
\hline Z7003 & 5 & $\mathrm{~F}$ & 2.542 & -31.9 & 38.9 & 1.429 & 4.1 & 1.4 \\
\hline Z7003 & 5 & F-1 & 2.048 & 195.6 & 58.2 & 1.438 & 10.3 & 3.3 \\
\hline Z7003 & 6 & $\mathrm{~F}$ & 2.400 & 336.1 & 31.4 & 1.455 & 7.7 & 1.4 \\
\hline Z7003 & 6 & F-1 & 3.408 & 474.9 & 33.0 & 1.484 & 6.5 & 1.3 \\
\hline Z7003 & 6 & F-2 & 2.343 & 316.1 & 37.6 & 1.406 & 8.6 & 0.9 \\
\hline Z7003 & 7 & $\mathrm{~F}-2$ & 3.821 & 1767.9 & 36.5 & 1.321 & 7.6 & 1.8 \\
\hline Z7003 & 8 & $\mathrm{~F}$ & 2.671 & 350.9 & 56.9 & 1.422 & 14.9 & 1.1 \\
\hline Z7003 & 8 & F-1 & 0.839 & -5639.5 & 0.4 & 1.315 & -19.2 & -0.9 \\
\hline Z7003 & 8 & F-2 & 3.297 & 1448.3 & 53.9 & 1.420 & 16.5 & 1.4 \\
\hline Z7003 & 9 & $\mathrm{~F}$ & 2.102 & -2319.5 & 33.5 & 1.519 & 78.5 & 0.9 \\
\hline Z7003 & 9 & F-1 & 2.957 & 800.6 & 47.4 & 1.426 & 3.2 & 1.1 \\
\hline Z7003 & 9 & $\mathrm{~F}-2$ & 2.628 & 511.7 & 31.2 & 1.498 & 7.2 & 1.3 \\
\hline Z7003 & 10 & $\mathrm{~F}$ & 2.019 & 943.9 & 19.9 & 1.389 & 6.3 & 1.0 \\
\hline Z7003 & 10 & F-1 & 3.831 & 781.9 & 35.0 & 1.372 & 11.6 & 0.9 \\
\hline Z7003 & 10 & $\mathrm{~F}-2$ & 2.844 & -1434.9 & 28.7 & 1.355 & 3.6 & 0.4 \\
\hline Z7003 & 11 & F-1 & 3.231 & 505.8 & 37.2 & 1.427 & 5.0 & 1.2 \\
\hline Z7003 & 12 & $\mathrm{~F}$ & 3.535 & 338.9 & 70.7 & 1.399 & 12.1 & 1.2 \\
\hline Z7003 & 12 & F-1 & 3.261 & 1290.2 & 18.5 & 1.488 & 13.6 & 2.5 \\
\hline Z7003 & 13 & $\mathrm{~F}$ & 3.382 & 1523.2 & 58.4 & 1.398 & 21.4 & 2.5 \\
\hline Z7003 & 13.1 & F-1 & 3.638 & 217.2 & 37.6 & 1.495 & 8.8 & 1.4 \\
\hline Z7003 & 13 & $\mathrm{~F}-2$ & 3.213 & 718.9 & 40.0 & 1.478 & 17.5 & 1.9 \\
\hline Z7003 & 14 & $\mathrm{~F}-1$ & 3.854 & 730.1 & 30.0 & 1.395 & 8.5 & 1.0 \\
\hline Z7003 & 14 & $\mathrm{~F}-2$ & 3.068 & 620.1 & 26.6 & 1.492 & 18.5 & 2.3 \\
\hline Z7003 & 15 & $\mathrm{~F}$ & 4.175 & 279.9 & 37.2 & 1.478 & 12.7 & 3.0 \\
\hline
\end{tabular}


Appendix A

\begin{tabular}{|c|c|c|c|c|c|c|c|c|}
\hline Site & Individual Number & Chamber & $\mathrm{Mg} / \mathrm{Ca}$ & $\mathrm{Al} / \mathrm{Ca}$ & $\mathrm{Mn} / \mathrm{Ca}$ & $\mathrm{Sr} / \mathrm{Ca}$ & $\mathrm{Zn} / \mathrm{Ca}$ & $\mathrm{Ba} / \mathrm{Ca}$ \\
\hline & & & $(\mathrm{mmol} / \mathrm{mol}$ & $\mu \mathrm{mol} / \mathrm{mc}$ & $\mathrm{amol} / \mathrm{mol}$ & $\mathrm{nmol} / \mathrm{m}$ & $\mathrm{umol} / \mathrm{m}$ & $\mathrm{imol} / \mathrm{mol}$ \\
\hline Z7003 & 15 & $\mathrm{~F}-1$ & 4.100 & 671.6 & 32.9 & 1.355 & 9.8 & 3.4 \\
\hline Z7003 & 15 & $\mathrm{~F}-2$ & 3.093 & 704.9 & 29.4 & 1.423 & 6.9 & 2.6 \\
\hline Z7003 & 1 & $\mathrm{~F}$ & 1.737 & 37.1 & 38.7 & 1.400 & & 0.9 \\
\hline Z7003 & 1 & $\mathrm{~F}-1$ & 2.011 & 104.3 & 49.9 & 1.422 & & 1.0 \\
\hline Z7003 & 1 & $\mathrm{~F}-2$ & 2.490 & 41.1 & 57.8 & 1.514 & & 1.3 \\
\hline Z7003 & 2 & $\mathrm{~F}$ & 1.392 & 36.4 & 25.4 & 1.460 & & 0.9 \\
\hline Z7003 & 2 & $\mathrm{~F}-2$ & 3.343 & 84.9 & 35.5 & 1.311 & & 1.3 \\
\hline Z7003 & 3 & $\mathrm{~F}-1$ & 1.938 & 17.3 & 30.8 & 1.404 & & 1.1 \\
\hline Z7003 & 3 & $\mathrm{~F}$ & 1.369 & 41.6 & 35.3 & 1.561 & & 1.0 \\
\hline Z7003 & 3 & $\mathrm{~F}-2$ & 2.286 & 18.3 & 37.9 & 1.477 & & 1.2 \\
\hline Z7003 & 4 & F-2 & 2.347 & 482.7 & 24.3 & 1.391 & & 1.9 \\
\hline Z7003 & 5 & $\mathrm{~F}$ & 1.598 & 37.9 & 25.7 & 1.316 & & 0.8 \\
\hline Z7003 & 5 & F-2 & 2.672 & 58.2 & 35.4 & 1.387 & & 1.0 \\
\hline Z7003 & 5 & F-1 & 2.798 & 100.7 & 47.9 & 1.281 & & 1.5 \\
\hline Z7003 & 6 & $\mathrm{~F}$ & 2.464 & 58.0 & 18.5 & 1.500 & & 0.8 \\
\hline Z7003 & 7 & $\mathrm{~F}$ & 1.645 & 12.6 & 15.7 & 1.590 & & 0.7 \\
\hline Z7003 & 7 & F-2 & 3.088 & 962.9 & 40.4 & 1.448 & & 1.2 \\
\hline Z7003 & 8 & F-1 & 2.867 & 96.7 & 25.0 & 1.310 & & 0.9 \\
\hline Z7003 & 8 & $\mathrm{~F}$ & 1.472 & 11.2 & 27.9 & 1.451 & & 0.8 \\
\hline Z7003 & 8 & $\mathrm{~F}-2$ & 3.088 & 46.9 & 34.0 & 1.323 & & 1.0 \\
\hline Z7003 & 9 & F-2 & 2.704 & 83.3 & 22.5 & 1.421 & & 0.9 \\
\hline Z7003 & 9 & $\mathrm{~F}$ & 1.802 & 76.9 & 34.7 & 1.411 & & 1.0 \\
\hline Z7003 & 9 & F-1 & 3.182 & 144.8 & 35.3 & 1.335 & & 1.2 \\
\hline Z7003 & 10 & $\mathrm{~F}$ & 2.225 & 76.7 & 35.5 & 1.525 & & 0.8 \\
\hline Z7003 & 10 & $\mathrm{~F}-2$ & 3.436 & 123.9 & 63.1 & 1.423 & & 1.3 \\
\hline Z7003 & 10 & F-1 & 4.045 & 96.5 & 85.1 & 1.330 & & 1.4 \\
\hline Z7003 & 15 & F-1 & 4.100 & 671.6 & 32.9 & 1.355 & 9.8 & 3.4 \\
\hline
\end{tabular}

Cells in bold are repeat analyses. 
Table A4: Paired t-test summary for $\mathrm{Mg} / \mathrm{Ca}$ in $\mathrm{Gs}$. ruber from core top and plankton tow sites in the Southwest Pacific Ocean.

\begin{tabular}{|c|c|c|c|c|c|c|c|c|c|}
\hline \multirow[b]{4}{*}{ Site } & \multirow{4}{*}{$\begin{array}{l}\text { Chamber } \\
\text { Pair } \\
(\mathrm{Mg} / \mathrm{Ca})\end{array}$} & \multicolumn{8}{|c|}{ Paired Samples Test ${ }^{\mathrm{a}}$} \\
\hline & & \multicolumn{5}{|c|}{ Paired Differences } & \multirow[t]{3}{*}{$\mathrm{t}$} & \multirow[t]{3}{*}{ df } & \multirow{3}{*}{$\begin{array}{c}\text { t-test }(p) \\
\text { Sig. }(2- \\
\text { tailed) }\end{array}$} \\
\hline & & \multirow[b]{2}{*}{ Mean } & \multirow{2}{*}{$\begin{array}{c}\text { Std. } \\
\text { Deviation }\end{array}$} & \multirow{2}{*}{$\begin{array}{l}\text { Std. } \\
\text { Error } \\
\text { Mean } \\
\end{array}$} & \multicolumn{2}{|c|}{$\begin{array}{c}95 \% \text { C.I. of the } \\
\text { Difference }\end{array}$} & & & \\
\hline & & & & & Lower & Upper & & & \\
\hline AIMS1361 & $F-2-F$ & 1.164 & 1.211 & 0.458 & 0.045 & 2.284 & 2.544 & 6 & 0.044 \\
\hline AIMS1361 & F-1 - F & 0.979 & 0.921 & 0.348 & 0.126 & 1.831 & 2.810 & 6 & 0.031 \\
\hline AIMS1631 & $\mathrm{F}-2-\mathrm{F}$ & 0.570 & 0.323 & 0.161 & 0.056 & 1.084 & 3.532 & 3 & 0.039 \\
\hline AIMS2078 & $\mathrm{F}-2-\mathrm{F}$ & 1.992 & 1.468 & 0.464 & 0.942 & 3.042 & 4.290 & 9 & 0.002 \\
\hline AIMS2078 & F-1 - F & 2.121 & 1.389 & 0.439 & 1.127 & 3.115 & 4.827 & 9 & 0.001 \\
\hline AIMS3703 & $\mathrm{F}-2-\mathrm{F}$ & 0.957 & 1.163 & 0.323 & 0.254 & 1.660 & 2.967 & 12 & 0.012 \\
\hline AIMS3703 & F-1 - F & 1.158 & 0.971 & 0.269 & 0.571 & 1.744 & 4.301 & 12 & 0.001 \\
\hline FR1/97/GC12 & F-1 - F & 1.242 & 2.030 & 0.586 & -0.048 & 2.532 & 2.118 & 11 & $0.058^{*}$ \\
\hline ODP Site 1123 & F-2 - F & 0.372 & 0.287 & 0.080 & 0.198 & 0.545 & 4.672 & 12 & 0.001 \\
\hline ODP Site 1123 & F-1 - F & 0.478 & 0.384 & 0.107 & 0.246 & 0.710 & 4.485 & 12 & 0.001 \\
\hline P71 & $F-2-F$ & 0.798 & 0.750 & 0.172 & 0.437 & 1.160 & 4.641 & 18 & 0.000 \\
\hline P71 & F-1 - F & 0.613 & 0.578 & 0.133 & 0.334 & 0.891 & 4.622 & 18 & 0.000 \\
\hline P81 & $\mathrm{F}-2-\mathrm{F}$ & 0.708 & 0.331 & 0.078 & 0.543 & 0.872 & 9.073 & 17 & 0.000 \\
\hline P81 & F-1 - F & 0.697 & 0.511 & 0.121 & 0.442 & 0.951 & 5.779 & 17 & 0.000 \\
\hline TAN0607 C4 & $F-2-F$ & 0.944 & 0.923 & 0.181 & 0.571 & 1.317 & 5.214 & 25 & 0.000 \\
\hline TAN0607 C4 & F-1 - F & 1.067 & 0.872 & 0.171 & 0.715 & 1.420 & 6.240 & 25 & 0.000 \\
\hline $\mathrm{U} 2315$ & $\mathrm{~F}-2-\mathrm{F}$ & 0.816 & 0.876 & 0.243 & 0.287 & 1.345 & 3.360 & 12 & 0.006 \\
\hline $\begin{array}{l}\text { U2315 } \\
\text { U2322 net } 6 \text { \& }\end{array}$ & F-1 - F & 1.442 & 0.937 & 0.260 & 0.875 & 2.008 & 5.546 & 12 & 0.000 \\
\hline 7 & F-1 - F & 0.746 & 0.724 & 0.218 & 0.260 & 1.232 & 3.418 & 10 & 0.007 \\
\hline Z7003 & $\mathrm{F}-2-\mathrm{F}$ & 0.607 & 1.188 & 0.297 & -0.026 & 1.240 & 2.045 & 15 & $0.059 *$ \\
\hline Z7003 & $\mathrm{F}-1-\mathrm{F}$ & 0.665 & 1.102 & 0.275 & 0.078 & 1.252 & 2.415 & 15 & 0.029 \\
\hline
\end{tabular}

${ }^{a} 2$-tailed significance level, p. Only values that are statistically $(\mathrm{p}<0.05)$ are shown except those with an asterix which are close to $\mathrm{p}=0.05$. This shows that there is a significant difference (at the $95 \%$ level) between $\mathrm{Mg} / \mathrm{Ca}$ and the specified chamber pairs. 
Table A5: Independent t-test summary for $\mathrm{Mg} / \mathrm{Ca}$ in different morphotypes of $\mathrm{Gs}$. ruber from core top and plankton tow sites in the Southwest Pacific Ocean.

\begin{tabular}{|c|c|c|c|c|c|c|c|c|c|}
\hline \multicolumn{10}{|c|}{ Independent Samples Test ${ }^{\mathrm{a}}$} \\
\hline \multirow{3}{*}{\begin{tabular}{l}
\multicolumn{1}{c}{$\mathrm{Mg} / \mathrm{Ca}$} \\
(Chamber) \\
$\begin{array}{l}\text { s.s. versus } \\
\text { s.l. }\end{array}$
\end{tabular}} & \multicolumn{2}{|c|}{$\begin{array}{c}\text { Equality of } \\
\text { Variances } \\
\end{array}$} & \multicolumn{7}{|c|}{ t-test for Equality of Means } \\
\hline & \multirow[b]{2}{*}{$\mathrm{F}$} & \multirow[b]{2}{*}{ Sig. } & \multirow[b]{2}{*}{$\mathrm{t}$} & \multirow[b]{2}{*}{ df } & \multirow[b]{2}{*}{ Sig. (2-tailed) } & \multirow[b]{2}{*}{$\begin{array}{c}\text { Mean } \\
\text { Difference }\end{array}$} & \multirow[b]{2}{*}{$\begin{array}{l}\text { Std. Error } \\
\text { Difference }\end{array}$} & \multicolumn{2}{|c|}{$\begin{array}{l}95 \% \text { Confidence } \\
\text { Interval of the } \\
\text { Difference }\end{array}$} \\
\hline & & & & & & & & Lower & Upper \\
\hline $\mathrm{F}-2$ & 1.933 & 0.167 & 0.225 & 140 & 0.822 & 0.058 & 0.259 & -0.454 & 0.571 \\
\hline F-1 & 2.709 & 0.102 & -0.091 & 140 & 0.927 & -0.025 & 0.269 & -0.556 & 0.507 \\
\hline $\mathrm{F}$ & 0.625 & 0.431 & 0.789 & 140 & 0.432 & 0.175 & 0.221 & -0.263 & 0.612 \\
\hline
\end{tabular}


Appendix B

Appendix B. Chapter 4. 
Table B1: Core top, plankton tow and $\mathrm{Mg} / \mathrm{Ca}$ ratios for individual Neogloboquadrina incompta $(150-300 \mu \mathrm{m})$ from sites in the Southwest Pacific Ocean

\begin{tabular}{|c|c|c|c|c|c|c|c|c|c|c|c|c|c|}
\hline Site & $\begin{array}{l}\text { Latit } \\
\text { ude }\end{array}$ & $\begin{array}{l}\text { Longi } \\
\text { tude }\end{array}$ & $\begin{array}{l}\text { Core } \\
\text { Type }\end{array}$ & $\begin{array}{l}\text { Dep } \\
\text { th }\end{array}$ & Age & $\begin{array}{c}\text { Indivi } \\
\text { dual } \\
\text { Num } \\
\text { ber }\end{array}$ & $\begin{array}{c}\mathrm{F}-3 \\
\mathrm{Mg} / \mathrm{Ca} \\
\text { (ICL) }\end{array}$ & $\begin{array}{c}\mathrm{F}-3 \\
\mathrm{Mg} / \mathrm{Ca} \\
(\mathrm{OCL})\end{array}$ & $\begin{array}{c}\mathrm{F} \\
\mathrm{Mg} / \mathrm{Ca} \\
\text { (ICL) }\end{array}$ & $\begin{array}{c}\mathrm{F} \\
\mathrm{Mg} / \mathrm{Ca} \\
(\mathrm{OCL})\end{array}$ & $\begin{array}{c}\text { Ultra- } \\
\text { structure }\end{array}$ & $\begin{array}{c}\text { WO } \\
\text { A05 } \\
\text { SST } \\
(0- \\
100 \\
\text { m) }\end{array}$ & $\begin{array}{l}\text { Sali } \\
\text { nity }\end{array}$ \\
\hline & $\begin{array}{c}\text { (degr } \\
\text { ees) }\end{array}$ & $\begin{array}{c}\text { (degre } \\
\text { es) }\end{array}$ & & $\begin{array}{l}\text { (met } \\
\text { res) }\end{array}$ & $(\mathrm{yr})$ & & $\begin{array}{c}(\mathrm{mmol} / \mathrm{m} \\
\mathrm{ol})\end{array}$ & $\begin{array}{c}(\mathrm{mmol} / \mathrm{mol} \\
)\end{array}$ & $\begin{array}{c}(\mathrm{mmol} \\
/ \mathrm{mol})\end{array}$ & $\begin{array}{c}(\mathrm{mmol} / \\
\mathrm{mol})\end{array}$ & & $\left({ }^{\circ} \mathrm{C}\right)$ & $\begin{array}{c}\text { (psu } \\
\text { ) }\end{array}$ \\
\hline $\begin{array}{l}271 / 61 / \mathrm{D} \\
\mathrm{R} 05 \mathrm{C} 1\end{array}$ & $\begin{array}{c}22.13 \\
3\end{array}$ & $\begin{array}{c}156.7 \\
4\end{array}$ & $\begin{array}{c}\text { dredg } \\
\mathrm{e}\end{array}$ & 1600 & & 1 & 1.13 & 0.64 & 1.75 & 0.98 & crystalline & 23.8 & $\begin{array}{r}35.4 \\
9\end{array}$ \\
\hline $\begin{array}{l}\text { 271/61/D } \\
\text { R05C1 } \\
\text { B32 }\end{array}$ & $\begin{array}{c}22.13 \\
3 \\
53.63 \\
0\end{array}$ & $\begin{array}{c}156.7 \\
4 \\
169.8 \\
7\end{array}$ & $\begin{array}{l}\text { dredg } \\
\text { e } \\
\text { core } \\
\text { top }\end{array}$ & $\begin{array}{l}1600 \\
799\end{array}$ & $\begin{array}{l}\text { Holo } \\
\text { cene }\end{array}$ & 2 & $\begin{array}{l}1.92 \\
2.18\end{array}$ & 0.72 & $\begin{array}{l}2.46 \\
1.68\end{array}$ & 0.72 & $\begin{array}{l}\text { crystalline } \\
\text { reticulate }\end{array}$ & $\begin{array}{l}23.8 \\
9.1\end{array}$ & $\begin{array}{c}35.4 \\
9 \\
34.3 \\
3\end{array}$ \\
\hline B32 & $\begin{array}{c}53.63 \\
0 \\
53.63 \\
0\end{array}$ & $\begin{array}{c}169.8 \\
7 \\
169.8 \\
7\end{array}$ & $\begin{array}{l}\text { core } \\
\text { top } \\
\text { core } \\
\text { top }\end{array}$ & 799 & $\begin{array}{l}\text { Holo } \\
\text { cene } \\
\text { Holo } \\
\text { cene }\end{array}$ & 2 & 1.23 & 0.31 & 1.26 & 0.60 & $\begin{array}{l}\text { crystalline } \\
\text { reticulate }\end{array}$ & $\begin{array}{l}9.1 \\
9.1\end{array}$ & $\begin{array}{c}34.3 \\
3 \\
34.3 \\
3\end{array}$ \\
\hline B32 & $\begin{array}{c}53.63 \\
0\end{array}$ & $\begin{array}{c}169.8 \\
7\end{array}$ & $\begin{array}{l}\text { core } \\
\text { top }\end{array}$ & 799 & $\begin{array}{l}\text { Holo } \\
\text { cene }\end{array}$ & 4 & & 1.93 & 1.28 & 0.59 & crystalline & 9.1 & $\begin{array}{c}34.3 \\
3\end{array}$ \\
\hline B32 & $\begin{array}{c}53.63 \\
0 \\
53.63\end{array}$ & $\begin{array}{c}169.8 \\
7 \\
169.8\end{array}$ & $\begin{array}{l}\text { core } \\
\text { top } \\
\text { core }\end{array}$ & 799 & $\begin{array}{l}\text { Holo } \\
\text { cene } \\
\text { Holo }\end{array}$ & 5 & 1.41 & 0.81 & 1.25 & 0.96 & crystalline & 9.1 & $\begin{array}{c}34.3 \\
3 \\
34.3\end{array}$ \\
\hline B32 & $\begin{array}{c}0 \\
53.63\end{array}$ & $\begin{array}{c}7 \\
169.8\end{array}$ & $\begin{array}{l}\text { top } \\
\text { core }\end{array}$ & 799 & $\begin{array}{l}\text { cene } \\
\text { Holo }\end{array}$ & 6 & 1.10 & & 0.95 & & reticulate & 9.1 & $\begin{array}{c}3 \\
34.3\end{array}$ \\
\hline B32 & 0 & 7 & top & 799 & cene & 7 & 1.52 & & 1.42 & & reticulate & 9.1 & 3 \\
\hline B32 & $\begin{array}{c}53.63 \\
0\end{array}$ & $\begin{array}{c}169.8 \\
7\end{array}$ & $\begin{array}{l}\text { core } \\
\text { top }\end{array}$ & 799 & $\begin{array}{l}\text { Holo } \\
\text { cene }\end{array}$ & 9 & 1.79 & 0.90 & 1.51 & & crystalline & 9.1 & $\begin{array}{c}34.3 \\
3\end{array}$ \\
\hline B32 & $\begin{array}{c}53.63 \\
0\end{array}$ & $\begin{array}{c}169.8 \\
7\end{array}$ & $\begin{array}{l}\text { core } \\
\text { top }\end{array}$ & 799 & $\begin{array}{l}\text { Holo } \\
\text { cene }\end{array}$ & 10 & & 0.29 & & 0.33 & crystalline & 9.1 & $\begin{array}{c}34.3 \\
3\end{array}$ \\
\hline B32 & $\begin{array}{c}53.63 \\
0 \\
53.63\end{array}$ & $\begin{array}{c}169.8 \\
7 \\
169.8\end{array}$ & $\begin{array}{l}\text { core } \\
\text { top } \\
\text { core }\end{array}$ & 799 & $\begin{array}{l}\text { Holo } \\
\text { cene } \\
\text { Holo }\end{array}$ & 11 & 1.79 & 1.15 & 1.81 & 1.02 & crystalline & 9.1 & $\begin{array}{c}34.3 \\
3 \\
34.3\end{array}$ \\
\hline B32 & $\begin{array}{c}0 \\
53.63\end{array}$ & $\begin{array}{c}7 \\
169.8\end{array}$ & $\begin{array}{l}\text { top } \\
\text { core }\end{array}$ & 799 & $\begin{array}{l}\text { cene } \\
\text { Holo }\end{array}$ & 17 & 0.72 & & 0.97 & & reticulate & 9.1 & $\begin{array}{c}3 \\
34.3\end{array}$ \\
\hline B32 & $\begin{array}{c}0 \\
53.63\end{array}$ & $\begin{array}{c}7 \\
169.8\end{array}$ & $\begin{array}{l}\text { top } \\
\text { core }\end{array}$ & 799 & $\begin{array}{l}\text { cene } \\
\text { Holo }\end{array}$ & 20 & & & 1.71 & & reticulate & 9.1 & $\begin{array}{c}3 \\
34.3\end{array}$ \\
\hline B32 & $\begin{array}{c}0 \\
53.63\end{array}$ & $\begin{array}{c}7 \\
169.8\end{array}$ & $\begin{array}{l}\text { top } \\
\text { core }\end{array}$ & 799 & $\begin{array}{l}\text { cene } \\
\text { Holo }\end{array}$ & 21 & & & 1.84 & & reticulate & 9.1 & $\begin{array}{c}3 \\
34.3\end{array}$ \\
\hline B32 & $\begin{array}{c}0 \\
53.63\end{array}$ & $\begin{array}{c}7 \\
169.8\end{array}$ & $\begin{array}{l}\text { top } \\
\text { core }\end{array}$ & 799 & $\begin{array}{l}\text { cene } \\
\text { Holo }\end{array}$ & 22 & 2.86 & & 2.81 & & reticulate & 9.1 & $\begin{array}{c}3 \\
34.3\end{array}$ \\
\hline B32 & $\begin{array}{c}0 \\
53.63\end{array}$ & $\begin{array}{c}7 \\
169.8\end{array}$ & $\begin{array}{l}\text { top } \\
\text { core }\end{array}$ & 799 & $\begin{array}{l}\text { cene } \\
\text { Holo }\end{array}$ & 24 & 2.43 & & 1.12 & & reticulate & 9.1 & $\begin{array}{c}3 \\
34.3\end{array}$ \\
\hline B32 & $\begin{array}{c}0 \\
53.63\end{array}$ & $\begin{array}{c}7 \\
169.8\end{array}$ & $\begin{array}{l}\text { top } \\
\text { core }\end{array}$ & 799 & $\begin{array}{l}\text { cene } \\
\text { Holo }\end{array}$ & 25 & & & 1.26 & & reticulate & 9.1 & $\begin{array}{c}3 \\
34.3\end{array}$ \\
\hline B32 & 0 & 7 & top & 799 & cene & 26 & 1.69 & & 1.53 & & reticulate & 9.1 & 3 \\
\hline D178 & $\begin{array}{c}51.72 \\
0\end{array}$ & $\begin{array}{c}167.8 \\
3\end{array}$ & $\begin{array}{l}\text { core } \\
\text { top }\end{array}$ & 629 & $\begin{array}{l}4835 \\
\pm 3\end{array}$ & 4 & & & 1.15 & 0.82 & crystalline & 10.3 & $\begin{array}{c}34.4 \\
6\end{array}$ \\
\hline
\end{tabular}




\begin{tabular}{|c|c|c|c|c|c|c|c|c|c|c|c|c|c|}
\hline Site & $\begin{array}{l}\text { Latit } \\
\text { ude }\end{array}$ & $\begin{array}{l}\text { Longi } \\
\text { tude }\end{array}$ & $\begin{array}{l}\text { Core } \\
\text { Type }\end{array}$ & $\begin{array}{c}\text { Dept } \\
\text { h }\end{array}$ & Age & $\begin{array}{c}\text { Indivi } \\
\text { dual } \\
\text { Num } \\
\text { ber }\end{array}$ & $\begin{array}{c}\mathrm{F}-3 \\
\mathrm{Mg} / \mathrm{Ca} \\
\text { (ICL) }\end{array}$ & $\begin{array}{c}\mathrm{F}-3 \mathrm{Mg} / \mathrm{Ca} \\
(\mathrm{OCL})\end{array}$ & $\begin{array}{c}\mathrm{F} \mathrm{Mg} / \mathrm{Ca} \\
\text { (ICL) }\end{array}$ & $\begin{array}{c}\mathrm{F} \mathrm{Mg} / \mathrm{Ca} \\
(\mathrm{OCL})\end{array}$ & $\begin{array}{l}\text { Ultra- } \\
\text { struct } \\
\text { ure }\end{array}$ & $\begin{array}{c}\text { WO } \\
\text { A05 } \\
\text { SST } \\
(0- \\
100 \\
\text { m) }\end{array}$ & $\begin{array}{l}\text { Sali } \\
\text { nity }\end{array}$ \\
\hline & $\begin{array}{l}\begin{array}{c}\text { degr } \\
\text { ees })\end{array} \\
\end{array}$ & $\begin{array}{l}\text { (degre } \\
\text { es) }\end{array}$ & & $\begin{array}{l}\text { (met } \\
\text { res) } \\
\end{array}$ & (yr) & & $\begin{array}{c}(\mathrm{mmol} / \mathrm{mo} \\
\mathrm{l})\end{array}$ & $\begin{array}{c}(\mathrm{mmol} / \mathrm{mol} \\
)\end{array}$ & $\begin{array}{c}(\mathrm{mmol} / \mathrm{m} \\
\mathrm{ol})\end{array}$ & $\begin{array}{c}(\mathrm{mmol} / \mathrm{m} \\
\mathrm{ol})\end{array}$ & & $\left({ }^{\circ} \mathrm{C}\right)$ & $\begin{array}{c}\text { (psu } \\
\text { ) }\end{array}$ \\
\hline & 51.72 & 167.8 & core & & 4835 & & & & & & crystal & & 34.4 \\
\hline D178 & $\begin{array}{c}0 \\
51.72\end{array}$ & $\begin{array}{c}3 \\
167.8\end{array}$ & $\begin{array}{l}\text { top } \\
\text { core }\end{array}$ & 629 & $\begin{array}{c} \pm 3 \\
4835\end{array}$ & 6 & & 0.60 & 0.76 & 0.76 & $\begin{array}{l}\text { line } \\
\text { reticul }\end{array}$ & 10.3 & $\begin{array}{c}6 \\
34.4\end{array}$ \\
\hline D178 & $\begin{array}{c}0 \\
51.72\end{array}$ & $\begin{array}{c}3 \\
167.8\end{array}$ & $\begin{array}{l}\text { top } \\
\text { core }\end{array}$ & 629 & $\begin{array}{c} \pm 3 \\
4835\end{array}$ & 22 & 1.30 & & 1.20 & & $\begin{array}{l}\text { ate } \\
\text { reticul }\end{array}$ & 10.3 & $\begin{array}{c}6 \\
34.4\end{array}$ \\
\hline D178 & $\begin{array}{c}0 \\
51.72\end{array}$ & $\begin{array}{c}3 \\
167.8\end{array}$ & $\begin{array}{l}\text { top } \\
\text { core }\end{array}$ & 629 & $\begin{array}{c} \pm 3 \\
4835\end{array}$ & 25 & 1.90 & & 0.87 & & $\begin{array}{l}\text { ate } \\
\text { crystal }\end{array}$ & 10.3 & $\begin{array}{c}6 \\
34.4\end{array}$ \\
\hline D178 & $\begin{array}{c}0 \\
48.95\end{array}$ & $\begin{array}{c}3 \\
174.9\end{array}$ & $\begin{array}{l}\text { top } \\
\text { core }\end{array}$ & 629 & $\begin{array}{c} \pm 3 \\
6755\end{array}$ & 26 & & & 1.98 & & $\begin{array}{l}\text { line } \\
\text { reticul }\end{array}$ & 10.3 & $\begin{array}{c}6 \\
34.2\end{array}$ \\
\hline F111 & $\begin{array}{c}0 \\
48.95\end{array}$ & $\begin{array}{c}8 \\
174.9\end{array}$ & $\begin{array}{l}\text { top } \\
\text { core }\end{array}$ & 704 & $\begin{array}{l} \pm 36 \\
6755\end{array}$ & 1 & 2.84 & & 2.80 & & $\begin{array}{l}\text { ate } \\
\text { reticul }\end{array}$ & 10.3 & $\begin{array}{c}9 \\
34.2\end{array}$ \\
\hline F111 & $\begin{array}{c}0 \\
48.95\end{array}$ & $\begin{array}{c}8 \\
174.9\end{array}$ & $\begin{array}{l}\text { top } \\
\text { core }\end{array}$ & 704 & $\begin{array}{l} \pm 36 \\
6755\end{array}$ & 2 & 2.06 & & 3.10 & & $\begin{array}{l}\text { ate } \\
\text { crystal }\end{array}$ & 10.3 & $\begin{array}{c}9 \\
34.2\end{array}$ \\
\hline F111 & $\begin{array}{c}0 \\
48.95\end{array}$ & $\begin{array}{c}8 \\
174.9\end{array}$ & $\begin{array}{l}\text { top } \\
\text { core }\end{array}$ & 704 & $\begin{array}{l} \pm 36 \\
6755\end{array}$ & 3 & 1.32 & 0.72 & 1.77 & 1.16 & $\begin{array}{l}\text { line } \\
\text { reticul }\end{array}$ & 10.3 & $\begin{array}{c}9 \\
34.2\end{array}$ \\
\hline F111 & $\begin{array}{c}0 \\
48.95\end{array}$ & $\begin{array}{c}8 \\
174.9\end{array}$ & $\begin{array}{l}\text { top } \\
\text { core }\end{array}$ & 704 & $\begin{array}{l} \pm 36 \\
6755\end{array}$ & 4 & 2.16 & & 1.58 & & $\begin{array}{l}\text { ate } \\
\text { reticul }\end{array}$ & 10.3 & $\begin{array}{c}9 \\
34.2\end{array}$ \\
\hline F111 & $\begin{array}{c}0 \\
48.95\end{array}$ & $\begin{array}{c}8 \\
174.9\end{array}$ & $\begin{array}{l}\text { top } \\
\text { core }\end{array}$ & 704 & $\begin{array}{l} \pm 36 \\
6755\end{array}$ & 5 & 2.14 & & 1.55 & & $\begin{array}{l}\text { ate } \\
\text { reticul }\end{array}$ & 10.3 & $\begin{array}{c}9 \\
34.2\end{array}$ \\
\hline F111 & $\begin{array}{c}0 \\
48.95\end{array}$ & $\begin{array}{c}8 \\
174.9\end{array}$ & $\begin{array}{l}\text { top } \\
\text { core }\end{array}$ & 704 & $\begin{array}{l} \pm 36 \\
6755\end{array}$ & 6 & 2.35 & & 1.79 & & $\begin{array}{l}\text { ate } \\
\text { reticul }\end{array}$ & 10.3 & $\begin{array}{c}9 \\
34.2\end{array}$ \\
\hline F111 & $\begin{array}{c}0 \\
48.95\end{array}$ & $\begin{array}{c}8 \\
174.9\end{array}$ & $\begin{array}{l}\text { top } \\
\text { core }\end{array}$ & 704 & $\begin{array}{l} \pm 36 \\
6755\end{array}$ & 7 & & & 1.42 & & $\begin{array}{l}\text { ate } \\
\text { crystal }\end{array}$ & 10.3 & $\begin{array}{c}9 \\
34.2\end{array}$ \\
\hline F111 & $\begin{array}{c}0 \\
48.95\end{array}$ & $\begin{array}{c}8 \\
174.9\end{array}$ & $\begin{array}{l}\text { top } \\
\text { core }\end{array}$ & 704 & $\begin{array}{l} \pm 36 \\
6755\end{array}$ & 12 & & & 1.50 & 1.50 & $\begin{array}{l}\text { line } \\
\text { crystal }\end{array}$ & 10.3 & $\begin{array}{c}9 \\
34.2\end{array}$ \\
\hline $\begin{array}{l}\text { F111 } \\
\text { FR97__ }\end{array}$ & $\begin{array}{c}0 \\
23.88\end{array}$ & $\begin{array}{c}8 \\
152.6\end{array}$ & $\begin{array}{l}\text { top } \\
\text { core }\end{array}$ & 704 & \pm 36 & 13 & & & 2.46 & 0.98 & $\begin{array}{l}\text { line } \\
\text { reticul }\end{array}$ & 10.3 & $\begin{array}{c}9 \\
35.4\end{array}$ \\
\hline GC09 & 5 & 4 & top & 991 & & 2 & 1.24 & & 2.95 & & ate & 23.5 & 8 \\
\hline FR97_ & 23.88 & 152.6 & core & & & & & & & & reticul & & 35.4 \\
\hline $\begin{array}{l}\text { GC09 } \\
\text { ODP11 }\end{array}$ & $\begin{array}{c}5 \\
4194\end{array}$ & $\begin{array}{c}4 \\
188,5\end{array}$ & top & 991 & & 3 & 0.81 & & 2.01 & & ate & 23.5 & 8 \\
\hline ODP11 & 41.94 & 188.5 & core & & & & & & & & crystal & & 35.1 \\
\hline $\begin{array}{l}23 \mathrm{C} \\
\text { ODP11 }\end{array}$ & $\begin{array}{c}2 \\
41.94\end{array}$ & $\begin{array}{c}0 \\
188.5\end{array}$ & $\begin{array}{l}\text { top } \\
\text { core }\end{array}$ & 3290 & & 1 & & 2.00 & 1.34 & 1.18 & $\begin{array}{l}\text { line } \\
\text { crystal }\end{array}$ & 13.5 & $\begin{array}{c}1 \\
35.1\end{array}$ \\
\hline $23 \mathrm{C}$ & 2 & 0 & top & 3290 & & 2 & 0.82 & & 0.78 & & line & 13.5 & 1 \\
\hline ODP11 & 41.94 & 188.5 & core & & & & & & & & reticul & & 35.1 \\
\hline $23 \mathrm{C}$ & 2 & 0 & top & 3290 & & 4 & 1.40 & & 1.35 & & ate & 13.5 & 1 \\
\hline ODP11 & 41.94 & 188.5 & core & & & & & & & & reticul & & 35.1 \\
\hline $23 \mathrm{C}$ & 2 & 0 & top & 3290 & & 5 & 1.18 & & 1.21 & & ate & 13.5 & 1 \\
\hline ODP11 & 41.94 & 188.5 & core & & & & & & & & crystal & & 35.1 \\
\hline $23 \mathrm{C}$ & 2 & 0 & top & 3290 & & 6 & & 0.80 & 1.29 & & line & 13.5 & 1 \\
\hline ODP11 & 41.94 & 188.5 & core & & & & & & & & reticul & & 35.1 \\
\hline $23 \mathrm{C}$ & 2 & 0 & top & 3290 & & 7 & 0.92 & & 1.28 & & ate & 13.5 & 1 \\
\hline ODP11 & 41.94 & 188.5 & core & & & & & & & & crystal & & 35.1 \\
\hline $23 \mathrm{C}$ & 2 & 0 & top & 3290 & & 12 & & 0.91 & 1.09 & 1.09 & line & 13.5 & 1 \\
\hline ODP11 & 41.94 & 188.5 & core & & & & & & & & crystal & & 35.1 \\
\hline $23 \mathrm{C}$ & 2 & $\begin{array}{c}0 \\
188\end{array}$ & top & 3290 & & 18 & & 1.60 & & 1.25 & line & 13.5 & $\begin{array}{c}1 \\
351\end{array}$ \\
\hline $\begin{array}{l}\text { ODP11 } \\
23 \mathrm{C}\end{array}$ & $\begin{array}{c}41.94 \\
2\end{array}$ & $\begin{array}{c}188.5 \\
0\end{array}$ & $\begin{array}{l}\text { core } \\
\text { top }\end{array}$ & 3290 & & 21 & & 0.54 & 0.50 & 0.50 & $\begin{array}{l}\text { crystal } \\
\text { line }\end{array}$ & 13.5 & $\begin{array}{c}35.1 \\
1\end{array}$ \\
\hline & 43.20 & 186.0 & core & & 6519 & & & & & & reticul & & 35.0 \\
\hline R623 & 0 & 0 & top & 1128 & \pm 35 & 1 & & & 0.91 & & ate & 12.7 & 1 \\
\hline & 43.20 & 186.0 & core & & 6519 & & & & & & crystal & & 35.0 \\
\hline R623 & $\begin{array}{c}0 \\
43.20\end{array}$ & $\begin{array}{c}0 \\
186.0\end{array}$ & $\begin{array}{l}\text { top } \\
\text { core }\end{array}$ & 1128 & $\begin{array}{l} \pm 35 \\
6519\end{array}$ & 2 & & & 1.24 & 0.89 & $\begin{array}{l}\text { line } \\
\text { crystal }\end{array}$ & 12.7 & $\begin{array}{c}1 \\
35.0\end{array}$ \\
\hline R623 & 0 & 0 & top & 1128 & \pm 35 & 3 & & & 2.05 & 1.02 & line & 12.7 & 1 \\
\hline
\end{tabular}




\begin{tabular}{|c|c|c|c|c|c|c|c|c|c|c|c|c|c|}
\hline $\begin{array}{l}\text { Sit } \\
\mathrm{e}\end{array}$ & $\begin{array}{l}\text { Latitu } \\
\text { de }\end{array}$ & $\begin{array}{l}\text { Longit } \\
\text { ude }\end{array}$ & $\begin{array}{l}\text { Core } \\
\text { Type }\end{array}$ & $\begin{array}{c}\text { Dept } \\
\text { h }\end{array}$ & Age & $\begin{array}{c}\text { Indivi } \\
\text { dual } \\
\text { Numb } \\
\text { er }\end{array}$ & $\begin{array}{c}\text { F-3 Mg/Ca } \\
\text { (ICL) }\end{array}$ & $\begin{array}{c}\mathrm{F}-3 \mathrm{Mg} / \mathrm{Ca} \\
(\mathrm{OCL})\end{array}$ & $\begin{array}{c}\mathrm{F} \underset{\text { (ICL) }}{\mathrm{Mg} / \mathrm{Ca}} \\
\text { (ICL) }\end{array}$ & $\begin{array}{c}\mathrm{F} \mathrm{Mg} / \mathrm{Ca} \\
\text { (OCL) }\end{array}$ & $\begin{array}{l}\text { Ultra- } \\
\text { struct } \\
\text { ure }\end{array}$ & $\begin{array}{c}\text { WO } \\
\text { A05 } \\
\text { SST } \\
(0- \\
100 \mathrm{~m} \\
)\end{array}$ & $\begin{array}{l}\text { Salin } \\
\text { ity }\end{array}$ \\
\hline & $\begin{array}{l}\text { (degr } \\
\text { ees) }\end{array}$ & $\begin{array}{c}\text { (degre } \\
\text { es) }\end{array}$ & & $\begin{array}{c}\text { (metr } \\
\text { es) }\end{array}$ & $(\mathrm{yr})$ & & $\begin{array}{c}(\mathrm{mmol} / \mathrm{mo} \\
\mathrm{l})\end{array}$ & $(\mathrm{mmol} / \mathrm{mol})$ & $\begin{array}{c}(\mathrm{mmol} / \mathrm{m} \\
\mathrm{ol})\end{array}$ & $\begin{array}{c}(\mathrm{mmol} / \mathrm{m} \\
\mathrm{ol})\end{array}$ & & $\left({ }^{\circ} \mathrm{C}\right)$ & $\begin{array}{c}\text { (psu } \\
\text { ) }\end{array}$ \\
\hline R6 & 43.20 & & core & & 6519 & & & & & & crystal & & 35.0 \\
\hline $\begin{array}{l}23 \\
\text { R6 }\end{array}$ & $\begin{array}{c}0 \\
43.20\end{array}$ & 186.00 & $\begin{array}{l}\text { top } \\
\text { core }\end{array}$ & 1128 & $\begin{array}{l} \pm 35 \\
6519\end{array}$ & 3 & & & 2.05 & 1.02 & $\begin{array}{l}\text { line } \\
\text { reticul }\end{array}$ & 12.7 & $\begin{array}{c}1 \\
35.0\end{array}$ \\
\hline $\begin{array}{l}23 \\
\text { R6 }\end{array}$ & $\begin{array}{c}0 \\
43.20\end{array}$ & 186.00 & $\begin{array}{l}\text { top } \\
\text { core }\end{array}$ & 1128 & $\begin{array}{l} \pm 35 \\
6519\end{array}$ & 4 & 1.21 & & 1.64 & & $\begin{array}{l}\text { ate } \\
\text { reticul }\end{array}$ & 12.7 & $\begin{array}{c}1 \\
35.0\end{array}$ \\
\hline 23 & 0 & 186.00 & top & 1128 & \pm 35 & 5 & 1.61 & & 1.01 & & ate & 12.7 & 1 \\
\hline $\begin{array}{l}\text { R6 } \\
23\end{array}$ & $\begin{array}{c}43.20 \\
0\end{array}$ & 186.00 & $\begin{array}{l}\text { core } \\
\text { top }\end{array}$ & 1128 & $\begin{array}{l}6519 \\
\pm 35\end{array}$ & 7 & 1.17 & 1.57 & 1.44 & 1.72 & $\begin{array}{l}\text { crystal } \\
\text { line }\end{array}$ & 12.7 & $\begin{array}{c}35.0 \\
1\end{array}$ \\
\hline R6 & 43.20 & & core & & 6519 & & & & & & reticul & & 35.0 \\
\hline 23 & 0 & 186.00 & top & 1128 & \pm 35 & 8 & 1.73 & & 1.96 & & ate & 12.7 & 1 \\
\hline R6 & 43.20 & & core & & 6519 & & & & & & reticul & & 35.0 \\
\hline 23 & 0 & 186.00 & top & 1128 & \pm 35 & 9 & & & 2.58 & & ate & 12.7 & 1 \\
\hline R6 & 43.20 & & $\begin{array}{l}1 \\
\text { core }\end{array}$ & & 6519 & & & & & & reticul & & 35.0 \\
\hline 23 & 0 & 186.00 & top & 1128 & \pm 35 & 12 & 1.88 & & 1.29 & & ate & 12.7 & 1 \\
\hline $\begin{array}{l}\mathrm{R} 6 \\
23\end{array}$ & $\begin{array}{c}43.20 \\
0\end{array}$ & 186.00 & $\begin{array}{l}\text { core } \\
\text { top }\end{array}$ & 1128 & $\begin{array}{l}6519 \\
\pm 35\end{array}$ & 31 & 1.25 & 0.72 & 1.36 & 0.93 & $\begin{array}{l}\text { crystal } \\
\text { line }\end{array}$ & 12.7 & $\begin{array}{c}35.0 \\
1\end{array}$ \\
\hline $\begin{array}{l}\text { R6 } \\
23 \\
\text { R6 }\end{array}$ & $\begin{array}{c}43.20 \\
0 \\
43.20\end{array}$ & 186.00 & $\begin{array}{l}\text { core } \\
\text { top }\end{array}$ & 1128 & $\begin{array}{r}6519 \\
\pm 35 \\
6519\end{array}$ & 32 & & & & 0.77 & $\begin{array}{l}\text { crystal } \\
\text { line }\end{array}$ & 12.7 & $\begin{array}{c}35.0 \\
1\end{array}$ \\
\hline $\begin{array}{l}\text { R6 } \\
23\end{array}$ & $\begin{array}{c}43.20 \\
0\end{array}$ & & core & & 6519 & & & & & & reticul & & 35.0 \\
\hline B6 & 4320 & 180.00 & top & 1128 & $\begin{array}{l} \pm 35 \\
6510\end{array}$ & 33 & 1.57 & & 1.65 & & ate & 12.7 & $\begin{array}{c}1 \\
35.0\end{array}$ \\
\hline 23 & 0 & 186.00 & top & 1128 & $\begin{array}{r}0519 \\
\pm 35\end{array}$ & 34 & & & & 0.87 & $\begin{array}{l}\text { crystal } \\
\text { line }\end{array}$ & 12.7 & 1 \\
\hline R6 & 43.20 & & core & & 6519 & & & & & & reticul & & 35.0 \\
\hline 23 & 0 & 186.00 & top & 1128 & \pm 35 & 35 & 1.24 & & 1.07 & & ate & 12.7 & 1 \\
\hline R6 & 43.20 & & core & & 6519 & & & & & & reticul & & 35.0 \\
\hline 23 & 0 & 186.00 & top & 1128 & \pm 35 & 36 & 1.37 & & 1.47 & & ate & 12.7 & 1 \\
\hline R6 & 43.20 & & core & & 6519 & & & & & & reticul & & 35.0 \\
\hline 23 & 0 & 186.00 & top & 1128 & \pm 35 & 37 & 2.02 & & 1.40 & & ate & 12.7 & 1 \\
\hline $\begin{array}{l}\text { R6 } \\
23\end{array}$ & $\begin{array}{c}43.20 \\
0\end{array}$ & 186.00 & $\begin{array}{l}\text { core } \\
\text { top }\end{array}$ & 1128 & $\begin{array}{c}6519 \\
\pm 35\end{array}$ & 40 & & 0.84 & & 1.16 & $\begin{array}{l}\text { crystal } \\
\text { line }\end{array}$ & 12.7 & $\begin{array}{c}35.0 \\
1\end{array}$ \\
\hline $\begin{array}{l}\text { R6 } \\
23\end{array}$ & $\begin{array}{c}43.20 \\
0\end{array}$ & 186.00 & $\begin{array}{l}\text { core } \\
\text { top }\end{array}$ & 1128 & $\begin{array}{r}6519 \\
\pm 35\end{array}$ & 41 & & 0.81 & & 1.00 & $\begin{array}{l}\text { crystal } \\
\text { line }\end{array}$ & 127 & $\begin{array}{c}35.0 \\
1\end{array}$ \\
\hline R6 & 43.20 & & core & & 6519 & & & & & & reticul & & 35.0 \\
\hline 23 & 0 & 186.00 & top & 1128 & \pm 35 & 42 & 1.90 & & 1.67 & & ate & 12.7 & 1 \\
\hline $\begin{array}{l}\text { R6 } \\
23 \\
\text { R6 }\end{array}$ & $\begin{array}{c}43.20 \\
0 \\
43.20\end{array}$ & 186.00 & $\begin{array}{l}\text { core } \\
\text { top } \\
\text { core }\end{array}$ & 1128 & $\begin{array}{r}6519 \\
\pm 35 \\
6519\end{array}$ & 43 & 0.98 & 0.65 & 1.47 & 0.94 & $\begin{array}{l}\text { crystal } \\
\text { line } \\
\text { reticul }\end{array}$ & 12.7 & $\begin{array}{c}35.0 \\
1 \\
35.0\end{array}$ \\
\hline 23 & 0 & 186.00 & top & 1128 & \pm 35 & 45 & 1.47 & & 1.10 & & ate & 12.7 & 1 \\
\hline R6 & 43.20 & & core & & 6519 & & & & & & reticul & & 35.0 \\
\hline 23 & 0 & 186.00 & top & 1128 & \pm 35 & 46 & & & 1.51 & & ate & 12.7 & 1 \\
\hline $\begin{array}{l}\text { R6 } \\
23\end{array}$ & $\begin{array}{c}43.20 \\
0\end{array}$ & 186.00 & $\begin{array}{l}\text { core } \\
\text { top }\end{array}$ & 1128 & $\begin{array}{l}6519 \\
\pm 35\end{array}$ & 48 & 1.48 & 0.95 & 1.81 & 0.95 & $\begin{array}{l}\text { crystal } \\
\text { line }\end{array}$ & 12.7 & $\begin{array}{c}35.0 \\
1\end{array}$ \\
\hline $\begin{array}{l}\text { R6 } \\
23\end{array}$ & $\begin{array}{c}43.20 \\
0\end{array}$ & 186.00 & $\begin{array}{l}\text { core } \\
\text { top }\end{array}$ & 1128 & $\begin{array}{l}6519 \\
\pm 35\end{array}$ & 50 & 1.03 & 0.70 & 1.47 & 0.64 & $\begin{array}{l}\text { crystal } \\
\text { line }\end{array}$ & 12.7 & $\begin{array}{c}35.0 \\
1\end{array}$ \\
\hline $\begin{array}{l}\text { R6 } \\
23\end{array}$ & $\begin{array}{c}43.20 \\
0\end{array}$ & 186.00 & $\begin{array}{l}\text { core } \\
\text { top }\end{array}$ & 1128 & $\begin{array}{r}6519 \\
\pm 35\end{array}$ & 52 & & 1.19 & 1.79 & 1.79 & $\begin{array}{l}\text { crystal } \\
\text { line }\end{array}$ & 12.7 & $\begin{array}{c}35.0 \\
1\end{array}$ \\
\hline $\begin{array}{l}\text { R6 } \\
23\end{array}$ & $\begin{array}{c}43.20 \\
0\end{array}$ & 186.00 & $\begin{array}{l}\text { core } \\
\text { top }\end{array}$ & 1128 & $\begin{array}{c}6519 \\
\pm 35\end{array}$ & 53 & 1.38 & 0.86 & 1.45 & 0.82 & $\begin{array}{l}\text { crystal } \\
\text { line }\end{array}$ & 12.7 & $\begin{array}{c}35.0 \\
1\end{array}$ \\
\hline $\begin{array}{l}\text { S9 } \\
38\end{array}$ & $\begin{array}{c}40.33 \\
0\end{array}$ & 179.99 & $\begin{array}{l}\text { core } \\
\text { top }\end{array}$ & 3003 & $\begin{array}{c}843 \pm \\
35\end{array}$ & 4 & 0.69 & & 0.74 & & $\begin{array}{l}\text { reticul } \\
\text { ate }\end{array}$ & 14.9 & $\begin{array}{c}35.3 \\
4\end{array}$ \\
\hline $\begin{array}{l}\text { S9 } \\
38\end{array}$ & $\begin{array}{c}40.33 \\
0\end{array}$ & 179.99 & $\begin{array}{l}\text { core } \\
\text { top }\end{array}$ & 3003 & $\begin{array}{c}843 \pm \\
35\end{array}$ & 5 & 1.33 & 0.91 & 1.28 & 0.97 & $\begin{array}{l}\text { crystal } \\
\text { line }\end{array}$ & 14.9 & $\begin{array}{c}35.3 \\
4\end{array}$ \\
\hline $\begin{array}{l}\text { S9 } \\
38\end{array}$ & $\begin{array}{c}40.33 \\
0\end{array}$ & 179.99 & $\begin{array}{l}\text { core } \\
\text { top }\end{array}$ & 3003 & $\begin{array}{c}843 \pm \\
35\end{array}$ & 6 & 1.68 & & 1.19 & & $\begin{array}{l}\text { reticul } \\
\text { ate }\end{array}$ & 14.9 & $\begin{array}{c}35.3 \\
4\end{array}$ \\
\hline $\begin{array}{l}\text { S9 } \\
38\end{array}$ & $\begin{array}{c}40.33 \\
0\end{array}$ & 179.99 & $\begin{array}{l}\text { core } \\
\text { top }\end{array}$ & 3003 & $\begin{array}{c}843 \pm \\
35\end{array}$ & 8 & 1.40 & & 1.33 & & reticul & 14.9 & $\begin{array}{c}35.3 \\
4\end{array}$ \\
\hline $\begin{array}{l}\text { S9 } \\
38\end{array}$ & $\begin{array}{c}40.33 \\
0\end{array}$ & 179.99 & $\begin{array}{l}\text { core } \\
\text { top }\end{array}$ & 3003 & $\begin{array}{c}843 \pm \\
35\end{array}$ & 9 & 1.04 & & 1.24 & & $\begin{array}{l}\text { reticul } \\
\text { ate }\end{array}$ & 14.9 & $\begin{array}{c}35.3 \\
4\end{array}$ \\
\hline
\end{tabular}




\begin{tabular}{|c|c|c|c|c|c|c|c|c|c|c|c|c|c|}
\hline Site & $\begin{array}{c}\text { Latit } \\
\text { ude }\end{array}$ & $\begin{array}{c}\text { Longi } \\
\text { tude }\end{array}$ & $\begin{array}{l}\text { Core } \\
\text { Type } \\
\end{array}$ & $\begin{array}{c}\text { Dep } \\
\text { th }\end{array}$ & Age & $\begin{array}{c}\text { Indiv } \\
\text { idual } \\
\text { Num } \\
\text { ber }\end{array}$ & $\begin{array}{c}\mathrm{F}-3 \\
\mathrm{Mg} / \mathrm{Ca} \\
\text { (ICL) }\end{array}$ & $\begin{array}{c}\mathrm{F}-3 \\
\mathrm{Mg} / \mathrm{Ca} \\
\text { (OCL) }\end{array}$ & $\begin{array}{c}\mathrm{F} \\
\mathrm{Mg} / \mathrm{Ca} \\
\text { (ICL) }\end{array}$ & $\begin{array}{c}\mathrm{F} \mathrm{Mg} / \mathrm{Ca} \\
(\mathrm{OCL})\end{array}$ & $\begin{array}{c}\text { Ultra } \\
- \\
\text { struct } \\
\text { ure } \\
\end{array}$ & $\begin{array}{c}\text { WO } \\
\text { A05 } \\
\text { SST } \\
(0- \\
100 \\
\text { m) } \\
\end{array}$ & $\begin{array}{l}\text { Sali } \\
\text { nity }\end{array}$ \\
\hline & $\begin{array}{l}\text { (degr } \\
\text { ees) }\end{array}$ & $\begin{array}{c}\text { (degr } \\
\text { ees) }\end{array}$ & & $\begin{array}{c}\text { (met } \\
\text { res) }\end{array}$ & (yr) & & $\begin{array}{c}(\mathrm{mmol} / \mathrm{m} \\
\mathrm{ol})\end{array}$ & $\begin{array}{c}(\mathrm{mmol} / \mathrm{mo} \\
\mathrm{l})\end{array}$ & $\begin{array}{c}(\mathrm{mmol} / \\
\mathrm{mol})\end{array}$ & $\begin{array}{c}(\mathrm{mmol} / \\
\mathrm{mol})\end{array}$ & & $\left({ }^{\circ} \mathrm{C}\right)$ & $\begin{array}{l}(\mathrm{ps} \\
\mathrm{u})\end{array}$ \\
\hline S938 & $\begin{array}{c}40.3 \\
30\end{array}$ & $\begin{array}{c}179.9 \\
9\end{array}$ & $\begin{array}{l}\text { core } \\
\text { top }\end{array}$ & $\begin{array}{c}300 \\
3\end{array}$ & $\begin{array}{c}843 \pm \\
35\end{array}$ & 10 & 1.57 & & 1.90 & & $\begin{array}{l}\text { reticu } \\
\text { late }\end{array}$ & 14.9 & $\begin{array}{c}35.3 \\
4\end{array}$ \\
\hline S938 & $\begin{array}{c}40.3 \\
30\end{array}$ & $\begin{array}{c}179.9 \\
9\end{array}$ & $\begin{array}{l}\text { core } \\
\text { top }\end{array}$ & $\begin{array}{c}300 \\
3\end{array}$ & $\begin{array}{c}843 \pm \\
35\end{array}$ & 11 & 1.40 & 0.91 & 1.17 & 0.82 & $\begin{array}{l}\text { crysta } \\
\text { lline }\end{array}$ & 14.9 & $\begin{array}{c}35.3 \\
4\end{array}$ \\
\hline S938 & $\begin{array}{c}40.3 \\
30\end{array}$ & $\begin{array}{c}179.9 \\
9\end{array}$ & $\begin{array}{l}\text { core } \\
\text { top }\end{array}$ & $\begin{array}{c}300 \\
3\end{array}$ & $\begin{array}{c}843 \pm \\
35\end{array}$ & 12 & & & 1.29 & 0.90 & $\begin{array}{l}\text { crysta } \\
\text { lline }\end{array}$ & 14.9 & $\begin{array}{c}35.3 \\
4\end{array}$ \\
\hline S938 & $\begin{array}{c}40.3 \\
30\end{array}$ & $\begin{array}{c}179.9 \\
9\end{array}$ & $\begin{array}{l}\text { core } \\
\text { top }\end{array}$ & $\begin{array}{c}300 \\
3\end{array}$ & $\begin{array}{c}843 \pm \\
35\end{array}$ & 14 & 1.16 & & 1.27 & & $\begin{array}{l}\text { reticu } \\
\text { late }\end{array}$ & 14.9 & $\begin{array}{c}35.3 \\
4\end{array}$ \\
\hline $\begin{array}{l}\text { TAN0103 } \\
\text { U2309 NET } 5\end{array}$ & $\begin{array}{c}46.6 \\
78\end{array}$ & $\begin{array}{c}178.5 \\
1\end{array}$ & $\begin{array}{c}\text { plankto } \\
\mathrm{n} \text { tow }\end{array}$ & 100 & $\begin{array}{l}\text { April } \\
2001\end{array}$ & 1 & 1.74 & & 1.36 & & $\begin{array}{l}\text { reticu } \\
\text { late }\end{array}$ & 7.9 & $\begin{array}{c}34.3 \\
7\end{array}$ \\
\hline $\begin{array}{l}\text { TAN0103 } \\
\text { U2309 NET } 5\end{array}$ & $\begin{array}{l}46.6 \\
78\end{array}$ & $\begin{array}{c}178.5 \\
1\end{array}$ & $\begin{array}{l}\text { plankto } \\
\mathrm{n} \text { tow }\end{array}$ & 100 & $\begin{array}{l}\text { April } \\
2001\end{array}$ & 2 & 1.59 & & 2.21 & & $\begin{array}{l}\text { reticu } \\
\text { late }\end{array}$ & 7.9 & $\begin{array}{c}34.3 \\
7\end{array}$ \\
\hline $\begin{array}{l}\text { TAN0103 } \\
\text { U2309 NET } 5\end{array}$ & $\begin{array}{c}46.6 \\
78\end{array}$ & $\begin{array}{c}178.5 \\
1\end{array}$ & $\begin{array}{c}\text { plankto } \\
\mathrm{n} \text { tow }\end{array}$ & 100 & $\begin{array}{l}\text { April } \\
2001\end{array}$ & 3 & 1.33 & & 1.59 & & $\begin{array}{l}\text { reticu } \\
\text { late }\end{array}$ & 7.9 & $\begin{array}{c}34.3 \\
7\end{array}$ \\
\hline $\begin{array}{l}\text { TAN0103 } \\
\text { U2309 NET } 5\end{array}$ & $\begin{array}{c}46.6 \\
78\end{array}$ & $\begin{array}{c}178.5 \\
1\end{array}$ & $\begin{array}{l}\text { plankto } \\
\mathrm{n} \text { tow }\end{array}$ & 100 & $\begin{array}{l}\text { April } \\
2001\end{array}$ & 4 & 1.73 & & 1.42 & & $\begin{array}{l}\text { reticu } \\
\text { late }\end{array}$ & 7.9 & $\begin{array}{c}34.3 \\
7\end{array}$ \\
\hline $\begin{array}{l}\text { TAN0103 } \\
\text { U2315 }\end{array}$ & $\begin{array}{c}38.5 \\
09\end{array}$ & $\begin{array}{c}179.0 \\
2\end{array}$ & $\begin{array}{c}\text { plankto } \\
\mathrm{n} \text { tow }\end{array}$ & 125 & $\begin{array}{l}\text { April } \\
2001\end{array}$ & 1 & 1.47 & & 5.25 & & $\begin{array}{l}\text { reticu } \\
\text { late }\end{array}$ & 20.3 & $\begin{array}{c}35.6 \\
5\end{array}$ \\
\hline $\begin{array}{l}\text { TAN0103 } \\
\text { U2315 }\end{array}$ & $\begin{array}{c}38.5 \\
09\end{array}$ & $\begin{array}{c}179.0 \\
2\end{array}$ & $\begin{array}{l}\text { plankto } \\
\mathrm{n} \text { tow }\end{array}$ & 125 & $\begin{array}{l}\text { April } \\
2001\end{array}$ & 2 & 1.71 & & 2.88 & & $\begin{array}{l}\text { reticu } \\
\text { late }\end{array}$ & 20.3 & $\begin{array}{c}35.6 \\
5\end{array}$ \\
\hline $\begin{array}{l}\text { TAN0103 } \\
\text { U2322 net } 6\end{array}$ & $\begin{array}{c}41.6 \\
01\end{array}$ & $\begin{array}{c}178.0 \\
5\end{array}$ & $\begin{array}{c}\text { plankto } \\
\mathrm{n} \text { tow }\end{array}$ & 100 & $\begin{array}{l}\text { April } \\
2001\end{array}$ & 1 & 2.52 & & 1.44 & & $\begin{array}{l}\text { reticu } \\
\text { late }\end{array}$ & 18.3 & $\begin{array}{c}35.6 \\
1\end{array}$ \\
\hline R623 & $\begin{array}{c}43.2 \\
00\end{array}$ & $\begin{array}{c}186.0 \\
0\end{array}$ & $\begin{array}{l}\text { core } \\
\text { top }\end{array}$ & $\begin{array}{c}112 \\
8\end{array}$ & $\begin{array}{l}6519 \\
\pm 35\end{array}$ & 52 & & 1.19 & 1.79 & 1.79 & $\begin{array}{l}\text { crysta } \\
\text { lline }\end{array}$ & 12.7 & $\begin{array}{c}35.0 \\
1\end{array}$ \\
\hline R623 & $\begin{array}{c}43.2 \\
00\end{array}$ & $\begin{array}{c}186.0 \\
0\end{array}$ & $\begin{array}{l}\text { core } \\
\text { top }\end{array}$ & $\begin{array}{c}112 \\
8\end{array}$ & $\begin{array}{l}6519 \\
\pm 35\end{array}$ & 53 & 1.38 & 0.86 & 1.45 & 0.82 & $\begin{array}{l}\text { crysta } \\
\text { lline }\end{array}$ & 12.7 & $\begin{array}{c}35.0 \\
1\end{array}$ \\
\hline S938 & $\begin{array}{c}40.3 \\
30\end{array}$ & $\begin{array}{c}179.9 \\
9\end{array}$ & $\begin{array}{l}\text { core } \\
\text { top }\end{array}$ & $\begin{array}{c}300 \\
3\end{array}$ & $\begin{array}{l}843 \pm \\
35\end{array}$ & 4 & 0.69 & & 0.74 & & $\begin{array}{l}\text { reticu } \\
\text { late }\end{array}$ & 14.9 & $\begin{array}{c}35.3 \\
4\end{array}$ \\
\hline S938 & $\begin{array}{c}40.3 \\
30\end{array}$ & $\begin{array}{c}179.9 \\
9\end{array}$ & $\begin{array}{l}\text { core } \\
\text { top }\end{array}$ & $\begin{array}{c}300 \\
3\end{array}$ & $\begin{array}{c}843 \pm \\
35\end{array}$ & 5 & 1.33 & 0.91 & 1.28 & 0.97 & $\begin{array}{l}\text { crysta } \\
\text { lline }\end{array}$ & 14.9 & $\begin{array}{c}35.3 \\
4\end{array}$ \\
\hline S938 & $\begin{array}{c}40.3 \\
30\end{array}$ & $\begin{array}{c}179.9 \\
9\end{array}$ & $\begin{array}{l}\text { core } \\
\text { top }\end{array}$ & $\begin{array}{c}300 \\
3\end{array}$ & $\begin{array}{c}843 \pm \\
35\end{array}$ & 6 & 1.68 & & 1.19 & & $\begin{array}{l}\text { reticu } \\
\text { late }\end{array}$ & 14.9 & $\begin{array}{c}35.3 \\
4\end{array}$ \\
\hline S938 & $\begin{array}{c}40.3 \\
30\end{array}$ & $\begin{array}{c}179.9 \\
9\end{array}$ & $\begin{array}{l}\text { core } \\
\text { top }\end{array}$ & $\begin{array}{c}300 \\
3\end{array}$ & $\begin{array}{c}843 \pm \\
35\end{array}$ & 8 & 1.40 & & 1.33 & & $\begin{array}{l}\text { reticu } \\
\text { late }\end{array}$ & 14.9 & $\begin{array}{c}35.3 \\
4\end{array}$ \\
\hline S938 & $\begin{array}{c}40.3 \\
30\end{array}$ & $\begin{array}{c}179.9 \\
9\end{array}$ & $\begin{array}{l}\text { core } \\
\text { top }\end{array}$ & $\begin{array}{c}300 \\
3\end{array}$ & $\begin{array}{c}843 \pm \\
35\end{array}$ & 9 & 1.04 & & 1.24 & & $\begin{array}{l}\text { reticu } \\
\text { late }\end{array}$ & 14.9 & $\begin{array}{c}35.3 \\
4\end{array}$ \\
\hline S938 & $\begin{array}{c}40.3 \\
30\end{array}$ & $\begin{array}{c}179.9 \\
9\end{array}$ & $\begin{array}{l}\text { core } \\
\text { top }\end{array}$ & $\begin{array}{c}300 \\
3\end{array}$ & $\begin{array}{c}843 \pm \\
35\end{array}$ & 10 & 1.57 & & 1.90 & & $\begin{array}{l}\text { reticu } \\
\text { late }\end{array}$ & 14.9 & $\begin{array}{c}35.3 \\
4\end{array}$ \\
\hline S938 & $\begin{array}{c}40.3 \\
30\end{array}$ & $\begin{array}{c}179.9 \\
9\end{array}$ & $\begin{array}{l}\text { core } \\
\text { top }\end{array}$ & $\begin{array}{c}300 \\
3\end{array}$ & $\begin{array}{c}843 \pm \\
35\end{array}$ & 11 & 1.40 & 0.91 & 1.17 & 0.82 & $\begin{array}{l}\text { crysta } \\
\text { lline }\end{array}$ & 14.9 & $\begin{array}{c}35.3 \\
4\end{array}$ \\
\hline S938 & $\begin{array}{c}40.3 \\
30\end{array}$ & $\begin{array}{c}179.9 \\
9\end{array}$ & $\begin{array}{l}\text { core } \\
\text { top }\end{array}$ & $\begin{array}{c}300 \\
3\end{array}$ & $\begin{array}{c}843 \pm \\
35\end{array}$ & 12 & & & 1.29 & 0.90 & $\begin{array}{l}\text { crysta } \\
\text { lline }\end{array}$ & 14.9 & $\begin{array}{c}35.3 \\
4\end{array}$ \\
\hline S938 & $\begin{array}{c}40.3 \\
30\end{array}$ & $\begin{array}{c}179.9 \\
9\end{array}$ & $\begin{array}{l}\text { core } \\
\text { top }\end{array}$ & $\begin{array}{c}300 \\
3\end{array}$ & $\begin{array}{c}843 \pm \\
35\end{array}$ & 14 & 1.16 & & 1.27 & & $\begin{array}{l}\text { reticu } \\
\text { late }\end{array}$ & 14.9 & $\begin{array}{c}35.3 \\
4\end{array}$ \\
\hline $\begin{array}{c}\text { TAN0103 } \\
\text { U2309 NET } 5\end{array}$ & $\begin{array}{c}46.6 \\
78\end{array}$ & $\begin{array}{c}178.5 \\
1\end{array}$ & $\begin{array}{c}\text { plankto } \\
\mathrm{n} \text { tow }\end{array}$ & 100 & $\begin{array}{l}\text { April } \\
2001\end{array}$ & 1 & 1.74 & & 1.36 & & $\begin{array}{l}\text { reticu } \\
\text { late }\end{array}$ & 7.9 & $\begin{array}{c}34.3 \\
7\end{array}$ \\
\hline $\begin{array}{c}\text { TAN0103 } \\
\text { U2309 NET } 5\end{array}$ & $\begin{array}{c}46.6 \\
78\end{array}$ & $\begin{array}{c}178.5 \\
1\end{array}$ & $\begin{array}{c}\text { plankto } \\
\mathrm{n} \text { tow }\end{array}$ & 100 & $\begin{array}{l}\text { April } \\
2001\end{array}$ & 2 & 1.59 & & 2.21 & & $\begin{array}{l}\text { reticu } \\
\text { late }\end{array}$ & 7.9 & $\begin{array}{c}34.3 \\
7\end{array}$ \\
\hline $\begin{array}{l}\text { TAN0103 } \\
\text { U2309 NET } 5\end{array}$ & $\begin{array}{c}46.6 \\
78\end{array}$ & $\begin{array}{c}178.5 \\
1\end{array}$ & $\begin{array}{c}\text { plankto } \\
\mathrm{n} \text { tow }\end{array}$ & 100 & $\begin{array}{l}\text { April } \\
2001\end{array}$ & 3 & 1.33 & & 1.59 & & $\begin{array}{l}\text { reticu } \\
\text { late }\end{array}$ & 7.9 & $\begin{array}{c}34.3 \\
7\end{array}$ \\
\hline $\begin{array}{c}\text { TAN0103 } \\
\text { U2309 NET } 5\end{array}$ & $\begin{array}{c}46.6 \\
78\end{array}$ & $\begin{array}{c}178.5 \\
1\end{array}$ & $\begin{array}{c}\text { plankto } \\
\mathrm{n} \text { tow }\end{array}$ & 100 & $\begin{array}{l}\text { April } \\
2001\end{array}$ & 4 & 1.73 & & 1.42 & & $\begin{array}{l}\text { reticu } \\
\text { late }\end{array}$ & 7.9 & $\begin{array}{c}34.3 \\
7\end{array}$ \\
\hline $\begin{array}{c}\text { TAN0103 } \\
\text { U2315 }\end{array}$ & $\begin{array}{c}38.5 \\
09\end{array}$ & $\begin{array}{c}179.0 \\
2\end{array}$ & $\begin{array}{c}\text { plankto } \\
\mathrm{n} \text { tow }\end{array}$ & 125 & $\begin{array}{l}\text { April } \\
2001\end{array}$ & 1 & 1.47 & & 5.25 & & $\begin{array}{l}\text { reticu } \\
\text { late }\end{array}$ & 20.3 & $\begin{array}{c}35.6 \\
5\end{array}$ \\
\hline
\end{tabular}




\begin{tabular}{|c|c|c|c|c|c|c|c|c|c|c|c|c|c|}
\hline Site & $\begin{array}{l}\text { Latit } \\
\text { ude }\end{array}$ & $\begin{array}{c}\text { Longi } \\
\text { tude }\end{array}$ & $\begin{array}{l}\text { Core } \\
\text { Type }\end{array}$ & $\begin{array}{c}\text { Dep } \\
\text { th }\end{array}$ & Age & $\begin{array}{c}\text { Indivi } \\
\text { dual } \\
\text { Num } \\
\text { ber }\end{array}$ & $\begin{array}{c}\mathrm{F}-3 \\
\mathrm{Mg} / \mathrm{Ca} \\
\text { (ICL) } \\
\end{array}$ & $\begin{array}{c}\mathrm{F}-3 \\
\mathrm{Mg} / \mathrm{Ca} \\
\text { (OCL) } \\
\end{array}$ & $\begin{array}{c}\mathrm{F} \\
\mathrm{Mg} / \mathrm{Ca} \\
(\mathrm{ICL}) \\
\end{array}$ & $\begin{array}{c}\mathrm{F} \mathrm{Mg} / \mathrm{Ca} \\
(\mathrm{OCL})\end{array}$ & $\begin{array}{c}\text { Ultra } \\
- \\
\text { struct } \\
\text { ure } \\
\end{array}$ & $\begin{array}{c}\text { WO } \\
\text { A05 } \\
\text { SST } \\
(0- \\
100 \\
\mathrm{~m}) \\
\end{array}$ & $\begin{array}{l}\text { Sali } \\
\text { nity }\end{array}$ \\
\hline & $\begin{array}{c}\text { (degr } \\
\text { ees) }\end{array}$ & $\begin{array}{l}\text { (degr } \\
\text { ees) }\end{array}$ & & $\begin{array}{c}\text { (met } \\
\text { res) }\end{array}$ & (yr) & & $\begin{array}{c}(\mathrm{mmol} / \mathrm{m} \\
\mathrm{ol})\end{array}$ & $\begin{array}{c}(\mathrm{mmol} / \mathrm{mo} \\
\mathrm{l})\end{array}$ & $\begin{array}{c}(\mathrm{mmol} / \\
\mathrm{mol})\end{array}$ & $\begin{array}{c}(\mathrm{mmol} / \\
\mathrm{mol})\end{array}$ & & $\left({ }^{\circ} \mathrm{C}\right)$ & $\begin{array}{l}\text { (ps } \\
\mathrm{u})\end{array}$ \\
\hline $\begin{array}{l}\text { TAN0103 } \\
\text { U2315 }\end{array}$ & $\begin{array}{c}38.5 \\
09\end{array}$ & $\begin{array}{c}179.0 \\
2\end{array}$ & $\begin{array}{l}\text { plankto } \\
\mathrm{n} \text { tow }\end{array}$ & 125 & $\begin{array}{l}\text { April } \\
2001\end{array}$ & 2 & 1.71 & & 2.88 & & $\begin{array}{l}\text { reticu } \\
\text { late }\end{array}$ & 20.3 & $\begin{array}{c}35.6 \\
5\end{array}$ \\
\hline $\begin{array}{l}\text { TAN0103 } \\
\text { U2322 net } 6\end{array}$ & $\begin{array}{c}41.6 \\
01\end{array}$ & $\begin{array}{c}178.0 \\
5\end{array}$ & $\begin{array}{l}\text { plankto } \\
\mathrm{n} \text { tow }\end{array}$ & 100 & $\begin{array}{l}\text { April } \\
2001\end{array}$ & 2 & 2.63 & & 2.49 & & $\begin{array}{l}\text { reticu } \\
\text { late }\end{array}$ & 18.3 & $\begin{array}{c}35.6 \\
1\end{array}$ \\
\hline $\begin{array}{l}\text { TAN0103 } \\
\text { U2322 net } 6\end{array}$ & $\begin{array}{l}41.6 \\
01\end{array}$ & $\begin{array}{l}178.0 \\
5\end{array}$ & $\begin{array}{l}\text { plankto } \\
\text { n tow }\end{array}$ & 100 & $\begin{array}{l}\text { April } \\
2001\end{array}$ & 6 & 1.37 & & 1.64 & & $\begin{array}{l}\text { reticu } \\
\text { late }\end{array}$ & 18.3 & $\begin{array}{l}35.6 \\
1\end{array}$ \\
\hline $\begin{array}{l}\text { TAN0103 } \\
\text { U2322 net } 6\end{array}$ & $\begin{array}{l}41.6 \\
01\end{array}$ & $\begin{array}{l}178.0 \\
5\end{array}$ & $\begin{array}{l}\text { plankto } \\
\text { n tow }\end{array}$ & 100 & $\begin{array}{l}\text { April } \\
2001\end{array}$ & 7 & 3.09 & & 1.69 & & $\begin{array}{l}\text { reticu } \\
\text { late }\end{array}$ & 18.3 & $\begin{array}{l}35.6 \\
1\end{array}$ \\
\hline Z7003 & $\begin{array}{l}36.6 \\
93\end{array}$ & $\begin{array}{l}176.2 \\
4\end{array}$ & $\begin{array}{l}\text { core } \\
\text { top }\end{array}$ & 430 & $\begin{array}{l}4650 \\
\pm 35\end{array}$ & 1 & 1.30 & & 1.10 & & $\begin{array}{l}\text { reticu } \\
\text { late }\end{array}$ & 16.9 & $\begin{array}{l}35.4 \\
6\end{array}$ \\
\hline Z7003 & $\begin{array}{l}36.6 \\
93\end{array}$ & $\begin{array}{l}176.2 \\
4\end{array}$ & $\begin{array}{l}\text { core } \\
\text { top }\end{array}$ & 430 & $\begin{array}{l}4650 \\
\pm 35\end{array}$ & 2 & 2.37 & & 2.24 & & $\begin{array}{l}\text { reticu } \\
\text { late }\end{array}$ & 16.9 & $\begin{array}{l}35.4 \\
6\end{array}$ \\
\hline Z7003 & $\begin{array}{l}36.6 \\
93\end{array}$ & $\begin{array}{l}176.2 \\
4\end{array}$ & $\begin{array}{l}\text { core } \\
\text { top }\end{array}$ & 430 & $\begin{array}{l}4650 \\
\pm 35\end{array}$ & 3 & 2.72 & & 2.22 & & $\begin{array}{l}\text { reticu } \\
\text { late }\end{array}$ & 16.9 & $\begin{array}{l}35.4 \\
6\end{array}$ \\
\hline Z7003 & $\begin{array}{l}36.6 \\
93\end{array}$ & $\begin{array}{l}176.2 \\
4\end{array}$ & $\begin{array}{l}\text { core } \\
\text { top }\end{array}$ & 430 & $\begin{array}{l}4650 \\
\pm 35\end{array}$ & 7 & 1.40 & & & 1.45 & $\begin{array}{l}\text { crysta } \\
\text { lline }\end{array}$ & 16.9 & $\begin{array}{l}35.4 \\
6\end{array}$ \\
\hline Z7003 & $\begin{array}{l}36.6 \\
93\end{array}$ & $\begin{array}{l}176.2 \\
4\end{array}$ & $\begin{array}{l}\text { core } \\
\text { top }\end{array}$ & 430 & $\begin{array}{l}4650 \\
\pm 35\end{array}$ & 9 & & & 1.13 & & $\begin{array}{l}\text { reticu } \\
\text { late }\end{array}$ & 16.9 & $\begin{array}{l}35.4 \\
6\end{array}$ \\
\hline Z7003 & $\begin{array}{l}36.6 \\
93\end{array}$ & $\begin{array}{l}176.2 \\
4\end{array}$ & $\begin{array}{l}\text { core } \\
\text { top }\end{array}$ & 430 & $\begin{array}{l}4650 \\
\pm 35\end{array}$ & 10 & & & 2.65 & & $\begin{array}{l}\text { reticu } \\
\text { late }\end{array}$ & 16.9 & $\begin{array}{l}35.4 \\
6\end{array}$ \\
\hline Z7003 & $\begin{array}{l}36.6 \\
93\end{array}$ & $\begin{array}{l}176.2 \\
4\end{array}$ & $\begin{array}{l}\text { core } \\
\text { top }\end{array}$ & 430 & $\begin{array}{l}4650 \\
\pm 35\end{array}$ & 11 & 1.53 & & 2.27 & & $\begin{array}{l}\text { reticu } \\
\text { late }\end{array}$ & 16.9 & $\begin{array}{l}35.4 \\
6\end{array}$ \\
\hline Z7003 & $\begin{array}{l}36.6 \\
93\end{array}$ & $\begin{array}{l}176.2 \\
4\end{array}$ & $\begin{array}{l}\text { core } \\
\text { top }\end{array}$ & 430 & $\begin{array}{l}4650 \\
\pm 35\end{array}$ & 12 & 2.11 & 1.93 & 2.50 & 1.97 & $\begin{array}{l}\text { crysta } \\
\text { lline }\end{array}$ & 16.9 & $\begin{array}{l}35.4 \\
6\end{array}$ \\
\hline Z7003 & $\begin{array}{l}36.6 \\
93\end{array}$ & $\begin{array}{l}176.2 \\
4\end{array}$ & $\begin{array}{l}\text { core } \\
\text { top }\end{array}$ & 430 & $\begin{array}{l}4650 \\
\pm 35\end{array}$ & 13 & 2.07 & & 2.21 & & $\begin{array}{l}\text { reticu } \\
\text { late }\end{array}$ & 16.9 & $\begin{array}{l}35.4 \\
6\end{array}$ \\
\hline Z7003 & $\begin{array}{l}36.6 \\
93\end{array}$ & $\begin{array}{l}176.2 \\
4\end{array}$ & $\begin{array}{l}\text { core } \\
\text { top }\end{array}$ & 430 & $\begin{array}{l}4650 \\
\pm 35\end{array}$ & 14 & 2.07 & 0.72 & 1.83 & 0.88 & $\begin{array}{l}\text { crysta } \\
\text { lline }\end{array}$ & 16.9 & $\begin{array}{l}35.4 \\
6\end{array}$ \\
\hline Z7003 & $\begin{array}{l}36.6 \\
93\end{array}$ & $\begin{array}{l}176.2 \\
4\end{array}$ & $\begin{array}{l}\text { core } \\
\text { top }\end{array}$ & 430 & $\begin{array}{l}4650 \\
\pm 35\end{array}$ & 16 & & & 1.09 & & $\begin{array}{l}\text { reticu } \\
\text { late }\end{array}$ & 16.9 & $\begin{array}{l}35.4 \\
6\end{array}$ \\
\hline Z7003 & $\begin{array}{l}36.6 \\
93\end{array}$ & $\begin{array}{l}176.2 \\
4\end{array}$ & $\begin{array}{l}\text { core } \\
\text { top }\end{array}$ & 430 & $\begin{array}{l}4650 \\
\pm 35\end{array}$ & 18 & 0.74 & & 1.67 & & $\begin{array}{l}\text { reticu } \\
\text { late }\end{array}$ & 16.9 & $\begin{array}{l}35.4 \\
6\end{array}$ \\
\hline Z7003 & $\begin{array}{l}36.6 \\
93\end{array}$ & $\begin{array}{l}176.2 \\
4\end{array}$ & $\begin{array}{l}\text { core } \\
\text { top }\end{array}$ & 430 & $\begin{array}{l}4650 \\
\pm 35\end{array}$ & 19 & 1.32 & & 1.22 & & $\begin{array}{l}\text { reticu } \\
\text { late }\end{array}$ & 16.9 & $\begin{array}{l}35.4 \\
6\end{array}$ \\
\hline Z7003 & $\begin{array}{l}36.6 \\
93\end{array}$ & $\begin{array}{l}176.2 \\
4\end{array}$ & $\begin{array}{l}\text { core } \\
\text { top }\end{array}$ & 430 & $\begin{array}{l}4650 \\
\pm 35\end{array}$ & 20 & 1.57 & & 1.28 & & $\begin{array}{l}\text { reticu } \\
\text { late }\end{array}$ & 16.9 & $\begin{array}{l}35.4 \\
6\end{array}$ \\
\hline Z7003 & $\begin{array}{l}36.6 \\
93\end{array}$ & $\begin{array}{l}176.2 \\
4\end{array}$ & $\begin{array}{l}\text { core } \\
\text { top }\end{array}$ & 430 & $\begin{array}{l}4650 \\
\pm 35\end{array}$ & 21 & & 1.38 & 1.20 & 0.69 & $\begin{array}{l}\text { crysta } \\
\text { lline }\end{array}$ & 16.9 & $\begin{array}{l}35.4 \\
6\end{array}$ \\
\hline Z7003 & $\begin{array}{l}36.6 \\
93\end{array}$ & $\begin{array}{l}176.2 \\
4\end{array}$ & $\begin{array}{l}\text { core } \\
\text { top }\end{array}$ & 430 & $\begin{array}{l}4650 \\
\pm 35\end{array}$ & 23 & 2.46 & & 1.90 & & $\begin{array}{l}\text { reticu } \\
\text { late }\end{array}$ & 16.9 & $\begin{array}{l}35.4 \\
6\end{array}$ \\
\hline Z7003 & $\begin{array}{l}36.6 \\
93\end{array}$ & $\begin{array}{l}176.2 \\
4\end{array}$ & $\begin{array}{l}\text { core } \\
\text { top }\end{array}$ & 430 & $\begin{array}{l}4650 \\
\pm 35\end{array}$ & 30 & 2.09 & & 1.65 & & $\begin{array}{l}\text { reticu } \\
\text { late }\end{array}$ & 16.9 & $\begin{array}{l}35.4 \\
6\end{array}$ \\
\hline Z7003 & $\begin{array}{l}36.6 \\
93\end{array}$ & $\begin{array}{l}176.2 \\
4\end{array}$ & $\begin{array}{l}\text { core } \\
\text { top }\end{array}$ & 430 & $\begin{array}{l}4650 \\
\pm 35\end{array}$ & 32 & 1.53 & & 1.00 & & $\begin{array}{l}\text { reticu } \\
\text { late }\end{array}$ & 16.9 & $\begin{array}{l}35.4 \\
6\end{array}$ \\
\hline
\end{tabular}


Table B2: Size and weight data for Neogloboquadrina incompta $(150-350 \mu \mathrm{m})$ for core top and plankton tow sites in the Southwest Pacific Ocean

\begin{tabular}{|c|c|c|c|c|c|c|c|c|c|}
\hline Site & Latitude & Longitude & Core Type & Depth & $\begin{array}{c}\text { Individual } \\
\text { Number }\end{array}$ & $\mathrm{X}$ & $\mathrm{Y}$ & Weight & $\begin{array}{c}\text { Size- } \\
\text { normalised } \\
\text { Weight }\end{array}$ \\
\hline & (degrees) & (degrees) & & (metres) & & $(\mu \mathrm{m})$ & $(\mu \mathrm{m})$ & $(\mu \mathrm{g})$ & $(\mu \mathrm{g} / \mu \mathrm{m})$ \\
\hline 271/61/DR05C1 & 22.133 & 156.74 & dredge & 1600 & 1 & 301 & 345 & & \\
\hline 271/61/DR05C1 & 22.133 & 156.74 & dredge & 1600 & 2 & 251 & 356 & & \\
\hline B32 & 53.630 & 169.87 & core top & 799 & 1 & 155 & 198 & 3.7 & 2.39 \\
\hline B32 & 53.630 & 169.87 & core top & 799 & 2 & 264 & 283 & 14.9 & 5.64 \\
\hline B32 & 53.630 & 169.87 & core top & 799 & 3 & 156 & 202 & 3.6 & 2.31 \\
\hline B32 & 53.630 & 169.87 & core top & 799 & 4 & 156 & 201 & 5.5 & 3.53 \\
\hline B32 & 53.630 & 169.87 & core top & 799 & 5 & 153 & 169 & 2.8 & 1.83 \\
\hline B32 & 53.630 & 169.87 & core top & 799 & 6 & 258 & 347 & 17.6 & 6.82 \\
\hline B32 & 53.630 & 169.87 & core top & 799 & 7 & 158 & 198 & 3.6 & 2.28 \\
\hline B32 & 53.630 & 169.87 & core top & 799 & 9 & 160 & 205 & 14.5 & 9.06 \\
\hline B32 & 53.630 & 169.87 & core top & 799 & 10 & 266 & 292 & 4.0 & 1.50 \\
\hline B32 & 53.630 & 169.87 & core top & 799 & 11 & 161 & 207 & 2.9 & 1.80 \\
\hline B32 & 53.630 & 169.87 & core top & 799 & 17 & 199 & 247 & 5.5 & 2.76 \\
\hline B32 & 53.630 & 169.87 & core top & 799 & 20 & 179 & 193 & 3.3 & 1.84 \\
\hline B32 & 53.630 & 169.87 & core top & 799 & 21 & 141 & 151 & 2.4 & 1.70 \\
\hline B32 & 53.630 & 169.87 & core top & 799 & 22 & 151 & 185 & 2.5 & 1.66 \\
\hline B32 & 53.630 & 169.87 & core top & 799 & 24 & 145 & 176 & 2.1 & 1.45 \\
\hline B32 & 53.630 & 169.87 & core top & 799 & 25 & 148 & 198 & 2.0 & 1.35 \\
\hline B32 & 53.630 & 169.87 & core top & 799 & 26 & 145 & 158 & 0.9 & 0.62 \\
\hline D178 & 51.720 & 167.83 & core top & 629 & 4 & 168 & 177 & 3.7 & 2.20 \\
\hline D178 & 51.720 & 167.83 & core top & 629 & 6 & 187 & 219 & 5.0 & 2.67 \\
\hline D178 & 51.720 & 167.83 & core top & 629 & 22 & 152 & 187 & 14.7 & 9.67 \\
\hline D178 & 51.720 & 167.83 & core top & 629 & 25 & 196 & 234 & 5.0 & 2.55 \\
\hline D178 & 51.720 & 167.83 & core top & 629 & 26 & 175 & 202 & 1.7 & 0.97 \\
\hline F111 & 48.950 & 174.98 & core top & 704 & 1 & 167 & 221 & 3.4 & 2.04 \\
\hline F111 & 48.950 & 174.98 & core top & 704 & 2 & 180 & 238 & 4.5 & 2.50 \\
\hline F111 & 48.950 & 174.98 & core top & 704 & 3 & 195 & 224 & 5.6 & 2.87 \\
\hline F111 & 48.950 & 174.98 & core top & 704 & 4 & 174 & 209 & 2.8 & 1.61 \\
\hline F111 & 48.950 & 174.98 & core top & 704 & 5 & 171 & 228 & 2.2 & 1.29 \\
\hline F111 & 48.950 & 174.98 & core top & 704 & 6 & 183 & 217 & 3.2 & 1.75 \\
\hline F111 & 48.950 & 174.98 & core top & 704 & 7 & 171 & 207 & 3.7 & 2.16 \\
\hline F111 & 48.950 & 174.98 & core top & 704 & 12 & 152 & 184 & 1.8 & 1.18 \\
\hline F111 & 48.950 & 174.98 & core top & 704 & 13 & 143 & 186 & 2.1 & 1.47 \\
\hline FR97_GC09 & 23.885 & 152.64 & core top & 991 & 2 & 314 & 296 & 16.3 & 5.19 \\
\hline FR97_GC09 & 23.885 & 152.64 & core top & 991 & 3 & 299 & 229 & 17.8 & 5.95 \\
\hline
\end{tabular}




\begin{tabular}{|c|c|c|c|c|c|c|c|c|c|}
\hline Site & Latitude & Longitude & Core Type & Depth & Individual Number & $\mathrm{x}$ & $\mathrm{Y}$ & Weight & Size-normalised Weight \\
\hline & (degrees) & (degrees) & & (metres) & & $(\mu \mathrm{m})$ & $(\mu \mathrm{m})$ & $(\mu \mathrm{g})$ & $(\mu \mathrm{g} / \mu \mathrm{m})$ \\
\hline ODP1123C & 41.942 & 188.50 & core top & 3290 & 1 & 193 & 223 & 6.0 & 3.11 \\
\hline ODP1123C & 41.942 & 188.50 & core top & 3290 & 2 & 209 & 185 & 5.0 & 2.39 \\
\hline ODP1123C & 41.942 & 188.50 & core top & 3290 & 4 & 213 & 198 & 3.0 & 1.41 \\
\hline ODP1123C & 41.942 & 188.50 & core top & 3290 & 5 & 222 & 206 & 3.2 & 1.44 \\
\hline ODP1123C & 41.942 & 188.50 & core top & 3290 & 6 & 213 & 197 & 2.6 & 1.22 \\
\hline ODP1123C & 41.942 & 188.50 & core top & 3290 & 7 & 248 & 228 & 3.9 & 1.57 \\
\hline ODP1123C & 41.942 & 188.50 & core top & 3290 & 12 & 197 & 136 & 2.7 & 1.37 \\
\hline ODP1123C & 41.942 & 188.50 & core top & 3290 & 18 & 202 & 175 & 8.0 & 3.96 \\
\hline ODP1123C & 41.942 & 188.50 & core top & 3290 & 21 & 162 & 133 & 3.3 & 2.04 \\
\hline R623 & 43.200 & 186.00 & core top & 1128 & 1 & 246 & 291 & 9.8 & 3.98 \\
\hline R623 & 43.200 & 186.00 & core top & 1128 & 2 & 231 & 286 & 8.7 & 3.77 \\
\hline R623 & 43.200 & 186.00 & core top & 1128 & 3 & 204 & 232 & 4.0 & 1.96 \\
\hline R623 & 43.200 & 186.00 & core top & 1128 & 4 & 174 & 212 & 4.0 & 2.30 \\
\hline R623 & 43.200 & 186.00 & core top & 1128 & 5 & 184 & 221 & 5.8 & 3.15 \\
\hline R623 & 43.200 & 186.00 & core top & 1128 & 7 & 179 & 231 & 5.4 & 3.02 \\
\hline R623 & 43.200 & 186.00 & core top & 1128 & 8 & 131 & 168 & 1.9 & 1.45 \\
\hline R623 & 43.200 & 186.00 & core top & 1128 & 9 & 167 & 197 & 3.4 & 2.04 \\
\hline R623 & 43.200 & 186.00 & core top & 1128 & 12 & 150 & 203 & 5.9 & 3.93 \\
\hline R623 & 43.200 & 186.00 & core top & 1128 & 31 & & 339 & 10.5 & \\
\hline R623 & 43.200 & 186.00 & core top & 1128 & 32 & 220 & 267 & 7.6 & 3.45 \\
\hline R623 & 43.200 & 186.00 & core top & 1128 & 33 & 274 & 346 & 6.8 & 2.48 \\
\hline R623 & 43.200 & 186.00 & core top & 1128 & 34 & & & 7.9 & \\
\hline R623 & 43.200 & 186.00 & core top & 1128 & 35 & 259 & 345 & 8.9 & 3.44 \\
\hline R623 & 43.200 & 186.00 & core top & 1128 & 36 & & & 7.6 & \\
\hline R623 & 43.200 & 186.00 & core top & 1128 & 37 & 262 & 247 & 15.1 & 5.76 \\
\hline R623 & 43.200 & 186.00 & core top & 1128 & 40 & 214 & 206 & 9.3 & 4.35 \\
\hline R623 & 43.200 & 186.00 & core top & 1128 & 41 & 217 & 198 & & 0.00 \\
\hline R623 & 43.200 & 186.00 & core top & 1128 & 42 & 241 & 195 & 7.7 & 3.20 \\
\hline R623 & 43.200 & 186.00 & core top & 1128 & 43 & 264 & 250 & 11.1 & 4.20 \\
\hline R623 & 43.200 & 186.00 & core top & 1128 & 45 & 234 & 226 & 8.4 & 3.59 \\
\hline R623 & 43.200 & 186.00 & core top & 1128 & 46 & 258 & 263 & 13.2 & 5.12 \\
\hline R623 & 43.200 & 186.00 & core top & 1128 & 48 & 257 & 221 & 9.4 & 3.66 \\
\hline R623 & 43.200 & 186.00 & core top & 1128 & 50 & 211 & 216 & 5.7 & 2.70 \\
\hline R623 & 43.200 & 186.00 & core top & 1128 & 51 & 245 & 235 & 8.2 & 3.35 \\
\hline R623 & 43.200 & 186.00 & core top & 1128 & 52 & 257 & 245 & 9.8 & 3.81 \\
\hline R623 & 43.200 & 186.00 & core top & 1128 & 53 & 278 & 232 & 11.0 & 3.96 \\
\hline S938 & 40.330 & 179.99 & core top & 3003 & 4 & 228 & 264 & 4.0 & 1.75 \\
\hline
\end{tabular}




\begin{tabular}{|c|c|c|c|c|c|c|c|c|c|}
\hline Site & Latitude & Longitude & Core Type & Depth & $\begin{array}{c}\text { Individual } \\
\text { Number }\end{array}$ & $\mathrm{X}$ & $\mathrm{Y}$ & Weight & $\begin{array}{c}\text { Size-normalised } \\
\text { Weight }\end{array}$ \\
\hline & (degrees) & (degrees) & & (metres) & & $(\mu \mathrm{m})$ & $(\mu \mathrm{m})$ & $(\mu \mathrm{g})$ & $(\mu \mathrm{g} / \mu \mathrm{m})$ \\
\hline S938 & 40.330 & 179.99 & core top & 3003 & 5 & 191 & 242 & 4.8 & 2.49 \\
\hline S938 & 40.330 & 179.99 & core top & 3003 & 6 & 164 & 213 & 2.0 & 1.22 \\
\hline S938 & 40.330 & 179.99 & core top & 3003 & 8 & 206 & 242 & 1.9 & 0.92 \\
\hline S938 & 40.330 & 179.99 & core top & 3003 & 9 & 161 & 206 & 3.8 & 2.36 \\
\hline S938 & 40.330 & 179.99 & core top & 3003 & 10 & 203 & 255 & 1.4 & 0.69 \\
\hline S938 & 40.330 & 179.99 & core top & 3003 & 11 & 157 & 180 & 3.1 & 1.97 \\
\hline S938 & 40.330 & 179.99 & core top & 3003 & 12 & 199 & 232 & 2.7 & 1.36 \\
\hline S938 & 40.330 & 179.99 & core top & 3003 & 14 & 188 & 212 & & 0.00 \\
\hline TAN0103 U2309 NET 5 & 46.678 & 178.51 & plankton tow & 100 & 1 & & & & \\
\hline TAN0103 U2309 NET 5 & 46.678 & 178.51 & plankton tow & 100 & 2 & 206 & 292 & 5.5 & 2.67 \\
\hline TAN0103 U2309 NET 5 & 46.678 & 178.51 & plankton tow & 100 & 3 & 202 & 257 & 4.5 & 2.23 \\
\hline TAN0103 U2309 NET 5 & 46.678 & 178.51 & plankton tow & 100 & 4 & 188 & 250 & 4.5 & 2.39 \\
\hline TAN0103 U2315 & 38.509 & 179.02 & plankton tow & 125 & 1 & 214 & 275 & & 0.00 \\
\hline TAN0103 U2315 & 38.509 & 179.02 & plankton tow & 125 & 2 & 214 & 275 & & 0.00 \\
\hline TAN0103 U2322 net 6 & 41.601 & 178.05 & plankton tow & 100 & 1 & & & 5.7 & \\
\hline TAN0103 U2322 net 6 & 41.601 & 178.05 & plankton tow & 100 & 2 & & & 4.4 & \\
\hline TAN0103 U2322 net 6 & 41.601 & 178.05 & plankton tow & 100 & 6 & & & 8.2 & \\
\hline TAN0103 U2322 net 6 & 41.601 & 178.05 & plankton tow & 100 & 7 & & & 2.2 & \\
\hline Z7003 & 36.693 & 176.24 & core top & 430 & 1 & 182 & 209 & 8.4 & 4.62 \\
\hline Z7003 & 36.693 & 176.24 & core top & 430 & 2 & 192 & 233 & 9.1 & 4.74 \\
\hline Z7003 & 36.693 & 176.24 & core top & 430 & 3 & 223 & 292 & 9.5 & 4.26 \\
\hline Z7003 & 36.693 & 176.24 & core top & 430 & 7 & 198 & 231 & 7.8 & 3.94 \\
\hline Z7003 & 36.693 & 176.24 & core top & 430 & 9 & 198 & 253 & 7.9 & 3.99 \\
\hline Z7003 & 36.693 & 176.24 & core top & 430 & 10 & 194 & 221 & 4.6 & 2.37 \\
\hline Z7003 & 36.693 & 176.24 & core top & 430 & 11 & 212 & 272 & 6.7 & 3.16 \\
\hline Z7003 & 36.693 & 176.24 & core top & 430 & 12 & 201 & 256 & 7.4 & 3.68 \\
\hline Z7003 & 36.693 & 176.24 & core top & 430 & 13 & 209 & 271 & 3.9 & 1.87 \\
\hline Z7003 & 36.693 & 176.24 & core top & 430 & 14 & & & 7.4 & \\
\hline Z7003 & 36.693 & 176.24 & core top & 430 & 16 & 202 & 249 & 1.5 & 0.72 \\
\hline Z7003 & 36.693 & 176.24 & core top & 430 & 18 & 225 & 285 & 5.8 & 2.58 \\
\hline Z7003 & 36.693 & 176.24 & core top & 430 & 19 & 186 & 244 & 5.5 & 2.93 \\
\hline $\mathrm{Z} 7003$ & 36.693 & 176.24 & core top & 430 & 20 & 194 & 257 & 3.3 & 1.70 \\
\hline Z7003 & 36.693 & 176.24 & core top & 430 & 21 & 210 & 241 & 5.7 & 2.71 \\
\hline Z7003 & 36.693 & 176.24 & core top & 430 & 23 & 162 & 233 & 4.4 & 2.72 \\
\hline Z7003 & 36.693 & 176.24 & core top & 430 & 30 & & & 4.5 & \\
\hline Z7003 & 36.693 & 176.24 & core top & 430 & 32 & 257 & 289 & 9.0 & 3.50 \\
\hline
\end{tabular}


Table B3: Other trace element data for Neogloboquadrina incompta $(150-350 \mu \mathrm{m})$ for core top and plankton tow sites in the Southwest Pacific Ocean

\begin{tabular}{|c|c|c|c|c|c|c|c|c|c|c|}
\hline Site & $\begin{array}{c}\text { Individu } \\
\text { al } \\
\text { Number }\end{array}$ & $\begin{array}{l}\text { Chamb } \\
\text { er }\end{array}$ & $\begin{array}{c}\text { Ultra- } \\
\text { structure }\end{array}$ & $\begin{array}{l}\text { Kummer- } \\
\text { form }\end{array}$ & $\begin{array}{c}\text { PD } \\
\text { intergrad } \\
\mathrm{e}\end{array}$ & $\begin{array}{l}\text { Quadrat } \\
\mathrm{e}\end{array}$ & $\mathrm{Al} / \mathrm{Ca}$ & $\mathrm{Mn} / \mathrm{Ca}$ & $\mathrm{Sr} / \mathrm{Ca}$ & $\mathrm{Ba} / \mathrm{Ca}$ \\
\hline & & & & & & & $\begin{array}{c}(\mu \mathrm{mol} / \mathrm{mo} \\
\mathrm{l})\end{array}$ & $\begin{array}{c}(\mu \mathrm{mol} / \mathrm{mo} \\
1)\end{array}$ & $\begin{array}{c}(\mathrm{mmol} / \mathrm{mo} \\
\mathrm{l})\end{array}$ & $\begin{array}{c}(\mu \mathrm{mol} / \mathrm{mo} \\
\mathrm{l})\end{array}$ \\
\hline 271/61/DR05 & & & crystallin & & & & & & & \\
\hline $\begin{array}{l}\text { C1 } \\
271 / 61 / \text { DR05 }\end{array}$ & 1 & F & $\begin{array}{c}\mathrm{e} \\
\text { crystallin }\end{array}$ & & 1 & 1 & 48.4 & 28.4 & 2.346 & 7.8 \\
\hline $\begin{array}{l}\text { C1 } \\
271 / 61 / \text { DR05 }\end{array}$ & 1 & F-3 & $\begin{array}{c}\mathrm{e} \\
\text { crystallin }\end{array}$ & & 1 & 1 & 118.0 & 17.7 & 2.462 & 2.2 \\
\hline $\begin{array}{l}\mathrm{C} 1 \\
271 / 61 / \mathrm{DR} 05\end{array}$ & 2 & F & $\begin{array}{c}\mathrm{e} \\
\text { crustallin }\end{array}$ & & 1 & 1 & 107.6 & 7.2 & 1.642 & 4.1 \\
\hline C1 & 2 & F-3 & $\begin{array}{c}\mathrm{e} \\
\text { reticulat }\end{array}$ & & 1 & 1 & 150.4 & 14.0 & 1.571 & 8.9 \\
\hline B32 & 1 & F & $\underset{\mathrm{e}}{\mathrm{e}}$ & & 1 & 2 & 7.8 & 34.6 & 1.314 & 3.2 \\
\hline B32 & 1 & F-3 & $\begin{array}{c}\mathrm{e} \\
\text { crystallin }\end{array}$ & & 1 & 2 & 14.2 & 26.3 & 1.291 & 3.0 \\
\hline B32 & 2 & F & $\begin{array}{c}\mathrm{e} \\
\text { crystallin }\end{array}$ & & 1 & 1 & 22.8 & 4.2 & 1.494 & 1.2 \\
\hline B32 & 2 & F-3 & $\begin{array}{c}\mathrm{e} \\
\text { reticulat }\end{array}$ & & 1 & 1 & 24.5 & 1.4 & 1.533 & 0.7 \\
\hline B32 & 3 & F & $\stackrel{\mathrm{e}}{\text { reticulat }}$ & & 1 & 1 & 24.3 & 15.8 & 1.309 & 1.5 \\
\hline B32 & 3 & F-3 & $\begin{array}{c}\mathrm{e} \\
\text { crystallin }\end{array}$ & & 1 & 1 & 45.5 & 11.0 & 1.399 & 1.4 \\
\hline B32 & 4 & F & $\begin{array}{c}\mathrm{e} \\
\text { crystallin }\end{array}$ & & 1 & 1 & 16.6 & 26.8 & 1.490 & 3.1 \\
\hline B32 & 4 & F-3 & $\begin{array}{c}\mathrm{e} \\
\text { crystallin }\end{array}$ & & 1 & 1 & 63.3 & 72.7 & 1.383 & 9.1 \\
\hline B32 & 5 & F & $\begin{array}{c}\mathrm{e} \\
\text { crystallin }\end{array}$ & & 1 & 1 & 12.4 & 7.5 & 1.386 & 2.2 \\
\hline B32 & 5 & F-3 & $\begin{array}{c}\mathrm{e} \\
\text { reticulat }\end{array}$ & & 1 & 1 & 54.7 & 11.7 & 1.345 & 3.1 \\
\hline B32 & 6 & F & $\stackrel{\mathrm{e}}{\text { reticulat }}$ & 1 & 1 & 2 & 41.0 & 5.1 & 1.234 & 2.1 \\
\hline B32 & 6 & F-3 & $\begin{array}{c}\mathrm{e} \\
\text { reticulat }\end{array}$ & & 1 & 2 & 44.1 & 1.7 & 1.268 & 1.4 \\
\hline B32 & 7 & F & $\underset{\text { reticulat }}{\mathrm{e}}$ & & 1 & 1 & 30.8 & 21.2 & 1.428 & 3.8 \\
\hline B32 & 7 & F-3 & $\begin{array}{c}\mathrm{e} \\
\text { crystallin }\end{array}$ & & 1 & 1 & 52.0 & 21.6 & 1.348 & 3.3 \\
\hline B32 & 9 & F & $\begin{array}{c}\mathrm{e} \\
\text { crystallin }\end{array}$ & & 1 & 1 & 13.4 & 43.1 & 1.635 & 4.2 \\
\hline B32 & 9 & F-3 & $\begin{array}{c}\mathrm{e} \\
\text { crystallin }\end{array}$ & & 1 & 1 & 32.1 & 47.6 & 1.565 & 10.3 \\
\hline B32 & 10 & $\mathrm{~F}$ & $\begin{array}{c}\mathrm{e} \\
\text { crystallin }\end{array}$ & & 1 & 1 & 8.4 & 2.2 & 1.384 & 0.8 \\
\hline B32 & 10 & F-3 & $\begin{array}{c}\mathrm{e} \\
\text { crystallin }\end{array}$ & & 1 & 1 & 22.3 & 0.8 & 1.428 & 0.8 \\
\hline B32 & 11 & F & $\begin{array}{c}\mathrm{e} \\
\text { crystallin }\end{array}$ & & 2 & 1 & 14.5 & 18.3 & 1.514 & 5.5 \\
\hline B32 & 11 & F-3 & $\begin{array}{c}\mathrm{e} \\
\text { reticulat }\end{array}$ & & 2 & 1 & 31.5 & 15.4 & 1.457 & 4.5 \\
\hline B32 & 17 & $\mathrm{~F}$ & $\underset{\text { reticulat }}{\mathrm{e}}$ & & 2 & 2 & 36.0 & 13.6 & 1.473 & 12.0 \\
\hline B32 & 17 & F-3 & $\underset{\text { reticulat }}{\mathrm{e}}$ & & 2 & 2 & 101.1 & 11.2 & 1.401 & 4.8 \\
\hline B32 & 20 & F & $\begin{array}{c}\mathrm{e} \\
\text { reticulat }\end{array}$ & & 2 & 2 & 105.9 & 26.2 & 1.352 & 16.7 \\
\hline B32 & 20 & F-1 & $\underset{\mathrm{e}}{\mathrm{e}}$ & & 2 & 2 & 12.8 & 14.1 & 1.520 & 3.6 \\
\hline B32 & 21 & $\mathrm{~F}$ & $\begin{array}{c}\mathrm{e} \\
\text { reticulat }\end{array}$ & 1 & 2 & 1 & 35.2 & 25.2 & 1.456 & 3.4 \\
\hline B32 & 21 & $\mathrm{~F}-1$ & $\begin{array}{c}\mathrm{e} \\
\text { reticulat }\end{array}$ & & 2 & 1 & 15.9 & 15.4 & 1.428 & 1.8 \\
\hline B32 & 22 & F & $\underset{\text { reticulat }}{\mathrm{e}}$ & & 2 & 1 & 36.9 & 24.0 & 1.471 & 6.2 \\
\hline B32 & 22 & F-3 & $\mathrm{e}$ & & 2 & 1 & 26.7 & 22.5 & 1.405 & 2.9 \\
\hline
\end{tabular}


Appendix B

\begin{tabular}{|c|c|c|c|c|c|c|c|c|c|c|}
\hline Site & $\begin{array}{c}\text { Individu } \\
\text { al } \\
\text { Number } \\
\end{array}$ & $\begin{array}{l}\text { Chambe } \\
\mathrm{r}\end{array}$ & $\begin{array}{c}\text { Ultra- } \\
\text { structure }\end{array}$ & $\begin{array}{l}\text { Kummer- } \\
\text { form }\end{array}$ & $\begin{array}{c}\text { PD } \\
\text { intergrad } \\
\mathrm{e} \\
\end{array}$ & $\begin{array}{l}\text { Quadrat } \\
\text { e }\end{array}$ & $\begin{array}{c}\mathrm{Al} / \mathrm{Ca} \\
(\mu \mathrm{mol} / \mathrm{mo} \\
1)\end{array}$ & $\begin{array}{c}\mathrm{Mn} / \mathrm{Ca} \\
(\mu \mathrm{mol} / \mathrm{mo} \\
\mathrm{l})\end{array}$ & $\begin{array}{c}\mathrm{Sr} / \mathrm{Ca} \\
(\mathrm{mmol} / \mathrm{mo} \\
\mathrm{l})\end{array}$ & $\begin{array}{c}\mathrm{Ba} / \mathrm{Ca} \\
(\mu \mathrm{mol} / \mathrm{mo} \\
\mathrm{l})\end{array}$ \\
\hline B32 & 24 & $\mathrm{~F}$ & reticulate & & 1 & 1 & 61.1 & 17.9 & 1.393 & 4.9 \\
\hline B32 & 24 & F-3 & reticulate & & 1 & 1 & 43.4 & 33.2 & 1.366 & 3.0 \\
\hline B32 & 25 & $\mathrm{~F}$ & reticulate & & 1 & 2 & 22.4 & 17.0 & 1.382 & 3.4 \\
\hline B32 & 25 & F-1 & reticulate & & 1 & 2 & 60.9 & 20.8 & 1.432 & 1.8 \\
\hline B32 & 26 & $\mathrm{~F}$ & reticulate & & 1 & 1 & 74.5 & 31.4 & 1.448 & 10.5 \\
\hline B32 & 26 & F-3 & $\begin{array}{l}\text { reticulate } \\
\text { crystallin }\end{array}$ & & 1 & 1 & 94.3 & 21.0 & 1.485 & 2.4 \\
\hline D178 & 4 & $\mathrm{~F}$ & $\begin{array}{c}\mathrm{e} \\
\text { crystallin }\end{array}$ & & 2 & 2 & 12.9 & 1.5 & 1.756 & 1.7 \\
\hline D178 & 4 & F-1 & $\begin{array}{c}\mathrm{e} \\
\text { crystallin }\end{array}$ & & 1 & 1 & 8.7 & 0.1 & 1.652 & 0.9 \\
\hline D178 & 6 & $\mathrm{~F}$ & $\begin{array}{c}\mathrm{e} \\
\text { crystallin }\end{array}$ & 1 & 1 & 1 & 14.8 & 3.5 & 1.606 & 4.9 \\
\hline D178 & 6 & F-3 & $\mathrm{e}$ & & 1 & 1 & 30.2 & 1.4 & 1.554 & 3.2 \\
\hline D178 & 22 & $\mathrm{~F}$ & reticulate & 1 & 2 & 1 & 31.0 & 4.3 & 1.503 & 3.4 \\
\hline D178 & 22 & F-3 & reticulate & & 2 & 1 & 11.7 & 5.6 & 1.615 & 2.5 \\
\hline D178 & 25 & $\mathrm{~F}$ & reticulate & & 1 & 1 & 24.0 & 3.9 & 1.619 & 50.9 \\
\hline D178 & 25 & F-3 & $\begin{array}{l}\text { reticulate } \\
\text { crystallin }\end{array}$ & & 1 & 1 & 130.4 & 6.2 & 1.517 & 216.9 \\
\hline D178 & 26 & $\mathrm{~F}$ & $\begin{array}{c}\mathrm{e} \\
\text { crystallin }\end{array}$ & 1 & 1 & 2 & 31.5 & 9.4 & 1.559 & 2.8 \\
\hline D178 & 26 & $\mathrm{~F}-2$ & e & & 1 & 2 & 11.9 & 10.3 & 1.558 & 3.8 \\
\hline F111 & 1 & $\mathrm{~F}$ & reticulate & & 2 & 2 & 26.4 & 15.8 & 1.451 & 15.3 \\
\hline F111 & 1 & F-3 & reticulate & & 2 & 2 & 58.9 & 20.6 & 1.460 & 18.4 \\
\hline F111 & 2 & $\mathrm{~F}$ & $\begin{array}{l}\text { reticulate } \\
\text { crystallin }\end{array}$ & & 2 & 2 & 83.2 & 6.8 & 1.518 & 6.7 \\
\hline $\begin{array}{l}\text { F111 } \\
\text { FR97_GC0 }\end{array}$ & 13 & F-1 & e & & 1 & 2 & 30.4 & 29.6 & 1.284 & 51.0 \\
\hline $\begin{array}{l}9 \\
\text { FR97_GC0 }\end{array}$ & 2 & $\mathrm{~F}$ & reticulate & & 2 & 1 & 806.3 & 23.3 & 1.563 & 1.9 \\
\hline $\begin{array}{l}9 \\
\text { FR97_GC0 }\end{array}$ & 2 & F-3 & reticulate & & 2 & 1 & 1487.9 & 2.9 & 1.448 & 0.6 \\
\hline $\begin{array}{l}9 \\
\text { FR97_GC0 }\end{array}$ & 3 & $\mathrm{~F}$ & reticulate & 1 & 2 & 1 & 908.9 & 3.0 & 1.326 & 0.6 \\
\hline 9 & 3 & F-3 & $\begin{array}{l}\text { reticulate } \\
\text { crystallin }\end{array}$ & & 2 & 1 & 291.4 & 2.1 & 1.375 & 0.4 \\
\hline ODP1123C & 1 & $\mathrm{~F}$ & $\begin{array}{c}\mathrm{e} \\
\text { crystallin }\end{array}$ & & 1 & 1 & 12.9 & 67.8 & 1.407 & 2.5 \\
\hline ODP1123C & 1 & F-3 & $\begin{array}{c}\mathrm{e} \\
\text { crystallin }\end{array}$ & & 1 & 1 & 1898.8 & 106.2 & 1.352 & 4.6 \\
\hline ODP1123C & 2 & $\mathrm{~F}$ & $\begin{array}{c}\mathrm{e} \\
\text { crystallin }\end{array}$ & 1 & 1 & 1 & 370.0 & 34.6 & 1.492 & 7.8 \\
\hline ODP1123C & 2 & F-3 & e & & 1 & 1 & 329.6 & 19.3 & 1.427 & 4.0 \\
\hline ODP1123C & 4 & $\mathrm{~F}$ & reticulate & & 1 & 2 & 116.3 & 69.2 & 1.296 & 10.9 \\
\hline ODP1123C & 4 & F-3 & reticulate & & 1 & 2 & 1685.8 & 68.3 & 1.365 & 8.4 \\
\hline ODP1123C & 5 & $\mathrm{~F}$ & reticulate & 1 & 1 & 1 & 125.1 & 16.5 & 1.502 & 2.7 \\
\hline ODP1123C & 5 & F-3 & $\begin{array}{l}\text { reticulate } \\
\text { crystallin }\end{array}$ & & 1 & 1 & 38.2 & 5.5 & 1.471 & 1.2 \\
\hline ODP1123C & 6 & $\mathrm{~F}$ & $\begin{array}{c}\mathrm{e} \\
\text { crystallin }\end{array}$ & 1 & 1 & 1 & 1399.9 & 98.4 & 1.461 & 12.5 \\
\hline ODP1123C & 6 & F-3 & e & & 1 & 1 & 580.2 & 23.7 & 1.370 & 5.9 \\
\hline ODP1123C & 7 & $\mathrm{~F}$ & reticulate & & 1 & & 103.8 & 324.2 & 1.468 & 7.4 \\
\hline
\end{tabular}




\begin{tabular}{|c|c|c|c|c|c|c|c|c|c|c|}
\hline Site & $\begin{array}{c}\text { Individu } \\
\text { al } \\
\text { Number } \\
\end{array}$ & $\begin{array}{l}\text { Chambe } \\
\mathrm{r}\end{array}$ & $\begin{array}{c}\text { Ultra- } \\
\text { structure }\end{array}$ & $\begin{array}{l}\text { Kummer- } \\
\text { form }\end{array}$ & $\begin{array}{c}\text { PD } \\
\text { intergrad } \\
\mathrm{e} \\
\end{array}$ & $\begin{array}{l}\text { Quadrat } \\
\mathrm{e}\end{array}$ & $\begin{array}{c}\mathrm{Al} / \mathrm{Ca} \\
(\mu \mathrm{mol} / \mathrm{mol} \\
)\end{array}$ & $\begin{array}{c}\mathrm{Mn} / \mathrm{Ca} \\
(\mu \mathrm{mol} / \mathrm{mol} \\
)\end{array}$ & $\begin{array}{c}\mathrm{Sr} / \mathrm{Ca} \\
(\mathrm{mmol} / \mathrm{mo} \\
\mathrm{l})\end{array}$ & $\begin{array}{c}\mathrm{Ba} / \mathrm{Ca} \\
(\mu \mathrm{mol} / \mathrm{mol} \\
)\end{array}$ \\
\hline $\begin{array}{l}\text { ODP1123 } \\
\text { C } \\
\text { ODP1123 }\end{array}$ & 7 & F-3 & $\begin{array}{l}\text { reticulate } \\
\text { crystallin }\end{array}$ & & 1 & & 1007.1 & 185.9 & 1.543 & 5.4 \\
\hline $\begin{array}{l}\text { C } \\
\text { ODP1123 }\end{array}$ & 12 & F & $\begin{array}{c}\mathrm{e} \\
\text { crystallin }\end{array}$ & & 1 & 1 & 113.5 & 244.6 & 1.518 & 6.0 \\
\hline $\begin{array}{l}\text { C } \\
\text { ODP1123 }\end{array}$ & 12 & F-3 & $\begin{array}{c}\mathrm{e} \\
\text { crystallin }\end{array}$ & & 1 & 1 & 93.1 & 133.7 & 1.392 & 3.2 \\
\hline $\begin{array}{l}\text { C } \\
\text { ODP1123 }\end{array}$ & 18 & F & $\begin{array}{c}\mathrm{e} \\
\text { crystallin }\end{array}$ & 1 & 1 & 1 & 678.3 & 196.2 & 1.310 & 14.4 \\
\hline $\begin{array}{l}\text { C } \\
\text { ODP1123 }\end{array}$ & 18 & F-3 & $\begin{array}{c}\mathrm{e} \\
\text { crystallin }\end{array}$ & & 1 & 1 & 959.9 & 145.3 & 1.380 & 32.8 \\
\hline $\begin{array}{l}\text { C } \\
\text { ODP1123 }\end{array}$ & 21 & F & $\begin{array}{c}\mathrm{e} \\
\text { crystallin }\end{array}$ & & 1 & & 17.6 & 14.7 & 1.452 & 3.6 \\
\hline C & 21 & F-3 & e & & 1 & & 139.7 & 14.4 & 1.327 & 4.5 \\
\hline $\mathrm{R} 623$ & 1 & F & reticulate & 1 & 1 & 1 & 601.4 & 15.9 & 1.408 & 2.9 \\
\hline $\mathrm{R} 623$ & 1 & F-1 & $\begin{array}{l}\text { reticulate } \\
\text { crystallin }\end{array}$ & & 1 & 1 & 54.3 & 35.7 & 1.447 & 4.3 \\
\hline R623 & 2 & F & $\begin{array}{c}\mathrm{e} \\
\text { crystallin }\end{array}$ & 1 & 1 & 1 & 631.3 & 12.7 & 1.333 & 2.7 \\
\hline R623 & 2 & F-1 & $\begin{array}{c}\mathrm{e} \\
\text { crystallin }\end{array}$ & & 1 & 1 & 31.1 & 13.5 & 1.505 & 2.5 \\
\hline R623 & 3 & F & $\begin{array}{c}\mathrm{e} \\
\text { crystallin }\end{array}$ & 1 & 1 & 1 & 199.8 & 12.1 & 1.434 & 2.7 \\
\hline R623 & 3 & F-1 & e & & 1 & 1 & 71.6 & 23.9 & 1.490 & 5.8 \\
\hline R623 & 4 & F & reticulate & & 1 & 1 & 60.2 & 37.3 & 1.470 & 5.2 \\
\hline R623 & 4 & F-3 & reticulate & & 1 & 1 & 851.2 & 15.1 & 1.411 & 3.5 \\
\hline R623 & 5 & F & reticulate & & 1 & 2 & 92.7 & 10.8 & 1.406 & 2.4 \\
\hline R623 & 5 & F-3 & $\begin{array}{l}\text { reticulate } \\
\text { crystallin }\end{array}$ & & 1 & 2 & 1150.0 & 14.9 & 1.324 & 6.1 \\
\hline R623 & 7 & F & $\begin{array}{c}\mathrm{e} \\
\text { crystallin }\end{array}$ & & 1 & 1 & 190.6 & 47.1 & 1.401 & 2.0 \\
\hline R623 & 7 & F-3 & e & & 1 & 1 & 1171.9 & 9.8 & 1.437 & 17.8 \\
\hline R623 & 8 & F & reticulate & 1 & 1 & 2 & 27.1 & 107.1 & 1.470 & 1.6 \\
\hline R623 & 8 & F-3 & reticulate & & 1 & 2 & 323.5 & 93.8 & 1.384 & 18.8 \\
\hline R623 & 9 & F & reticulate & 1 & 1 & 1 & 194.9 & 28.4 & 1.425 & 7.2 \\
\hline R623 & 9 & F-1 & reticulate & & 1 & 1 & 55.6 & 32.5 & 1.493 & 7.1 \\
\hline $\mathrm{R} 623$ & 12 & F & reticulate & & 1 & 2 & 173.6 & 44.5 & 1.400 & 2.5 \\
\hline R623 & 12 & F-3 & $\begin{array}{l}\text { reticulate } \\
\text { crystallin }\end{array}$ & & 1 & 2 & 297.3 & 56.0 & 1.403 & 5.5 \\
\hline $\mathrm{R} 623$ & 31 & F & $\begin{array}{c}\mathrm{e} \\
\text { crystallin }\end{array}$ & & 2 & 2 & 17.0 & 55.7 & 1.361 & 69.6 \\
\hline R623 & 31 & F-3 & $\begin{array}{c}\mathrm{e} \\
\text { crystallin }\end{array}$ & & 2 & 2 & 80.7 & 83.9 & 1.349 & 36.8 \\
\hline $\mathrm{R} 623$ & 32 & F & $\begin{array}{c}\mathrm{e} \\
\text { crystallin }\end{array}$ & & 1 & 2 & 328.7 & 7.8 & 1.385 & 3.3 \\
\hline R623 & 32 & F-1 & e & & 1 & 2 & 187.3 & 15.5 & 1.337 & 4.8 \\
\hline R623 & 33 & F & reticulate & & 2 & 2 & 35.9 & 57.2 & 1.238 & 82.8 \\
\hline $\mathrm{R} 623$ & 33 & F-3 & $\begin{array}{l}\text { reticulate } \\
\text { crystallin }\end{array}$ & & 2 & 2 & 331.4 & 58.7 & 1.256 & 66.0 \\
\hline $\mathrm{R} 623$ & 34 & F & $\begin{array}{c}\mathrm{e} \\
\text { crystallin }\end{array}$ & & 1 & 2 & 62.9 & 23.7 & 1.483 & 2.6 \\
\hline R623 & 34 & F-1 & $\mathrm{e}$ & & 1 & 2 & 257.6 & 45.4 & 1.394 & 4.0 \\
\hline R623 & 35 & F & reticulate & & 1 & 2 & 67.4 & 52.4 & 1.333 & 5.2 \\
\hline R623 & 35 & F-3 & reticulate & & 1 & 2 & 386.2 & 44.1 & 1.274 & 4.5 \\
\hline
\end{tabular}


Appendix B

\begin{tabular}{|c|c|c|c|c|c|c|c|c|c|c|}
\hline Site & $\begin{array}{l}\text { Individua } \\
1 \text { Number } \\
\end{array}$ & $\begin{array}{l}\text { Chambe } \\
\mathrm{r}\end{array}$ & $\begin{array}{c}\text { Ultra- } \\
\text { structure }\end{array}$ & $\begin{array}{l}\text { Kummerfor } \\
\mathrm{m}\end{array}$ & $\begin{array}{c}\text { PD } \\
\text { intergrad } \\
\mathrm{e} \\
\end{array}$ & $\begin{array}{l}\text { Quadrat } \\
\mathrm{e}\end{array}$ & $\begin{array}{c}\mathrm{Al} / \mathrm{Ca} \\
(\mu \mathrm{mol} / \mathrm{mol} \\
)\end{array}$ & $\begin{array}{c}\mathrm{Mn} / \mathrm{Ca} \\
(\mu \mathrm{mol} / \mathrm{mol} \\
)\end{array}$ & $\begin{array}{c}\mathrm{Sr} / \mathrm{Ca} \\
(\mathrm{mmol} / \mathrm{mol} \\
)\end{array}$ & $\begin{array}{c}\mathrm{Ba} / \mathrm{Ca} \\
(\mu \mathrm{mol} / \mathrm{mol} \\
)\end{array}$ \\
\hline R62 & & & & & & & & & & \\
\hline $\begin{array}{l}3 \\
\text { R62 }\end{array}$ & 35 & F-3 & reticulate & & 1 & 2 & 386.2 & 44.1 & 1.274 & 4.5 \\
\hline $\begin{array}{l}3 \\
\text { R62 }\end{array}$ & 35 & F-3 & reticulate & & 1 & 2 & 386.2 & 44.1 & 1.274 & 4.5 \\
\hline $\begin{array}{l}3 \\
\text { R62 }\end{array}$ & 36 & $\mathrm{~F}$ & reticulate & & 1 & & 9.0 & 55.3 & 1.415 & 4.8 \\
\hline $\begin{array}{l}3 \\
\text { R62 }\end{array}$ & 36 & F-3 & reticulate & & 1 & & 596.6 & 20.3 & 1.344 & 3.6 \\
\hline $\begin{array}{l}3 \\
\text { R62 }\end{array}$ & 37 & $\mathrm{~F}$ & reticulate & & 1 & 2 & 317.0 & 4.0 & 1.582 & 3.0 \\
\hline $\begin{array}{l}3 \\
\text { R62 }\end{array}$ & 37 & F-1 & reticulate & & 1 & 2 & 515.0 & 14.0 & 1.488 & 12.0 \\
\hline $\begin{array}{l}3 \\
\text { R62 }\end{array}$ & 37 & F-2 & reticulate & & 1 & 2 & 302.0 & 6.0 & 1.534 & 4.0 \\
\hline $\begin{array}{l}3 \\
\text { R62 }\end{array}$ & 37 & F-3 & $\begin{array}{l}\text { reticulate } \\
\text { crystallin }\end{array}$ & & 1 & 2 & 468.0 & 15.0 & 1.444 & 29.0 \\
\hline $\begin{array}{l}3 \\
\text { R62 }\end{array}$ & 40 & $\mathrm{~F}$ & $\begin{array}{c}\mathrm{e} \\
\text { crystallin }\end{array}$ & & 1 & 2 & 219.0 & 4.0 & 1.534 & 4.0 \\
\hline $\begin{array}{l}3 \\
\text { R62 }\end{array}$ & 40 & F-1 & $\begin{array}{c}\mathrm{e} \\
\text { crystallin }\end{array}$ & & 1 & 2 & 148.0 & 3.0 & 1.382 & 3.0 \\
\hline $\begin{array}{l}3 \\
\mathrm{R} 62\end{array}$ & 40 & $\mathrm{~F}-2$ & $\begin{array}{c}\mathrm{e} \\
\text { crystallin }\end{array}$ & & 1 & 2 & 339.0 & -7.0 & 1.562 & 1.0 \\
\hline $\begin{array}{l}3 \\
\text { R62 }\end{array}$ & 40 & F-3 & $\begin{array}{c}\mathrm{e} \\
\text { crystallin }\end{array}$ & & 1 & 2 & 565.0 & -5.0 & 1.533 & 1.0 \\
\hline $\begin{array}{l}3 \\
\text { R62 }\end{array}$ & 41 & $\mathrm{~F}$ & $\begin{array}{c}\mathrm{e} \\
\text { crystallin }\end{array}$ & & 1 & 1 & 42.0 & 1.0 & 1.483 & 4.0 \\
\hline $\begin{array}{l}3 \\
\text { R62 }\end{array}$ & 41 & F-1 & $\begin{array}{c}\mathrm{e} \\
\text { crystallin }\end{array}$ & & 1 & 1 & 91.0 & 10.0 & 1.408 & 4.0 \\
\hline $\begin{array}{l}3 \\
\text { R62 }\end{array}$ & 41 & F-2 & $\begin{array}{c}\mathrm{e} \\
\text { crystallin }\end{array}$ & & 1 & 1 & 106.0 & 7.0 & 1.551 & 2.0 \\
\hline $\begin{array}{l}3 \\
\text { R62 }\end{array}$ & 41 & F-3 & e & & 1 & 1 & 91.0 & 3.0 & 1.536 & 2.0 \\
\hline $\begin{array}{l}3 \\
\mathrm{R} 62\end{array}$ & 42 & $\mathrm{~F}$ & reticulate & & 1 & 2 & 129.0 & 6.0 & 1.345 & 4.0 \\
\hline $\begin{array}{l}3 \\
\text { R62 }\end{array}$ & 42 & F-1 & reticulate & & 1 & 2 & 320.0 & 3.0 & 1.288 & 5.0 \\
\hline $\begin{array}{l}3 \\
\text { R62 }\end{array}$ & 42 & $\mathrm{~F}-2$ & reticulate & & 1 & 2 & 616.0 & 7.0 & 1.348 & 3.0 \\
\hline $\begin{array}{l}3 \\
\text { R62 }\end{array}$ & 42 & F-3 & $\begin{array}{l}\text { reticulate } \\
\text { crystallin }\end{array}$ & & 1 & 2 & 1056.0 & 8.0 & 1.531 & 5.0 \\
\hline $\begin{array}{l}3 \\
\text { R62 }\end{array}$ & 43 & $\mathrm{~F}$ & $\begin{array}{c}\mathrm{e} \\
\text { crystallin }\end{array}$ & & 1 & 2 & 37.0 & 3.0 & 1.498 & 1.0 \\
\hline $\begin{array}{l}3 \\
\text { R62 }\end{array}$ & 43 & F-1 & $\begin{array}{c}\mathrm{e} \\
\text { crystallin }\end{array}$ & & 1 & 2 & 276.0 & 8.0 & 1.411 & 5.0 \\
\hline $\begin{array}{l}3 \\
\mathrm{R} 62\end{array}$ & 43 & $\mathrm{~F}-2$ & $\begin{array}{c}\mathrm{e} \\
\text { crystallin }\end{array}$ & & 1 & 2 & 146.0 & 2.0 & 1.434 & 2.0 \\
\hline $\begin{array}{l}3 \\
\text { R62 }\end{array}$ & 43 & F-3 & e & & 1 & 2 & 127.0 & -1.0 & 1.467 & 1.0 \\
\hline $\begin{array}{l}3 \\
\text { R62 }\end{array}$ & 45 & $\mathrm{~F}$ & reticulate & & 1 & 2 & 105.0 & 6.0 & 1.518 & 2.0 \\
\hline $\begin{array}{l}3 \\
\mathrm{R} 62\end{array}$ & 45 & F-1 & reticulate & & 1 & 2 & 54.0 & 4.0 & 1.459 & 4.0 \\
\hline $\begin{array}{l}3 \\
\text { R62 }\end{array}$ & 45 & $\mathrm{~F}-2$ & reticulate & & 1 & 2 & 157.0 & 0.0 & 1.514 & 5.0 \\
\hline $\begin{array}{l}3 \\
\text { R62 }\end{array}$ & 45 & F-3 & reticulate & 2 & 1 & 2 & 228.0 & 6.0 & 1.534 & 6.0 \\
\hline $\begin{array}{l}3 \\
\text { R62 }\end{array}$ & 46 & $\mathrm{~F}$ & reticulate & & 1 & 2 & 37.0 & 1.0 & 1.606 & 15.0 \\
\hline $\begin{array}{l}3 \\
\text { R62 }\end{array}$ & 46 & F-1 & reticulate & & 1 & 2 & 62.0 & 6.0 & 1.454 & 27.0 \\
\hline $\begin{array}{l}3 \\
\text { R62 }\end{array}$ & 46 & $\mathrm{~F}-2$ & $\begin{array}{l}\text { reticulate } \\
\text { crystallin }\end{array}$ & & 1 & 2 & 581.0 & 2.0 & 1.502 & 16.0 \\
\hline $\begin{array}{l}3 \\
\text { R62 }\end{array}$ & 48 & $\mathrm{~F}$ & $\begin{array}{c}\mathrm{e} \\
\text { crystallin }\end{array}$ & & 1 & 1 & -71.0 & 6.0 & 1.405 & 2.0 \\
\hline $\begin{array}{l}3 \\
\text { R62 }\end{array}$ & 48 & F-1 & $\begin{array}{c}\mathrm{e} \\
\text { crystallin }\end{array}$ & & 1 & 1 & 56.0 & 13.0 & 1.223 & 3.0 \\
\hline $\begin{array}{l}3 \\
\text { R62 }\end{array}$ & 48 & F-2 & $\begin{array}{c}\mathrm{e} \\
\text { crystallin }\end{array}$ & & 1 & 1 & 155.0 & 2.0 & 1.337 & 1.0 \\
\hline 3 & 48 & F-3 & e & & 1 & 1 & 261.0 & 4.0 & 1.351 & 2.0 \\
\hline
\end{tabular}


Appendix B

\begin{tabular}{|c|c|c|c|c|c|c|c|c|c|c|}
\hline Site & $\begin{array}{l}\text { Individua } \\
1 \text { Number }\end{array}$ & $\begin{array}{l}\text { Chambe } \\
\mathrm{r}\end{array}$ & $\begin{array}{c}\text { Ultra- } \\
\text { structure }\end{array}$ & $\begin{array}{l}\text { Kummerfor } \\
\mathrm{m}\end{array}$ & $\begin{array}{c}\text { PD } \\
\text { intergrad } \\
\mathrm{e} \\
\end{array}$ & $\begin{array}{l}\text { Quadrat } \\
\mathrm{e}\end{array}$ & $\begin{array}{c}\mathrm{Al} / \mathrm{Ca} \\
(\mu \mathrm{mol} / \mathrm{mol} \\
)\end{array}$ & $\begin{array}{c}\mathrm{Mn} / \mathrm{Ca} \\
(\mu \mathrm{mol} / \mathrm{mol} \\
)\end{array}$ & $\begin{array}{c}\mathrm{Sr} / \mathrm{Ca} \\
(\mathrm{mmol} / \mathrm{mol} \\
)\end{array}$ & $\begin{array}{c}\mathrm{Ba} / \mathrm{Ca} \\
(\mu \mathrm{mol} / \mathrm{mol} \\
)\end{array}$ \\
\hline R62 & & & crystallin & & & & & & & \\
\hline $\begin{array}{l}3 \\
\text { R62 }\end{array}$ & 50 & $\mathrm{~F}$ & $\begin{array}{c}\mathrm{e} \\
\text { crystallin }\end{array}$ & & 1 & 2 & 71.0 & 7.0 & 1.581 & 4.0 \\
\hline $\begin{array}{l}3 \\
\text { R62 }\end{array}$ & 50 & $\mathrm{~F}$ & $\begin{array}{c}\mathrm{e} \\
\text { crystallin }\end{array}$ & & 1 & 2 & 28.0 & 5.0 & 1.582 & 2.0 \\
\hline $\begin{array}{l}3 \\
\text { R62 }\end{array}$ & 50 & F-1 & $\begin{array}{c}\mathrm{e} \\
\text { crystallin }\end{array}$ & & 1 & 2 & 40.0 & 10.0 & 1.491 & 7.0 \\
\hline $\begin{array}{l}3 \\
\text { R62 }\end{array}$ & 50 & F-1 & $\begin{array}{c}\mathrm{e} \\
\text { crystallin }\end{array}$ & & 1 & 2 & 176.0 & 5.0 & 1.455 & 4.0 \\
\hline $\begin{array}{l}3 \\
\text { R62 }\end{array}$ & 50 & F-2 & $\begin{array}{c}\mathrm{e} \\
\text { crystallin }\end{array}$ & & 1 & 2 & 336.0 & 0.0 & 1.523 & 3.0 \\
\hline $\begin{array}{l}3 \\
\text { R62 }\end{array}$ & 50 & $\mathrm{~F}-2$ & $\begin{array}{c}\mathrm{e} \\
\text { crystallin }\end{array}$ & & 1 & 2 & 93.0 & -1.0 & 1.468 & 2.0 \\
\hline $\begin{array}{l}3 \\
\text { R62 }\end{array}$ & 50 & F-3 & $\begin{array}{c}\mathrm{e} \\
\text { crystallin }\end{array}$ & & 1 & 2 & 138.0 & 0.0 & 1.552 & 4.0 \\
\hline $\begin{array}{l}3 \\
\mathrm{R} 62\end{array}$ & 50 & F-3 & e & & 1 & 2 & 825.0 & 4.0 & 1.468 & 6.0 \\
\hline $\begin{array}{l}3 \\
\text { R62 }\end{array}$ & 51 & F & reticulate & & 1 & 1 & 153.0 & 13.0 & 1.496 & 43.0 \\
\hline $\begin{array}{l}3 \\
\text { R62 }\end{array}$ & 51 & $\mathrm{~F}$ & reticulate & & 1 & 1 & 347.0 & 14.0 & 1.467 & 38.0 \\
\hline $\begin{array}{l}3 \\
\text { R62 }\end{array}$ & 51 & F-1 & reticulate & & 1 & 1 & 340.0 & 11.0 & 1.526 & 32.0 \\
\hline $\begin{array}{l}3 \\
\text { R62 }\end{array}$ & 51 & F-1 & reticulate & & 1 & 1 & 403.0 & 9.0 & 1.402 & 35.0 \\
\hline $\begin{array}{l}3 \\
\mathrm{R} 62\end{array}$ & 51 & $\mathrm{~F}-2$ & reticulate & & 1 & 1 & 1303.0 & 18.0 & 1.417 & 22.0 \\
\hline $\begin{array}{l}3 \\
\text { R62 }\end{array}$ & 51 & $\mathrm{~F}-2$ & reticulate & & 1 & 1 & 1123.0 & 15.0 & 1.393 & 19.0 \\
\hline $\begin{array}{l}3 \\
\text { R62 }\end{array}$ & 51 & F-3 & reticulate & & 1 & 1 & 940.0 & 9.0 & 1.464 & 11.0 \\
\hline $\begin{array}{l}3 \\
\text { R62 }\end{array}$ & 51 & F-3 & $\begin{array}{l}\text { reticulate } \\
\text { crystallin }\end{array}$ & & 1 & 1 & 946.0 & 14.0 & 1.391 & 14.0 \\
\hline $\begin{array}{l}3 \\
\mathrm{R} 62\end{array}$ & 52 & $\mathrm{~F}$ & $\begin{array}{c}\mathrm{e} \\
\text { crystallin }\end{array}$ & & 1 & 1 & -45.0 & 3.0 & 1.461 & 6.0 \\
\hline $\begin{array}{l}3 \\
\text { R62 }\end{array}$ & 52 & F-1 & $\begin{array}{c}\mathrm{e} \\
\text { crystallin }\end{array}$ & & 1 & 1 & -6.0 & 11.0 & 1.390 & 6.0 \\
\hline $\begin{array}{l}3 \\
\text { R62 }\end{array}$ & 52 & $\mathrm{~F}-2$ & $\begin{array}{c}\mathrm{e} \\
\text { crystallin }\end{array}$ & & 1 & 1 & 470.0 & 1.0 & 1.440 & 3.0 \\
\hline 3 & 52 & F-3 & $\mathrm{e}$ & & 1 & 1 & 419.0 & 5.0 & 1.440 & 2.0 \\
\hline $\begin{array}{l}\text { S938 } \\
\text { R62 }\end{array}$ & 4 & $\mathrm{~F}$ & $\begin{array}{l}\text { reticulate } \\
\text { crystallin }\end{array}$ & & 1 & 2 & 82.9 & 96.3 & 1.700 & 7.6 \\
\hline $\begin{array}{l}3 \\
\text { R62 }\end{array}$ & 53 & $\mathrm{~F}$ & $\begin{array}{c}\mathrm{e} \\
\text { crystallin }\end{array}$ & & 1 & 1 & -6.0 & 3.0 & 1.612 & 4.0 \\
\hline $\begin{array}{l}3 \\
\text { R62 }\end{array}$ & 53 & F-1 & $\begin{array}{c}\mathrm{e} \\
\text { crystallin }\end{array}$ & & 1 & 1 & 34.0 & 3.0 & 1.434 & 7.0 \\
\hline $\begin{array}{l}3 \\
\text { R62 }\end{array}$ & 53 & $\mathrm{~F}-2$ & $\begin{array}{c}\mathrm{e} \\
\text { crystallin }\end{array}$ & & 1 & 1 & 44.0 & 2.0 & 1.634 & 2.0 \\
\hline 3 & 53 & F-3 & $\mathrm{e}$ & & 1 & 1 & 167.0 & 2.0 & 1.538 & 6.0 \\
\hline S938 & 4 & F-3 & $\begin{array}{l}\text { reticulate } \\
\text { crystallin }\end{array}$ & & 1 & 2 & 265.9 & 31.0 & 1.696 & 2.5 \\
\hline S938 & 5 & $\mathrm{~F}$ & $\begin{array}{c}\mathrm{e} \\
\text { crystallin }\end{array}$ & & 1 & 2 & 88.3 & 250.5 & 1.577 & 4.6 \\
\hline S938 & 5 & F-3 & e & & 1 & 2 & 326.9 & 177.1 & 1.486 & 5.8 \\
\hline S938 & 6 & $\mathrm{~F}$ & reticulate & & 1 & 1 & 14.9 & 91.8 & 1.596 & 2.7 \\
\hline S938 & 6 & F-3 & reticulate & & 1 & 1 & 685.2 & 182.3 & 1.485 & 4.6 \\
\hline S938 & 8 & $\mathrm{~F}$ & reticulate & 1 & 2 & 1 & 15.6 & 104.0 & 1.582 & 4.2 \\
\hline S938 & 8 & F-3 & reticulate & & 2 & 1 & 118.2 & 74.5 & 1.530 & 4.6 \\
\hline S938 & 9 & $\mathrm{~F}$ & reticulate & & 1 & 2 & 29.1 & 79.3 & 1.510 & 7.7 \\
\hline S938 & 9 & F-3 & reticulate & & 1 & 2 & 785.2 & 31.0 & 1.486 & 4.3 \\
\hline S938 & 10 & $\mathrm{~F}$ & reticulate & & 1 & 2 & 3.2 & 81.9 & 1.377 & 3.8 \\
\hline
\end{tabular}




\begin{tabular}{|c|c|c|c|c|c|c|c|c|c|c|}
\hline Site & $\begin{array}{c}\text { Individu } \\
\text { al } \\
\text { Number }\end{array}$ & $\begin{array}{l}\text { Chamb } \\
\text { er }\end{array}$ & $\begin{array}{c}\text { Ultra- } \\
\text { structur } \\
\text { e }\end{array}$ & $\begin{array}{l}\text { Kummerfo } \\
\text { rm }\end{array}$ & $\begin{array}{c}\text { PD } \\
\text { intergra } \\
\text { de }\end{array}$ & $\begin{array}{l}\text { Quadra } \\
\text { te }\end{array}$ & $\mathrm{Al} / \mathrm{Ca}$ & $\mathrm{Mn} / \mathrm{Ca}$ & $\mathrm{Sr} / \mathrm{Ca}$ & $\mathrm{Ba} / \mathrm{Ca}$ \\
\hline & & & & & & & $\begin{array}{c}(\mu \mathrm{mol} / \mathrm{m} \\
\mathrm{ol})\end{array}$ & $\begin{array}{c}(\mu \mathrm{mol} / \mathrm{m} \\
\mathrm{ol})\end{array}$ & $\begin{array}{c}(\mathrm{mmol} / \mathrm{m} \\
\mathrm{ol})\end{array}$ & $\begin{array}{c}(\mu \mathrm{mol} / \mathrm{m} \\
\mathrm{ol})\end{array}$ \\
\hline S938 & 10 & F-3 & $\begin{array}{c}\text { reticulat } \\
\text { e } \\
\text { crystalli }\end{array}$ & & 1 & 2 & 433.2 & 165.4 & 1.396 & 7.8 \\
\hline S938 & 11 & $\mathrm{~F}$ & $\begin{array}{c}\text { ne } \\
\text { crystalli }\end{array}$ & & 1 & 1 & 28.4 & 68.9 & 1.501 & 3.8 \\
\hline S938 & 11 & F-3 & $\begin{array}{l}\text { ne } \\
\text { crystalli }\end{array}$ & & 1 & 1 & 73.3 & 46.9 & 1.562 & 3.1 \\
\hline S938 & 12 & $\mathrm{~F}$ & $\begin{array}{l}\text { ne } \\
\text { crystalli }\end{array}$ & 1 & 1 & 1 & 47.7 & 75.7 & 1.579 & 8.2 \\
\hline S938 & 12 & F-1 & $\begin{array}{l}\text { ne } \\
\text { reticulat }\end{array}$ & & 1 & 1 & 622.1 & 35.2 & 1.448 & 10.4 \\
\hline S938 & 14 & $\mathrm{~F}$ & $\begin{array}{l}\mathrm{e} \\
\text { reticulat }\end{array}$ & & 1 & 1 & 38.7 & 52.1 & 1.614 & 4.6 \\
\hline $\begin{array}{l}\text { S938 } \\
\text { TAN0103 U2309 }\end{array}$ & 14 & F-3 & $\underset{\text { reticulat }}{\mathrm{e}}$ & & 1 & 1 & 105.6 & 22.6 & 1.541 & 1.7 \\
\hline $\begin{array}{l}\text { NET } 5 \\
\text { TAN0103 U2309 }\end{array}$ & 1 & $\mathrm{~F}$ & $\begin{array}{l}\mathrm{e} \\
\text { reticulat }\end{array}$ & & 1 & 1 & 16.5 & 2.0 & 2.576 & 2.8 \\
\hline $\begin{array}{l}\text { NET } 5 \\
\text { TAN0103 U2309 }\end{array}$ & 1 & F-3 & $\begin{array}{c}\mathrm{e} \\
\text { reticulat }\end{array}$ & & 1 & 1 & 9.2 & 8.5 & 2.605 & 5.7 \\
\hline $\begin{array}{l}\text { NET } 5 \\
\text { TAN0103 U2309 }\end{array}$ & 2 & $\mathrm{~F}$ & $\begin{array}{c}\mathrm{e} \\
\text { reticulat }\end{array}$ & & 1 & 2 & 7.1 & 4.0 & 2.698 & 2.6 \\
\hline $\begin{array}{l}\text { NET } 5 \\
\text { TAN0103 U2309 }\end{array}$ & 2 & F-3 & $\begin{array}{l}\mathrm{e} \\
\text { reticulat }\end{array}$ & & 1 & 2 & 22.3 & 10.0 & 2.492 & 3.5 \\
\hline $\begin{array}{l}\text { NET } 5 \\
\text { TAN0103 U2309 }\end{array}$ & 3 & $\mathrm{~F}$ & $\begin{array}{l}\mathrm{e} \\
\text { reticulat }\end{array}$ & & 1 & 2 & 6.8 & 4.6 & 2.643 & 3.0 \\
\hline $\begin{array}{l}\text { NET } 5 \\
\text { TAN0103 U2309 }\end{array}$ & 3 & F-3 & $\begin{array}{c}\mathrm{e} \\
\text { reticulat }\end{array}$ & & 1 & 2 & 11.8 & 6.8 & 2.476 & 4.4 \\
\hline $\begin{array}{l}\text { NET } 5 \\
\text { TAN0103 U2309 }\end{array}$ & 4 & $\mathrm{~F}$ & $\begin{array}{c}\mathrm{e} \\
\text { reticulat }\end{array}$ & & 1 & 2 & 9.5 & 6.4 & 2.719 & 2.7 \\
\hline NET 5 & 4 & F-3 & $\stackrel{\mathrm{e}}{\text { reticulat }}$ & & 1 & 2 & 104.8 & 25.9 & 2.444 & 5.4 \\
\hline TAN0103 U2315 & 1 & $\mathrm{~F}$ & $\begin{array}{c}\mathrm{e} \\
\text { reticulat }\end{array}$ & & 1 & 1 & 17.7 & 6.5 & 1.582 & 7.0 \\
\hline TAN0103 U2315 & 1 & F-1 & $\begin{array}{l}\mathrm{e} \\
\text { reticulat }\end{array}$ & & 1 & 1 & 4.2 & 1.1 & 1.466 & 1.7 \\
\hline TAN0103 U2315 & 1 & $\mathrm{~F}-2$ & $\begin{array}{l}\mathrm{e} \\
\text { reticulat }\end{array}$ & & 1 & 1 & 6.1 & 1.6 & 1.518 & 1.1 \\
\hline TAN0103 U2315 & 1 & F-3 & $\begin{array}{l}\mathrm{e} \\
\text { reticulat }\end{array}$ & & 1 & 1 & 1.1 & 1.7 & 1.418 & 1.5 \\
\hline TAN0103 U2315 & 2 & $\mathrm{~F}$ & $\begin{array}{c}\mathrm{e} \\
\text { reticulat }\end{array}$ & & 1 & 1 & 46.4 & 3.4 & 1.527 & 2.5 \\
\hline TAN0103 U2315 & 2 & F-1 & $\begin{array}{l}\mathrm{e} \\
\text { reticulat }\end{array}$ & & 1 & 1 & 47.4 & 4.3 & 1.441 & 2.1 \\
\hline TAN0103 U2315 & 2 & $\mathrm{~F}-2$ & $\begin{array}{c}\mathrm{e} \\
\text { reticulat }\end{array}$ & & 1 & 1 & 1.6 & 2.5 & 1.362 & 1.3 \\
\hline $\begin{array}{l}\text { TAN0103 U2315 } \\
\text { TAN0103 U2322 net }\end{array}$ & 2 & F-3 & $\begin{array}{l}\mathrm{e} \\
\text { reticulat }\end{array}$ & & 1 & 1 & 1.9 & 1.7 & 1.373 & 2.1 \\
\hline $\begin{array}{l}6 \\
\text { TAN0103 U2322 net }\end{array}$ & 1 & $\mathrm{~F}$ & $\begin{array}{l}\mathrm{e} \\
\text { reticulat }\end{array}$ & & 2 & 2 & 19.3 & 95.6 & 1.399 & 4.8 \\
\hline $\begin{array}{l}6 \\
\text { TAN0103 U2322 net }\end{array}$ & 1 & F-3 & $\begin{array}{l}\mathrm{e} \\
\text { reticulat }\end{array}$ & & 2 & 2 & 15.2 & 48.4 & 1.429 & 27.2 \\
\hline $\begin{array}{l}6 \\
\text { TAN0103 U2322 net }\end{array}$ & 2 & $\mathrm{~F}$ & $\begin{array}{c}\mathrm{e} \\
\text { reticulat }\end{array}$ & & 2 & 2 & 6.9 & 40.8 & 1.293 & 3.7 \\
\hline $\begin{array}{l}6 \\
\text { TAN0103 U2322 net }\end{array}$ & 2 & F-3 & $\begin{array}{l}\mathrm{e} \\
\text { reticulat }\end{array}$ & & 2 & 2 & 8.3 & 10.2 & 1.307 & 4.6 \\
\hline $\begin{array}{l}6 \\
\text { TAN0103 U2322 net }\end{array}$ & 6 & $\mathrm{~F}$ & $\underset{\text { reticulat }}{\mathrm{e}}$ & & 1 & 2 & 6.8 & 7.4 & 1.308 & 19.3 \\
\hline $\begin{array}{l}6 \\
\text { TAN0103 U2322 net }\end{array}$ & 6 & F-3 & $\begin{array}{l}\mathrm{e} \\
\text { reticulat }\end{array}$ & & 1 & 2 & 12.8 & 15.5 & 1.360 & 3.5 \\
\hline $\begin{array}{l}6 \\
\text { TAN0103 U2322 net }\end{array}$ & 7 & $\mathrm{~F}$ & $\begin{array}{c}\mathrm{e} \\
\text { reticulat }\end{array}$ & & 1 & & 24.4 & 17.9 & 1.329 & 1.9 \\
\hline 6 & 7 & F-3 & $\begin{array}{l}\mathrm{e} \\
\text { reticulat }\end{array}$ & & 1 & & 44.2 & 19.7 & 1.391 & 3.5 \\
\hline Z7003 & 1 & $\mathrm{~F}$ & $\underset{\text { reticulat }}{\mathrm{e}}$ & 1 & 2 & 1 & 113.6 & 14.3 & 1.486 & 1.5 \\
\hline Z7003 & 1 & F-3 & $\begin{array}{l}\mathrm{e} \\
\text { reticulat }\end{array}$ & & 2 & 1 & 2821.5 & 5.5 & 1.430 & 2.1 \\
\hline Z7003 & 2 & $\mathrm{~F}$ & $\stackrel{\mathrm{e}}{\text { reticulat }}$ & 1 & 1 & 2 & 55.2 & 34.1 & 1.503 & 5.3 \\
\hline Z7003 & 2 & F-3 & e & & 1 & 2 & 1420.3 & 37.9 & 1.384 & 13.7 \\
\hline
\end{tabular}


Appendix B

\begin{tabular}{|c|c|c|c|c|c|c|c|c|c|c|}
\hline Site & $\begin{array}{l}\text { Individua } \\
1 \text { Number }\end{array}$ & $\begin{array}{l}\text { Chambe } \\
\mathrm{r}\end{array}$ & $\begin{array}{c}\text { Ultra- } \\
\text { structure }\end{array}$ & $\begin{array}{l}\text { Kummerfor } \\
\mathrm{m}\end{array}$ & $\begin{array}{c}\mathrm{PD} \\
\text { intergrad } \\
\mathrm{e} \\
\end{array}$ & $\begin{array}{l}\text { Quadrat } \\
\mathrm{e}\end{array}$ & $\begin{array}{c}\mathrm{Al} / \mathrm{Ca} \\
(\mu \mathrm{mol} / \mathrm{mol} \\
)\end{array}$ & $\begin{array}{c}\mathrm{Mn} / \mathrm{Ca} \\
(\mu \mathrm{mol} / \mathrm{mol} \\
)\end{array}$ & $\begin{array}{c}\mathrm{Sr} / \mathrm{Ca} \\
(\mathrm{mmol} / \mathrm{mol} \\
)\end{array}$ & $\begin{array}{c}\mathrm{Ba} / \mathrm{Ca} \\
(\mu \mathrm{mol} / \mathrm{mol} \\
)\end{array}$ \\
\hline $\begin{array}{l}\text { Z700 } \\
3 \\
Z 700\end{array}$ & 3 & F & reticulate & 1 & 1 & 2 & 1333.8 & 18.7 & 1.426 & 49.2 \\
\hline $\begin{array}{l}3 \\
\mathrm{Z} 700\end{array}$ & 3 & F-3 & $\begin{array}{l}\text { reticulate } \\
\text { crystallin }\end{array}$ & & 1 & 2 & 2646.4 & 38.4 & 1.409 & 37.2 \\
\hline $\begin{array}{l}3 \\
\mathrm{Z} 700\end{array}$ & 7 & F & $\begin{array}{c}\mathrm{e} \\
\text { crystallin }\end{array}$ & & 2 & 2 & 1774.3 & 12.3 & 1.353 & 12.9 \\
\hline $\begin{array}{l}3 \\
Z 700\end{array}$ & 7 & F-1 & $\mathrm{e}$ & & 2 & 2 & 102.6 & 2.7 & 1.455 & 1.8 \\
\hline $\begin{array}{l}3 \\
\mathrm{Z} 700\end{array}$ & 9 & F & reticulate & 1 & 1 & 1 & 43.4 & 17.0 & 1.730 & 3.9 \\
\hline $\begin{array}{l}3 \\
\text { Z700 }\end{array}$ & 9 & F-3 & reticulate & & 1 & 1 & 178.4 & 33.0 & 1.581 & 23.9 \\
\hline $\begin{array}{l}3 \\
\mathrm{Z} 700\end{array}$ & 10 & F & reticulate & & 1 & 1 & 380.0 & 27.6 & 1.405 & 5.5 \\
\hline $\begin{array}{l}3 \\
\text { Z700 }\end{array}$ & 10 & F-1 & reticulate & & 1 & 1 & 37.9 & 22.7 & 1.574 & 1.3 \\
\hline $\begin{array}{l}3 \\
\mathrm{Z} 700\end{array}$ & 11 & F & reticulate & 1 & 2 & 2 & 573.1 & 40.5 & 1.519 & 34.6 \\
\hline $\begin{array}{l}3 \\
Z 700\end{array}$ & 11 & F-3 & $\begin{array}{l}\text { reticulate } \\
\text { crystallin }\end{array}$ & & 2 & 2 & 588.2 & 16.4 & 1.428 & 16.2 \\
\hline $\begin{array}{l}3 \\
\mathrm{Z} 700\end{array}$ & 12 & F & $\begin{array}{c}\mathrm{e} \\
\text { crystallin }\end{array}$ & & 1 & 2 & 19.0 & 3.2 & 1.538 & 6.0 \\
\hline $\begin{array}{l}3 \\
\text { Z700 }\end{array}$ & 12 & F-3 & e & & 1 & 2 & 90.8 & 2.1 & 1.466 & 3.3 \\
\hline $\begin{array}{l}3 \\
\mathrm{Z} 700\end{array}$ & 13 & F & reticulate & 1 & 1 & 2 & 401.5 & 47.2 & 1.399 & 1.1 \\
\hline $\begin{array}{l}3 \\
Z 700\end{array}$ & 13 & F-3 & $\begin{array}{l}\text { reticulate } \\
\text { crystallin }\end{array}$ & & 1 & 2 & 125.0 & 56.4 & 1.413 & 1.0 \\
\hline $\begin{array}{l}3 \\
\mathrm{Z} 700\end{array}$ & 14 & F & $\begin{array}{c}\mathrm{e} \\
\text { crystallin }\end{array}$ & 1 & 1 & 1 & 701.2 & 17.2 & 1.355 & 6.7 \\
\hline $\begin{array}{l}3 \\
Z 700\end{array}$ & 14 & F-3 & e & & 1 & 1 & 644.7 & 3.6 & 1.386 & 0.7 \\
\hline $\begin{array}{l}3 \\
\mathrm{Z} 700\end{array}$ & 16 & F & reticulate & & 1 & 1 & 80.0 & 3.8 & 1.519 & 1.6 \\
\hline $\begin{array}{l}3 \\
Z 700\end{array}$ & 18 & F & reticulate & 1 & 2 & 2 & 23.6 & 24.6 & 1.444 & 2.7 \\
\hline $\begin{array}{l}3 \\
\text { Z700 }\end{array}$ & 18 & F-3 & reticulate & & 2 & 2 & 474.0 & 5.7 & 1.420 & 1.3 \\
\hline $\begin{array}{l}3 \\
Z 700\end{array}$ & 19 & F & reticulate & 1 & 1 & 2 & 21.4 & 26.8 & 1.369 & 1.0 \\
\hline $\begin{array}{l}3 \\
Z 700\end{array}$ & 19 & F-3 & reticulate & & 1 & 2 & 726.3 & 19.2 & 1.327 & 2.5 \\
\hline $\begin{array}{l}3 \\
Z 700\end{array}$ & 20 & F & reticulate & & 1 & 2 & 80.7 & 21.4 & 1.369 & 4.4 \\
\hline $\begin{array}{l}3 \\
\mathrm{Z} 700\end{array}$ & 20 & F-3 & $\begin{array}{l}\text { reticulate } \\
\text { crystallin }\end{array}$ & & 1 & 2 & 1810.5 & 16.3 & 1.409 & 4.8 \\
\hline $\begin{array}{l}3 \\
Z 700\end{array}$ & 21 & $\mathrm{~F}$ & $\begin{array}{c}\mathrm{e} \\
\text { crystallin }\end{array}$ & 1 & 1 & 2 & 27.0 & 11.0 & 1.491 & 17.2 \\
\hline $\begin{array}{l}3 \\
Z 700\end{array}$ & 21 & F-3 & $\mathrm{e}$ & & 1 & 2 & 3205.8 & 8.1 & 1.477 & 11.9 \\
\hline $\begin{array}{l}3 \\
\text { Z700 }\end{array}$ & 23 & F & reticulate & & 1 & 2 & 70.6 & 32.3 & 1.383 & 2.6 \\
\hline $\begin{array}{l}3 \\
\text { Z700 }\end{array}$ & 23 & F-3 & reticulate & & 1 & 2 & 458.8 & 3.1 & 1.511 & 0.6 \\
\hline $\begin{array}{l}3 \\
\text { Z700 }\end{array}$ & 30 & F & reticulate & & 1 & 1 & 94.7 & 37.5 & 1.517 & 3.8 \\
\hline $\begin{array}{l}3 \\
Z 700\end{array}$ & 30 & F-3 & reticulate & & 1 & 1 & 2378.9 & 34.0 & 1.616 & 3.3 \\
\hline $\begin{array}{l}3 \\
Z 700\end{array}$ & 32 & $\mathrm{~F}$ & reticulate & 1 & 1 & 1 & 16.3 & 16.8 & 1.358 & 0.9 \\
\hline 3 & 32 & F-3 & reticulate & & 1 & 1 & 730.6 & 16.4 & 1.278 & 1.5 \\
\hline
\end{tabular}


Table B4: Independent t-test summary for size normalised weight versus ultrastructure (reticulate or crystalline) in $N$. incompta from core top and plankton tow sites in the Southwest Pacific Ocean.

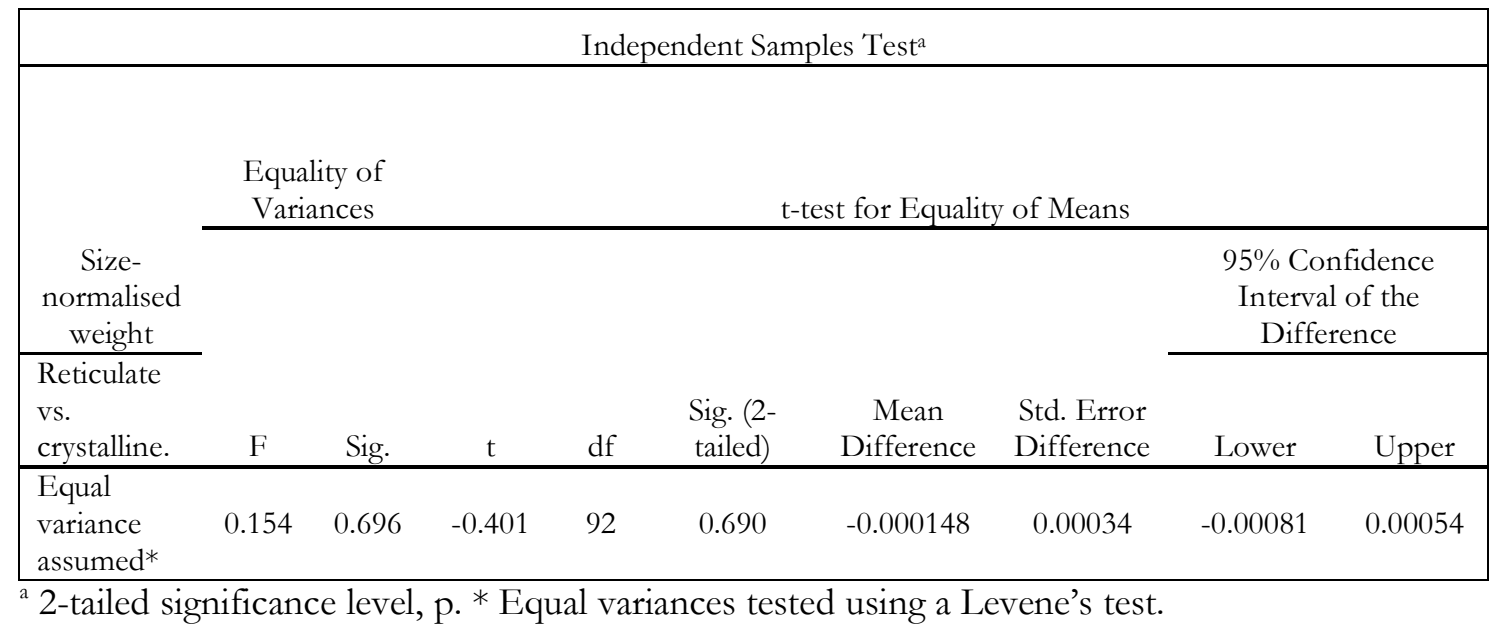


Appendix $C$

Appendix C. Chapter 5. 
Table C1: Mean trace element/Ca data for Globigerinoides ruber $(250-350 \mu \mathrm{m})$ from ODP Site 1123, 1140 to $1000 \mathrm{Kyr}$.

\begin{tabular}{|c|c|c|c|c|c|c|c|c|c|c|c|}
\hline \multicolumn{5}{|c|}{$\begin{array}{l}\text { ODP } 1123 \mathrm{C} \text { Leg } 181 \text { Core } 005 \mathrm{H} \\
\text { Core, section, interval }(\mathrm{cm})\end{array}$} & \multicolumn{7}{|c|}{ Gs. ruber } \\
\hline Section & Top & Bottom & Depth & Age & & $\mathrm{Sr} / \mathrm{Ca}$ & $\mathrm{Al} / \mathrm{Ca}$ & $\mathrm{Mn} / \mathrm{Ca}$ & $\mathrm{Zn} / \mathrm{Ca}$ & $\mathrm{Ba} / \mathrm{Ca}$ & $\mathrm{n}$ \\
\hline & $(\mathrm{cm})$ & $(\mathrm{cm})$ & (mbsf) & $(\mathrm{Kyr})$ & $(\mathrm{mmol} / \mathrm{mol})$ & $(\mathrm{mmol} / \mathrm{mol})$ & $(\mathrm{mmol} / \mathrm{mol})$ & $(\mathrm{mmol} / \mathrm{mol})$ & $(\mu \mathrm{mol} / \mathrm{mol})$ & $(\mu \mathrm{mol} / \mathrm{mol})$ & \\
\hline 2 & 90 & 91 & 39.9 & 1017.60 & 3.296 & 1.294 & 0.544 & 0.256 & 45 & 2 & 1 \\
\hline 2 & 94 & 95 & 39.94 & 1018.78 & 1.891 & 1.366 & 0.212 & 0.075 & 13 & 4 & 1 \\
\hline 2 & 98 & 99 & 39.98 & 1019.96 & 2.100 & 1.304 & 0.200 & 0.112 & 23 & 4 & 8 \\
\hline 2 & 102 & 103 & 40.02 & 1020.00 & 2.266 & 1.330 & 0.365 & 0.121 & 25 & 3 & 12 \\
\hline 2 & 106 & 107 & 40.06 & 1022.32 & 2.402 & 1.392 & 0.187 & 0.087 & 7 & 6 & 4 \\
\hline 2 & 110 & 111 & 40.1 & 1022.36 & 2.077 & 1.344 & 0.086 & 0.180 & 32 & 2 & 4 \\
\hline 2 & 114 & 115 & 40.14 & 1024.68 & 2.943 & 1.372 & 0.378 & 0.116 & 43 & 42 & 3 \\
\hline 2 & 118 & 119 & 40.18 & 1025.86 & 2.875 & 1.408 & 0.337 & 0.080 & 9 & 3 & 3 \\
\hline 2 & 122 & 123 & 40.22 & 1027.04 & & & & & & & \\
\hline 2 & 126 & 127 & 40.26 & 1029.39 & & & & & & & \\
\hline 2 & 130 & 131 & 40.3 & 1029.43 & 2.886 & 1.415 & 0.619 & 0.070 & 21 & 37 & 2 \\
\hline 2 & 134 & 135 & 40.34 & 1029.47 & 2.504 & 1.340 & 0.173 & 0.089 & 77 & 1 & 2 \\
\hline 2 & 138 & 139 & 40.38 & 1031.75 & 1.867 & 1.366 & 0.060 & 0.113 & 23 & 1 & 2 \\
\hline 2 & 142 & 143 & 40.42 & 1032.93 & 1.798 & 1.338 & 0.164 & 0.054 & 16 & 10 & 2 \\
\hline 2 & 146 & 147 & 40.46 & 1034.11 & 3.179 & 1.374 & 0.908 & 0.044 & 16 & 5 & 1 \\
\hline 2 & 149 & 150 & 40.49 & 1035.00 & 2.130 & 1.364 & 0.298 & 0.042 & 13 & 2 & 6 \\
\hline 3 & 4 & 5 & 40.54 & 1036.47 & 2.111 & 1.408 & 0.212 & 0.063 & 10 & 2 & 7 \\
\hline 3 & 8 & 9 & 40.58 & 1036.50 & 1.398 & 1.445 & 0.299 & 0.046 & 20 & 1 & 1 \\
\hline 3 & 12 & 13 & 40.62 & 1038.83 & & & & & & & \\
\hline 3 & 16 & 17 & 40.66 & 1038.86 & 1.896 & 1.385 & 0.060 & 0.030 & 26 & 1 & 2 \\
\hline 3 & 20 & 21 & 40.7 & 1038.90 & 2.184 & 1.323 & 0.167 & 0.157 & 179 & 4 & 6 \\
\hline 3 & 24 & 25 & 40.74 & 1038.93 & 1.970 & 1.459 & 0.103 & 0.062 & 44 & 1 & 5 \\
\hline 3 & 28 & 29 & 40.78 & 1043.54 & & & & & & & \\
\hline 3 & 32 & 33 & 40.82 & 1043.58 & 2.444 & 1.309 & 0.073 & 0.195 & 15 & 3 & 2 \\
\hline 3 & 36 & 37 & 40.86 & 1043.62 & 3.330 & 1.406 & 0.462 & 0.205 & 59 & 3 & 1 \\
\hline 3 & 40 & 41 & 40.9 & 1043.66 & 2.667 & 1.293 & 1.590 & 0.124 & 97 & 10 & 1 \\
\hline 3 & 44 & 45 & 40.94 & 1048.26 & 2.322 & 1.560 & 1.259 & 0.120 & 39 & 30 & 1 \\
\hline 3 & 48 & 49 & 40.98 & 1048.30 & & & & & & & \\
\hline 3 & 52 & 53 & 41.02 & 1048.34 & 2.851 & 1.337 & 0.366 & 0.345 & 20 & 3 & 1 \\
\hline 3 & 56 & 57 & 41.06 & 1051.80 & & & & & & & \\
\hline 3 & 60 & 61 & 41.1 & 1051.84 & & & & & & & \\
\hline 3 & 64 & 65 & 41.14 & 1051.88 & & & & & & & \\
\hline 3 & 68 & 69 & 41.18 & 1051.92 & & & & & & & \\
\hline 3 & 72 & 73 & 41.22 & 1056.51 & & & & & & & \\
\hline 3 & 76 & 77 & 41.26 & 1056.55 & & & & & & & \\
\hline 3 & 80 & 81 & 41.3 & 1058.84 & 2.266 & 1.291 & 0.085 & 0.101 & 26 & 4 & 1 \\
\hline 3 & 82 & 83 & 41.32 & 1058.88 & 1.677 & 1.366 & 0.062 & 0.142 & 15 & 3 & 1 \\
\hline 3 & 84 & 85 & 41.34 & 1060.01 & 2.624 & 1.283 & 0.235 & 0.429 & 342 & 5 & 3 \\
\hline 3 & 86 & 87 & 41.36 & 1060.04 & & & & & & & \\
\hline 3 & 88 & 89 & 41.38 & 1060.08 & & & & & & & \\
\hline 3 & 90 & 91 & 41.4 & 1061.75 & & & & & & & \\
\hline 3 & 92 & 93 & 41.42 & 1061.79 & & & & & & & \\
\hline 3 & 94 & 95 & 41.44 & 1062.92 & & & & & & & \\
\hline 3 & 96 & 97 & 41.46 & 1063.50 & & & & & & & \\
\hline 3 & 98 & 99 & 41.48 & 1063.53 & & & & & & & \\
\hline 3 & 100 & 101 & 41.5 & 1064.66 & 3.057 & 1.433 & 0.740 & 0.171 & 40 & 5 & 1 \\
\hline 3 & 102 & 103 & 41.52 & 1065.24 & & & & & & & \\
\hline 3 & 104 & 105 & 41.54 & 1065.82 & 2.755 & 1.291 & 1.530 & 0.215 & 20 & 24 & 1 \\
\hline 3 & 106 & 107 & 41.56 & 1066.41 & & & & & & & \\
\hline 3 & 108 & 109 & 41.58 & 1066.99 & 1.847 & 1.365 & 0.173 & 0.024 & 20 & 2 & 2 \\
\hline 3 & 110 & 111 & 41.6 & 1067.57 & & & & & & & \\
\hline 3 & 112 & 113 & 41.62 & 1068.15 & 2.345 & 1.378 & 0.146 & 0.171 & 11 & 3 & 3 \\
\hline 3 & 114 & 115 & 41.64 & 1068.73 & 2.091 & 1.375 & 0.177 & 0.165 & 13 & 2 & 3 \\
\hline 3 & 116 & 117 & 41.66 & 1068.77 & 2.614 & 1.334 & 0.079 & 0.152 & 8 & 1 & 1 \\
\hline 3 & 118 & 119 & 41.68 & 1069.90 & 2.187 & 1.345 & 0.299 & 0.141 & 18 & 3 & 6 \\
\hline 3 & 120 & 121 & 41.7 & 1070.45 & 2.961 & 1.306 & 0.573 & 0.305 & 66 & 3 & 6 \\
\hline 3 & 122 & 123 & 41.72 & 1070.96 & 2.797 & 1.341 & 0.213 & 0.211 & 81 & 2 & 6 \\
\hline 3 & 124 & 125 & 41.74 & 1071.00 & 2.461 & 1.302 & 0.282 & 0.258 & 57 & 3 & 4 \\
\hline 3 & 126 & 127 & 41.76 & 1072.00 & 2.913 & 1.345 & 0.367 & 0.119 & 28 & 5 & 2 \\
\hline 3 & 128 & 129 & 41.78 & 1072.04 & 2.325 & 1.307 & 0.248 & 0.150 & 58 & 3 & 7 \\
\hline 3 & 130 & 131 & 41.8 & 1073.03 & 2.893 & 1.297 & 0.177 & 0.197 & 160 & 3 & 6 \\
\hline 3 & 132 & 133 & 41.82 & 1073.55 & 2.707 & 1.293 & 0.270 & 0.243 & 30 & 0 & 3 \\
\hline 3 & 134 & 135 & 41.84 & 1074.07 & 2.681 & 1.290 & 0.283 & 0.128 & 56 & 4 & 8 \\
\hline
\end{tabular}


Appendix $C$

\begin{tabular}{|c|c|c|c|c|c|c|c|c|c|c|c|}
\hline \multicolumn{5}{|c|}{$\begin{array}{l}\text { ODP 1123C Leg } 181 \text { Core } 005 \mathrm{H} \\
\text { Core, section, interval }(\mathrm{cm})\end{array}$} & \multicolumn{7}{|c|}{ Gs. ruber } \\
\hline Section & Top & Bottom & Depth & Age & $\mathrm{Mg} / \mathrm{Ca}$ & $\mathrm{Sr} / \mathrm{Ca}$ & $\mathrm{Al} / \mathrm{Ca}$ & $\mathrm{Mn} / \mathrm{Ca}$ & $\mathrm{Zn} / \mathrm{Ca}$ & $\mathrm{Ba} / \mathrm{Ca}$ & $\mathrm{n}$ \\
\hline & $(\mathrm{cm})$ & $(\mathrm{cm})$ & (mbsf) & $(\mathrm{Kyr})$ & $(\mathrm{mmol} / \mathrm{mol})$ & $(\mathrm{mmol} / \mathrm{mol})$ & $(\mathrm{mmol} / \mathrm{mol})$ & $(\mathrm{mmol} / \mathrm{mol})$ & $(\mu \mathrm{mol} / \mathrm{mol})$ & $(\mu \mathrm{mol} / \mathrm{mol})$ & \\
\hline 3 & 136 & 137 & 41.86 & 1074.59 & 2.553 & 1.343 & 0.108 & 0.097 & 16 & 0 & 13 \\
\hline 3 & 138 & 139 & 41.88 & 1075.11 & 2.753 & 1.337 & 0.252 & 0.198 & 13 & 2 & 9 \\
\hline 3 & 140 & 141 & 41.9 & 1075.62 & 2.501 & 1.341 & 0.321 & 0.120 & 16 & 22 & 10 \\
\hline 3 & 142 & 143 & 41.92 & 1075.66 & 2.693 & 1.362 & 0.493 & 0.156 & 9 & 3 & 12 \\
\hline 3 & 144 & 145 & 41.94 & 1076.66 & 2.842 & 1.371 & 0.340 & 0.141 & 10 & 2 & 18 \\
\hline 3 & 146 & 147 & 41.96 & 1077.18 & 2.514 & 1.361 & 0.430 & 0.205 & 12 & 2 & 4 \\
\hline 3 & 148 & 149 & 41.98 & 1077.22 & 2.820 & 1.361 & 0.193 & 0.182 & 11 & 14 & 11 \\
\hline 4 & 4 & 5 & 42.04 & 1079.25 & 2.729 & 1.343 & 0.412 & 0.208 & 10 & 2 & 13 \\
\hline 4 & 8 & 9 & 42.08 & 1079.29 & 2.818 & 1.382 & 0.328 & 0.246 & 9 & 14 & 19 \\
\hline 4 & 10 & 11 & 42.1 & 1080.80 & 2.653 & 1.340 & 0.298 & 0.274 & 11 & 19 & 14 \\
\hline 4 & 12 & 13 & 42.12 & 1080.84 & 2.704 & 1.348 & 0.423 & 0.252 & 17 & 5 & 16 \\
\hline 4 & 14 & 15 & 42.14 & 1081.84 & 2.807 & 1.372 & 0.203 & 0.219 & 10 & 1 & 16 \\
\hline 4 & 16 & 17 & 42.16 & 1081.88 & 2.887 & 1.397 & 0.154 & 0.222 & 13 & 2 & 15 \\
\hline 4 & 18 & 19 & 42.18 & 1082.87 & 2.719 & 1.384 & 0.210 & 0.296 & 12 & 22 & 15 \\
\hline 4 & 20 & 21 & 42.2 & 1082.91 & 2.970 & 1.356 & 0.382 & 0.244 & 22 & 2 & 13 \\
\hline 4 & 22 & 23 & 42.22 & 1082.95 & 2.697 & 1.369 & 0.266 & 0.273 & 9 & 6 & 28 \\
\hline 4 & 24 & 25 & 42.24 & 1084.43 & 2.780 & 1.376 & 0.175 & 0.293 & 8 & 2 & 13 \\
\hline 4 & 26 & 27 & 42.26 & 1084.46 & 2.796 & 1.343 & 0.346 & 0.265 & 10 & 8 & 13 \\
\hline 4 & 28 & 29 & 42.28 & 1084.49 & 2.673 & 1.333 & 0.356 & 0.304 & 11 & 5 & 13 \\
\hline 4 & 30 & 31 & 42.3 & 1086.31 & 2.741 & 1.326 & 0.410 & 0.225 & 14 & 2 & 12 \\
\hline 4 & 32 & 33 & 42.32 & 1086.34 & 2.444 & 1.351 & 0.308 & 0.199 & 15 & 3 & 8 \\
\hline 4 & 34 & 35 & 42.34 & 1087.63 & 2.195 & 1.347 & 0.395 & 0.217 & 10 & 19 & 9 \\
\hline 4 & 38 & 39 & 42.38 & 1087.66 & 2.313 & 1.339 & 0.371 & 0.200 & 9 & 2 & 7 \\
\hline 4 & 42 & 43 & 42.42 & 1090.26 & 3.251 & 1.276 & 0.797 & 0.328 & 16 & 5 & 2 \\
\hline 4 & 46 & 47 & 42.46 & 1090.29 & 2.180 & 1.274 & 0.265 & 0.174 & 22 & 3 & 2 \\
\hline 4 & 50 & 51 & 42.5 & 1092.90 & 2.886 & 1.367 & 0.395 & 0.195 & 8 & 3 & 2 \\
\hline 4 & 54 & 55 & 42.54 & 1092.93 & 2.078 & 1.360 & 0.339 & 0.206 & 12 & 5 & 6 \\
\hline 4 & 58 & 59 & 42.58 & 1092.96 & 3.143 & 1.278 & 0.124 & 0.316 & 77 & 2 & 1 \\
\hline 4 & 62 & 63 & 42.62 & 1096.85 & 2.262 & 1.302 & 0.236 & 0.150 & 7 & 3 & 4 \\
\hline 4 & 66 & 67 & 42.66 & 1096.88 & & & & & & & \\
\hline 4 & 70 & 71 & 42.7 & 1096.91 & & & & & & & \\
\hline 4 & 74 & 75 & 42.74 & 1100.81 & 2.705 & 1.235 & 0.161 & 0.390 & 16 & 4 & 1 \\
\hline 4 & 78 & 79 & 42.78 & 1102.12 & & & & & & & \\
\hline 4 & 82 & 83 & 42.82 & 1102.15 & & & & & & & \\
\hline 4 & 86 & 87 & 42.86 & 1104.76 & & & & & & & \\
\hline 4 & 90 & 91 & 42.9 & 1104.79 & 2.519 & 1.365 & 0.282 & 0.148 & 7 & 2 & 6 \\
\hline 4 & 94 & 95 & 42.94 & 1107.40 & 2.869 & 1.334 & 0.177 & 0.090 & 7 & 1 & 4 \\
\hline 4 & 98 & 99 & 42.98 & 1108.84 & 2.363 & 1.305 & 0.241 & 0.150 & 13 & 2 & 9 \\
\hline 4 & 102 & 103 & 43.02 & 1110.89 & 2.224 & 1.336 & 0.171 & 0.117 & 11 & 1 & 22 \\
\hline 4 & 106 & 107 & 43.06 & 1110.91 & 2.673 & 1.326 & 0.464 & 0.150 & 6 & 2 & 12 \\
\hline 4 & 110 & 111 & 43.1 & 1114.99 & 2.414 & 1.340 & 0.464 & 0.195 & 17 & 4 & 12 \\
\hline 4 & 114 & 115 & 43.14 & 1115.01 & 2.517 & 1.316 & 0.258 & 0.288 & 15 & 5 & 7 \\
\hline 4 & 118 & 119 & 43.18 & 1119.10 & 2.495 & 1.330 & 0.455 & 0.370 & 23 & 7 & 2 \\
\hline 4 & 122 & 123 & 43.22 & 1121.15 & 2.252 & 1.320 & 0.417 & 0.236 & 50 & 6 & 2 \\
\hline 4 & 126 & 127 & 43.26 & 1121.17 & 2.532 & 1.287 & 0.674 & 0.234 & 12 & 10 & 2 \\
\hline 4 & 130 & 131 & 43.3 & 1125.26 & 2.625 & 1.338 & 0.346 & 0.240 & 13 & 3 & 1 \\
\hline 4 & 134 & 135 & 43.34 & 1127.31 & 2.995 & 1.426 & 0.932 & 0.241 & 25 & 3 & 1 \\
\hline
\end{tabular}


Table C2: Mean trace element/Ca data for Globigerina bulloides $(250-350 \mu \mathrm{m})$ from ODP Site 1123, 1140 to $1000 \mathrm{Kyr}$.

\begin{tabular}{|c|c|c|c|c|c|c|c|c|c|c|c|}
\hline \multicolumn{11}{|c|}{ ODP $1123 \mathrm{C}$ Leg 181 Core $005 \mathrm{H}$} & \\
\hline Section & Top & Bottom & Depth & Age & $\mathrm{Mg} / \mathrm{Ca}$ & $\mathrm{Sr} / \mathrm{Ca}$ & $\mathrm{Al} / \mathrm{Ca}$ & $\mathrm{Mn} / \mathrm{Ca}$ & $\mathrm{Zn} / \mathrm{Ca}$ & $\mathrm{Ba} / \mathrm{Ca}$ & $\mathrm{n}$ \\
\hline & $(\mathrm{cm})$ & $(\mathrm{cm})$ & $(\mathrm{mbsf})$ & $(\mathrm{Kyr})$ & $(\mathrm{mmol} / \mathrm{mol})$ & $(\mathrm{mmol} / \mathrm{mol})$ & $(\mathrm{mmol} / \mathrm{mol})$ & $(\mathrm{mmol} / \mathrm{mol})$ & $(\mu \mathrm{mol} / \mathrm{mol})$ & $(\mu \mathrm{mol} / \mathrm{mol})$ & \\
\hline 2 & 90 & 91 & 39.9 & 1017.60 & 2.471 & 1.244 & 0.450 & 0.228 & 69 & 5 & 6 \\
\hline 2 & 94 & 95 & 39.94 & 1018.78 & 2.276 & 1.282 & 0.332 & 0.188 & 20 & 14 & 10 \\
\hline 2 & 98 & 99 & 39.98 & 1019.96 & 2.476 & 1.336 & 0.157 & 0.196 & 39 & 5 & 6 \\
\hline 2 & 102 & 103 & 40.02 & 1020.00 & 2.240 & 1.330 & 0.206 & 0.172 & 47 & 5 & 9 \\
\hline 2 & 106 & 107 & 40.06 & 1022.32 & 2.131 & 1.282 & 0.274 & 0.163 & 46 & 13 & 8 \\
\hline 2 & 110 & 111 & 40.1 & 1022.36 & 2.446 & 1.302 & 0.330 & 0.148 & 44 & 8 & 7 \\
\hline 2 & 114 & 115 & 40.14 & 1024.68 & 2.341 & 1.301 & 0.235 & 0.180 & 41 & 4 & 6 \\
\hline 2 & 118 & 119 & 40.18 & 1025.86 & 2.118 & 1.318 & 0.484 & 0.146 & 30 & 14 & 6 \\
\hline 2 & 122 & 123 & 40.22 & 1027.04 & 2.127 & 1.310 & 0.721 & 0.134 & 28 & 11 & 9 \\
\hline 2 & 126 & 127 & 40.26 & 1029.39 & 1.908 & 1.320 & 0.243 & 0.155 & 63 & 27 & 5 \\
\hline 2 & 130 & 131 & 40.3 & 1029.43 & 2.505 & 1.324 & 0.291 & 0.179 & 47 & 15 & 10 \\
\hline 2 & 134 & 135 & 40.34 & 1029.47 & 2.111 & 1.268 & 0.241 & 0.176 & 28 & 3 & 7 \\
\hline 2 & 138 & 139 & 40.38 & 1031.75 & 2.624 & 1.332 & 0.564 & 0.203 & 47 & 79 & 13 \\
\hline 2 & 142 & 143 & 40.42 & 1032.93 & 2.210 & 1.322 & 0.344 & 0.139 & 43 & 19 & 13 \\
\hline 2 & 146 & 147 & 40.46 & 1034.11 & 2.382 & 1.323 & 0.652 & 0.151 & 62 & 6 & 8 \\
\hline 2 & 149 & 150 & 40.49 & 1035.00 & 1.923 & 1.308 & 0.345 & 0.131 & 54 & 62 & 10 \\
\hline 3 & 4 & 5 & 40.54 & 1036.47 & 1.657 & 1.292 & 0.295 & 0.100 & 26 & 18 & 14 \\
\hline 3 & 8 & 9 & 40.58 & 1036.50 & 1.682 & 1.338 & 0.189 & 0.078 & 17 & 2 & 11 \\
\hline 3 & 12 & 13 & 40.62 & 1038.83 & 1.759 & 1.286 & 0.257 & 0.099 & 74 & 10 & 10 \\
\hline 3 & 16 & 17 & 40.66 & 1038.86 & 2.126 & 1.298 & 0.839 & 0.145 & 47 & 5 & 13 \\
\hline 3 & 20 & 21 & 40.7 & 1038.90 & 2.188 & 1.320 & 0.158 & 0.153 & 156 & 16 & 13 \\
\hline 3 & 24 & 25 & 40.74 & 1038.93 & 1.795 & 1.301 & 0.240 & 0.125 & 96 & 34 & 12 \\
\hline 3 & 28 & 29 & 40.78 & 1043.54 & 1.942 & 1.309 & 0.292 & 0.095 & 46 & 1 & 9 \\
\hline 3 & 32 & 33 & 40.82 & 1043.58 & 1.791 & 1.288 & 0.411 & 0.122 & 51 & 3 & 10 \\
\hline 3 & 36 & 37 & 40.86 & 1043.62 & 2.108 & 1.297 & 0.251 & 0.131 & 59 & 4 & 13 \\
\hline 3 & 40 & 41 & 40.9 & 1043.66 & 1.966 & 1.326 & 0.261 & 0.119 & 105 & 5 & 10 \\
\hline 3 & 44 & 45 & 40.94 & 1048.26 & 2.376 & 1.268 & 0.343 & 0.224 & 188 & 5 & 11 \\
\hline 3 & 48 & 49 & 40.98 & 1048.30 & 2.173 & 1.269 & 0.568 & 0.198 & 97 & 6 & 11 \\
\hline 3 & 52 & 53 & 41.02 & 1048.34 & 2.192 & 1.272 & 0.316 & 0.180 & 135 & 4 & 7 \\
\hline 3 & 56 & 57 & 41.06 & 1051.80 & 1.743 & 1.339 & 0.289 & 0.123 & 16 & 5 & 3 \\
\hline 3 & 60 & 61 & 41.1 & 1051.84 & 1.917 & 1.292 & 0.426 & 0.142 & 95 & 5 & 14 \\
\hline 3 & 64 & 65 & 41.14 & 1051.88 & 2.278 & 1.316 & 0.568 & 0.176 & 232 & 39 & 10 \\
\hline 3 & 68 & 69 & 41.18 & 1051.92 & 2.797 & 1.345 & 0.332 & 0.224 & 112 & 17 & 9 \\
\hline 3 & 72 & 73 & 41.22 & 1056.51 & 2.979 & 1.341 & 0.150 & 0.178 & 129 & 6 & 5 \\
\hline 3 & 76 & 77 & 41.26 & 1056.55 & 2.563 & 1.301 & 0.370 & 0.263 & 127 & 5 & 18 \\
\hline 3 & 80 & 81 & 41.3 & 1058.84 & 2.411 & 1.256 & 0.259 & 0.258 & 70 & 65 & 3 \\
\hline 3 & 82 & 83 & 41.32 & 1058.88 & 3.053 & 1.302 & 0.148 & 0.403 & 70 & 7 & 6 \\
\hline 3 & 84 & 85 & 41.34 & 1060.01 & 2.201 & 1.279 & 0.210 & 0.222 & 147 & 6 & 13 \\
\hline 3 & 86 & 87 & 41.36 & 1060.04 & 2.501 & 1.286 & 0.358 & 0.293 & 85 & 8 & 11 \\
\hline 3 & 88 & 89 & 41.38 & 1060.08 & 2.006 & 1.345 & 0.081 & 0.205 & 12 & 3 & 17 \\
\hline 3 & 90 & 91 & 41.4 & 1061.75 & 3.035 & 1.290 & 0.195 & 0.299 & 15 & 23 & 15 \\
\hline 3 & 92 & 93 & 41.42 & 1061.79 & 2.449 & 1.306 & 0.182 & 0.265 & 51 & 3 & 7 \\
\hline 3 & 94 & 95 & 41.44 & 1062.92 & 1.967 & 1.334 & 0.147 & 0.186 & 13 & 8 & 20 \\
\hline 3 & 96 & 97 & 41.46 & 1063.50 & 1.691 & 1.283 & 0.168 & 0.119 & 16 & 3 & 4 \\
\hline 3 & 98 & 99 & 41.48 & 1063.53 & 2.912 & 1.349 & 0.233 & 0.338 & 119 & 5 & 4 \\
\hline 3 & 100 & 101 & 41.5 & 1064.66 & 2.464 & 1.275 & 0.430 & 0.298 & 117 & 42 & 10 \\
\hline 3 & 102 & 103 & 41.52 & 1065.24 & 2.560 & 1.280 & 0.257 & 0.299 & 272 & 29 & 7 \\
\hline 3 & 104 & 105 & 41.54 & 1065.82 & 1.777 & 1.257 & 0.129 & 0.150 & 172 & 6 & 7 \\
\hline 3 & 106 & 107 & 41.56 & 1066.41 & 1.996 & 1.257 & 0.227 & 0.224 & 121 & 16 & 9 \\
\hline 3 & 108 & 109 & 41.58 & 1066.99 & 1.836 & 1.249 & 0.082 & 0.247 & 74 & 30 & 3 \\
\hline 3 & 110 & 111 & 41.6 & 1067.57 & 2.464 & 1.298 & 0.420 & 0.216 & 25 & 10 & 6 \\
\hline 3 & 112 & 113 & 41.62 & 1068.15 & 2.087 & 1.309 & 0.134 & 0.231 & 160 & 37 & 9 \\
\hline 3 & 114 & 115 & 41.64 & 1068.73 & 2.112 & 1.287 & 0.166 & 0.211 & 58 & 6 & 22 \\
\hline 3 & 116 & 117 & 41.66 & 1068.77 & 2.472 & 1.272 & 0.395 & 0.232 & 46 & 21 & 17 \\
\hline 3 & 118 & 119 & 41.68 & 1069.90 & 2.201 & 1.279 & 0.331 & 0.217 & 27 & 3 & 14 \\
\hline 3 & 120 & 121 & 41.7 & 1070.45 & 2.494 & 1.313 & 0.371 & 0.230 & 53 & 21 & 14 \\
\hline 3 & 122 & 123 & 41.72 & 1070.96 & 2.629 & 1.293 & 0.362 & 0.218 & 90 & 4 & 11 \\
\hline 3 & 124 & 125 & 41.74 & 1071.00 & 2.340 & 1.311 & 0.397 & 0.239 & 68 & 10 & 10 \\
\hline 3 & 126 & 127 & 41.76 & 1072.00 & 1.893 & 1.205 & 0.707 & 0.075 & 20 & 5 & 2 \\
\hline 3 & 128 & 129 & 41.78 & 1072.04 & 1.956 & 1.276 & 0.403 & 0.125 & 38 & 6 & 7 \\
\hline 3 & 130 & 131 & 41.8 & 1073.03 & 2.481 & 1.281 & 0.350 & 0.199 & 308 & 125 & 9 \\
\hline 3 & 132 & 133 & 41.82 & 1073.55 & 2.276 & 1.347 & 0.425 & 0.173 & 21 & 72 & 7 \\
\hline 3 & 134 & 135 & 41.84 & 1074.07 & 1.535 & 1.247 & 0.290 & 0.053 & 18 & 8 & 2 \\
\hline 3 & 136 & 137 & 41.86 & 1074.59 & 2.307 & 1.280 & 0.620 & 0.198 & 36 & 18 & 9 \\
\hline
\end{tabular}




\begin{tabular}{|c|c|c|c|c|c|c|c|c|c|c|c|}
\hline \multicolumn{5}{|c|}{$\begin{array}{l}\text { ODP 1123C Leg } 181 \text { Core } 005 \mathrm{H} \\
\text { Core, section, interval }(\mathrm{cm})\end{array}$} & \multicolumn{7}{|c|}{ G. bulloides } \\
\hline Section & Top & Bottom & Depth & Age & $\mathrm{Mg} / \mathrm{Ca}$ & $\mathrm{Sr} / \mathrm{Ca}$ & $\mathrm{Al} / \mathrm{Ca}$ & $\mathrm{Mn} / \mathrm{Ca}$ & $\mathrm{Zn} / \mathrm{Ca}$ & $\mathrm{Ba} / \mathrm{Ca}$ & $\mathrm{n}$ \\
\hline & $(\mathrm{cm})$ & $(\mathrm{cm})$ & (mbsf) & $(\mathrm{Kyr})$ & $(\mathrm{mmol} / \mathrm{mol})$ & $(\mathrm{mmol} / \mathrm{mol})$ & $(\mathrm{mmol} / \mathrm{mol})$ & $(\mathrm{mmol} / \mathrm{mol})$ & $(\mu \mathrm{mol} / \mathrm{mol})$ & $(\mu \mathrm{mol} / \mathrm{mol})$ & \\
\hline 3 & 138 & 139 & 41.88 & 1075.11 & 2.674 & 1.296 & 0.301 & 0.239 & 30 & 2 & 10 \\
\hline 3 & 140 & 141 & 41.9 & 1075.62 & 2.198 & 1.256 & 0.277 & 0.180 & 35 & 2 & 3 \\
\hline 3 & 142 & 143 & 41.92 & 1075.66 & 3.201 & 1.280 & 0.876 & 0.274 & 30 & 3 & 8 \\
\hline 3 & 144 & 145 & 41.94 & 1076.66 & 2.632 & 1.248 & 0.682 & 0.181 & 22 & 12 & 14 \\
\hline 3 & 146 & 147 & 41.96 & 1077.18 & 2.363 & 1.272 & 0.644 & 0.201 & 27 & 18 & 11 \\
\hline 3 & 148 & 149 & 41.98 & 1077.22 & 2.753 & 1.250 & 0.271 & 0.211 & 26 & 17 & 13 \\
\hline 4 & 4 & 5 & 42.04 & 1079.25 & 2.562 & 1.252 & 0.376 & 0.181 & 10 & 23 & 14 \\
\hline 4 & 8 & 9 & 42.08 & 1079.29 & 3.406 & 1.275 & 0.497 & 0.234 & 22 & 15 & 13 \\
\hline 4 & 10 & 11 & 42.1 & 1080.80 & 3.033 & 1.307 & 1.055 & 0.310 & 28 & 51 & 15 \\
\hline 4 & 12 & 13 & 42.12 & 1080.84 & 3.167 & 1.341 & 1.226 & 0.273 & 18 & 135 & 18 \\
\hline 4 & 14 & 15 & 42.14 & 1081.84 & 3.039 & 1.284 & 0.256 & 0.232 & 21 & 2 & 16 \\
\hline 4 & 16 & 17 & 42.16 & 1081.88 & 2.986 & 1.292 & 0.339 & 0.202 & 13 & 2 & 18 \\
\hline 4 & 18 & 19 & 42.18 & 1082.87 & 3.130 & 1.283 & 0.297 & 0.220 & 22 & 2 & 17 \\
\hline 4 & 20 & 21 & 42.2 & 1082.91 & 2.930 & 1.293 & 0.248 & 0.234 & 22 & 6 & 17 \\
\hline 4 & 22 & 23 & 42.22 & 1082.95 & 3.010 & 1.293 & 0.272 & 0.241 & 30 & 5 & 17 \\
\hline 4 & 24 & 25 & 42.24 & 1084.43 & 2.974 & 1.300 & 0.242 & 0.247 & 26 & 6 & 14 \\
\hline 4 & 26 & 27 & 42.26 & 1084.46 & 3.502 & 1.308 & 0.495 & 0.242 & 30 & 5 & 14 \\
\hline 4 & 28 & 29 & 42.28 & 1084.49 & 2.611 & 1.304 & 0.468 & 0.216 & 15 & 6 & 17 \\
\hline 4 & 30 & 31 & 42.3 & 1086.31 & 2.834 & 1.289 & 0.391 & 0.207 & 11 & 6 & 19 \\
\hline 4 & 32 & 33 & 42.32 & 1086.34 & 2.908 & 1.333 & 0.851 & 0.201 & 13 & 38 & 22 \\
\hline 4 & 34 & 35 & 42.34 & 1087.63 & 3.327 & 1.291 & 0.922 & 0.210 & 11 & 4 & 9 \\
\hline 4 & 38 & 39 & 42.38 & 1087.66 & 3.025 & 1.306 & 0.886 & 0.240 & 13 & 2 & 22 \\
\hline 4 & 42 & 43 & 42.42 & 1090.26 & 2.530 & 1.324 & 1.300 & 0.190 & 11 & 19 & 17 \\
\hline 4 & 46 & 47 & 42.46 & 1090.29 & 3.007 & 1.315 & 1.340 & 0.214 & 11 & 26 & 17 \\
\hline 4 & 50 & 51 & 42.5 & 1092.90 & 3.283 & 1.302 & 1.047 & 0.241 & 16 & 22 & 17 \\
\hline 4 & 54 & 55 & 42.54 & 1092.93 & 2.708 & 1.319 & 1.219 & 0.191 & 13 & 11 & 15 \\
\hline 4 & 58 & 59 & 42.58 & 1092.96 & 2.551 & 1.315 & 0.534 & 0.179 & 12 & 3 & 9 \\
\hline 4 & 62 & 63 & 42.62 & 1096.85 & 2.892 & 1.323 & 0.573 & 0.195 & 8 & 18 & 17 \\
\hline 4 & 66 & 67 & 42.66 & 1096.88 & 2.460 & 1.313 & 0.491 & 0.235 & 20 & 5 & 7 \\
\hline 4 & 70 & 71 & 42.7 & 1096.91 & 1.815 & 1.273 & 0.283 & 0.173 & 24 & 4 & 2 \\
\hline 4 & 74 & 75 & 42.74 & 1100.81 & 2.439 & 1.306 & 0.731 & 0.222 & 16 & 5 & 11 \\
\hline 4 & 78 & 79 & 42.78 & 1102.12 & 2.086 & 1.223 & 0.248 & 0.124 & 10 & 4 & 3 \\
\hline 4 & 82 & 83 & 42.82 & 1102.15 & 2.979 & 1.343 & 0.940 & 0.353 & 18 & 4 & 7 \\
\hline 4 & 86 & 87 & 42.86 & 1104.76 & 2.870 & 1.271 & 2.589 & 0.205 & 12 & 13 & 5 \\
\hline 4 & 90 & 91 & 42.9 & 1104.79 & 2.667 & 1.257 & 1.385 & 0.137 & 12 & 3 & 10 \\
\hline 4 & 94 & 95 & 42.94 & 1107.40 & 2.819 & 1.299 & 0.987 & 0.209 & 11 & 26 & 14 \\
\hline 4 & 98 & 99 & 42.98 & 1108.84 & 2.048 & 1.300 & 0.586 & 0.158 & 9 & 4 & 13 \\
\hline 4 & 102 & 103 & 43.02 & 1110.89 & 2.682 & 1.297 & 0.809 & 0.179 & 12 & 4 & 14 \\
\hline 4 & 106 & 107 & 43.06 & 1110.91 & 2.569 & 1.324 & 0.786 & 0.195 & 12 & 23 & 15 \\
\hline 4 & 110 & 111 & 43.1 & 1114.99 & 2.764 & 1.354 & 0.745 & 0.218 & 20 & 35 & 11 \\
\hline 4 & 114 & 115 & 43.14 & 1115.01 & 2.704 & 1.294 & 0.617 & 0.197 & 11 & 22 & 14 \\
\hline 4 & 118 & 119 & 43.18 & 1119.10 & 2.270 & 1.289 & 0.328 & 0.168 & 8 & 5 & 15 \\
\hline 4 & 122 & 123 & 43.22 & 1121.15 & 2.273 & 1.278 & 0.554 & 0.161 & 6 & 25 & 14 \\
\hline 4 & 126 & 127 & 43.26 & 1121.17 & 2.228 & 1.297 & 0.518 & 0.148 & 11 & 21 & 19 \\
\hline 4 & 130 & 131 & 43.3 & 1125.26 & 2.556 & 1.294 & 0.982 & 0.131 & 10 & 5 & 16 \\
\hline 4 & 134 & 135 & 43.34 & 1127.31 & 2.461 & 1.281 & 1.470 & 0.126 & 15 & 8 & 11 \\
\hline
\end{tabular}


Table C3: Mean stable oxygen and carbon isotope data for Uvigerina spp., Globigerinoides ruber and Globerina bulloides from ODP Site 1123, 1140 to 1000 Kyr. Grey shaded cells indicate replicate analysis on the same sample.

\begin{tabular}{|c|c|c|c|c|c|c|c|c|c|c|c|}
\hline \multicolumn{4}{|c|}{ Core, section, interval $(\mathrm{cm})$} & \multicolumn{2}{|l|}{$\begin{array}{l}\text { Adjusted } \\
\text { Depth }^{1}\end{array}$} & \multicolumn{2}{|c|}{ Uvigerina spp. } & \multicolumn{2}{|c|}{ Gs. ruber } & \multicolumn{2}{|c|}{ G. bulloides } \\
\hline Section & Top & Bottom & Depth & Uvigerina spp. & Age & $\delta^{13} \mathrm{C}$ & $\delta^{18} \mathrm{O}$ & $\delta^{13} \mathrm{C}$ & $\delta^{18} \mathrm{O}$ & $\delta^{13} \mathrm{C}$ & $\delta^{18} \mathrm{O}$ \\
\hline & $(\mathrm{cm})$ & $(\mathrm{cm})$ & $\overline{(\mathrm{mbsf})}$ & (mbsf) & (Kyr) & $(\% 0)$ & $(\% 0)$ & $(\%)$ & $(\% 0)$ & $(\% 0)$ & $(\% 0)$ \\
\hline 2 & 90 & 91 & 39.90 & 39.90 & $1,017.60$ & -0.884 & 3.860 & & & & \\
\hline 2 & 94 & 95 & 39.94 & 39.94 & $1,018.78$ & -0.973 & 3.858 & & & 0.073 & 1.243 \\
\hline 2 & 98 & 99 & 39.98 & 40.00 & $1,019.96$ & $\begin{array}{l}-0.671 \\
-0.706\end{array}$ & $\begin{array}{l}3.890 \\
3.789\end{array}$ & & & -0.178 & 1.317 \\
\hline 2 & 102 & 103 & 40.02 & & $1,020.00$ & & & 0.77 & 0.97 & -0.496 & 0.885 \\
\hline 2 & 106 & 107 & 40.06 & 40.08 & $1,022.32$ & -0.872 & 3.769 & & & -0.105 & 1.232 \\
\hline 2 & 110 & 111 & 40.10 & & $1,022.36$ & & & & & -1.263 & 0.563 \\
\hline 2 & 114 & 115 & 40.14 & 40.16 & $1,024.68$ & -1.123 & 4.095 & & & & \\
\hline 2 & 118 & 119 & 40.18 & 40.18 & $1,025.86$ & -1.001 & 4.108 & & & -0.536 & 1.148 \\
\hline 2 & 122 & 123 & 40.22 & 40.24 & $1,027.04$ & $\begin{array}{l}-1.101 \\
-1.139\end{array}$ & $\begin{array}{l}4.399 \\
4.246\end{array}$ & & & & \\
\hline 2 & 126 & 127 & 40.26 & & $1,029.39$ & & & & & & \\
\hline 2 & 130 & 131 & 40.30 & 40.32 & $1,029.43$ & -1.248 & 4.083 & & & & \\
\hline 2 & 134 & 135 & 40.34 & & $1,029.47$ & & & & & -0.173 & 1.788 \\
\hline 2 & 138 & 139 & 40.38 & 40.38 & $1,031.75$ & -1.102 & 4.586 & & & -0.670 & 1.209 \\
\hline 2 & 142 & 143 & 40.42 & 40.42 & $1,032.93$ & -1.445 & 4.648 & & & -0.355 & 1.928 \\
\hline 2 & 146 & 147 & 40.46 & 40.46 & $1,034.11$ & -1.259 & 4.484 & & & -0.015 & 1.620 \\
\hline 2 & 149 & 150 & 40.49 & 40.49 & $1,035.00$ & -1.392 & 4.821 & & & 0.059 & 2.374 \\
\hline \multirow[t]{2}{*}{3} & 4 & 5 & 40.54 & 40.56 & $1,036.47$ & -1.316 & 4.620 & & & -0.571 & 1.824 \\
\hline & & & & & & & & & & 0.185 & 2.378 \\
\hline 3 & 8 & 9 & 40.58 & & $1,036.50$ & & & & & & \\
\hline 3 & 12 & 13 & 40.62 & 40.68 & $1,038.83$ & -1.371 & 4.793 & & & 0.196 & 2.528 \\
\hline 3 & 16 & 17 & 40.66 & & $1,038.86$ & & & & & -0.389 & 1.922 \\
\hline 3 & 20 & 21 & 40.70 & & $1,038.90$ & & & & & 0.088 & 2.153 \\
\hline 3 & 24 & 25 & 40.74 & & $1,038.93$ & & & & & -0.095 & 1.892 \\
\hline 3 & 28 & 29 & 40.78 & 40.84 & $1,043.54$ & -1.477 & 4.637 & & & 0.124 & 1.837 \\
\hline 3 & 32 & 33 & 40.82 & & $1,043.58$ & & & & & 0.562 & 2.213 \\
\hline 3 & 36 & 37 & 40.86 & & $1,043.62$ & & & & & 0.244 & 2.036 \\
\hline 3 & 36 & 37 & 40.86 & & & & & & & 0.187 & 1.966 \\
\hline 3 & 40 & 41 & 40.90 & & $1,043.66$ & & & & & 0.203 & 2.166 \\
\hline 3 & 44 & 45 & 40.94 & 40.98 & $1,048.26$ & -1.355 & 4.419 & & & -1.167 & 1.113 \\
\hline 3 & 48 & 49 & 40.98 & & $1,048.30$ & & & & & -1.402 & -0.296 \\
\hline 3 & 52 & 53 & 41.02 & & $1,048.34$ & & & & & -0.193 & 1.720 \\
\hline 3 & 56 & 57 & 41.06 & 41.12 & $1,051.80$ & -1.435 & 4.423 & & & & \\
\hline 3 & 60 & 61 & 41.10 & & $1,051.84$ & & & & & 0.211 & 2.091 \\
\hline 3 & 64 & 65 & 41.14 & & $1,051.88$ & & & & & -0.226 & 1.850 \\
\hline 3 & 68 & 69 & 41.18 & & $1,051.92$ & & & & & -0.558 & 1.575 \\
\hline 3 & 72 & 73 & 41.22 & 41.24 & $1,056.51$ & -1.322 & 4.557 & & & & \\
\hline 3 & 76 & 77 & 41.26 & & $1,056.55$ & & & & & -0.764 & 1.095 \\
\hline \multirow[t]{2}{*}{3} & 80 & 81 & 41.30 & 41.31 & $1,058.84$ & -1.549 & 4.445 & & & -0.104 & 1.370 \\
\hline & & & & & & -1.422 & 4.323 & & & & \\
\hline 3 & 82 & 83 & 41.32 & & $1,058.88$ & & & & & -0.059 & 1.785 \\
\hline \multirow[t]{2}{*}{3} & 84 & 85 & 41.34 & 41.36 & $1,060.01$ & -1.157 & 4.154 & & & -0.660 & 1.533 \\
\hline & & & & & & -1.180 & 4.175 & & & & \\
\hline 3 & 86 & 87 & 41.36 & & $1,060.04$ & & & & & -0.123 & 1.748 \\
\hline \multirow[t]{2}{*}{3} & 88 & 89 & 41.38 & & $1,060.08$ & & & & & -0.001 & 2.308 \\
\hline & & & & & & & & & & 0.341 & 2.414 \\
\hline
\end{tabular}




\begin{tabular}{|c|c|c|c|c|c|c|c|c|c|c|c|}
\hline & ODP & $123 \mathrm{C} \mathrm{Le}$ & 181 Cor & $5 \mathrm{H}$ & & & & & & & \\
\hline Core & sectiol & , interval & $\mathrm{cm})$ & $\begin{array}{l}\text { Adjusted } \\
\text { Depth }^{1}\end{array}$ & & Uvigeri & a spp. & Gs. & uber & G. $b t$ & loides \\
\hline Section & Top & Bottom & Depth & Uvigerina spp. & Age & $\delta^{13} \mathrm{C}$ & $\delta^{18} \mathrm{O}$ & $\delta^{13} \mathrm{C}$ & $\delta^{18} \mathrm{O}$ & $\delta^{13} \mathrm{C}$ & $\delta^{18} \mathrm{O}$ \\
\hline 3 & 90 & 91 & 41.40 & 41.41 & $1,061.75$ & -1.427 & 4.342 & & & -0.406 & 1.239 \\
\hline & & & & & & -1.256 & 4.394 & & & & \\
\hline 3 & 92 & 93 & 41.42 & & $1,061.79$ & & & & & -1.063 & -0.110 \\
\hline 3 & 94 & 95 & 41.44 & 41.44 & $1,062.92$ & -1.148 & 4.344 & & & 0.344 & 2.612 \\
\hline 3 & 96 & 97 & 41.46 & 41.47 & $1,063.50$ & -1.194 & 4.132 & & & & \\
\hline 3 & 98 & 99 & 41.48 & & $1,063.53$ & & & & & 0.021 & 2.068 \\
\hline 3 & 100 & 101 & 41.50 & 41.50 & $1,064.66$ & -0.908 & 3.981 & & & -0.154 & 1.449 \\
\hline 3 & 102 & 103 & 41.52 & 41.52 & $1,065.24$ & -0.763 & 4.090 & & & -0.068 & 0.760 \\
\hline 3 & 104 & 105 & 41.54 & 41.54 & $1,065.82$ & -0.737 & 3.774 & & & & \\
\hline & & & & & & -0.821 & 3.614 & & & & \\
\hline 3 & 106 & 107 & 41.56 & 41.56 & $1,066.41$ & -0.816 & 3.593 & & & 0.230 & 1.657 \\
\hline & & & & & & -0.828 & 3.927 & & & & \\
\hline 3 & 108 & 109 & 41.58 & 41.58 & $1,066.99$ & -0.733 & 4.022 & & & 0.255 & 1.287 \\
\hline 3 & 110 & 111 & 41.60 & 41.60 & $1,067.57$ & -0.834 & 3.986 & & & & \\
\hline 3 & 112 & 113 & 41.62 & 41.62 & $1,068.15$ & -0.776 & 3.792 & & & -0.141 & 1.175 \\
\hline 3 & 114 & 115 & 41.64 & 41.65 & $1,068.73$ & -0.751 & 3.647 & & & 0.339 & 1.382 \\
\hline 3 & 116 & 117 & 41.66 & & $1,068.77$ & & & & & 0.031 & 1.065 \\
\hline 3 & 118 & 119 & 41.68 & 41.68 & $1,069.90$ & -0.569 & 3.476 & & & 0.153 & 0.811 \\
\hline 3 & 120 & 121 & 41.70 & 41.70 & $1,070.45$ & -0.780 & 3.672 & & & 0.013 & 0.797 \\
\hline 3 & 122 & 123 & 41.72 & 41.73 & $1,070.96$ & -0.738 & 3.702 & & & 0.038 & 0.652 \\
\hline 3 & 124 & 125 & 41.74 & & $1,071.00$ & & & & & 0.316 & 1.085 \\
\hline 3 & 126 & 127 & 41.76 & 41.77 & $1,072.00$ & -0.591 & 3.570 & & & 0.554 & 1.831 \\
\hline 3 & 128 & 129 & 41.78 & & $1,072.04$ & & & & & 0.417 & 1.171 \\
\hline 3 & 130 & 131 & 41.80 & 41.80 & $1,073.03$ & -0.857 & 3.700 & & & 0.466 & 1.311 \\
\hline 3 & 132 & 133 & 41.82 & 41.82 & $1,073.55$ & -0.806 & 3.491 & & & 0.283 & 0.895 \\
\hline & & & & & & -0.874 & 3.270 & & & & \\
\hline 3 & 134 & 135 & 41.84 & 41.84 & $1,074.07$ & -0.861 & 3.838 & & & & \\
\hline & & & & & & -0.894 & 3.818 & & & & \\
\hline 3 & 136 & 137 & 41.86 & 41.86 & $1,074.59$ & -0.652 & 3.602 & & & 0.105 & 1.119 \\
\hline 3 & 138 & 139 & 41.88 & 41.88 & $1,075.11$ & -0.709 & 3.498 & & & -0.622 & 0.777 \\
\hline 3 & 140 & 141 & 41.90 & 41.91 & $1,075.62$ & -0.641 & 3.614 & 1.23 & 0.98 & 0.303 & 1.494 \\
\hline 3 & 142 & 143 & 41.92 & & $1,075.66$ & & & 1.39 & 1.03 & & \\
\hline 3 & 144 & 145 & 41.94 & 41.94 & $1,076.66$ & -0.659 & 3.629 & 1.25 & 0.66 & 0.001 & 1.053 \\
\hline & & & & & & & & 1.12 & 0.68 & & \\
\hline & & & & & & & & 1.16 & 0.56 & & \\
\hline 3 & 146 & 147 & 41.96 & 41.97 & $1,077.18$ & -0.706 & 3.462 & & & 0.257 & 1.401 \\
\hline & & & & & & -0.625 & 3.395 & & & & \\
\hline 3 & 148 & 149 & 41.98 & & $1,077.22$ & & & & & -0.384 & 0.889 \\
\hline 4 & 4 & 5 & 42.04 & 42.04 & $1,079.25$ & -0.659 & 3.385 & & & 0.402 & 1.655 \\
\hline 4 & 8 & 9 & 42.08 & & $1,079.29$ & & & 1.16 & 0.39 & 0.461 & 1.453 \\
\hline & & & & & & & & 1.14 & 0.72 & & \\
\hline 4 & 10 & 11 & 42.10 & 42.12 & $1,080.80$ & -0.683 & 3.663 & 1.20 & 0.92 & -0.037 & 1.485 \\
\hline 4 & 12 & 13 & 42.12 & & $1,080.84$ & & & 1.19 & 0.98 & 0.311 & 1.467 \\
\hline & & & & & & & & & & 0.323 & 1.240 \\
\hline 4 & 14 & 15 & 42.14 & 42.15 & $1,081.84$ & -0.724 & 3.431 & & & 0.087 & 1.403 \\
\hline 4 & 16 & 17 & 42.16 & & $1,081.88$ & & & 1.36 & 0.71 & 0.230 & 1.409 \\
\hline & & & & & & & & 1.44 & 0.67 & & \\
\hline 4 & 18 & 19 & 42.18 & 42.20 & $1,082.87$ & -0.538 & 3.917 & 1.58 & 0.70 & 0.239 & 1.682 \\
\hline & & & & & & -0.695 & 3.946 & & & & \\
\hline 4 & 20 & 21 & 42.20 & & $1,082.91$ & & & 1.47 & 0.62 & 0.001 & 1.372 \\
\hline 4 & 22 & 23 & 42.22 & & $1,082.95$ & & & 1.66 & 0.85 & -0.171 & 1.629 \\
\hline & & & & & & & & 1.27 & 0.50 & & \\
\hline
\end{tabular}




\begin{tabular}{|c|c|c|c|c|c|c|c|c|c|c|c|}
\hline \multicolumn{4}{|c|}{ Core, section, interval $(\mathrm{cm})$} & \multirow{2}{*}{$\begin{array}{c}\text { Adjusted } \\
\text { Depth }{ }^{1} \\
\text { Uvigerina spp. }\end{array}$} & \multirow[b]{2}{*}{ Age } & \multicolumn{2}{|c|}{ Uvigerina spp. } & \multicolumn{2}{|c|}{ Gs. ruber } & \multicolumn{2}{|c|}{ G. bulloides } \\
\hline Section & Top & Bottom & Depth & & & $\delta^{13} \mathrm{C}$ & $\delta^{18} \mathrm{O}$ & $\delta^{13} \mathrm{C}$ & $\delta^{18} \mathrm{O}$ & $\delta^{13} \mathrm{C}$ & $\delta^{18} \mathrm{O}$ \\
\hline 4 & 24 & 25 & 42.24 & 42.26 & $1,084.43$ & $\begin{array}{l}-0.675 \\
-0.619\end{array}$ & $\begin{array}{l}3.929 \\
4.020\end{array}$ & & & 0.270 & 1.392 \\
\hline 4 & 26 & 27 & 42.26 & & $1,084.46$ & & & $\begin{array}{l}1.18 \\
1.74\end{array}$ & $\begin{array}{l}0.50 \\
0.56\end{array}$ & -0.012 & 1.345 \\
\hline 4 & 28 & 29 & 42.28 & & $1,084.49$ & & & 1.29 & 0.70 & $\begin{array}{c}-0.179 \\
0.141\end{array}$ & $\begin{array}{l}1.512 \\
1.325\end{array}$ \\
\hline 4 & 30 & 31 & 42.30 & 42.31 & $1,086.31$ & $\begin{array}{l}-0.725 \\
-0.665\end{array}$ & $\begin{array}{l}4.376 \\
4.392\end{array}$ & 1.15 & 0.90 & 0.096 & 1.720 \\
\hline 4 & 32 & 33 & 42.32 & & $1,086.34$ & & & & & & \\
\hline 4 & 34 & 35 & 42.34 & 42.36 & $1,087.63$ & -0.890 & 4.135 & & & -0.277 & 1.686 \\
\hline 4 & 38 & 39 & 42.38 & & $1,087.66$ & & & 0.98 & 1.31 & -0.274 & 1.676 \\
\hline 4 & 42 & 43 & 42.42 & 42.44 & $1,090.26$ & -0.918 & 4.494 & & & -0.527 & 1.620 \\
\hline 4 & 46 & 47 & 42.46 & & $1,090.29$ & & & & & -0.536 & 1.259 \\
\hline 4 & 50 & 51 & 42.50 & 42.54 & $1,092.90$ & $\begin{array}{l}-1.135 \\
-1.113\end{array}$ & $\begin{array}{l}4.736 \\
4.368\end{array}$ & & & -0.804 & 1.015 \\
\hline 4 & 54 & 55 & 42.54 & & $1,092.93$ & & & & & -0.640 & 1.187 \\
\hline 4 & 58 & 59 & 42.58 & & $1,092.96$ & & & & & -0.392 & 1.506 \\
\hline 4 & 62 & 63 & 42.62 & 42.66 & $1,096.85$ & $\begin{array}{l}-1.323 \\
-1.175\end{array}$ & $\begin{array}{l}4.636 \\
4.436\end{array}$ & & & -0.911 & 1.079 \\
\hline 4 & 66 & 67 & 42.66 & & $1,096.88$ & & & & & & \\
\hline 4 & 70 & 71 & 42.70 & & $1,096.91$ & & & & & & \\
\hline 4 & 74 & 75 & 42.74 & 42.74 & $1,100.81$ & -1.252 & 4.486 & & & -0.329 & 1.967 \\
\hline 4 & 78 & 79 & 42.78 & 42.80 & $1,102.12$ & -1.358 & 4.539 & & & & \\
\hline 4 & 82 & 83 & 42.82 & & $1,102.15$ & & & & & 0.507 & 2.017 \\
\hline 4 & 86 & 87 & 42.86 & 42.88 & $1,104.76$ & $\begin{array}{l}-0.918 \\
-0.757\end{array}$ & $\begin{array}{l}4.101 \\
4.076\end{array}$ & & & & \\
\hline 4 & 90 & 91 & 42.90 & & $1,104.79$ & & & & & & \\
\hline 4 & 94 & 95 & 42.94 & 42.94 & $1,107.40$ & -0.867 & 4.178 & & & -0.548 & 0.959 \\
\hline 4 & 98 & 99 & 42.98 & 42.98 & $1,108.84$ & -0.730 & 4.019 & & & -0.432 & 1.273 \\
\hline 4 & 102 & 103 & 43.02 & 43.04 & $1,110.89$ & -0.956 & 4.042 & $\begin{array}{l}1.07 \\
1.02 \\
1.16\end{array}$ & $\begin{array}{l}1.13 \\
0.99 \\
0.98\end{array}$ & & \\
\hline 4 & 106 & 107 & 43.06 & & 1,110.91 & & & $\begin{array}{l}1.00 \\
0.84\end{array}$ & $\begin{array}{l}1.18 \\
1.27\end{array}$ & -0.541 & 1.190 \\
\hline 4 & 110 & 111 & 43.10 & 43.13 & $1,114.99$ & -0.752 & 4.089 & 1.12 & 1.05 & -0.532 & 1.367 \\
\hline 4 & 114 & 115 & 43.14 & & $1,115.01$ & & & & & -0.800 & 1.174 \\
\hline 4 & 118 & 119 & 43.18 & 43.18 & $1,119.10$ & -1.010 & 4.417 & & & -0.642 & 1.449 \\
\hline 4 & 122 & 123 & 43.22 & 43.24 & $1,121.15$ & -1.159 & 4.537 & & & -0.683 & 1.490 \\
\hline 4 & 126 & 127 & 43.26 & & $1,121.17$ & & & & & -0.678 & 1.546 \\
\hline 4 & 130 & 131 & 43.30 & 43.30 & $1,125.26$ & -1.238 & 4.616 & & & & \\
\hline 4 & 134 & 135 & 43.34 & 43.34 & $1,127.31$ & -0.937 & 4.126 & & & -0.052 & 2.293 \\
\hline
\end{tabular}

${ }^{1}$ Represents the linear interpolation where more than one sample was analysed to provide minimum weights for stable isotope analysis. 
Appendix $C$

Table C4: Calculated $\delta^{18} \mathrm{O}, \mathrm{Mg} / \mathrm{Ca}$ and SST used to estimate $\delta^{18} \mathrm{O}_{\mathrm{sw}}$ in Globerina bulloides from ODP Site 1123, 1140 to $1000 \mathrm{Kyr}$.

\begin{tabular}{cccccc}
\hline Age & $\delta^{18} \mathrm{O}$ & $\mathrm{Mg} / \mathrm{Ca}$ & $\mathrm{SST}$ & $\delta^{18} \mathrm{O}_{\text {scawater }}$ & Salinity \\
\hline$(\mathrm{Kyr})$ & $(\% \mathrm{\%})$ & $(\mathrm{mmol} / \mathrm{mol})$ & $\left({ }^{\circ} \mathrm{C}\right)$ & $(\% 0)$ & $(\mathrm{psu})$ \\
\hline 1017.60 & - & 2.471 & 13.75 & - & - \\
1018.78 & 1.24 & 2.276 & 12.53 & 0.69 & 35.01 \\
1019.96 & 1.32 & 2.476 & 13.79 & 1.02 & 35.50 \\
1020.00 & 0.88 & 2.240 & 12.30 & 0.28 & 34.41 \\
1022.32 & 1.23 & 2.131 & 11.55 & 0.47 & 34.69 \\
1022.36 & 0.56 & 2.446 & 13.60 & 0.23 & 34.34 \\
1024.68 & - & 2.341 & 12.95 & - & - \\
1025.86 & 1.15 & 2.118 & 11.45 & 0.37 & 34.54 \\
1027.04 & - & 2.127 & 11.52 & - & - \\
1029.39 & - & 1.908 & 9.90 & - & - \\
1029.43 & - & 2.505 & 13.96 & - & - \\
1029.47 & 1.79 & 2.111 & 11.40 & 1.00 & 35.46 \\
1031.75 & 1.21 & 2.624 & 14.66 & 1.10 & 35.60 \\
1032.93 & 1.93 & 2.210 & 12.09 & 1.28 & 35.87 \\
1034.11 & 1.62 & 2.382 & 13.21 & 1.20 & 35.76 \\
1035.00 & 2.37 & 1.923 & 10.02 & 1.29 & 35.89 \\
1036.47 & 2.10 & 1.657 & 7.79 & 0.56 & 34.82 \\
1036.50 & - & 1.682 & 8.02 & - & - \\
1038.83 & 2.53 & 1.759 & 8.68 & 1.17 & 35.71 \\
1038.86 & 1.92 & 2.126 & 11.51 & 1.15 & 35.69 \\
1038.90 & 2.15 & 2.188 & 11.95 & 1.47 & 36.16 \\
1038.93 & 1.89 & 1.795 & 8.99 & 0.60 & 34.88 \\
1043.54 & 1.84 & 1.942 & 10.17 & 0.79 & 35.15 \\
1043.58 & 2.21 & 1.791 & 8.96 & 0.91 & 35.34 \\
1043.62 & 2.00 & 2.108 & 11.39 & 1.21 & 35.77 \\
1043.66 & 2.17 & 1.966 & 10.34 & 1.15 & 35.69 \\
1048.26 & 1.11 & 2.376 & 13.17 & 0.69 & 35.01 \\
1048.30 & -0.30 & 2.173 & 11.84 & -1.00 & 32.54 \\
1048.34 & 1.72 & 2.192 & 11.97 & 1.05 & 35.53 \\
1051.80 & - & 1.743 & 8.55 & - & - \\
1051.84 & 2.09 & 1.917 & 9.97 & 1.00 & 35.47 \\
1051.88 & 1.85 & 2.278 & 12.54 & 1.30 & 35.90 \\
1051.92 & 1.58 & 2.797 & 15.61 & 1.66 & 36.43 \\
1056.51 & - & 2.979 & 16.55 & - & - \\
1056.55 & 1.10 & 2.563 & 14.30 & 0.91 & 35.33 \\
1058.84 & 1.37 & 2.411 & 13.39 & 0.99 & 35.45 \\
1058.88 & 1.78 & 3.053 & 16.91 & 2.14 & 37.14 \\
1060.01 & 1.53 & 2.201 & 12.03 & 0.87 & 35.28 \\
1060.04 & 1.75 & 2.501 & 13.94 & 1.48 & 36.17
\end{tabular}




\begin{tabular}{cccccc}
\hline Age & $\delta^{18} \mathrm{O}$ & $\mathrm{Mg} / \mathrm{Ca}$ & $\mathrm{SST}$ & $\delta^{18} \mathrm{O}_{\text {seawater }}$ & Salinity \\
\hline$(\mathrm{Kyr})$ & $(\% \mathrm{o})$ & $(\mathrm{mmol} / \mathrm{mol})$ & $\left({ }^{\circ} \mathrm{C}\right)$ & $(\% \mathrm{o})$ & $(\mathrm{psu})$ \\
\hline 1060.08 & 2.36 & 2.006 & 10.64 & 1.41 & 36.07 \\
1061.75 & 1.24 & 3.035 & 16.83 & 1.58 & 36.31 \\
1061.79 & -0.11 & 2.449 & 13.62 & -0.44 & 33.36 \\
1062.92 & 2.61 & 1.967 & 10.35 & 1.60 & 36.35 \\
1063.50 & - & 1.691 & 8.10 & - & - \\
1063.53 & 2.07 & 2.912 & 16.21 & 2.28 & 37.34 \\
1064.66 & 1.45 & 2.464 & 13.72 & 1.14 & 35.67 \\
1065.24 & 0.76 & 2.560 & 14.29 & 0.57 & 34.83 \\
1065.82 & - & 1.777 & 8.84 & - & - \\
1066.41 & 1.66 & 1.996 & 10.57 & 0.69 & 35.01 \\
1066.99 & 1.29 & 1.836 & 9.32 & 0.06 & 34.09 \\
1067.57 & - & 2.464 & 13.71 & - & - \\
1068.15 & 1.17 & 2.087 & 11.24 & 0.35 & 34.51 \\
1068.73 & 1.38 & 2.112 & 11.42 & 0.59 & 34.87 \\
1068.77 & 1.07 & 2.472 & 13.76 & 0.77 & 35.12 \\
1069.90 & 0.81 & 2.201 & 12.03 & 0.15 & 34.22 \\
1070.45 & 0.80 & 2.494 & 13.90 & 0.52 & 34.77 \\
1070.96 & 0.65 & 2.629 & 14.68 & 0.54 & 34.80 \\
1071.00 & 1.08 & 2.340 & 12.94 & 0.61 & 34.90 \\
1072.00 & 1.83 & 1.893 & 9.78 & 0.70 & 35.03 \\
1072.04 & 1.17 & 1.956 & 10.27 & 0.14 & 34.21 \\
1073.03 & 1.31 & 2.481 & 13.82 & 1.02 & 35.50 \\
1073.55 & 0.89 & 2.276 & 12.53 & 0.34 & 34.49 \\
1074.07 & - & 1.535 & 6.65 & - & - \\
1074.59 & 1.12 & 2.307 & 12.73 & 0.60 & 34.88 \\
1075.11 & 0.78 & 2.674 & 14.94 & 0.72 & 35.06 \\
1075.62 & 1.49 & 2.198 & 12.01 & 0.83 & 35.21 \\
1075.66 & - & 3.201 & 17.62 & - & - \\
1076.66 & 1.05 & 2.632 & 14.70 & 0.95 & 35.39 \\
1077.18 & 1.40 & 2.363 & 13.09 & 0.96 & 35.41 \\
1077.22 & 0.89 & 2.753 & 15.37 & 0.92 & 35.35 \\
1079.25 & 1.66 & 2.562 & 14.30 & 1.47 & 36.15 \\
1079.29 & 1.45 & 3.406 & 18.55 & 2.15 & 37.15 \\
1080.80 & 1.48 & 3.033 & 16.82 & 1.82 & 36.67 \\
1080.84 & 1.35 & 3.167 & 17.46 & 1.82 & 36.67 \\
1081.84 & 1.40 & 3.039 & 16.84 & 1.75 & 36.56 \\
1081.88 & 1.41 & 2.986 & 16.58 & 1.70 & 36.49 \\
1082.87 & 1.68 & 3.130 & 17.28 & 2.12 & 37.10 \\
1082.91 & 1.37 & 2.930 & 16.30 & 1.60 & 36.34 \\
1082.95 & 1.63 & 3.010 & 16.70 & 1.94 & 36.84 \\
1084.46 & 1.39 & 2.974 & 16.52 & 1.67 & 36.44 \\
& & 3.502 & 18.96 & 2.13 & 37.12
\end{tabular}


Appendix $C$

\begin{tabular}{|c|c|c|c|c|c|}
\hline Age & $\delta^{18} \mathrm{O}$ & $\mathrm{Mg} / \mathrm{Ca}$ & SST & $\delta^{18} \mathrm{O}_{\text {seawater }}$ & Salinity \\
\hline$(\mathrm{Kyr})$ & $(\% 0)$ & $(\mathrm{mmol} / \mathrm{mol})$ & $\left({ }^{\circ} \mathrm{C}\right)$ & $(\% 0)$ & (psu) \\
\hline 1084.49 & 1.42 & 2.611 & 14.58 & 1.29 & 35.89 \\
\hline 1086.31 & 1.72 & 2.834 & 15.80 & 1.85 & 36.70 \\
\hline 1086.34 & - & 2.908 & 16.19 & - & - \\
\hline 1087.63 & 1.69 & 3.327 & 18.20 & 2.31 & 37.38 \\
\hline 1087.66 & 1.68 & 3.025 & 16.78 & 2.00 & 36.94 \\
\hline 1090.26 & 1.62 & 2.530 & 14.11 & 1.39 & 36.04 \\
\hline 1090.29 & 1.26 & 3.007 & 16.69 & 1.57 & 36.30 \\
\hline 1092.90 & 1.02 & 3.283 & 18.00 & 1.60 & 36.34 \\
\hline 1092.93 & 1.19 & 2.708 & 15.12 & 1.17 & 35.71 \\
\hline 1092.96 & 1.51 & 2.551 & 14.23 & 1.30 & 35.91 \\
\hline 1096.85 & 1.08 & 2.892 & 16.11 & 1.27 & 35.86 \\
\hline 1096.88 & - & 2.460 & 13.69 & - & - \\
\hline 1096.91 & - & 1.815 & 9.16 & - & - \\
\hline 1100.81 & 1.97 & 2.439 & 13.56 & 1.63 & 36.38 \\
\hline 1102.12 & - & 2.086 & 11.23 & - & - \\
\hline 1102.15 & 2.02 & 2.979 & 16.55 & 2.30 & 37.36 \\
\hline 1104.76 & - & 2.870 & 15.99 & - & - \\
\hline 1104.79 & - & 2.667 & 14.90 & - & - \\
\hline 1107.40 & 0.96 & 2.819 & 15.73 & 1.07 & 35.56 \\
\hline 1108.84 & 1.27 & 2.048 & 10.96 & 0.39 & 34.57 \\
\hline 1110.89 & - & 2.682 & 14.98 & - & - \\
\hline 1110.91 & 1.19 & 2.569 & 14.34 & 1.01 & 35.48 \\
\hline 1114.99 & 1.37 & 2.764 & 15.43 & 1.41 & 36.07 \\
\hline 1115.01 & 1.17 & 2.704 & 15.10 & 1.15 & 35.69 \\
\hline 1119.10 & 1.45 & 2.270 & 12.49 & 0.88 & 35.30 \\
\hline 1121.15 & 1.49 & 2.273 & 12.51 & 0.93 & 35.36 \\
\hline 1121.17 & 1.55 & 2.228 & 12.21 & 0.92 & 35.35 \\
\hline 1125.26 & - & 2.556 & 14.26 & - & - \\
\hline 1127.31 & 2.29 & 2.461 & 13.70 & 1.98 & 36.90 \\
\hline
\end{tabular}


Appendix $C$

Table C5: Calculated $\delta^{18} \mathrm{O}, \mathrm{Mg} / \mathrm{Ca}$ and SST used to estimate $\delta^{18} \mathrm{O}_{\mathrm{sw}}$ in Globigerinoides ruber from ODP Site 1123, 1140 to $1000 \mathrm{Kyr}$.

\begin{tabular}{|c|c|c|c|c|c|}
\hline Age & $\delta^{18} \mathrm{O}$ & $\mathrm{Mg} / \mathrm{Ca}$ & SST & $\delta^{18} \mathrm{O}_{\text {seawater }}$ & Salinity \\
\hline$(\mathrm{Kyr})$ & $(\%)$ & $(\mathrm{mmol} / \mathrm{mol})$ & $\left({ }^{\circ} \mathrm{C}\right)$ & $(\%)$ & (psu) \\
\hline 1017.60 & & 3.296 & 20.26 & & \\
\hline 1018.78 & & 1.891 & 12.32 & & \\
\hline 1019.96 & & 2.100 & 13.82 & & \\
\hline 1020.00 & 0.97 & 2.266 & 14.91 & 1.24 & 35.82 \\
\hline 1022.32 & & 2.402 & 15.74 & & \\
\hline 1022.36 & & 2.077 & 13.66 & & \\
\hline 1024.68 & & 2.943 & 18.64 & & \\
\hline 1025.86 & & 2.875 & 18.31 & & \\
\hline \multicolumn{6}{|l|}{1027.04} \\
\hline \multicolumn{6}{|l|}{1029.39} \\
\hline 1029.43 & & 2.886 & 18.36 & & \\
\hline 1029.47 & & 2.504 & 16.34 & & \\
\hline 1031.75 & & 1.867 & 12.14 & & \\
\hline 1032.93 & & 1.798 & 11.60 & & \\
\hline 1034.11 & & 3.179 & 19.75 & & \\
\hline 1035.00 & & 2.130 & 14.02 & & \\
\hline 1036.47 & & 2.111 & 13.90 & & \\
\hline 1036.50 & & 1.398 & 8.01 & & \\
\hline \multicolumn{6}{|l|}{1038.83} \\
\hline 1038.86 & & 1.896 & 12.36 & & \\
\hline 1038.90 & & 2.184 & 14.38 & & \\
\hline 1038.93 & & 1.970 & 12.91 & & \\
\hline \multicolumn{6}{|l|}{1043.54} \\
\hline 1043.58 & & 2.444 & 15.99 & & \\
\hline 1043.62 & & 3.330 & 20.41 & & \\
\hline 1043.66 & & 2.667 & 17.24 & & \\
\hline 1048.26 & & 2.322 & 15.26 & & \\
\hline \multicolumn{6}{|l|}{1048.30} \\
\hline 1048.34 & & 2.851 & 18.19 & & \\
\hline \multicolumn{6}{|l|}{1051.80} \\
\hline \multicolumn{6}{|l|}{1051.84} \\
\hline \multicolumn{6}{|l|}{1051.88} \\
\hline \multicolumn{6}{|l|}{1051.92} \\
\hline \multicolumn{6}{|l|}{1056.51} \\
\hline \multicolumn{6}{|l|}{1056.55} \\
\hline 1058.84 & & 2.266 & 14.91 & & \\
\hline 1058.88 & & 1.677 & 10.61 & & \\
\hline 1060.01 & & 2.624 & 17.00 & & \\
\hline
\end{tabular}


Appendix $C$

\begin{tabular}{|c|c|c|c|c|c|}
\hline Age & $\delta^{18} \mathrm{O}$ & $\mathrm{Mg} / \mathrm{Ca}$ & SST & $\delta^{18} \mathrm{O}_{\text {seawater }}$ & Salinity \\
\hline (Kyr) & $(\% 0)$ & $(\mathrm{mmol} / \mathrm{mol})$ & $\left({ }^{\circ} \mathrm{C}\right)$ & $(\% 0)$ & (psu) \\
\hline 1060.04 & & & & & \\
\hline 1060.08 & & & & & \\
\hline 1061.75 & & & & & \\
\hline 1061.79 & & & & & \\
\hline 1062.92 & & & & & \\
\hline 1063.50 & & & & & \\
\hline 1063.53 & & & & & \\
\hline 1064.66 & & 3.057 & 19.19 & & \\
\hline 1065.24 & & & & & \\
\hline 1065.82 & & 2.755 & 17.70 & & \\
\hline 1066.41 & & & & & \\
\hline 1066.99 & & 1.847 & 11.99 & & \\
\hline 1067.57 & & & & & \\
\hline 1068.15 & & 2.345 & 15.40 & & \\
\hline 1068.73 & & 2.091 & 13.76 & & \\
\hline 1068.77 & & 2.614 & 16.95 & & \\
\hline 1069.90 & & 2.187 & 14.40 & & \\
\hline 1070.45 & & 2.961 & 18.73 & & \\
\hline 1070.96 & & 2.797 & 17.92 & & \\
\hline 1071.00 & & 2.461 & 16.09 & & \\
\hline 1072.00 & & 2.913 & 18.50 & & \\
\hline 1072.04 & & 2.325 & 15.28 & & \\
\hline 1073.03 & & 2.893 & 18.40 & & \\
\hline 1073.55 & & 2.707 & 17.45 & & \\
\hline 1074.07 & & 2.681 & 17.31 & & \\
\hline 1074.59 & & 2.553 & 16.61 & & \\
\hline 1075.11 & & 2.753 & 17.69 & & \\
\hline 1075.62 & 0.98 & 2.501 & 16.32 & 1.55 & 36.27 \\
\hline 1075.66 & 1.03 & 2.693 & 17.38 & 1.82 & 36.66 \\
\hline 1076.66 & 0.63 & 2.842 & 18.15 & 1.58 & 36.31 \\
\hline 1077.18 & & 2.514 & 16.39 & & \\
\hline 1077.22 & & 2.820 & 18.04 & & \\
\hline 1079.25 & & 2.729 & 17.57 & & \\
\hline 1079.29 & 0.55 & 2.818 & 18.02 & 1.48 & 36.16 \\
\hline 1080.80 & 0.92 & 2.653 & 17.16 & 1.66 & 36.43 \\
\hline 1080.84 & 0.98 & 2.704 & 17.44 & 1.78 & 36.60 \\
\hline 1081.84 & & 2.807 & 17.97 & & \\
\hline 1081.88 & 0.69 & 2.887 & 18.37 & 1.68 & 36.47 \\
\hline 1082.87 & 0.70 & 2.719 & 17.51 & 1.51 & 36.22 \\
\hline 1082.91 & 0.62 & 2.970 & 18.77 & 1.69 & 36.48 \\
\hline 1082.95 & 0.68 & 2.697 & 17.40 & 1.47 & 36.15 \\
\hline 1084.43 & & 2.780 & 17.83 & & \\
\hline
\end{tabular}


Appendix $C$

\begin{tabular}{|c|c|c|c|c|c|}
\hline Age & $\delta^{18} \mathrm{O}$ & $\mathrm{Mg} / \mathrm{Ca}$ & SST & $\delta^{18} \mathrm{O}_{\text {seawater }}$ & Salinity \\
\hline (Kyr) & $(\% 0)$ & $(\mathrm{mmol} / \mathrm{mol})$ & $\left({ }^{\circ} \mathrm{C}\right)$ & $(\%)$ & (psu) \\
\hline 1084.46 & 0.53 & 2.796 & 17.91 & 1.42 & 36.09 \\
\hline 1084.49 & 0.70 & 2.673 & 17.27 & 1.46 & 36.14 \\
\hline 1086.31 & 0.90 & 2.741 & 17.63 & 1.73 & 36.54 \\
\hline 1086.34 & & 2.444 & 15.99 & & \\
\hline 1087.63 & & 2.195 & 14.45 & & \\
\hline 1087.66 & 1.31 & 2.313 & 15.20 & 1.64 & 36.40 \\
\hline 1090.26 & & 3.251 & 20.06 & & \\
\hline 1090.29 & & 2.180 & 14.36 & & \\
\hline 1092.90 & & 2.886 & 18.37 & & \\
\hline 1092.93 & & 2.078 & 13.67 & & \\
\hline 1092.96 & & 3.143 & 19.58 & & \\
\hline 1096.85 & & 2.262 & 14.88 & & \\
\hline 1096.88 & & & & & \\
\hline 1096.91 & & & & & \\
\hline 1100.81 & & 2.705 & 17.44 & & \\
\hline 1102.12 & & & & & \\
\hline 1102.15 & & & & & \\
\hline 1104.76 & & & & & \\
\hline 1104.79 & & 2.519 & 16.42 & & \\
\hline 1107.40 & & 2.869 & 18.28 & & \\
\hline 1108.84 & & 2.363 & 15.51 & & \\
\hline 1110.89 & 1.04 & 2.224 & 14.64 & 1.25 & 35.84 \\
\hline 1110.91 & 1.23 & 2.673 & 17.27 & 1.99 & 36.91 \\
\hline 1114.99 & 1.05 & 2.414 & 15.81 & 1.50 & 36.20 \\
\hline 1115.01 & & 2.517 & 16.41 & & \\
\hline 1119.10 & & 2.495 & 16.28 & & \\
\hline 1121.15 & & 2.252 & 14.82 & & \\
\hline 1121.17 & & 2.532 & 16.49 & & \\
\hline 1125.26 & & 2.625 & 17.01 & & \\
\hline 1127.31 & & 2.995 & 18.90 & & \\
\hline
\end{tabular}


Table C6: Mean weight, width, height, size-normalised weight and predicted weight data for Globigerinoides ruber and Globigerina bulloides $(250-350 \mu \mathrm{m})$ from ODP Site 1123, 1140 to $1000 \mathrm{Kyr}$.

\begin{tabular}{|c|c|c|c|c|c|c|c|c|c|c|c|c|}
\hline \multicolumn{5}{|c|}{ ODP 1123C Leg 181 Core 005H } & \multirow{2}{*}{\multicolumn{3}{|c|}{ Gs. ruber }} & \multirow{2}{*}{\multicolumn{5}{|c|}{ G. bulloides }} \\
\hline Cor & , sectio & , interval & & & & & & & & & & \\
\hline \multirow[t]{2}{*}{ Section } & Top & Bottom & Depth & Age & $\begin{array}{c}\text { Mean } \\
\text { Weight }\end{array}$ & Width (x) & Height (y) & $\begin{array}{c}\text { Mean } \\
\text { Weight }\end{array}$ & Width (x) & Height (y) & $\begin{array}{c}\text { Size } \\
\text { normalised } \\
\text { weight } \\
\end{array}$ & $\begin{array}{c}\text { Predicted } \\
\text { Weight }\end{array}$ \\
\hline & $(\mathrm{cm})$ & $(\mathrm{cm})$ & (mbsf) & $(\mathrm{Kyr})$ & $(\mu g)$ & $(\mu \mathrm{m})$ & $(\mu \mathrm{m})$ & $(\mu \mathrm{g})$ & $(\mu \mathrm{m})$ & $(\mu \mathrm{m})$ & $(\mu \mathrm{g} / \mu \mathrm{m})$ & $(\mu g)$ \\
\hline 2 & 90 & 91 & 39.90 & 1017.60 & 9 & 315 & 307 & 15 & 305 & 370 & 5.05 & 8.38 \\
\hline 2 & 94 & 95 & 39.94 & 1018.78 & 11 & 306 & 279 & 10 & 332 & 379 & 2.98 & 8.65 \\
\hline 2 & 98 & 99 & 39.98 & 1019.96 & 10 & 313 & 309 & 10 & 330 & 373 & 3.09 & 8.37 \\
\hline 2 & 102 & 103 & 40.02 & 1020.00 & 12 & 315 & 302 & 8 & 328 & 395 & 2.57 & 8.70 \\
\hline 2 & 106 & 107 & 40.06 & 1022.32 & 10 & 317 & 300 & 11 & 339 & 391 & 3.13 & 8.86 \\
\hline 2 & 110 & 111 & 40.10 & 1022.36 & 9 & 289 & 270 & 10 & 359 & 422 & 2.85 & 8.41 \\
\hline 2 & 114 & 115 & 40.14 & 1024.68 & 8 & 293 & 269 & 9 & 352 & 410 & 2.61 & 8.55 \\
\hline 2 & 118 & 119 & 40.18 & 1025.86 & 10 & 322 & 310 & 10 & 316 & 381 & 3.02 & 8.88 \\
\hline 2 & 122 & 123 & 40.22 & 1027.04 & & & & 11 & 330 & 378 & 3.43 & 8.87 \\
\hline 2 & 126 & 127 & 40.26 & 1029.39 & & & & 11 & 308 & 362 & 3.53 & 9.22 \\
\hline 2 & 130 & 131 & 40.30 & 1029.43 & 16 & 305 & 304 & 12 & 333 & 400 & 3.64 & 8.33 \\
\hline 2 & 134 & 135 & 40.34 & 1029.47 & 14 & 325 & 300 & 14 & 340 & 415 & 4.06 & 8.89 \\
\hline 2 & 138 & 139 & 40.38 & 1031.75 & 14 & 326 & 333 & 8 & 328 & 388 & 2.34 & 8.18 \\
\hline 2 & 142 & 143 & 40.42 & 1032.93 & 13 & 333 & 293 & 12 & 332 & 407 & 3.73 & 8.74 \\
\hline 2 & 146 & 147 & 40.46 & 1034.11 & 12 & 225 & 292 & 11 & 346 & 390 & 3.14 & 8.50 \\
\hline 2 & 149 & 150 & 40.49 & 1035.00 & 11 & 312 & 301 & 17 & 324 & 429 & 5.14 & 9.20 \\
\hline 3 & 4 & 5 & 40.54 & 1036.47 & 15 & 322 & 303 & 16 & 332 & 421 & 4.89 & 9.69 \\
\hline 3 & 8 & 9 & 40.58 & 1036.50 & 16 & 364 & 330 & 16 & 365 & 437 & 4.36 & 9.64 \\
\hline 3 & 12 & 13 & 40.62 & 1038.83 & & & & 18 & 384 & 451 & 4.65 & 9.49 \\
\hline 3 & 16 & 17 & 40.66 & 1038.86 & 17 & 351 & 344 & 12 & 327 & 387 & 3.82 & 8.87 \\
\hline 3 & 20 & 21 & 40.70 & 1038.90 & 14 & 327 & 297 & 14 & 357 & 418 & 4.02 & 8.77 \\
\hline 3 & 24 & 25 & 40.74 & 1038.93 & 10 & 303 & 283 & 16 & 336 & 392 & 4.78 & 9.42 \\
\hline 3 & 28 & 29 & 40.78 & 1043.54 & & & & 15 & 337 & 395 & 4.31 & 9.17 \\
\hline 3 & 32 & 33 & 40.82 & 1043.58 & 12 & 308 & 315 & 16 & 375 & 438 & 4.23 & 9.43 \\
\hline 3 & 36 & 37 & 40.86 & 1043.62 & 12 & 315 & 288 & 15 & 357 & 419 & 4.22 & 8.90 \\
\hline 3 & 40 & 41 & 40.90 & 1043.66 & 16 & 384 & 364 & 14 & 362 & 422 & 4.00 & 9.13 \\
\hline 3 & 44 & 45 & 40.94 & 1048.26 & 17 & & & 10 & 329 & 402 & 2.94 & 8.50 \\
\hline 3 & 48 & 49 & 40.98 & 1048.30 & & & & 9 & 317 & 376 & 2.88 & 8.80 \\
\hline 3 & 52 & 53 & 41.02 & 1048.34 & 10 & 239 & 312 & 13 & 353 & 425 & 3.82 & 8.77 \\
\hline 3 & 56 & 57 & 41.06 & 1051.80 & & & & 19 & 388 & 473 & 5.00 & 9.52 \\
\hline 3 & 60 & 61 & 41.10 & 1051.84 & & & & 12 & 362 & 413 & 3.39 & 9.21 \\
\hline 3 & 64 & 65 & 41.14 & 1051.88 & & & & 11 & 328 & 389 & 3.36 & 8.64 \\
\hline 3 & 68 & 69 & 41.18 & 1051.92 & & & & 10 & 332 & 378 & 2.93 & 7.97 \\
\hline 3 & 72 & 73 & 41.22 & 1056.51 & & & & 8 & 336 & 389 & 2.51 & 7.76 \\
\hline 3 & 76 & 77 & 41.26 & 1056.55 & & & & 8 & 349 & 405 & 2.32 & 8.26 \\
\hline 3 & 80 & 81 & 41.30 & 1058.84 & 11 & 278 & 269 & 16 & 427 & 461 & 3.80 & 8.46 \\
\hline 3 & 82 & 83 & 41.32 & 1058.88 & 9 & & & 12 & 326 & 389 & 3.66 & 7.68 \\
\hline 3 & 84 & 85 & 41.34 & 1060.01 & 9 & 316 & 293 & 9 & 313 & 361 & 2.73 & 8.76 \\
\hline 3 & 86 & 87 & 41.36 & 1060.04 & & & & 10 & 331 & 401 & 3.16 & 8.34 \\
\hline 3 & 88 & 89 & 41.38 & 1060.08 & & & & 13 & 343 & 418 & 3.86 & 9.06 \\
\hline 3 & 90 & 91 & 41.40 & 1061.75 & & & & 9 & 343 & 406 & 2.69 & 7.70 \\
\hline 3 & 92 & 93 & 41.42 & 1061.79 & & & & 11 & 344 & 387 & 3.32 & 8.41 \\
\hline 3 & 94 & 95 & 41.44 & 1062.92 & & & & 15 & & & & \\
\hline 3 & 96 & 97 & 41.46 & 1063.50 & & & & 15 & 333 & 414 & 4.36 & 9.62 \\
\hline 3 & 98 & 99 & 41.48 & 1063.53 & & & & 13 & 330 & 397 & 3.94 & 7.84 \\
\hline 3 & 100 & 101 & 41.50 & 1064.66 & 7 & 275 & 269 & 11 & 359 & 426 & 3.16 & 8.39 \\
\hline 3 & 102 & 103 & 41.52 & 1065.24 & & & & 10 & 340 & 399 & 2.85 & 8.26 \\
\hline 3 & 104 & 105 & 41.54 & 1065.82 & 8 & 287 & 268 & 8 & 317 & 365 & 2.54 & 9.46 \\
\hline 3 & 106 & 107 & 41.56 & 1066.41 & & & & 12 & 345 & 420 & 3.44 & 9.08 \\
\hline 3 & 108 & 109 & 41.58 & 1066.99 & 13 & 308 & 281 & 13 & 366 & 407 & 3.53 & 9.35 \\
\hline 3 & 110 & 111 & 41.60 & 1067.57 & & & & 9 & 324 & 396 & 2.81 & 8.39 \\
\hline 3 & 112 & 113 & 41.62 & 1068.15 & 11 & 300 & 271 & 13 & 351 & 398 & 3.83 & 8.93 \\
\hline 3 & 114 & 115 & 41.64 & 1068.73 & 7 & 276 & 265 & 10 & 328 & 391 & 2.98 & 8.89 \\
\hline 3 & 116 & 117 & 41.66 & 1068.77 & 10 & 305 & 259 & 10 & 349 & 395 & 2.99 & 8.38 \\
\hline 3 & 118 & 119 & 41.68 & 1069.90 & 13 & 305 & 293 & 9 & 332 & 382 & 2.63 & 8.76 \\
\hline 3 & 120 & 121 & 41.70 & 1070.45 & 12 & 291 & 303 & 9 & 345 & 396 & 2.53 & 8.35 \\
\hline 3 & 122 & 123 & 41.72 & 1070.96 & 10 & 297 & 279 & 10 & 345 & 390 & 2.83 & 8.17 \\
\hline 3 & 124 & 125 & 41.74 & 1071.00 & 9 & 305 & 305 & 10 & 353 & 397 & 2.72 & 8.56 \\
\hline
\end{tabular}


Appendix $C$

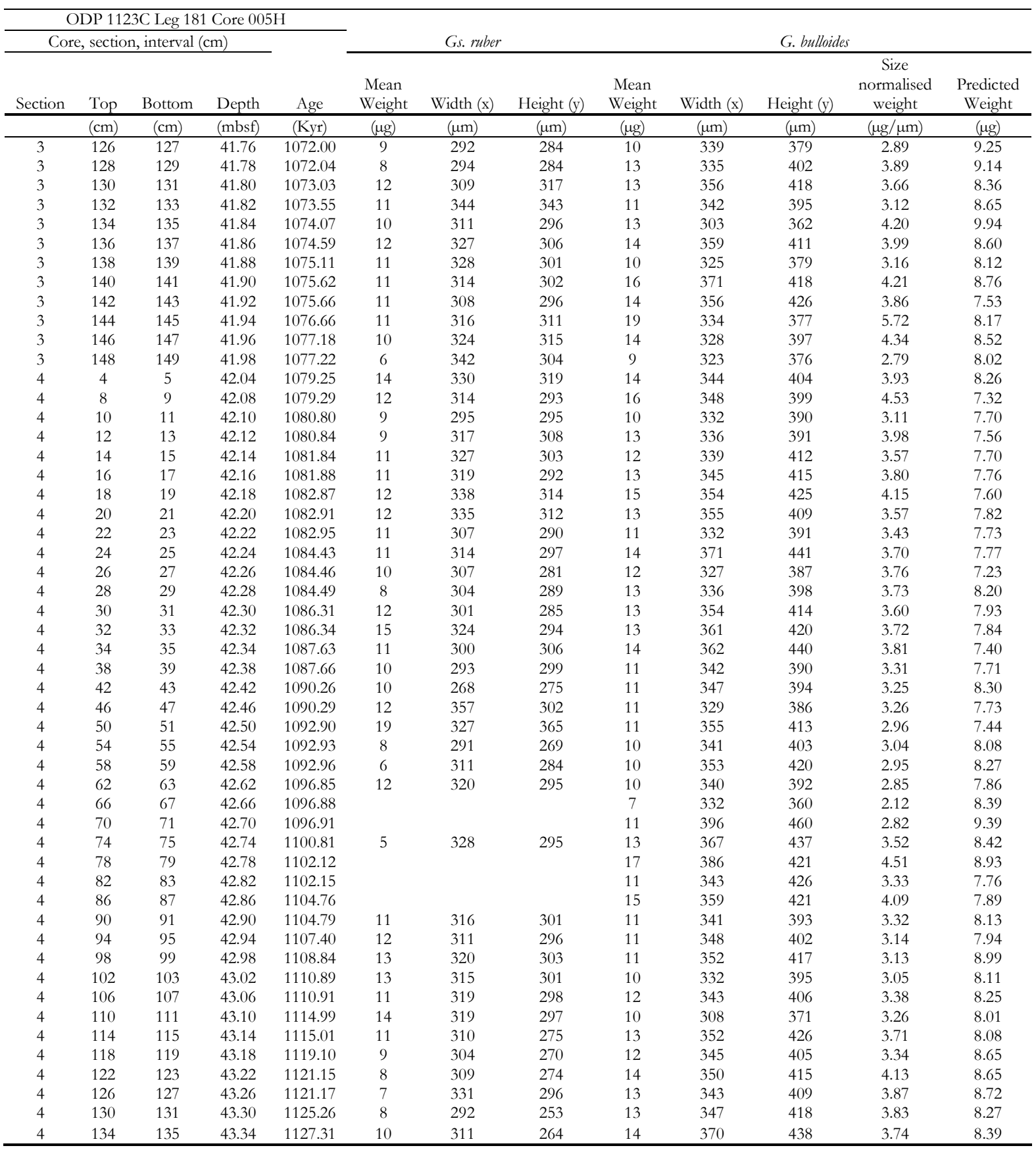


Table C7: Mean Trace element/Ca, data from Chambers F-2 and F measured in Globigerinoides ruber from ODP Site 1123, at various depth intervals. Analyses in bold refer to anomalous data that was excluded from further analysis.

\begin{tabular}{|c|c|c|c|c|c|c|c|c|c|c|c|c|c|c|c|c|}
\hline \multicolumn{4}{|c|}{$\begin{array}{l}\text { Core, section, interval } \\
(\mathrm{cm})\end{array}$} & \multicolumn{3}{|c|}{ Gs. ruber } & \multirow{2}{*}{\multicolumn{2}{|c|}{$\mathrm{Sr} / \mathrm{Ca}$}} & \multirow{2}{*}{\multicolumn{2}{|c|}{$\mathrm{Al} / \mathrm{Ca}$}} & \multirow{2}{*}{\multicolumn{2}{|c|}{$\mathrm{Mn} / \mathrm{Ca}$}} & \multirow{2}{*}{\multicolumn{2}{|c|}{$\mathrm{Zn} / \mathrm{Ca}$}} & \multirow{2}{*}{\multicolumn{2}{|c|}{$\mathrm{Ba} / \mathrm{Ca}$}} \\
\hline Secti & To & Bott & Dep & Age & $\mathrm{Mg}$ & $/ \mathrm{Ca}$ & & & & & & & & & & \\
\hline & & & & & $\begin{array}{c}\text { Chambe } \\
\text { r F-2 }\end{array}$ & $\begin{array}{c}\text { Chambe } \\
\text { r F }\end{array}$ & $\begin{array}{c}\text { Chambe } \\
\text { r F-2 }\end{array}$ & $\begin{array}{c}\text { Chambe } \\
\text { r F }\end{array}$ & $\begin{array}{c}\text { Chambe } \\
\text { r F-2 }\end{array}$ & $\begin{array}{c}\text { Chambe } \\
\text { r F }\end{array}$ & $\begin{array}{c}\text { Chambe } \\
\text { r F-2 }\end{array}$ & $\begin{array}{c}\text { Chambe } \\
\text { rF }\end{array}$ & $\begin{array}{c}\text { Chambe } \\
\text { r F-2 }\end{array}$ & $\begin{array}{c}\text { Chambe } \\
\text { r F }\end{array}$ & $\begin{array}{c}\text { Chambe } \\
\text { r F-2 }\end{array}$ & $\begin{array}{c}\text { Chambe } \\
\text { rF }\end{array}$ \\
\hline & $\begin{array}{l}\text { (c } \\
\mathrm{m})\end{array}$ & $(\mathrm{cm})$ & $\begin{array}{c}(\mathrm{mb} \\
\mathrm{sf})\end{array}$ & $(\mathrm{Ma})$ & $\begin{array}{c}(\mathrm{mmol} / \\
\mathrm{mol})\end{array}$ & $\begin{array}{c}(\mathrm{mmol} / \\
\mathrm{mol})\end{array}$ & $\begin{array}{c}(\mathrm{mmol} / \\
\mathrm{mol})\end{array}$ & $\begin{array}{c}(\mathrm{mmol} / \\
\mathrm{mol})\end{array}$ & $\begin{array}{c}(\mathrm{mmol} / \\
\mathrm{mol})\end{array}$ & $\begin{array}{c}(\mathrm{mmol} / \\
\mathrm{mol})\end{array}$ & $\begin{array}{c}(\mathrm{mmol} / \\
\mathrm{mol})\end{array}$ & $\begin{array}{c}(\mathrm{mmol} / \\
\mathrm{mol})\end{array}$ & $\begin{array}{c}(\mathrm{mmol} / \\
\mathrm{mol})\end{array}$ & $\begin{array}{c}(\mathrm{mmol} / \\
\mathrm{mol})\end{array}$ & $\begin{array}{c}(\mu \mathrm{mol} / \\
\mathrm{mol})\end{array}$ & $\begin{array}{c}(\mu \mathrm{mol} / \\
\mathrm{mol})\end{array}$ \\
\hline 3 & 8 & 9 & $\begin{array}{c}40.5 \\
8\end{array}$ & $\begin{array}{c}1036 . \\
50\end{array}$ & 1.40 & 1.85 & 1.45 & 1.28 & 0.30 & 0.05 & 0.05 & 0.06 & 0.02 & 0.02 & 1.45 & 0.90 \\
\hline 3 & 16 & 17 & $\begin{array}{c}40.6 \\
6\end{array}$ & $\begin{array}{c}1038 . \\
86\end{array}$ & 1.40 & 1.56 & 1.34 & 1.36 & 0.08 & 0.54 & 0.03 & 0.13 & 0.01 & 0.08 & 1.22 & 2.10 \\
\hline 3 & 16 & 17 & $\begin{array}{c}40.6 \\
6\end{array}$ & $\begin{array}{c}1038 . \\
86\end{array}$ & 2.83 & 2.67 & 1.33 & 1.47 & 1.72 & 0.63 & 0.08 & 0.13 & 0.08 & 0.14 & 30.25 & 3.78 \\
\hline 3 & 16 & 17 & $\begin{array}{c}40.6 \\
6\end{array}$ & $\begin{array}{c}1038 . \\
86\end{array}$ & 2.40 & 1.55 & 1.42 & 1.43 & 0.04 & 0.39 & 0.03 & 0.14 & 0.04 & 0.05 & 1.01 & 2.29 \\
\hline 3 & 20 & 21 & 40.7 & $\begin{array}{c}1038 . \\
90\end{array}$ & 2.73 & 1.65 & 1.33 & 1.44 & 0.07 & 0.00 & 0.29 & 0.10 & 0.23 & 0.01 & 5.65 & 0.60 \\
\hline 3 & 20 & 21 & 40.7 & $\begin{array}{c}1038 . \\
90\end{array}$ & 1.57 & 2.09 & 1.40 & 1.47 & 0.04 & 0.00 & 0.07 & 0.25 & 0.10 & 0.29 & 1.00 & 2.20 \\
\hline 3 & 20 & 21 & 40.7 & $\begin{array}{c}1038 . \\
90\end{array}$ & 3.79 & 1.17 & 1.33 & 1.58 & 0.06 & 0.01 & 0.19 & 0.07 & 0.43 & 0.14 & 4.11 & 1.36 \\
\hline 3 & 20 & 21 & 40.7 & $\begin{array}{c}1038 . \\
90\end{array}$ & 1.87 & 3.62 & 1.29 & 1.40 & 0.65 & 0.14 & 0.11 & 0.23 & 0.13 & 0.56 & 9.97 & 8.29 \\
\hline 3 & 20 & 21 & 40.7 & $\begin{array}{c}1038 . \\
90\end{array}$ & 35.24 & 1.40 & 1.55 & 1.43 & 17.82 & 0.06 & 7.65 & 0.06 & 0.50 & 0.14 & $\begin{array}{c}13308.8 \\
5\end{array}$ & 2.02 \\
\hline 3 & 20 & 21 & 40.7 & $\begin{array}{c}1038 . \\
90\end{array}$ & 3.38 & 2.67 & 1.33 & 1.43 & 2.59 & & 1.02 & 0.41 & 0.35 & 0.37 & 3242.84 & 3.28 \\
\hline 3 & 20 & 21 & 40.7 & $\begin{array}{c}1038 . \\
90\end{array}$ & 3.56 & 1.52 & 1.49 & 1.42 & 5.60 & 0.20 & 0.22 & 0.15 & 0.06 & 0.17 & 760.68 & 0.90 \\
\hline 3 & 20 & 21 & 40.7 & $\begin{array}{c}1038 . \\
90\end{array}$ & 1.84 & 1.59 & 1.16 & 1.36 & 0.01 & & 0.25 & 0.13 & 0.17 & 0.08 & 3.09 & 1.04 \\
\hline 3 & 24 & 25 & $\begin{array}{c}40.7 \\
4\end{array}$ & $\begin{array}{c}1038 . \\
93\end{array}$ & 1.97 & 1.46 & 1.52 & 1.37 & 0.19 & 0.02 & 0.04 & 0.17 & 0.04 & 0.15 & 1.76 & 1.29 \\
\hline 3 & 24 & 25 & $\begin{array}{c}40.7 \\
4\end{array}$ & $\begin{array}{c}1038 . \\
93\end{array}$ & 2.24 & 1.39 & 1.57 & 1.42 & 0.06 & 0.90 & 0.05 & 0.09 & 0.01 & 0.11 & 0.89 & 3.36 \\
\hline 3 & 24 & 25 & $\begin{array}{c}40.7 \\
4\end{array}$ & $\begin{array}{c}1038 . \\
93\end{array}$ & 2.27 & 1.73 & 1.44 & 1.48 & 0.13 & 0.03 & 0.05 & 0.06 & 0.08 & 0.06 & 1.63 & 2.41 \\
\hline 3 & 24 & 25 & $\begin{array}{c}40.7 \\
4\end{array}$ & $\begin{array}{c}1038 . \\
93\end{array}$ & 1.28 & 2.42 & 1.45 & 2.40 & 0.04 & 0.05 & 0.03 & 0.08 & 0.01 & 0.06 & 0.82 & 1.87 \\
\hline 3 & 24 & 25 & $\begin{array}{c}40.7 \\
4\end{array}$ & $\begin{array}{c}1038 . \\
93\end{array}$ & 3.33 & 3.04 & 1.35 & 2.77 & 6.42 & & 0.27 & 0.08 & 0.01 & 0.20 & 10.90 & 1.76 \\
\hline 3 & 24 & 25 & $\begin{array}{c}40.7 \\
4\end{array}$ & $\begin{array}{c}1038 . \\
93\end{array}$ & 2.10 & 1.04 & 1.31 & 1.41 & 0.10 & 0.05 & 0.15 & 0.06 & 0.08 & 0.01 & 1.36 & 0.77 \\
\hline 3 & 32 & 33 & $\begin{array}{c}40.8 \\
2\end{array}$ & $\begin{array}{c}1043 . \\
58\end{array}$ & 2.83 & 2.30 & 1.34 & 1.37 & 0.14 & 2.74 & 0.28 & 0.30 & 0.02 & 0.06 & 4.00 & 4.46 \\
\hline 3 & 32 & 33 & $\begin{array}{c}40.8 \\
2\end{array}$ & $\begin{array}{c}1043 . \\
58\end{array}$ & 2.06 & 2.07 & 1.28 & 1.25 & 0.01 & 0.85 & 0.12 & 0.30 & 0.01 & 0.03 & 1.23 & 4.35 \\
\hline 3 & $\begin{array}{c}14 \\
8\end{array}$ & 149 & $\begin{array}{c}41.9 \\
8\end{array}$ & $\begin{array}{c}1077 . \\
22\end{array}$ & 2.85 & 1.97 & 1.44 & 1.45 & 0.10 & 0.20 & 0.17 & 0.17 & 0.01 & 0.01 & 1.32 & 1.31 \\
\hline 3 & $\begin{array}{c}14 \\
8\end{array}$ & 149 & $\begin{array}{c}41.9 \\
8\end{array}$ & $\begin{array}{c}1077 . \\
22\end{array}$ & 2.22 & 2.29 & 1.29 & 1.35 & 0.02 & 0.03 & 0.20 & 0.21 & 0.01 & 0.01 & 1.24 & 1.19 \\
\hline 3 & $\begin{array}{c}14 \\
8\end{array}$ & 149 & $\begin{array}{c}41.9 \\
8\end{array}$ & $\begin{array}{c}1077 . \\
22\end{array}$ & 3.01 & 1.77 & 1.34 & 1.37 & 0.09 & 0.38 & 0.38 & 0.25 & 0.01 & 0.01 & 1.87 & 1.50 \\
\hline 3 & $\begin{array}{c}14 \\
8\end{array}$ & 149 & $\begin{array}{c}41.9 \\
8\end{array}$ & $\begin{array}{c}1077 . \\
22\end{array}$ & 3.07 & 1.96 & 1.37 & 1.44 & 0.20 & 0.02 & 0.22 & 0.36 & 0.03 & 0.01 & 1.74 & 1.60 \\
\hline 3 & $\begin{array}{c}14 \\
8\end{array}$ & 149 & $\begin{array}{c}41.9 \\
8\end{array}$ & $\begin{array}{c}1077 . \\
22\end{array}$ & 3.06 & 2.39 & 1.43 & 1.39 & 0.16 & 0.06 & 0.24 & 0.42 & 0.01 & 0.02 & 1.73 & 1.57 \\
\hline 3 & $\begin{array}{c}14 \\
8\end{array}$ & 149 & $\begin{array}{c}41.9 \\
8\end{array}$ & $\begin{array}{c}1077 . \\
22\end{array}$ & 2.63 & 2.98 & 1.41 & 1.42 & 0.36 & 0.44 & 0.13 & 0.30 & 0.00 & 0.03 & 2.94 & 2.20 \\
\hline 3 & $\begin{array}{c}14 \\
8\end{array}$ & 149 & $\begin{array}{c}41.9 \\
8\end{array}$ & $\begin{array}{c}1077 . \\
22\end{array}$ & 2.33 & 2.93 & 1.36 & 1.42 & 0.53 & 1.26 & 0.18 & 0.19 & 0.01 & 0.01 & 1.59 & 0.96 \\
\hline 3 & $\begin{array}{c}14 \\
8\end{array}$ & 149 & $\begin{array}{c}41.9 \\
8\end{array}$ & $\begin{array}{c}1077 . \\
22\end{array}$ & 2.89 & 1.95 & 1.42 & 1.41 & 0.14 & 0.03 & 0.06 & 0.13 & 0.00 & 0.01 & 0.70 & 0.94 \\
\hline
\end{tabular}




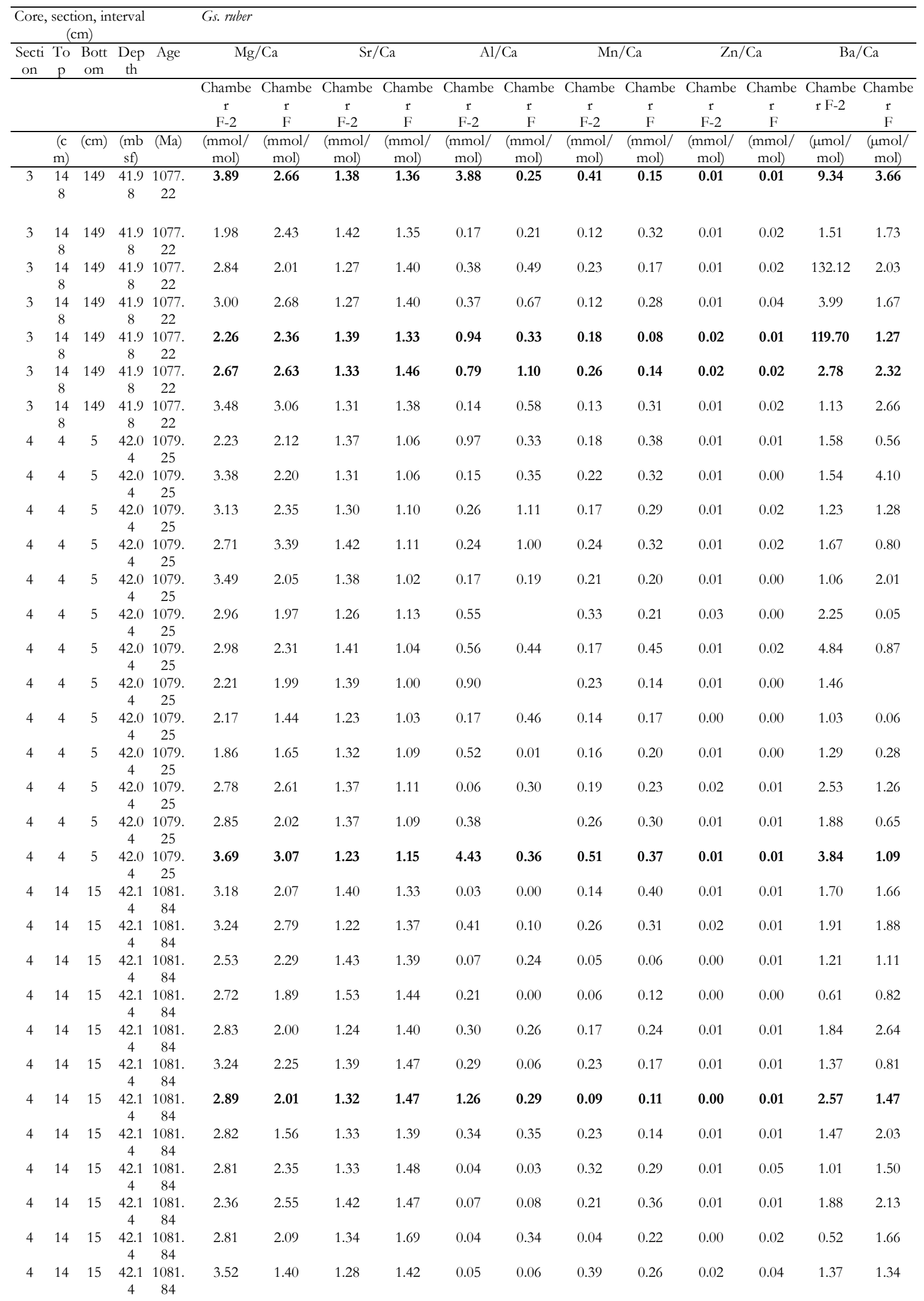




\begin{tabular}{|c|c|c|c|c|c|c|c|c|c|c|c|c|c|c|c|c|}
\hline \multicolumn{5}{|c|}{$\begin{array}{l}\text { Core, section, interval } \\
(\mathrm{cm})\end{array}$} & \multicolumn{12}{|l|}{ Gs. ruber } \\
\hline \multirow{3}{*}{$\begin{array}{c}\text { Secti } \\
\text { on } \\
\end{array}$} & \multirow{2}{*}{$\begin{array}{c}\text { To } \\
\mathrm{p}\end{array}$} & \multirow{2}{*}{$\begin{array}{c}\text { Bott } \\
\text { om }\end{array}$} & \multirow{2}{*}{$\begin{array}{c}\text { Dep } \\
\text { th }\end{array}$} & \multirow[t]{2}{*}{ Age } & \multicolumn{2}{|c|}{$\mathrm{Mg} / \mathrm{Ca}$} & \multicolumn{2}{|c|}{$\mathrm{Sr} / \mathrm{Ca}$} & \multicolumn{2}{|c|}{$\mathrm{Al} / \mathrm{Ca}$} & \multicolumn{2}{|c|}{$\mathrm{Mn} / \mathrm{Ca}$} & \multicolumn{2}{|c|}{$\mathrm{Zn} / \mathrm{Ca}$} & \multicolumn{2}{|c|}{$\mathrm{Ba} / \mathrm{Ca}$} \\
\hline & & & & & $\begin{array}{c}\text { Chambe } \\
\text { r } \\
\text { F-2 }\end{array}$ & $\begin{array}{c}\text { Chambe } \\
\text { r } \\
\text { F }\end{array}$ & $\begin{array}{c}\text { Chambe } \\
\text { r } \\
\text { F-2 }\end{array}$ & $\begin{array}{c}\text { Chambe } \\
\text { r } \\
\text { F }\end{array}$ & $\begin{array}{c}\text { Chambe } \\
\text { r } \\
\text { F-2 }\end{array}$ & $\begin{array}{c}\text { Chambe } \\
\text { r } \\
\text { F }\end{array}$ & $\begin{array}{c}\text { Chambe } \\
\text { r } \\
\text { F-2 }\end{array}$ & $\begin{array}{c}\text { Chambe } \\
\text { r } \\
\text { F }\end{array}$ & $\begin{array}{c}\text { Chambe } \\
\text { r } \\
\text { F-2 }\end{array}$ & $\begin{array}{c}\text { Chambe } \\
\text { r } \\
\text { F }\end{array}$ & $\begin{array}{c}\text { Chambe } \\
\text { r F-2 }\end{array}$ & $\begin{array}{c}\text { Chambe } \\
\text { r } \\
\text { F }\end{array}$ \\
\hline & $\begin{array}{l}\text { (c } \\
\mathrm{m})\end{array}$ & $(\mathrm{cm})$ & $\begin{array}{l}(\mathrm{mb} \\
\mathrm{sf}) \\
\end{array}$ & (Ma) & $\begin{array}{c}(\mathrm{mmol} / \\
\mathrm{mol})\end{array}$ & $\begin{array}{c}(\mathrm{mmol} / \\
\mathrm{mol})\end{array}$ & $\begin{array}{c}(\mathrm{mmol} / \\
\mathrm{mol})\end{array}$ & $\begin{array}{c}(\mathrm{mmol} / \\
\mathrm{mol})\end{array}$ & $\begin{array}{c}(\mathrm{mmol} / \\
\mathrm{mol})\end{array}$ & $\begin{array}{c}(\mathrm{mmol} / \\
\mathrm{mol})\end{array}$ & $\begin{array}{c}(\mathrm{mmol} / \\
\mathrm{mol})\end{array}$ & $\begin{array}{c}(\mathrm{mmol} / \\
\mathrm{mol})\end{array}$ & $\begin{array}{c}(\mathrm{mmol} / \\
\mathrm{mol})\end{array}$ & $\begin{array}{c}(\mathrm{mmol} / \\
\mathrm{mol})\end{array}$ & $\begin{array}{c}(\mu \mathrm{mol} / \\
\mathrm{mol})\end{array}$ & $\begin{array}{c}(\mu \mathrm{mol} / \\
\mathrm{mol})\end{array}$ \\
\hline 4 & 14 & 15 & $\begin{array}{c}42.1 \\
4\end{array}$ & $\begin{array}{c}1081 . \\
84\end{array}$ & 1.90 & 1.61 & 1.41 & 1.56 & 0.07 & 0.15 & 0.18 & 0.18 & 0.00 & 0.05 & 1.23 & 1.06 \\
\hline 4 & 14 & 15 & $\begin{array}{c}42.1 \\
4\end{array}$ & $\begin{array}{c}1081 . \\
84\end{array}$ & 3.21 & 2.23 & 1.46 & 1.34 & 0.55 & 0.10 & 0.58 & 0.18 & 0.01 & 0.00 & 2.71 & 2.22 \\
\hline
\end{tabular}

Table C8: Mean Trace element/Ca, data from Chambers F-2 and F measured in Globigerina bulloides from ODP Site 1123, at various depth intervals. Analyses in bold refer to anomalous data that was excluded from further analysis.

\begin{tabular}{|c|c|c|c|c|c|c|c|c|c|c|c|c|c|c|c|c|}
\hline \multicolumn{5}{|c|}{$\begin{array}{l}\text { Core, section, interval } \\
(\mathrm{cm})\end{array}$} & \multicolumn{12}{|l|}{$\begin{array}{c}G . \\
\text { bulloides }\end{array}$} \\
\hline \multirow{2}{*}{$\begin{array}{c}\text { Secti } \\
\text { on }\end{array}$} & & $\begin{array}{c}\text { Bott } \\
\text { om }\end{array}$ & \multirow{2}{*}{$\begin{array}{c}\text { Dep } \\
\text { th }\end{array}$} & Age & \multicolumn{2}{|c|}{$\mathrm{Mg} / \mathrm{Ca}$} & \multicolumn{2}{|c|}{$\mathrm{Sr} / \mathrm{Ca}$} & \multicolumn{2}{|c|}{$\mathrm{Al} / \mathrm{Ca}$} & \multicolumn{2}{|c|}{$\mathrm{Mn} / \mathrm{Ca}$} & \multicolumn{2}{|c|}{$\mathrm{Zn} / \mathrm{Ca}$} & \multicolumn{2}{|c|}{$\mathrm{Ba} / \mathrm{Ca}$} \\
\hline & $\begin{array}{l}(\mathrm{c} \\
\mathrm{m})\end{array}$ & $(\mathrm{cm})$ & & (Ma) & $\begin{array}{c}\text { Chambe } \\
\text { r F-2 } \\
(\mathrm{mmol} / \\
\mathrm{mol})\end{array}$ & $\begin{array}{c}\text { Chambe } \\
\text { r F } \\
\begin{array}{c}\text { (mmol/ } \\
\mathrm{mol})\end{array} \\
\end{array}$ & $\begin{array}{c}\text { Chambe } \\
\text { r F-2 } \\
(\mathrm{mmol} / \\
\mathrm{mol})\end{array}$ & $\begin{array}{c}\text { Chambe } \\
\text { r F } \\
\begin{array}{c}(\mathrm{mmol} / \\
\mathrm{mol})\end{array} \\
\end{array}$ & $\begin{array}{c}\text { Chambe } \\
\text { r F-2 } \\
(\mathrm{mmol} / \\
\mathrm{mol})\end{array}$ & $\begin{array}{c}\text { Chambe } \\
\text { r F } \\
\begin{array}{c}\text { (mmol/ } \\
\mathrm{mol})\end{array} \\
\end{array}$ & $\begin{array}{c}\text { Chambe } \\
\text { r F-2 } \\
\begin{array}{c}(\mathrm{mmol} / \\
\mathrm{mol})\end{array} \\
\end{array}$ & $\begin{array}{c}\text { Chambe } \\
\text { r F }\end{array}$ & $\begin{array}{c}\begin{array}{c}\text { Chambe } \\
\text { r F-2 }\end{array} \\
\begin{array}{c}\text { (mmol/ } \\
\mathrm{mol})\end{array} \\
\end{array}$ & $\begin{array}{c}\text { Chambe } \\
\text { r F } \\
\begin{array}{c}\text { (mmol/ } \\
\mathrm{mol})\end{array} \\
\end{array}$ & $\begin{array}{c}\text { Chambe } \\
\text { r F-2 } \\
\begin{array}{c}\mu \mathrm{mol} / \\
\mathrm{mol})\end{array} \\
\end{array}$ & $\begin{array}{c}\text { Chambe } \\
\text { r F }\end{array}$ \\
\hline 2 & 98 & 99 & $\begin{array}{c}39.9 \\
8 \\
39.9\end{array}$ & $\begin{array}{c}1029 . \\
39 \\
1029 .\end{array}$ & 1.64 & 1.72 & 1.37 & 1.34 & 0.03 & 0.15 & 0.07 & 0.15 & 0.08 & 0.13 & 5.03 & 12.59 \\
\hline 2 & 98 & 99 & $\begin{array}{c}8 \\
39.9\end{array}$ & $\begin{array}{c}39 \\
1029\end{array}$ & 1.17 & 1.43 & 1.32 & 1.23 & 0.07 & 0.24 & 0.05 & 0.13 & 0.06 & 0.21 & 4.36 & 9.61 \\
\hline 2 & 98 & 99 & $\begin{array}{c}8 \\
39.9\end{array}$ & $\begin{array}{c}39 \\
1029 .\end{array}$ & 1.43 & 1.22 & 1.25 & 1.26 & 0.08 & 0.02 & 0.12 & 0.10 & 0.06 & 0.08 & 8.75 & 10.74 \\
\hline 2 & 98 & 99 & $\begin{array}{c}8 \\
39.9\end{array}$ & $\begin{array}{c}39 \\
1029 .\end{array}$ & 1.39 & 1.21 & 1.36 & 1.29 & 0.09 & 0.08 & 0.10 & 0.14 & 0.26 & 0.36 & 7.41 & 12.63 \\
\hline 2 & $\begin{array}{l}98 \\
10\end{array}$ & 99 & $\begin{array}{c}8 \\
40.0\end{array}$ & $\begin{array}{c}39 \\
1029 .\end{array}$ & 2.12 & 1.38 & 1.26 & 1.31 & 0.11 & 0.05 & 0.21 & 0.12 & 0.21 & 0.17 & 6.48 & 5.84 \\
\hline 2 & $\begin{array}{c}2 \\
10\end{array}$ & 103 & $\begin{array}{c}2 \\
40.0\end{array}$ & $\begin{array}{c}43 \\
1029 .\end{array}$ & 3.38 & 1.73 & 1.49 & 1.47 & 0.62 & 0.03 & 0.27 & 0.15 & 0.19 & 0.10 & 16.69 & 11.69 \\
\hline 2 & $\begin{array}{c}2 \\
10\end{array}$ & 103 & $\begin{array}{c}2 \\
40.0\end{array}$ & $\begin{array}{c}43 \\
1029 .\end{array}$ & 2.78 & 1.95 & 1.52 & 1.59 & 0.11 & 0.05 & 0.05 & 0.12 & 0.02 & 0.06 & 8.11 & 7.95 \\
\hline 2 & $\begin{array}{c}2 \\
10\end{array}$ & 103 & $\begin{array}{c}2 \\
40.0\end{array}$ & $\begin{array}{c}43 \\
1029 .\end{array}$ & 2.27 & 1.67 & 1.54 & 1.40 & 0.12 & 0.09 & 0.15 & 0.15 & 0.02 & 0.07 & 3.71 & 8.29 \\
\hline 2 & $\begin{array}{c}2 \\
10\end{array}$ & 103 & $\begin{array}{c}2 \\
40.0\end{array}$ & $\begin{array}{c}43 \\
1029 .\end{array}$ & 2.60 & 1.83 & 1.40 & 1.34 & 0.04 & 0.18 & 0.30 & 0.16 & 0.24 & 0.13 & 24.30 & 3.61 \\
\hline 2 & $\begin{array}{c}2 \\
10\end{array}$ & 103 & $\begin{array}{c}2 \\
40.0\end{array}$ & $\begin{array}{c}43 \\
1029 .\end{array}$ & 2.93 & 1.58 & 1.39 & 1.58 & 0.27 & 0.04 & 0.21 & 0.13 & 0.08 & 0.05 & 5.47 & 2.75 \\
\hline 2 & $\begin{array}{c}2 \\
10\end{array}$ & 103 & $\begin{array}{c}2 \\
40.0\end{array}$ & $\begin{array}{c}43 \\
1029 .\end{array}$ & 2.35 & 2.61 & 1.27 & 1.33 & 0.14 & 0.14 & 0.14 & 0.14 & 0.09 & 0.13 & 3.52 & 5.07 \\
\hline 2 & 2 & 103 & $\begin{array}{c}2 \\
42.3\end{array}$ & $\begin{array}{c}43 \\
1086 .\end{array}$ & 1.89 & 1.50 & 1.32 & 1.37 & 0.23 & 0.14 & 0.13 & 0.18 & 0.07 & 0.10 & 4.15 & 5.60 \\
\hline 4 & 32 & 33 & $\begin{array}{c}2 \\
42.3\end{array}$ & $\begin{array}{c}34 \\
1086\end{array}$ & 1.64 & 1.72 & 1.37 & 1.34 & 0.03 & 0.15 & 0.07 & 0.15 & 0.08 & 0.13 & 5.03 & 12.59 \\
\hline 4 & 32 & 33 & $\begin{array}{c}2 \\
42.3\end{array}$ & $\begin{array}{c}34 \\
1086\end{array}$ & 1.17 & 1.43 & 1.32 & 1.23 & 0.07 & 0.24 & 0.05 & 0.13 & 0.06 & 0.21 & 4.36 & 9.61 \\
\hline 4 & 32 & 33 & $\begin{array}{c}2 \\
42.3\end{array}$ & $\begin{array}{c}34 \\
1086\end{array}$ & 1.43 & 1.22 & 1.25 & 1.26 & 0.08 & 0.02 & 0.12 & 0.10 & 0.06 & 0.08 & 8.75 & 10.74 \\
\hline 4 & 32 & 33 & $\begin{array}{c}2 \\
42.3\end{array}$ & $\begin{array}{c}34 \\
1086 .\end{array}$ & 1.39 & 1.21 & 1.36 & 1.29 & 0.09 & 0.08 & 0.10 & 0.14 & 0.26 & 0.36 & 7.41 & 12.63 \\
\hline 4 & 32 & 33 & $\begin{array}{c}2 \\
42.3\end{array}$ & $\begin{array}{c}34 \\
1086\end{array}$ & 2.12 & 1.38 & 1.26 & 1.31 & 0.11 & 0.05 & 0.21 & 0.12 & 0.21 & 0.17 & 6.48 & 5.84 \\
\hline 4 & 32 & 33 & $\begin{array}{c}2 \\
42.3\end{array}$ & $\begin{array}{c}34 \\
1086\end{array}$ & 3.38 & 1.73 & 1.49 & 1.47 & 0.62 & 0.03 & 0.27 & 0.15 & 0.19 & 0.10 & 16.69 & 11.69 \\
\hline 4 & 32 & 33 & $\begin{array}{c}2 \\
42.3\end{array}$ & $\begin{array}{c}34 \\
1086 .\end{array}$ & 2.78 & 1.95 & 1.52 & 1.59 & 0.11 & 0.05 & 0.05 & 0.12 & 0.02 & 0.06 & 8.11 & 7.95 \\
\hline 4 & 32 & 33 & 2 & 34 & 2.27 & 1.67 & 1.54 & 1.40 & 0.12 & 0.09 & 0.15 & 0.15 & 0.02 & 0.07 & 3.71 & 8.29 \\
\hline
\end{tabular}


Appendix C

\begin{tabular}{|c|c|c|c|c|c|c|c|c|c|c|c|c|c|c|c|c|}
\hline \multicolumn{5}{|c|}{$\begin{array}{l}\text { Core, section, interval } \\
(\mathrm{cm})\end{array}$} & \multicolumn{12}{|l|}{$\begin{array}{c}\text { G. } \\
\text { bulloides }\end{array}$} \\
\hline \multirow{3}{*}{$\begin{array}{c}\text { Secti } \\
\text { on }\end{array}$} & \multirow{2}{*}{$\begin{array}{l}\text { To } \\
\mathrm{p}\end{array}$} & \multirow{2}{*}{$\begin{array}{c}\text { Bott } \\
\text { om }\end{array}$} & \multirow{2}{*}{$\begin{array}{c}\text { Dep } \\
\text { th }\end{array}$} & \multirow[t]{2}{*}{ Age } & \multicolumn{2}{|c|}{$\mathrm{Mg} / \mathrm{Ca}$} & \multicolumn{2}{|c|}{$\mathrm{Sr} / \mathrm{Ca}$} & \multicolumn{2}{|c|}{$\mathrm{Al} / \mathrm{Ca}$} & \multicolumn{2}{|c|}{$\mathrm{Mn} / \mathrm{Ca}$} & \multicolumn{2}{|c|}{$\mathrm{Zn} / \mathrm{Ca}$} & \multicolumn{2}{|c|}{$\mathrm{Ba} / \mathrm{Ca}$} \\
\hline & & & & & $\begin{array}{c}\text { Chambe } \\
\text { r F-2 }\end{array}$ & $\begin{array}{l}\text { Chambe } \\
\text { rF }\end{array}$ & $\begin{array}{l}\text { Chambe } \\
\text { rF-2 }\end{array}$ & $\begin{array}{c}\text { Chambe } \\
\text { rF }\end{array}$ & $\begin{array}{c}\text { Chambe } \\
\text { r F-2 }\end{array}$ & $\begin{array}{c}\text { Chambe } \\
\text { rF }\end{array}$ & $\begin{array}{c}\text { Chambe } \\
\text { r F-2 }\end{array}$ & $\begin{array}{c}\text { Chambe } \\
\text { rF }\end{array}$ & $\begin{array}{c}\text { Chambe } \\
\text { r F-2 }\end{array}$ & $\begin{array}{c}\text { Chambe } \\
\text { rF }\end{array}$ & $\begin{array}{c}\text { Chambe } \\
\text { r F-2 }\end{array}$ & $\begin{array}{c}\text { Chambe } \\
\text { rF }\end{array}$ \\
\hline & $\begin{array}{l}(\mathrm{c} \\
\mathrm{m})\end{array}$ & $(\mathrm{cm})$ & $\begin{array}{c}(\mathrm{mb} \\
\mathrm{sf})\end{array}$ & (Ma) & $\begin{array}{c}(\mathrm{mmol} / \\
\mathrm{mol})\end{array}$ & $\begin{array}{c}(\mathrm{mmol} / \\
\mathrm{mol})\end{array}$ & $\begin{array}{c}(\mathrm{mmol} / \\
\mathrm{mol})\end{array}$ & $\begin{array}{c}(\mathrm{mmol} / \\
\mathrm{mol})\end{array}$ & $\begin{array}{c}(\mathrm{mmol} / \\
\mathrm{mol})\end{array}$ & $\begin{array}{c}(\mathrm{mmol} / \\
\mathrm{mol})\end{array}$ & $\begin{array}{c}(\mathrm{mmol} / \\
\mathrm{mol})\end{array}$ & $\begin{array}{c}(\mathrm{mmol} / \\
\mathrm{mol})\end{array}$ & $\begin{array}{c}(\mathrm{mmol} / \\
\mathrm{mol})\end{array}$ & $\begin{array}{c}(\mathrm{mmol} / \\
\mathrm{mol})\end{array}$ & $\begin{array}{c}(\mu \mathrm{mol} / \\
\mathrm{mol})\end{array}$ & $\begin{array}{c}(\mu \mathrm{mol} / \\
\mathrm{mol})\end{array}$ \\
\hline 4 & 32 & 33 & $\begin{array}{c}42.3 \\
2 \\
42.3\end{array}$ & $\begin{array}{c}1086 . \\
34 \\
1086 .\end{array}$ & 2.60 & 1.83 & 1.40 & 1.34 & 0.04 & 0.18 & 0.30 & 0.16 & 0.24 & 0.13 & 24.30 & 3.61 \\
\hline 4 & 32 & 33 & $\begin{array}{c}2 \\
42.3\end{array}$ & $\begin{array}{c}34 \\
1086 .\end{array}$ & 2.93 & 1.58 & 1.39 & 1.58 & 0.27 & 0.04 & 0.21 & 0.13 & 0.08 & 0.05 & 5.47 & 2.75 \\
\hline 4 & 32 & 33 & $\begin{array}{c}2 \\
42.3\end{array}$ & $\begin{array}{c}34 \\
1086 .\end{array}$ & 2.35 & 2.61 & 1.27 & 1.33 & 0.14 & 0.14 & 0.14 & 0.14 & 0.09 & 0.13 & 3.52 & 5.07 \\
\hline 4 & 32 & 33 & 2 & 34 & 1.89 & 1.50 & 1.32 & 1.37 & 0.23 & 0.14 & 0.13 & 0.18 & 0.07 & 0.10 & 4.15 & 5.60 \\
\hline
\end{tabular}




\section{DVD Contents}

\section{$\underline{\text { Data Processing Programs }}$}

$01 \quad$ MATLAB Scripts

02 Excel Macros

\section{Chapter 2 Data}

01 Materials and Methods

02 Lab Comparison Data

\section{Chapter 3 Data}

01 Gs. ruber LA-ICP-MS depth profiles

02 Gs. ruber photographs

03 Gs. muber core top and plk tow SEM images

04 Gs. ruber Trace Element Summary

05 Gs. ruber SPSS Files

06 Bolton et al 2011 Paleoceanography MS

07 Clay Model SW Pacfic Ocean

08 Supplementary Data

\section{Chapter 4 Data}

$01 \quad$ N. incompta LA-ICP-MS depth profiles

$02 \quad$ N. incompta photographs

$03 \quad$ N. incompta core top and plk tow SEM images

04 N. incompta Trace Element Summary

$05 \quad$ N. incompta SPSS Files

06 N. incompta CTD Plk Tow Data NZ

\section{Chapter 5 Data}

01 Gs. muber LA-ICP-MS depth profiles

02 Gs. ruber photographs

03 Gs. ruber SEM images

04 Gs. ruber Analysis Summary

05 Gs. ruber SPSS Files

06 G. bulloides LA-ICP-MS depth profiles

07 G. bulloides photographs

08 G. bulloides SEM images

09 G. bulloides Analysis Summary

$10 \quad$ G. bulloides SPSS Files

11 Uvigerina Data

12 Age Model

13 Supplementary Material

14 Unused Data 